\title{
SYNTHESIS AND \\ CHARACTERIZATION OF \\ ZEOLITIC MATERIALS USING \\ PHOSPHOROUS ORGANIC \\ STRUCTURE DIRECTING AGENTS
}

\author{
PhD THESIS SUBMITTED BY: \\ JORGE SIMANCAS COLOMA
}

PhD ADVISOR:

Prof. FERNANDO REY GARCÍA

VALENCIA, JULY 2021 


\section{Acknowledgements}

I wish to firstly acknowledge the Spanish Government for the necessary funding for the FPI pre-doctoral fellowship (BES-2013-062999). Also, this thesis would not have been possible without the infrastructures provided by the UPV and the CSIC staff, fused into the ITQ. Furthermore, I want to acknowledge the Microscopy Service of the UPV for their support in sample microscopy characterization.

I want to deeply thank Prof. F. Rey for his support, advice and trust placed in me along the development of this thesis. I also want to thank Prof. A. Corma for his support, advice and scientific discussion. Likewise, I want to thank to Prof. C. Martineau for her helpful teaching on NMR techniques and for her assistance during my short stay at the Institut Lavoisier de Versailles, to Dr. J.A. Vidal-Moya for his helping hand on NMR characterization at the ITQ, and to Dr. J.L. Jordá and Dr. P.J. Bereciartúa for their invaluable help in crystallography characterization techniques. And I want to thank to V.J. Margarit, A. Moraleda and, especially, to Dr. R. Simancas, for their assistance and discussion on laboratory work and zeolite synthesis techniques.

I also want to thank to all colleagues and personal friends who supported me during the completion of this thesis.

Finalmente, quiero agradecer especialmente todo el apoyo de mi familia, a los que dedico esta tesis. 


\begin{abstract}
Zeolites are microporous crystalline materials with channels and pore openings of molecular dimensions. The structure and composition of zeolites confers them interesting properties that allow their application in a wide range of industrial applications as adsorption, separation or catalysis. The synthesis of zeolites is the most important stage to control the structure and composition of zeolites, and thus, critical to optimize their properties.

This thesis has been focused on the synthesis of zeolites using phosphorous containing compounds (phosphonium and aminophosphonium cations) as Organic Structure Directing Agents (P-OSDA). The use of these phosphorous compounds influence the crystallization and properties of the obtained zeolites compared to zeolites obtained with classical ammonium cations.

Phosphorous compounds were chosen because of their different chemistry and stability properties respect to classical ammonium cations commonly used in the synthesis of zeolites. These aspects were studied in a comparative study with different ammonium and phosphorous cations.

The phosphorous compounds used in this work have yielded new crystalline structures (ITQ-58 and ITQ-66) and opened new routes for the synthesis of already known zeolites (RTH, IWV and DON), widening their chemical composition range.

The thermal decomposition of the P-OSDA's entrapped inside the zeolites yields to the formation of extra-framework phosphorus species that remain inside the channels and voids of the zeolites. These species modulate the adsorption and acid properties of the final materials depending on the post-synthesis treatments. In this work, a route for the incorporation of controlled amounts of phosphorus during the synthesis stage has been studied. This has allowed to control the adsorption and acid properties in small pores zeolites, which cannot be achieved by post-synthesis methodologies.
\end{abstract}




\section{Resumen}

Las zeolitas son materiales cristalinos microporosos con canales y tamaños de poro de dimensiones moleculares. La estructura y composición de las zeolitas les confiere interesantes propiedades que permiten su aplicación en una amplia gama de aplicaciones industriales como adsorción, separación o catálisis. La síntesis de zeolitas es la etapa más importante para el control de la estructura y composición de las zeolitas y, por tanto, crítica para la optimización de sus propiedades.

Esta tesis se ha centrado en la síntesis de zeolitas utilizando compuestos que contienen fósforo (cationes fosfonio y aminofosfonio) como Agentes Directores de Estructura ( $\mathrm{P}$ ADE). El uso de compuestos fosforados influye en la cristalización y propiedades de las zeolitas obtenidas en comparación con las zeolitas obtenidas con cationes de amonio clásicos.

Los compuestos fosforados se eligieron debido a su diferente química y estabilidad con respecto a los cationes de amonio clásicos comúnmente usados en la síntesis de zeolitas. Estos aspectos se estudiaron con un estudio comparativo de diferentes cationes de amonio y fosforados.

Los compuestos de fósforo utilizados en este trabajo han dado lugar a nuevas estructuras cristalinas (ITQ-58 e ITQ-66) y han abierto nuevas vías de síntesis de zeolitas ya conocidas (RTH, IWV y DON), ampliando su gama de composiciones químicas.

La descomposición térmica de los P-ADE confinados dentro de las zeolitas da lugar a la formación de especies de fósforo extra-red que permanecen dentro de los canales y cavidades de las zeolitas. Estas especies modulan las propiedades ácidas y de adsorción de los materiales finales dependiendo de los tratamientos post-síntesis. En este trabajo se ha estudiado una ruta para la incorporación de cantidades controladas de fósforo durante la etapa de síntesis. Esto ha permitido controlar la adsorción y las propiedades ácidas en las zeolitas de poro pequeño, lo que no se puede lograr mediante metodologías de post-síntesis. 


\section{Resum}

Les zeolites són materials cristal-lins microporosos amb canals i mides de porus de dimensions moleculars. L'estructura i composició de les zeolites els confereix interessants propietats que permeten la seua aplicació en una àmplia gamma d'aplicacions industrials com adsorció, separació o catàlisi. La síntesi de zeolites és l'etapa més important per al control de l'estructura i composició de les zeolites i, per tant, crítica per a l'optimització de les seues propietats.

Aquesta tesi s'ha centrat en la síntesi de zeolites utilitzant compostos que contenen fòsfor (cations fosfoni i aminofosfoni) com a agents directors d'estructura (P-ADE). L'ús de compostos fosforats influeix en la cristal-lització i propietats de les zeolites obtingudes en comparació amb les zeolites obtingudes amb cations d'amoni clàssics.

Els compostos fosforats es van triar a causa de la seua diferent química i estabilitat pel que fa als cations d'amoni clàssics utilitzats en la síntesi de zeolites. Aquests aspectes s'estudiaren amb un estudi comparatiu de diferents cations d'amoni i fosforats.

Els compostos de fòsfor utilitzats en aquest treball han donat lloc a noves estructures cristal-lines (ITQ-58 i ITQ-66) i han obert noves vies de síntesi de zeolites ja conegudes (RTH, IWV i DO), ampliant la seua gamma de composicions químiques.

La descomposició tèrmica dels P-ADE atrapats dins de les zeolites dona lloc a la formació d'espècies de fòsfor extra-xarxa que romanen dins dels canals i cavitats de les zeolites. Aquestes espècies modulen les propietats àcides i d'adsorció dels materials finals depenent dels tractaments post-síntesi. En aquest treball s'ha estudiat una ruta per la incorporació de quantitats controlades de fòsfor durant l'etapa de síntesi. Això ha permés controlar l'adsorció i les propietats àcides en les zeolites de porus petit, el que no es pot aconseguir mitjançant metodologies de post-síntesi. 


\section{Index}

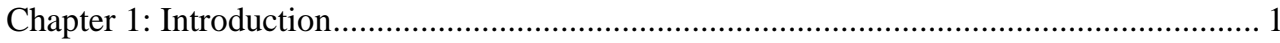

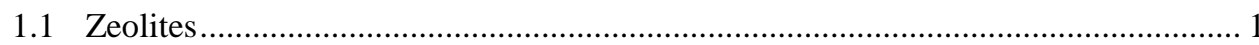

1.1.1 Zeolites structure and classification................................................................... 1

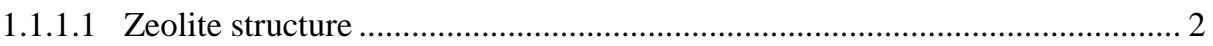

1.1.1.2 Zeolites chemical composition.................................................................. 4

1.1.1.3 Classification of zeolites ........................................................................ 4

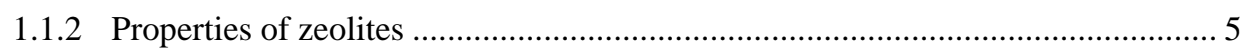

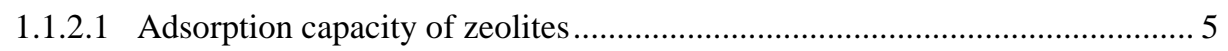

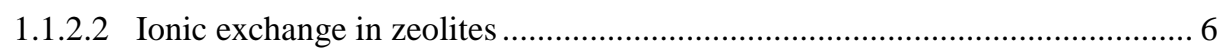

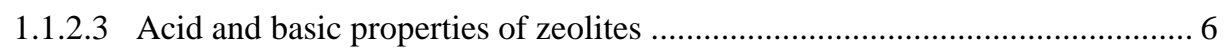

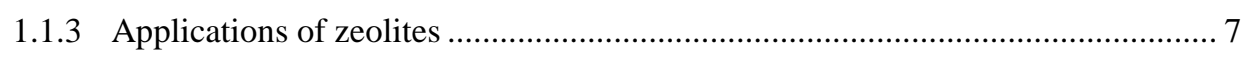

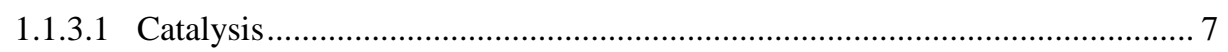

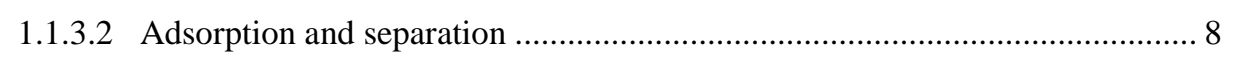

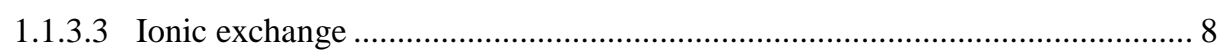

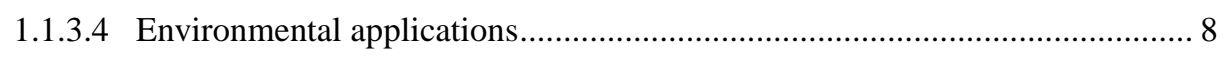

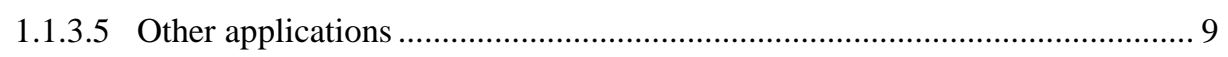

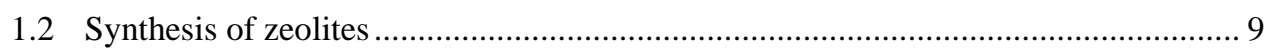

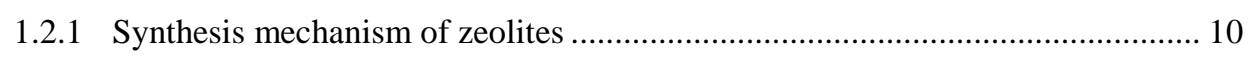

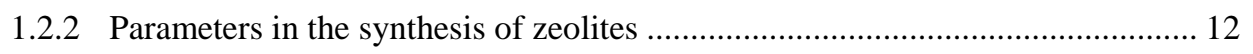

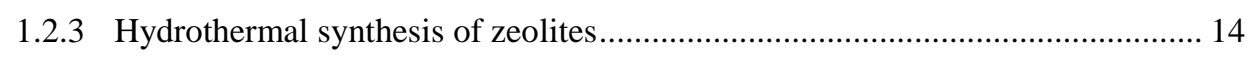

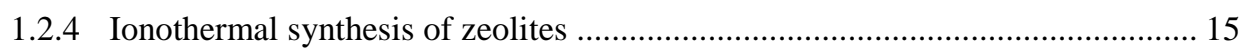

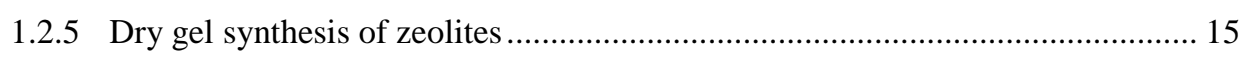

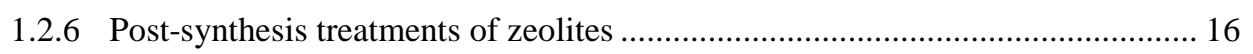

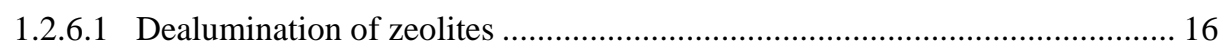

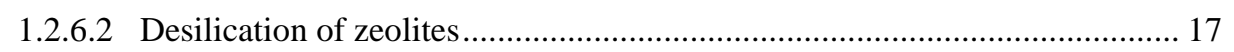

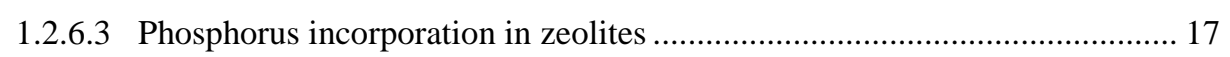

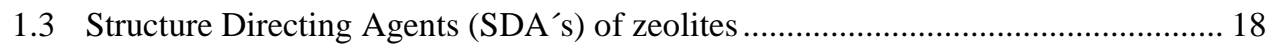

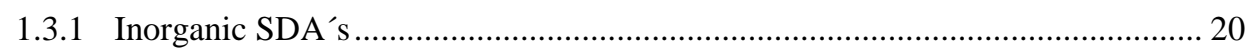

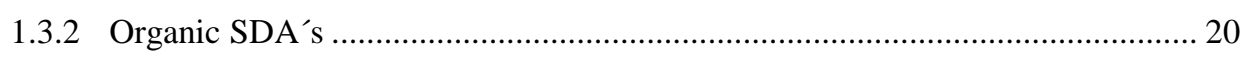

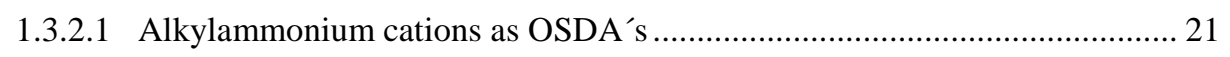

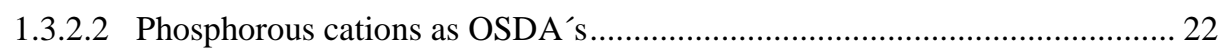

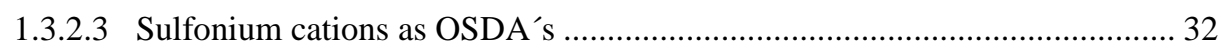

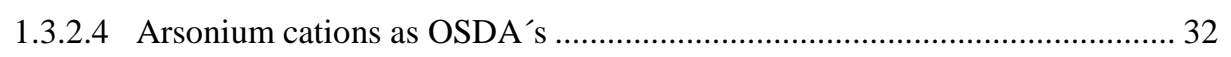

1.3.2.5 Oxo crown macrocycles (crown ethers) OSDA`s ……................................... 32 


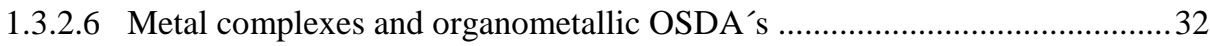

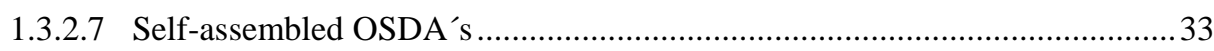

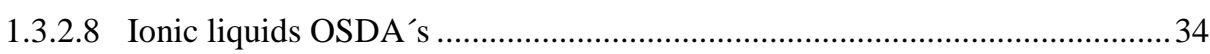

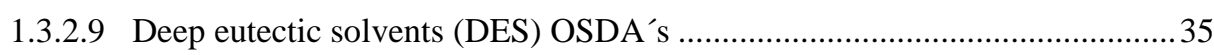

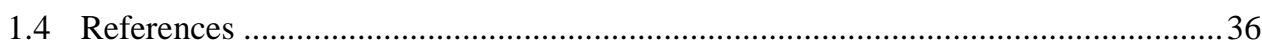

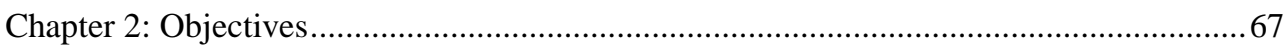

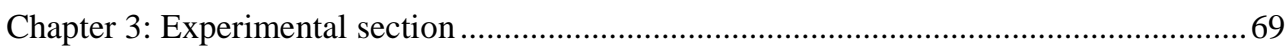

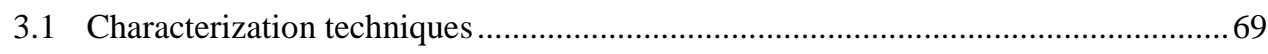

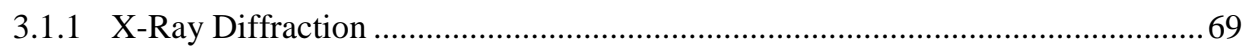

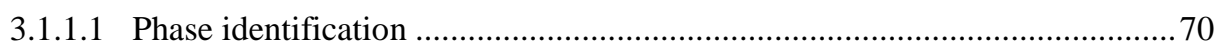

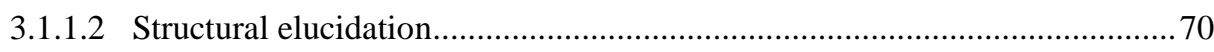

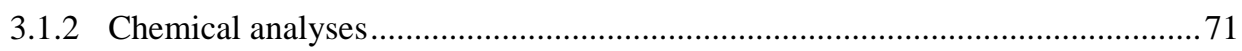

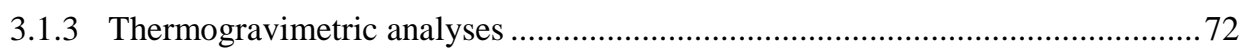

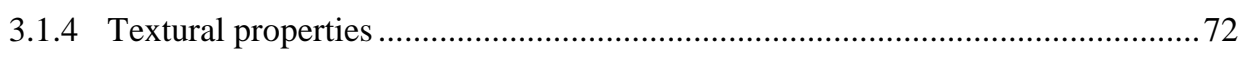

3.1.4.1 Surface area and micropore volume determination ..................................... 73

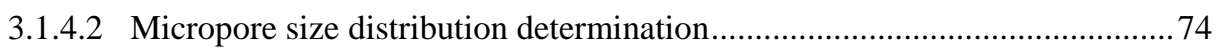

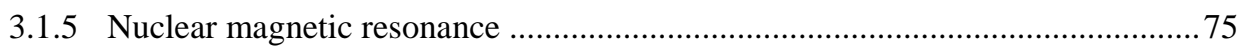

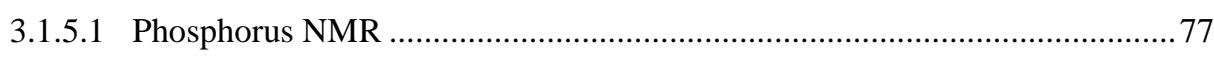

3.1.5.2 Silicon NMR ......................................................................................... 78

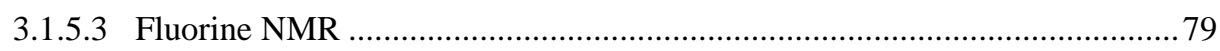

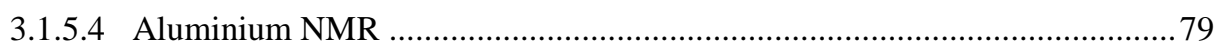

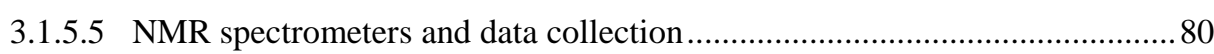

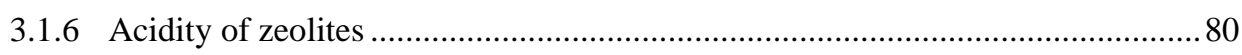

3.1.6.1 Fourier Transform-Infrared spectroscopy using pyridine as probe molecule 81

3.1.6.2 Ammonia Thermoprogrammed Desorption Mass Spectrometry (TPD-MS). 83

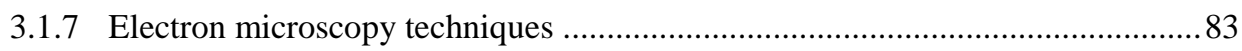

3.1.7.1 Scanning Electron Microscopy (SEM) ....................................................... 84

3.1.7.2 Energy Dispersive X-Ray spectroscopy (EDX) ........................................... 84

3.1.7.3 Transmission Electron Microscopy (TEM) ................................................. 85

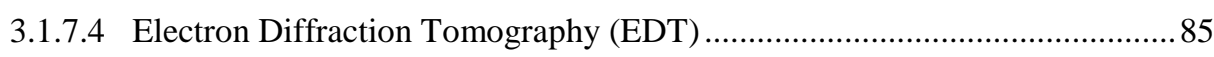

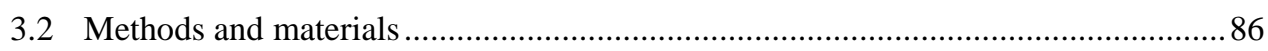

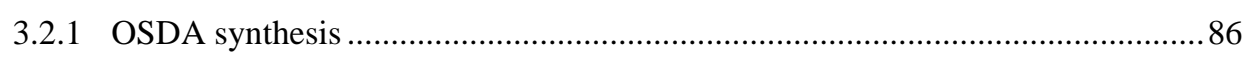

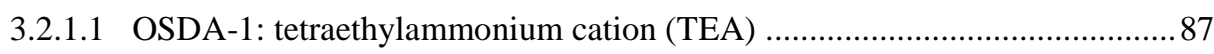

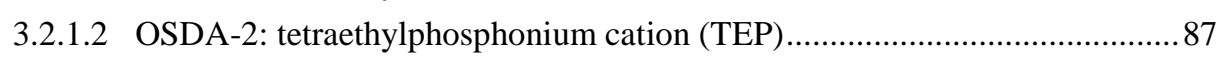

3.2.1.3 OSDA-3: methyl-tris-(dimethylamino)-phosphonium cation (MNP) ........... 88 
3.2.1.4 OSDA-4: methyl-tri-isopropylphosphonium cation (MIP) ........................... 90

3.2.1.5 OSDA-5: di-isopropyl-diethylammonium cation (IEN) .............................. 92

3.2.1.6 OSDA-6: phosphazene base P1-t-Bu (PB1) ................................................ 94

3.2.1.7 OSDA-7: tris(diethylamino)(methyl)phosphonium cation ......................... 95

3.2.1.8 OSDA-8: butane - 1,4-diylbis [tris(dimethylamino) phosphonium] cation (PN-

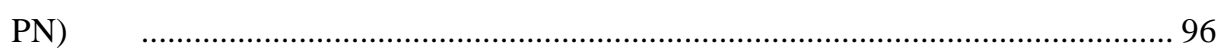

3.2.1.9 OSDA-9: butane-1,4-diylbis(triisopropylphosphonium) cation.................... 98

3.2.1.10 OSDA-10: tris(dimethylamino) [4-(tri-tert-butylphosphonio) butyl]

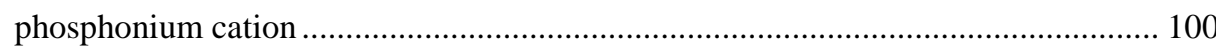

3.2.1.11 OSDA-11: Butane-1,4-diylbis(triethylphosphonium) cation ....................... 103

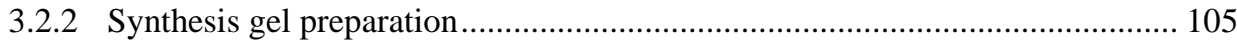

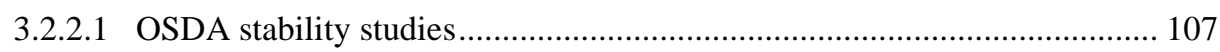

3.2.2.2 Dual template synthesis of MFI (ZSM-5, TS-1) zeolite ............................. 109

3.2.2.3 Dual template synthesis of RTH (RUB-13) zeolite .................................. 111

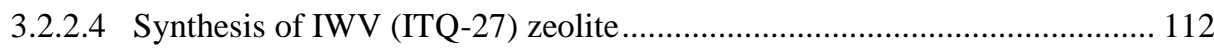

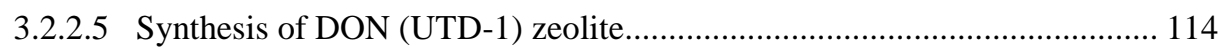

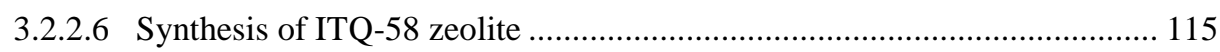

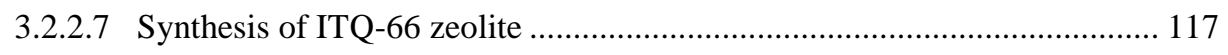

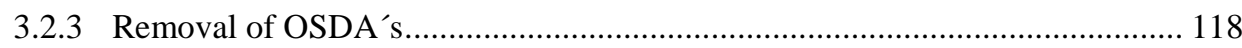

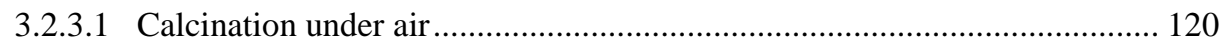

3.2.3.2 High temperature treatment under $\mathrm{H}_{2}$ stream.......................................... 120

3.2.3.3 Washing of residual phosphorous species.............................................. 122

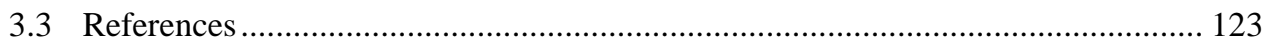

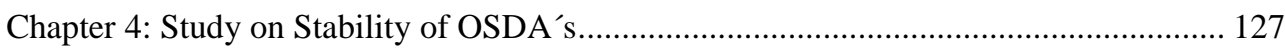

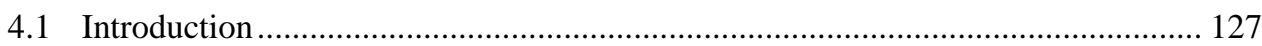

4.2 Experiment 1: effect of the hydrothermal parameters on OSDA's in MFI synthesis...

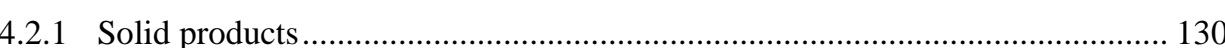

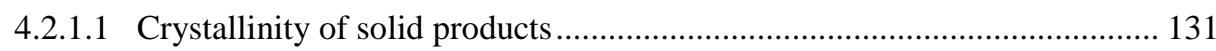

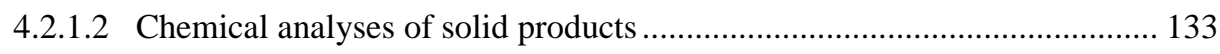

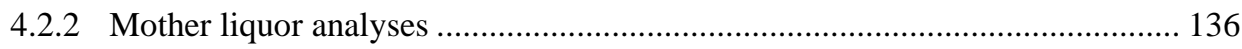

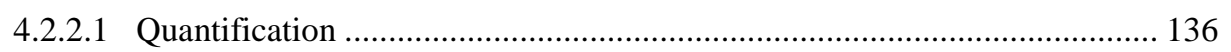

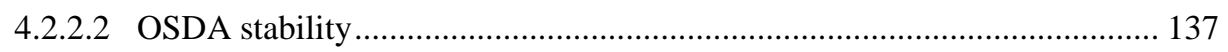

4.3 Experiment 2: generalized study of the OSDA stability ..................................... 141

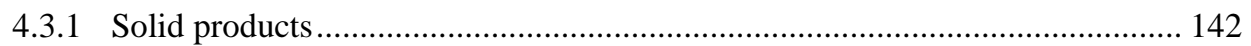

VI 


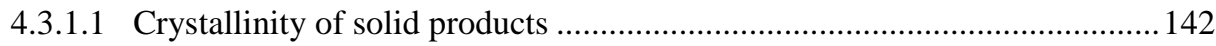

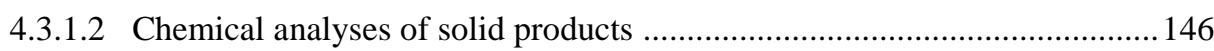

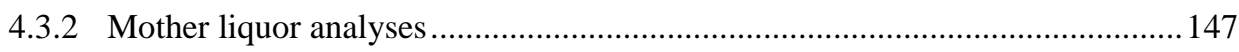

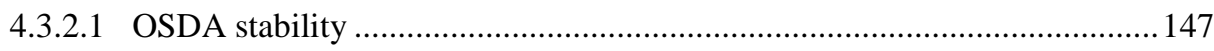

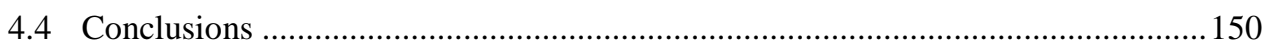

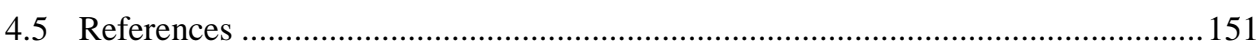

Chapter 5: Phosphorous Modified Zeolites ................................................................ 153

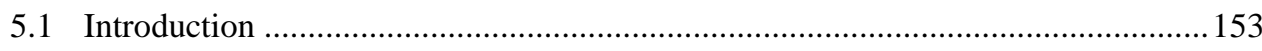

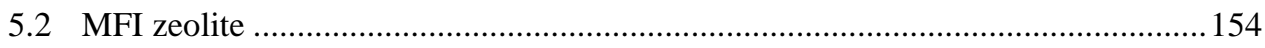

5.2.1 Dual template P-modified all-silica MFI zeolite ........................................... 155

5.2.1.1 Chemical analyses of as-made P-modified all-silica MFI zeolite................. 158

5.2.1.2 Morphology of as-made P-modified all-silica MFI zeolite .......................... 160

5.2.1.3 Thermogravimetric analysis of as-made P-modified all-silica MFI zeolite. 161

5.2.2 Dual template P-modified aluminosilicate MFI zeolite ................................... 162

5.2.2.1 Chemical analyses of as-made P-modified aluminosilicate MFI zeolite ..... 163

5.2.2.2 Morphology of P-modified aluminosilicate MFI zeolite .............................. 166

5.2.2.3 Thermogravimetric analysis of as-made P-modified alumino- silicate MFI

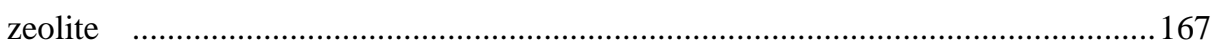

5.2.3 Thermal treatments of P-modified aluminosilicate MFI zeolite ....................... 168

5.2.3.1 Crystallinity of thermally treated P-modified aluminosilicate MFI zeolite. 168

5.2.3.2 Chemical analyses of thermally treated P-modified alumino- silicate MFI

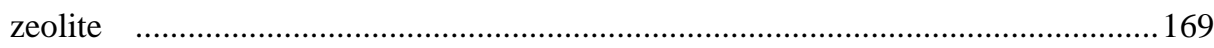

5.2.3.3 Textural properties of P-modified aluminosilicate MFI zeolite .................. 170

5.2.3.4 Acidic properties of thermally treated aluminosilicate MFI zeolite ............ 172

5.2.4 NMR analyses of P-modified aluminosilicate MFI zeolite ............................. 174

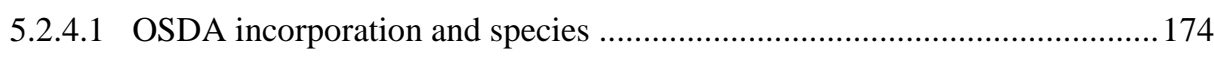

5.2.4.2 Aluminium incorporation and species .................................................. 178

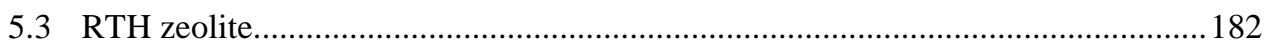

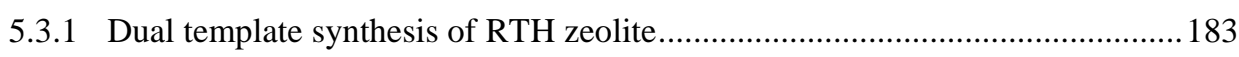

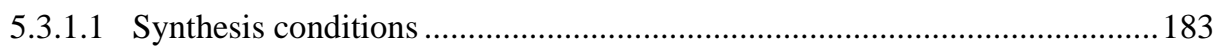

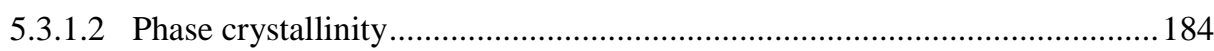

5.3.2 Sample analyses of as-made P-modified RTH zeolite ..................................... 185

5.3.2.1 Chemical analyses of as-made P-modified RTH zeolite ............................ 185

5.3.2.2 Morphology of as-made P-modified RTH zeolite ...................................... 187

5.3.2.3 Thermogravimetric analysis of as-made P-modified RTH zeolite ............... 188 
5.3.3 Thermal treatments of P-modified RTH zeolite ......................................... 190

5.3.3.1 Crystallinity of thermally treated P-modified RTH zeolite.......................... 190

5.3.3.2 Chemical analyses of thermally treated P-modified RTH zeolite ................ 191

5.3.3.3 Textural properties of thermally treated P-modified RTH zeolite .............. 191

5.3.3.4 Acidic properties of thermally treated RTH zeolite ................................... 193

5.3.4 NMR study of P-modified RTH zeolite...................................................... 194

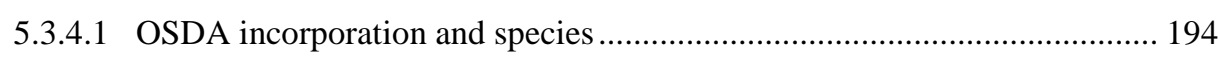

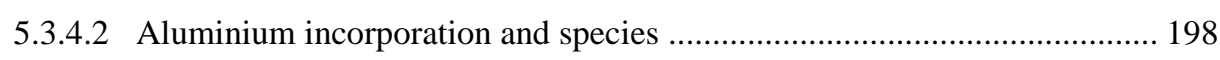

5.4 NMR study of phosphorus species in P-modified MFI and RTH ....................... 203

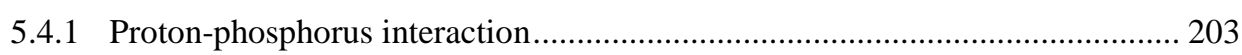

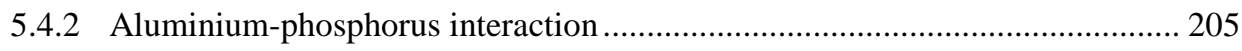

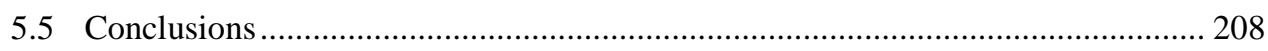

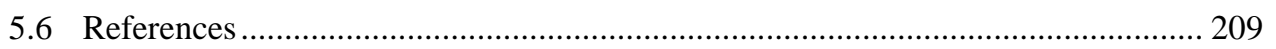

Chapter 6: Synthesis of ITQ-27 (IWV) and UTD-1 (DON) Zeolites ............................... 217

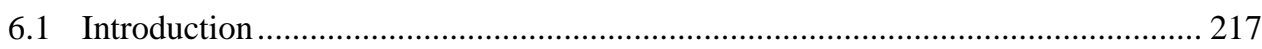

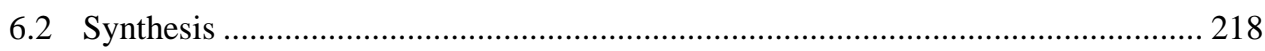

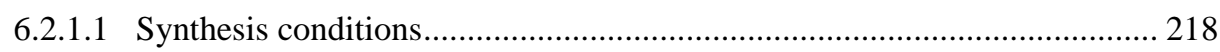

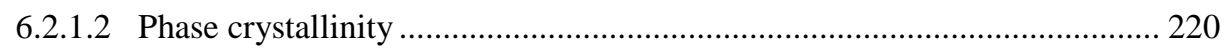

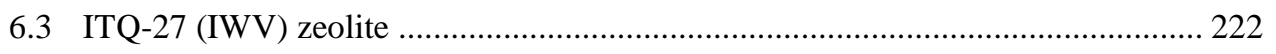

6.3.1 Sample analyses of as-made IWV zeolite................................................... 223

6.3.1.1 Chemical analyses of as-made IWV zeolite............................................... 223

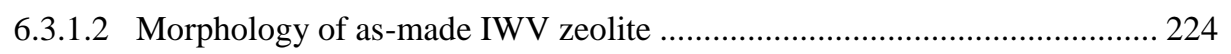

6.3.1.3 Thermogravimetric analysis of the as-made IWV zeolite ........................... 226

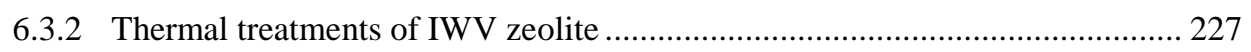

6.3.2.1 Crystallinity of thermally treated IWV zeolite........................................... 227

6.3.2.2 Chemical analyses of thermally treated IWV zeolite ................................. 228

6.3.2.3 Morphology of thermally treated IWV zeolite.......................................... 230

6.3.2.4 Textural properties of thermally treated IWV zeolite ................................. 231

6.3.2.5 Acidic properties of thermally treated IWV zeolite .................................. 233

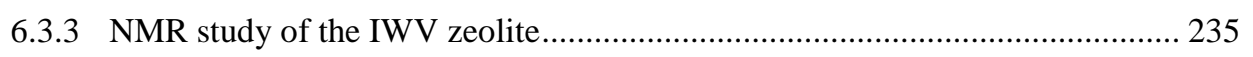

6.3.3.1 Incorporation and stability of the OSDA into the IWV zeolite................... 235

6.3.3.2 Aluminium incorporation in the IWV zeolite .............................................. 239

6.3.3.3 Boron incorporation in the IWV zeolite................................................... 242

6.3.3.4 Fluorine incorporation in the IWV zeolite framework ................................ 243

6.3.3.5 Silicon framework of the IWV zeolite ................................................... 244 


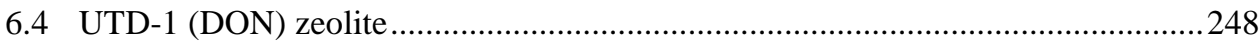

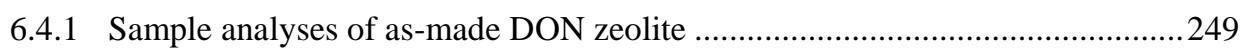

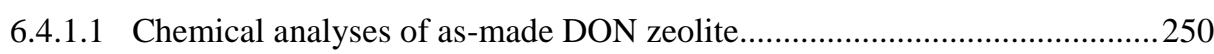

6.4.1.2 Morphology of as-made DON zeolite ..........................................................251

6.4.1.3 Thermogravimetric analysis of the as-made DON zeolite............................252

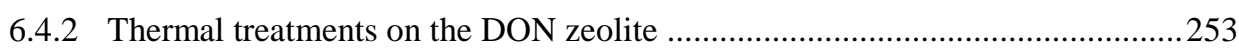

6.4.2.1 Crystallinity of thermally treated DON zeolite..............................................254

6.4.2.2 Chemical analyses of thermally treated DON zeolite..................................254

6.4.2.3 Morphology of thermally treated DON zeolite............................................256

6.4.2.4 Textural properties of thermally treated DON zeolite ..................................257

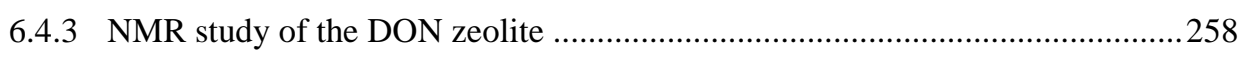

6.4.3.1 Incorporation and stability of the OSDA to the DON zeolite.......................259

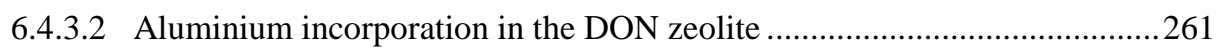

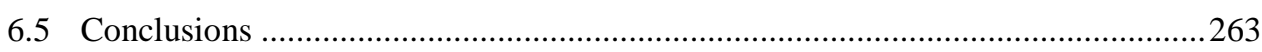

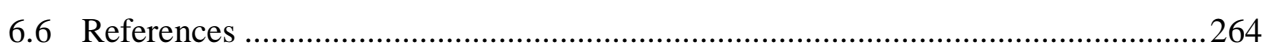

Chapter 7: Synthesis of New Zeolite Materials ...........................................................269

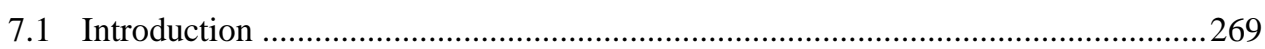

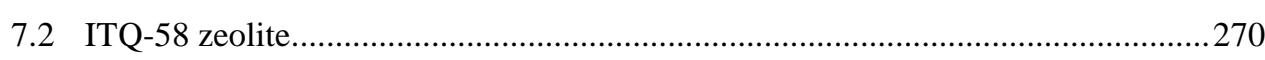

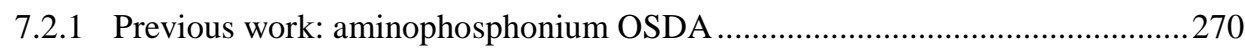

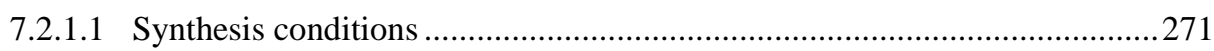

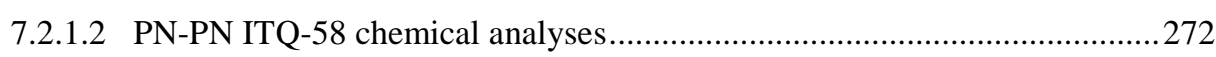

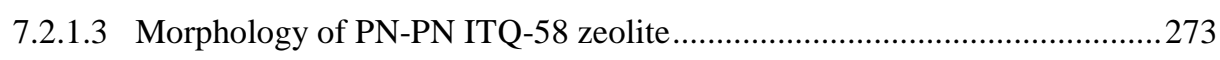

7.2.1.4 Thermogravimetric analysis of the PN-PN ITQ-58 zeolite ..........................274

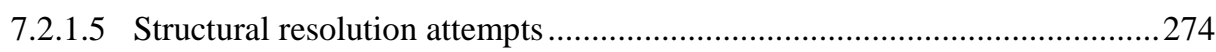

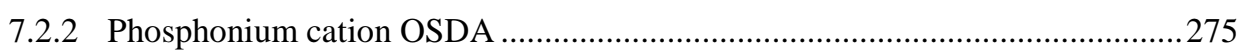

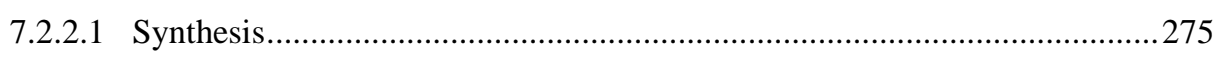

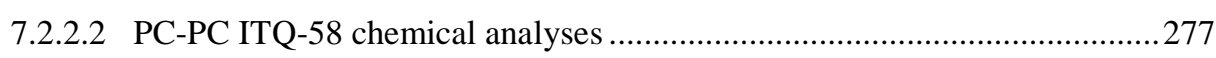

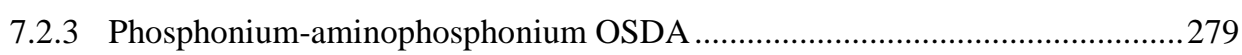

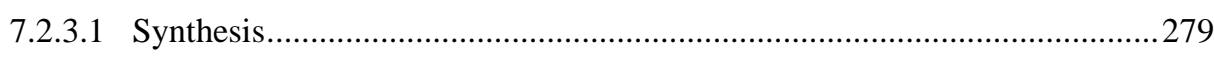

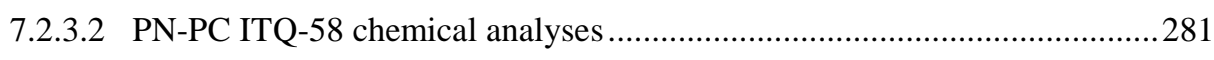

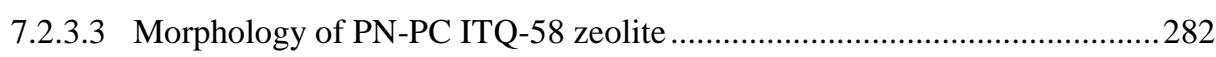

7.2.3.4 Thermogravimetric analysis of the PN-PC ITQ-58 zeolite ..........................282

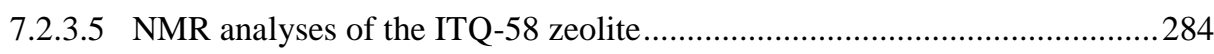

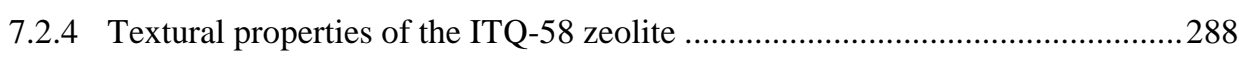

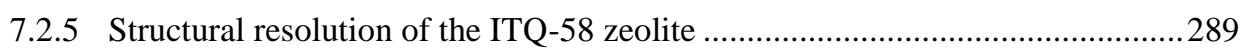




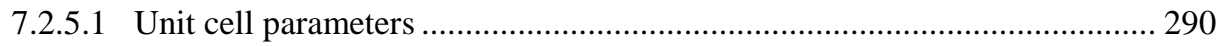

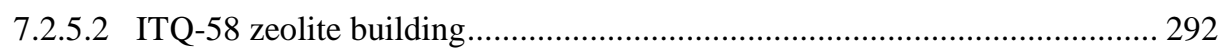

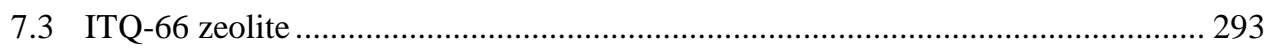

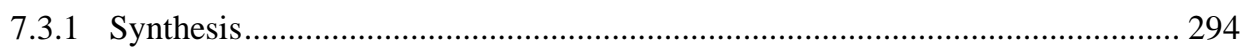

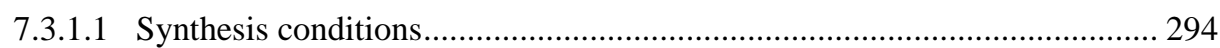

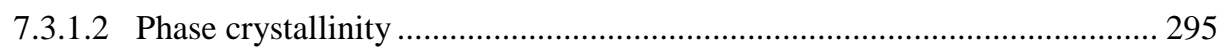

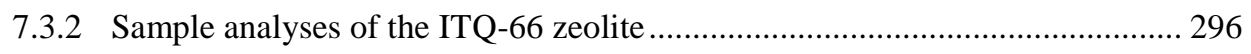

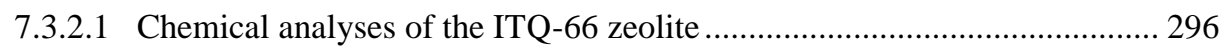

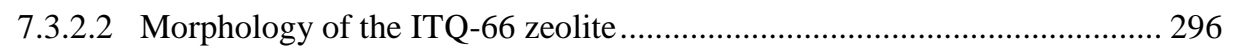

7.3.2.3 Thermogravimetric analysis of the as-made ITQ-66 zeolite........................ 297

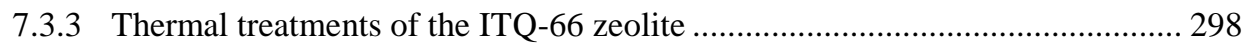

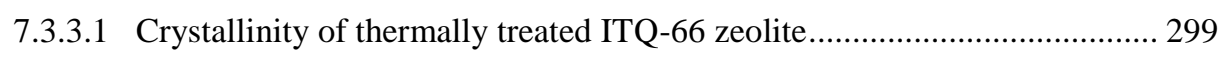

7.3.3.2 Chemical analyses of thermally treated ITQ-66 zeolite ................................ 300

7.3.3.3 Morphology of thermally treated ITQ-66 zeolite........................................ 301

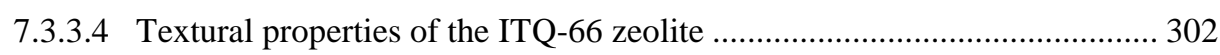

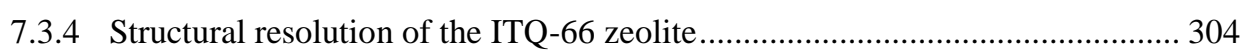

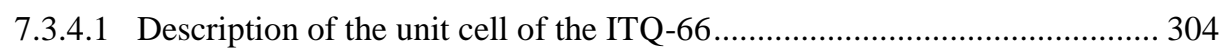

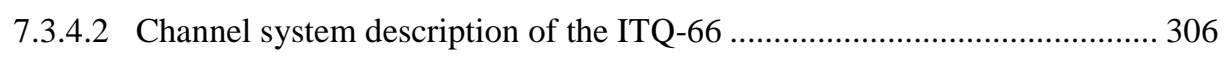

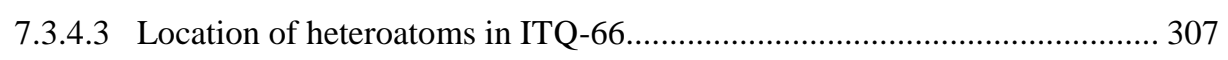

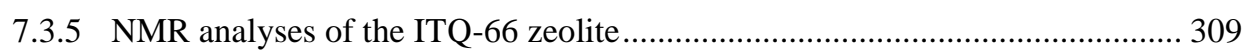

7.3.5.1 Incorporation and stability of the OSDA into the ITQ-66 zeolite................ 309

7.3.5.2 Gallium incorporation into the ITQ-66 zeolite ……………..................... 312

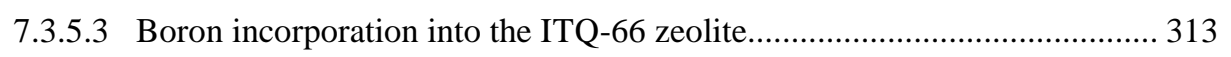

7.3.5.4 Fluorine incorporation into the ITQ-66 zeolite framework ........................... 314

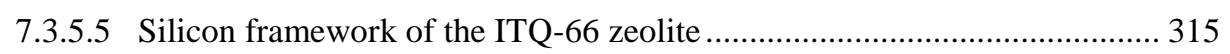

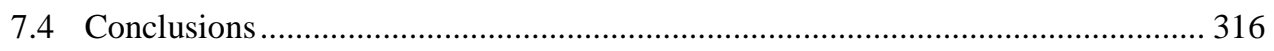

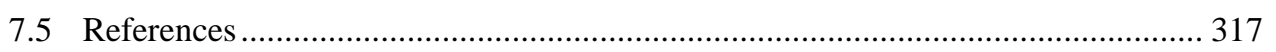

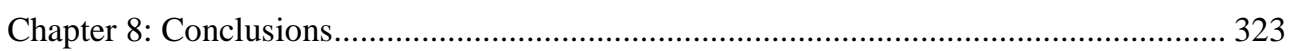

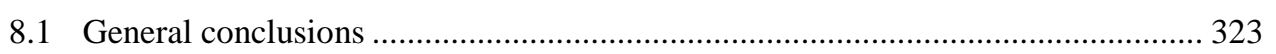

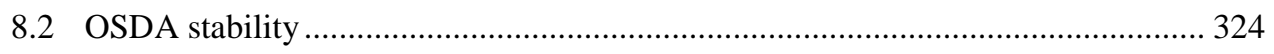

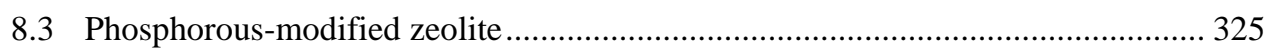

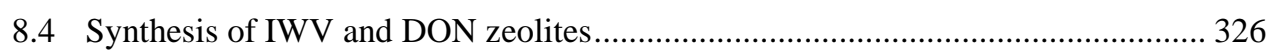

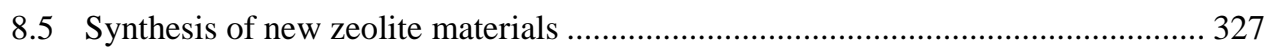




\section{Chapter 1}

\section{Introduction}

\subsection{Zeolites}

Zeolite and zeolite-like materials (zeotypes) are defined by IUPAC as microporous materials with inorganic 3D host frameworks composed of tetrahedral [TX $\left.\mathrm{TX}_{4}\right]$ units. ${ }^{[1]}$ Zeolites constitute the largest group of the ordered microporous materials family. Microporous materials present an ordered array of accessible pores with pore openings below $2 \mathrm{~nm} .{ }^{[2]}$

The term zeolite was coined by A. F. Cronstedt in 1756 to name a mineral which expelled boiling water when heated, which resulted to be the stilbite zeolite. ${ }^{[3]}$ Since then, several natural zeolites, like chabazite, faujasite or analcime zeolites, among others, had been discovered and studied. ${ }^{[4]}$

\subsubsection{Zeolites structure and classification}

Zeolites are commonly defined as crystalline microporous materials with a framework built of corner sharing $\mathrm{SiO}_{4}{ }^{-}$and $\mathrm{AlO}_{4}{ }^{-}$tetrahedral units that form channels and cages, ${ }^{[5]}$ filled with water and exchangeable cations. ${ }^{[6]}$ 


\subsubsection{Zeolite structure}

Zeolites present a tridimensional structure made up by $\mathrm{T}$ atoms tetrahedrally bonded to bi-coordinated $\mathrm{X}$ atoms. Typically, $\mathrm{T}$ atoms comprise silicon and aluminium atoms, while $\mathrm{X}$ typically comprise oxygen atoms. These tetrahedral units are linked between them by corner sharing. The build-up of these tridimensional structures leads to the formation of voids and regular channels of molecular dimensions (3 - $12 \AA$ ). Zeolites present low framework densities, usually less than $21 \mathrm{~T} / 1000 \AA^{3}$, being $T$ the number of tetrahedral units per unit cell. ${ }^{[7]}$

The different spatial arrangement of these tetrahedral units leads to different zeolite structures or framework types. Up to date (March 2021), the International Zeolite Association (IZA) has accepted 253 different framework types, ${ }^{[8]}$ although there are many other zeolites whose structures are yet unknown. Furthermore, there is a high number of theorized structures that have not yet been synthesized. ${ }^{[9,10]}$

Zeolitic structures can be described from units built by a relatively small number of tetrahedra, known as Secondary Building Units (SBU's), ${ }^{[7]}$ depicted in Figure 1.1.

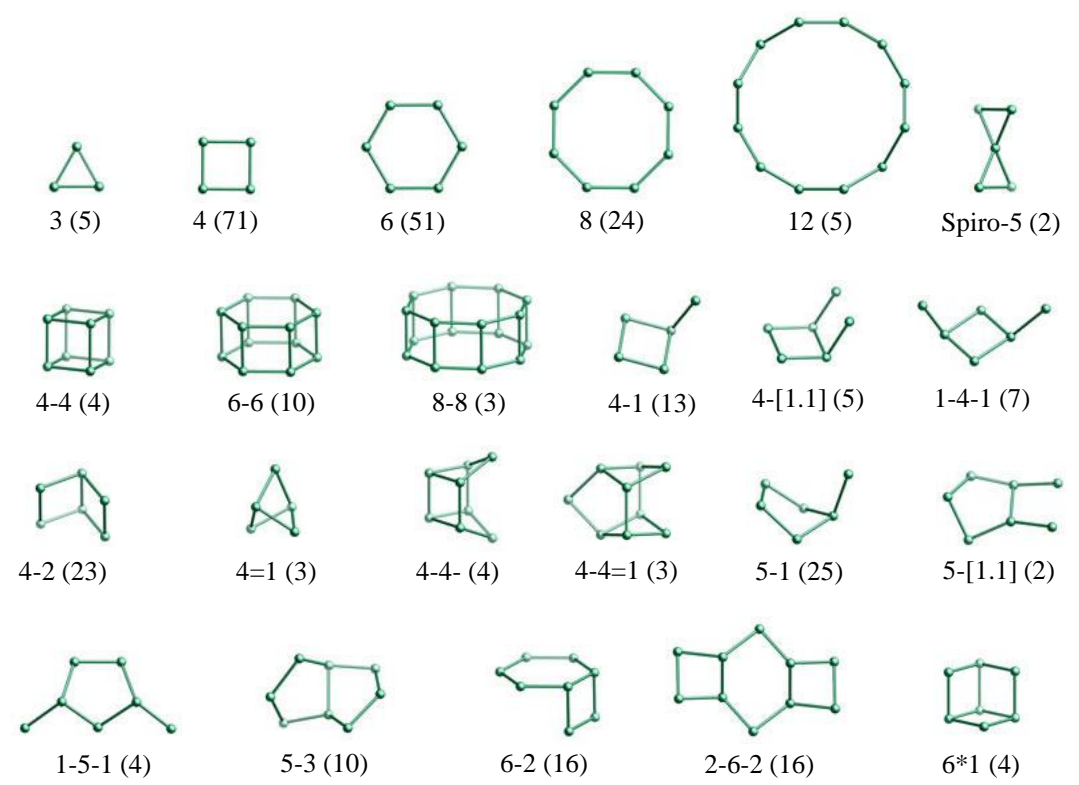

Figure 1.1. Zeolitic Secondary Building Units (SBU's). Frequency of occurrence is given in brackets. $^{[8]}$ 
Additionally, zeolitic structures could be also described by more complex construction units named Composite Building Units (CBU's), shown in Figure 1.2. ${ }^{[7]}$ Each $\mathrm{CBU}$ is assigned a three letter code corresponding to the zeolitic structure where it was first described.

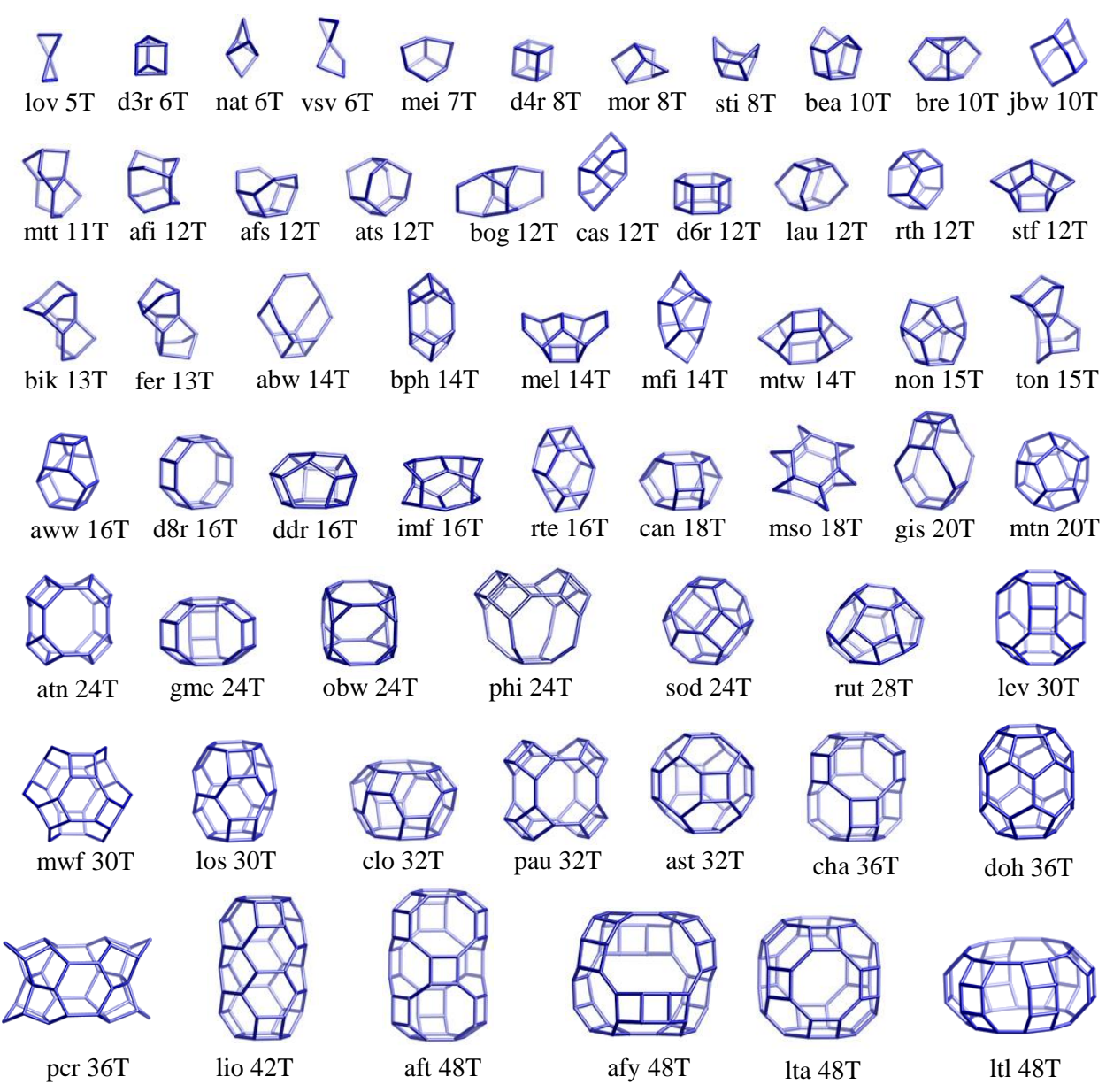

Figure 1.2. Zeolitic Composite Building Units (CBU's). ${ }^{[8]}$ 


\subsubsection{Zeolites chemical composition}

The empirical formulation of zeolites is generally described as:

$$
\mathrm{SiO}_{2}: \mathrm{M}_{2 / n} \mathrm{O}: x \mathrm{X}_{2} \mathrm{O}_{3}: y \mathrm{YO}_{2}: z \mathrm{H}_{2} \mathrm{O}
$$

where $\mathrm{M}^{\mathrm{n}+}$ corresponds to a cation, most commonly alkaline cations like $\mathrm{Na}^{+}, \mathrm{Ca}^{2+}$, $\mathrm{K}^{+}$and $\mathrm{Ba}^{2+}$. These cations neutralize the negative charge introduced in the structure by the isomorphic substitution of silicon atoms by trivalent elements $(\mathrm{X})$, being $\mathrm{Al}^{3+}$ or $\mathrm{B}^{3+}$ the most common. The silicon atoms may also be isomorphically substituted by other tetravalent atoms (Y) such as $\mathrm{Ti}^{4+},{ }^{[11]} \mathrm{Ge}^{4+[12]}$ and $\mathrm{Sn}^{4+},{ }^{[13]}$ among others. ${ }^{[14]}$

\subsubsection{Classification of zeolites}

Zeolites could be classified by their pore size, pore topology or chemical composition. The most typical classification attends to the size of their pore openings, which is usually related to the number of tetrahedra building the pore, named as member rings (MR or simply $\mathrm{R})$, as detailed in Table 1.1.

Table 1.1. Classification of zeolites attending their pore size.

\begin{tabular}{cccc}
\hline Zeolite pore size & MR & Pore diameter $/ \AA$ & Examples \\
\hline Extra-large & $>14$ & $>7.5$ & CFI, DON, CLO \\
Large & 12 & $5.5-7.5$ & FAU, BEA, IWV \\
Medium & 10 & $4-6$ & MFI, FER, MTT \\
Small & 8 & $3.5-5$ & LTA, ITE, RTH \\
\hline
\end{tabular}

Zeolites are also classified attending their pore channel dimensionality depending on whether the pore channels run along one, two or three directions in the space as: ${ }^{[8]}$ i) mono-dimensional, like RTE, STF and TON zeolites, for example; ii) bi-dimensional, like FER, MOR and RTH zeolites for example; iii) or tri-dimensional, like FAU, LTA and MFI zeolites for example. Also, there are microporous materials with cage structures that are classified as zero-dimensional, such as AST, MTN and SOD zeolites for example, with channels equal or below $6 \mathrm{MR}$, and thus, inaccessible to molecules of industrial interest. ${ }^{[1]}$

Zeolites are also classified by their composition. Thus, depending on the $\mathrm{Si} / \mathrm{X}$ molar ratio, the materials are classified as zeolites when the $\mathrm{Si} / \mathrm{X}<500$ and as zeosils when the $\mathrm{Si} / \mathrm{X}>500 .{ }^{[15,16]}$ Also, silicon atoms could be completely replaced by other elements as 
germanium or aluminium and phosphorus, giving rise to germanate ${ }^{[17,18]}$ and aluminophosphate zeotypes, ${ }^{[19,}{ }^{20]}$ respectively, keeping the structure of typical zeolites. ${ }^{[1]}$ Each framework type comprises all materials that fulfils the same structure connectivity regardless of their composition.

\subsubsection{Properties of zeolites}

Zeolites present interesting properties due to their crystalline structure and their molecular-size pore openings. Also, the feasibility of zeolites to isomorphically substitute silicon atoms by trivalent elements provides the material structure of an excess of negative charge. This charge must be compensated by extra-framework cations, would it be alkali cations, alkali-earth cations, organic cations or protons. ${ }^{[21]}$ In the case of alkali, alkali-earth and organic cations, zeolites mostly present neutral, or even basic properties, ${ }^{[22,23]}$ while in the case of protons, zeolites present acidic properties. ${ }^{[24]}$ Some of the most relevant properties of zeolites are described next:

\subsubsection{Adsorption capacity of zeolites}

Zeolites, due to their microporous structure, present a large surface area with a discrete range of pore openings. These properties allow the selective adsorption of molecules of different sizes depending on the size of the zeolite channels, allowing to discriminate between molecules with kinetic diameters barely differentiated by $0.1 \AA$. Two different adsorption mechanisms exist: ${ }^{[25]}$

- Physisorption: the adsorbed chemical species (adsorbate) weakly interacts with the solid surface. This weak interaction corresponds with an adsorption enthalpy below $50 \mathrm{~kJ} / \mathrm{mol}$. The microporous nature of zeolites produces capillary condensation of the adsorbate at very low partial pressures. Thus, liquid phase-like reactions could take place at temperatures much higher than the boiling point or at very low partial pressure of the adsorbate.

- Chemisorption: the adsorbate strongly interacts with the solid surface. This strong interaction can achieve an adsorption enthalpy of up to $800 \mathrm{~kJ} / \mathrm{mol}$. The adsorbate undergoes a chemical transformation that leads to a different chemical species. Chemisorption is a selective process and occurs on isolated centres corresponding to the active sites in the zeolite. 


\subsubsection{Ionic exchange in zeolites}

The presence of trivalent elements, mainly $\mathrm{Al}^{3+}$, in the zeolite structure generate negative charges that must be compensated by extra-framework cations located in the channels and voids of the zeolite. These cations are usually highly mobile and easily exchangeable with other cations present in the surrounding media. This cationic exchange does not modify the zeolite structure, differing from other ionic exchangers. The ionic exchange capacity increases as the cationic load does, and thus, with the decrease of the $\mathrm{Si} / \mathrm{Al}$ ratio of the zeolite. ${ }^{[26,27]}$

\subsubsection{Acid and basic properties of zeolites}

The isomorphic substitution of $\mathrm{Si}^{4+}$ by $\mathrm{Al}^{3+}$ atoms leads to a negatively charged structure, which is balanced by extra-framework cations located inside the solid. These cations could be inorganic, mainly alkaline and alkaline-earth cations, $\mathrm{NH}_{4}{ }^{+}$cation or organic cations. Depending on the nature and chemical properties of this balancing cation, zeolites could display basic or acidic properties. ${ }^{[21]}$ The thermal treatment of zeolites with $\mathrm{NH}_{4}{ }^{+}$or organic cations occluded inside the material leads to the decomposition of these species, being replaced by protons $\left(\mathrm{H}^{+}\right)$which counter-balance the negative charge of the zeolitic framework. ${ }^{[28]}$

When an alkaline or an alkaline-earth cation balances the negative charge of the zeolite framework, the zeolite present neutral or basic properties. ${ }^{[22,23]}$ In the latter case, the oxygen atoms of the crystalline lattice form Lewis type basic sites, and the balancing cations and framework composition modulate that basicity. ${ }^{[29]}$ Small charge/mass ratio cations, like $\mathrm{Cs}^{+}$, have a low interaction with the structure, increasing the negative charge density over the oxygen atoms, and thus, increasing the basicity of the zeolite. ${ }^{[30,31]} \mathrm{Low} \mathrm{Si} / \mathrm{Al}$ ratios also provide higher electronic densities over oxygen atoms than high $\mathrm{Si} / \mathrm{Al}$ ratios, resulting in stronger bases. $^{[32]}$

On the other hand, the acidic properties of zeolites are characterized by the presence of $\mathrm{Al}^{3+}$ species. Depending on the specific $\mathrm{Al}$ chemical species, two different acidic centres could be discerned: ${ }^{[24,33]}$

- Brönsted acid centres: they are generated by the protons created after the thermal decomposition of $\mathrm{NH}_{4}{ }^{+}$or organic cations. The number of acid centres is proportional 
to the aluminium content of the material. The increase of acidic centres increases the total acidity of the zeolite, but the acid strength of each centre decreases. ${ }^{[22,32]}$

- Lewis acid centres: they are usually associated to aluminium oxyhydroxide species in extra-framework positions, typically formed by the dealumination of the zeolite during thermal treatments. These centres are not associated to protons as balancing cations of the zeolite, but their presence is the result of the hydrolysis of Si-O-Al bonds. ${ }^{[34]}$ Also, the isomorphical substitution of $\mathrm{T}$ atoms by d-elements, like $\mathrm{Ti}^{4+}$ or $\mathrm{Sn}^{4+}$, provides of Lewis acidity to the resulting solids. ${ }^{[35-37]}$

\subsubsection{Applications of zeolites}

Zeolites, because of their properties, are very interesting materials for several industrial applications. Some of the applications described here have been applied for decades, while others represent a promising hope for the successful implementation of green chemistry. ${ }^{[38-42]}$

\subsubsection{Catalysis}

Zeolites are widely used in a large number of reactions as heterogeneous catalysts due to their high activity, and especially, due to their shape selectivity. Catalysts decrease the activation energy of a given reaction to occur, and the microporous structure of the zeolite allow improving the reaction selectivity towards the desired products. The shape selectivity of zeolites could be due to: i) the favoured adsorption of one reagent because of its size and shape; ii) the favoured formation of a given transitional state along the reaction pathway; iii) the preferential diffusion of one of the possible reaction products throughout their channels. ${ }^{[43,44]}$

Zeolites have been mostly used as acid catalysts in oil refining processes for decades. ${ }^{[45-47]}$ However, in recent years the application of zeolites has spread to the synthesis of fine chemicals ${ }^{[48,49]}$ the processing of renewable raw materials, such as obtaining biofuels: ${ }^{[50,51]}$ the catalytic transformation of synthesis gas into hydrocarbons $;{ }^{[52,53]}$ or the conversion of methanol to hydrocarbons. ${ }^{[54,55]}$ 


\subsubsection{Adsorption and separation}

Zeolites present adsorption properties that allow their use in separation processes, like the enrichment of gas streams in one of its components. This enrichment may be due to one of the gas stream components being bulkier than other component, and thus, being not able to diffuse through the channel of the zeolite, or may be due to a selective adsorption of one of the stream components over the active sites of the material.

The separation of the components could be performed using zeolite membranes or zeolites with different adsorption affinities for each gas stream component. ${ }^{[56-58]}$ High aluminium content zeolites lead to the adsorption of polar molecules, allowing the removal of $\mathrm{H}_{2} \mathrm{O}, \mathrm{CO}_{2}$ and sulphur species in hydrocarbon streams. ${ }^{\left[{ }^{[5-61]}\right.}$ Also, the different size of the channels of zeolites allow the separation of linear and branched hydrocarbons, ${ }^{[62,63]}$ and even paraffins and olefins. ${ }^{[64,65]}$

\subsubsection{Ionic exchange}

The main application of zeolites in terms of total production is as ionic exchangers, mainly for the removal of cations in water effluents. For example, zeolites are widely employed as detergent additives, like the $\mathrm{NaA}$ zeolite, used to soften water instead of pollutant polyphosphates. ${ }^{[6]}$

Also, the clinoptilolite zeolite, due to its high affinity towards ammonia, is used for ammonia removal from municipal, agricultural and industrial waste water. ${ }^{\left[67,{ }^{68]}\right.}$ Finally, zeolites may also be used for radioactive cation removal of ${ }^{137} \mathrm{Cs}^{+}$by mordenite, NaA, clinoptilolite or Rho zeolites. ${ }^{[69,70]}$

\subsubsection{Environmental applications}

Zeolites are used in environmental applications like the removal of $\mathrm{NO}_{\mathrm{x}}$ and VOC's from air by reduction and oxidation processes, respectively. ${ }^{[71-74]}$ It is also important the use of copper substituted zeolites in DeNOx process in gasoline and diesel engines using $\mathrm{NH}_{3}$ as reductor agent. ${ }^{[75-77]}$ 


\subsubsection{Other applications}

Beyond the previously applications, zeolites are also used in further applications. For example, the incorporation of silver to zeolites provides biocide activity to the materials, allowing their use in medical and environmental application, likewise their use in consumer goods. ${ }^{[78-82]}$

Finally, zeolite membranes present properties, like high temperature stability or endurance to extreme conditions, that have promoted their use as a support for active phases or as membrane reactors, ${ }^{[83]}$ as well as their use for gas sensors. ${ }^{[4,85]}$

\subsection{Synthesis of zeolites}

Zeolite synthesis began in 1862 when H. Saint-Claire-Deville reported the first hydrothermal synthesis of levynite zeolite. ${ }^{[86]}$ In 1930, W. H. Taylor reported the first resolution of the crystal structure of a zeolite, the analcime zeolite. ${ }^{[87]}$ The modern era of the zeolite synthesis started in 1940's, when R. M. Barrer reported the synthesis of zeolites P (GIS) and Q (KFI), without any natural counterpart at that time, ${ }^{[88]}$ while R. Milton developed a synthesis methodology based on freshly prepared aluminosilicate gels that it is still in use, with slight modifications, to this day. ${ }^{[89]}$

Within the materials science field, the research into the synthesis of microporous zeolitic materials has been and keeps on being, a field in steady expansion since the first synthesis of zeolite was reported. However, the synthesis of zeolites mostly remains as a trial-and-error science, and the prediction and rational design of a given microporous material still heavily relies on previous experience in the synthesis of the chosen material. Nonetheless, progress in the area is still considerable and thousands of publications dealing about zeolitic materials are yearly published, and among them, the number of papers discussing the synthesis of these materials is increasing every year, as shown in Figure 1.3. 

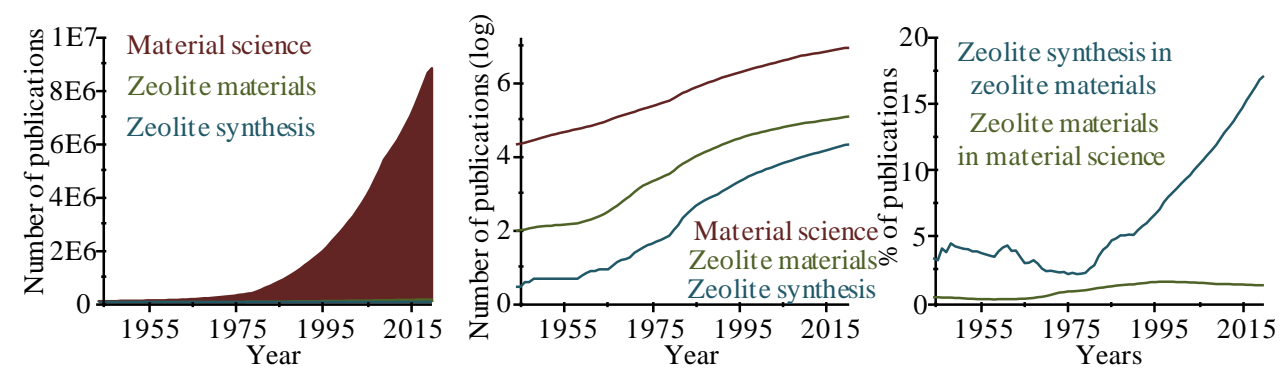

Figure 1.3. Number of material science (red), zeolite materials (green) and zeolite synthesis (blue) publications per year (left), number of publications per year in logarithmic scale (middle) and share of publications for each field (right). Font: Web of Science.

\subsubsection{Synthesis mechanism of zeolites}

The crystallization of zeolites is a complex process not fully understood yet, due to the large number of different physical and chemical parameters affecting to the synthesis in order to yield a specific material. ${ }^{[00-97]}$ However, it is widely acknowledged the presence of three different consecutive and overlapping stages, schematized in Figure 1.4.

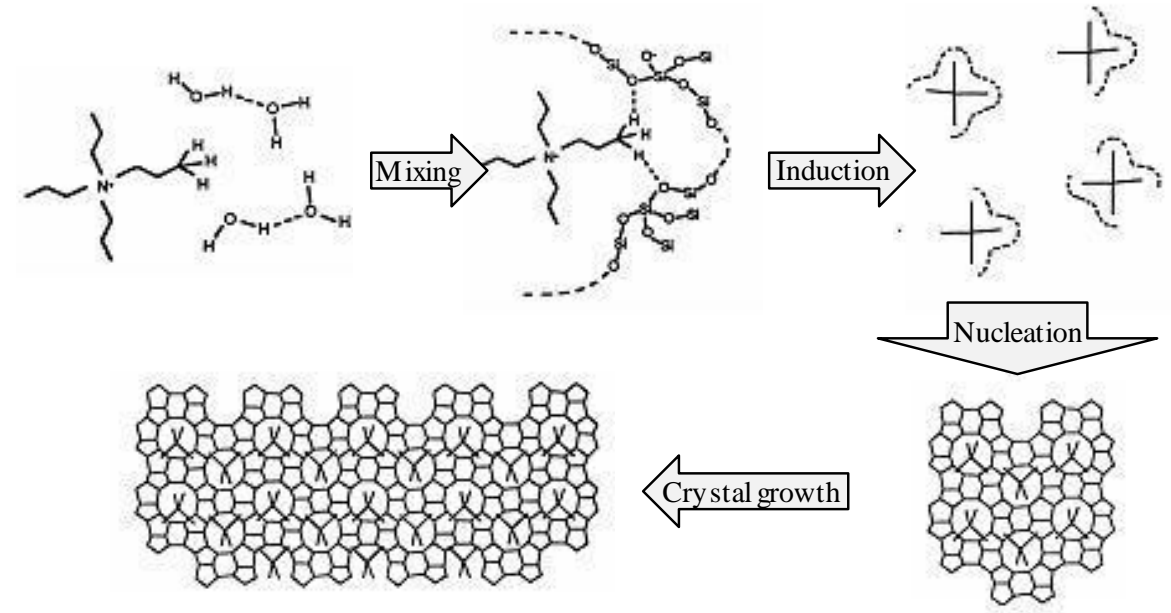

Figure 1.4. Synthesis mechanism scheme of zeolites from zeolite precursors into crystalline zeolite during the synthesis of zeolites. 
- Induction time: it is the time that elapses from obtaining a supersaturated solution to the formation of the first nuclei. A series of chemical equilibria occur in the medium between the silica and alumina precursors, being rearranged until giving rise to the formation of varying complexity silicate and/or aluminosilicate oligomer species, balanced by cations that will be subsequently incorporated into the crystalline solid.

- Nucleation stage: the formation of stable nanometric crystallites or crystalline precursors takes place along this stage. These nanocrystals or crystalline precursors are indistinguishable by diffraction techniques due to the lack of long range order. Due to the abundance of foreign surface in the synthesis media, like container walls, heterogeneous nucleation is the main nucleation process. The addition of zeolite seeds in the synthesis gel improve the nucleation stage as secondary nucleation occurs over the seeds, easing the formation of stable nuclei within the media. Zeolite nucleation and crystal growth may occur both in dense gel and colloidal suspension.

- Crystal growth: the growth of previously formed nuclei takes place in this stage, giving rise to the formation of submicrometric and micrometric zeolite crystallites, easily identifiable by diffraction techniques. The crystal growth process of zeolites is typically described with S-shaped crystallization curves, depicted in Figure 1.5. The development of the zeolite structure comprises weak and strong interactions between building units, forming a covalently bonded framework stabilized by extra-framework species. During this development, nanoparticles play an important role regardless of whether the precursors appear as gels or colloidal suspensions. The size of these nanoparticles is determined by the presence of alkaline or organic cations. The composition of the gel particles approaches the stoichiometric zeolite composition once a chemical equilibrium between the solid and the liquid in the reacting system is reached. Finally, the crystal growth rate decrease, and eventually stops, when any of the zeolite precursors is depleted. 


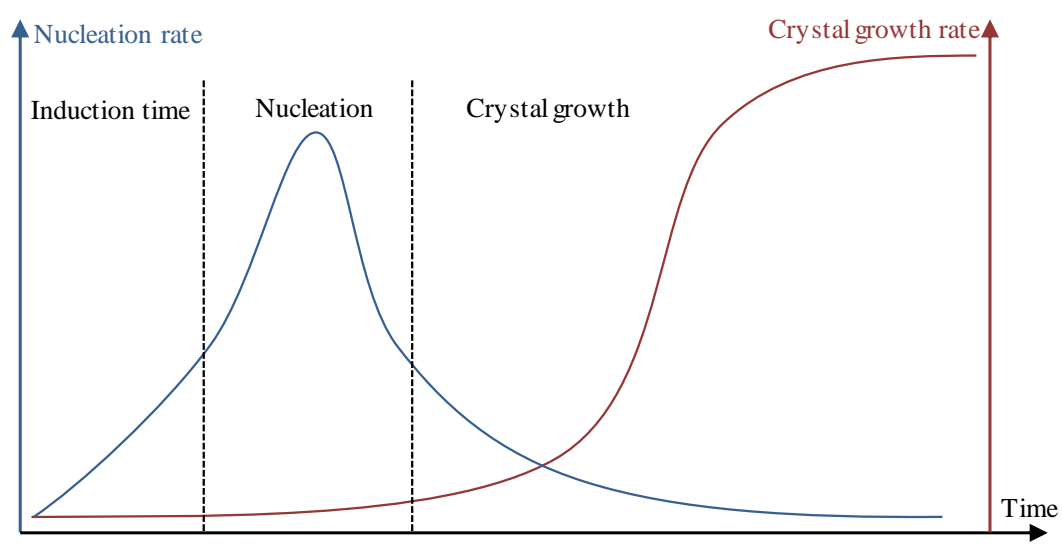

Figure 1.5. Schematic representation of the nucleation rate (blue) and crystal growth rate (red) of zeolites along synthesis time.

\subsubsection{Parameters in the synthesis of zeolites}

There are several parameters to take in account for the successful synthesis of zeolites:

- Composition of the synthesis gel and nature of the reagents used: changes in the gel composition modify the nucleation and crystal growth kinetics, the nature and structure of the material obtained, or the size distribution and morphology of the crystals. The nucleation and crystallization kinetics are also affected by the chemical nature of the used precursors.

- Synthesis time: the crystallinity of the solid generally increases with time, although it must be taken into account that zeolites are metastable phases and, therefore, tend to transform into more stable and denser phases with time. This makes that each zeolite has an optimal synthesis time screen.

- Temperature: the increase of the temperature speeds up the crystallization process, reducing the time required for the crystal growth. However, it can adversely affect the crystallization process of a particular structure if the temperature is high enough to favour the nucleation of another zeolite structure or even decompose the used structure directing agent.

- Mineralizing agent: the mineralizing agent is a chemical species that increases the solubility of the silicate and/or aluminosilicate species, which leads to a decrease in 
the induction period and an acceleration of crystal growth. The main mineralizing agents used are hydroxyl and fluoride anions. Fluoride anions allow the synthesis of zeolites in neutral medium, favours the formation of small cages in the structure and usually leads to the growth of larger crystallites with fewer structural defects than those obtained in basic medium. Some studies also show the influence of gel concentration on phase selectivity, favouring more open structures at a higher concentration of the structure directing agent and fluoride. ${ }^{[98]}$

- Presence of heteroatoms: the isomorphical substitution of $\mathrm{Si}$ atoms by heteroatoms as $\mathrm{Al}, \mathrm{Ga}, \mathrm{Ge}$ or $\mathrm{B}$, can significantly affect the relative stability of the secondary building units because these heteroatoms bond with $\mathrm{Si}$ atoms at slightly different angles and distances than those formed by the $\mathrm{Si}$ atoms between them.

- Nature of the structure directing agent: the structure of the zeolite obtained is highly influenced by the use of inorganic cations $\left(\mathrm{Na}^{+}, \mathrm{Li}^{+}, \mathrm{K}^{+}, \mathrm{NH}_{4}^{+}\right)$and, especially, by the use of organic cations. A large number of research on obtaining zeolitic materials focuses on the role played by organic cations, due to the possibility for easily modifying their structure, size or charge, which may affect selectivity towards one or another crystalline phase during the synthesis process.

- Ageing of the synthesis gel: the treatment of the synthesis gel at a lower or higher temperature than the crystallization temperature for a given time could favour the nucleation step of a given zeolite structure.

- Seeding: the introduction of crystals in the reaction media generally produces a decrease in the induction time. This reduction results in the easier formation of stable nuclei within the media, reducing the overall crystallization time and increasing the selectivity towards the desired zeolite.

- Other:

Design of the reactor, it can affect the mass and energy transfer processes in the synthesis gel, and thus, affecting the induction time for the formation of stable nuclei.

Stirring, it influences the process of mass transfer in the synthesis gel. In highly diluted homogeneous synthesis gels this parameter is usually disregarded, but it is usually critical in highly concentrated or heterogeneous synthesis gels. 
Reagent purity, impurities can also have a structure directing effect. For example, some silica sources could contain ammonia as stabilizer, like colloidal silica.

Preparation method, the addition order of the reagents can affect the synthesis process. For example, the addition of methanol, sometimes used as OSDA co-solvent, extremely accelerates the hydrolysis of orthosilicate silica sources, which could be avoided if methanol is first evaporated.

\subsubsection{Hydrothermal synthesis of zeolites}

The synthesis of zeolites is usually carried out under hydrothermal conditions, i.e., in closed vessels at temperatures ranging between $60^{\circ} \mathrm{C}$ and $200^{\circ} \mathrm{C}$ under presence of water at its autogenous pressure. Also, the presence of cations and a mineralizing agent are required. The cations compensate for the charges generated during the synthesis process, while the mineralizing agent mobilizes the different silica species present in the synthesis media.

The synthesis process is carried out in three steps, schematized in Figure 1.6: $:^{[92]}$

1. Mixture of the silica and alumina (and/or boron, titanium, germanium, etc.) sources with cations that act as structure directing agents, compensating for the charges generated by the mineralizing agent, which is added to the mixture in a crystallization medium, generally water. The mineralizing agent could be: hydroxyl anions, in which case the synthesis is carried out in alkaline media; or fluoride anions, in which case the synthesis is carried out at a pH close to neutrality.

2. Heating of the aqueous mixture, normally at temperatures between $100^{\circ} \mathrm{C}$ and $200^{\circ} \mathrm{C}$ in closed steel autoclaves.

3. After a certain time, which will depend on the specific conditions of synthesis and the structure directing agent, the zeolite crystals are obtained, and then recovered by filtering, washing and drying the formed solid. 


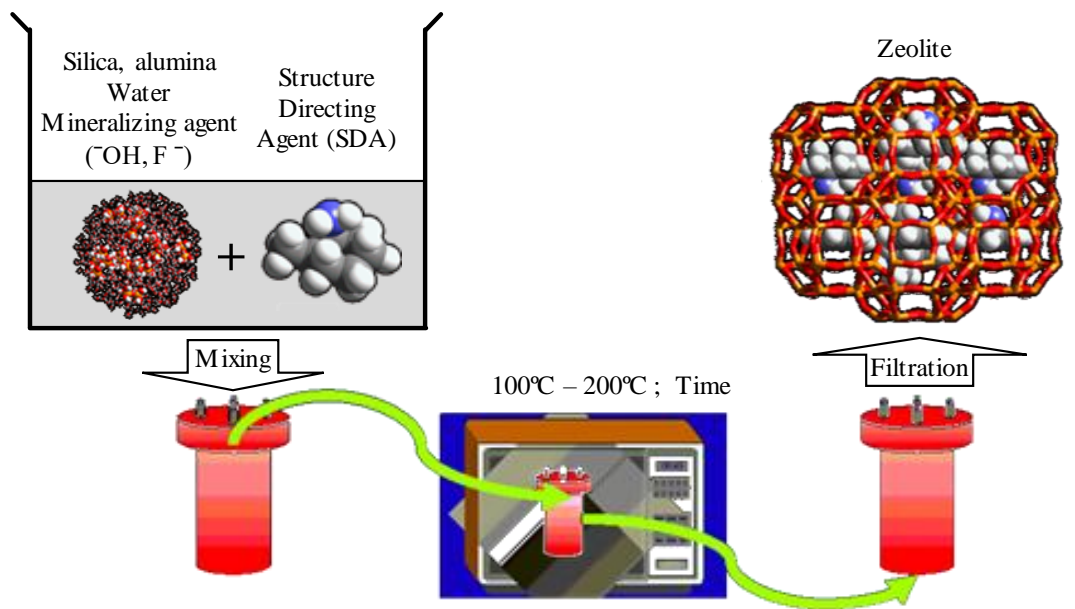

Figure 1.6. Hydrothermal synthesis scheme of a zeolite.

\subsubsection{Ionothermal synthesis of zeolites}

The ionothermal synthesis of zeolites is an alternative zeolite synthesis route, introduced by Morris et al ${ }^{\left[{ }^{99]}\right.}$ It consists in the use of ionic liquids that work as both structure directing agent and solvent, instead of water molecules. This features removes the competition between the solvent, the structure directing agent and the growing zeolite frameworks that are present during the hydrothermal synthesis process. Furthermore, this method almost completely removes safety concerns about the high autogenous pressures produced by the reaction process due to the very low vapour pressure of ionic liquids. ${ }^{[100]}$ However, ionothermal synthesis is limited to ionic liquid availability and stability.

\subsubsection{Dry gel synthesis of zeolites}

The first dry gel synthesis of zeolites was performed on 1990 by Xu et al. ${ }^{[101]}$ The dry gel synthesis method consists in the conversion of a dry aluminosilicate gel in contact with steam and vapours of volatile amines into zeolites, also referred as "vapour-phase transport" method (VPT). If non-volatile quaternary ammonium cations are used as templates, they must be incorporated into the dry gel, and only water vapour is then supplied via the gas phase ("steam assisted conversion", or SAC). ${ }^{[102]}$ The dry-gel samples are placed on a porous support so it is never in contact with the liquid, but reacts under the assistance of its vapour at autogenous pressure. This method allowed to successfully synthesize SOD, MFI, FAU, 
MOR, CHA, MTN, BEA, EUO and TON zeolites. ${ }^{[103-110]}$ However, dry gel synthesis is limited by its highly heterogeneous nature, hindering obtaining pure phases.

\subsubsection{Post-synthesis treatments of zeolites}

After the synthesis of the zeolite and the removal of the structure directing agent, zeolites may be submitted to post-synthesis treatments to further improve some of their properties. In this section, it is briefly discussed some of the most common post-synthesis treatments such as dealumination, desilication and phosphorus incorporation. This could be done by a partial and controlled removal of some of the framework atoms (dealumination and desilication), or by introducing extra-framework species inside the channels and voids of the zeolite (phosphorus incorporation). Also, aluminosilicate zeolites under catalyst regeneration conditions (high temperature and moist) are usually unstable, suffering a dealumination of the structure that could ultimately lead to a lowering of the catalytic activity. ${ }^{[111]}$

\subsubsection{Dealumination of zeolites}

Dealumination is a post-synthesis treatment for removing aluminium from zeolite structure by steam calcination or using chemical agents. ${ }^{[12-114]}$ The extraction of aluminium atoms is accompanied by a partial breakdown of the local zeolite structure and the formation of vacancies, which lead to the formation of an additional porosity, mainly in the range of mesopores. Dealumination constituted the first method to introduce mesoporosity in zeolites. ${ }^{[115]}$

The most frequent dealumination methods are the post-synthesis high temperature treatment in the presence of water vapour, or steaming, ${ }^{[116,117]}$ and the elution of aluminium with acid, mostly $\mathrm{HCl}$, at relatively high temperatures. ${ }^{[118]}$ Dealumination could also be performed in solid state by thermal treatment of ground mixtures of a zeolite and crystalline $\left(\mathrm{NH}_{4}\right)\left(\mathrm{SiF}_{6}\right) \cdot{ }^{[118]}$ However, the extraction of aluminium atoms may severely change the acidic properties of the zeolite, depending on the applied method of dealumination. ${ }^{[19,}{ }^{120]}$ Some treatment parameters may be tuned to limit the drawbacks from aluminium removal, like the use of complexing agents like acid EDTA instead of $\mathrm{HCl}^{\left[{ }^{[121]}\right.}$ the control of the acid concentration, time and temperature of the acidic treatment; ${ }^{[122]}$ or the synthesis of the zeolite with higher crystallinity prior to acid treatment. ${ }^{[123]}$ Interestingly, delaminated zeolites may 
be realuminated, although aluminium is preferentially inserted in previously dealuminated crystallographic positions. ${ }^{[124]}$ After dealumination, silicon atoms could be introduced in dealuminated positions using gaseous $\mathrm{SiCl}_{4}{ }^{[125,126]}$

\subsubsection{Desilication of zeolites}

Desilication is one of the most universal methods used for generating secondary porosity in zeolites. This method is based on the preferential removal of silicon atoms from the zeolite structure in an alkaline solution. The obtained hierarchical material is characterized by the presence of a secondary system of mesopores within the crystallites, while simultaneously maintaining its microporous character and general acidic properties. The introduction of an additional system of pores by desilication also affects the structural and acidic properties of the final materials. These new properties could affect the activity, selectivity, and life-span of zeolites used in catalysis. ${ }^{[113,127-129]}$

The most typical method for the removal of silicon atoms is by treating the zeolite under aqueous alkaline media, mostly $\mathrm{NaOH}$, at varying temperatures. ${ }^{[130]}$ Desilication method allows to introduce mesoporosity in zeolites, however, it also frequently causes a loss of microporosity and/or affect the acidic properties of the final material. The reduction of microporosity is linked with a lower crystallinity of the zeolite, which could also affect to the shape selectivity of the zeolite. The acidic properties could be affected by the removal of silicon atoms close to or directly bonded to aluminium oxide tetrahedra, which could also provoke the dealumination of the zeolite. In order to avoid these drawbacks, the conditions of the alkaline treatments, like the $\mathrm{NaOH}$ concentration or the treatment temperature and time, should be optimized. ${ }^{[131,132]}$ Additionally, other alkali sources may be used, like organic alkali $\mathrm{TPAOH}$ or $\mathrm{TBAOH}$, both separately or jointly with $\mathrm{NaOH}$, which decrease the removal of silicon atoms close to aluminium centres. ${ }^{[133-135]}$

\subsubsection{Phosphorus incorporation in zeolites}

Zeolite acid centres may be stabilized by the incorporation of phosphorus in the zeolite. These extra-framework phosphorous species interact with the aluminium centres of the framework, modulating their acidity. ${ }^{[136-140]}$ This interaction decrease the acidity of the material, ${ }^{[141]}$ while increasing the stability of the zeolite during steaming ${ }^{[142]}$ and under reaction conditions. ${ }^{[143]}$ 
The incorporation of phosphorus has been carried out by several methods like wet impregnation with $\mathrm{H}_{3} \mathrm{PO}_{4}{ }^{[144]}$ and $\mathrm{NH}_{4} \mathrm{H}_{2} \mathrm{PO}_{4},{ }^{[138]}$ or by gas deposition of $\mathrm{PCl}_{3}{ }^{[145]}$ $\mathrm{P}\left(\mathrm{OCH}_{3}\right)_{3}{ }^{[146]}$ or $\mathrm{P}\left(\mathrm{CH}_{3}\right)_{3},{ }^{[136]}$ among others. The most studied materials include zeolites ZSM-5, ${ }^{[136,147,148]}$ USY, ${ }^{[149,}$ 150] Beta, ${ }^{[151]}$ ZSM-8, ${ }^{[152]}$ MCM-22, ${ }^{[153]}$ and mesoporous MCM-41 zeolite. ${ }^{[154]}$ Despite the large number of studies on phosphorus incorporation, the phosphorus-zeolite interaction is still unclear, and several interaction theories have been proposed to explain the observed properties of the final catalysts. ${ }^{[138,144,155-160]}$

The incorporation of phosphorus could present some drawbacks, like a catalytic activity decrease. This decrease could be due to: i) partial blocking of the zeolite channel system by the extra-framework phosphorous species; ii) blocking of the aluminium acid centres due to their interaction with the extra-framework phosphorous species; iii) and dealumination of the zeolite by extraction of the aluminium from the zeolite lattice due to the use of acid solutions, mainly $\mathrm{H}_{3} \mathrm{PO}_{4}$. Furthermore, the incorporation of phosphorus is only possible in zeolites with medium or larger pore size openings, since phosphorous species must diffuse along the channel system to dock at the active centres. Therefore, it is almost impossible to incorporate phosphorus in small pore size zeolites, as these phosphorous species are larger than their pore openings and their diffusion through the zeolite channels is severely limited. Similarly, the incorporation of phosphorous into uni-directional zeolites is also limited by the diffusion constraints that can arise from the introduction of phosphorous species.

\subsection{Structure Directing Agents (SDA's) of zeolites}

Structure Directing Agents, or SDA's, are cations that are introduced in the zeolite synthesis media to favour the crystallization of a given zeolitic structure against other structures. SDA's could be classified by its nature as inorganic and organic cations (OSDA's).

The successful synthesis of new zeolitic structures and compositions still remains heavily dependent on the use of SDA's. In this way, ammonium OSDA's have been extensively used because of the large existing knowledge about the synthesis and modification of this family of compounds. The use of ammonium OSDA's, either to substitute or to complement the use of alkaline inorganic SDA's, has led to the synthesis of at least 186 zeolitic structures of the 253 known structures up to date, and the widening of 
the chemical composition of most zeolites to improve their industrial applicability (March 2021). ${ }^{[8]}$

While the use of ammonium OSDA's has led to the synthesis of most of the known zeolitic structures, several different families of compounds have also been successfully used in the synthesis of zeolites. These compounds comprise phosphorous compounds (quaternary and di-quaternary alkylphosphonium cations, quaternary and di-quaternary alkyl-aminophosphonium cations and phosphazene bases), which have led to at least 18 zeolitic structures; sulfonium cations, which have led to at least 8 zeolitic structures; aza- and oxo-crown macrocycles, which have led to at least 12 zeolitic structures; organometallic complexes, which have led to at least 14 zeolitic structures; self-assembled compounds, which have led to at least 10 zeolitic structures; ionic liquids and deep eutectic solvents, which have led to at least 21 zeolitic structures; and arsonium cations, which have led to 1 zeolitic structure. The share of zeolitic structures synthesized by the different SDA's families is shown in Figure 1.7 .

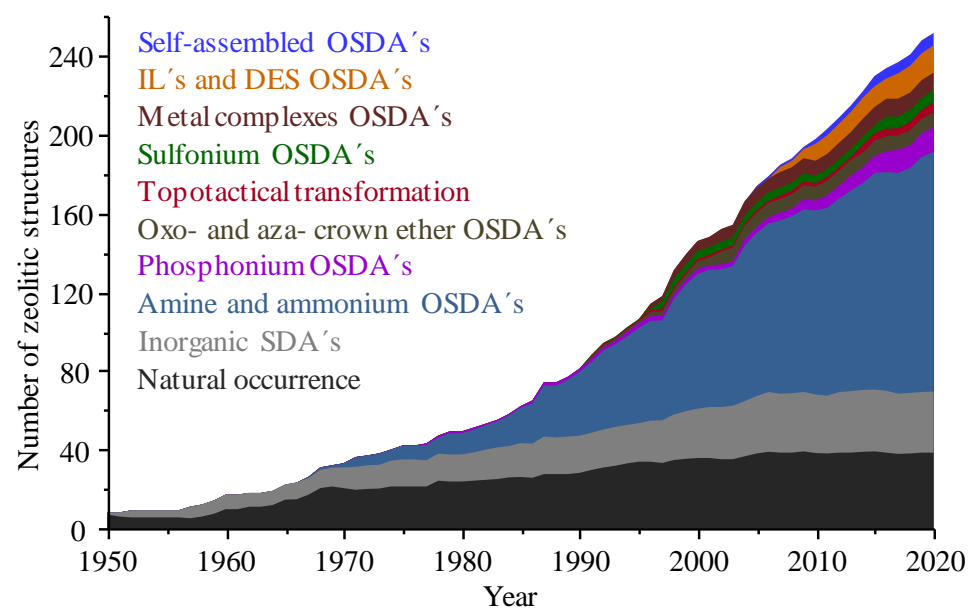

Figure 1.7. Number of zeolite structures synthesized and share of each type of SDA described for the synthesis of zeolitic structures per year.

The influence of OSDA's in the synthesis of zeolites has been recently fully reviewed in Structure and Bonding. ${ }^{[161]}$ 


\subsubsection{Inorganic SDA's}

The synthesis of zeolites begun using alkaline and alkaline-earth hydroxides as SDA's. ${ }^{[88,89]}$ Alkaline hydroxide fulfilled two functions in the synthesis. Firstly, the cations neutralize the negative charges introduced by the substitution of silicon by aluminium atoms in the zeolite framework. And secondly, they provide the synthesis media with a large amount of hydroxyl anions as mineralizing agent. These conditions favour the synthesis of low silicon to aluminium ratio, like LTA and FAU zeolites with Si/Al ratios below 2.5, for example. ${ }^{[162-164]}$ However, these materials usually present a low (hydro)thermal stability due to their high aluminium content.

Hydrated cations present a lower energy in water solution, with water molecules enveloping the cation. Under zeolite synthesis conditions, some of these water molecules are exchanged by silicate and/or aluminosilicate species, which start to interact between them leading to the formation of SBU's, previously detailed in section 1.1.1.1.

\subsubsection{Organic SDA's}

The introduction of organic cations by Barrer and Denny in 1961 broadened the possibilities in the synthesis of zeolites. ${ }^{[165]}$ Organic Structure Directing Agents (OSDA's) allowed for higher silicon to aluminium ratios, the synthesis of new structures without natural analogous, a speed up of the crystallization rate and the preferential crystallization of specific phases.

The synthesis mechanism when organic cations are used as OSDA's was proposed by Burkett and Davis. ${ }^{[166]}$ According to this mechanism, the organic cation is found in the solution solvated by water molecules that are gradually replaced by silicate species present in the synthesis media. The successive addition of silicate species allows for the formation of synthesis nuclei from which the zeolite will start growing.

The efficient use of OSDA's require some properties of the organic cation: ${ }^{[167,168]}$

- Stability in the reaction media: hydrothermal synthesis conditions are quite harsh for organic compounds, as temperatures are moderately high $\left(100^{\circ} \mathrm{C}-200^{\circ} \mathrm{C}\right)$ and several nucleophilic species, like water molecules, hydroxyl or fluoride anions are present in the synthesis media, which could react with the organic cation. 
- Solubility in the reaction media: the organic cations must be soluble in water, which therefore limits the size of the organic cation to a carbon to nitrogen ratio lower than 15 .

- Stiffness: conformational stiffness favours the crystallization of single phases.

- Bulkiness: bulky OSDA's favour the formation of low framework density structures.

- Branched molecules: large hydrocarbon chains favour the formation of channels and their cross-linking in bi- and tri-directional pore channel systems.

The effect of the OSDA in the synthesis of zeolites is dependent on the interaction between the OSDA cation and the inorganic matrix. OSDA's could be classified by this interaction into three different types:

- True template: the organic cation directs the synthesis towards a single zeolite structure which adopts the geometric and electronic configuration of the cation. Up to date, the only cations with true template effect are the OSDA's used in the synthesis of ZSM-18 zeolite ${ }^{[169,170]}$ and MCM-61 zeolite, ${ }^{[171]}$ although this "template" interaction is controversial. ${ }^{[172]}$

- Structure directing agents: the cation presents an interaction with the inorganic matrix, favouring the formation of some phases or others depending on the synthesis conditions. ${ }^{[173]}$

- Void filler: the cation does not favour the preferential crystallization of some phases against others, but increases the framework stability respect to the absence of the cation. ${ }^{[174]}$

Besides ammonium cations, organic cations with different chemical natures had also been used, which have resulted in the synthesis of very interesting zeolite materials. These cations include phosphorous, sulfonium and arsonium cations, crown macrocycles, organometallic complexes, proton sponges, self-assembled compounds and ionic liquids. ${ }^{[175]}$

\subsubsection{Alkylammonium cations as OSDA's}

Quaternary ammonium cations were the first OSDA's used in the synthesis of zeolites. Alkylammonium cations are positively charged compounds that have been widely used due to their low price and their well-known chemistry. Beginning with the most simple 
tetramethyl ammonium used by Barrer and Denny, ${ }^{[165]}$ the family of ammonium cations used as OSDA's has grown into a wide variety of ammonium compounds. ${ }^{[176,177]}$

However, there are some limitations in the application of ammonium cations as OSDA's due to their hydrothermal stability. The main degradation pathways of ammonium cations are the Hofmann elimination of alkyl chains under alkaline media, the thermal degradation and the carbon rearrangement by internal displacement of alkyl chains, as schematized in Figure 1.8. ${ }^{[178]}$
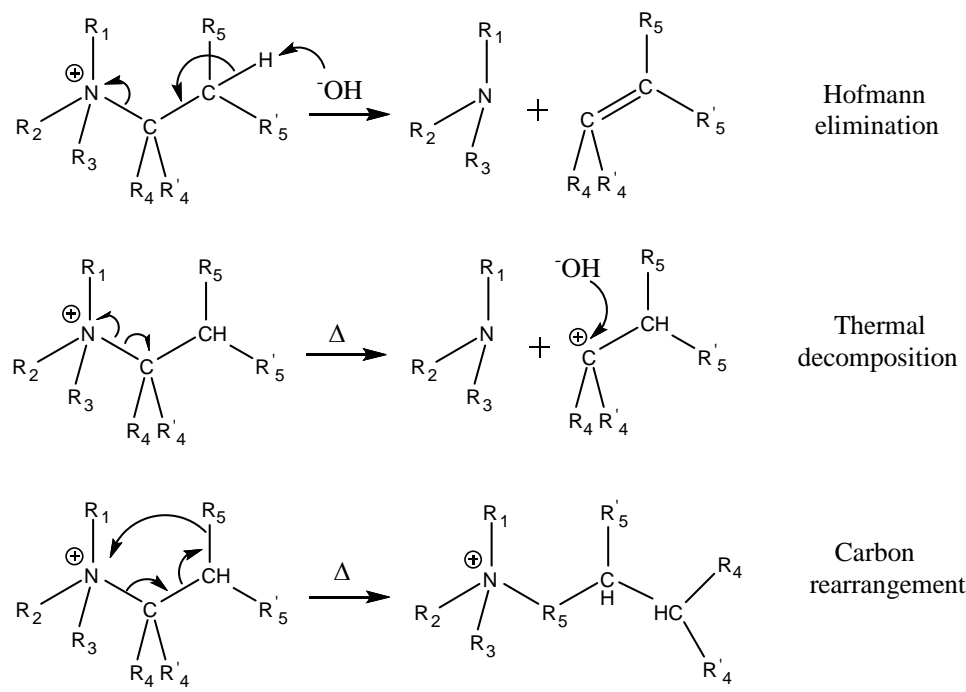

Figure 1.8. Main degradation pathways of ammonium cations under hydrothermal treatment.

It is important to note that some of the formed degradation products could also act as structure directing agents, and due to their smaller size, direct the synthesis towards the formation of dense zeolites such as clathrates.

\subsubsection{Phosphorous cations as OSDA's}

Alkylphosphonium cations are compounds known for a long time and are used in numerous fields of applications as a source of ylides in organic chemistry, the production of organic polymers, insecticides and fungicides, flame retardants for textiles and paper, anti-static and softening agents in textile and resins, and corrosion inhibitors of photographic chemicals. ${ }^{[179]}$ Recently, these compounds have received additional interest because of their 
ability to form ionic liquids with superior properties compared to their nitrogen-based analogues. ${ }^{[180-183]}$

The typical synthesis procedure to obtain alkylphosphonium cations relies on the use of phosphine derivatives, as schematized in Figure 1.9. ${ }^{[179,184-187]}$

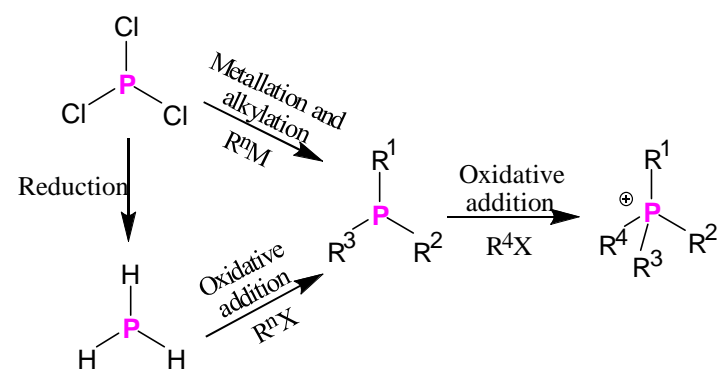

Figure 1.9. General schematic pathway for the synthesis of tetraalkylphosphonium cations.

First, it should be stated that special safety precautions must be taken when working with phosphines because of their very high toxicity. Phosphines are usually less stable than their amines counterparts because of their high reactivity and, furthermost, they are unstable in contact with water or air, yielding the corresponding oxidized compounds, although these properties are heavily linked with the compound volatility (for example, the solid triphenylphosphine is almost inert in contact with water and air, but keeps the general reactivity of phosphines). ${ }^{[185,188]}$ Because of that, the working up to synthesize complex phosphonium derivatives turns into a demanding task to comply. However, when properly handled, the synthesis of phosphonium compounds is achieved with nearly quantitative yields and few undesired products, opposed to the medium yields obtained in the synthesis of ammonium OSDA's. $\left.{ }^{[179,} 181,184,189\right]$

Phosphonium cations exhibit a higher stability than ammonium cations, lessening the occurrence of the $\beta$-Hofmann elimination, as schematized in Figure $1.10 .{ }^{[186,190-193]}$ This is extremely important because most zeolite syntheses are carried out under hydrothermal conditions. Therefore, the use of phosphonium cations would allow to widen the range of physical synthesis conditions, like increasing the synthesis temperature, the alkalinity of the media, or synthesis/crystallization time without any significant decrease in the concentration of the cationic species active as OSDA's. 


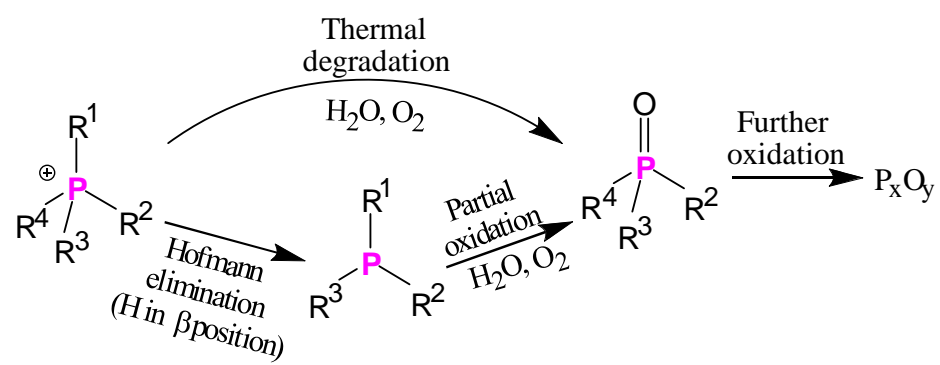

Figure 1.10. Main degradation pathways of tetraalkylphosphonium cations under hydrothermal treatment.

Additionally, phosphorous compounds exhibit a more versatile chemistry than nitrogen compounds, and thus we can also find the phosphorus atom directly bonded to an uncharged nitrogen atom. These molecules are interesting because they allow tuning the charge distribution around the quaternized phosphorus atom by exchanging a carbon atom with a nitrogen atom. This property gives rise to two different compound families, aminophosphines, ${ }^{[187,194]}$ that can be turned into alkyl-aminophosphonium cations; and phosphazenium cations. ${ }^{[195,196]}$ Both are readily available to be used as OSDA's, as phosphazenium cations are commercially available as phosphazene proton sponges, ${ }^{[196]}$ and aminophosphines are common complexing agents that are less hazardous and volatile than their alkylphosphines counterparts. ${ }^{[197,198]}$ The three types of P-OSDA's are schemed in Figure 1.11.<smiles>[R][PH]([R7])([R7])[R7]</smiles>

$\mathrm{R}^{\mathrm{n}}=$ alkyl or aryl Alkylphosphonium cation<smiles>[R7]N[Pb]([R7])([R7])[17NH]</smiles>

$$
\mathrm{R}^{\mathrm{n}}=\text { alkyl or aryl }
$$
Alkylaminophosphonium cation

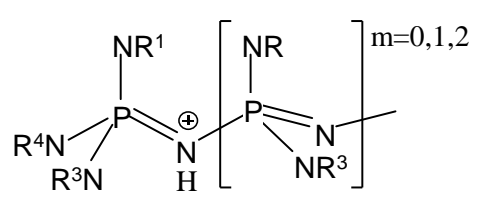

$\mathrm{R}^{\mathrm{n}}=\mathrm{H}$ or alkyl Phosphazenium cation

Figure 1.11. Types of phosphorous cations used as OSDA's.

The first attempts to use phosphonium cations for the synthesis of zeolites in the 70's, 80's and 90's mainly came from the petrochemical industry. These syntheses involved the use of simple tetraalkylphosphonium cations analogous to the well-known tetraalkylammonium cations, namely tetraethyl, tetrapropyl and tetrabutyl phosphonium cations, which were made readily available shortly before their use as OSDA's. Several patents were issued claiming the use of phosphonium OSDA's to yield different zeolites: 
zeolite Theta-3 (MTW), related with the Theta-1 and MFI zeolites and possessing a ZSM-12 structure; ${ }^{[199]}$ the zeolite ZSM-5 (MFI); ${ }^{[200]}$ and the zeolite EU-13 (MTT). ${ }^{[201]}$ Next, patents and academic articles addressed the use of these phosphorous OSDA's, yielding several known zeolites: ZSM-5 (MFI); ${ }^{[202]}$ TS-2 (MEL); ${ }^{[203]}$ TS-1 (MFI); ${ }^{[204]}$ ZSM-5 (MFI) and ZSM-11 (MEL); ${ }^{[205]}$ and RUB-35 (a disordered EUO-NES-NON family material). ${ }^{[206]}$

However, this first series of syntheses provided the same phase selectivity than the chemically equivalent ammonium cations and no new zeolite was obtained. It was not until 2006 that a new zeolite structure was described using a phosphorous OSDA, the large pore zeolite ITQ-27 (IWV), ${ }^{[207]}$ using a more complex and asymmetrical tetraalkylphosphonium cation. From then on, several novel zeolite structures have been obtained with phosphonium cations, all of them included within the ITQ series of zeolites: the large pore germanosilicate ITQ-26 (IWS); ${ }^{[208]}$ the medium pore germanosilicate ITQ-34 (ITR); ${ }^{[209]}$ the extra-large pore germanosilicate ITQ-40 (-IRY); ${ }^{[210]}$ the medium pore zeolite ITQ-45; ${ }^{[211]}$ the small pore germanosilicate ITQ-49 (ITN); ${ }^{[212]}$ the small and medium multi-pore borosilicate ITQ-52 $(\mathrm{IFW}) ;{ }^{[213]}$ the extra-large pore germanosilicate ITQ-53 (-IFT); ${ }^{[214]}$ and the small pore borosilicate ITQ-58. ${ }^{[215]}$ (Table 1.2)

Also, known zeolites have been obtained with phosphorous-OSDA's over last years. For example, zeolite Beta (BEA) with extra-framework phosphorous species can be obtained after direct calcination avoiding post-synthesis treatments; ${ }^{[216]}$ the use of a phosphorous proton sponge allowed obtaining the zeolite ITQ-47, the first synthetic analogue of the large and medium multi-pore natural boggsite zeolite (BOG); ${ }^{[217,218]}$ the extra-large pore germanosilicate ITQ-33 (ITT), allowing to introduce $\mathrm{P}$ without any post-synthesis treatment in this sensitive structure; ${ }^{[219]}$ the use of phosphonium and ammonium cations allowed obtaining the one-pot self-pillaring of the medium pore ZSM-11 (MEL); ${ }^{[220]}$ the zeolite ZSM-5 (MFI), to introduce phosphorus without any post-synthesis treatment; ${ }^{[221]}$ the synthesis of high silica AEI zeolite by topotactic transformation of FAU zeolite using a dual template synthesis with ammonium and phosphonium cations; ${ }^{[222]}$ the synthesis of self-pillared zeolites ZSM-5 (MFI) and Beta (BEA), and titanosilicates ETS-4 and ETS-10; ${ }^{[223]}$ the synthesis of high silica CHA zeolite by topotactic transformation of FAU zeolite using a dual template synthesis with ammonium and phosphonium cations; ${ }^{[224]}$ the synthesis of small pore all-silica zeolite RUB-13 (RTH), to introduce P as probe atom for NMR and INS techniques; ${ }^{[225]}$ and the synthesis of nanocrystalline zeolite SSZ-39 (AEI) by topotactic transformation of FAU zeolite using a single phosphonium OSDA. ${ }^{[226]}$ (Table 1.3) 


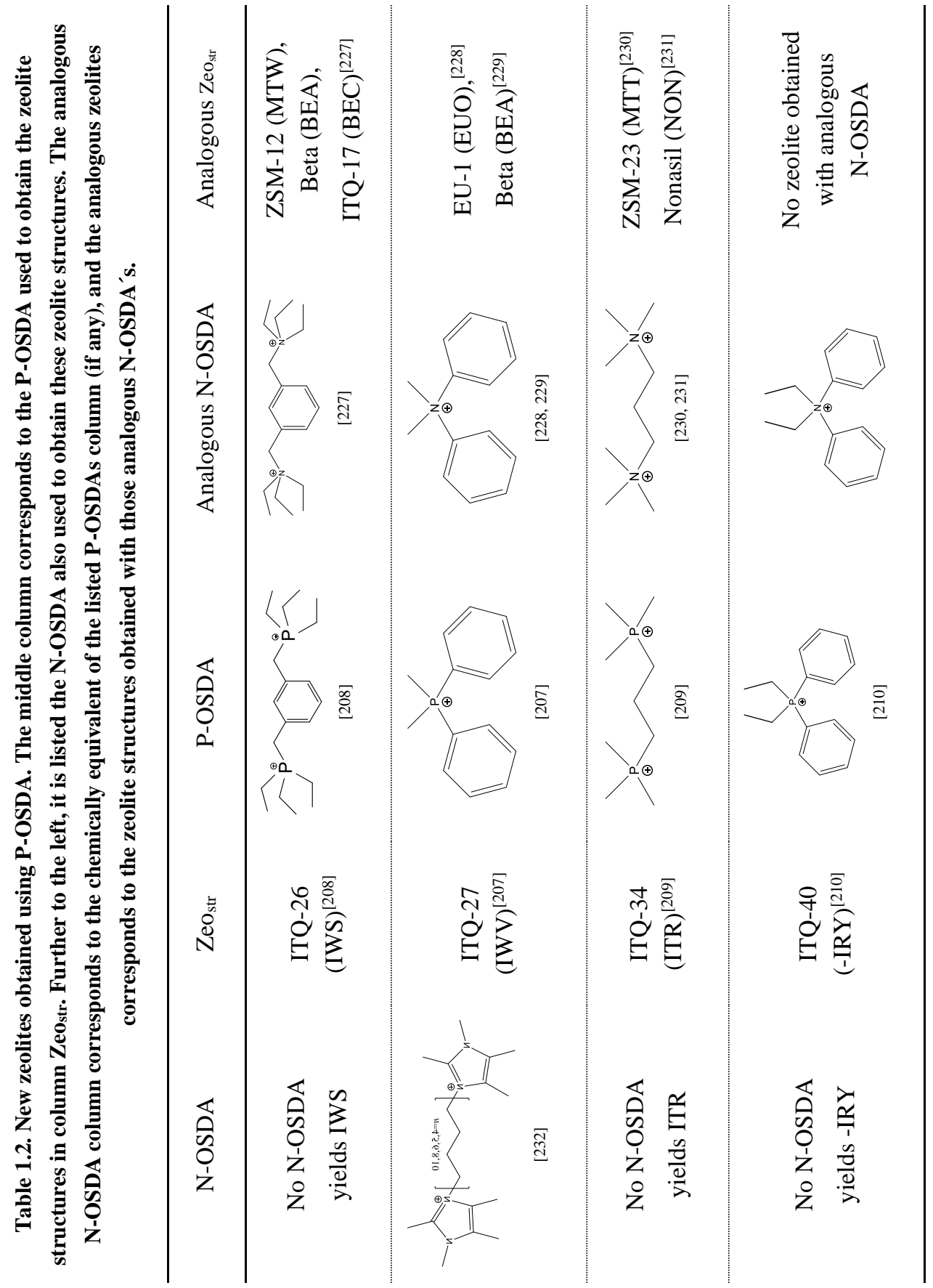




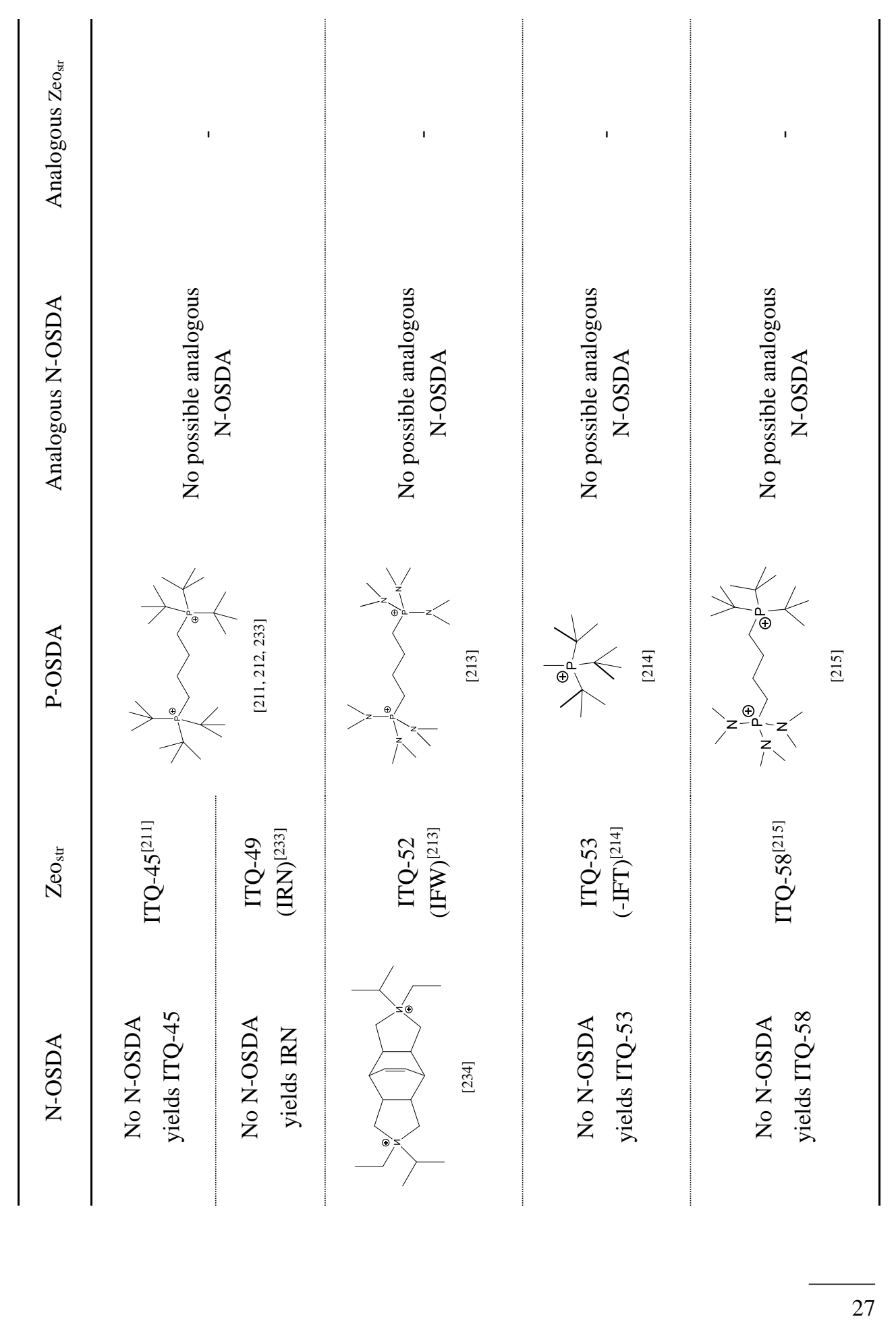




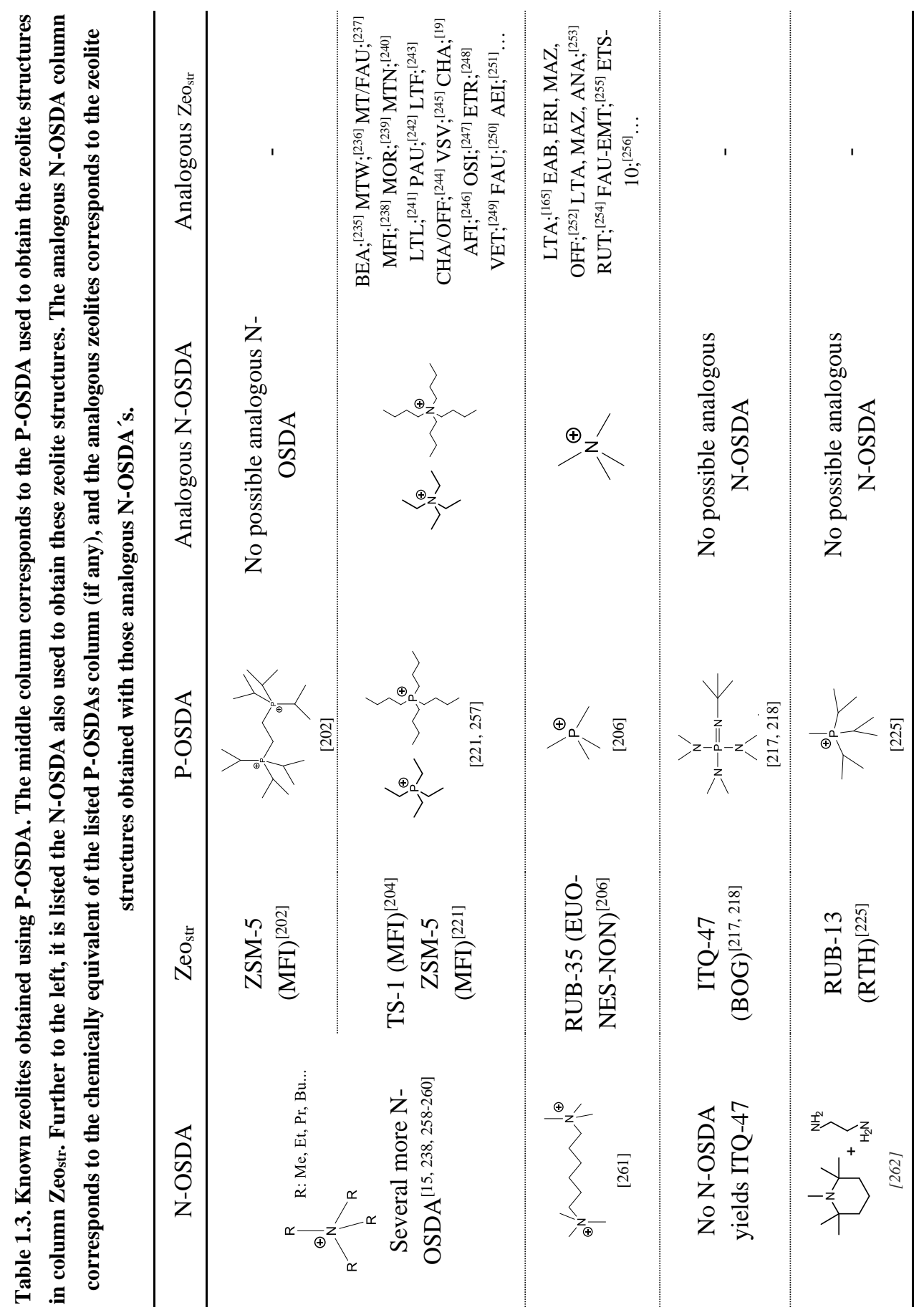




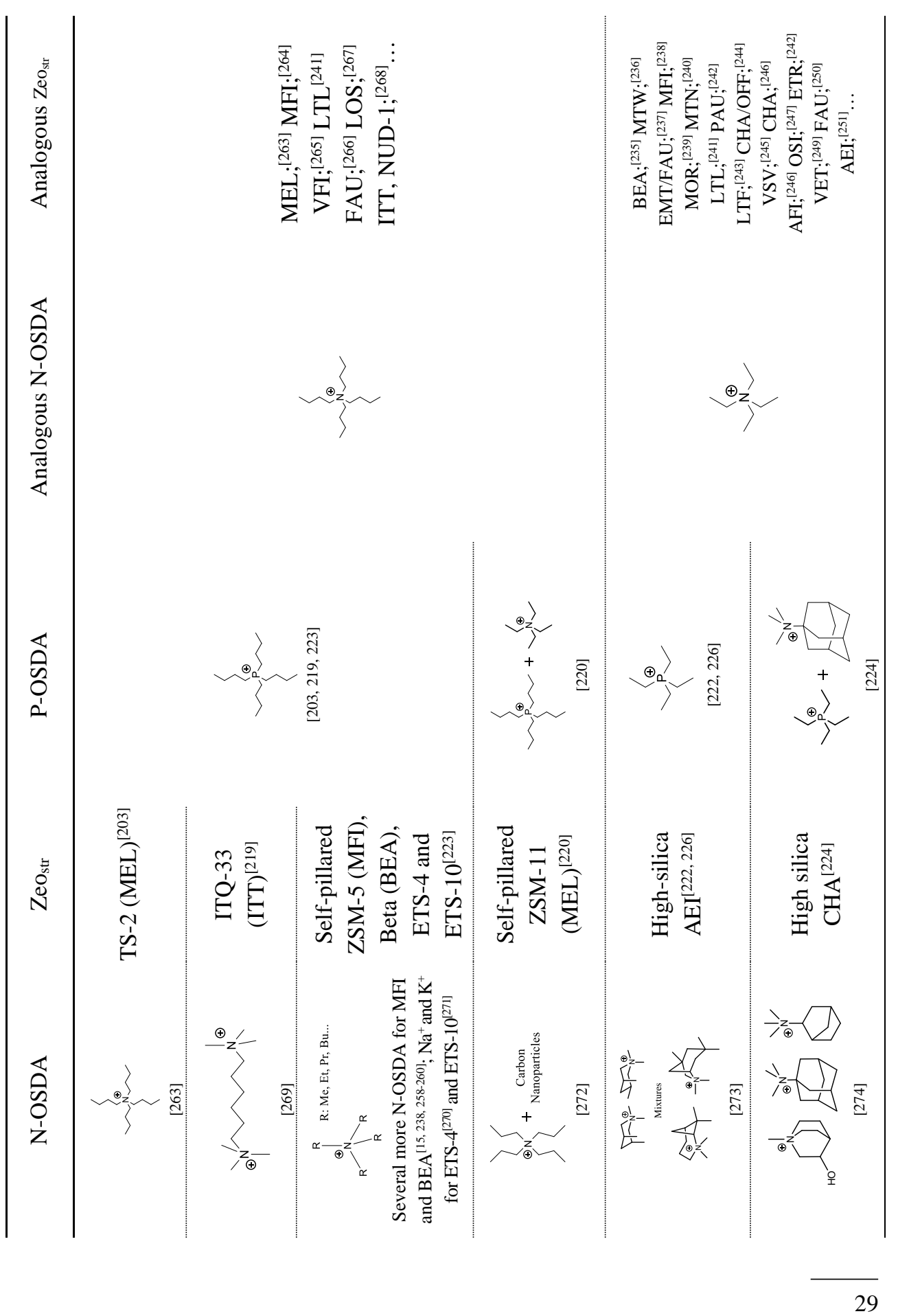


The use of phosphorus containing cations as OSDA's is interesting because, commonly, their ammonium equivalents yield different phase selectivity as observed in Table 1.2 and Table 1.3. Also, phosphorus is a valuable element to incorporate into zeolites, as it has been used for many years to improve the hydrothermal stability of the aluminium catalytic centres to further extent the catalytic lifetime of these materials. However, the interaction between the phosphorous and aluminium species is not yet fully understood, but some proposals for the aluminium stabilization are shown in Figure 1.12. ${ }^{[138,140,142,160,275,276]}$<smiles>C[Si](C)(C)OP(=O)(O)O</smiles>

(a)<smiles></smiles>

(b)<smiles>C[Si](C)(C)O[Si](C)(C)O[PbH2]</smiles>

(c)<smiles>CO[Si](C)(C)O[Al](C)(C)O[Si](C)(C)O[Al+](C)(C)C</smiles>

(d)

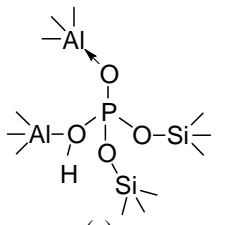

(e)

Figure 1.12. Proposed models for phosphorus-zeolite interaction. (a) Vedrine et al., ${ }^{[158]}$ (b) Lercher et al.., ${ }^{[14]}$ (c) and (d) Corma et al., ${ }^{[138]}$ (e) Xue et al. ${ }^{[159]}$

Phosphorus can be introduced in the zeolite by direct impregnation with several compounds, as $\mathrm{H}_{3} \mathrm{PO}_{4}, \mathrm{NH}_{4} \mathrm{H}_{2} \mathrm{PO}_{4}, \mathrm{PCl}_{3}, \mathrm{P}\left(\mathrm{OCH}_{3}\right)_{3}, \mathrm{P}\left(\mathrm{C}_{6} \mathrm{H}_{5}\right)_{3}$, etc., followed by calcination. ${ }^{[138,140,142,143,276-280]}$ However, most of these treatments present the disadvantage of being only available in medium or large pore zeolites, as these molecules are larger than the pore openings of small pore zeolites. The use of phosphonium cations as OSDA's proves to be a convenient way to introduce phosphorus in small pore zeolites. ${ }^{[224,226]}$

After the synthesis of zeolites aided by OSDA's, it is required to remove the OSDA to empty the pores of the material. This is usually made by calcination under air, yielding gaseous molecules (mostly, $\mathrm{H}_{2} \mathrm{O}, \mathrm{CO}_{2}, \mathrm{NO}_{\mathrm{x}}$ and small amines), except in some modular and self-assembled OSDA's. ${ }^{[281,282]}$ In contrast, the calcination of P-OSDA containing zeolites also gives rise to gaseous molecules $\left(\mathrm{H}_{2} \mathrm{O}\right.$ and $\left.\mathrm{CO}_{2}\right)$, but most of the phosphorus remains inside the zeolite as extra-framework phosphorous oxide-like species, as depicted in Figure 1.13. ${ }^{[138,144,158,159,278]}$ 


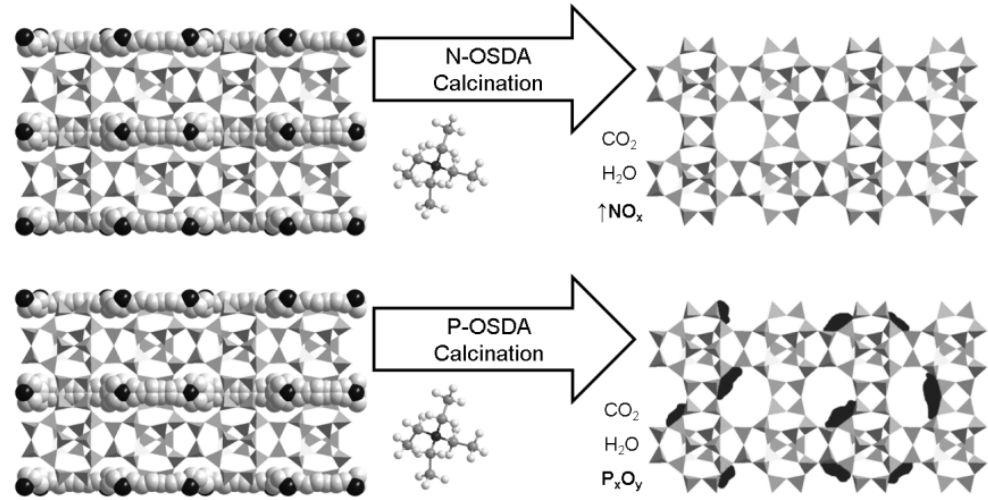

Figure 1.13. Schematic view of the calcination process of N-OSDA and P-OSDA inside a zeolite structure.

On the other hand, P-OSDA containing materials could be subjected to a hydrogenation process at high temperature, avoiding the oxidation of the phosphorous

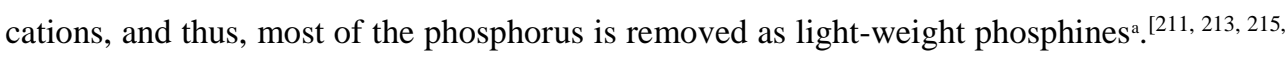
${ }^{217,218]}$ However, in both processes, it is difficult to control the removal of the phosphorous species, as it depends on the temperature, heating rate and time of the thermal treatment, the composition of the zeolite and, especially, the structure, pore openings and channel dimensionality and crystal size of each zeolite. A smarter way for controlling the remaining amount of phosphorus inside the zeolite would be the employ of the dual-template synthesis methodology, [112, 257, 283-285] employing a combination of N-OSDA's and P-OSDA's, and optimizing the final aluminium/phosphorus ratio just by changing the ratio between the $\mathrm{N}-\mathrm{OSDA}$ and P-OSDA in the synthesis stage, as most of the $\mathrm{P}$ will remain inside the zeolite upon calcination. ${ }^{[224,286]}$

${ }^{a}$ Warning: these compounds are extremely hazardous, even in small quantities, and appropriated facilities for their use and disposal must be used. 


\subsubsection{Sulfonium cations as OSDA's}

The use of trialkylsulfonium cations as OSDA's is relatively new, and despite the low number of studies that have addressed these compounds, many aluminophosphate zeotypes as AlPO-5, SAPO-5 and MAPO-5 (AFI), AlPO-31 (ATO), AlPO-41 and SAPO-41 (AFO), SAPO-11 and MAPO-11 (AEL), MAPO-14 and CoAPO-14 (AFN), and MAPO-34 (CHA) have been obtained. ${ }^{[287]}$ Also, the crystallization of several zeolites has been reported, such as ITQ-33 (ITT), ITQ-7 (ISV), ZSM-11 (MEL) zeolites and silicogermanate GeZA have been obtained. ${ }^{[288]}$

\subsubsection{Arsonium cations as OSDA's}

Up to date, only the MFI zeolite has been successfully synthesized using arsonium cations. ${ }^{[28]}$ The use of arsonium OSDA's allows the introduction of Ar as Trojan Horse element for the characterization and evolution of the OSDA entrapped in the zeolitic void. However, there are few commercially available arsines and they are even more hazardous than phosphines, which limits their test as OSDA's for the time being.

\subsubsection{Oxo crown macrocycles (crown ethers) OSDA's}

Since their discovery by Pedersen, ${ }^{[290]}$ crown ethers have found several applications because of their high affinity for cations in solution. ${ }^{\text {[291-294] }}$ The first report of these compounds being used as OSDA's in the synthesis of zeolites came several years later, when high silica faujasite (FAU) with a Si/Al 5 (SAR 5) and pure hexagonal faujasite (EMT) were synthesized. ${ }^{[295-297]}$ Since then, high silica zeolite Rho (RHO); ${ }^{[298, ~ 299]}$ high silica zeolite $\mathrm{KFI} ;^{[300]}$ aluminosilicate clathrate MCM-61 (MSO) $;^{[171]}$ and all-silica zeolite sodalite $(\mathrm{SOD})^{[301,302]}$ have been synthesized using crown ethers as OSDA's.

\subsubsection{Metal complexes and organometallic OSDA's}

Metal complexes and organometallic compounds have been used for years in the synthesis of zeolites to incorporate metal complexes into zeolites. This strategy has allowed to keep properties of the original organometallic compounds (or the metal clusters that could be created after the decomposition of the organic compounds) in a stable zeolitic support. The most studied system for the incorporation of several organometallic compounds has been the large-pore zeolite Y (FAU). ${ }^{[303-308]}$ 
However, the synthesis of all-silica clathrasils nonasil (NON), octadecasil (AST) and dodecasil $1 \mathrm{H}(\mathrm{DOH})$ using $\mathrm{Co}(\mathrm{Cp})_{2}$ as $\mathrm{OSDA},{ }^{[309]}$ and shortly after, the synthesis of the extra-large pore zeolite UTD-1 (DON) with the $\mathrm{Co}\left(\mathrm{Me}_{5} \mathrm{Cp}\right)_{2}$ compound, opened a new frontier in the synthesis of zeolites. ${ }^{[310-312]}$ Since then, several zeolites and zeotypes have been synthesized with organometallic compounds, like the synthesis of the aluminophosphate ALPO-16 (AST); ${ }^{[313]}$ the synthesis of aluminophosphates STA-6 (SAS) and STA-7 (SAV) $;^{[314]}$ the synthesis of the gallogermanates GaGeO-CJ63 (JST) ${ }^{[315]}$ and JU-64 (JSR); ${ }^{[316]}$ the synthetic equivalent of Phillipsite DAF-8 (PHI); ${ }^{[317]}$ the synthesis of aluminophosphates UCSB-6 (SBS), UCSB-8 (SBE) and UCSB-10 (SBT), ${ }^{[318]}$ and the synthesis of Rho-like aluminophosphates (RHO). ${ }^{[319]}$

Also, organometallic compounds have also been applied in the dual-template synthesis approach using metal complexes jointly with alkylammonium cations. Using this methodology, the metal complexes would work as pore space fillers instead of proper OSDA's. This approach has yielded the synthesis of the zeolite Cu-SSZ-13 (CHA);[320, 321] and the silicoaluminophosphates Cu-SAPO-34 (CHA) ${ }^{[322,323]}$ and Cu-STA-7 (SAV). ${ }^{[324]}$ This methodology has made it possible to homogeneously disperse metal functionalities inside the channels and voids of small pore zeotypes that would be difficult, if not impossible, by post-synthesis treatments. ${ }^{[325,326]}$ Additionally, the number of intermediate stages is reduced by several steps that decrease the energy consumption and the waste disposal of metal-containing water streams when compared to traditional cation exchange methods. ${ }^{[327]}$

\subsubsection{Self-assembled OSDA's}

Self-assembled OSDA's consist in organic compounds with aromatic rings that are able to self-assemble to form macromolecular moieties. This is usually achieved by parallel $\pi-\pi$ interactions between aromatic rings. Thus, self-assembled OSDA's are relatively simple molecules that, when assembled, constitute OSDA's with a suitable size, rigidity, thermal stability and hydrophilicity properties. Under appropriate conditions, these compounds have been able to create zeolitic topologies with low framework densities or large pore openings due to their supramolecular aggregation. ${ }^{[62,328]}$

The first examples of the use of this kind of OSDA's yielded already known zeolitic structures with interesting novel features. Thus, all-silica ITQ-29 (LTA); ${ }^{[62]}$ MTN-type zeolite; ${ }^{[329]}$ all-silica zeolite ZSM-12 (MTW); ${ }^{[330]}$ nanosheet ZSM-5 (MFI); ${ }^{[331]}$ MWW-like zeolite ${ }^{[332]}$ and the extra-large pore zeolite ITQ-37 (-ITV $)^{[333]}$ were reported. Novel zeolite 
structures have also been obtained, like the zeolite extra-large pore zeolite ITQ-51 (IFO) ${ }^{[334]}$ and extra-large pore germanosilicate NUD-1 and NUD-2 zeolites. ${ }^{[355,336]}$

Also, the syntheses of several zeotypes aided by self-assembled OSDA's have also been described. For example, the synthesis of aluminophosphates AlPO-5 and SAPO-5 (AFI); ${ }^{[337-339]}$ the synthesis of aluminophosphate STA-1 (SAO); ${ }^{[340,341]}$ the synthesis of AFIlike aluminophosphate $;^{[342-344]}$ the synthesis of the aluminophosphate ICP- $1 ;{ }^{[345]}$ and the synthesis of the small pore silicoaluminophosphates STA-6 (SAS) ${ }^{[346]}$ and SAPO-42 (LTA). ${ }^{[37]}$

\subsubsection{Ionic liquids OSDA's}

Ionic liquids (IL's) are organic solvents with high polarity, excellent solvating properties and, usually, high thermal stability. They consist in molten salts with melting points below $100^{\circ} \mathrm{C}$ with an almost negligible vapour pressure. As molten salts, they consist in a variety of fused anions and cations that could be combined between them, giving rise to an almost unlimited number of salts (as long as their melting point is below $100^{\circ} \mathrm{C}$ ) with tuneable properties depending on the ions forming them. Typical cations include choline, alkylammonium, alkylphosphonium, $\mathrm{N}$-alkylpyridinium, and especially, N,N'-dialkylimidazolium cations, among others, and the anions are also quite varied. ${ }^{[348-350]}$ The use of IL's as both OSDA's and solvents (known as ionothermal synthesis) arose from the fact that many of the cations forming IL's are chemically very similar to known OSDA's in zeolite syntheses, as well as their polarity also allows using them as solvents, which, together with their low vapour pressure, remove most of the safety issues regarding hydrothermal synthesis. ${ }^{[351-353]}$

The first ionothermal synthesis made use of 1-Methyl 3-ethyl imidazolium bromide as IL, which yielded the new aluminophosphate SIZ-1, and other aluminophosphates with already known structures: SIZ-3 (AEL), SIZ-4 (CHA) and SIZ-5 (AFO). ${ }^{[99]}$ Since then, a number of ionothermal syntheses have been reported, like the aluminophosphate SIZ-6; ${ }^{[354]}$ the aluminophosphates SIZ-7 (SIV), SIZ-8 (AEI) and SIZ-9 (SOD); $;^{[355]}$ the Fe and Co-substituted aluminophosphates with SOD structure; ${ }^{[356]}$ the gallophosphates GaPO-4, CLO and LTA; $;^{[357]}$ the aluminophosphate MnAlPO-5 (AFI); ${ }^{[358]}$ the aluminophosphate AlPO-5 (AFI) ${ }^{[359]}$ the aluminophosphates AlPO-5 (AFI) and AlPO-11 (AEL); ${ }^{[360]}$ the zincaluminophosphate DAF-1 (DFO); ${ }^{[361]}$ and the aluminophosphate SAPO-34 (CHA). ${ }^{[362]}$ 
Ionic liquids have also been intensively used in cooperation with amines, as the presence of the IL changes the phase selectivity of the amines with respect to conventional syntheses. Thus, aluminophosphates AlPO-5 (AFI) and AlPO-25 (ATV); ${ }^{[363]}$ the aluminophosphate AlPO-5 (AFI) ${ }^{[364]}$ the aluminophosphates AlPO-42 (LTA), AlPO-5 (AFI) and AlPO-11 (AEL); ${ }^{[365]}$ the aluminophosphate LTA; $;^{[366]}$ and the aluminophosphate CoAPO-34 (CHA) ${ }^{[367]}$ the aluminophosphate JIS-1; ${ }^{[368]}$ and the extra-large aluminophosphate DNL-1 ${ }^{[369]}$ have been obtained. Also, some silica based-zeolites have been successfully obtained with IL's, as the all-silica Silicalite-1 (MFI) and Theta-1 (TON) zeolites, ${ }^{[370]}$ and MTT, TON, ITW and MFI zeolites. ${ }^{[100]}$

\subsubsection{Deep eutectic solvents (DES) OSDA's}

Deep-Eutectic Solvents (DES's) consist in binary or ternary mixtures of compounds with an extremely low freezing point compared to that of the separate components. The most used DES's comprise mixtures of organic halide salts, such as choline chloride, with hydrogen-bond donors, such as amides, amines, alcohols, and carboxylic acids. ${ }^{[371-373]}$

The first synthesis using DES's dates back to the first ionothermal synthesis, when choline chloride/urea eutectic mixture IL yielded the aluminophosphate SIZ-2 ${ }^{[99]}$ From then on, several materials have been obtained, as the aluminophosphates SIZ-13 and SIZ-14 (LEV): ${ }^{[374]}$ the zincphosphate ZnPO 4-EU1 (DFT); ${ }^{[375]}$ the aluminophosphates UiO-7 (ZON), AlPO-17 (ERI), AlPO-22 (AWW), AlPO-5 (AFI) and SIZ-10 (CHA); ${ }^{[376]}$ the aluminophosphate FeAIPO-16 (AST); ${ }^{[377]}$ the aluminophosphate FeAlPO-5 (AFI); ${ }^{[378]}$ and the silicoaluminophosphate SAPO-5 (AFI). ${ }^{[379]}$ Like in the IL's case, the number of zeolites synthesized using DES's is very scarce, with only the all-silica $\mathrm{SOD}^{[380]}$ and the all-silica ZSM-5 (MFI), ZSM-11 (MEL), Beta (BEA) and ZSM-39 (MTN) zeolites. ${ }^{[381]}$ 


\subsection{References}

[1] F. Liebau, Ordered microporous and mesoporous materials with inorganic hosts: definitions of terms, formula notation, and systematic classification, Microporous and Mesoporous materials, 58, 1, 2003, 15-72.

[2] L. McCusker, F. Liebau, G. Engelhardt, Nomenclature of structural and compositional characteristics of ordered microporous and mesoporous materials with inorganic hosts (IUPAC Recommendations 2001), Pure and Applied Chemistry, 73, 2, 2001, 381-394.

[3] A.F. Cronstedt, Rön och beskrifning om en obekant bärg art, som kallas Zeolites, Svenska Vetenskaps akademiens Handlingar, 1756.

[4] C.S. Cundy, P.A. Cox, The hydrothermal synthesis of zeolites: history and development from the earliest days to the present time, Chemical Reviews, 103, 3, 2003, 663-702.

[5] V. Valtchev, S. Mintova, Hierarchical zeolites, MRS Bulletin, 41, 9, 2016, 689-693.

[6] G. Gottardi, E. Galli, Natural zeolites, Springer Science \& Business Media, 2012.

[7] C. Baerlocher, L.B. McCusker, D.H. Olson, Atlas of zeolite framework types, 6th ed., Elsevier, 2007.

[8] C. Baerlocher, M. L., Database of Zeolite Structures: http://www.izastructure.org/databases/.

[9] M.D. Foster, A. Simperler, R.G. Bell, O.D. Friedrichs, F.A.A. Paz, J. Klinowski, Chemically feasible hypothetical crystalline networks, Nature Materials, 3, 4, 2004, 234238.

[10] V.A. Blatov, G.D. Ilyushin, D.M. Proserpio, The zeolite conundrum: why are there so many hypothetical zeolites and so few observed? A possible answer from the zeolite-type frameworks perceived as packings of tiles, Chemistry of Materials, 25, 3, 2013, 412-424.

[11] G. Peregot, G. Bellussi, C. Corno, M. Taramasso, F. Buonomot, A. Esposito, Titaniumsilicalite: a novel derivative in the pentasil family, in: Studies in Surface Science and Catalysis, Elsevier, 28, 1986, 129-136.

[12] T.M. Nenoff, W.T. Harrison, T.E. Gier, N.L. Keder, C.M. Zaremba, V.I. Srdanov, J.M. Nicol, G.D. Stucky, Structural and Chemical Investigations of $\mathrm{Na}_{3}\left(\mathrm{ABO}_{4}\right)_{3}$. cntdot. $4 \mathrm{H}_{2} \mathrm{O}-$ Type Sodalite Phases, Inorganic Chemistry, 33, 11, 1994, 2472-2480.

[13] A. Corma, L.T. Nemeth, M. Renz, S. Valencia, Sn-zeolite beta as a heterogeneous chemoselective catalyst for Baeyer-Villiger oxidations, Nature, 412, 6845, 2001, 423-425. 
[14] T. Pang, X. Yang, C. Yuan, A.A. Elzatahry, A. Alghamdi, X. He, X. Cheng, Y. Deng, Recent advance in synthesis and application of heteroatom zeolites, Chinese Chemical Letters, 32, 1, 2020, 328-338.

[15] H. Gies, B. Marker, The structure-controlling role of organic templates for the synthesis of porosils in the systems $\mathrm{SiO}_{2} /$ template/ $\mathrm{H}_{2} \mathrm{O}$, Zeolites, 12, 1, 1992, $42-49$.

[16] A. Burton, Recent trends in the synthesis of high-silica zeolites, Catalysis Reviews, 60, 1, 2018, 132-175.

[17] H. Li, O.M. Yaghi, Transformation of Germanium Dioxide to Microporous Germanate 4-Connected Nets, Journal of the American Chemical Society, 120, 40, 1998, 10569-10570.

[18] Y. Mathieu, J.-L. Paillaud, P. Caullet, N. Bats, Synthesis and characterization of IM-10: a new microporous silicogermanate with a novel topology, Microporous and Mesoporous Materials, 75, 1, 2004, 13-22.

[19] B.M. Lok, C.A. Messina, R.L. Patton, R.T. Gajek, T.R. Cannan, E.M. Flanigen, Silicoaluminophosphate molecular sieves: another new class of microporous crystalline inorganic solids, Journal of the American Chemical Society, 106, 20, 1984, 6092-6093.

[20] H.O. Pastore, S. Coluccia, L. Marchese, Porous Aluminophosphates: From Molecular Sieves to Designed Acid Catalysts, Annual Review of Materials Research, 35, 1, 2005, 351395.

[21] D. Barthomeuf, Conjugate acid-base pairs in zeolites, The Journal of Physical Chemistry, 88, 1, 1984, 42-45.

[22] D. Barthomeuf, G. Coudurier, J. Vedrine, Basicity and basic catalytic properties of zeolites, Materials Chemistry and Physics, 18, 5-6, 1988, 553-575.

[23] A. Corma, S. Iborra, Optimization of alkaline earth metal oxide and hydroxide catalysts for base-catalyzed reactions, Advances in Catalysis, 49, 2006, 239-302.

[24] E. Derouane, J.C. Vedrine, R.R. Pinto, P. Borges, L. Costa, M. Lemos, F. Lemos, F.R. Ribeiro, The acidity of zeolites: Concepts, measurements and relation to catalysis: A review on experimental and theoretical methods for the study of zeolite acidity, Catalysis Reviews, $55,4,2013,454-515$.

[25] K. Oura, V. Lifshits, A. Saranin, A. Zotov, M. Katayama, Surface science: an introduction, Springer Science \& Business Media, 2013.

[26] R. Townsend, Ion exchange in zeolites, in: Studies in Surface Science and Catalysis, Elsevier, 58, 1991, 359-390. 
[27] J. Weitkamp, L. Puppe, Catalysis and zeolites: fundamentals and applications, Springer Science \& Business Media, 2013.

[28] V.E. Stiles, Hydrogen zeolite y having improved hydrothermal stability, Union Oil Co., US3287282, 1966.

[29] G. Busca, Acidity and basicity of zeolites: A fundamental approach, Microporous and Mesoporous Materials, 254, 2017, 3-16.

[30] R.A. Schoonheydt, P. Geerlings, E.A. Pidko, R.A. van Santen, The framework basicity of zeolites, Journal of Materials Chemistry, 22, 36, 2012, 18705-18717.

[31] M. Sánchez-Sánchez, T. Blasco, Characterization of zeolite basicity using probe molecules by means of infrared and solid state NMR spectroscopies, Catalysis Today, 143, 3-4, 2009, 293-301.

[32] R. Beaumont, D. Barthomeuf, X, Y, aluminum-deficient and ultrastable faujasite-type zeolites: I. Acidic and structural properties, Journal of Catalysis, 26, 2, 1972, 218-225.

[33] L.-E. Sandoval-Díaz, J.-A. González-Amaya, C.-A. Trujillo, General aspects of zeolite acidity characterization, Microporous and mesoporous materials, 215, 2015, 229-243.

[34] J.W. Ward, The nature of active sites on zeolites: I. The decationated Y zeolite, Journal of Catalysis, 9, 3, 1967, 225-236.

[35] M. Boronat, P. Concepción, A. Corma, M. Renz, S. Valencia, Determination of the catalytically active oxidation Lewis acid sites in Sn-beta zeolites, and their optimisation by the combination of theoretical and experimental studies, Journal of Catalysis, 234, 1, 2005, 111-118.

[36] S. Roy, K. Bakhmutsky, E. Mahmoud, R.F. Lobo, R.J. Gorte, Probing Lewis Acid Sites in Sn-Beta Zeolite, ACS Catalysis, 3, 4, 2013, 573-580.

[37] J.D. Lewis, S. Van de Vyver, Y. Román-Leshkov, Acid-base pairs in Lewis acidic zeolites promote direct aldol reactions by soft enolization, Angewandte Chemie, 127, 34, 2015, 9973-9976.

[38] P.T. Anastas, M.M. Kirchhoff, T.C. Williamson, Catalysis as a foundational pillar of green chemistry, Applied Catalysis A: General, 221, 1-2, 2001, 3-13.

[39] J.H. Clark, Solid acids for green chemistry, Accounts of Chemical Research, 35, 9, 2002, 791-797.

[40] A. Chica, Zeolites: promised materials for the sustainable production of hydrogen, International Scholarly Research Notices, 2013, 2013.

[41] F.-S. Xiao, X. Meng, Zeolites in Sustainable Chemistry, Springer, 2016. 
[42] Y. Li, L. Li, J. Yu, Applications of zeolites in sustainable chemistry, Chem, 3, 6, 2017, 928-949.

[43] J. Weitkamp, Zeolites and catalysis, Solid State Ionics, 131, 1-2, 2000, 175-188.

[44] A. Corma, State of the art and future challenges of zeolites as catalysts, Journal of Catalysis, 216, 1, 2003, 298-312.

[45] J.G. Speight, Petroleum Refining and Environmental Control and Environmental Effects, in: Fossil Energy, Springer, 2017, 101-131.

[46] S. Treese, P. Pujadó, D. Jones, Handbook of petroleum processing, 2nd ed., Springer, 2015.

[47] A. Corma, E. Corresa, Y. Mathieu, L. Sauvanaud, S. Al-Bogami, M. Al-Ghrami, A. Bourane, Crude oil to chemicals: light olefins from crude oil, Catalysis Science \& Technology, 7, 1, 2017, 12-46.

[48] M.J. Climent, A. Corma, S. Iborra, Zeolites as catalysts for the synthesis of fine chemicals, in: Zeolites and Catalysis: Synthesis, reactions and applications, John Wiley \& Sons Inc., 2010, 775-826.

[49] J. Čejka, G. Centi, J. Perez-Pariente, W.J. Roth, Zeolite-based materials for novel catalytic applications: Opportunities, perspectives and open problems, Catalysis Today, 179, 1, 2012, 2-15.

[50] A. Corma, G.W. Huber, L. Sauvanaud, P. O'connor, Processing biomass-derived oxygenates in the oil refinery: Catalytic cracking (FCC) reaction pathways and role of catalyst, Journal of Catalysis, 247, 2, 2007, 307-327.

[51] T. Ennaert, J. Van Aelst, J. Dijkmans, R. De Clercq, W. Schutyser, M. Dusselier, D. Verboekend, B.F. Sels, Potential and challenges of zeolite chemistry in the catalytic conversion of biomass, Chemical Society Reviews, 45, 3, 2016, 584-611.

[52] S. Sie, M. Senden, H. Van Wechem, Conversion of natural gas to transportation fuels via the shell middle distillate synthesis process (SMDS), Catalysis Today, 8, 3, 1991, 371394.

[53] C. Bouchy, G. Hastoy, E. Guillon, J.A. Martens, Fischer-Tropsch Waxes Upgrading via Hydrocracking and Selective Hydroisomerization, Oil \& Gas Science and Technology, 64, 1, 2009, 91-112.

[54] T. Degnan Jr, Recent progress in the development of zeolitic catalysts for the petroleum refining and petrochemical manufacturing industries, in: Studies in Surface Science and Catalysis, Elsevier, 170, 2007, 54-65. 
[55] J.-P. Gilson, O. Marie, S. Mintova, V. Valtchev, Emerging Applications of Zeolites, in: Zeolites and Ordered Porous Solids: Fundamentals and Applications, Universitat Politècnica de València, 2011, 245-299.

[56] T. Bein, Synthesis and applications of molecular sieve layers and membranes, Chemistry of Materials, 8, 8, 1996, 1636-1653.

[57] J. Caro, M. Noack, Zeolite membranes-recent developments and progress, Microporous and Mesoporous Materials, 115, 3, 2008, 215-233.

[58] N. Kosinov, J. Gascon, F. Kapteijn, E.J. Hensen, Recent developments in zeolite membranes for gas separation, Journal of Membrane Science, 499, 2016, 65-79.

[59] M. Palomino, A. Corma, F. Rey, S. Valencia, New Insights on $\mathrm{CO}_{2}-$ Methane separation using LTA zeolites with different $\mathrm{Si} / \mathrm{Al}$ ratios and a first comparison with MOFs, Langmuir, 26, 3, 2010, 1910-1917.

[60] A.J. Hernández-Maldonado, R.T. Yang, Desulfurization of liquid fuels by adsorption via $\pi$ complexation with $\mathrm{Cu}(\mathrm{I})-\mathrm{Y}$ and $\mathrm{Ag}-\mathrm{Y}$ zeolites, Industrial \& Engineering Chemistry Research, 42, 1, 2003, 123-129.

[61] M. Palomino, A. Corma, J.L. Jordá, F. Rey, S. Valencia, Zeolite Rho: a highly selective adsorbent for $\mathrm{CO}_{2} / \mathrm{CH}_{4}$ separation induced by a structural phase modification, Chemical Communications, 48, 2, 2012, 215-217.

[62] A. Corma, F. Rey, J. Rius, M.J. Sabater, S. Valencia, Supramolecular self-assembled molecules as organic directing agent for synthesis of zeolites, Nature, 431, 7006, 2004, 287290 .

[63] A. Luna-Triguero, P. Gómez-Álvarez, S. Calero, Adsorptive process design for the separation of hexane isomers using zeolites, Physical Chemistry Chemical Physics, 19, 7, 2017, 5037-5042.

[64] M. Palomino, A. Cantín, A. Corma, S. Leiva, F. Rey, S. Valencia, Pure silica ITQ-32 zeolite allows separation of linear olefins from paraffins, Chemical Communications, 12, 12, 2007, 1233-1235.

[65] P.J. Bereciartua, Á. Cantín, A. Corma, J.L. Jordá, M. Palomino, F. Rey, S. Valencia, E.W. Corcoran, P. Kortunov, P.I. Ravikovitch, Control of zeolite framework flexibility and pore topology for separation of ethane and ethylene, Science, 358, 6366, 2017, 1068-1071.

[66] J. Wen, H. Dong, G. Zeng, Application of zeolite in removing salinity/sodicity from wastewater: A review of mechanisms, challenges and opportunities, Journal of Cleaner Production, 197, 2018, 1435-1446. 
[67] J.H. Koon, W.J. Kaufman, Optimization of ammonia removal by ion exchange using clinoptilolite, University of California Berkeley Sanitary Engineering Research Lab., 1971, Environmental Protection Agency.

[68] C.E. Bower, D.T. Turner, Ammonia removal by clinoptilolite in the transport of ornamental freshwater fishes, The Progressive Fish-Culturist, 44, 1, 1982, 19-23.

[69] R. Harjula, J. Lehto, Effect of sodium and potassium ions on cesium absorption from nuclear power plant waste solutions on synthetic zeolites, Nuclear and Chemical Waste Management, 6, 2, 1986, 133-137.

[70] H.Y. Lee, H.S. Kim, H.-K. Jeong, M. Park, D.-Y. Chung, K.-Y. Lee, E.-H. Lee, W.T. Lim, Selective removal of radioactive cesium from nuclear waste by zeolites: on the origin of cesium selectivity revealed by systematic crystallographic studies, The Journal of Physical Chemistry C, 121, 19, 2017, 10594-10608.

[71] B. Wichtelová, Z. Sobalík, J. Dědeček, Redox catalysis over metallo-zeolites: contribution to environmental catalysis, Applied Catalysis B: Environmental, 41, 1-2, 2003, 97-114.

[72] R. Beauchet, P. Magnoux, J. Mijoin, Catalytic oxidation of volatile organic compounds (VOCs) mixture (isopropanol/o-xylene) on zeolite catalysts, Catalysis Today, 124, 3-4, 2007, 118-123.

[73] S. Brandenberger, O. Kröcher, A. Tissler, R. Althoff, The State of the art in selective catalytic reduction of $\mathrm{NO}_{\mathrm{x}}$ by ammonia using metal-exchanged zeolite catalysts, Catalysis Reviews, 50, 4, 2008, 492-531.

[74] S. Mohan, P. Dinesha, S. Kumar, NOx reduction behaviour in copper zeolite catalysts for ammonia SCR systems: A review, Chemical Engineering Journal, 384, 2020, 123253.

[75] H. Yahiro, M. Iwamoto, Copper ion-exchanged zeolite catalysts in de $\mathrm{NO}_{\mathrm{x}}$ reaction, Applied Catalysis A: General, 222, 1-2, 2001, 163-181.

[76] M. Rutkowska, U. Díaz, A. Palomares, L. Chmielarz, $\mathrm{Cu}$ and Fe modified derivatives of 2D MWW-type zeolites (MCM-22, ITQ-2 and MCM-36) as new catalysts for $\mathrm{DeNO}_{\mathrm{x}}$ process, Applied Catalysis B: Environmental, 168, 2015, 531-539.

[77] N. Martín, C.R. Boruntea, M. Moliner, A. Corma, Efficient synthesis of the Cu-SSZ-39 catalyst for DeNOx applications, Chemical Communications, 51, 55, 2015, 11030-11033.

[78] C. Marambio-Jones, E.M. Hoek, A review of the antibacterial effects of silver nanomaterials and potential implications for human health and the environment, Journal of Nanoparticle Research, 12, 5, 2010, 1531-1551. 
[79] J. Cerrillo, A. Palomares, F. Rey, S. Valencia, L. Palou, M.B. Pérez-Gago, Ag-zeolites as fungicidal material: Control of citrus green mold caused by Penicillium digitatum, Microporous and Mesoporous Materials, 254, 2017, 69-76.

[80] J.L. Cerrillo, A.E. Palomares, F. Rey, S. Valencia, M.B. Pérez-Gago, D. Villamón, L. Palou, Functional Ag-Exchanged Zeolites as Biocide Agents, ChemistrySelect, 3, 17, 2018, 4676-4682.

[81] J. Cerrillo, A. Palomares, F. Rey, Silver exchanged zeolites as bactericidal additives in polymeric materials, Microporous and Mesoporous Materials, 305, 2020, 110367-110386.

[82] L. Bacakova, M. Vandrovcova, I. Kopova, I. Jirka, Applications of zeolites in biotechnology and medicine-a review, Biomaterials Science, 6, 5, 2018, 974-989.

[83] J. Coronas, J. Santamaria, The use of zeolite films in small-scale and micro-scale applications, Chemical Engineering Science, 59, 22-23, 2004, 4879-4885.

[84] K. Sahner, G. Hagen, D. Schönauer, S. Reiß, R. Moos, Zeolites-Versatile materials for gas sensors, Solid State Ionics, 179, 40, 2008, 2416-2423.

[85] D.C. Pugh, I.P. Parkin, Zeolite modified vanadium pentoxide sensors for the selective detection of volatile organic compounds, MRS Advances, 1, 49, 2016, 3349-3354.

[86] H.d.S.C. Deville, Production artificielle de la levyne, Comptes Rendus de l'Academie des Sciences, 54, 1862, 324-327.

[87] W. Taylor, I. The structure of analcite $\left(\mathrm{NaAlSi}_{2} \mathrm{O}_{6} \cdot \mathrm{H}_{2} \mathrm{O}\right)$, Zeitschrift für Kristallographie-Crystalline Materials, 74, 1-6, 1930, 1-19.

[88] R.M. Barrer, 33. Synthesis of a zeolitic mineral with chabazite-like sorptive properties, Journal of the Chemical Society (Resumed), 1948, 127-132.

[89] R.M. Milton, Molecular sieve science and technology: a historical perspective, in: Zeolite Synthesis, American Chemical Society, 398, 1989, 1-10.

[90] C.S. Cundy, B.M. Lowe, D.M. Sinclair, Direct measurements of the crystal growth rate and nucleation behaviour of silicalite, a zeolitic silica polymorph, Journal of Crystal Growth, 100, 1-2, 1990, 189-202.

[91] S. Mintova, N.H. Olson, V. Valtchev, T. Bein, Mechanism of zeolite A nanocrystal growth from colloids at room temperature, Science, 283, 5404, 1999, 958-960.

[92] C.S. Cundy, P.A. Cox, The hydrothermal synthesis of zeolites: Precursors, intermediates and reaction mechanism, Microporous and Mesoporous Materials, 82, 1-2, 2005, 1-78. 
[93] P. Cubillas, M.W. Anderson, Synthesis mechanism: crystal growth and nucleation, in: Zeolites and Catalysis: Synthesis, reactions and applications, John Wiley \& Sons Inc., 1, 2010, 1-55.

[94] N.D. Hould, A. Foster, R.F. Lobo, Zeolite beta mechanisms of nucleation and growth, Microporous and Mesoporous Materials, 142, 1, 2011, 104-115.

[95] J. Grand, H. Awala, S. Mintova, Mechanism of zeolites crystal growth: new findings and open questions, CrystEngComm, 18, 5, 2016, 650-664.

[96] S.J. Turner, J. Chen, A.M. Slawin, W. Zhou, New mechanism for the nucleation and growth of large zeolite $\mathrm{X}$ crystals in the presence of triethanolamine, Chemical Communications, 55, 6, 2019, 862-865.

[97] C.-T. Chen, K. Iyoki, Y. Yonezawa, T. Okubo, T. Wakihara, Understanding the Nucleation and Crystal Growth of Zeolites: A Case Study on the Crystallization of ZSM-5 from a Hydrogel System under Ultrasonication, The Journal of Physical Chemistry C, 124, 21, 2020, 11516-11524.

[98] A.W. Burton, S.I. Zones, Chapter 5 Organic molecules in zeolite synthesis: Their preparation and structure-directing effects, in: Studies in Surface Science and Catalysis, Elsevier, Volume 168, 2007, 137-179.

[99] E.R. Cooper, C.D. Andrews, P.S. Wheatley, P.B. Webb, P. Wormald, R.E. Morris, Ionic liquids and eutectic mixtures as solvent and template in synthesis of zeolite analogues, Nature, 430, 7003, 2004, 1012-1016.

[100] Q. Wu, X. Hong, L. Zhu, X. Meng, S. Han, J. Zhang, X. Liu, C. Jin, F.-S. Xiao, Generalized ionothermal synthesis of silica-based zeolites, Microporous and Mesoporous Materials, 286, 2019, 163-168.

[101] W. Xu, J. Dong, J. Li, J. Li, F. Wu, A novel method for the preparation of zeolite ZSM5, Journal of the Chemical Society, Chemical Communications, 10, 1990, 755-756.

[102] Q. Wu, X. Meng, X. Gao, F.-S. Xiao, Solvent-free synthesis of zeolites: mechanism and utility, Accounts of Chemical Research, 51, 6, 2018, 1396-1403.

[103] L. Ren, Q. Wu, C. Yang, L. Zhu, C. Li, P. Zhang, H. Zhang, X. Meng, F.-S. Xiao, Solvent-free synthesis of zeolites from solid raw materials, Journal of the American Chemical Society, 134, 37, 2012, 15173-15176.

[104] D.I. Petkowicz, S. Canal, P.H. Finger, M.L. Mignoni, J.H.Z. dos Santos, Synthesis of hybrid zeolites using a solvent-free method in the presence of different organosilanes, Microporous and Mesoporous Materials, 241, 2017, 98-106. 
[105] C. Zhang, Q. Wu, C. Lei, S. Pan, C. Bian, L. Wang, X. Meng, F.-S. Xiao, Solvent-free and mesoporogen-free synthesis of mesoporous aluminosilicate ZSM-5 zeolites with superior catalytic properties in the methanol-to-olefins reaction, Industrial \& Engineering Chemistry Research, 56, 6, 2017, 1450-1460.

[106] W. Gao, C.C. Amoo, G. Zhang, M. Javed, B. Mazonde, C. Lu, R. Yang, C. Xing, N. Tsubaki, Insight into solvent-free synthesis of MOR zeolite and its laboratory scale production, Microporous and Mesoporous Materials, 280, 2019, 187-194.

[107] V. Pashkova, K. Mlekodaj, P. Klein, L. Brabec, R. Zouzelka, J. Rathousky, V. Tokarova, J. Dedecek, Mechanochemical Pretreatment for Efficient Solvent-Free Synthesis of SSZ-13 Zeolite, Chemistry-A European Journal, 25, 52, 2019, 12068-12073.

[108] Q. Wu, X. Liu, L. Zhu, L. Ding, P. Gao, X. Wang, S. Pan, C. Bian, X. Meng, J. Xu, Solvent-free synthesis of zeolites from anhydrous starting raw solids, Journal of the American Chemical Society, 137, 3, 2015, 1052-1055.

[109] Q. Wu, X. Wang, G. Qi, Q. Guo, S. Pan, X. Meng, J. Xu, F. Deng, F. Fan, Z. Feng, Sustainable synthesis of zeolites without addition of both organotemplates and solvents, Journal of the American Chemical Society, 136, 10, 2014, 4019-4025.

[110] X. Wang, Q. Wu, C. Chen, S. Pan, W. Zhang, X. Meng, S. Maurer, M. Feyen, U. Müller, F.-S. Xiao, Atom-economical synthesis of a high silica CHA zeolite using a solventfree route, Chemical Communications, 51, 95, 2015, 16920-16923.

[111] J. Schulz, F. Bandermann, Conversion of ethanol over zeolite H-ZSM-5, Chemical Engineering \& Technology: Industrial Chemistry-Plant Equipment-Process EngineeringBiotechnology, 17, 3, 1994, 179-186.

[112] K. Na, M. Choi, R. Ryoo, Recent advances in the synthesis of hierarchically nanoporous zeolites, Microporous and Mesoporous Materials, 166, 2013, 3-19.

[113] A. Feliczak-Guzik, Hierarchical zeolites: Synthesis and catalytic properties, Microporous and Mesoporous Materials, 259, 2018, 33-45.

[114] M.-C. Silaghi, C. Chizallet, P. Raybaud, Challenges on molecular aspects of dealumination and desilication of zeolites, Microporous and Mesoporous Materials, 191, 2014, 82-96.

[115] R. Barrer, M. Makki, Molecular sieve sorbents from clinoptilolite, Canadian Journal of Chemistry, 42, 6, 1964, 1481-1487.

[116] Q. Wang, G. Giannetto, M. Torrealba, G. Perot, C. Kappenstein, M. Guisnet, Dealumination of zeolites II. Kinetic study of the dealumination by hydrothermal treatment of a $\mathrm{NH}_{4} \mathrm{NaY}$ zeolite, Journal of Catalysis, 130, 2, 1991, 459-470.

44 
[117] R. Beyerlein, C. Choi-Feng, J. Hall, B. Huggins, G. Ray, Effect of steaming on the defect structure and acid catalysis of protonated zeolites, Topics in Catalysis, 4, 1, 1997, 2742.

[118] H.K. Beyer, Dealumination techniques for zeolites, in: Post-synthesis modification I, Springer, 2002, 203-255.

[119] C.S. Triantafillidis, A.G. Vlessidis, N.P. Evmiridis, Dealuminated H-Y zeolites: influence of the degree and the type of dealumination method on the structural and acidic characteristics of $\mathrm{H}-\mathrm{Y}$ zeolites, Industrial \& Engineering Chemistry Research, 39, 2, 2000, 307-319.

[120] M.-C. Silaghi, C. Chizallet, J. Sauer, P. Raybaud, Dealumination mechanisms of zeolites and extra-framework aluminum confinement, Journal of Catalysis, 339, 2016, 242255.

[121] B. Sulikowski, The fractal dimension in molecular sieves: synthetic faujasite and related solids, American Chemical Society, 97, 7, 1993, 1420-1425.

[122] C. Coutanceau, J. Da Silva, M. Alvarez, F. Ribeiro, M. Guisnet, Dealumination of zeolites-Part VII. Influence of the acid treatment of a HBEA zeolite on the framework composition and on the porosity, Journal de Chimie Physique, 94, 1997, 765-781.

[123] C.J. Van Oers, W.J. Stevens, E. Bruijn, M. Mertens, O.I. Lebedev, G. Van Tendeloo, V. Meynen, P. Cool, Formation of a combined micro-and mesoporous material using zeolite Beta nanoparticles, Microporous and Mesoporous Materials, 120, 2009, 29-34.

[124] A. Omegna, M. Vasic, J.A. van Bokhoven, G. Pirngruber, R. Prins, Dealumination and realumination of microcrystalline zeolite beta: an XRD, FTIR and quantitative multinuclear (MQ) MAS NMR study, Physical Chemistry Chemical Physics, 6, 2, 2004, 447-452.

[125] H.K. Beyer, I. Belenykaja, A New Method for the Dealumination of Faujasite-Type Zeolites, in: Studies in Surface Science and Catalysis, Elsevier, 5, 1980, 203-210.

[126] M. Müller, G. Harvey, R. Prins, Comparison of the dealumination of zeolites beta, mordenite, ZSM-5 and ferrierite by thermal treatment, leaching with oxalic acid and treatment with $\mathrm{SiCl}_{4}$ by ${ }^{1} \mathrm{H},{ }^{29} \mathrm{Si}$ and ${ }^{27} \mathrm{Al}$ MAS NMR, Microporous and Mesoporous Materials, 34, 2, 2000, 135-147.

[127] J.C. Groen, J.A. Moulijn, J. Pérez-Ramírez, Alkaline posttreatment of MFI zeolites. From accelerated screening to scale-up, Industrial \& engineering chemistry research, 46, 12, 2007, 4193-4201. 
[128] D. Verboekend, J. Pérez-Ramírez, Desilication Mechanism Revisited: Highly Mesoporous All-Silica Zeolites Enabled Through Pore-Directing Agents, Chemistry - A European Journal, 17, 4, 2011, 1137-1147.

[129] D. Verboekend, J. Pérez-Ramírez, Design of hierarchical zeolite catalysts by desilication, Catalysis Science \& Technology, 1, 6, 2011, 879-890.

[130] M. Ogura, S.-y. Shinomiya, J. Tateno, Y. Nara, E. Kikuchi, M. Matsukata, Formation of uniform mesopores in ZSM-5 zeolite through treatment in alkaline solution, Chemistry Letters, 29, 8, 2000, 882-883.

[131] D. Verboekend, G. Vilé, J. Pérez-Ramírez, Mesopore Formation in USY and Beta Zeolites by Base Leaching: Selection Criteria and Optimization of Pore-Directing Agents, Crystal Growth \& Design, 12, 6, 2012, 3123-3132.

[132] M. Ogura, S.Y. Shinomiya, J. Tateno, Y. Nara, M. Nomura, E. Kikuchi, M. Matsukata, Alkali-treatment technique - New method for modification of structural and acid-catalytic properties of ZSM-5 zeolites, Applied Catalysis A: General, 219, 1-2, 2001, 33-43.

[133] S. Abelló, A. Bonilla, J. Pérez-Ramírez, Mesoporous ZSM-5 zeolite catalysts prepared by desilication with organic hydroxides and comparison with $\mathrm{NaOH}$ leaching, Applied Catalysis A: General, 364, 1-2, 2009, 191-198.

[134] K. Sadowska, K. Góra-Marek, M. Drozdek, P. Kuśtrowski, J. Datka, J. Martinez Triguero, F. Rey, Desilication of highly siliceous zeolite ZSM-5 with $\mathrm{NaOH}$ and $\mathrm{NaOH} /$ tetrabutylamine hydroxide, Microporous and Mesoporous Materials, 168, 2013, 195205.

[135] K. Tarach, K. Góra-Marek, J. Tekla, K. Brylewska, J. Datka, K. Mlekodaj, W. Makowski, M.C. Igualada López, J. Martínez Triguero, F. Rey, Catalytic cracking performance of alkaline-treated zeolite Beta in the terms of acid sites properties and their accessibility, Journal of Catalysis, 312, 2014, 46-57.

[136] A. Jentys, G. Rumplmayr, J.A. Lercher, Hydroxyl groups in phosphorus-modified HZSM-5, Applied Catalysis, 53, 2-3, 1989, 299-312.

[137] G. Lischke, R. Eckelt, H.-G. Jerschkewitz, B. Parlitz, E. Schreier, W. Storek, B. Zibrowius, G. Öhlmann, Spectroscopic and physicochemical characterization of P-modified H-ZSM-5, Journal of Catalysis, 132, 1991, 229-243.

[138] T. Blasco, A. Corma, J. Martínez-Triguero, Hydrothermal stabilization of ZSM-5 catalytic-cracking additives by phosphorus addition, Journal of Catalysis, 237, 2, 2006, 267 277. 
[139] V. Valtchev, G. Majano, S. Mintova, J. Pérez-Ramírez, Tailored crystalline microporous materials by post-synthesis modification, Chemical Society Reviews, 42, 2013, 263-290.

[140] H.E. van der Bij, B.M. Weckhuysen, Phosphorus promotion and poisoning in zeolitebased materials: synthesis, characterisation and catalysis, Chemical Society Reviews, 44, 20, 2015, 7406-7428.

[141] J. Lercher, G. Rumplmayr, Controlled decrease of acid strength by orthophosphoric acid on ZSM5, Applied Catalysis, 25, 1-2, 1986, 215-222.

[142] N. Xue, R. Olindo, J.A. Lercher, Impact of forming and modification with phosphoric acid on the acid sites of HZSM-5, The Journal of Physical Chemistry C, 114, 37, 2010, 15763-15770.

[143] A. Corma, J. Mengual, P.J. Miguel, Stabilization of ZSM-5 zeolite catalysts for steam catalytic cracking of naphtha for production of propene and ethene, Applied Catalysis A: General, 421-422, 2012, 121-134.

[144] H. Vinek, G. Rumplmayr, J.A. Lercher, Catalytic properties of postsynthesis phosphorus-modified H-ZSM5 zeolites, Journal of Catalysis, 115, 2, 1989, 291-300.

[145] I. Hannus, I. Kiricsi, P. Fejes, A. Fonseca, J. Nagy, W. Parker Jr, Z. Szendi, Interaction of phosphorus trichloride with zeolites, Zeolites, 16, 2-3, 1996, 142-148.

[146] W.J.H. Dehertog, G.F. Froment, Production of light alkenes from methanol on ZSM-5 catalysts, Applied Catalysis, 71, 1, 1991, 153-165.

[147] M. Kaarsholm, F. Joensen, J. Nerlov, R. Cenni, J. Chaouki, G.S. Patience, Phosphorous modified ZSM-5: Deactivation and product distribution for MTO, Chemical Engineering Science, 62, 18, 2007, 5527-5532.

[148] Y. Furumoto, Y. Harada, N. Tsunoji, A. Takahashi, T. Fujitani, Y. Ide, M. Sadakane, T. Sano, Effect of acidity of ZSM-5 zeolite on conversion of ethanol to propylene, Applied Catalysis A: General, 399, 1-2, 2011, 262-267.

[149] A. Abramova, Y. Slivinsky, L. Kitaev, A. Kubasov, H. Lechert, W. Basler, V. Yushchenko, Z. Matieva, 11-P-23-Ultrastable zeolites Y (USY) modified with phosphorus and boron, Studies in Surface Science and Catalysis, 135, 2001, 213.

[150] Y. Wang, B. Shen, K. Hao, J. Li, L. Wang, B. Feng, Q. Guo, The combined modification of Ti and $\mathrm{P}$ to USY and its function in hydrogenation and ring opening reaction of tetralin, Catalysis Communications, 25, 2012, 59-63. 
[151] J.-F. Gu, X.-J. Zhang, J.-Z. Wang, J. Xu, F. Deng, Z.-Y. Yuan, Synthesis of B-Beta zeolite and its modification with orthophosphoric acid, in: Studies in Surface Science and Catalysis, Elsevier, 174, 2008, 209-212.

[152] V.R. Choudhary, A.S. Mamman, Diffusion of cumene in H-ZSM-8 and modified HZSM-8 Zeolites, AIChE journal, 36, 10, 1990, 1577-1580.

[153] X. Wang, W. Dai, G. Wu, L. Li, N. Guan, M. Hunger, Phosphorus modified HMCM22: Characterization and catalytic application in methanol-to-hydrocarbons conversion, Microporous and Mesoporous Materials, 151, 2012, 99-106.

[154] D. Zhang, R. Wang, X. Yang, W. Yao, Vapor-phase Beckmann rearrangement of cyclohexanone oxime over phosphorus modified Si-MCM-41, Reaction Kinetics, Mechanisms and Catalysis, 101, 2, 2010, 455-463.

[155] J. Zhuang, D. Ma, G. Yang, Z. Yan, X. Liu, X. Liu, X. Han, X. Bao, P. Xie, Z. Liu, Solid-state MAS NMR studies on the hydrothermal stability of the zeolite catalysts for residual oil selective catalytic cracking, Journal of Catalysis, 228, 1, 2004, 234-242.

[156] H.E. Van Der Bij, B.M. Weckhuysen, Local silico-aluminophosphate interfaces within phosphated H-ZSM-5 zeolites, Physical Chemistry Chemical Physics, 16, 21, 2014, 98929903.

[157] S.M. Abubakar, D.M. Marcus, J.C. Lee, J.O. Ehresmann, C.-Y. Chen, P.W. Kletnieks, D.R. Guenther, M.J. Hayman, M. Pavlova, J.B. Nicholas, Structural and mechanistic investigation of a phosphate-modified HZSM-5 catalyst for methanol conversion, Langmuir, 22, 10, 2006, 4846-4852.

[158] J.C. Védrine, A. Auroux, P. Dejaifve, V. Ducarme, H. Hoser, S. Zhou, Catalytic and physical properties of phosphorus-modified ZSM-5 zeolite, Journal of Catalysis, 73, 1, 1982, 147-160.

[159] N. Xue, X. Chen, L. Nie, X. Guo, W. Ding, Y. Chen, M. Gu, Z. Xie, Understanding the enhancement of catalytic performance for olefin cracking: Hydrothermally stable acids in P/HZSM-5, Journal of Catalysis, 248, 1, 2007, 20-28.

[160] R. Simancas, A. Chokkalingam, S.P. Elangovan, Z. Liu, T. Sano, K. Iyoki, T. Wakihara, T. Okubo, Recent progress in the improvement of hydrothermal stability of zeolites, Chemical Science, 12, 2021, 7677-7695.

[161] L. Gómez-Hortigüela, B. Bernardo-Maestro, Insights into the chemistry of organic structure-directing agents in the synthesis of zeolitic materials, Springer, 2018.

[162] R.M. Milton, Molecual Sieve Adsorbents, Union Carbide Corp., US2882243, 1959. 
[163] D. Breck, W. Eversole, R. Milton, T. Reed, T. Thomas, Crystalline zeolites. I. The properties of a new synthetic zeolite, type A, Journal of the American chemical society, 78, 23, 1956, 5963-5972.

[164] R. Barrer, J. Baynham, F. Bultitude, W. Meier, 36. Hydrothermal chemistry of the silicates. Part VIII. Low-temperature crystal growth of aluminosilicates, and of some gallium and germanium analogues, Journal of the Chemical Society (Resumed), 1959, 195-208.

[165] R. Barrer, P. Denny, 201. Hydrothermal chemistry of the silicates. Part IX. Nitrogenous aluminosilicates, Journal of the Chemical Society (Resumed), 1961, 971-982.

[166] S.L. Burkett, M.E. Davis, Mechanism of Structure Direction in the Synthesis of SiZSM-5: An Investigation by Intermolecular ${ }^{1} \mathrm{H}^{29} \mathrm{Si} \mathrm{CP}$ MAS NMR, American Chemical Society, 98, 17, 1994, 4647-4653.

[167] Y. Kubota, M.M. Helmkamp, S.I. Zones, M.E. Davis, Properties of organic cations that lead to the structure-direction of high-silica molecular sieves, Microporous Materials, 6, 4, 1996, 213-229.

[168] S. Zones, Y. Nakagawa, G. Lee, C. Chen, L.-T. Yuen, Searching for new high silica zeolites through a synergy of organic templates and novel inorganic conditions, Microporous and Mesoporous Materials, 21, 4-6, 1998, 199-211.

[169] S.L. Lawton, W.J. Rohrbaugh, The Framework topology of ZSM-18, a novel zeolite containing rings of three (Si, Al)-O Species, Science, 247, 4948, 1990, 1319-1322.

[170] M.J. Sabater, G. Sastre, A computational study on the templating ability of the trispyrrolidinium cation in the synthesis of ZSM-18 zeolite, Chemistry of Materials, 13, 12, 2001, 4520-4526.

[171] D.F. Shantz, A. Burton, R.F. Lobo, Synthesis, structure solution, and characterization of the aluminosilicate MCM-61: the first aluminosilicate clathrate with 18-membered rings, Microporous and mesoporous materials, 31, 1, 1999, 61-73.

[172] M.E. Davis, Zeolites from a materials chemistry perspective, Chemistry of Materials, 26, 1, 2014, 239-245.

[173] M.W. Anderson, K.S. Pachis, F. Prébin, S.W. Carr, O. Terasaki, T. Ohsuna, V. Alfreddson, Intergrowths of cubic and hexagonal polytypes of faujasitic zeolites, Journal of the Chemical Society, Chemical Communications, 23, 1991, 1660-1664.

[174] B. Lok, T.R. Cannan, C. Messina, The role of organic molecules in molecular sieve synthesis, Zeolites, 3, 4, 1983, 282-291. 
[175] F. Rey, J. Simancas, Beyond Nitrogen OSDAs, in: Insights into the Chemistry of Organic Structure-Directing Agents in the Synthesis of Zeolitic Materials, Springer International Publishing, 2018, 103-138.

[176] M. Moliner, F. Rey, A. Corma, Towards the Rational Design of Efficient Organic Structure-Directing Agents for Zeolite Synthesis, Angewandte Chemie International Edition, 52, 52, 2013, 13880-13889.

[177] J. Li, A. Corma, J. Yu, Synthesis of new zeolite structures, Chemical Society Reviews, 44, 20, 2015, 7112-7127.

[178] M.B. Smith, March's Advanced organic chemistry: reactions, mechanisms, and structure, 8th ed., John Wiley \& Sons, 2019.

[179] D.E. Corbridge, Phosphorus: chemistry, biochemistry and technology, 6th ed., CRC Press, 2013.

[180] C.J. Bradaric, A. Downard, C. Kennedy, A.J. Robertson, Y. Zhou, Industrial preparation of phosphonium ionic liquids, Green Chemistry, 5, 2, 2003, 143-152.

[181] C.J. Bradaric-Baus, Y. Zhou, Phosphonium salts and methods of their preparation, Cytec Canada Inc., CA2424215, 2014.

[182] F. Atefi, M.T. Garcia, R.D. Singer, P.J. Scammells, Phosphonium ionic liquids: design, synthesis and evaluation of biodegradability, Green Chemistry, 11, 10, 2009, 1595-1604.

[183] K.J. Fraser, D.R. MacFarlane, Phosphonium-based ionic liquids: An overview, Australian Journal of Chemistry, 62, 4, 2009, 309-321.

[184] M. Selva, A. Perosa, M. Noè, Phosphonium salts and P-ylides, Organophosphorus Chemistry: Volume 45, 45, 2016, 132.

[185] D. Bryant, The Chemistry of phosphorus, in: Phosphorus in Environmental Technology, IWA Publishing, 2004, 3-19.

[186] L.D. Quin, A guide to organophosphorus chemistry, John Wiley \& Sons, 2000.

[187] H. Hudson, F. Hartley, The chemistry of organophosphorus compounds: Primary, Secondary and Tertiary Phosphines, Polyphosphines and Heterocyclic Organophosphorus (III) Compounds, Volume 1, John Wiley \& Sons Ltd., 1990.

[188] B. Stewart, A. Harriman, L.J. Higham, Predicting the Air Stability of Phosphines, Organometallics, 30, 20, 2011, 5338-5343.

[189] P. Vollhardt, N. Schore, Organic Chemistry: Structure and Function, 6th ed., W. H. Freeman and Company, 2011. 
[190] W. Xie, R. Xie, W.-P. Pan, D. Hunter, B. Koene, L.-S. Tan, R. Vaia, Thermal stability of quaternary phosphonium modified montmorillonites, Chemistry of Materials, 14, 11, 2002, 4837-4845.

[191] M. Zanger, C.A. Vander Werf, W.E. McEwen, Kinetic Study of the Decomposition of Quaternary Phosphonium Hydroxides, Journal of the American Chemical Society, 81, 14, 1959, 3806-3807.

[192] E.M.G.A. Van Kruchten, Quaternary phosphonium salt catalysts in catalytic hydrolysis of alkylene oxides, Shell Int. Research, WO0035840, 2000.

[193] A. Ates, C. Hardacre, The effect of various treatment conditions on natural zeolites: Ion exchange, acidic, thermal and steam treatments, Journal of Colloid and Interface Science, 372, 1, 2012, 130-140.

[194] J. Gopalakrishnan, Aminophosphines: their chemistry and role as ligands and synthons, Applied Organometallic Chemistry, 23, 8, 2009, 291-318.

[195] R. Schwesinger, H. Schlemper, Peralkylated Polyaminophosphazenes-Extremely Strong, Neutral Nitrogen Bases, Angewandte Chemie International Edition in English, 26, 11, 1987, 1167-1169.

[196] T. Ishikawa, Superbases for organic synthesis: guanidines, amidines, phosphazenes and related organocatalysts, John Wiley \& Sons Inc., 2009.

[197] G. Stringfellow, Organometallic Vapor-Phase Epitaxy: Theory and Practice, 2nd ed., Academic Press, 1999.

[198] R. Edmundson, Dictionary of organophosphorus compounds, CRC Press, 1987.

[199] T.V. Whittam, Zeolites, Imperial Chemical Industries Ltd., DE2548695, 1976.

[200] S. Butter, A. Jurewicz, W. Kaeding, Conversion of alcohols, mercaptans, sulfides, halides and/or amines, Mobil Oil Corp., US3894107, 1976.

[201] A.L. Araya, Barrie Milner Zeolites, Imperial Chemical Industries PLC, EP108486, 1983.

[202] H.P.D. Rieck, H.D. Litterer, Process for the production of zeolites, Hoechst Ag., DE3333124, 1985.

[203] A. Tuel, Y.B. Taarit, Synthesis, characterization, and catalytic properties of titanium silicates prepared using phosphonium ions, Zeolites, 13, 5, 1993, 357-364.

[204] A. Tuel, Y.B. Taarit, Synthesis and characterization of titanium silicalite TS-1 prepared using phosphonium ions, Zeolites, 14, 4, 1994, 272-281. 
[205] N. Lingappan, V. Krishnasamy, Synthesis of ZSM-5 Using a TBP Template and an Oligomeric Silicic Ester, Bulletin of the Chemical Society of Japan, 69, 4, 1996, 1125-1128.

[206] B. Marler, P. Daniels, J.S. i Muné, Synthesis and structure of RUB-35, a disordered material of the EUO-NES-NON family, Microporous and Mesoporous Materials, 64, 1, 2003, 185-201.

[207] D.L. Dorset, G.J. Kennedy, K.G. Strohmaier, M.J. Diaz-Cabañas, F. Rey, A. Corma, P-Derived Organic Cations as Structure-Directing Agents: Synthesis of a High-Silica Zeolite (ITQ-27) with a Two-Dimensional 12-Ring Channel System, Journal of the American Chemical Society, 128, 27, 2006, 8862-8867.

[208] D.L. Dorset, K.G. Strohmaier, C.E. Kliewer, A. Corma, M.J. Díaz-Cabañas, F. Rey, C.J. Gilmore, Crystal structure of ITQ-26, a 3D framework with extra-large pores, Chemistry of Materials, 20, 16, 2008, 5325-5331.

[209] A. Corma, M.J. Diaz-Cabanas, J.L. Jorda, F. Rey, G. Sastre, K.G. Strohmaier, A Zeolitic Structure (ITQ-34) with Connected 9- and 10-Ring Channels Obtained with Phosphonium Cations as Structure Directing Agents, Journal of the American Chemical Society, 130, 49, 2008, 16482-16483.

[210] A. Corma, M. Díaz-Cabañas, J. Jiang, M. Afeworki, D. Dorset, S. Soled, K. Strohmaier, Extra-large pore zeolite (ITQ-40) with the lowest framework density containing double fourand double three-rings, Proceedings of the National Academy of Sciences, 107, 32, 2010, 13997-14002.

[211] A. Corma, F. Rey, M.T. Navarro, R. Simancas, N. Velamazan, Á. Cantín, J.L. Jordá, ITQ-45 material, method for obtaining same and use thereof, Consejo Superior de Investigaciones Científicas, WO2012049344, 2012.

[212] F. Rey, M. Hernández-Rodríguez, J.L. Jordá, ITQ-49 material, method for the production thereof and use of same, Consejo Superior de Investigaciones Científicas, CA2870579, 2014.

[213] R. Simancas, J.L. Jordá, F. Rey, A. Corma, A. Cantín, I. Peral, C. Popescu, A New Microporous Zeolitic Silicoborate (ITQ-52) with Interconnected Small and Medium Pores, Journal of the American Chemical Society, 136, 9, 2014, 3342-3345.

[214] Y. Yun, M. Hernandez, W. Wan, X. Zou, J.L. Jorda, A. Cantin, F. Rey, A. Corma, The first zeolite with a tri-directional extra-large 14-ring pore system derived using a phosphonium-based organic molecule, Chemical Communications, 51, 36, 2015, 7602-7605.

[215] J. Simancas, R. Simancas, P.J. Bereciartua, J.L. Jorda, F. Rey, A. Corma, S. Nicolopoulos, P. Pratim Das, M. Gemmi, E. Mugnaioli, Ultrafast Electron Diffraction 
Tomography for Structure Determination of the New Zeolite ITQ-58, Journal of the American Chemical Society, 138, 32, 2016, 10116-10119.

[216] K. Itabashi, T. Okubo, S.P. Elangovan, Method for manufacture of phosphoruscontaining $\beta$-zeolites, Nippon Chemical Industrial Co., JP2010260777, 2010.

[217] R. Simancas, D. Dari, N. Velamazán, M.T. Navarro, A. Cantín, J.L. Jordá, G. Sastre, A. Corma, F. Rey, Modular organic structure-directing agents for the synthesis of zeolites, Science, 330, 6008, 2010, 1219-1222.

[218] A. Corma, F. Rey, M.T. Navarro, R. Simancas, N. Velamazán, Á. Cantín, J.L. Jordá, ITQ-47 material, method for obtaining same and use thereof, Consejo Superior de Investigaciones Científicas, US20130046123, 2012.

[219] Q. Kun, S. Xiao-Wei, X. Da, L. Ji-Yang, Synthesis and Characterization of Extra-large 18-Ring Zeolite ITQ-33 Using Phosphonium as Structure-directing Agent, Chemical Journal of Chinese Universities, 33, 10, 2012, 2141-2145.

[220] X. Zhang, D. Liu, D. Xu, S. Asahina, K.A. Cychosz, K.V. Agrawal, Y. Al Wahedi, A. Bhan, S. Al Hashimi, O. Terasaki, Synthesis of self-pillared zeolite nanosheets by repetitive branching, Science, 336, 6089, 2012, 1684-1687.

[221] Y. Wang, Z.D. Li, Q. Jian; Wang, M. He, Q. Liu, X. Gao, L. Yan, X. Pang, F. Li, Method for synthesizing MFI molecular sieve containing phosphorus element, PetroChina Co., CN104098111, 2014.

[222] T. Sonoda, T. Maruo, Y. Yamasaki, N. Tsunoji, Y. Takamitsu, M. Sadakane, T. Sano, Synthesis of high-silica AEI zeolites with enhanced thermal stability by hydrothermal conversion of FAU zeolites, and their activity in the selective catalytic reduction of $\mathrm{NO}_{\mathrm{x}}$ with $\mathrm{NH}_{3}$, Journal of Materials Chemistry A, 3, 2, 2015, 857-865.

[223] M. Tsapatsis, X. Zhang, One-step synthesis of mesoporous pentasil zeolite with singleunit-cell lamellar structural features, Univ. Minneapolis, US2013059722, 2015.

[224] Y. Yamasaki, N. Tsunoji, Y. Takamitsu, M. Sadakane, T. Sano, Synthesis of phosphorus-modified small-pore zeolites utilizing tetraalkyl phosphonium cations as both structure-directing and phosphorous modification agents, Microporous and Mesoporous Materials, 223, 2016, 129-139.

[225] T. Lemishko, J. Simancas, M. Hernández-Rodríguez, M. Jiménez-Ruiz, G. Sastre, F. Rey, An INS study of entrapped organic cations within the micropores of zeolite RTH, Physical Chemistry Chemical Physics, 18, 2016, 17244-17252. 
[226] N. Martín, Z. Li, J. Martínez-Triguero, J. Yu, M. Moliner, A. Corma, Nanocrystalline SSZ-39 zeolite as an efficient catalyst for the methanol-to-olefin (MTO) process, Chemical Communications, 52, 36, 2016, 6072-6075.

[227] Á. Cantín, A. Corma, M.J. Díaz-Cabañas, J.L. Jordá, M. Moliner, F. Rey, Synthesis and Characterization of the All-Silica Pure Polymorph $\mathrm{C}$ and an Enriched Polymorph B Intergrowth of Zeolite Beta, Angewandte Chemie International Edition, 45, 47, 2006, 80138015 .

[228] J. Xu, L. Wang, P. Gui, T. Dou, X. Li, The method of preparing molecular sieve with EUO structure from silicon aluminum oxide powder, Univ. Taiyuan Technology, CN100540471C, 2007.

[229] R.B. Calvert, C.D. Chang, M.K. Rubin, E.W. Valyocsik, Process for the preparation of zeolite Beta using dibenzyldimethylammonium ions and the product produced, Mobil Oil Corp., US4642226, 1987.

[230] A. Burton, Process for preparing mtt zeolites using $n, n, n, n^{\prime}, n^{\prime}, n^{\prime}$-hexamethyl-propane1,3-diammonium dication structure directing agent, Chevron USA Inc., US20070128105, 2007.

[231] E.W. Valyocsik, Zeolite ZSM-51 composition, Mobil Oil Corp., US4568654, 1986.

[232] J.E. Schmidt, C.-Y. Chen, S.K. Brand, S.I. Zones, M.E. Davis, Facile Synthesis, Characterization, and Catalytic Behavior of a Large-Pore Zeolite with the IWV Framework, Chemistry - A European Journal, 22, 2016, 4022-4029.

[233] M. Hernández-Rodríguez, J.L. Jordá, F. Rey, A. Corma, Synthesis and Structure Determination of a New Microporous Zeolite with Large Cavities Connected by Small Pores, Journal of the American Chemical Society, 134, 32, 2012, 13232-13235.

[234] S. Smeets, L.B. McCusker, C. Baerlocher, D. Xie, C.-Y. Chen, S.I. Zones, SSZ-87: a borosilicate zeolite with unusually flexible 10-ring pore openings, Journal of the American Chemical Society, 137, 5, 2015, 2015-2020.

[235] R.L. Wadlinger, G.T. Kerr, E.J. Rosinski, Catalytic composition of a crystalline zeolite, Mobil Oil Corp., US3308069, 1967.

[236] E. Rosinski, M.K. Rubin, Crystalline Zeolite ZSM-12, Mobil Oil Corp., US3832449, 1974.

[237] J. Ciric, Organic compound conversion by zeolite ZSM-20 catalysts, Mobil Oil Corp., US4021331, 1977.

[238] G. Kokotailo, S. Lawton, D. Olson, Structure of synthetic zeolite ZSM-5, Nature, 272, 1978, 437-438. 
Chapter 1: Introduction

[239] L.D. Rollmann, E.W. Valyocsik, Manufacture of synthetic mordenite, Mobil Corp., US4205052, 1980.

[240] J.L. Schlenker, F.G. Dwyer, E.E. Jenkins, W.J. Rohrbaugh, G.T. Kokotailo, W.M. Meier, Crystal structure of a synthetic high silica zeolite-ZSM-39, Nature, 294, 5839, 1981, 340-342.

[241] D.E. Vaughan, Process for preparing a zeolite of the L type using organic templates, Exxon Research Engineering Co., US4554146, 1985.

[242] K.G. Strohmaier, D.E.W. Vaughan, Zeolite (ECR-18) isostructural with paulingite and a method for its preparation, Exxon Research Engineering Co., US4661332, 1987.

[243] B.M. Lok, B.K. Marcus, Zeolite LZ-135 and process for preparing same, UOP Inc., US4857288A, 1989.

[244] M. Franco, J. Perez-Pariente, V. Fornes, Synthesis and characterization of zeolite PHI, Zeolites, 11, 4, 1991, 349-355.

[245] M.J. Annen, M.E. Davis, J.B. Higgins, J.L. Schlenker, VPI-7: The first zincosilicate molecular sieve containing three-membered T-atom rings, Journal of the Chemical Society, Chemical Communications, 17, 1991, 1175-1176.

[246] S.T. Wilson, B.M. Lok, C.A. Messina, T.R. Cannan, E.M. Flanigen, Aluminophosphate molecular sieves: a new class of microporous crystalline inorganic solids, Journal of the American Chemical Society, 104, 4, 1982, 1146-1147.

[247] D. Akporiaye, H. Fjellvag, E. Halvorsen, T. Haug, A. Karlsson, K. Lillerud, UiO-6: a novel 12-ring $\mathrm{AlPO}_{4}$, made in an inorganic-organic cation system, Chemical Communications, 13, 1996, 1553-1554.

[248] D.E.W. Vaughan, Gallium silicate having 12-ring pores (ECR-34) and a method for its preparation, Exxon Research Engineering Co., US5455020, 1995.

[249] M. Yoshikawa, S.I. Zones, M.E. Davis, Synthesis of VPI-8: I. The effects of reaction components, Microporous Materials, 11, 3-4, 1997, 127-136.

[250] S.J. Miller, Preparation of Y-type faujasite using an organic template, Chevron USA. Inc., US5716593, 1998.

[251] A. Simmen, L. McCusker, C. Baerlocher, W. Meier, The structure determination and rietveld refinement of the aluminophosphate AIPO4-18, Zeolites, 11, 7, 1991, 654-661.

[252] R. Aiello, R. Barrer, Hydrothermal chemistry of silicates. Part XIV. Zeolite crystallisation in presence of mixed bases, Journal of the Chemical Society A: Inorganic, Physical, Theoretical, 1970, 1470-1475. 
[253] P. Hopkins, Role of the Tetramethylammonium Cation in the Synthesis of Zeolites ZK4, Y, and HS, in: Zeolite Synthesis, ACS Publications, 398, 1989, 152-160.

[254] J. Patarin, P. Caullet, B. Marler, A. Faust, J. Guth, Synthesis and characterization of zeolite $\mathrm{Nu}-1$ prepared from near-neutral fluoride aluminosilicate gels, Zeolites, 14, 8, 1994, 675-681.

[255] B.J. Schoeman, J. Sterte, J.-E. Otterstedt, Synthesis of colloidal suspensions of zeolite ZSM-2, Journal of Colloid and Interface Science, 170, 2, 1995, 449-456.

[256] V.P. Valtchev, Influence of different organic bases on the crystallization of titanium silicate ETS-10, Journal of the Chemical Society, Chemical Communications, 3, 1994, 261262.

[257] A. Tuel, Y.B. Taărit, C. Naccache, Characterization of TS-1 synthesized using mixtures of tetrabutyl and tetraethyl ammonium hydroxides, Zeolites, 13, 6, 1993, 454-461.

[258] Y.H. Chou, C.S. Cundy, A.A. Garforth, V.L. Zholobenko, Mesoporous ZSM-5 catalysts: Preparation, characterisation and catalytic properties. Part I: Comparison of different synthesis routes, Microporous and Mesoporous Materials, 89, 1-3, 2006, 78-87.

[259] N.L. Chauhan, J. Das, R.V. Jasra, P.A. Parikh, Z.V.P. Murthy, Synthesis of small-sized ZSM-5 zeolites employing mixed structure directing agents, Materials Letters, 74, 2012, 115-117.

[260] K.R. Franklin, B.M. Lowe, Hydrothermal crystallisation of silica molecular sieves and clathrasils from amine containing reaction mixtures, Studies in Surface Science and Catalysis, 49, 1989, 179-188.

[261] N. Briscoe, D. Johnson, M. Shannon, G. Kokotailo, L. McCusker, The framework topology of zeolite EU-1, Zeolites, 8, 1, 1988, 74-76.

[262] S. Vortmann, B. Marler, H. Gies, P. Daniels, Synthesis and crystal structure of the new borosilicate zeolite RUB-13, Microporous Materials, 4, 2, 1995, 111-121.

[263] D. Bibby, N. Milestone, L. Aldridge, Silicalite-2, a silica analogue of the aluminosilicate zeolite ZSM-11, Nature, 280, 5724, 1979, 664-665.

[264] M.R. Klotz, Crystalline borosilicate and process of preparation, Standard Oil Co. Indiana, US4269813, 1981.

[265] M. Davis, C. Montes, P. Hathaway, J. Garces, Synthesis of aluminophosphate and element substituted aluminophosphate VPI-5, Studies in Surface Science and Catalysis, 49, 1989, $199-214$. 
[266] D.E. Vaughan, K.G. Strohmaier, Process for preparing a high silica zeolite having the faujasite topology, ECR-32, Exxon Research Engineering Co., US4931267, 1990.

[267] S. Kowalak, A. Jankowska, E. Mikołajska, Using of zeolite LOS for preparation of sulfur pigments, Microporous and Mesoporous Materials, 127, 1, 2010, 126-132.

[268] R. Bai, Q. Sun, N. Wang, Y. Zou, G. Guo, S. Iborra, A. Corma, J. Yu, Simple Quaternary Ammonium Cations-Templated Syntheses of Extra-Large Pore Germanosilicate Zeolites, Chemistry of Materials, 28, 18, 2016, 6455-6458.

[269] A. Corma, M.J. Díaz-Cabañas, J.L. Jordá, C. Martinez, M. Moliner, High-throughput synthesis and catalytic properties of a molecular sieve with 18-and 10-member rings, Nature, 443, 7113, 2006, 842-845.

[270] S. Nair, H.-K. Jeong, A. Chandrasekaran, C.M. Braunbarth, M. Tsapatsis, S.M. Kuznicki, Synthesis and structure determination of ETS-4 single crystals, Chemistry of Materials, 13, 11, 2001, 4247-4254.

[271] M. Anderson, O. Terasaki, T. Ohsuna, P. Malley, A. Philippou, S. MacKay, A. Ferreira, J. Rocha, S. Lidin, Microporous titanosilicate ETS-10: a structural survey, Philosophical magazine $B, 71,5, \mathbf{1 9 9 5}, 813-841$.

[272] M.Y. Kustova, P. Hasselriis, C.H. Christensen, Mesoporous MEL-type zeolite single crystal catalysts, Catalysis Letters, 96, 3-4, 2004, 205-211.

[273] P. Wagner, Y. Nakagawa, G.S. Lee, M.E. Davis, S. Elomari, R.C. Medrud, S. Zones, Guest/host relationships in the synthesis of the novel cage-based zeolites SSZ-35, SSZ-36, and SSZ-39, Journal of the American Chemical Society, 122, 2, 2000, 263-273.

[274] S.I. Zones, Zeolite SSZ-13 and its method of preparation, Chevron Res., US4544538, 1985.

[275] S.A. Butter, W.W. Kaeding, Phosphorus-containing zeolite catalyst, Mobil Oil Corp., US3972832, 1976.

[276] G. Caeiro, P. Magnoux, J. Lopes, F.R. Ribeiro, S. Menezes, A. Costa, H. Cerqueira, Stabilization effect of phosphorus on steamed H-MFI zeolites, Applied Catalysis A: General, 314, 2, 2006, 160-171.

[277] N. Rahimi, R. Karimzadeh, Catalytic cracking of hydrocarbons over modified ZSM-5 zeolites to produce light olefins: A review, Applied Catalysis A: General, 398, 1, 2011, 1-17.

[278] K. Damodaran, J.W. Wiench, S.M. Cabral de Menezes, Y.L. Lam, J. Trébosc, J.-P. Amoureux, M. Pruski, Modification of H-ZSM-5 zeolites with phosphorus. 2. Interaction between phosphorus and aluminum studied by solid-state NMR spectroscopy, Microporous and Mesoporous Materials, 95, 1-3, 2006, 296-305. 
[279] S.M. Cabral de Menezes, Y.L. Lam, K. Damodaran, M. Pruski, Modification of HZSM-5 zeolites with phosphorus. 1. Identification of aluminum species by ${ }^{27} \mathrm{Al}$ solid-state NMR and characterization of their catalytic properties, Microporous and Mesoporous Materials, 95, 1-3, 2006, 286-295.

[280] A. Galadima, O. Muraza, Stability improvement of zeolite catalysts under hydrothermal conditions for their potential applications in biomass valorization and heavy oil upgrading, Microporous and Mesoporous Materials, 249, 1, 2017, 42-54.

[281] H. Lee, S.I. Zones, M.E. Davis, A combustion-free methodology for synthesizing zeolites and zeolite-like materials, Nature, 425, 6956, 2003, 385-388.

[282] H. Lee, S.I. Zones, M.E. Davis, Zeolite Synthesis Using Degradable StructureDirecting Agents and Pore-Filling Agents, The Journal of Physical Chemistry B, 109, 6, 2005, 2187-2191.

[283] V.J. Margarit, M.E. Martínez-Armero, M.T. Navarro, C. Martínez, A. Corma, Direct Dual-Template Synthesis of MWW Zeolite Monolayers, Angewandte Chemie, 127, 46, 2015, 13928-13932.

[284] K.R. Kloetstra, H.W. Zandbergen, J.C. Jansen, H. van Bekkum, Overgrowth of mesoporous MCM-41 on faujasite, Microporous Materials, 6, 5, 1996, 287-293.

[285] J. Martinez-Ortigosa, J. Simancas, J.A. Vidal-Moya, P. Gaveau, F. Rey, B. Alonso, T. Blasco, Host-Guest and Guest-Guest Interactions of P-and N-Containing Structure Directing Agents Entrapped inside MFI-Type Zeolite by Multinuclear NMR Spectroscopy, The Journal of Physical Chemistry C, 123, 36, 2019, 22324-22334.

[286] Y. Kakiuchi, Y. Yamasaki, N. Tsunoji, Y. Takamitsu, M. Sadakane, T. Sano, One-pot synthesis of phosphorus-modified AEI zeolites derived from the dual-template method as a durable catalyst with enhanced thermal/hydrothermal stability for selective catalytic reduction of $\mathrm{NO}_{x}$ by $\mathrm{NH}_{3}$, Chemistry Letters, 45, 2, 2016, 122-124.

[287] S.T. Evans, Preparing a crystalline aluminophosphate composition, Chevron USA Inc., WO9613460, 1996.

[288] C. Jo, S. Lee, S.J. Cho, R. Ryoo, Synthesis of Silicate Zeolite Analogues Using Organic Sulfonium Compounds as Structure-Directing Agents, Angewandte Chemie International Edition, 54, 43, 2015, 12805-12808.

[289] S. Sáez-Ferre, C.W. Lopes, J. Simancas, A. Vidal-Moya, T. Blasco, G. Agostini, G. Mínguez Espallargas, J.L. Jordá, F. Rey, P. Oña-Burgos, Use of alkylarsonium directing agents for the synthesis and study of zeolites, Chemistry-A European Journal, 25, 71, 2019, 16390-16396. 
[290] C.J. Pedersen, Cyclic polyethers and their complexes with metal salts, Journal of the American Chemical Society, 89, 26, 1967, 7017-7036.

[291] M. Yoshio, H. Noguchi, Crown ethers for chemical analysis: A Review, Analytical Letters, 15, 15, 1982, 1197-1276.

[292] V. Alexander, Design and synthesis of macrocyclic ligands and their complexes of lanthanides and actinides, Chemical Reviews, 95, 2, 1995, 273-342.

[293] G.W. Gokel, W.M. Leevy, M.E. Weber, Crown ethers: sensors for ions and molecular scaffolds for materials and biological models, Chemical Reviews, 104, 5, 2004, 2723-2750.

[294] M. Hiraoka, Crown ethers and analogous compounds, Elsevier, 2016.

[295] F. Delprato, L. Delmotte, J. Guth, L. Huve, Synthesis of new silica-rich cubic and hexagonal faujasites using crown-etherbased supramolecules as templates, Zeolites, 10, 6, 1990, 546-552.

[296] F. Dougnier, J. Patarin, J. Guth, D. Anglerot, Synthesis, characterization, and catalytic properties of silica-rich faujasite-type zeolite (FAU) and its hexagonal analog (EMT) prepared by using crown-ethers as templates, Zeolites, 12, 2, 1992, 160-166.

[297] S.L. Burkett, M.E. Davis, Structure-directing effects in the crown ether-mediated syntheses of FAU and EMT zeolites, Microporous Materials, 1, 4, 1993, 265-282.

[298] T. Chatelain, J. Patarin, E. Fousson, M. Soulard, J. Guth, P. Schulz, Synthesis and characterization of high-silica zeolite RHO prepared in the presence of 18-crown-6 ether as organic template, Microporous Materials, 4, 2-3, 1995, 231-238.

[299] Q. Ke, T. Sun, H. Cheng, H. Chen, X. Liu, X. Wei, S. Wang, Targeted Synthesis of Ultrastable High-Silica RHO Zeolite Through Alkali Metal-Crown Ether Interaction, Chemistry - An Asian Journal, 12, 10, 2017, 1043-1047.

[300] T. Chatelain, J. Patarin, R. Farre, O. Petigny, P. Schulz, Synthesis and characterization of 18-crown-6 ether-containing KFI-type zeolite, Zeolites, 17, 4, 1996, 328-333.

[301] G. van de Goor, P. Behrens, J. Felsche, $\left(\mathrm{C}_{3} \mathrm{H}_{6} \mathrm{O}_{2}\right)_{2},\left(\mathrm{Si}_{6} \mathrm{O}_{12}\right)_{2}$, a new silica sodalite synthesized, using 1, 3-dioxolane as template, Microporous Materials, 2, 6, 1994, 501-514.

[302] J. Keijsper, C. Den Ouden, M. Post, Synthesis of High-Silica Sodalite from Aqueous Systems; A Combined Experimental and Model-Based Approach, Studies in Surface Science and Catalysis, 49, 1989, 237-247.

[303] K. Möller, A. Borvornwattananont, T. Bein, Chemistry of cyclopentadienyliron dicarbonyl dimer and ferrocene in zeolite $\mathrm{Y}$ cavities. Anchoring organometallic fragments into microporous solids, American Chemical Society, 11, 1989, 4562-4571. 
[304] W. DeWilde, G. Peeters, J.H. Lunsford, Synthesis and spectroscopic properties of tris (2,2'-bipyridine) ruthenium (II) in zeolite Y, American Chemical Society, 84, 18, 1980, 23062310 .

[305] S. Kawi, J. Chang, B. Gates, Chemistry in cages. Zeolite-entrapped hexairidium cluster catalysts, Journal of the American Chemical Society, 115, 11, 1993, 4830-4843.

[306] S. Recchia, C. Dossi, A. Fusi, L. Sordelli, R. Psaro, Zeolite-supported metals by design: organometallic-based tin-promoted rhodium/NaY catalysts, Applied Catalysis A: General, 182, 1, 1999, 41-51.

[307] M. Dams, L. Drijkoningen, B. Pauwels, G. Van Tendeloo, D. De Vos, P. Jacobs, Pdzeolites as heterogeneous catalysts in heck chemistry, Journal of Catalysis, 209, 1, 2002, 225-236.

[308] J. Basset, A. Choplin, Surface organometallic chemistry: A new approach to heterogeneous Catalysis?, Journal of Molecular Catalysis, 21, 1-3, 1983, 95-108.

[309] G. van de Goor, C.C. Freyhardt, P. Behrens, The Cobalticinium Cation [CoIII $\left(\eta^{5}-\right.$ $\left.\left.\mathrm{C}_{5} \mathrm{H}_{5}\right)_{2}\right]^{+}$: A metal-organic complex as a novel template for the synthesis of clathrasils, Zeitschrift für Anorganische und Allgemeine Chemie, 621, 2, 1995, 311-322.

[310] K. Balkus, A. Gabrielov, S. Zones, The synthesis of UTD-1, Ti-UTD-1 and Ti-UTD-8 using $\mathrm{CP}_{2}{ }_{2} \mathrm{CoOH}$ as a structure directing agent, Studies in Surface Science and Catalysis, 97, 1995, 519-525.

[311] R.F. Lobo, M. Tsapatsis, C.C. Freyhardt, S. Khodabandeh, P. Wagner, C.-Y. Chen, K.J. Balkus, S.I. Zones, M.E. Davis, Characterization of the Extra-Large-Pore Zeolite UTD1, Journal of the American Chemical Society, 119, 36, 1997, 8474-8484.

[312] C. Freyhardt, M. Tsapatsis, R. Lobo, K. Balkus, M. Davis, A high-silica zeolite with a 14-tetrahedral-atom pore opening, Nature, 381, 6580, 1996, 295-298.

[313] K.J. Balkus, A.G. Gabrielov, S. Shepelev, Synthesis of aluminum phosphate molecular sieves using cobalticinium hydroxide, Microporous Materials, 3, 4, 1995, 489-495.

[314] R. Garcia, E.F. Philp, A.M. Slawin, P.A. Wright, P.A. Cox, Nickel complexed within an azamacrocycle as a structure directing agent in the crystallization of the framework metalloaluminophosphates STA-6 and STA-7, Journal of Materials Chemistry, 11, 5, 2001, 1421-1427.

[315] Y. Han, Y. Li, J. Yu, R. Xu, A Gallogermanate Zeolite Constructed Exclusively by Three-Ring Building Units, Angewandte Chemie International Edition, 50, 13, 2011, 3003 3005 .

60 
[316] Y. Xu, Y. Li, Y. Han, X. Song, J. Yu, A Gallogermanate Zeolite with ElevenMembered-Ring Channels, Angewandte Chemie International Edition, 52, 21, 2013, 55015503.

[317] P.A. Barrett, G. Sankar, R. Stephenson, C.R.A. Catlow, J.M. Thomas, R.H. Jones, S.J. Teat, A new addition to the Phillipsite family of molecular sieves: A divalent metal-ionframework substituted microporous aluminophosphate (DAF-8), Solid State Sciences, 8, 3, 2006, 337-341.

[318] X. Bu, P. Feng, G.D. Stucky, Large-cage zeolite structures with multidimensional 12ring channels, Science, 278, 5346, 1997, 2080-2085.

[319] P. Feng, X. Bu, G.D. Stucky, Amine-templated syntheses and crystal structures of zeolite rho analogs, Microporous and Mesoporous Materials, 23, 5, 1998, 315-322.

[320] R. Martínez-Franco, M. Moliner, J.R. Thogersen, A. Corma, Efficient One-Pot Preparation of $\mathrm{Cu}-\mathrm{SSZ}-13$ Materials using Cooperative OSDAs for their Catalytic Application in the SCR of $\mathrm{NO}_{x}$, ChemCatChem, 5, 11, 2013, 3316-3323.

[321] L. Ren, L. Zhu, C. Yang, Y. Chen, Q. Sun, H. Zhang, C. Li, F. Nawaz, X. Meng, F.-S. Xiao, Designed copper-amine complex as an efficient template for one-pot synthesis of $\mathrm{Cu}$ SSZ-13 zeolite with excellent activity for selective catalytic reduction of $\mathrm{NO}_{x}$ by $\mathrm{NH}_{3}$, Chemical Communications, 47, 35, 2011, 9789-9791.

[322] U. Deka, I. Lezcano-Gonzalez, S.J. Warrender, A. Lorena Picone, P.A. Wright, B.M. Weckhuysen, A.M. Beale, Changing active sites in $\mathrm{Cu}-\mathrm{CHA}$ catalysts: deNO ${ }_{\mathrm{x}}$ selectivity as a function of the preparation method, Microporous and Mesoporous Materials, 166, 2013, 144-152.

[323] R. Martínez-Franco, M. Moliner, C. Franch, A. Kustov, A. Corma, Rational direct synthesis methodology of very active and hydrothermally stable $\mathrm{Cu}$-SAPO-34 molecular sieves for the SCR of $\mathrm{NO}_{\mathrm{x}}$, Applied Catalysis B: Environmental, 127, 2012, 273-280.

[324] A. Lorena Picone, S.J. Warrender, A.M.Z. Slawin, D.M. Dawson, S.E. Ashbrook, P.A. Wright, S.P. Thompson, L. Gaberova, P.L. Llewellyn, B. Moulin, A. Vimont, M. Daturi, M.B. Park, S.K. Sung, I.-S. Nam, S.B. Hong, A co-templating route to the synthesis of $\mathrm{Cu}$ SAPO STA-7, giving an active catalyst for the selective catalytic reduction of NO, Microporous and Mesoporous Materials, 146, 1-3, 2011, 36-47.

[325] A. Maes, A. Cremers, Transition-Metal Ion Exchange in Synthetic X and Y Zeolites, in: Molecular Sieves, America Chemical Society, 121, 1973, 230-239. 
[326] L. Guczi, I. Kiricsi, Zeolite supported mono- and bimetallic systems: structure and performance as CO hydrogenation catalysts, Applied Catalysis A: General, 186, 1-2, 1999, 375-394.

[327] M. Moliner, Direct synthesis of functional zeolitic materials, ISRN Materials Science, 2012, 2012.

[328] L. Gómez-Hortigüela, F. López-Arbeloa, F. Corà, J. Pérez-Pariente, Supramolecular chemistry in the structure direction of microporous materials from aromatic structuredirecting agents, Journal of the American Chemical Society, 130, 40, 2008, 13274-13284.

[329] A. Huang, J. Caro, Fabrication of MTN-type zeolite by self-assembling of supramolecular compound, Journal of Crystal Growth, 311, 21, 2009, 4570-4574.

[330] R. García, L. Gómez-Hortigüela, F. Sánchez, J.n. Pérez-Pariente, Diasteroselective Structure Directing Effect of $(1 S, 2 S)$-2-Hydroxymethyl-1-benzyl-1-methylpyrrolidinium in the Synthesis of ZSM-12, Chemistry of Materials, 22, 7, 2010, 2276-2286.

[331] D. Xu, Y. Ma, Z. Jing, L. Han, B. Singh, J. Feng, X. Shen, F. Cao, P. Oleynikov, H. Sun, $\pi-\pi$ interaction of aromatic groups in amphiphilic molecules directing for singlecrystalline mesostructured zeolite nanosheets, Nature Communications, 5, 2014, 4262.

[332] L. Xu, X. Ji, S. Li, Z. Zhou, X. Du, J. Sun, F. Deng, S. Che, P. Wu, Self-Assembly of Cetyltrimethylammonium Bromide and Lamellar Zeolite Precursor for the Preparation of Hierarchical MWW Zeolite, Chemistry of Materials, 28, 12, 2016, 4512-4521.

[333] F.-J. Chen, Z.-H. Gao, L.-L. Liang, J. Zhang, H.-B. Du, Facile preparation of extralarge pore zeolite ITQ-37 based on supramolecular assemblies as structure-directing agents, CrystEngComm, 18, 15, 2016, 2735-2741.

[334] R. Martínez-Franco, J. Sun, G. Sastre, Y. Yun, X. Zou, M. Moliner, A. Corma, Supramolecular assembly of aromatic proton sponges to direct the crystallization of extra-largepore zeotypes, Proc. R. Soc. A, The Royal Society, 470, 2014, 20140107.

[335] F.J. Chen, Y. Xu, H.B. Du, An Extra-Large-Pore Zeolite with Intersecting 18-, 12-, and 10-Membered Ring Channels, Angewandte Chemie International Edition, 53, 36, 2014, 9592-9596.

[336] Z.-H. Gao, F.-J. Chen, L. Xu, L. Sun, Y. Xu, H.-B. Du, A Stable Extra-Large-Pore Zeolite with Intersecting 14- and 10-Membered-Ring Channels, Chemistry - A European Journal, 22, 40, 2016, 14367-14372.

[337] L. Gómez-Hortigüela, F. Corà, C.R.A. Catlow, J. Pérez-Pariente, Computational Study of the Structure-Directing Effect of Benzylpyrrolidine and Its Fluorinated Derivatives in the 
Chapter 1: Introduction

Synthesis of the Aluminophosphate AlPO-5, Journal of the American Chemical Society, 126, 38, 2004, 12097-12102.

[338] L. Gómez-Hortigüela, J. Pérez-Pariente, F. Corà, C.R.A. Catlow, T. Blasco, StructureDirecting Role of Molecules Containing Benzyl Rings in the Synthesis of a Large-Pore Aluminophosphate Molecular Sieve: An Experimental and Computational Study, The Journal of Physical Chemistry B, 109, 46, 2005, 21539-21548.

[339] L. Gómez-Hortigüela, F. López-Arbeloa, J. Pérez-Pariente, Aggregation behavior of $(S)-(-)-\mathrm{N}$-benzylpyrrolidine-2-methanol in the synthesis of the AFI structure in the presence of dopants, Microporous and Mesoporous Materials, 119, 1-3, 2009, 299-305.

[340] L. Gómez-Hortigüela, A.B. Pinar, J. Pérez-Pariente, F. Corà, Structure-Directing Effect of $(S)-(-)$-N-Benzylpyrrolidine-2-methanol and Benzylpyrrolidine in the Synthesis of STA1: A New Computational Model for Structure Direction of Nanoporous Systems, Chemistry of Materials, 21, 14, 2009, 3447-3457.

[341] A.B. Pinar, L. Gomez-Hortiguela, L.B. McCusker, J. Perez-Pariente, Synthesis of Zncontaining microporous aluminophosphate with the STA-1 structure, Dalton Transactions, 40, 32, 2011, 8125-8131.

[342] T. Alvaro-Munoz, F. Lopez-Arbeloa, J. Perez-Pariente, L. Gómez-Hortigüela, (1 R, 2 S)-Ephedrine: A New Self-Assembling Chiral Template for the Synthesis of Aluminophosphate Frameworks, The Journal of Physical Chemistry C, 118, 6, 2014, 30693077.

[343] L. Gomez-Hortiguela, T. Alvaro-Munoz, B. Bernardo-Maestro, J. Perez-Pariente, Towards chiral distributions of dopants in microporous frameworks: helicoidal supramolecular arrangement of (1R,2S)-ephedrine and transfer of chirality, Physical Chemistry Chemical Physics, 17, 1, 2015, 348-357.

[344] B. Bernardo-Maestro, E. Vos, F. López-Arbeloa, J. Pérez-Pariente, L. GómezHortigüela, Supramolecular chemistry controlled by packing interactions during structuredirection of nanoporous materials: Effect of the addition of methyl groups on ephedrine derivatives, Microporous and Mesoporous Materials, 239, 2017, 432-443.

[345] T. Álvaro-Muñoz, A.B. Pinar, D. Šišak, J. Pérez-Pariente, L. Gómez-Hortigüela, Synthesis of the Aluminophosphate ICP-1 by Self-Assembly of 1,3-Diphenylguanidine: Insights into Supramolecular Aggregation, The Journal of Physical Chemistry C, 118, 9, 2014, 4835-4845.

[346] R. Martínez-Franco, Á. Cantín, M. Moliner, A. Corma, Synthesis of the Small Pore Silicoaluminophosphate STA- 6 by Using Supramolecular Self-Assembled Organic Structure Directing Agents, Chemistry of Materials, 26, 15, 2014, 4346-4353. 
[347] R. Martínez-Franco, A.n. Cantín, A. Vidal-Moya, M. Moliner, A. Corma, SelfAssembled Aromatic Molecules as Efficient Organic Structure Directing Agents to Synthesize the Silicoaluminophosphate SAPO-42 with Isolated Si Species, Chemistry of Materials, 27, 8, 2015, 2981-2989.

[348] T. Welton, Room-temperature ionic liquids. Solvents for synthesis and catalysis, Chemical Reviews, 99, 8, 1999, 2071-2084.

[349] P. Wasserscheid, T. Welton, Ionic liquids in synthesis, John Wiley \& Sons, 2008.

[350] S.P. Ventura, A.M. Gonçalves, T. Sintra, J.L. Pereira, F. Gonçalves, J.A. Coutinho, Designing ionic liquids: the chemical structure role in the toxicity, Ecotoxicology, 22, 1, 2013, 1-12.

[351] E.R. Parnham, R.E. Morris, Ionothermal Synthesis of Zeolites, Metal-Organic Frameworks, and Inorganic-Organic Hybrids, Accounts of Chemical Research, 40, 10, 2007, 1005-1013.

[352] R.E. Morris, Ionothermal synthesis-ionic liquids as functional solvents in the preparation of crystalline materials, Chemical Communications, 21, 2009, 2990-2998.

[353] Z.-J. Tian, H. Liu, Ionothermal Synthesis of Molecular Sieves, in: Zeolites in Sustainable Chemistry, Springer, 2016, 37-76.

[354] E.R. Parnham, P.S. Wheatley, R.E. Morris, The ionothermal synthesis of SIZ-6-a layered aluminophosphate, Chemical Communications, 4, 2006, 380-382.

[355] E.R. Parnham, R.E. Morris, The ionothermal synthesis of cobalt aluminophosphate zeolite frameworks, Journal of the American Chemical Society, 128, 7, 2006, 2204-2205.

[356] L. Han, Y. Wang, C. Li, S. Zhang, X. Lu, M. Cao, Simple and safe synthesis of microporous aluminophosphate molecular sieves by ionothermal approach, AIChE Journal, $54,1,2008,280-288$.

[357] H. Ma, R. Xu, W. You, G. Wen, S. Wang, Y. Xu, B. Wang, L. Wang, Y. Wei, Y. Xu, W. Zhang, Z. Tian, L. Lin, Ionothermal synthesis of gallophosphate molecular sieves in 1alkyl-3-methyl imidazolium bromide ionic liquids, Microporous and Mesoporous Materials, 120, 3, 2009, 278-284.

[358] E.-P. Ng, S.S. Sekhon, S. Mintova, Discrete MnAlPO-5 nanocrystals synthesized by an ionothermal approach, Chemical Communications, 13, 2009, 1661-1663.

[359] D.Y. Khoo, W.-M. Kok, R.R. Mukti, S. Mintova, E.-P. Ng, Ionothermal approach for synthesizing AlPO-5 with hexagonal thin-plate morphology influenced by various parameters at ambient pressure, Solid State Sciences, 25, 2013, 63-69.

64 
[360] Y. Shi, G. Liu, L. Wang, X. Zhang, Ionothermal synthesis of phase pure $\mathrm{AlPO}_{4}-5$ using a series of tri-substituted imidazolium bromides, Microporous and Mesoporous Materials, 193, 2014, 1-6.

[361] A.B. Pinar, L.B. McCusker, C. Baerlocher, S.-J. Hwang, D. Xie, A.I. Benin, S.I. Zones, Synthesis and structural characterization of Zn-containing DAF-1, New Journal of Chemistry, 40, 5, 2016, 4160-4166.

[362] M. Sánchez-Sánchez, Á.A. Romero, I. Pinilla-Herrero, E. Sastre, Ionothermal preparation of triclinic SAPO-34 and its catalytic performance in the MTO process, Catalysis Today, 296, 2017, 239-246.

[363] L. Wang, Y. Xu, Y. Wei, J. Duan, A. Chen, B. Wang, H. Ma, Z. Tian, L. Lin, StructureDirecting Role of Amines in the Ionothermal Synthesis, Journal of the American Chemical Society, 128, 23, 2006, 7432-7433.

[364] R. Xu, W. Zhang, J. Guan, Y. Xu, L. Wang, H. Ma, Z. Tian, X. Han, L. Lin, X. Bao, New Insights into the Role of Amines in the Synthesis of Molecular Sieves in Ionic Liquids, Chemistry - A European Journal, 15, 21, 2009, 5348-5354.

[365] R. Pei, Z. Tian, Y. Wei, K. Li, Y. Xu, L. Wang, H. Ma, Ionothermal synthesis of $\mathrm{AlPO}_{4}$ molecular sieves in the presence of quaternary ammonium cation, Materials Letters, 64, 19, 2010, 2118-2121.

[366] E.J. Fayad, N. Bats, C.E.A. Kirschhock, B. Rebours, A.-A. Quoineaud, J.A. Martens, A Rational Approach to the Ionothermal Synthesis of an $\mathrm{AlPO}_{4}$ Molecular Sieve with an LTA-Type Framework, Angewandte Chemie, 122, 27, 2010, 4689-4692.

[367] M. Musa, D.M. Dawson, S.E. Ashbrook, R.E. Morris, Ionothermal synthesis and characterization of CoAPO-34 molecular sieve, Microporous and Mesoporous Materials, 239, 2017, 336-341.

[368] H. Xing, J. Li, W. Yan, P. Chen, Z. Jin, J. Yu, S. Dai, R. Xu, Cotemplating Ionothermal Synthesis of a New Open-Framework Aluminophosphate with Unique Al/P Ratio of 6/7, Chemistry of Materials, 20, 13, 2008, 4179-4181.

[369] Y. Wei, Z. Tian, H. Gies, R. Xu, H. Ma, R. Pei, W. Zhang, Y. Xu, L. Wang, K. Li, B. Wang, G. Wen, L. Lin, Ionothermal Synthesis of an Aluminophosphate Molecular Sieve with 20-Ring Pore Openings, Angewandte Chemie, 122, 31, 2010, 5495-5498.

[370] P.S. Wheatley, P.K. Allan, S.J. Teat, S.E. Ashbrook, R.E. Morris, Task specific ionic liquids for the ionothermal synthesis of siliceous zeolites, Chemical Science, 1, 4, 2010, 483487. 
[371] A.P. Abbott, D. Boothby, G. Capper, D.L. Davies, R.K. Rasheed, Deep eutectic solvents formed between choline chloride and carboxylic acids: versatile alternatives to ionic liquids, Journal of the American Chemical Society, 126, 29, 2004, 9142-9147.

[372] Q. Zhang, K.D.O. Vigier, S. Royer, F. Jérôme, Deep eutectic solvents: syntheses, properties and applications, Chemical Society Reviews, 41, 21, 2012, 7108-7146.

[373] H. Zhao, G.A. Baker, Ionic liquids and deep eutectic solvents for biodiesel synthesis: a review, Journal of Chemical Technology and Biotechnology, 88, 1, 2013, 3-12.

[374] E.A. Drylie, D.S. Wragg, E.R. Parnham, P.S. Wheatley, A.M.Z. Slawin, J.E. Warren, R.E. Morris, Ionothermal Synthesis of Unusual Choline-Templated Cobalt Aluminophosphates, Angewandte Chemie International Edition, 46, 41, 2007, 7839-7843.

[375] L. Liu, Y. Kong, H. Xu, J.P. Li, J.X. Dong, Z. Lin, Ionothermal synthesis of a threedimensional zinc phosphate with DFT topology using unstable deep-eutectic solvent as template-delivery agent, Microporous and Mesoporous Materials, 115, 3, 2008, 624-628.

[376] L. Liu, X. Li, H. Xu, J. Li, Z. Lin, J. Dong, Template control in ionothermal synthesis of aluminophosphate microporous materials, Dalton Transactions, 47, 2009, 10418-10421.

[377] X. Zhao, C. Kang, H. Wang, C. Luo, G. Li, X. Wang, Ionothermal synthesis of FeAlPO-16 molecular sieve by microwave irradiation in eutectic mixture, Journal of Porous Materials, 18, 5, 2011, 615-621.

[378] X. Zhao, H. Wang, B. Dong, Z. Sun, G. Li, X. Wang, Facile synthesis of FeAlPO-5 molecular sieve in eutectic mixture via a microwave-assisted process, Microporous and Mesoporous Materials, 151, 2012, 56-63.

[379] X. Zhao, H. Wang, C. Kang, Z. Sun, G. Li, X. Wang, Ionothermal synthesis of mesoporous SAPO-5 molecular sieves by microwave heating and using eutectic solvent as structure-directing agent, Microporous and Mesoporous Materials, 151, 2012, 501-505.

[380] X.T. Zhou, Q.F. Liu, Y. Liu, Ionothermal Synthesis of Sodalite from Metakaolin, Advanced Materials Research, 487, 2012, 789-792.

[381] Z.S. Lin, Y. Huang, Syntheses of high-silica zeolites in urea/choline chloride deep eutectic solvent, Canadian Journal of Chemistry, 94, 6, 2016, 533-540. 


\section{Chapter 2}

\section{$\underline{\text { Objectives }}$}

The main objective in this thesis has been the use of phosphorous OSDA's for obtaining new zeolite structures or known zeolites by alternative synthesis pathways.

New phosphorous cations, both phosphonium and aminophosphonium cations, have been synthesized and tested as OSDA's in the synthesis of zeolites. The synthesis of zeolites with some of these phosphorous OSDA's constitute a continuation of the work reported in previous closely related theses (Simancas, R., 2015 and M. Hernández-Rodríguez, M., 2014). The synthesis of these cations, as well as the materials obtained thereof, have been characterized by several techniques detailed in Chapter 3.

As previously stated, the stability of the OSDA's is very important during the synthesis of zeolites. Therefore, the relative stability between different phosphorous and ammonium cations was studied. The objective in this study was to clearly stablish the differences between ammonium, phosphonium and aminophosphonium cations under hydrothermal conditions. This topic is developed in Chapter 4.

The use of phosphorous OSDA's allows introducing phosphorus into zeolites. Therefore, the possibility of modulating the amount of the incorporated phosphorous OSDA when jointly used with ammonium OSDA's in dual template synthesis conditions was studied in Chapter 5. The objective here was to select the amount of incorporated phosphorus in the material in the synthesis stage. This would allow controlling the textural 
and acidic properties of the final material while avoiding post-synthesis processes over the zeolite material.

Finally, newly synthesized phosphorous cations were tested as OSDA's. The objectives here were:

- Synthesis of new zeolite materials with new structures. The synthesis of new structures is linked with an in-depth characterization of the material, especially regarding their structure. The syntheses of the new zeolites obtained during this thesis are developed in Chapter 7.

- Synthesis of known zeolite materials with novel compositions. The synthesis of zeolites with novel compositions is usually based on trying to incorporate heteroatoms that provide the final material with new textural, acidic or oxidative properties, or the synthesis of all-silica materials. The most relevant results of this topic are addressed in Chapter 6 for the synthesis of zeolites ITQ-27 (IWV) and UTD-1 (DON).

- Synthesis of known zeolite materials by alternative synthesis pathways, allowing for an easier synthesis of the material, different properties of the material, or the incorporation of phosphorus as probe atom for characterization techniques as MAS-NMR. This topic has been thoroughly studied in Chapter 5, Chapter 6 and Chapter 7 in the materials presented in each chapter. 


\section{Chapter 3}

\section{$\underline{\text { Experimental section }}$}

\subsection{Characterization techniques}

\subsubsection{X-Ray Diffraction}

The X-Ray Diffraction (XRD) technique is a powerful tool for the identification and characterization of zeolites, as it gives information about the structure of crystalline materials, presenting a X-Ray diffraction pattern characteristic for each material. This technique is based on the elastic scattering of X-Ray photon beams incident to the atomic array of a crystal. Only the constructive scattering reflections will be observed, following the Bragg's law:

$$
n \lambda=2 d_{h k l} \sin \theta
$$

being $n$ any integer, $\lambda$ the X-Ray wavelength, $d$ the spacing between diffracting planes and $\theta$ the X-Ray beam incident angle (Figure 3.1). ${ }^{[1-3]}$ 


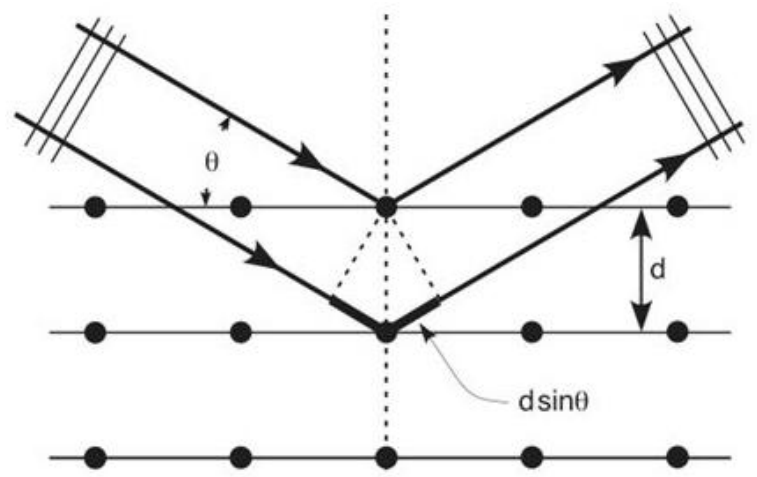

Figure 3.1. Schematic view of the interaction between X-Rays and a crystalline material, following the Bragg's law.

\subsubsection{Phase identification}

The crystallinity and purity of the obtained materials was measured by the powder $\mathrm{X}$-Ray diffraction technique (XRPD) in a Bragg-Bretano geometry, employing a PANalytical Cubix PRO diffractometer. $\mathrm{Cu} \mathrm{K} \alpha$ X-Ray radiation $\left(\lambda_{1}=1.5406 \AA, \lambda_{2}=1.5444 \AA, \mathrm{I}_{2} / \mathrm{I}_{1}=0.5\right)$ was used, with a tube voltage and intensity of $45 \mathrm{kV}$ and $40 \mathrm{~mA}$, respectively. The goniometer arm length was $200 \mathrm{~mm}$, using an automatic divergence slit with a sample irradiated area of $5 \mathrm{~mm}^{2}$. The detector was a Panalytical X'Celerator, using a scan range from $2.0^{\circ}$ to $40.0^{\circ}$ $\left(2 \theta^{\circ}\right)$, with a scan step size of $0.020\left(2 \theta^{\circ}\right)$ and a counting time of $35 \mathrm{~s} / \mathrm{step}$. Measurements were registered at room temperature $(298 \mathrm{~K})$ and samples were kept rotating at $30 \mathrm{rpm}$ during the data acquisition.

\subsubsection{Structural elucidation}

The X-Ray data used for the structural elucidation, i.e., Rietveld refinements, were collected using a Panalytical X'Pert PRO diffractometer with Bragg-Brentano geometry. $\mathrm{Cu} \mathrm{K} \alpha$ X-Ray radiation $\left(\lambda_{1}=1.5406 \AA, \lambda_{2}=1.5441 \AA, \mathrm{I}_{2} / \mathrm{I}_{1}=0.5\right)$ was used, with a tube voltage and intensity of $45 \mathrm{kV}$ and $40 \mathrm{~mA}$, respectively. The goniometer arm length was $240 \mathrm{~mm}$, using a divergence slit fixed at $1 / 16^{\circ}$. The detector was a Panalytical X'Celerator, using a scan range from $3.0^{\circ}$ to $75.0^{\circ}\left(2 \theta^{\circ}\right)$, with a scan step size of $0.017^{\circ}\left(2 \theta^{\circ}\right)$ and a counting time of $12414 \mathrm{~s} /$ step. Measurements were registered at room temperature $(298 \mathrm{~K})$ and samples were kept rotating at $30 \mathrm{rpm}$ during the data acquisition. 


\subsubsection{Chemical analyses}

The chemical analyses of the obtained materials could be obtained by several methodologies, but in this thesis only Inductively Coupled Plasma (ICP) and Elemental Analysis (EA) were routinely used, depending on the studied elements.

\subsubsection{Inductively Coupled Plasma (ICP)}

The Inductively Coupled Plasma Optical Emission Spectroscopy (ICP-OES) allows the analysis of most of the chemical elements. By this technique, individual atoms present in a solution are nebulized and then excited by a high temperature plasma. Excited atoms relax to their fundamental state by photon emission, with an associated energy characteristic of each element. Intensity of this emission is proportional to the concentration of the element in the solution, and therefore, it is possible to get qualitative and quantitative information when the measure is compared with a calibration curve made by standards for each measured element. ${ }^{[4,5]}$

Samples were analysed in a Varian 710-ES device. Solid samples were grinded and then dissolved in a 1/1/3 (volumetric ratios) solution of $\mathrm{HNO}_{3}(65 \mathrm{v} / \mathrm{v} . \%) / \mathrm{HF}(40 \mathrm{v} / \mathrm{v} . \%) /$ $\mathrm{HCl}(30 \mathrm{v} / \mathrm{v} . \%)$, filling with Milli-Q water up to $60 \mathrm{~mL}$. Calibration curves were built with commercial standard solutions.

\subsubsection{Elemental Analysis (EA)}

Elemental Analysis (EA) consists in the combustion of samples at high temperature $\left(1100^{\circ} \mathrm{C}\right)$ under a pure oxygen atmosphere allowing the formation of $\mathrm{CO}_{2}, \mathrm{~N}_{2}$ and $\mathrm{H}_{2} \mathrm{O}$ from the $\mathrm{C}, \mathrm{N}$ and $\mathrm{H}$ contained in the sample, respectively. When formed, these compounds are separated by a chromatographic column and measured with a thermal conductivity detector (TCD).

Elemental analyses were measured using a Fisons EA1108 elemental analyser, employing sulphanilamide as standard. 


\subsubsection{Thermogravimetric analyses}

Thermogravimetry analysis (TG) monitors the mass change of a sample when continuously heated at a given heating rate under controlled atmosphere, typically dry air or $\mathrm{N}_{2}$.

Differential Thermal Analysis (DTA) gives information about the process nature measuring the difference of the TG measures against a standard, which allows distinguishing between endothermic and exothermic processes. ${ }^{[4]}$

TG analyses were performed on a Mettler Toledo TGA/SDTA851e device. Measured samples ( $\mathrm{ca} .5 \mathrm{mg}$ ) were heated up to $800^{\circ} \mathrm{C}$, at $10^{\circ} \mathrm{C} / \mathrm{min}$ heating speed and under a $20 \mathrm{~mL} / \mathrm{min}$ dry air stream.

\subsubsection{Textural properties}

The surface area and the pore volume and size of a catalyst are key properties in catalysis and separation processes. The surface area and the pore volume set the reagent accessibility to the active centres, while the pore size and morphology determine the process selectivity. Surface area and pore volume are calculated from the $\mathrm{N}_{2}$ adsorption-desorption isotherms at liquid nitrogen temperature $(77 \mathrm{~K})$. The pore size distribution is calculated from the high-resolution Ar adsorption isotherm at liquid Ar temperature (87 K). Porous materials could be classified by the curve shape of the adsorption-desorption isotherm as shown in Figure 3.2. ${ }^{[6,7]}$

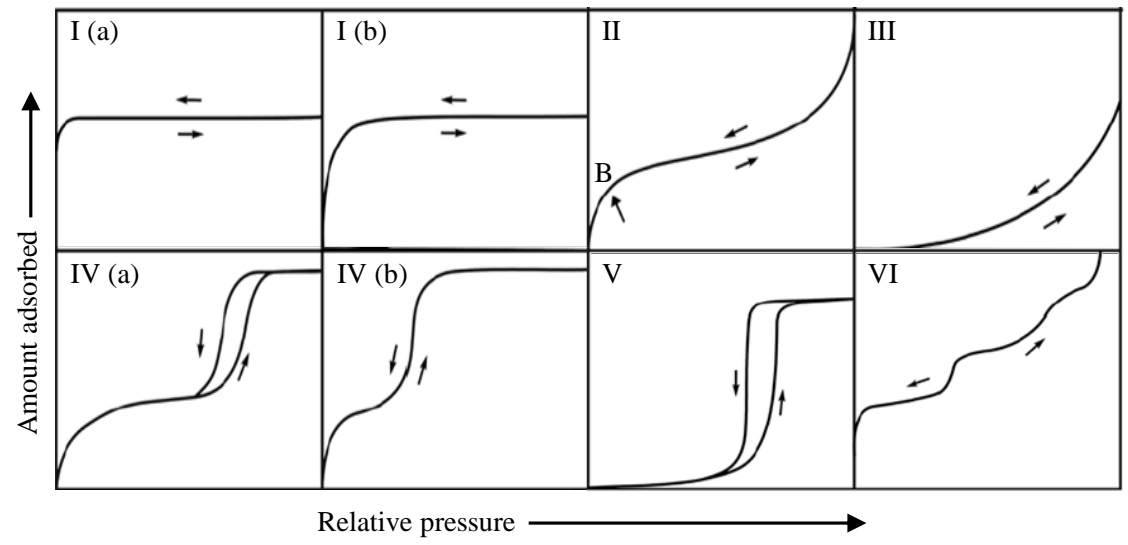

Figure 3.2. Classification of adsorption-desorption isotherms. 
Type I isotherm corresponds to microporous solids with a relatively small external surface, having mostly narrow pores (a), wider pores or, partially, even mesopores (b); type II corresponds to the monolayer adsorption over non-porous or macroporous materials; type III corresponds to the multilayer adsorption over non-porous or macroporous materials; type IV corresponds to mesoporous materials with mesopores wider than (a) or narrower than $4 \mathrm{~nm}$ (b); type $\mathrm{V}$ corresponds to the multilayer adsorption in materials with a weak adsorbent-adsorbate interaction; and type VI corresponds to the layer-by-layer adsorption over highly uniform non-porous surfaces.

Samples were calcined and sieved between $0.2-0.4 \mathrm{~mm}$ and then measured in a Micromeritics ASAP 2020 device, with a $400^{\circ} \mathrm{C}$ pre-treatment under vacuum $\left(10^{-3} \mathrm{~Pa}\right)$ for 12 hours.

\subsubsection{Surface area and micropore volume determination}

The surface area was calculated by the BET method, proposed by Brunauer, Emmett and Teller ${ }^{[8]}$ This method is based on the hypothesis that the adsorbent surface is uniform and porous-less, and the gas molecules are adsorbed layer by layer, without taking in account the adsorbate molecular lateral interactions. This method is therefore only applicable at low pressures or to non-porous solids. As zeolites are microporous materials and no multilayer of adsorbate is formed, the surface area values obtained from the BET method are just for guidance, but the values allow to compare related materials.

The BET equation can be described as:

$$
\frac{P}{V\left(P_{0}-P\right)}=\frac{1}{V_{m} c}+\frac{c-1}{V_{m} c} \frac{P}{P_{0}}
$$

where $V$ is the amount of adsorbed gas at $P$ pressure, $V_{m}$ is the adsorbed gas volume when the entire surface is covered with a monolayer, $c$ is a constant value related with the adsorption heat and the adsorbate affinity for the adsorbent, $P$ is the equilibrium pressure and $P_{0}$ is the saturation pressure. The $P /\left(V\left(P-P_{0}\right)\right.$ versus $P / P_{0}$ graph gives the required gas volume to cover a monolayer, $V_{m}$, as well as the $c$ constant.

In order to calculate the surface area, the adsorbate molecular area $\left(A_{m}\right)$ is required to be known $\left(A_{m}\right)$, being this value $16.2 \AA^{2}$ for the $\mathrm{N}_{2}$. The BET surface area is calculated by: 


$$
S_{B E T}=\frac{V_{m} \cdot N_{A} \cdot A_{m}}{M}
$$

With $N_{A}$ being the Avogadro number and $M$ the volume occupied by a mole of adsorbate gas at ideal conditions.

The micropore volume was determined by the t-plot method developed by Boer et al. ${ }^{[9,10]}$ This method consists in the graph of the adsorbed $\mathrm{N}_{2}$ volume versus the average width of the adsorbed layer, $t$. When employing $\mathrm{N}_{2}$ as adsorbate, the $t$ value is calculated from the relative pressure employing the Harkins-Jura equation for the non-porous titanium oxide (anatase)..$^{[1]}$

$$
t=\left(\frac{13.99}{0.034}-\log \left[P / P_{0}\right]\right)^{1 / 2}
$$

With the equation proposed by Boer et al., ${ }^{[9]}$ where a $\mathrm{N}_{2}$ monolayer width equals to $3.54 \AA$,

$$
t=3.54\left(\frac{V}{V_{m}}\right) \AA
$$

the adsorbed $\mathrm{N}_{2}$ volume versus $t$ graph generates a linear equation, whose $y$-intercept value $i$ equals to the micropore volume, $V_{\text {mic }}$.

$$
V_{\text {mic }}\left(\mathrm{cm}^{3} / \mathrm{g}\right)=0.00157 \cdot t+i
$$

\subsubsection{Micropore size distribution determination}

The micropore size distribution was calculated from the argon adsorption isotherm applying the Horvath-Kawazoe method. ${ }^{[12]}$ This method is based on the assumption that only appropriately sized pores will be filled given an adsorbate relative pressure.

$$
\ln \left(\frac{P}{P_{0}}\right)=\frac{N_{A}}{R T} \frac{N_{S} A_{S}+N_{A} A_{a}}{\sigma^{4}\left(L-2 d_{0}\right)}\left[\frac{\sigma^{4}}{3\left(L-d_{0}\right)^{3}}-\frac{\sigma^{10}}{9\left(L-d_{0}\right)^{9}}-\frac{\sigma^{4}}{3\left(d_{0}\right)^{3}}+\frac{\sigma^{10}}{9\left(d_{0}\right)^{9}}\right]
$$


being:

- $L$ : solid pore diameter in $\AA$.

- $P / P_{0}$ : relative pressure.

- $N_{A}$ : Avogadro constant.

- $N_{S}$ : atoms amount per adsorbent area.

- $A_{s}$ : adsorbent Kirkwood-Mueller constant.

- $A_{A}$ : adsorbate Kirkwood-Mueller constant.

- $\Sigma$ : intermolecular distance with zero energy interaction.

- $d_{0}=\left(d_{s}+d_{a}\right) / 2:$ distance between adsorbent and adsorbate molecules.

- $d_{s}$ : adsorbent molecular diameter.

- $d_{a}$ : adsorbate molecular diameter.

Then, the micropore size radial distribution is calculated from the derivative of the adsorbed volume versus the pore diameter.

\subsubsection{Nuclear magnetic resonance}

The nuclear magnetic resonance (NMR) spectroscopy studies the behaviour of atomic nuclei when exposed to an external magnetic field. This technique allows the study of the chemical environment of selected atomic nuclei. The interaction of atomic nuclei with non-zero spin atomic number $(I \neq 0)$ and the angular spin momentum when exposed to an external magnetic field $\left(\mathrm{B}_{0}\right)$ leads to a splitting of the energy levels of the nuclei. ${ }^{[13]}$ In the absence of the magnetic field the nuclear spins are randomly oriented, but when exposed to a magnetic field, positive spins are aligned towards the magnetic field direction, while negative spins are aligned against, resulting in a minimum energy states $\alpha$ and $\beta$, respectively. These levels present very small energy and population differences, being the low energy level $\alpha$ the most populated (Figure 3.3). 


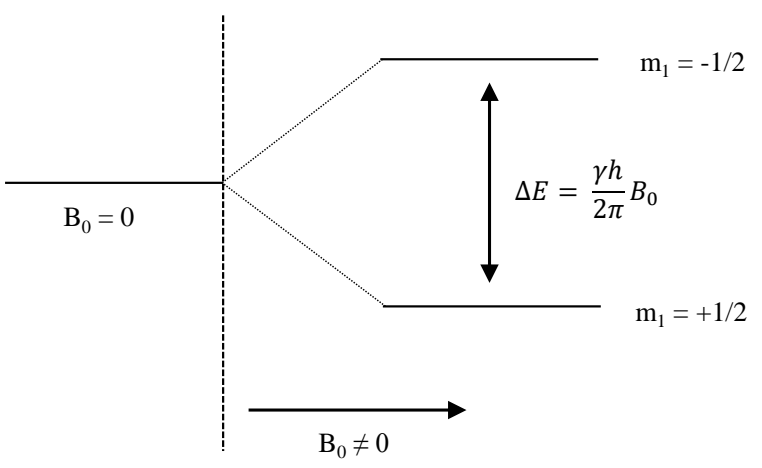

Figure 3.3. Energy levels of a $1 / 2$ spin nuclei exposed to a magnetic field.

The energy difference between the two levels is proportional to the applied magnetic field. Resonant absorption by nuclear spins occurs when a pulse of electromagnetic radiation $\mathrm{B}_{1}\left(\mathrm{~B}_{1}>>>\mathrm{B}_{0}\right)$ of the correct frequency (i. e., a frequency nearby to the Larmor precession frequency of the nuclei) is applied to the sample. This provokes an energy transition from the $\alpha$ spin to the $\beta$ spin energy levels, and the following relaxation to the low $\alpha$ energy level provokes an electromagnetic emission that is recorded as a free induction decay (FID, also called Bloch-Decay). The FID is a time dependent spectrum that is converted to a frequency dependent spectrum when Fourier transform is applied.

Molecules nuclei are surrounded by mobile electrons that induce a small magnetic field opposing the external field. Therefore, the effective magnetic field applied over the nuclei is less intense than the nominal magnetic field. This shielding effect depends on the electronic density and its distribution around the nuclei, which allows the identification of the chemical environment of individual atoms in a molecule. The chemical shift $(\delta)$ represent the frequency variation due to the different electronic shielding in each nucleus.

Liquid NMR spectra present very sharp and defined resonances as molecules quickly refocus in homogeneous liquid media. On the other hand, solid NMR spectra generally present broad resonances, which provokes a great loss of resolution. This is due to several interactions, being the most important: ${ }^{[14]}$

- Dipolar interactions: these interactions are due to the dipole-dipole interaction between the magnetic moments of nearby nuclei. When the sample is submitted to an external magnetic field, the nuclear spins align towards or against the external field, which generates a small magnetic field that interact with the nearby nuclei. 
- Quadrupolar interactions: these interactions occur in nuclei with I > 1/2. These nuclei present a non-spherical nuclear spin gradient, which interacts with electronic fields generated by the asymmetric electric charge distribution.

- Chemical shift anisotropy: these interactions are due to the interaction between the external magnetic field and the magnetic field induced by the electrons close to the nuclei. The electron distribution is usually non-spherical, and therefore, the frequency modification depends on the relative orientation between the electron cloud and the external magnetic field.

The fast spinning of the sample at the magic angle (54 $\left.4^{\circ} 4^{\prime}\right)$ relative to the external magnetic field allows lowering the dipolar interactions, the chemical shift anisotropy and the quadrupolar interactions. ${ }^{[15]}$ Additionally, when measuring low abundance nuclei, cross polarization $(\mathrm{CP})$ technique allows increasing the signal to noise ratio. This technique is based on the dipolar coupling of low abundance nuclei (e.g., ${ }^{13} \mathrm{C}$ or $\left.{ }^{15} \mathrm{~N}\right)$ and a high abundance and gyromagnetic ratio nuclei (e.g., $\left.{ }^{1} \mathrm{H}\right)$.

Finally, nuclei could interact with the electron cloud of other nuclei though chemical bonds. This heteronuclear interaction is named J-coupling or spin-spin coupling, and leads to the unfolding of the resonance signal from the measured nuclei, giving rise to a signal multiplicity. The multiplicity provides information on the number of centres coupled with the measured nuclei, producing multiplet patterns which are denoted by the number of resonance signals produced as singlet (s), doublets (d), triplets (t), quartets (q), quintets (quint), etc, and combinations between them like doublet of triplets (dt) and so on. Complex patterns are simply denoted as multiplet $(\mathrm{m})$.

\subsubsection{Phosphorus NMR}

The ${ }^{31} \mathrm{P}$ is a medium sensitive nucleus with a spherical nuclear charge distribution $(\mathrm{I}=1 / 2)$. It presents a $100 \mathrm{wt} . \%$ natural abundance, a relatively high magnetogyric ratio $\left(10.84 \cdot 10^{7} \mathrm{rad} \cdot \mathrm{T}^{-1} \cdot \mathrm{s}^{-1}\right)$, a wide chemical shifts range and yields sharp resonances, which makes its spectra easily interpretable. Liquid and MAS-NMR ${ }^{13} \mathrm{C}$ and ${ }^{31} \mathrm{P}$ were employed to study the OSDA along the synthesis, crystallization, and post-synthesis treatments of the obtained materials. ${ }^{[16-19]}$ 


\subsubsection{Silicon NMR}

The ${ }^{29} \mathrm{Si}$ is a low sensitive nucleus with a spherical nuclear charge distribution $(I=1 / 2)$. It presents a $4.68 \mathrm{wt} . \%$ natural abundance, a medium magnetogyric ratio $\left(-5.32 \cdot 10^{7}\right.$ $\left.\mathrm{rad} \cdot \mathrm{T}^{-1} \cdot \mathrm{s}^{-1}\right)$, a wide chemical shifts range and yields sharp resonances, which makes its spectra easily interpretable for determining the chemical environment in silicon compounds.

Silicon atoms in the zeolite framework tetrahedrally coordinated to other $\mathrm{T}$ atoms are denoted as $\mathrm{Q}^{4}$, resulting in five different silicon environments denoted as $\operatorname{Si}(n \mathrm{Al})$ units, where $n$ corresponds to the number of aluminium atoms in the second coordination sphere. Each type of $\mathrm{Si}(n \mathrm{Al})$ unit ( $n=0,1,2,3$ or 4 ) yields ${ }^{29} \mathrm{Si}$ MAS-NMR resonances in a well-defined range of chemical shifts. These ranges are summarized for the various aluminosilicate units in Figure 3.4.

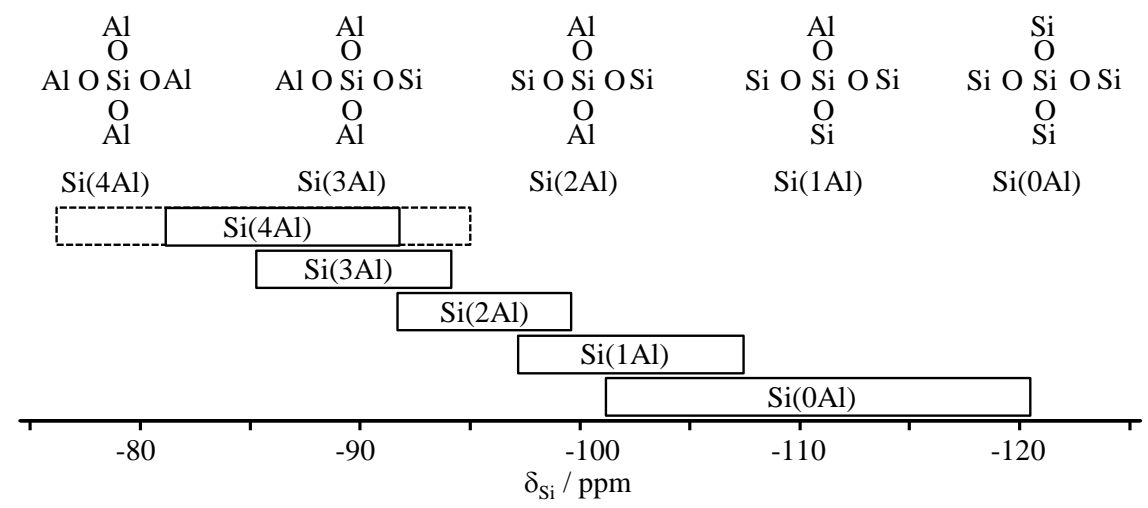

Figure 3.4. ${ }^{29} \mathrm{Si}$ MAS-NMR chemical shifts of $\mathrm{Si}(n \mathrm{Al})$ units in zeolite frameworks. The dotted lines for $\mathrm{Si}(4 \mathrm{AI})$ designate the chemical shift range observed for 1:1 aluminosilicate sodalites with different cage fillings.

The ${ }^{29} \mathrm{Si}$ MAS-NMR spectra of zeolites consisting in silicon atoms on crystallographically equivalent $\mathrm{T}$-sites are a function of the framework composition. Therefore, the framework $n \mathrm{Si} / n \mathrm{Al}$ ratio of these materials may be calculated directly from the different ${ }^{29} \mathrm{Si}$ resonance intensities using the formula:

$$
n_{S i} / n_{A l}=\sum_{n=0}^{4} I_{S i(n A l)} / \sum_{n=0}^{4} 0.25 \cdot n \cdot I_{S i(n A l)}
$$


where the terms $I_{S i(n A l)}$ are the intensities of the different $\mathrm{Si}(n \mathrm{Al})$ resonances. The comparison of the framework $n \mathrm{Si} / n \mathrm{Al}$ ratio calculated by ${ }^{29} \mathrm{Si}$ MAS-NMR with the bulk composition determined by chemical analysis allows to calculate the amount of non-framework aluminium atoms. Also, in each zeolite there are connectivity defects like hydroxyl groups bounded to silicon atoms $\left(\mathrm{Q}^{3}, \mathrm{Q}^{2}\right)$, located at the outer surface of the zeolite particles or at framework defects. ${ }^{[14]}$

\subsubsection{Fluorine NMR}

The ${ }^{19} \mathrm{~F}$ is a high sensitive nucleus with a spherical nuclear charge distribution $(\mathrm{I}=1 / 2)$. It presents a $100 \mathrm{wt} . \%$ natural abundance, a high magnetogyric ratio $\left(25.18 \cdot 10^{7}\right.$ $\mathrm{rad} \cdot \mathrm{T}^{-1} \cdot \mathrm{s}^{-1}$ ), a wide chemical shifts range and yields sharp resonances, which makes its spectra easily interpretable, similar to ${ }^{1} \mathrm{H}$ NMR spectra.

The multiplet structure of the ${ }^{19} \mathrm{~F}$ resonances yields information about the neighbourhood of fluorine atoms. Spin-spin couplings are transmitted through chemical bonds and yield information about the immediate molecular environment. The interaction of ${ }^{19} \mathrm{~F}$ with ${ }^{31} \mathrm{P}$ and ${ }^{29}$ Si nuclei can unfold the multiplet structure in the ${ }^{19} \mathrm{~F}$ NMR spectra.

\subsubsection{Aluminium NMR}

The ${ }^{27} \mathrm{Al}$ is a sensitive nucleus with a quadrupolar nuclear charge distribution $(I=5 / 2)$. It presents a $100 \mathrm{wt} . \%$ natural abundance, a medium magnetogyric ratio $\left(6.98 \cdot 10^{7} \mathrm{rad} \cdot \mathrm{T}^{-1}\right.$. $\left.\mathrm{s}^{-1}\right)$ and a wide chemical shifts range. The resonance shape depends on the environment symmetry, being broader as asymmetry increases.

The ${ }^{27} \mathrm{Al}$ MAS-NMR spectra are very useful to identify the $\mathrm{Al}$ coordination in a given material. Tetrahedral coordination is usually identified as aluminium incorporated in framework positions replacing $\mathrm{Si}$ atoms, with a resonance centred around $55 \mathrm{ppm}$. On the other hand, octahedral coordination is usually identified as extra-framework Al, with resonances centred at $0 \mathrm{ppm} \cdot{ }^{[20]}$ However, it is possible to have octahedrally coordinated framework $\mathrm{Al}$ atoms when $\mathrm{Al}$ also interacts with some species, like water of phosphorous oxides. Then, after post-synthesis treatments, it is possible to reassess the $\mathrm{Al}$ atoms as tetrahedrally coordinated framework $\mathrm{Al}$ atoms. ${ }^{[21,22]}$ There is also the possibility of $\mathrm{Al}$ atoms presenting a distorted-tetrahedrally coordination or even pentacoordinated. These configurations result in broad resonances typically centred around $30 \mathrm{ppm} \cdot{ }^{[23]}$ Finally, it is 
also possible to measure no $\mathrm{Al}$ at all because of the so-called "invisible aluminium" effect. The effect consist in the extreme broadening of low intensity $\mathrm{Al}$ signals because of the high nuclear spin moment $(I=5 / 2)$ and the environment asymmetry, especially in dehydrated

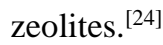

\subsubsection{NMR spectrometers and data collection}

Liquid NMR measures were performed to solutions of the OSDA's in a deuterated solvent (mainly $\mathrm{D}_{2} \mathrm{O}$ ) in a Bruker AV-300-SB NMR device at room temperature. Unless otherwise stated, ${ }^{1} \mathrm{H}$ NMR spectra were acquired as direct Bloch decay, ${ }^{13} \mathrm{C}$ NMR spectra were acquired after ${ }^{1} \mathrm{H}$ cross polarization to ${ }^{13} \mathrm{C}$ nuclei to enhance the ${ }^{13} \mathrm{C}$ spectra resolution and signal to noise ratio, and ${ }^{31} \mathrm{P}$ NMR spectra were acquired in proton decoupled conditions to avoid the coupling of ${ }^{1} \mathrm{H}$ and ${ }^{31} \mathrm{P}$ nuclei.

MAS-NMR measures were performed to zeolite samples in a Bruker-400-WB device at room temperature. Single pulse acquisition parameters are shown in Table 3.1.

Table 3.1. Single pulse MAS-NMR acquisition parameters for each nucleus.

\begin{tabular}{|c|c|c|c|c|c|c|c|c|}
\hline Nuclei & I & $\begin{array}{c}\text { Natural } \\
\text { abundance } \\
\text { (wt.\%) }\end{array}$ & $\begin{array}{c}\text { Frequency } \\
\text { at } \mathrm{B}_{0}=9.4 \mathrm{~T} \\
(\mathrm{MHz})\end{array}$ & $\begin{array}{l}\text { Pulse } \\
\text { angle } \\
\text { (rad) }\end{array}$ & $\begin{array}{l}\text { Pulse } \\
\text { length } \\
(\mu \mathrm{s})\end{array}$ & $\begin{array}{l}\text { Time be- } \\
\text { tween } \\
\text { pulses (s) }\end{array}$ & Reference & $\begin{array}{c}\text { Spinning } \\
\text { speed } \\
(\mathrm{kHz})\end{array}$ \\
\hline${ }^{29} \mathrm{Si}$ & $1 / 2$ & 4.7 & 79.5 & $\pi / 3$ & 6 & $40^{\mathrm{a}}, 240^{\mathrm{b}}$ & TMS & 5 \\
\hline${ }^{11} \mathrm{~B}$ & $3 / 2$ & 80.1 & 128.4 & $\pi / 12$ & 1 & 1 & $\mathrm{BF}_{3} . \mathrm{OEt}_{2}$ & 10 \\
\hline${ }^{27} \mathrm{Al}$ & $5 / 2$ & 100 & 103.8 & $\pi / 18$ & 1 & 1 & $\mathrm{AlNO}_{3}$ & 15 \\
\hline${ }^{31} \mathrm{P}$ & $1 / 2$ & 100 & 165.8 & $\pi / 2$ & 5 & 20 & $\mathrm{H}_{3} \mathrm{PO}_{4}$ & 10 \\
\hline${ }^{19} \mathrm{~F}$ & $1 / 2$ & 100 & 376.3 & $\pi / 2$ & 4.5 & 100 & $\mathrm{CFCl}_{3}$ & 25,15 \\
\hline${ }^{13} \mathrm{C}$ & $1 / 2$ & 1.108 & 100.6 & $\pi / 4$ & 6 & 30 & Ad. ${ }^{c}$ & 5 \\
\hline${ }^{71} \mathrm{Ga}$ & $3 / 2$ & 30.83 & 122 & $\pi / 12$ & 25 & 0.5 & $\mathrm{Ga}_{2} \mathrm{O}_{3}$ & 30 \\
\hline
\end{tabular}

\subsubsection{Acidity of zeolites}

The acidity is a key property for the characterization of zeolites because of their potential application in catalytic processes. The acidity could be measured by several techniques ${ }^{[25]}$ but in this thesis only Fourier Transform-Infrared (FT-IR) spectroscopy using pyridine as probe molecule and Ammonia Thermoprogrammed Desorption Mass Spectrometry (TPD-MS) were used. 
Chapter 3: Experimental section

\subsubsection{Fourier Transform-Infrared spectroscopy using pyridine as probe molecule}

The Fourier Transform-Infrared (FT-IR) spectroscopy using pyridine as probe molecule is a useful technique to elucidate the catalyst acidity. This technique is based on the adsorption of pyridine over the studied material. The pyridine is retained by the different types of acid centres, Lewis or Brönsted, of the zeolite. Then, the material is increasingly heated to desorb the pyridine, being stepwise desorbed at different temperatures. The material is then studied by infrared (IR) spectroscopy, as the IR radiation corresponds to the vibration frequencies of the functional groups being present in the molecules adsorbed over the sample.

The information obtained by the FT-IR depends on the spectra region. Thus, it can be distinguished the following regions:

- 4000-3000 $\mathrm{cm}^{-1}$ region: This region, called hydroxyl $(\mathrm{OH})$ stretching in the case of zeolites, gives information about the nature of $\mathrm{OH}$ species in the zeolite due to the occurrence of trivalent cations, like $\mathrm{B}$ or $\mathrm{Al}$, or due to structural defects. ${ }^{[25]}$ The following bands are often observed within this region:

- 3745 - $3700 \mathrm{~cm}^{-1}$ : assigned to surface $\mathrm{OH}$ groups or due to structural defects inside the voids of the zeolite. These centres are weakly acidic.

- 3680 - $3660 \mathrm{~cm}^{-1}$ : assigned to $\mathrm{OH}$ groups in extra-framework Al species, or to $\mathrm{OH}$ bonded to the $\mathrm{P}$ incorporated in the solids, both of them weakly acidic. ${ }^{[26,27]}$

- 3650 - $3500 \mathrm{~cm}^{-1}$ : assigned to bridge $\mathrm{OH}$ groups $\mathrm{Si}-\mathrm{OH}-\mathrm{Al}$ units. This band is associated with framework $\mathrm{Al}$ species that present a strong acidity.

- $3500 \mathrm{~cm}^{-1}$ : it is a wide band associated to species related to hydrogen bonds and other framework silanol groups or oxygen species. These centres are weakly acidic.

- $1300-1700 \mathrm{~cm}^{-1}$ region: This spectra region allows studying the organic molecules adsorbed over the material surface. When pyridine is employed as probe molecule, this molecule interacts differently with the Brönsted and Lewis acid centres of the material. Therefore, this technique allows distinguishing the nature of the acid centre. When the adsorbed pyridine molecule (Py) interacts with a Brönsted acid centre, the base is protonated, yielding a pyridinium cation $\left(\mathrm{PyH}^{+}\right)$, which possesses a characteristic band at $1545 \mathrm{~cm}^{-1}$ in the FTIR spectra. On the other hand, when the 
pyridine molecule interacts with a Lewis acid centre $(\mathrm{PyL})$, the pyridine is coordinated to the acid centre by the donation of a pair of electrons to the metallic atom, being observed a characteristic band at $1455 \mathrm{~cm}^{-1}$ in the FTIR spectra. ${ }^{[28]}$

The concentrations of pyridine molecules adsorbed on the Lewis or Brönsted acid centres are calculated using the extinction coefficients proposed by Emeis. ${ }^{[29]}$

$$
\begin{aligned}
& C(B)=1.88 A(B) R^{2} / W \\
& C(L)=1.42 A(L) R^{2} / W
\end{aligned}
$$

being:

- $C(B)$ : pyridine concentration adsorbed over Brönsted acid centres (mmol/g. catal.).

- $C(L)$ : pyridine concentration adsorbed over Lewis acid centres (mmol/g. catal.).

- $A(B, L)$ : absorbance band area for Brönsted $(B)$ or Lewis $(L)$ acid centres $\left(\mathrm{cm}^{-1}\right)$.

- $R$ : catalyst pellet radius $(\mathrm{cm})$.

- W: catalyst pellet weight $(\mathrm{mg})$.

Measures were performed in self-supporting pellets of $c a .10 \mathrm{mg}$ sample weight and $13 \mathrm{~mm}$ diameter. The samples were pre-treated at $400^{\circ} \mathrm{C}$ under $10^{-3} \mathrm{~Pa}$ vacuum for 12 hours to remove water and any organic matter remaining in the solid. In order to adsorb the pyridine, the pellet was exposed to gaseous pyridine at $650 \mathrm{~Pa}$ and room temperature until equilibrium is reached. Then, the desorption of the pyridine was done at room temperature and vacuum, followed by a treatment under vacuum and temperature for an hour. Essayed temperatures were $150^{\circ} \mathrm{C}, 250^{\circ} \mathrm{C}$ and $350^{\circ} \mathrm{C}$. After desorption, the infrared spectra were recorded at room temperature in a Thermo Scientific Nicolet 710 FTIR infrared spectrometer for each one of the applied desorption temperatures. 
Chapter 3: Experimental section

\subsubsection{Ammonia Thermoprogrammed Desorption Mass Spectrometry (TPD-MS)}

The adsorption of ammonia over a solid is a technique employed to study the catalyst acidity. This technique is based on the adsorption of a probe molecule over the catalyst followed by the desorption of the probe molecule after the stepwise heating of the samples. The probe molecule, ammonia in this case, is analysed at the gas outlet by mass spectrometry using a TCD detector. The amount of adsorbed ammonia is related to the number of acid centres in the solid, while the temperature at which the desorption takes places is dependent on the acid strength of those centres. Ammonia is usually used as probe molecule because of its small size, allowing the analysis of most of the catalyst acid centres. ${ }^{[30,31]}$

However, the use of the Ammonia Thermoprogrammed Desorption (TPD) present some disadvantages versus the FTIR pyridine adsorption. First, it is impossible to distinguish between Brönsted and Lewis acid centres. Also, experimental curves of the ammonia mass spectrum with $\mathrm{m} / \mathrm{e}=17$ and $\mathrm{m} / \mathrm{e}=16$ are usually strongly influenced by the presence of water, so the acidity is studied using the signal corresponding to $\mathrm{m} / \mathrm{e}=15$. $^{[6]}$

The ammonia TPD experiments were performed in a Micromeritics Autochem 2910 TPD-TPR device, using $c a .200 \mathrm{mg}$ of the samples sieved between 0.4-0.8 mm, and pre-treated with a heating rate of $10^{\circ} \mathrm{C} / \mathrm{min}$ up to $450^{\circ} \mathrm{C}$. When this temperature was achieved, samples were kept for an hour under an oxygen stream. Next, the samples were treated for 30 minutes under an argon stream, and then, under a helium stream. When stabilized, the samples were cooled down to $100^{\circ} \mathrm{C}$ under a helium stream and were submitted to a set of ammonia pulses of $10 \mathrm{~min}$ at $176^{\circ} \mathrm{C}$ until saturation was reached. Finally, the samples were heated with a heating rate of $10^{\circ} \mathrm{C} / \mathrm{min}$ up to $800^{\circ} \mathrm{C}$ under an argon stream and the desorbed ammonia was analysed by mass spectroscopy with a thermal conductivity detector (TCD).

\subsubsection{Electron microscopy techniques}

Crystalline materials crystallize in a wide variety of shapes and sizes. The characterization of those parameters could be done by a number of techniques, ${ }^{[32]}$ but in this thesis only scanning electron microscopy was used. Additionally, a modification of transmission electron microscopy was also used to study the crystallography of selected materials. 


\subsubsection{Scanning Electron Microscopy (SEM)}

The Scanning Electron Microscopy (SEM) technique allows determining the size and morphology of the crystallites of materials. With this technique, the size distribution of crystallites could be calculated, and it is sometimes possible to detect the presence of impurities or amorphous material inside the sample.

The SEM technique involves illuminating a sample with a focused electron beam through a system of magnetic lenses. When the beam interacts with the sample, a series of phenomena takes place and secondary electrons, Auger electrons, backscattered electrons, $\mathrm{X}$-Rays, etc. are generated. The signal obtained from the secondary electrons is used to obtain images of high resolution SEM to study the shape and size of the crystals of zeolites. ${ }^{[33]}$

Two SEM devices were used:

- SEM microscope: The samples were submitted to a pre-treatment. First, the sample is dispersed over a double adhesive carbon tape attached to the sample-holder. Then, due to the low electric conductivity of zeolites, the samples were metallized with a gold coating, using a BAL-TEC SCD005 sputter coater along $90 \mathrm{~s}$ with a 40 $\mathrm{mA}$ current and a $5 \cdot 10^{-2}$ mbar pressure, obtaining a $c a$. $10 \mathrm{~nm}$ gold layer. SEM images were measured in a JEOL JSM6300 microscope.

- FESEM microscope: A Field Emission SEM (FESEM) microscope is a variation of a SEM microscope where the source of electrons comes from a field emission cannon that provides highly focused high and low energy beams, which significantly improves spatial resolution and allows working at very low potentials. In this case no pre-treatment of the samples is usually needed and samples are dispersed over a double adhesive carbon tape attached to the sample-holder. FESEM images were measured in a ZEISS ULTRA55 microscope.

\subsubsection{Energy Dispersive X-Ray spectroscopy (EDX)}

The Energy Dispersive X-Ray spectroscopy (EDX) technique measures the chemical analysis of the irradiated samples. The sample receives $\mathrm{X}$-Ray radiation when the electron beam strikes over the surface. The X-Rays are then scattered with an X-Ray energy characteristic of each chemical element, providing qualitative and quantitative analytical information of selected points, lines or areas over the surface of the sample. 
EDX analyses were registered both in JEOL JSM6300 SEM microscope and ZEISS ULTRA55 FESEM microscope. EDX technique was used as a complementary tool of chemical analyses described in section 3.1.2.

\subsubsection{Transmission Electron Microscopy (TEM)}

The Transmission Electron Microscopy (TEM) technique generates a contrast image from the emitted electrons that pass through the sample, located in the path of an accelerated electron beam. This technique was no directly used in this thesis, but it was the starting point for the application of Electron Diffraction Tomography (EDT), described next.

\subsubsection{Electron Diffraction Tomography (EDT)}

The Electron Diffraction Tomography (EDT) is a technique that combines the features of the TEM technique and the X-Ray diffraction. This is done using electrons instead of $\mathrm{X}$-Rays to induce diffraction. The electrons interact stronger with the matter than the X-Rays, and thus, nano-sized crystals could be studied as single-crystals in X-Ray diffraction. ${ }^{[34-36]}$

The EDT technique used in this thesis was modified to allow the study of small crystallites recording the data as fast as possible to avoid the sample degradation during the measure, naming the technique as Ultrafast Electron Diffraction Tomography. A sample holder consisting in an automatic goniometer was used, allowing the data collection at different electron beam incidence angles in the sample specimen. In order to minimize the amorphization of the samples, a novel fast data collection methodology was developed in which the crystal is rapidly and continuously tilted during sequential pattern acquisition avoiding the relocation of the crystal during intermediate steps. ${ }^{[37,38]}$

The samples were prepared by grinding them on an agate mortar and then dispersed in dichloroethane. A drop of this solution was deposited on a carbon-coated copper grid. The grid was kept at room temperature in a fume hood until the solvent was fully evaporated. EDT measures were taken on a JEOL JEM-2100F microscope operating at $200 \mathrm{kV}$, in parallel microdiffraction mode, and equipped with a NanoMEGAS-Digistar P1000 for beam precession and a GATAN Orius SC600A CCD camera. 


\subsection{Methods and materials}

\subsubsection{OSDA synthesis}

Most of the cations used in this thesis are not commercial, and thus were synthesized by the Menshutkin reaction or oxidative addition. ${ }^{[39]}$ In this reaction, a tertiary amine, phosphine or aminophosphine is alkylated with an alkyl halide, which yields the desired quaternized cation. Most of the OSDA's used in this thesis are phosphorous containing cations, both tetraalkylphosphonium and alkyltriaminophosphonium cations, but some tetraalkylammonium cations were also used.

One critical issue with the use of phosphines and aminophosphines as reagents is their hazardousness. In addition to their high toxicity, these reagents are also pyrophoric and thus, react with oxygen and water. This property has limited the development of these kinds of OSDA's, as most of the laboratory working up should be done under controlled atmosphere. This is especially important for phosphines, which generally react violently with water and oxygen (and the more violent the smaller and lighter the phosphine is). Because of that, ampouled reagents were preferred when available, and then transferred to reaction flasks inside a gloves box. Also, the use of anhydrous solvents is a must. Prior to their use, the solvents are dried and deoxygenated by passing them through commercial $\mathrm{CuO}$ and alumina columns under nitrogen atmosphere.

After the quaternization of phosphines and aminophosphines, the alkylphosphonium and alkylaminophosphonium cations are completely stable and do not react with oxygen or water, and thus, could be safely stored for a long time. When commercially available, the quaternized compounds are preferred, taking care of the presence of phosphine traces.

The cations tested as OSDA's were always used as hydroxides. Thus, the cation halide salts were dissolved in water or methanol in a beaker. After that, an anionic exchange Amberlite IRN-78 resin was added to the solution. The amount of added resin corresponded to 1 gram of resin per milliequivalent of halide salt.

The detailed synthesis protocols and properties of the OSDA's employed along this thesis are given in the next sub-sections. 


\subsubsection{OSDA-1: tetraethylammonium cation (TEA)}

Commercial tetraethylammonium hydroxide (35 wt.\% in $\mathrm{H}_{2} \mathrm{O}$, Aldrich) was used as received.

The purity of the solution was checked by liquid NMR (Figure 3.5).

${ }^{1} \mathrm{H}$ NMR $\left(\mathrm{D}_{2} \mathrm{O}\right)$ : a: $1.09 \mathrm{ppm}\left(\mathrm{tt}, 12 \times \mathrm{H}, \mathrm{N}\left(\mathrm{CH}_{2} \mathrm{CH}_{3}\right)_{4}\right) ;$ b: $3.08 \mathrm{ppm}(\mathrm{c}, 8 \times \mathrm{H}$, $\left.\mathrm{N}\left(\mathrm{CH}_{2} \mathrm{CH}_{3}\right)_{4}\right)$.

${ }^{13} \mathrm{C}$ NMR $\left(\mathrm{D}_{2} \mathrm{O}\right)$ : A: $51.82 \mathrm{ppm}\left(\mathrm{t}, \mathrm{N}\left(\mathrm{CH}_{2} \mathrm{CH}_{3}\right)_{4}\right)$; B: $6.50 \mathrm{ppm}\left(\mathrm{s}, \mathrm{N}\left(\mathrm{CH}_{2} \mathrm{CH}_{3}\right)_{4}\right)$.

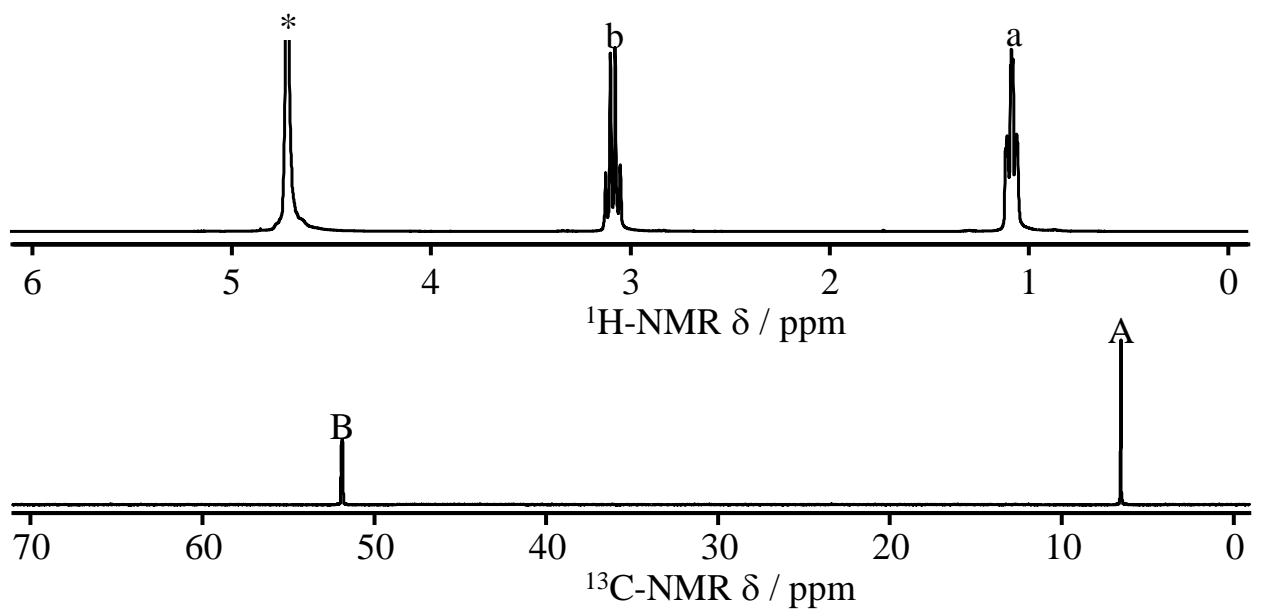

Figure 3.5. ${ }^{1} \mathrm{H}-\mathrm{NMR}$ (above) and ${ }^{13} \mathrm{C}$-NMR (below) spectra of tetraethylammonium hydroxide in deuterated water solution $\left(\mathrm{D}_{2} \mathrm{O}\right)$. Asterisk in ${ }^{1} \mathrm{H}-\mathrm{NMR}$ spectrum marks proton resonance of water.

\subsubsection{OSDA-2: tetraethylphosphonium cation (TEP)}

Tetraethylphosphonium hydroxide was obtained from commercial tetraethylphosphonium bromide (99 wt.\%, Aldrich). The commercial salt was dissolved in Milli-Q water solution and anionic exchanged with Amberlite IRN-78 resin in batch overnight, resulting in a $0.46 \mathrm{M}$ solution of tetraethylphosphonium hydroxide. 
The purity of the halide salt was checked by liquid NMR (Figure 3.6).

${ }^{1} \mathrm{H}$ NMR $\left(\mathrm{D}_{2} \mathrm{O}\right)$ : a: $1.08 \mathrm{ppm}\left(\mathrm{dt}, 12 \mathrm{xH}, \mathrm{P}\left(\mathrm{CH}_{2} \mathrm{CH}_{3}\right)_{4}\right)$; b: $2.26 \mathrm{ppm}(\mathrm{dq}, 8 \mathrm{xH}$, $\left.\mathrm{P}\left(\mathrm{CH}_{2} \mathrm{CH}_{3}\right)_{4}\right)$.

${ }^{13} \mathrm{C}$ NMR $\left(\mathrm{D}_{2} \mathrm{O}\right): \mathrm{A}: 4.50 \mathrm{ppm}\left(\mathrm{d}, \mathrm{P}\left(\mathrm{CH}_{2} \mathrm{CH}_{3}\right)_{4}\right)$; B: $10.42 \mathrm{ppm}\left(\mathrm{d}, \mathrm{P}\left(\mathrm{CH}_{2} \mathrm{CH}_{3}\right)_{4}\right)$.

${ }^{31} \mathrm{P}$ NMR ( $\left.\mathrm{D}_{2} \mathrm{O}\right): 40.22$ ppm (s, H decoup.).
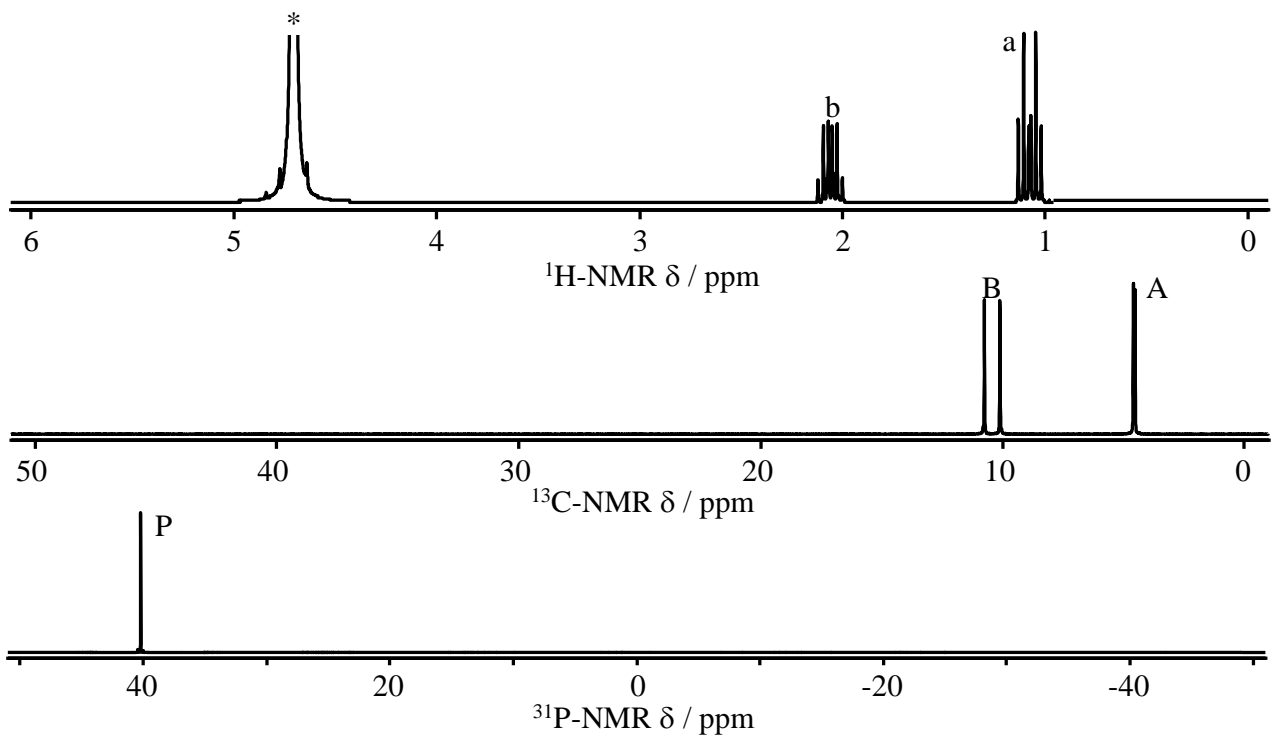

Figure 3.6. ${ }^{1} \mathrm{H}$-NMR (above), ${ }^{13} \mathrm{C}-\mathrm{NMR}$ (middle) and ${ }^{31} \mathrm{P}$-NMR (below) spectra of tetraethylphosphonium bromide in deuterated water solution $\left(\mathrm{D}_{2} \mathrm{O}\right)$. Asterisk in ${ }^{1} \mathrm{H}$-NMR spectrum marks proton resonance of water.

\subsubsection{OSDA-3: methyl-tris-(dimethylamino)-phosphonium cation (MNP)}

In a typical synthesis (Figure 3.7), a solution of $24.0 \mathrm{~g}$ (179.8 $169.5 \mathrm{mmol}, 99 \mathrm{wt} \%$, Aldrich) of iodomethane (b) in $50 \mathrm{ml}$ of anhydrous acetonitrile (99 wt.\%, Alfa-Aesar) was added dropwise under stirring to a solution of $18.5 \mathrm{~g}$ (113.0 mmol, $97 \mathrm{wt} \%$, Alfa-Aesar) of tris(dimethylamino)phosphine (a) in $200 \mathrm{ml}$ of anhydrous acetonitrile (99 wt.\%, Alfa-Aesar) under nitrogen atmosphere. The mixture was stirred at room temperature for two days until the reaction takes place. The resulting solution was rotary evaporated until a white precipitate appeared and then, diethyl ether was added to completely precipitate the desired product. The 
precipitate was recovered by filtration, washed with a mixture of acetonitrile and diethyl ether and dried under vacuum. The product methyl-tris-(dimethylamino)-phosphonium iodide (c) was obtained as a white powder with a yield over $98 \%$.

Then, the product was dissolved in Milli-Q water and exchanged to the hydroxide form using an anionic exchange Amberlite IRN-78 resin in batch overnight, resulting in a $0.25 \mathrm{M}$ solution of the methyl-tris-(dimethylamino)-phosphonium hydroxide (d).

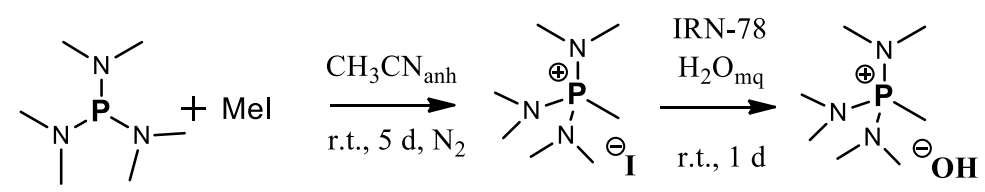

(a)

(b)

(c)

(d)

Figure 3.7. Synthesis scheme of the methyl-tris-(dimethylamino)-phosphonium cation (MNP).

Chemical purity of the iodide salt was checked by chemical analyses (Table 3.2) and liquid NMR (Figure 3.8).

Table 3.2. Theoretical and experimental chemical composition of methyl-tris-(dimethylamino)phosphonium iodide. Ratios are given as molar ratios.

\begin{tabular}{ccccccc}
\hline $\mathrm{C}_{7} \mathrm{H}_{21} \mathrm{~N}_{3} \mathrm{PI}$ & wt.\% C & wt.\% P & wt.\% $\mathrm{N}$ & wt.\% H & C/P & N/P \\
\hline Theoretical & 27.5 & 10.1 & 13.8 & 6.9 & 7 & 3 \\
Experimental & 25.1 & 9.3 & 12.6 & 7.2 & 7 & 3 \\
\hline
\end{tabular}

${ }^{1} \mathrm{H}$ NMR $\left(\mathrm{D}_{2} \mathrm{O}\right): \mathbf{a}: 1.85 \mathrm{ppm}\left(\mathrm{d}, 3 \mathrm{xH}, \mathrm{PC} \boldsymbol{H}_{3}\right)$; b: $2.63 \mathrm{ppm}\left(\mathrm{d}, 18 \mathrm{xH}, \mathrm{P}\left(\mathrm{N}\left(\mathrm{CH}_{3}\right)_{2}\right)_{3}\right)$.

${ }^{13} \mathrm{C}$ NMR $\left(\mathrm{D}_{2} \mathrm{O}\right): \mathbf{A}: 6.74$ ppm (d, $\left.\mathrm{PCH}_{3}\right) ; \mathbf{B}: 35.53$ ppm (d, $\left.\mathrm{P}\left(\mathrm{N}\left(\mathrm{CH}_{3}\right)_{2}\right)_{3}\right)$.

${ }^{31} \mathrm{P}$ NMR $\left(\mathrm{D}_{2} \mathrm{O}\right): 58.80 \mathrm{ppm}$ (s, $\mathrm{H}$ decoup., $\boldsymbol{P} \mathrm{N}_{3} \mathrm{C}$ ). 


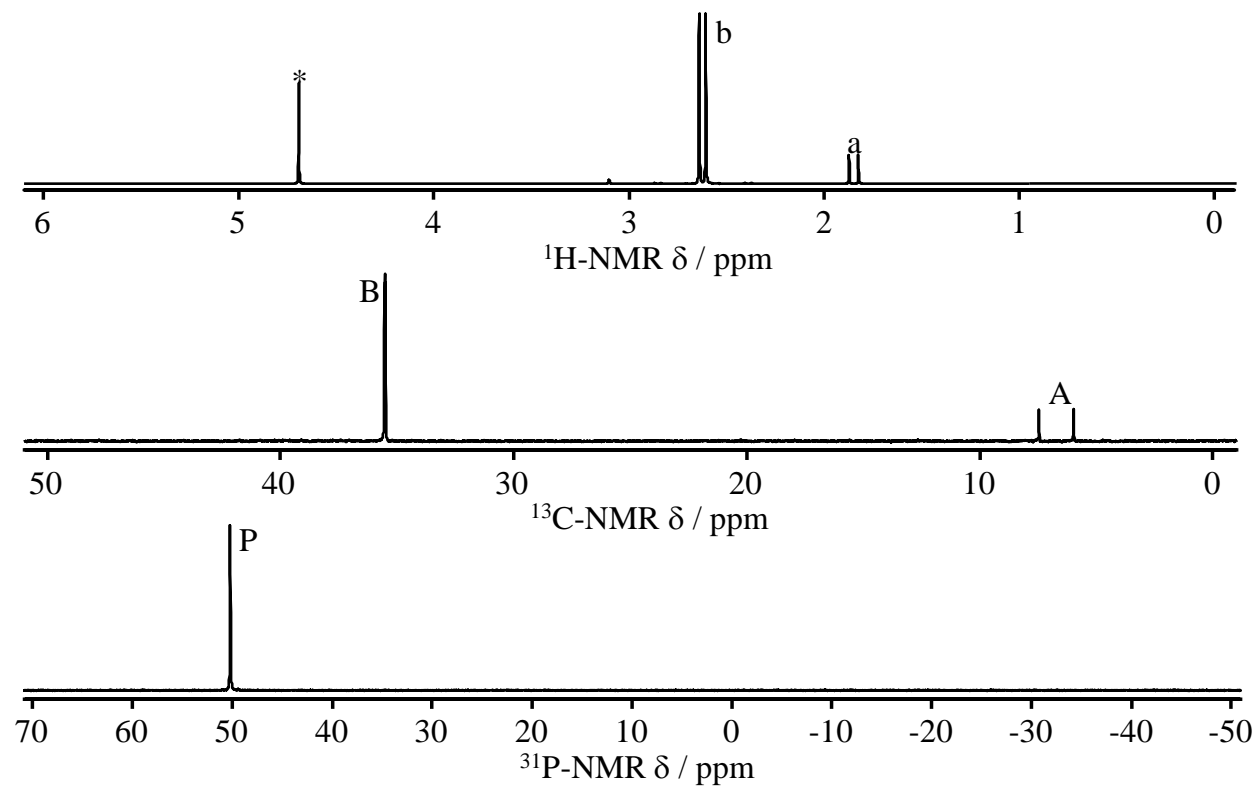

Figure 3.8. ${ }^{1} \mathrm{H}$-NMR (above) ${ }^{13} \mathrm{C}$-NMR (middle) and ${ }^{31} \mathrm{P}$-NMR (below) spectra of methyl-tris(dimethylamino)-phosphonium iodide in deuterated water solution $\left(\mathrm{D}_{2} \mathrm{O}\right)$. Asterisk in ${ }^{1} \mathrm{H}$-NMR spectrum marks proton resonance of water.

\subsubsection{OSDA-4: methyl-tri-isopropylphosphonium cation (MIP)}

In a typical synthesis (Figure 3.9), a solution of $25.5 \mathrm{~g}$ (179.8 mmol, $99 \mathrm{wt} . \%$, Aldrich) of iodomethane (b) in $50 \mathrm{ml}$ of anhydrous acetonitrile (99 wt.\%, Alfa-Aesar) was added dropwise under stirring to a solution of $17.6 \mathrm{~g}$ (119.9 mmol, $98 \mathrm{wt} \%$, ABCR) of triisopropylphosphine (a) in $200 \mathrm{ml}$ of anhydrous acetonitrile (99 wt.\%, Alfa-Aesar) under nitrogen atmosphere at the ice bath temperature. The mixture was stirred at room temperature for three days until the reaction takes place. The resulting solution was rotary evaporated until a white precipitate appeared and then, diethyl ether was added to completely precipitate the desired product. The precipitate was recovered by filtration, washed with a mixture of acetonitrile and diethyl ether and dried under vacuum. The product methyl-tri-isopropylphosphonium iodide (c) was obtained as a white powder with a yield over $98 \%$.

Then, the product was dissolved in Milli-Q water and exchanged to the hydroxide form using an anionic exchange Amberlite IRN-78 resin in batch overnight, resulting in a $0.22 \mathrm{M}$ solution of the methyl-tri-isopropylphosphonium hydroxide (d). 


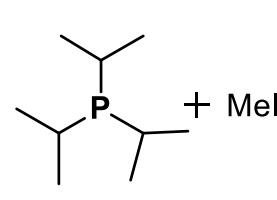

(a)

(b)

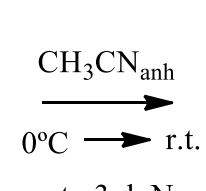

r.t., $3 \mathrm{~d}, \mathrm{~N}_{2}$
IRN-78

$\mathrm{H}_{2} \mathrm{O}_{\mathrm{mq}}$

r.t., $1 \mathrm{~d}$<smiles>CC(C)[PH](C(C)C)(C(C)C)C(C)C</smiles>

(d)

Figure 3.9. Synthesis scheme of the methyl-tri-isopropylphosphonium cation (MIP).

Chemical purity of the iodide salt was checked by chemical analyses (Table 3.3) and liquid NMR (Figure 3.10).

Table 3.3. Theoretical and experimental chemical composition of methyl-tri-isopropylphosphonium iodide. Ratios are given as molar ratios.

\begin{tabular}{ccccc}
\hline $\mathrm{C}_{10} \mathrm{H}_{24} \mathrm{PI}$ & wt.\% C & wt.\% P & wt.\% H & $\mathrm{C} / \mathrm{P}$ \\
\hline Theoretical & 39.7 & 10.2 & 8.0 & 10 \\
Experimental & 40.1 & 9.1 & 8.5 & 11.3 \\
\hline
\end{tabular}

${ }^{1} \mathrm{H}$ NMR $\left(\mathrm{D}_{2} \mathrm{O}\right): \mathbf{a}: 1.26 \mathrm{ppm}\left(\mathrm{dd}, 18 \times \mathrm{H}, \mathrm{P}\left(\mathrm{CH}\left(\mathrm{CH}_{3}\right)_{2}\right)_{3}\right) ; \mathbf{b}: 1.64 \mathrm{ppm}\left(\mathrm{d}, 3 \times \mathrm{H}, \mathrm{PC} \boldsymbol{H}_{3}\right)$, c: 2.63 ppm (dquint, $\left.3 \times \mathrm{HH}, \mathrm{P}\left(\mathrm{CH}\left(\mathrm{CH}_{3}\right)_{2}\right)_{3}\right)$.

${ }^{13} \mathrm{C}$ NMR $\left(\mathrm{D}_{2} \mathrm{O}\right): \mathbf{A}: 0.34$ ppm $\left(\mathrm{d}, \mathrm{P}\left(\mathrm{CH}\left(\boldsymbol{C H}_{3}\right)_{2}\right)_{3}\right)$; B: $17.96 \mathrm{ppm}\left(\mathrm{d}, \mathrm{P}\left(\boldsymbol{C H}\left(\mathrm{CH}_{3}\right)_{2}\right)_{3}\right)$; C: $22.40 \mathrm{ppm}\left(\mathrm{d}, \mathrm{PCH}_{3}\right)$.

${ }^{31} \mathrm{P}$ NMR $\left(\mathrm{D}_{2} \mathrm{O}\right): 44.55$ ppm (s, $\mathrm{H}$ decoup., $\left.\boldsymbol{P} \mathrm{N}_{3} \mathrm{C}\right)$. 

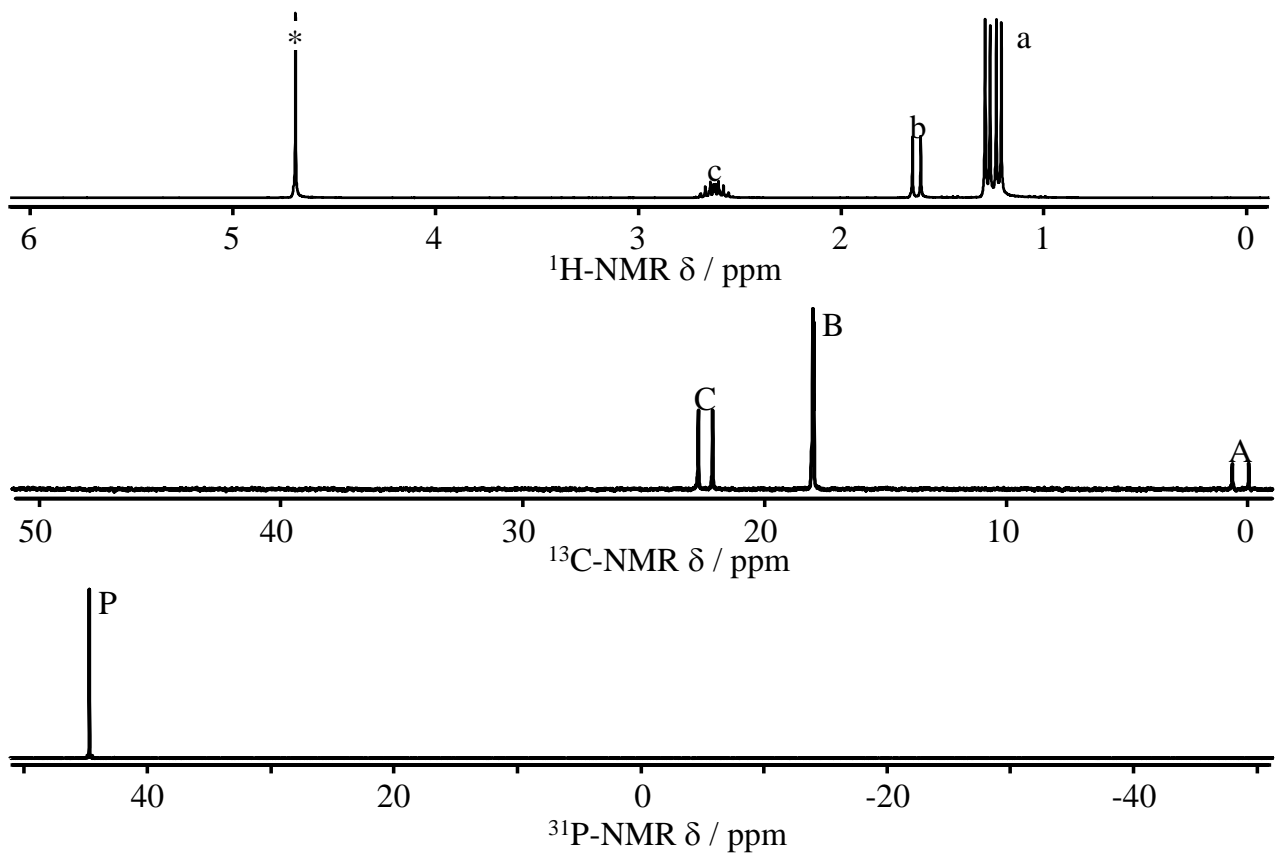

Figure 3.10. ${ }^{1} \mathrm{H}-\mathrm{NMR}$ (above), ${ }^{13} \mathrm{C}-\mathrm{NMR}$ (middle) and ${ }^{31} \mathrm{P}$-NMR (below) spectra of methyl-triisopropylphosphonium iodide in deuterated water solution $\left(\mathrm{D}_{2} \mathrm{O}\right)$. Asterisk in ${ }^{1} \mathrm{H}$-NMR spectrum marks proton resonance of water.

\subsubsection{OSDA-5: di-isopropyl-diethylammonium cation (IEN)}

In a typical synthesis (Figure 3.11), a solution of $46.8 \mathrm{~g}$ (300 mmol, 99 wt.\% Aldrich) of ethyl iodide (b) in $50 \mathrm{ml}$ of acetonitrile (99 wt.\%, Alfa-Aesar) was added dropwise under stirring to a solution of $25.8 \mathrm{~g}$ (200 mmol, $97 \mathrm{wt} . \%$, Alfa Aesar) of ethyldiisopropylamine (a) in $300 \mathrm{ml}$ of acetonitrile (99 wt.\%, Alfa-Aesar). The mixture was stirred at $80^{\circ} \mathrm{C}$ for ten days until the reaction takes place. The resulting solution was rotary evaporated until a white precipitate appeared and then, diethyl ether was added to completely precipitate the desired product. The precipitate was recovered by filtration, washed with a mixture of acetonitrile and diethyl ether and dried under vacuum. The product di-isopropyl-diethylammonium iodide (c) was obtained as a white powder with a yield over $78 \%$.

Then, the product was dissolved in Milli-Q water and exchanged to the hydroxide form using an anionic exchange Amberlite IRN-78 resin in batch overnight, resulting in a $0.37 \mathrm{M}$ solution of the di-isopropyl-diethylammonium hydroxide (d). 


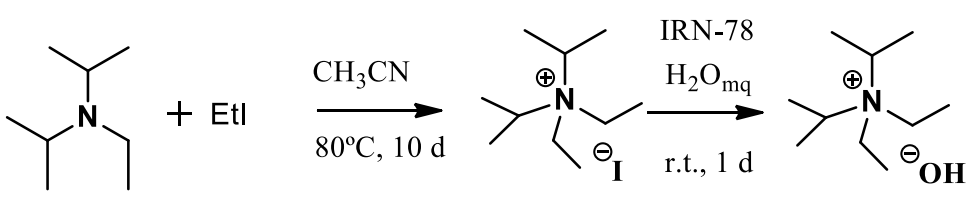

(a) (b)

(c)

(d)

Figure 3.11. Synthesis scheme of the di-isopropyl-diethylammonium cation (IEN).

Chemical purity of the iodide salt was checked by chemical analyses (Table 3.4) and liquid NMR (Figure 3.12).

Table 3.4. Theoretical and experimental chemical composition of di-isopropyl-diethylammonium cation iodide. Ratios are given as molar ratios.

\begin{tabular}{ccccc}
\hline $\mathrm{C}_{10} \mathrm{H}_{24} \mathrm{NI}$ & wt.\% $\mathrm{C}$ & wt.\% $\mathrm{N}$ & wt.\% $\mathrm{H}$ & $\mathrm{C} / \mathrm{N}$ \\
\hline Theoretical & 42.1 & 4.9 & 8.5 & 10 \\
Experimental & 41.8 & 5.0 & 8.9 & 9.8 \\
\hline
\end{tabular}

${ }^{1} \mathrm{H}$ NMR $\left(\mathrm{D}_{2} \mathrm{O}\right)$ : a: $1.27 \mathrm{ppm}\left(\mathrm{tt}, 6 \mathrm{xH}, \mathrm{N}\left(\mathrm{CH}_{2} \mathrm{CH}_{3}\right)_{2}\right) ; \mathbf{b}: 1.38 \mathrm{ppm}(\mathrm{dd}, 12 \mathrm{xH}$, $\left.\mathrm{N}\left(\mathrm{CH}\left(\mathrm{CH}_{3}\right)_{2}\right)_{2}\right)$; c: 3.32 ppm (q, 4xH, N($\left.\left(\mathrm{CH}_{2} \mathrm{CH}_{3}\right)_{2}\right)$; d: 3.84 ppm (v, 2xH, N(CH(CH$\left.\left.)_{2}\right)_{2}\right)$.

${ }^{13} \mathrm{C} \mathrm{NMR}\left(\mathrm{D}_{2} \mathrm{O}\right)$ : A: 9.59 ppm (s, N(CH(CH$\left.\left.)_{2}\right)_{2}\right) ; \mathbf{B}: 17.95 \mathrm{ppm}\left(\mathrm{s}, \mathrm{N}\left(\mathrm{CH}_{2} \boldsymbol{C H}_{3}\right)_{2}\right) ; \mathbf{C}$ : 52.08 ppm (t, N(C $\left.\left.\mathrm{CH}_{2} \mathrm{CH}_{3}\right)_{2}\right)$; D: 62.20 ppm (t, $\left.\mathrm{N}\left(\boldsymbol{C} \mathrm{H}\left(\mathrm{CH}_{3}\right)_{2}\right)_{2}\right)$.

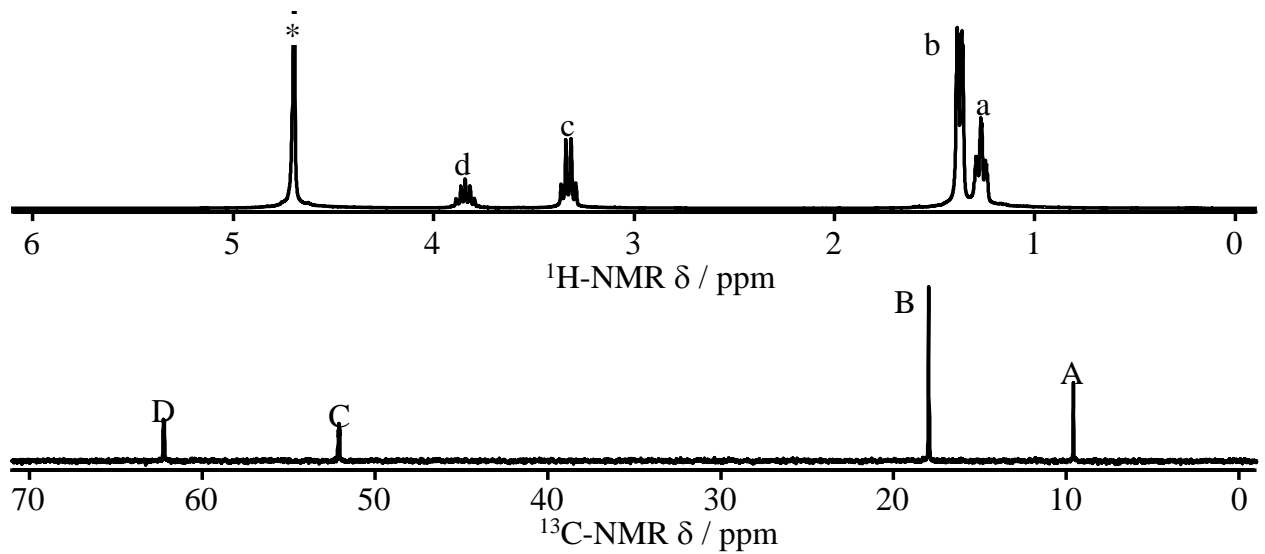

Figure 3.12. ${ }^{1} \mathrm{H}-\mathrm{NMR}$ (above) and ${ }^{13} \mathrm{C}-\mathrm{NMR}$ (below) spectra of di-isopropyl-diethylammonium iodide in deuterated water solution $\left(\mathrm{D}_{2} \mathrm{O}\right)$. Asterisk in ${ }^{1} \mathrm{H}$-NMR spectrum marks proton resonance of water. 


\subsubsection{OSDA-6: phosphazene base P1-t-Bu (PB1)}

Commercial phosphazene base P1-t-Bu (97 wt.\%, Aldrich) is lightly soluble in water but, once protonated into the cationic phosphazenium form, it is highly soluble.

Chemical purity of the reagent was checked by liquid NMR (Figure 3.13).

${ }^{1} \mathrm{H}$ NMR (MeOD): a: $1.34 \mathrm{ppm}\left(\mathrm{s}, 9 \mathrm{xH}, \operatorname{PNC}\left(\mathrm{CH}_{3}\right)_{3}\right) ;$ b: $2.78 \mathrm{ppm}(\mathrm{d}, 12 \mathrm{xH}$, $\left.\mathrm{P}\left(\mathrm{N}\left(\mathrm{CH}_{3}\right)_{2}\right)_{3}\right)$.

${ }^{13} \mathrm{C} \mathrm{NMR}(\mathrm{MeOD}): \mathrm{A}: 32.10 \mathrm{ppm}\left(\mathrm{d}, \mathrm{PNC}\left(\boldsymbol{C} \mathrm{H}_{3}\right)_{3}\right) ; \mathrm{B}: 38.04 \mathrm{ppm}\left(\mathrm{d}, \mathrm{P}\left(\mathrm{N}\left(\boldsymbol{C H}_{3}\right)_{2}\right)_{3}\right)$; C: $53.08 \mathrm{ppm}\left(\mathrm{s}, \mathrm{PNC}\left(\mathrm{CH}_{3}\right)_{3}\right)$.

${ }^{31} \mathrm{P}$ NMR (MeOD): 33.73 ppm (s, H decoup.).
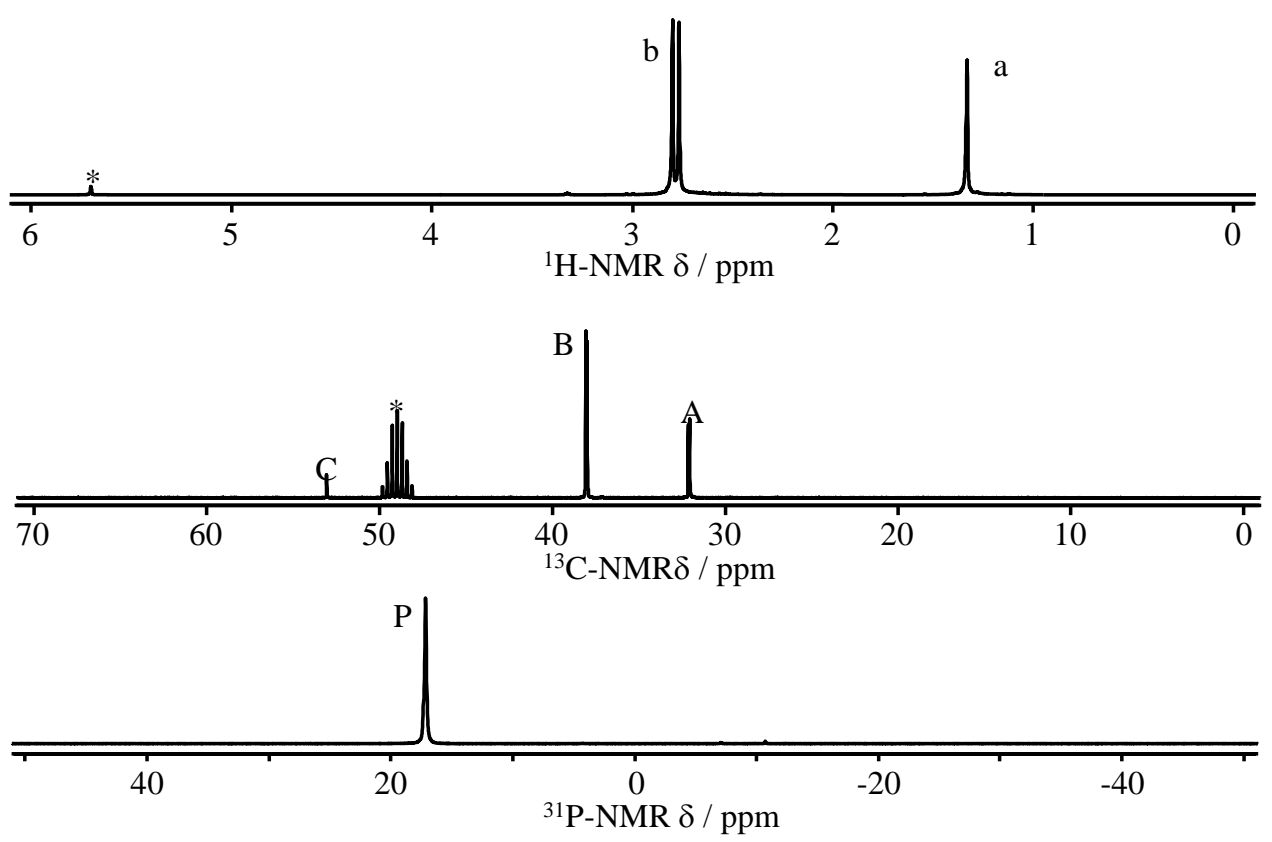

Figure 3.13. ${ }^{1} \mathrm{H}$-NMR (above), ${ }^{13} \mathrm{C}$-NMR (middle) and ${ }^{31} \mathrm{P}$-NMR (below) spectra of phosphazene base P1-t-Bu in deuterated methanol solution (MeOD). Asterisk in ${ }^{1} \mathrm{H}-\mathrm{NMR}$ and ${ }^{13} \mathrm{C}-\mathrm{NMR}$ spectra marks proton and carbon resonances of $\mathrm{MeOD}$. 


\subsubsection{OSDA-7: tris(diethylamino)(methyl)phosphonium cation}

In a typical synthesis (Figure 3.14), a solution of $50 \mathrm{~g}$ (196.08 mmol, 97 wt.\%, Aldrich) of tris(diethylamino)phosphine (a) in $200 \mathrm{ml}$ of ethyl acetate (99 wt.\%, Alfa-Aesar) was added dropwise under stirring to a solution of $41.8 \mathrm{~g}$ (294.12 mmol, $99 \mathrm{wt} . \%$, Aldrich) of iodomethane (b) in $50 \mathrm{ml}$ of ethyl acetate (99 wt.\%, Alfa-Aesar). The mixture was stirred at room temperature for five days until the reaction takes place. The mixture separates in two phases, an almost colourless top solution, which mainly comprises ethyl acetate and the unreacted reagents, and a yellowish bottom solution, which mainly contains the desired product and a small amount of ethyl acetate. The product was purified by successive extractions with Milli-Q water, and quantified by ICP spectroscopy. The product tris(diethylamino)(methyl)phosphonium iodide (c) was obtained in a water solution with a yield over $95 \%$.

Then, the solution of the product was exchanged to the hydroxide form using an anionic exchange Amberlite IRN-78 resin in batch overnight, resulting in a $0.38 \mathrm{M}$ solution of the tris(diethylamino)(methyl)phosphonium hydroxide.

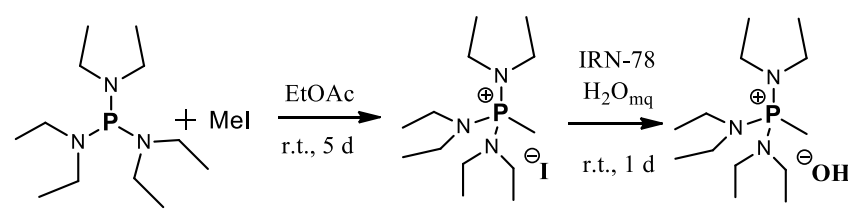

(a) (b)

(c)

(d)

Figure 3.14. Synthesis scheme of the tris(diethylamino)(methyl)phosphonium cation (PN-PN).

Purity of the iodide salt was checked by liquid NMR (Figure 3.15).

${ }^{1} \mathrm{H}$ NMR (MeOD): a: 1.03 ppm (t, $\left.18 x \mathrm{H}, \mathrm{P}\left(\mathrm{N}\left(\mathrm{CH}_{2} \mathrm{CH}_{3}\right)_{2}\right)_{3}\right) ; \mathbf{b}: 1.83$ ppm (d, 3xH, PCH 3$)$, c: 2.98 ppm (dq, 6xH, $\left.\mathrm{P}\left(\mathrm{N}\left(\mathrm{CH}_{2} \mathrm{CH}_{3}\right)_{2}\right)_{3}\right)$.

${ }^{13} \mathrm{C}$ NMR (MeOD): A: $8.32 \mathrm{ppm}\left(\mathrm{s}, \mathrm{PC} \mathrm{H}_{3}\right) ; \mathbf{B}: 14.55 \mathrm{ppm}\left(\mathrm{d}, \mathrm{P}\left(\mathrm{N}\left(\mathrm{CH}_{2} \mathrm{CH}_{3}\right)_{2}\right)_{3}\right)$; $\mathbf{C}$ : $39.68 \mathrm{ppm}\left(\mathrm{d}, \mathrm{P}\left(\mathrm{N}\left(\boldsymbol{C H}_{2} \mathrm{CH}_{3}\right)_{2}\right)_{3}\right)$.

${ }^{31} \mathrm{P}$ NMR (MeOD): 56.92 ppm (s, H decoup.). 

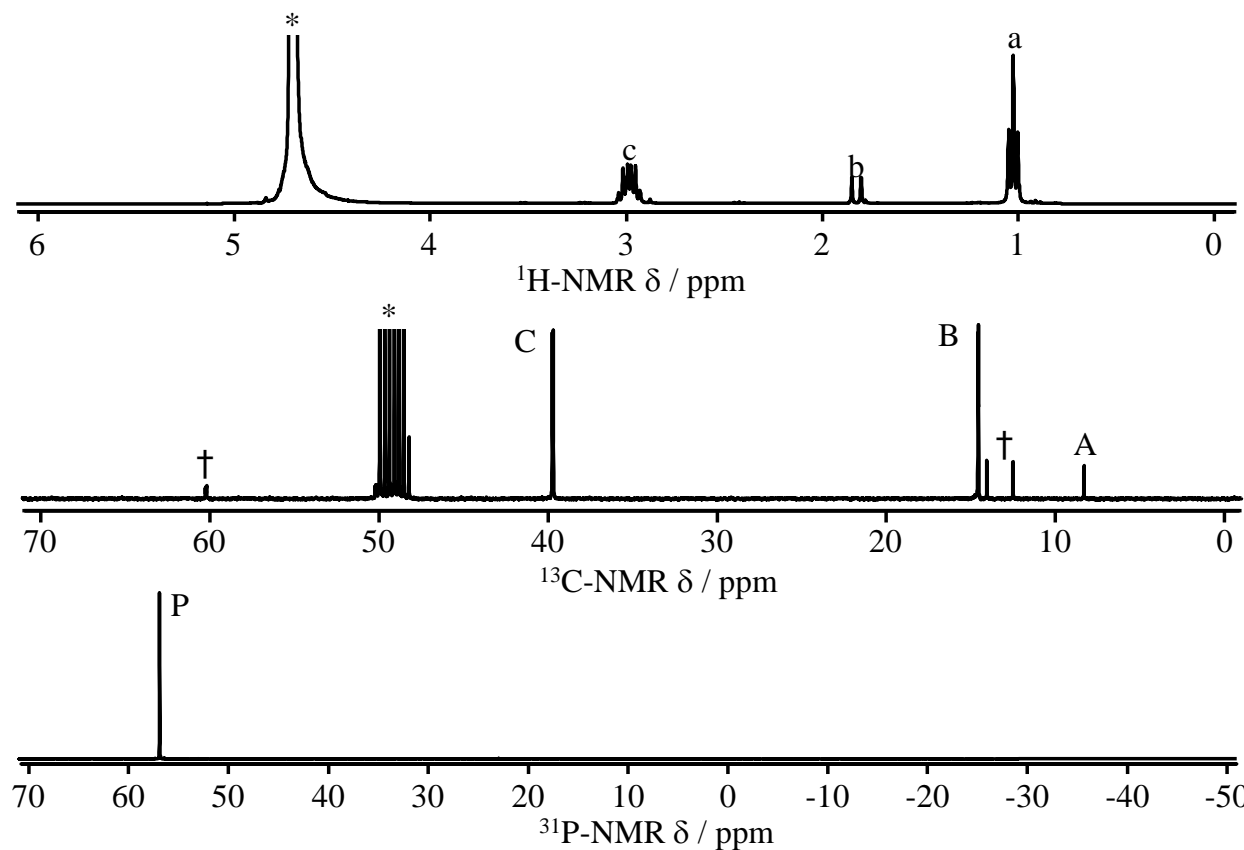

Figure 3.15. ${ }^{1} \mathrm{H}-\mathrm{NMR}$ (above), ${ }^{13} \mathrm{C}$-NMR (middle) and ${ }^{31} \mathrm{P}-\mathrm{NMR}$ (below) spectra of tris(diethylamino)(methyl)phosphonium iodide in deuterated methanol (MeOD). Asterisk in ${ }^{1} \mathrm{H}-\mathrm{NMR}$ and

${ }^{13} \mathrm{C}$-NMR marks proton and carbon resonances of $\mathrm{MeOD}, \uparrow$ in ${ }^{13} \mathrm{C}$-NMR marks residual ethyl acetate resonances.

\subsubsection{OSDA-8: butane - 1,4-diylbis [tris(dimethylamino) phospho- nium] cation (PN-PN)}

In a typical synthesis (Figure 3.16), a solution of $31.1 \mathrm{~g} \mathrm{(100} \mathrm{mmol,} 99 \mathrm{wt} \%$, Aldrich) of 1,4-diiodobutane (b) in $75 \mathrm{ml}$ of acetonitrile (99 w.\%, Alfa-Aesar) was added dropwise under stirring to a solution of $40.8 \mathrm{~g}(250 \mathrm{mmol}, 97 \mathrm{wt} \%$, Aldrich) of tris(dimethylamino)phosphine (a) in $75 \mathrm{ml}$ of acetonitrile (99 wt.\%, Alfa-Aesar). The mixture was stirred at room temperature for two days until the reaction takes place. The precipitate was recovered by filtration, washed with acetonitrile and diethyl ether and dried under vacuum. The product butane - 1,4-diylbis[tris(dimethylamino)phosphonium] iodide (c) was obtained as a white powder with a yield over $95 \%$. 
Then, the product was dissolved in Milli-Q water and exchanged to the hydroxide form using an anionic exchange Amberlite IRN-78 resin in batch overnight, resulting in a 0.25 M solution of the butane - 1,4-diylbis[tris(dimethylamino)phosphonium] hydroxide (d).

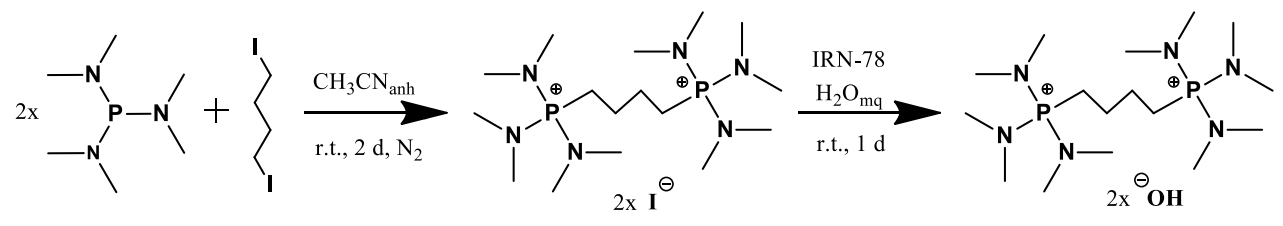

(a)

(b)

(c)

(d)

Figure 3.16. Synthesis scheme of the butane-1,4-diylbis[tris(dimethylamino)phosphonium] cation (PN-PN).

Chemical purity of the iodide salt was checked by chemical analyses (Table 3.5) and liquid NMR (Figure 3.17).

Table 3.5. Theoretical and experimental chemical composition of butane - 1,4-diylbis [tris(dimethylamino) phosphonium] iodide. Ratios are given as molar ratios.

\begin{tabular}{ccccccc}
\hline $\mathrm{C}_{16} \mathrm{H}_{44} \mathrm{I}_{2} \mathrm{~N}_{6} \mathrm{P}_{2}$ & wt.\%C & wt.\%P & wt. $\% \mathrm{~N}$ & wt. $\% \mathrm{H}$ & $\mathrm{C} / \mathrm{P}$ & $\mathrm{N} / \mathrm{P}$ \\
\hline Theoretical & 37.7 & 12.2 & 16.5 & 8.7 & 8 & 3 \\
Experimental & 38.1 & 11.9 & 15.8 & 9.1 & 8.3 & 2.9 \\
\hline
\end{tabular}

${ }^{1} \mathrm{H}$ NMR $\left(\mathrm{D}_{2} \mathrm{O}\right): \mathbf{a}: 1.71 \mathrm{ppm}\left(\mathrm{m}, 4 \mathrm{xH}, \mathrm{P}\left(\mathrm{CH}_{2} \mathrm{CH}_{2} \mathrm{CH}_{2} \mathrm{CH}_{2}\right) \mathrm{P}\right) ; \mathbf{b}: 2.47 \mathrm{ppm}(\mathrm{m}, 4 \mathrm{xH}$, $\left.\mathrm{P}\left(\mathrm{CH}_{2} \mathrm{CH}_{2} \mathrm{CH}_{2} \mathrm{CH}_{2}\right) \mathrm{P}\right)$, c: $2.68 \mathrm{ppm}\left(\mathrm{d}, 36 \mathrm{H}, \mathrm{P}\left(\mathrm{NCH}_{2}\right)_{3}\right)$.

${ }^{13} \mathrm{C}$ NMR (D $\left.{ }_{2} \mathrm{O}\right): \mathbf{A}: 22.17$ ppm (d, $\left.\mathrm{P}\left(\boldsymbol{C} \mathrm{H}_{2} \boldsymbol{C} \mathrm{H}_{2} \boldsymbol{C} \mathrm{H}_{2} \boldsymbol{C H}_{2}\right) \mathrm{P}\right) ; \mathbf{B}: 23.02$ ppm (d, $\left.\mathrm{P}\left(\mathrm{CH}_{2} \mathrm{CH}_{2} \mathrm{CH}_{2} \mathrm{CH}_{2}\right) \mathrm{P}\right)$; $\mathbf{C}: 36.22$ ppm (d, $\left.\mathrm{P}\left(\mathrm{NCH}_{2}\right)_{3}\right)$.

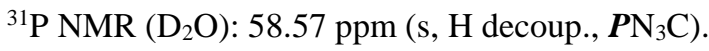



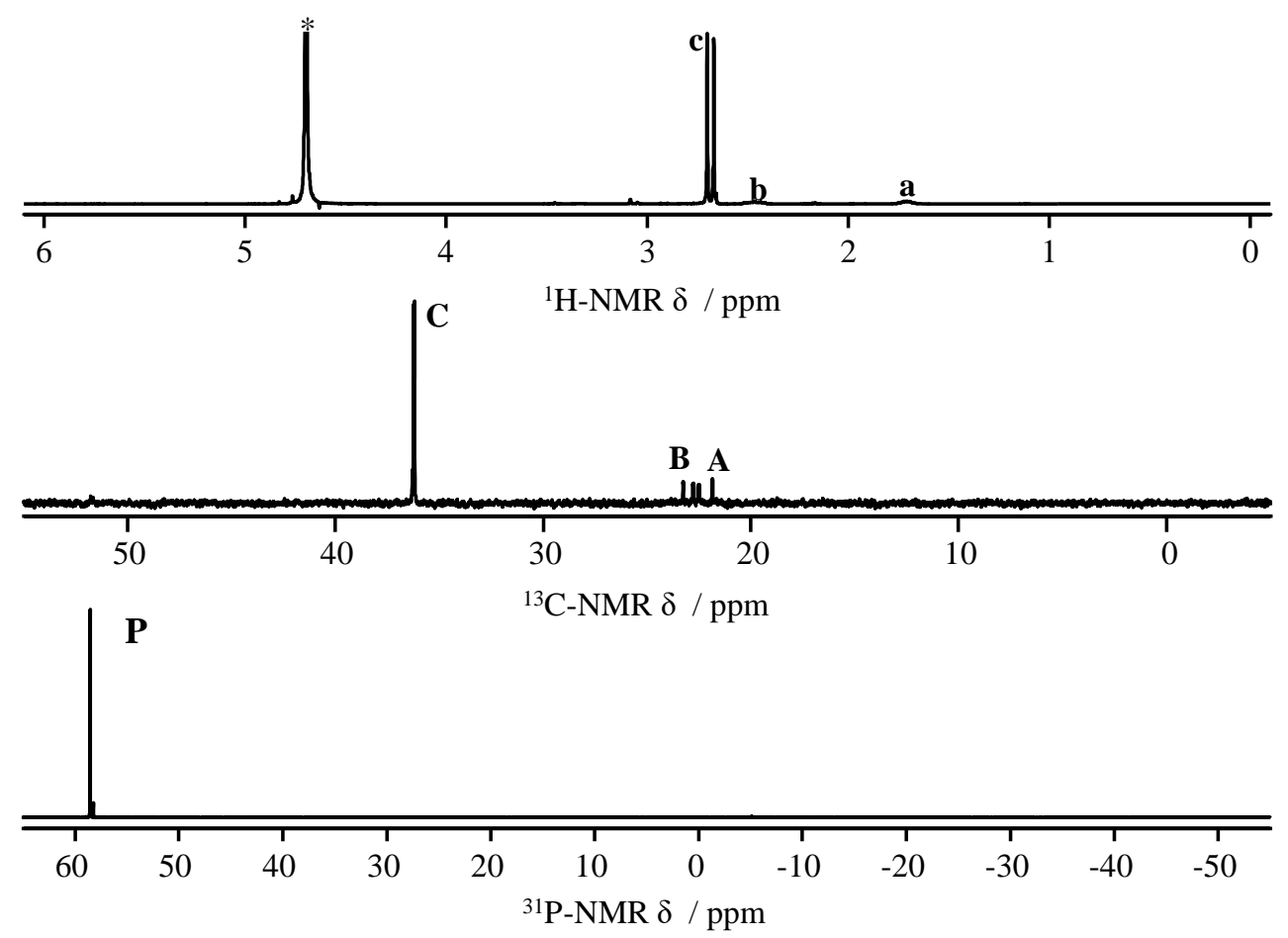

Figure 3.17. ${ }^{1} \mathrm{H}$-NMR (above), ${ }^{13} \mathrm{C}$-NMR (middle) and ${ }^{31} \mathrm{P}$-NMR (below) spectra of butane - 1,4diylbis[tris(dimethylamino)phosphonium] iodide in deuterated water solution $\left(\mathrm{D}_{2} \mathrm{O}\right)$. Asterisk in ${ }^{1}$ H-NMR marks proton resonance of water.

\subsubsection{OSDA-9: butane-1,4-diylbis(triisopropylphosphonium) cation}

In a typical synthesis (Figure 3.18), a solution of $14.1 \mathrm{~g}$ (45 mmol, 99 wt.\%, Aldrich) of 1,4-diiodobutane (b) in $100 \mathrm{ml}$ of anhydrous acetonitrile (99 wt.\%, Alfa-Aesar) was added dropwise under stirring to a solution of $16.2 \mathrm{~g}$ (100 mmol, $98 \mathrm{wt} \%$, Acros) of triisopropylphosphine (a) in $50 \mathrm{ml}$ of anhydrous acetonitrile (99 wt.\%, Alfa-Aesar). The resulting mixture was stirred at room temperature for two days until the reaction takes place. The precipitate was recovered by filtration, washed with acetonitrile and diethyl ether and dried under vacuum. The product butane-1,4-diylbis(triisopropylphosphonium) iodide (c) was obtained as a white powder with a yield over $95 \%$. 
Then, the product was dissolved in Milli-Q water and exchanged to the hydroxide form using an anionic exchange Amberlite IRN-78 resin in batch overnight, resulting in a 0.3 M solution of the butane-1,4-diylbis(triisopropylphosphonium) hydroxide (d).

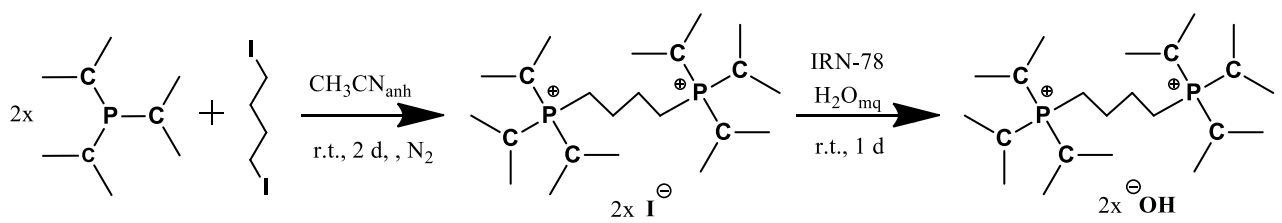

(a)

(c)

(d)

Figure 3.18. Synthesis scheme of the butane-1,4-diylbis(triisopropylphosphonium) cation (PC-PC).

Chemical purity of the iodide salt was checked by chemical analyses (Table 3.6) and liquid NMR (Figure 3.19).

Table 3.6. Theoretical and experimental chemical composition of butane-1,4-diylbis(triisopropylphosphonium) iodide. Ratios are given as molar ratios.

\begin{tabular}{ccccc}
\hline $\mathrm{C}_{22} \mathrm{H}_{44} \mathrm{P}_{2} \mathrm{I}_{2}$ & wt.\% C & wt.\% P & wt.\% H & C/P \\
\hline Theoretical & 42.3 & 9.9 & 7.1 & 11 \\
Experimental & 42.9 & 10.3 & 7.3 & 10.7 \\
\hline
\end{tabular}

${ }^{1} \mathrm{H}$ NMR $\left(\mathrm{D}_{2} \mathrm{O}\right)$ : a: $1.21 \mathrm{ppm}\left(\mathrm{dd}, 36 \times \mathrm{H}, \mathrm{P}\left(\mathrm{CH}\left(\mathrm{CH}_{3}\right)_{2}\right)_{3}\right)$; b: $1.67 \mathrm{ppm}(\mathrm{m}, 8 \times \mathrm{H}$, $\left.\mathrm{P}\left(\mathrm{CH}_{2} \mathrm{CH}_{2} \mathrm{CH}_{2} \mathrm{CH}_{2}\right) \mathrm{P}\right)$, c: 2.17 ppm (m, 8xH, $\left.\mathrm{P}\left(\mathrm{CH}_{2} \mathrm{CH}_{2} \mathrm{CH}_{2} \mathrm{CH}_{2}\right) \mathrm{P}\right)$; d: 2.63 ppm (dv, 6xH, $\left.\mathrm{P}\left(\mathrm{CH}\left(\mathrm{CH}_{3}\right)_{2}\right)_{3}\right)$.

${ }^{13} \mathrm{C}$ NMR (D $\left.{ }_{2} \mathrm{O}\right): \mathbf{A}: 14.69$ ppm (d, $\left.\mathrm{P}\left(\boldsymbol{C H}_{2} \mathrm{CH}_{2} \mathrm{CH}_{2} \boldsymbol{C H}_{2}\right) \mathrm{P}\right) ; \mathbf{B}: 15.99$ ppm (d, $\left.\mathrm{P}\left(\mathrm{CH}\left(\boldsymbol{C} \mathrm{H}_{3}\right)_{2}\right)_{3}\right)$; $\mathbf{C}: 19.71$ ppm (d, $\left.\mathrm{P}\left(\mathrm{CH}_{2} \boldsymbol{C H}_{2} \boldsymbol{C H}_{2} \mathrm{CH}_{2}\right) \mathrm{P}\right)$; D: 23.37 ppm (dd, $\left.\mathrm{P}\left(\boldsymbol{C H}\left(\mathrm{CH}_{3}\right)_{2}\right)_{3}\right)$.

${ }^{31} \mathrm{P}$ NMR $\left(\mathrm{D}_{2} \mathrm{O}\right): 42.64$ ppm (s, $\mathrm{H}$ decoup., $\left.\boldsymbol{P R}_{4}\right)$. 

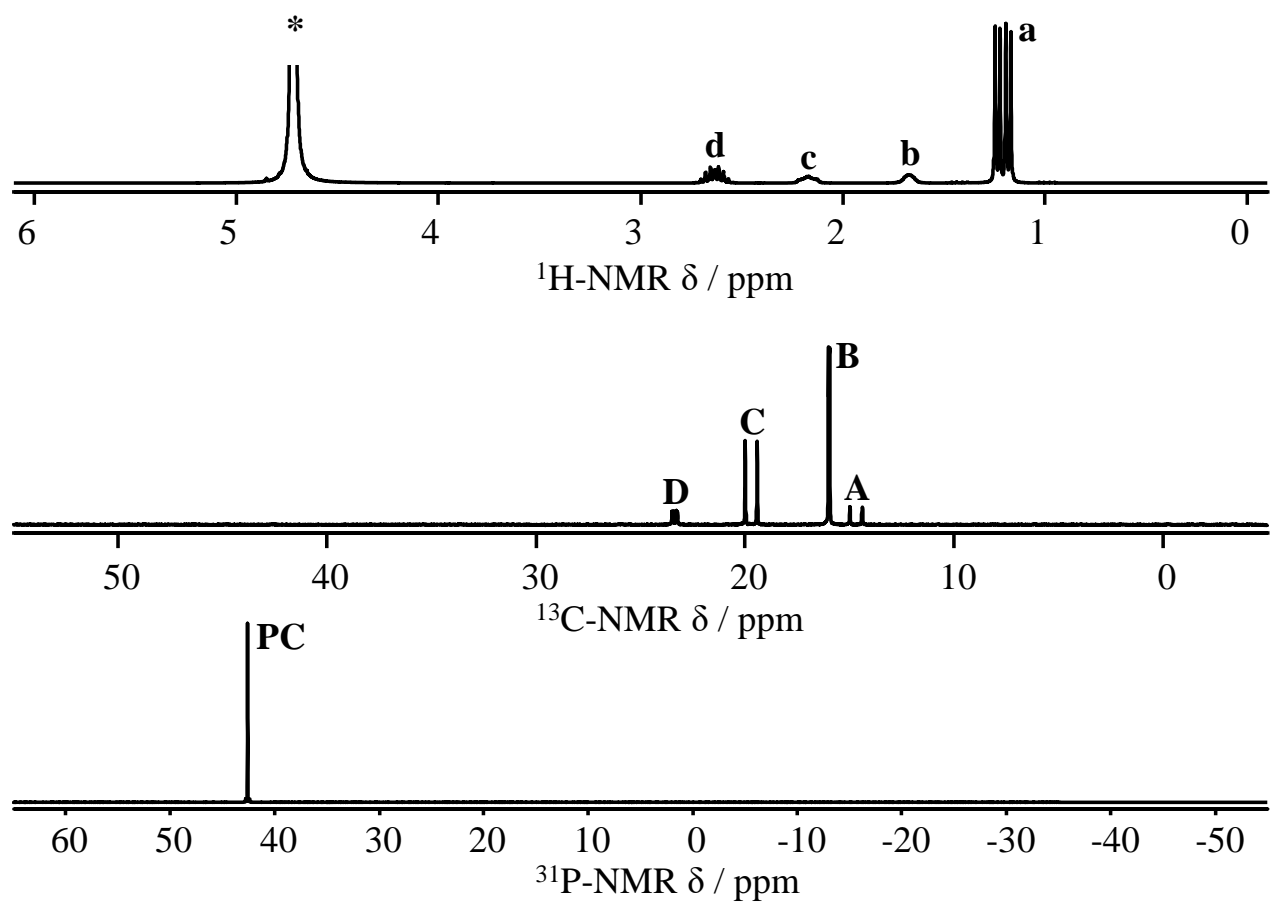

Figure 3.19. ${ }^{1} \mathrm{H}-\mathrm{NMR}$ (above), ${ }^{13} \mathrm{C}-\mathrm{NMR}$ (middle) and ${ }^{31} \mathrm{P}-\mathrm{NMR}$ (below) spectra of butane-1,4diylbis(triisopropylphosphonium) iodide in deuterated water solution $\left(\mathrm{D}_{2} \mathrm{O}\right)$. Asterisk in ${ }^{1} \mathrm{H}$-NMR marks proton resonance of water.

\subsubsection{OSDA-10: tris(dimethylamino) [4-(tri-tert-butylphosphonio) butyl] phosphonium cation}

In this case, measures have to be taken to avoid undesirable products like the PN-PN cation, or unreacted monoquaternary aminophosphonium cation. Specific synthesis conditions are given next: In a typical synthesis (Figure 3.20), a solution of $4.896 \mathrm{~g} \mathrm{(30} \mathrm{mmol,}$ 97 wt.\%, Aldrich) of tris(dimethylamino)phosphine (a) in $50 \mathrm{ml}$ of acetonitrile (99 wt.\%, Alfa-Aesar) was slowly added dropwise under stirring to a solution of $55.782 \mathrm{~g} \mathrm{(180} \mathrm{mmol,}$ 99 wt.\%, Aldrich) of 1,4-diiodobutane (b) in $200 \mathrm{ml}$ of acetonitrile (99 wt.\%, Alfa-Aesar). The resulting mixture was stirred at room temperature for three days. The precipitate was recovered by filtration, washed with acetonitrile and diethyl ether and dried under vacuum. The product tris(dimethylamino)(4-iodobutyl)phosphonium iodide (c) was obtained as a white powder with a yield over $87 \%$. 
Then, $8.815 \mathrm{~g}(18.63 \mathrm{mmol})$ of the previously obtained tris(dimethylamino)(4-iodobutyl)phosphonium iodide (c) were dissolved in $75 \mathrm{ml}$ of anhydrous acetonitrile (99 wt.\%, Alfa-Aesar) and added dropwise under stirring to a solution of $5 \mathrm{~g}$ (24.22 mmol, $98 \mathrm{wt} . \%$, Acros) of tri-tert-butylphosphine (d) in $25 \mathrm{ml}$ of anhydrous acetonitrile (99 wt.\%, Alfa-Aesar). The mixture was stirred at room temperature for five days until the reaction takes place. The precipitate was recovered by filtration, washed with acetonitrile and diethyl ether and dried under vacuum. The product tris(dimethylamino)[4-(tri-tert-butylphosphonio)butyl]phosphonium iodide (e) was obtained as a white powder with a yield over $75 \%$. Small impurities were seen in the final product, probably due to some oxidized aminophosphine.

The final product was dissolved in Milli-Q water and exchanged to the hydroxide form using an anionic exchange Amberlite IRN-78 resin in batch overnight, resulting in a $0.2 \mathrm{M}$ solution tris(dimethylamino)[4-(tri-tert-butylphosphonio)butyl]phosphonium hydroxide (f). After this step, the oxidized aminophoshine was removed (probably adsorbed over the exchange resin).

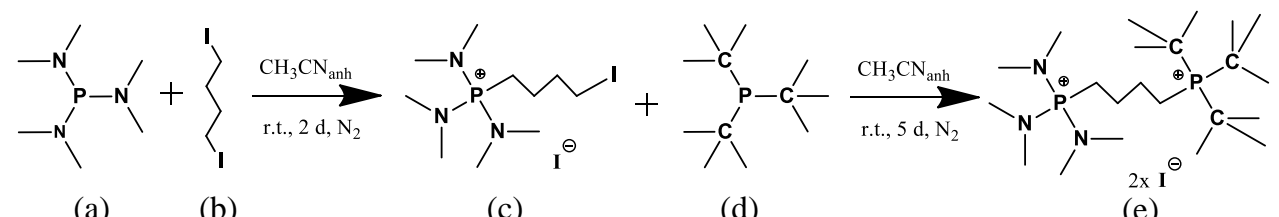

(a)

(b)

(c)

(d)

(e)

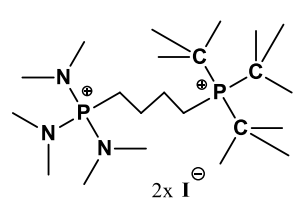

(e)

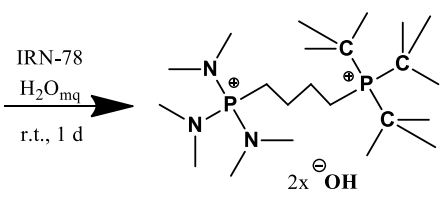

(f)

Figure 3.20. Synthesis scheme of the tris(dimethylamino)[4-(tri-tert-butylphosphonio) butyl]phosphonium cation (PN-PC).

Chemical purity of the iodide salt was checked by chemical analyses (Table 3.7) and liquid NMR (Figure 3.21). 
Synthesis and characterization of zeolitic materials using P-OSDA

Table 3.7. Theoretical and experimental chemical composition of tris(dimethylamino)[4-(tritert-butylphosphonio)butyl]phosphonium iodide. Ratios are given as molar ratios.

\begin{tabular}{ccccccc}
\hline $\mathrm{C}_{22} \mathrm{H}_{53} \mathrm{~N}_{3} \mathrm{P}_{2} \mathrm{I}_{2}$ & wt.\% C & wt.\% P & wt.\% N & wt.\% H & C/P & N/P \\
\hline Theoretical & 39.1 & 9.2 & 6.2 & 7.9 & 11 & 1.5 \\
Experimental & 37.1 & 9.4 & 6.7 & 8.5 & 10.2 & 1.6 \\
\hline
\end{tabular}

${ }^{1} \mathrm{H}$ NMR (MeOD): a: 1.67 ppm (d, 27H, $\mathrm{P}\left(\mathrm{C}\left(\mathrm{CH}_{3}\right)_{3}\right) ; \mathbf{b}: 1.95$ ppm (m, 8H, $\left.\mathrm{P}\left(\mathrm{CH}_{2} \mathrm{CH}_{2} \mathrm{CH}_{2} \mathrm{CH}_{2}\right) \mathrm{P}\right)$, c: $2.17 \mathrm{ppm}\left(\mathrm{m}, 8 \mathrm{H}, \mathrm{P}\left(\mathrm{CH}_{2} \mathrm{CH}_{2} \mathrm{CH}_{2} \mathrm{CH}_{2}\right) \mathrm{P}\right) ; \mathbf{d}: 2.83$ ppm (d, $18 \mathrm{H}$, $\left.\mathrm{P}\left(\mathrm{N}\left(\mathrm{CH}_{3}\right)_{2}\right)_{3}\right)$.

${ }^{13} \mathrm{C}$ NMR (MeOD): A: 24.96 ppm (s, $\left.\mathrm{P}\left(\boldsymbol{C H}_{2} \boldsymbol{C H}_{2} \boldsymbol{C H}_{2} \boldsymbol{C H}_{2}\right) \mathrm{P}\right) ; \mathbf{B}: 27.13$ ppm (s, $\left.\mathrm{P}\left(\boldsymbol{C} \mathrm{H}_{2} \boldsymbol{C H}_{2} \boldsymbol{C} \mathrm{H}_{2} \boldsymbol{C H} \mathrm{H}_{2}\right) \mathrm{P}\right)$; $\mathbf{C}: 30.28$ ppm (s, $\mathrm{P}\left(\mathrm{C}\left(\boldsymbol{C} \mathrm{H}_{3}\right)_{3}\right)$; D: 37.46 ppm (d, $\left.\mathrm{P}\left(\mathrm{N}_{(}\left(\mathrm{CH}_{3}\right)_{2}\right)_{3}\right)$; $\mathbf{E}$ : $40.35 \mathrm{ppm}\left(\mathrm{d}, \mathrm{P}()\left(\boldsymbol{C}\left(\mathrm{CH}_{3}\right)_{3}\right)_{3}\right)$.

${ }^{31}$ P NMR (MeOD): 51.30 ppm (s, H decoup., $\boldsymbol{P N}_{3}$ ); 49.90 ppm (s, H decoup., $\boldsymbol{P R}_{4}$ ). 

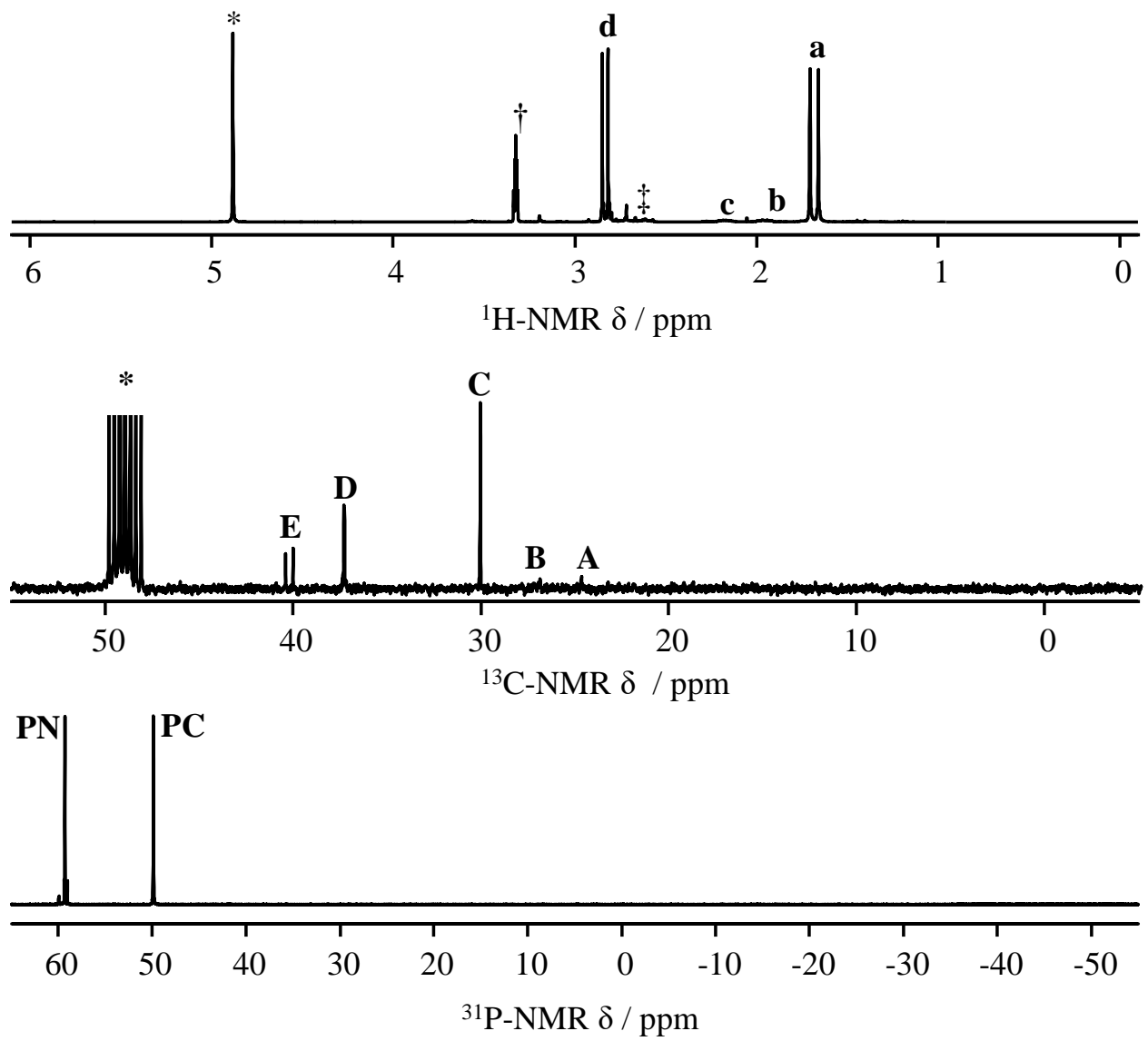

Figure 3.21. ${ }^{1} \mathrm{H}-\mathrm{NMR}$ (above), ${ }^{13} \mathrm{C}-\mathrm{NMR}$ (middle) and ${ }^{31} \mathrm{P}-\mathrm{NMR}$ (below) spectra of tris(dimethylamino)[4-(tri-tert-butylphosphonio)butyl]phosphonium iodide in deuterated methanol solution (MeOD). Asterisk in ${ }^{1} \mathrm{H}$-NMR spectrum marks proton resonance of water, $\uparrow$ in

${ }^{1} \mathrm{H}-\mathrm{NMR}$ spectrum marks proton resonance of $\mathrm{MeOH},+$ in ${ }^{1} \mathrm{H}-\mathrm{NMR}$ spectrum marks small impurities in the product; Asterisk in ${ }^{13} \mathrm{C}$-NMR marks carbon resonance of $\mathrm{MeOH}$.

\subsubsection{OSDA-11: Butane-1,4-diylbis(triethylphosphonium) cation}

In a typical synthesis (Figure 3.22), a solution of $58.02 \mathrm{~g}(187.28 \mathrm{mmol}, 99 \mathrm{wt} \%$, Aldrich) of 1,4-diiodobutane (b) in $50 \mathrm{ml}$ of anhydrous acetonitrile (99.9 wt.\%, Alfa-Aesar)

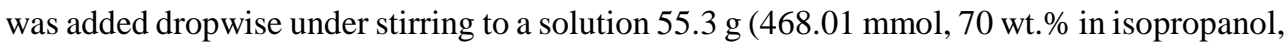
Aldrich) of triethylphosphine. The mixture was stirred under nitrogen atmosphere at the ice bath temperature for one day, and then at room temperature for four days until the reaction 
takes place. The resulting solution was then rotary evaporated until a white precipitate appeared. Then, diethyl ether was added to completely precipitate the desired product. Finally, the white precipitate was recovered by filtration, washed with a mixture of acetonitrile and diethyl ether and dried under vacuum. The product butane-1,4-diylbis(triethylphosphonium) iodide (c) was obtained as a white powder with a typical yield over $95 \%$.

Next, the iodide salt was dissolved in Milli-Q water and exchanged to its hydroxide form using an anionic exchange Amberlite IRN-78 resin in batch overnight with a typical yield of $92 \%$, resulting in a $0.29 \mathrm{M}$ solution of the butane-1,4-diylbis(triethylphosphonium) hydroxide (d).

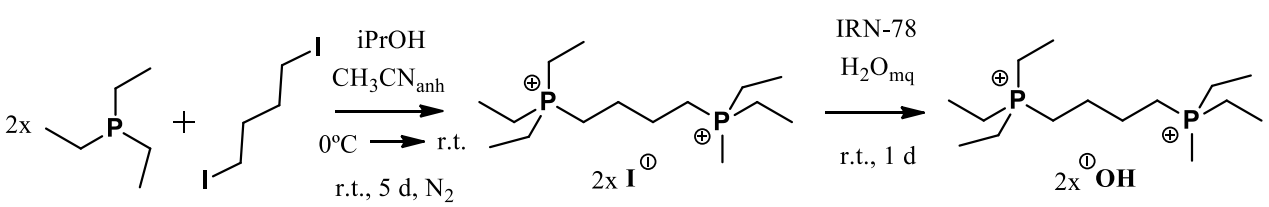

(a)

(b)

(c)

(d)

Figure 3.22. Synthesis scheme of the butane-1,4-diylbis(triethylphosphonium) cation.

The chemical purity of the iodide salt was checked by chemical analyses (Table 3.8) and liquid NMR (Figure 3.23).

Table 3.8. Theoretical and experimental chemical composition of butane-1,4-diylbis(triethylphosphonium) iodide. Ratios are given as molar ratios.

\begin{tabular}{ccccc}
\hline $\mathrm{C}_{16} \mathrm{H}_{38} \mathrm{P}_{2} \mathrm{I}_{2}$ & wt.\% C & wt.\% P & wt.\% H & C/P \\
\hline Theoretical & 35.2 & 11.3 & 7.0 & 8 \\
Experimental & 35.4 & 12.4 & 7.9 & 7.4 \\
\hline
\end{tabular}

${ }^{1} \mathrm{H}$ NMR $\left(\mathrm{D}_{2} \mathrm{O}\right)$ : a: $1.13 \mathrm{ppm}\left(\mathrm{dt}, 36 \mathrm{H}, \mathrm{P}\left(\mathrm{CH}_{2} \mathrm{CH}_{3}\right)_{3}\right) ; \mathbf{b}: 1.67 \mathrm{ppm}(\mathrm{m}, 8 \mathrm{H}$, $\left.\mathrm{P}\left(\mathrm{CH}_{2} \mathrm{CH}_{2} \mathrm{CH}_{2} \mathrm{CH}_{2}\right) \mathrm{P}\right)$, c: $2.14 \mathrm{ppm}\left(\mathrm{dc}, 24 \mathrm{H}, \mathrm{P}\left(\mathrm{CH}_{2} \mathrm{CH}_{3}\right)_{3}\right)$.

${ }^{13} \mathrm{C}$ NMR $\left(\mathrm{D}_{2} \mathrm{O}\right): \mathbf{A}: 4.68$ ppm $\left(\mathrm{d}, \mathrm{P}\left(\mathrm{CH}_{2} \mathrm{CH}_{3}\right)_{3}\right) ; \mathbf{B}: 10.91 \mathrm{ppm}\left(\mathrm{d}, \mathrm{P}\left(\mathrm{CH}_{2} \mathrm{CH}_{3}\right)_{3}\right)$; $\mathbf{C}$ :

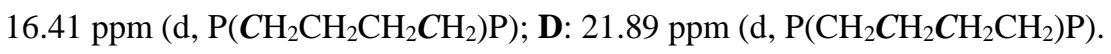

${ }^{31}$ P NMR (D $\left.2 \mathrm{O}\right): 38.74$ ppm (s, $\mathrm{H}$ decoup., $\left.\boldsymbol{P R}_{4}\right)$. 


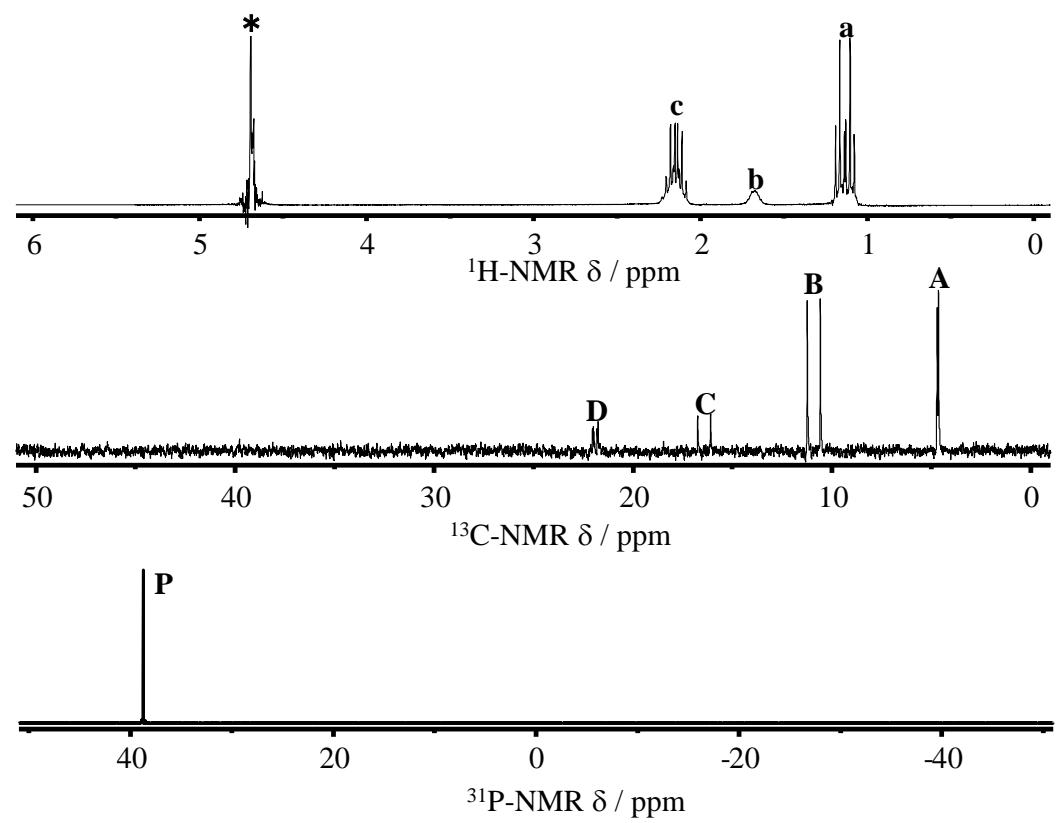

Figure 3.23. ${ }^{1} \mathrm{H}-\mathrm{NMR}$ (above), ${ }^{13} \mathrm{C}-\mathrm{NMR}$ (middle) and ${ }^{31} \mathrm{P}-\mathrm{NMR}$ (below) spectra of butane-1,4diylbis(triethylphosphonium) iodide in deuterated water solution $\left(\mathrm{D}_{2} \mathrm{O}\right)$. Asterisk in ${ }^{1} \mathrm{H}-\mathrm{NMR}$ marks proton resonance of water.

\subsubsection{Synthesis gel preparation}

The synthesis of zeolites was performed using the sol-gel methodology. ${ }^{[40]}$ The general methodology consists in the preparation of a suspension by mixing the different reactants that constitute the synthesis gel. ${ }^{[41]}$ For the synthesis of zeolites a silica source, water, a cation and a mineralizing agent are needed. The addition of OSDA's as cations instead of inorganic cations generally favours different phase selectivity. Also, heteroatoms are added when needed for obtaining aluminosilicates, germanosilicates, borosilicates or gallosilicates (Figure 3.24). 


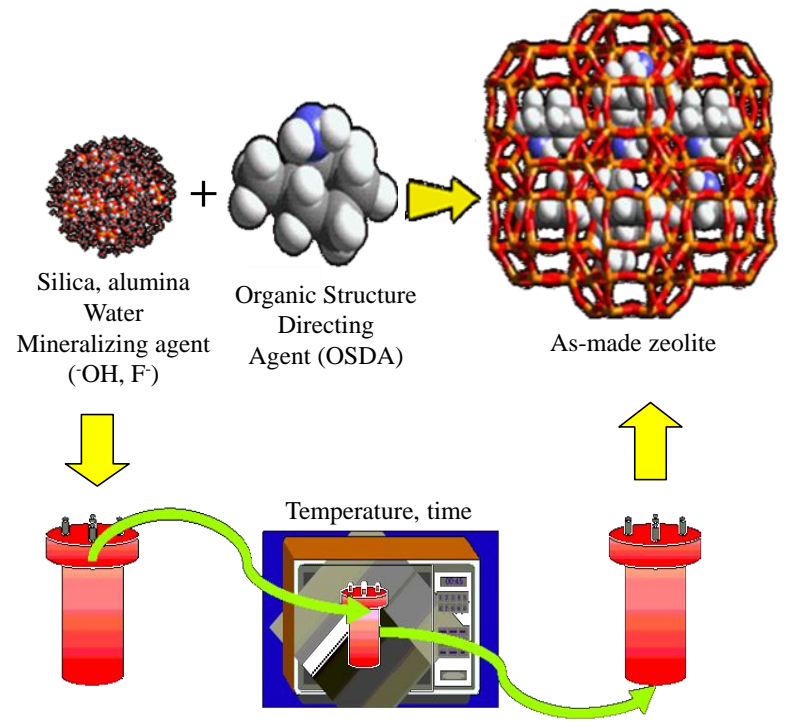

Figure 3.24. Schematic view of the synthesis of zeolite materials.

Typical silica sources comprise tetramethyl or tetraethyl orthosilicate, fumed silica, aqueous sodium silicate solution, colloidal silica solutions or hydrolysed zeolites. Typical aluminium sources comprise aluminium alkoxides, aluminium hydroxides, sodium aluminate or aluminium phosphate. Titanium sources comprise powdered titanium oxide or titanium alkoxides. Germanium is commonly added as powdered germanium oxide. Gallium is usually added as powdered gallium oxide. Boron is usually added as powdered boric acid. The mineralizing agent could be hydroxyl or fluoride anions. In the case of alkaline media, the addition of hydroxyl anions could be fulfilled by adding inorganic hydroxides or using the OSDA's in their hydroxide form. For the synthesis in fluoride media, the addition of fluoride anions could be done by adding hydrofluoric acid or ammonium fluoride.

Unless otherwise stated, the general preparation of syntheses gels in this thesis is performed in polypropylene beakers, mixing the OSDA hydroxide solution, tetraethyl orthosilicate as silica source and the heteroatom source following this order. The solution is then stirred for 6-8 hours. The stirring rate is dependent on the necessary amount of water to be evaporated, trying to keep the ageing time as constant as possible. For fluoride media syntheses, hydrofluoric acid (48 wt.\% in water) is added one hour prior to ageing completion. When the necessary amount of water is evaporated, the $\mathrm{pH}$ of the gel is measured, and then, the gel is poured inside $35 \mathrm{~mL}$ Teflon liners. The Teflon liners are then mounted into steel autoclaves and heated up in an oven under tumbling conditions at $60 \mathrm{rpm}$. The autoclaves are 
heated between $125^{\circ} \mathrm{C}$ and $175^{\circ} \mathrm{C}$ at the autogenous pressure of the synthesis gel for a time ranging from few hours to several months.

When the necessary time for the crystallization of the zeolite has passed, the $\mathrm{pH}$ of the resulting mixture is measured and the solid is recovered by filtration. The mother liquor is stored and the solid is suspended in $100 \mathrm{~mL}$ of boiling distilled water, re-filtered and washed with an additional 1-2 $\mathrm{L}$ of boiling distilled water. Next, the solid is dried overnight in an oven at $100^{\circ} \mathrm{C}$.

After use, the Teflon liners are cleaned with $20 \mathrm{wt} . \%$ hydrofluoric acid in water. The solution is left inside Teflon liners for 1 hour and then, thoroughly washed with soap and distilled water. By doing this, all inorganic residues are removed, which avoids the cross contamination between syntheses. Next, Milli-Q water is put inside the Teflon liners and mounted into steel autoclaves. The autoclave is then heated up for one hour to the same temperature at which it was used along the synthesis, and then it is retrieved. This step allows for a better cleaning of organic and inorganic compounds, as Teflon liners, as polymeric materials, swell when heated. When this happens, some components of the synthesis gel, both organic and inorganic, could be absorbed inside the polymer matrix, which could trigger a cross contamination for future syntheses.

\subsubsection{OSDA stability studies}

The stability studies were carried out using similar synthesis conditions using different OSDA's. Three different synthesis could be summarized as blank experiments, all-silica syntheses and borosilicate syntheses:

\section{- Synthesis procedure of blank experiments}

In a typical blank experiment, $30 \mathrm{mmol}$ of the corresponding OSDA hydroxide (details of the OSDA solutions are given in Table 3.9) were added over Milli-Q water, when needed, and followed by the addition of $1.25 \mathrm{~g}(30 \mathrm{mmol})$ of a $48 \mathrm{wt} . \%$ solution of $\mathrm{HF}$ in water (Aldrich), when needed, in order to obtain a blank synthesis gel with the following molar composition:

$$
0.4 \mathrm{OSDA}(\mathrm{OH}): 7 \mathrm{H}_{2} \mathrm{O}: x \mathrm{HF}
$$

With $x$ being 0 or 0.4 for syntheses in hydroxide or fluoride media, respectively. 
Synthesis and characterization of zeolitic materials using P-OSDA

Table 3.9. Summary of the amounts of OSDA hydroxide solutions used in blank experiments.

\begin{tabular}{ccc}
\hline OSDA & OSDA $\left._{\text {solution }}\right]$ & OSDA $_{\text {solution }} / \mathrm{g}(\mathrm{mmol})$ \\
\hline TEA (OSDA-1) & $35 \mathrm{wt} \%$ & $12.622(30)$ \\
TEP (OSDA-2) & $0.46 \mathrm{M}$ & $65.217(30)$ \\
\hline
\end{tabular}

The solution was transferred to Teflon lined stainless-steel autoclaves and heated at temperatures ranging from $135^{\circ} \mathrm{C}$ to $175^{\circ} \mathrm{C}$ at its autogenous pressure under tumbling conditions at $60 \mathrm{rpm}$ for a time ranging from 1 to 20 days. Then, the solution was filtered, and the mother liquor was recovered and weighted for further analyses.

\section{- Synthesis procedure of all-silica materials}

In a typical all-silica synthesis, $15.600 \mathrm{~g}(75 \mathrm{mmol})$ of tetraethylorthosilicate (TEOS, 99 wt.\%, Aldrich) were added over $30 \mathrm{mmol}$ of the corresponding OSDA hydroxide (details of the OSDA solutions are given in Table 3.10). Then, the solution was stirred until the complete hydrolysis of TEOS and the evaporation of the necessary amount of water and ethanol, followed by the addition of $1.25 \mathrm{~g}(30 \mathrm{mmol})$ of a $48 \mathrm{wt} . \%$ solution of HF in water (Aldrich), when needed, in order to obtain a synthesis gel with the following molar composition:

$$
1 \mathrm{SiO}_{2}: 0.4 \operatorname{OSDA}(\mathrm{OH})_{\mathrm{P}+\mathrm{N}}: 7 \mathrm{H}_{2} \mathrm{O}: x \mathrm{HF}
$$

With $x$ being 0 or 0.4 for syntheses in hydroxide or fluoride media, respectively.

Table 3.10. Summary of the amounts of OSDA hydroxide solutions used in all-silica syntheses.

\begin{tabular}{ccc}
\hline OSDA & {$\left[\right.$ OSDA $\left._{\text {solution }}\right]$} & OSDA $_{\text {solution }}$ g (mmol) \\
\hline TEA (OSDA-1) & $35 \mathrm{wt} . \%$ & $12.622(30)$ \\
TEP (OSDA-2) & $0.46 \mathrm{M}$ & $65.217(30)$ \\
MNP (OSDA-3) & $0.25 \mathrm{M}$ & $120.012(30)$ \\
MIP (OSDA-4) & $0.22 \mathrm{M}$ & $136.364(30)$ \\
IEN (OSDA-5) & $0.37 \mathrm{M}$ & $81.081(30)$ \\
P1-t-Bu (OSDA-6) & $97 \mathrm{wt} \%$ & $7.247(30)$ \\
\hline
\end{tabular}

The resulting gel was transferred to Teflon lined stainless-steel autoclaves and heated at temperatures, ranging from $135^{\circ} \mathrm{C}$ to $175^{\circ} \mathrm{C}$ for TEA and TEP OSDA's, and at $150^{\circ} \mathrm{C}$ for 
MNP, MIP, IEN and P1 OSDA's, at its autogenous pressure under tumbling conditions at 60 rpm for a time ranging from 1 to 20 days. Then, the mixture was filtered, the mother liquors were recovered and weighted for further analyses, and the solid was dried at $100^{\circ} \mathrm{C}$ overnight.

\section{- Synthesis procedure of borosilicate materials}

In a typical borisilicate synthesis, $14.851 \mathrm{~g}(71.4 \mathrm{mmol})$ of tetraethylorthosilicate (TEOS, 99 wt.\%, Aldrich) and $0.225 \mathrm{~g}(3.6 \mathrm{mmol})$ of $\mathrm{H}_{3} \mathrm{BO}_{3}(99 \mathrm{wt} . \%$, Aldrich) were added over $30 \mathrm{mmol}$ of the corresponding OSDA hydroxide (details of the OSDA solutions are given in Table 3.11). Then, the solution was stirred until the complete hydrolysis of TEOS and the evaporation of the necessary amount of water and ethanol, followed by the addition

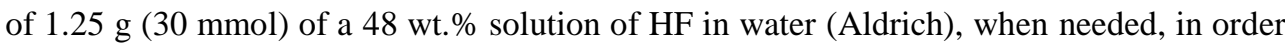
to obtain a synthesis gel with the following molar composition:

$$
0.952 \mathrm{SiO}_{2}: 0.024 \mathrm{~B}_{2} \mathrm{O}_{3}: 0.4 \operatorname{OSDA}(\mathrm{OH}): 7 \mathrm{H}_{2} \mathrm{O}: x \mathrm{HF} \quad(\mathrm{Si} / \mathrm{B}=20)
$$

With $x$ being 0 or 0.4 for syntheses in hydroxide or fluoride media, respectively.

Table 3.11. Summary of the amounts of OSDA hydroxide solutions used in borosilicate syntheses.

\begin{tabular}{ccc}
\hline OSDA & {$\left[\mathrm{OSDA}_{\text {solution }}\right]$} & OSDA $_{\text {solution }} / \mathrm{g}(\mathrm{mmol})$ \\
\hline MNP (OSDA-3) & $0.25 \mathrm{M}$ & $120.012(30)$ \\
MIP (OSDA-4) & $0.22 \mathrm{M}$ & $136.364(30)$ \\
IEN (OSDA-5) & $0.37 \mathrm{M}$ & $81.081(30)$ \\
P1-t-Bu (OSDA-6) & 97 wt.\% & $7.247(30)$ \\
\hline
\end{tabular}

The resulting gel was transferred to Teflon lined stainless-steel autoclaves and heated at $150^{\circ} \mathrm{C}$ at its autogenous pressure under tumbling conditions at $60 \mathrm{rpm}$ for a time ranging from 1 to 20 days. Then, the mixture was filtered, the mother liquor was recovered and weighted for further analyses and the solid was dried at $100^{\circ} \mathrm{C}$ overnight.

\subsubsection{Dual template synthesis of MFI (ZSM-5, TS-1) zeolite}

The dual template MFI zeolite was synthesized using tetraethylammonium (OSDA-1 or N-OSDA) and tetraethylphosphonium (OSDA-2 or P-OSDA). This zeolite was synthesized as all-silica and aluminosilicate materials. The detailed synthesis conditions for these materials are given next: 


\section{- Synthesis procedure of all-silica dual template MFI}

In a typical all-silica synthesis, $6.313 \mathrm{~g}(30 \mathrm{mmol})$ of tetraethylorthosilicate (TEOS, $99 \mathrm{wt} . \%$, Aldrich) were added over a solution containing a mix of the P-OSDA and N-OSDA. The specific amounts of P-OSDA and N-OSDA are given in Table 3.12. Then, the solution was stirred until the complete hydrolysis of TEOS and the evaporation of the necessary amount of water and ethanol, followed by the addition of $0.250 \mathrm{~g}(6 \mathrm{mmol})$ of a $48 \mathrm{wt} . \%$ solution of HF in water (Aldrich) in order to obtain a synthesis gel with the following molar composition:

$$
1 \mathrm{SiO}_{2}: 0.4 \mathrm{OSDA}(\mathrm{OH})_{\mathrm{P}+\mathrm{N}}: 10 \mathrm{H}_{2} \mathrm{O}: 0.4 \mathrm{HF}
$$

Table 3.12. Summary of the amounts of P-OSDA and N-OSDA hydroxide solutions used in the dual template syntheses of all-silica MFI materials.

\begin{tabular}{|c|c|c|}
\hline$[\mathrm{P} /(\mathrm{P}+\mathrm{N})]_{\mathrm{gel}}$ & $\mathrm{P}-\mathrm{OSDA}_{\text {solution }} / \mathrm{g}(\mathrm{mmol})$ & $\mathrm{N}-\mathrm{OSDA}_{\text {solution }} / \mathrm{g}(\mathrm{mmol})$ \\
\hline 0 & $0(0)$ & $2.524(6)$ \\
\hline 0.0625 & $0.815(0.375)$ & $2.367(5.625)$ \\
\hline 0.12 & $1.565(0.72)$ & $2.222(5.28)$ \\
\hline 0.25 & $3.261(1.5)$ & $1.893(4.5)$ \\
\hline 0.36 & $4.696(2.16)$ & $1.616(3.84)$ \\
\hline 0.5 & $6.522(3)$ & $1.262(3)$ \\
\hline 0.75 & $9.783(4.5)$ & $0.631(1.5)$ \\
\hline 1 & $13.043(6)$ & $0(0)$ \\
\hline
\end{tabular}

The resulting gel was transferred to Teflon lined stainless-steel autoclaves and heated at $175^{\circ} \mathrm{C}$ at its autogenous pressure under tumbling conditions at $60 \mathrm{rpm}$ for at least 1 day up to 8 days. The solid was recovered by filtration and washed with boiling distilled water. The resulting solid was dried at $100^{\circ} \mathrm{C}$ overnight to obtain the as-made dual template all-silica MFI zeolite.

\section{- Synthesis procedure of aluminosilicate dual template MFI}

In a typical aluminosilicate synthesis, $10.265 \mathrm{~g}(48.78 \mathrm{mmol})$ of tetraethylorthosilicate (TEOS, 99 wt.\%, Aldrich) and $0.096 \mathrm{~g}$ (1.22 mmol) of $\mathrm{Al}(\mathrm{OH})_{3}$ (99 wt.\%, Wako) were added over a solution containing a mix of the P-OSDA and N-OSDA. The specific amounts of P-OSDA and N-OSDA are given in Table 3.13. Then, the solution was stirred until the 
complete hydrolysis of TEOS and the evaporation of the necessary amount of water and ethanol, followed by the addition of $0.417 \mathrm{~g}(10 \mathrm{mmol})$ of a $48 \mathrm{wt} . \%$ solution of HF in water (Aldrich) in order to obtain a synthesis gel with the following molar composition:

$$
0.976 \mathrm{SiO}_{2}: 0.012 \mathrm{Al}_{2} \mathrm{O}_{3}: 0.4 \operatorname{OSDA}(\mathrm{OH})_{\mathrm{P}+\mathrm{N}}: 15 \mathrm{H}_{2} \mathrm{O}: 0.4 \mathrm{HF} \quad(\mathrm{Si} / \mathrm{Al}=40)
$$

Table 3.13. Summary of the amounts of P-OSDA and N-OSDA hydroxide solutions used in the dual template syntheses of aluminosilicate MFI materials.

\begin{tabular}{ccc}
\hline$[\mathrm{P} /(\mathrm{P}+\mathrm{N})]_{\text {gel }}$ & ${\mathrm{P}-O S D A_{\text {solution }} / \mathrm{g}(\mathrm{mmol})}$ & N-OSDA $_{\text {solution }} / \mathrm{g}(\mathrm{mmol})$ \\
\hline 0 & $0(0)$ & $4.207(10)$ \\
0.0625 & $1.359(0.625)$ & $3.944(9.375)$ \\
0.125 & $2.609(1.2)$ & $3.702(8.8)$ \\
0.25 & $5.435(2.5)$ & $3.155(7.5)$ \\
1 & $21.739(10)$ & $0(0)$ \\
\hline
\end{tabular}

The resulting gel was transferred to Teflon lined stainless-steel autoclaves and heated at $175^{\circ} \mathrm{C}$ at its autogenous pressure under tumbling conditions at $60 \mathrm{rpm}$ for at least 5 days and up to 18 days. The solid was recovered by filtration and washed with boiling distilled water. The resulting solid was dried at $100^{\circ} \mathrm{C}$ overnight to obtain the as-made dual template aluminosilicate MFI zeolites.

\subsubsection{Dual template synthesis of RTH (RUB-13) zeolite}

The dual template RTH zeolite was synthesized using mixes of methyl-tri-isopropylphosphonium (OSDA-4 or P-OSDA) and di-isopropyl-diethylammonium (OSDA-5 or N-OSDA) as OSDA's. This zeolite was only synthesized as aluminosilicate material, with different silicon to aluminium ratios were used for each mix of OSDA's. The detailed synthesis conditions for this material are given next:

In a typical aluminosilicate synthesis, the needed amounts of tetraethylorthosilicate (TEOS, 99 wt.\%, Aldrich) and $\mathrm{Al}(\mathrm{OH})_{3}(99$ wt.\%, Wako) were added over a solution containing a mix of the P-OSDA and N-OSDA. The specific amounts of TEOS, $\mathrm{Al}(\mathrm{OH})_{3}$, P-OSDA and N-OSDA are given in Table 3.14. Then, the solution was stirred until the complete hydrolysis of TEOS and the evaporation of the necessary amount of water and ethanol, followed by the addition of $0.300 \mathrm{~g}(20 \mathrm{mmol})$ of a $48 \mathrm{wt} . \%$ solution of HF in water (Aldrich) in order to obtain a synthesis gel with the following molar compositions: 
Synthesis and characterization of zeolitic materials using P-OSDA

$$
\begin{array}{ll}
0.968 \mathrm{SiO}_{2}: 0.016 \mathrm{Al}_{2} \mathrm{O}_{3}: 0.4 \operatorname{OSDA}(\mathrm{OH})_{\mathrm{P}+\mathrm{N}}: 15 \mathrm{H}_{2} \mathrm{O}: 0.4 \mathrm{HF} & (\mathrm{Si} / \mathrm{Al}=30) \\
0.972 \mathrm{SiO}_{2}: 0.014 \mathrm{Al}_{2} \mathrm{O}_{3}: 0.4 \operatorname{OSDA}(\mathrm{OH})_{\mathrm{P}+\mathrm{N}}: 15 \mathrm{H}_{2} \mathrm{O}: 0.4 \mathrm{HF} & (\mathrm{Si} / \mathrm{Al}=35) \\
0.952 \mathrm{SiO}_{2}: 0.024 \mathrm{Al}_{2} \mathrm{O}_{3}: 0.4 \operatorname{OSDA}(\mathrm{OH})_{\mathrm{P}+\mathrm{N}}: 15 \mathrm{H}_{2} \mathrm{O}: 0.4 \mathrm{HF} & (\mathrm{Si} / \mathrm{Al}=20)
\end{array}
$$

Table 3.14. Summary of the amount of TEOS, $\mathrm{Al}(\mathrm{OH})_{3}, \mathrm{P}-\mathrm{OSDA}$ and N-OSDA hydroxide solutions used in the dual template syntheses of aluminosilicate RTH materials.

\begin{tabular}{cccccc}
\hline$[\mathrm{P} /(\mathrm{P}+\mathrm{N})]_{\text {gel }}$ & $\begin{array}{c}\mathrm{P}-\mathrm{OSDA} \text { solution } \\
/ \mathrm{g}(\mathrm{mmol})\end{array}$ & $\begin{array}{c}\mathrm{N}-\mathrm{OSDA} \text { solution } \\
/ \mathrm{g}(\mathrm{mmol})\end{array}$ & $\begin{array}{c}\mathrm{m} \mathrm{Al}(\mathrm{OH})_{3} \\
/ \mathrm{g}(\mathrm{mmol})\end{array}$ & $\begin{array}{c}\mathrm{m} \mathrm{TEOS} \\
/ \mathrm{g}(\mathrm{mmol})\end{array}$ & $\mathrm{Si} / \mathrm{Al}$ \\
\hline 0 & $0(0)$ & $54.054(20)$ & $0.254(3.23)$ & $20.365(96.77)$ & 30 \\
0.125 & $10.909(2.4)$ & $47.567(17.6)$ & $0.254(3.23)$ & $20.365(96.77)$ & 30 \\
0.25 & $22.727(5)$ & $40.540(15)$ & $0.173(2.78)$ & $20.459(97.22)$ & 35 \\
0.5 & $45.454(10)$ & $27.027(10)$ & $0.173(2.78)$ & $20.459(97.22)$ & 35 \\
1 & $90.909(20)$ & $0(0)$ & $0.297(4.76)$ & $20.041(95.24)$ & 20 \\
\hline
\end{tabular}

The resulting gel was transferred to Teflon lined stainless-steel autoclaves and heated at $175^{\circ} \mathrm{C}$ at its autogenous pressure under tumbling conditions at $60 \mathrm{rpm}$ for at least 5 days and up to 18 days. The solid was recovered by filtration and washed with boiling distilled water. The resulting solid was dried at $100^{\circ} \mathrm{C}$ overnight to obtain the as-made dual template aluminosilicate RTH zeolite.

\subsubsection{Synthesis of IWV (ITQ-27) zeolite}

The IWV zeolite was synthesized using the OSDA-7. This zeolite was obtained as all-silica, borosilicate, aluminosilicate and germanosilicate materials. The detailed synthesis conditions for some of these materials are given next:

\section{- Synthesis procedure of all-silica IWV zeolite}

In a typical all-silica synthesis, $10.704 \mathrm{~g}(50 \mathrm{mmol})$ of tetraethylorthosilicate (TEOS, 99 wt.\%, Aldrich) were added over $39.473 \mathrm{~g}$ of a $0.380 \mathrm{M}(15 \mathrm{mmol})$ solution of the OSDA-7. Then, the mixture was stirred until the complete hydrolysis of TEOS and the evaporation of the necessary amount of water and ethanol, followed by the addition of 0.150 $\mathrm{g}$ of ITQ-27 seeds, stirring for one hour. Then, $0.625 \mathrm{~g}(15 \mathrm{mmol})$ of a $48 \mathrm{wt} \%$ solution of $\mathrm{HF}$ in water (Aldrich) were added in order to obtain a synthesis gel with the following molar composition: 


$$
1.0 \mathrm{SiO}_{2}: 0.3 \mathrm{OSDA}(\mathrm{OH}): 3.5 \mathrm{H}_{2} \mathrm{O}: 0.3 \mathrm{HF}
$$

The resulting gel was transferred to Teflon lined stainless-steel autoclaves and heated at $175^{\circ} \mathrm{C}$ at its autogenous pressure under stirring $(60 \mathrm{rpm})$ for 10 days. The solid was recovered by filtration and washed with boiling distilled water. The resulting solid was dried at $100^{\circ} \mathrm{C}$ overnight to obtain the as-made all-silica IWV zeolite.

\section{- Synthesis procedure of borosilicate IWV zeolite}

In a typical borosilicate synthesis, $10.187 \mathrm{~g}(48.40 \mathrm{mmol})$ of tetraethylorthosilicate (TEOS, 99 wt.\%, Aldrich) and $0.102 \mathrm{~g}(1.62 \mathrm{mmol})$ of $\mathrm{H}_{3} \mathrm{BO}_{3}(99 \mathrm{wt} . \%$, Aldrich) were added over $39.473 \mathrm{~g}$ of a $0.380 \mathrm{M}(15 \mathrm{mmol})$ solution of the OSDA-7. Then, the mixture was stirred until the complete hydrolysis of TEOS and the evaporation of the necessary amount of water and ethanol, followed by the addition of $0.625 \mathrm{~g}(15 \mathrm{mmol})$ of a $48 \mathrm{wt} . \%$ solution of HF in water (Aldrich) in order to obtain a synthesis gel with the following molar composition:

$$
0.968 \mathrm{SiO}_{2}: 0.016 \mathrm{~B}_{2} \mathrm{O}_{3}: 0.3 \mathrm{OSDA}(\mathrm{OH}): 4.5 \mathrm{H}_{2} \mathrm{O}: 0.3 \mathrm{HF} \quad(\mathrm{Si} / \mathrm{B}=30)
$$

The resulting gel was transferred to Teflon lined stainless-steel autoclaves and heated at $175^{\circ} \mathrm{C}$ at its autogenous pressure under tumbling conditions at $60 \mathrm{rpm}$ for 30 days. The solid was recovered by filtration and washed with boiling distilled water. The resulting solid was dried at $100^{\circ} \mathrm{C}$ overnight to obtain the as-made borosilicate IWV zeolite.

\section{- Synthesis procedure of aluminosilicate IWV zeolite}

In a typical aluminosilicate synthesis, $10.177 \mathrm{~g}(48.35 \mathrm{mmol})$ of tetraethylorthosilicate (TEOS, 99 wt.\%, Aldrich) and, either $0.397 \mathrm{~g}(1.61 \mathrm{mmol})$ of $\mathrm{Al}(\text { secbutO) })_{3}(97 \mathrm{wt} . \%$, Aldrich), or $0.127 \mathrm{~g}(1.61 \mathrm{mmol})$ of aluminium hydroxide ( $99.5 \mathrm{wt} \%$, Wako) were added over $39.473 \mathrm{~g}$ of a $0.380 \mathrm{M}(15 \mathrm{mmol})$ solution of the OSDA-7. Then, the mixture was stirred until the complete hydrolysis of TEOS and the evaporation of the necessary amount of water and ethanol, followed by the addition of $0.625 \mathrm{~g}(15 \mathrm{mmol})$ of a $48 \mathrm{wt} . \%$ solution of HF in water (Aldrich) in order to obtain a synthesis gel with the following molar composition:

$$
0.968 \mathrm{SiO}_{2}: 0.016 \mathrm{Al}_{2} \mathrm{O}_{3}: 0.3 \operatorname{OSDA}(\mathrm{OH}): 4.5 \mathrm{H}_{2} \mathrm{O}: 0.3 \mathrm{HF} \quad(\mathrm{Si} / \mathrm{Al}=30)
$$

The resulting gel was transferred to Teflon lined stainless-steel autoclaves and heated at $175^{\circ} \mathrm{C}$ at its autogenous pressure under tumbling conditions at $60 \mathrm{rpm}$ for 20 days. The solid was recovered by filtration and washed with boiling distilled water. The resulting solid was dried at $100^{\circ} \mathrm{C}$ overnight to obtain the as-made aluminosilicate IWV zeolite. 


\section{- Synthesis procedure of germanosilicate IWV zeolite}

In a typical germanosilicate synthesis, $8.784 \mathrm{~g}(41.72 \mathrm{mmol})$ of tetraethylorthosilicate (TEOS, 99 wt. \%, Aldrich) and $0.878 \mathrm{~g}(8.5 \mathrm{mmol})$ of $\mathrm{GeO}_{2}(99.5 \mathrm{wt} . \%$ Aldrich) were added over $39.473 \mathrm{~g}$ of a $0.380 \mathrm{M}(15 \mathrm{mmol})$ solution of the OSDA-7. Then, the mixture was stirred until the complete hydrolysis of TEOS and the evaporation of the necessary amount of water and ethanol, followed by the addition of $0.625 \mathrm{~g}(15 \mathrm{mmol})$ of a $48 \mathrm{wt} . \%$ solution of HF in water (Aldrich) in order to obtain a synthesis gel with the following molar composition:

$$
0.834 \mathrm{SiO}_{2}: 0.167 \mathrm{GeO}_{2}: 0.3 \mathrm{OSDA}(\mathrm{OH}): 4.5 \mathrm{H}_{2} \mathrm{O}: 0.3 \mathrm{HF} \quad(\mathrm{Si} / \mathrm{Ge}=5)
$$

The resulting gel was transferred to Teflon lined stainless-steel autoclaves and heated at $175^{\circ} \mathrm{C}$ at its autogenous pressure under tumbling conditions at $60 \mathrm{rpm}$ for 5 days. The solid was recovered by filtration and washed with boiling distilled water. The resulting solid was dried at $100^{\circ} \mathrm{C}$ overnight to obtain the as-made germanosilicate IWV zeolite.

\subsubsection{Synthesis of DON (UTD-1) zeolite}

The DON zeolite was synthesized using the OSDA-7. This zeolite was obtained as all-silica, borosilicate and aluminosilicate materials. The detailed synthesis conditions for some of these materials are given next:

\section{- Synthesis procedure of all-silica DON zeolite}

In a typical all-silica synthesis, $10.704 \mathrm{~g}(50 \mathrm{mmol})$ of tetraethylorthosilicate (TEOS, 99 wt.\%, Aldrich) were added over $39.473 \mathrm{~g}$ of a $0.380 \mathrm{M}(15 \mathrm{mmol})$ solution of the OSDA-7. Then, the mixture was stirred until the complete hydrolysis of TEOS and the evaporation of the necessary amount of water and ethanol in order to obtain a synthesis gel with the following molar composition:

$$
1.0 \mathrm{SiO}_{2}: 0.3 \operatorname{OSDA}(\mathrm{OH}): 15 \mathrm{H}_{2} \mathrm{O}
$$

The resulting gel was transferred to Teflon lined stainless-steel autoclaves and heated at $175^{\circ} \mathrm{C}$ at its autogenous pressure under tumbling conditions at $60 \mathrm{rpm}$ for 10 days. The solid was recovered by filtration and washed with boiling distilled water. The resulting solid was dried at $100^{\circ} \mathrm{C}$ overnight to obtain the as-made all-silica DON zeolite. 
Chapter 3: Experimental section

\section{- Synthesis procedure of borosilicate DON zeolite}

In a typical borosilicate synthesis, $10.187 \mathrm{~g}(48.40 \mathrm{mmol})$ of tetraethylorthosilicate (TEOS, 99 wt.\%, Aldrich) and $0.102 \mathrm{~g}(1.62 \mathrm{mmol})$ of $\mathrm{H}_{3} \mathrm{BO}_{3}$ (99 wt.\% Aldrich) were added over $39.473 \mathrm{~g}$ of a $0.380 \mathrm{M}(15 \mathrm{mmol})$ solution of the OSDA-7. Then, the mixture was stirred until the complete hydrolysis of TEOS and the evaporation of the necessary amount of water and ethanol in order to obtain a synthesis gel with the following molar composition:

$$
0.968 \mathrm{SiO}_{2}: 0.016 \mathrm{~B}_{2} \mathrm{O}_{3}: 0.3 \mathrm{OSDA}(\mathrm{OH}): 15 \mathrm{H}_{2} \mathrm{O} \quad(\mathrm{Si} / \mathrm{B}=30)
$$

The resulting gel was transferred to Teflon lined stainless-steel autoclaves and heated at $175^{\circ} \mathrm{C}$ at its autogenous pressure under tumbling conditions at $60 \mathrm{rpm}$ for 30 days. The solid was recovered by filtration and washed with boiling distilled water. The resulting solid was dried at $100^{\circ} \mathrm{C}$ overnight to obtain the as-made borosilicate DON zeolite.

\section{- Synthesis procedure of aluminosilicate DON zeolite}

In a typical aluminosilicate synthesis $(\mathrm{Si} / \mathrm{Al}=30), 10.177 \mathrm{~g}(48.35 \mathrm{mmol})$ of tetraethylorthosilicate (TEOS, $99 \mathrm{wt} \%$, Aldrich) and, either $0.397 \mathrm{~g}(1.61 \mathrm{mmol})$ of $\mathrm{Al}(\text { secbutO })_{3}(97 \%$, Aldrich), or $0.127 \mathrm{~g}(1.61 \mathrm{mmol})$ of aluminium hydroxide $(99.5 \mathrm{wt} . \%$, Wako) were added over $39.473 \mathrm{~g}$ of a $0.380 \mathrm{M}(15 \mathrm{mmol})$ solution of the OSDA-7. Then, the mixture was stirred until the complete hydrolysis of TEOS and the evaporation of the necessary amount of water and ethanol in order to obtain a synthesis gel with the following molar composition:

$$
0.968 \mathrm{SiO}_{2}: 0.016 \mathrm{Al}_{2} \mathrm{O}_{3}: 0.3 \operatorname{OSDA}(\mathrm{OH}): 15 \mathrm{H}_{2} \mathrm{O} \quad(\mathrm{Si} / \mathrm{Al}=30)
$$

The resulting gel was transferred to Teflon lined stainless-steel autoclaves and heated at $175^{\circ} \mathrm{C}$ at its autogenous pressure under tumbling conditions at $60 \mathrm{rpm}$ for 20 days. The solid was recovered by filtration and washed with boiling distilled water. The resulting solid was dried at $100^{\circ} \mathrm{C}$ overnight to obtain the as-made aluminosilicate DON zeolite.

\subsubsection{Synthesis of ITQ-58 zeolite}

The ITQ-58 was synthesized using three different OSDA's, the OSDA-8 (PN-PN OSDA), the OSDA-9 (PC-PC OSDA) and the OSDA-10 (PN-PC OSDA. This zeolite has been obtained as borosilicate and as aluminium and borosilicate. In this thesis, only the borosilicate material obtained with the different OSDA's will be described, although the 
aluminium and borosilicate materials were previously described. ${ }^{[42]}$ The detailed synthesis conditions for this material are given next:

\section{- Synthesis procedure of PN-PN ITQ-58}

In a typical synthesis, $4.919 \mathrm{~g}(23.6 \mathrm{mmol})$ of tetraethylorthosilicate (TEOS, $99 \mathrm{wt}$. $\%$, Aldrich) and $0.293 \mathrm{~g}(4.7 \mathrm{mmol})$ of $\mathrm{H}_{3} \mathrm{BO}_{3}(99 \mathrm{wt} \%$, Aldrich) were added over $22.531 \mathrm{~g}$ of a $0.25 \mathrm{M}(5.6 \mathrm{mmol})$ solution of the OSDA-8 (PN-PN). Then, the mixture was stirred until the complete hydrolysis of TEOS and the evaporation of the necessary amount of water and ethanol to obtain a synthesis gel with the following molar composition:

$$
0.834 \mathrm{SiO}_{2}: 0.083 \mathrm{~B}_{2} \mathrm{O}_{3}: 0.2 \operatorname{OSDA}(\mathrm{OH})_{2}: 2.0 \mathrm{H}_{2} \mathrm{O} \quad(\mathrm{Si} / \mathrm{B}=5)
$$

The resulting gel was transferred to Teflon lined stainless-steel autoclaves and heated at $150^{\circ} \mathrm{C}$ at its autogenous pressure under tumbling conditions at $60 \mathrm{rpm}$ for 7 days. The solid was recovered by filtration and washed with boiling distilled water. The resulting solid was dried at $100^{\circ} \mathrm{C}$ overnight to obtain the as-made zeolite PN-PN ITQ-58.

\section{- Synthesis procedure of PC-PC ITQ-58}

The purest zeolite ITQ-58 was obtained with a small amount of STF. In order to get this material, $7.174 \mathrm{~g}(29.0 \mathrm{mmol})$ of tetraethylorthosilicate (TEOS, $99 \mathrm{wt} . \%$, Aldrich) and $0.213 \mathrm{~g}$ (3.41 mmol) of $\mathrm{H}_{3} \mathrm{BO}_{3}$ ( $99 \mathrm{wt} . \%$, Aldrich) were added over $25.000 \mathrm{~g}$ of a $0.3 \mathrm{M}$ (7.5 mmol) solution of the OSDA-9 (PC-PC). Then, the mixture was stirred until the complete hydrolysis of TEOS and the evaporation of the necessary amount of water and ethanol, followed by the addition of $0.625 \mathrm{~g}(15 \mathrm{mmol})$ of a $48 \mathrm{wt} . \%$ solution of $\mathrm{HF}$ in water (Aldrich), in order to obtain a synthesis gel with the following molar composition:

$$
0.91 \mathrm{SiO}_{2}: 0.045 \mathrm{~B}_{2} \mathrm{O}_{3}: 0.2 \operatorname{OSDA}(\mathrm{OH})_{2}: 10 \mathrm{H}_{2} \mathrm{O}: 0.4 \mathrm{HF} \quad(\mathrm{Si} / \mathrm{B}=10)
$$

The resulting gel was transferred to Teflon lined stainless-steel autoclaves and heated at $150^{\circ} \mathrm{C}$ at its autogenous pressure under tumbling conditions at $60 \mathrm{rpm}$ for 7 days. The solid was recovered by filtration and washed with boiling distilled water. The resulting solid was dried at $100^{\circ} \mathrm{C}$ overnight to obtain the as-made zeolite PC-PC ITQ-58.

\section{- Synthesis procedure of PN-PC ITQ-58}

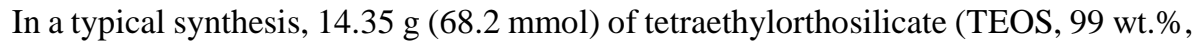
Aldrich) and $0.43 \mathrm{~g}(6.8 \mathrm{mmol})$ of $\mathrm{H}_{3} \mathrm{BO}_{3}(99 \mathrm{wt} . \%$, Aldrich) were added over $75.00 \mathrm{~g}$ of a $0.2 \mathrm{M}(15 \mathrm{mmol})$ solution of the OSDA-10 (PN-PC). Then, the mixture was stirred until the 
complete hydrolysis of TEOS and the evaporation of the necessary amount of water and ethanol to obtain a synthesis gel with the following molar composition:

$$
0.91 \mathrm{SiO}_{2}: 0.045 \mathrm{~B}_{2} \mathrm{O}_{3}: 0.2 \operatorname{OSDA}(\mathrm{OH})_{2}: 7.5 \mathrm{H}_{2} \mathrm{O} \quad(\mathrm{Si} / \mathrm{B}=10)
$$

The resulting gel was transferred to Teflon lined stainless-steel autoclaves and heated at $150^{\circ} \mathrm{C}$ at its autogenous pressure under tumbling conditions at $60 \mathrm{rpm}$ for 12 days. The solid was recovered by filtration and washed with boiling distilled water. The resulting solid was dried at $100^{\circ} \mathrm{C}$ overnight to obtain the as-made zeolite PN-PC ITQ-58.

\subsubsection{Synthesis of ITQ-66 zeolite}

The ITQ-66 was only synthesized using the OSDA-11. This zeolite was obtained as borosilicate and gallosillicate materials. The detailed synthesis conditions for this material are given next:

\section{- Synthesis procedure of gallium ITQ-66}

In a typical gallosilicate synthesis, $6.189 \mathrm{~g}(29.412 \mathrm{mmol})$ of tetraethylorthosilicate (TEOS, 99 wt.\%, Aldrich) and $0.151 \mathrm{~g}(0.588 \mathrm{mmol})$ of $\mathrm{Ga}\left(\mathrm{NO}_{3}\right)_{3}(99.5 \mathrm{wt} . \%$, Aldrich) were added over $20.548 \mathrm{~g}$ of a $0.292 \mathrm{M}(6 \mathrm{mmol})$ solution of the OSDA-11. Then, the mixture was stirred until the complete hydrolysis of TEOS and the evaporation of the necessary amount of water and ethanol, followed by the addition of $0.500 \mathrm{~g}(12 \mathrm{mmol})$ of a $48 \mathrm{wt} . \%$ solution of HF in water (Aldrich) in order to obtain a synthesis gel with the following molar composition:

$$
0.980 \mathrm{SiO}_{2}: 0.010 \mathrm{Ga}_{2} \mathrm{O}_{3}: 0.2 \operatorname{OSDA}(\mathrm{OH})_{2}: 10 \mathrm{H}_{2} \mathrm{O}: 0.4 \mathrm{HF} \quad(\mathrm{Si} / \mathrm{Ga}=49)
$$

The resulting gel was transferred to Teflon lined stainless-steel autoclaves and heated at $175^{\circ} \mathrm{C}$ at its autogenous pressure under tumbling conditions at $60 \mathrm{rpm}$ for at least 14 days up to 46 days. The solid was recovered by filtration and washed with boiling distilled water. The resulting solid was dried at $100^{\circ} \mathrm{C}$ overnight to obtain the as-made gallosilicate ITQ-66 zeolite.

\section{- Synthesis procedure of boron ITQ-66}

In a typical borosilicate synthesis, $10.021 \mathrm{~g}(47.62 \mathrm{mmol})$ of tetraethylorthosilicate (TEOS, $99 \mathrm{wt} \%$, Aldrich) and $0.149 \mathrm{~g}(2.38 \mathrm{mmol})$ of $\mathrm{H}_{3} \mathrm{BO}_{3}$ ( $99 \mathrm{wt} . \%$, Aldrich) were added over $34.247 \mathrm{~g}$ of a $0.292 \mathrm{M}(10 \mathrm{mmol})$ solution of the OSDA-11 Then, the mixture was stirred 
until the complete hydrolysis of TEOS and the evaporation of the necessary amount of water and ethanol, followed by the addition of $0.833 \mathrm{~g}(20 \mathrm{mmol})$ of a $48 \mathrm{wt} . \%$ solution of $\mathrm{HF}$ in water (Aldrich) in order to obtain a synthesis gel with the following molar composition:

$$
0.952 \mathrm{SiO}_{2}: 0.024 \mathrm{~B}_{2} \mathrm{O}_{3}: 0.2 \operatorname{OSDA}(\mathrm{OH})_{2}: 10 \mathrm{H}_{2} \mathrm{O}: 0.4 \mathrm{HF} \quad(\mathrm{Si} / \mathrm{B}=20)
$$

The resulting gel was transferred to Teflon lined stainless-steel autoclaves and heated at $175^{\circ} \mathrm{C}$ at its autogenous pressure under tumbling conditions at $60 \mathrm{rpm}$ for at least 5 days and up to 18 days. The solid was recovered by filtration and washed with boiling distilled water. The resulting solid was dried at $100^{\circ} \mathrm{C}$ overnight to obtain the as-made borosilicate ITQ-66 zeolite.

\subsubsection{Removal of OSDA's}

After the synthesis of the zeolitic materials, the OSDA is occluded inside the material. In order to free the porous network of the zeolite, the OSDA must be removed or decomposed.

The most commonly used method consist in the decomposition of the organic moiety by calcination of the material in air. Classical alkylammonium OSDA's yields volatile compounds as $\mathrm{CO}_{2}, \mathrm{H}_{2} \mathrm{O}$ and $\mathrm{NO}_{\mathrm{x}}$ upon calcination. These small molecules easily diffuse through the porous network of the zeolite, and are thus removed from the material (Figure 3.25). 


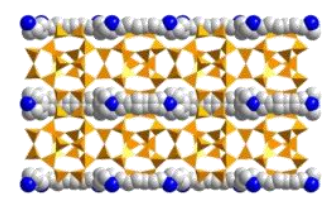

As-made zeolite

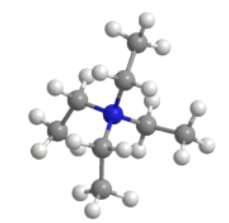

Tetraalkylammonium OSDA

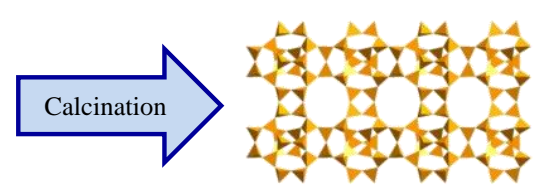

Calcined zeolite

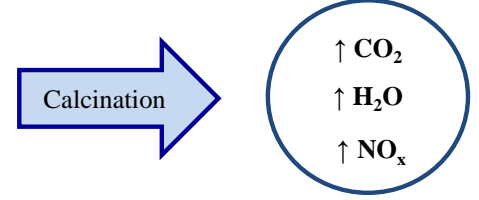

$\uparrow \mathbf{N O}_{\mathbf{x}}$

Figure 3.25. Schematic view of the calcination of as-made zeolites synthesized using alkylammonium cations as OSDA's (tetraethylammonium cation shown here).

However, the calcination of zeolites synthesized with P-OSDA's yield $\mathrm{CO}_{2}, \mathrm{H}_{2} \mathrm{O}$ and $\mathrm{PO}_{\mathrm{y}}$ upon calcination. This phosphorous oxide-like species are mostly non-volatile and do not easily diffuse though the porous network of the zeolite, remaining most of them entrapped inside the material (Figure 3.26). The presence of these phosphorous species affects the textural properties of the final material, as well as the acid properties of aluminiumcontaining zeolites.

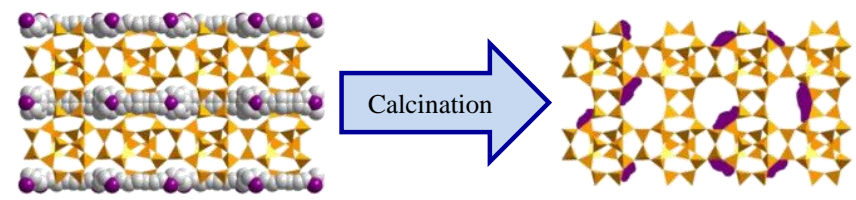

As-made zeolite

Calcined zeolite

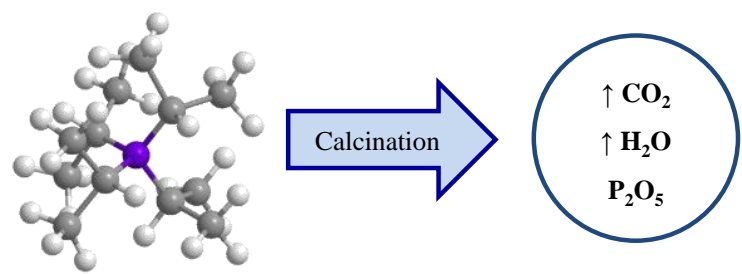

Tetraalkylphosphonium

$$
\text { OSDA }
$$

Figure 3.26. Schematic view of the calcination of as-made zeolites synthesized using phosphorous cations as OSDA's (methyl-tri-isopropyl-phosphonium cation shown here). 
Alternatively, the as-made zeolites could be treated at high temperature under a 60/40 vol.\% flow of hydrogen/nitrogen stream to reduce the occluded OSDA avoiding $\mathrm{PO}_{\mathrm{y}}$ formation. By doing this, most of the phosphorous organic species located inside the zeolite could be removed as $\mathrm{PH}_{3}$ and small $\mathrm{PR}_{3}$ species.

\subsubsection{Calcination under air}

The as-made materials were placed inside an alumina crucible and heated inside an oven until reaching the necessary temperature to fully decompose the OSDA. The heating ramp consisted in multiple steps, whose temperatures were defined by the TG profile of the specific material, while heating rates were kept the same for all materials (Figure 3.27).

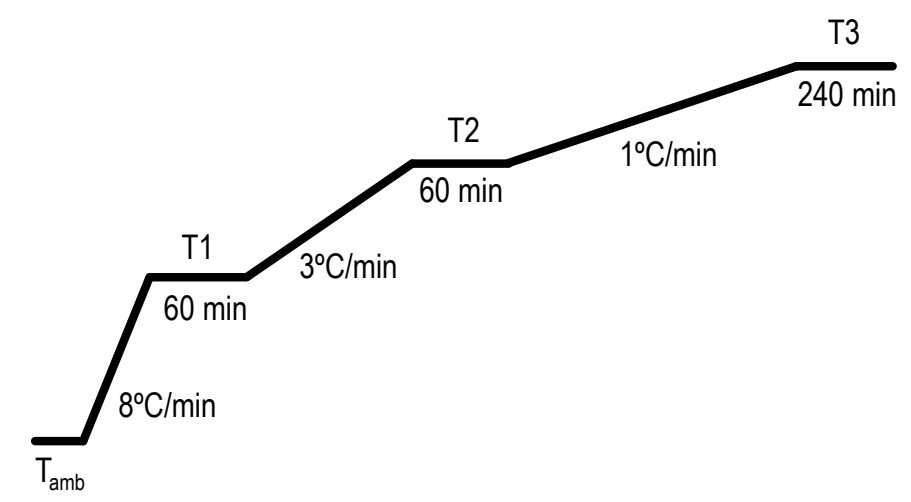

Figure 3.27. Heating ramp used for the calcination of zeolites in air.

$\mathrm{T} 1$ is the temperature at which water or other species are desorbed and before the decomposition of the OSDA starts, usually $300^{\circ} \mathrm{C}$. T2 corresponds to the temperature at which the OSDA starts to decompose, and could vary between $450^{\circ} \mathrm{C}$ and $650^{\circ} \mathrm{C}$ depending on the specific zeolites and OSDA's. T3 corresponds to the temperature at which the OSDA is fully decomposed, usually $700^{\circ} \mathrm{C}$.

\subsubsection{High temperature treatment under $\mathrm{H}_{2}$ stream}

Firstly, the as-made materials are sieved between 0.1 and $0.8 \mathrm{~mm}$. The sieving of the materials prevents the compaction of the material, which in turn avoids the creation of preferred gas pathways through the zeolite bed during thermal treatment. Next, the material is placed inside a quartz tubular reactor, which is put inside a tubular oven. The $\mathrm{N}_{2}$ and $\mathrm{H}_{2}$ inlets are then connected and the system is purged with a $100 \mathrm{~mL} / \mathrm{min}$ flow of $\mathrm{N}_{2}$ for 5 
minutes. After purge, a $120 \mathrm{~mL} / \mathrm{min}$ flow of $60 / 40 \mathrm{v} / \mathrm{v} . \% \mathrm{H}_{2} / \mathrm{N}_{2}$ stream is set and the thermal treatment begins. Like in calcination treatment, the heating ramp consists in multiple steps, whose temperatures are guided by the TG profile of the specific material, while heating rates are kept the same for all materials (Figure 3.28). TG profiles are used just as a reference, as temperature programmed reduction (TPR) analyses were unavailable because of released hazardous phosphines during TPR analysis.

As previously stated, the hydrogenation of the phosphorous OSDA's allows for the removal of the phosphorus as $\mathrm{PH}_{3}$ and small $\mathrm{PR}_{3}$ species. These species are trapped by bubbling the outlet stream through an aqueous solution of $1 \mathrm{M}$ copper (II) nitrate. The colour of the solution is a clear indicative of the removal of the phosphorus, as prior to the thermal treatment the solution presents an intense blue colour. After some phosphine pass through the solution, the solution colour turns into black. After stopping the gas stream, a black solid precipitates, while the solution remains blue, although less intense, which is indicative that phosphine is reacting and consuming the $\mathrm{Cu}$ from the solution. After the thermal treatment, the suspension is filtered and the copper nitrate solution is reused, while the black precipitate is conveniently disposed.

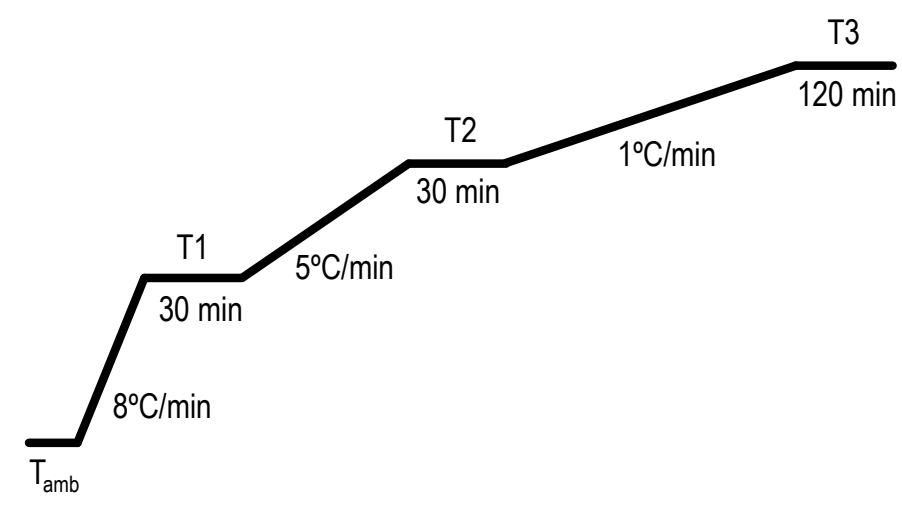

Figure 3.28. Heating ramp used for the thermal treatment of zeolites under $\mathrm{H}_{2}$ stream.

The heating ramp scheme for the thermal treatment under $\mathrm{H}_{2}$ resembles to the calcination ramp scheme, but temperatures are higher in all cases. $\mathrm{T} 1$ is the temperature at which water or other species are desorbed and before the decomposition of the OSDA starts, usually $350^{\circ} \mathrm{C}$. T2 corresponds to the temperature at which the OSDA starts to decompose, which is tracked as the temperature at which the trap solution changes its colour from blue to black. This temperature could vary between $500^{\circ} \mathrm{C}$ and $600^{\circ} \mathrm{C}$ depending on the specific zeolites and OSDA's. T3 would correspond to the maximum temperature at which 
the zeolite is stable, but it was usually limited to $850^{\circ} \mathrm{C}$, unless stated. This temperature was set so high because the removal of phosphine seems to be slightly dependent on the temperature, and the higher the temperature, the higher the removal. However, after several trial and error, no significant additional phosphorus removal occurs above $850^{\circ} \mathrm{C}$. Additionally, the removal of phosphorus appears to be independent of the thermal treatment time, as increasing the time at $\mathrm{T} 3$ step does not allow for higher removal of phosphorus.

After the thermal treatment under hydrogen, samples are calcined in air to ensure the total removal of any organic residues.

\subsubsection{Washing of residual phosphorous species}

After thermal treatment of the zeolitic materials, some phosphorus usually remains inside the material as extra-framework phosphorous oxide-like species. These species could be usually removed from medium (10 MR) and large (12 MR) pore zeolites by washing the thermally treated material with either an ammonium acetate solution or ethanol. However, as the phosphate species formed during the washing cannot diffuse through 8 MR pores, the washing of small pore zeolites is not possible or quite limited.

The washing procedures used in this thesis are given next:

\section{- Washing with ammonium acetate}

The thermally treated zeolite is suspended into an aqueous $3 \mathrm{M}$ solution of ammonium acetate ( $98 \mathrm{wt} . \%$, Aldrich), using a ratio of $40 \mathrm{~mL}$ of solution per gram of zeolite. Then, the mixture is heated up to $80^{\circ} \mathrm{C}$ for four hours. Next, the solid is recovered by filtration and washed with distilled boiling water. After this, the solid is dried overnight in an oven at $100^{\circ} \mathrm{C}$, followed by calcination under air using the same procedure as described in section 3.2.3.1.

\section{- Washing with ethanol}

Alternatively, phosphorous residues could be removed using absolute ethanol when the amount of remaining phosphorus is low, as well as when the material possess large pore openings. The procedure used is the same than the described for ammonium acetate, but using absolute ethanol instead of ammonium acetate. 
Chapter 3: Experimental section

\subsection{References}

[1] J. Rius, J.F. Piniella, C. Miravitlles, Caracterización de materiales: avances teóricos y experimentales de la metodología de la difracción, Editorial CSIC, 1992.

[2] R. Jenkins, R.L. Snyder, Introduction to X-ray powder diffractometry, John Wiley \& Sons Inc., 1996.

[3] C. Hammond, C. Hammond, The basics of crystallography and diffraction, Oxford University Press Oxford, 2009.

[4] M. Faraldos, C. Goberna, Técnicas de análisis y caracterización de materiales, Editorial CSIC, 2002.

[5] C.B. Boss, K.J. Fredeen, Concepts, instrumentation and techniques in inductively coupled plasma optical emission spectrometry, Perkin Elmer Norwalk, 1999.

[6] P.A. Webb, C. Orr, Analytical methods in fine particle technology, Micromeritics Instrument Corp., 1997.

[7] M. Thommes, K. Kaneko, A.V. Neimark, J.P. Olivier, F. Rodriguez-Reinoso, J. Rouquerol, K.S. Sing, Physisorption of gases, with special reference to the evaluation of surface area and pore size distribution (IUPAC Technical Report), Pure and Applied Chemistry, 87, 9-10, 2015, 1051-1069.

[8] S. Brunauer, P.H. Emmett, E. Teller, Adsorption of gases in multimolecular layers, Journal of the American chemical society, 60, 2, 1938, 309-319.

[9] B. Lippens, B. Linsen, J. de Boer, Pore systems in adsorbents and catalysts, Journal of Catalysis, 3, 1964, 32-37.

[10] J. De Boer, B. Lippens, B. Linsen, J. Broekhoff, A. Van den Heuvel, T.J. Osinga, Thetcurve of multimolecular N2-adsorption, Journal of Colloid and Interface Science, 21, 4, 1966, 405-414.

[11] W.D. Harkins, G. Jura, Surfaces of solids. XIII. A vapor adsorption method for the determination of thearea of a solid without the assumption of a molecular area, and the areas occupied by Nitrogen and other molecules on the surface of a solid, J. Am. Chem. Soc, 66, 1944, 1366-1373.

[12] G. Horváth, K. Kawazoe, Method for the calculation of effective pore size distribution in molecular sieve carbon, Journal of Chemical Engineering of Japan, 16, 6, 1983, 470-475.

[13] N.E. Jacobsen, NMR spectroscopy explained: simplified theory, applications and examples for organic chemistry and structural biology, John Wiley \& Sons, 2007.

[14] M. Hunger, E. Brunner, NMR Spectroscopy, in: Characterization I: Molecular Sieves Science and Technology, Springer Berlin Heidelberg, 4, 2004, 201-293. 
[15] E. Andrew, A. Bradbury, R. Eades, Removal of dipolar broadening of nuclear magnetic resonance spectra of solids by specimen rotation, Nature, 183, 4678, 1959, 1802-1803.

[16] G. Lischke, R. Eckelt, H.-G. Jerschkewitz, B. Parlitz, E. Schreier, W. Storek, B. Zibrowius, G. Öhlmann, Spectroscopic and physicochemical characterization of P-modified H-ZSM-5, Journal of Catalysis, 132, 1991, 229-243.

[17] K. Damodaran, J.W. Wiench, S.M. Cabral de Menezes, Y.L. Lam, J. Trébosc, J.-P. Amoureux, M. Pruski, Modification of H-ZSM-5 zeolites with phosphorus. 2. Interaction between phosphorus and aluminum studied by solid-state NMR spectroscopy, Microporous and Mesoporous Materials, 95, 1-3, 2006, 296-305.

[18] J.-F. Gu, X.-J. Zhang, J.-Z. Wang, J. Xu, F. Deng, Z.-Y. Yuan, Synthesis of B-Beta zeolite and its modification with orthophosphoric acid, in: Studies in Surface Science and Catalysis, Elsevier, 174, 2008, 209-212.

[19] M. Göhlich, W. Reschetilowski, S. Paasch, Spectroscopic study of phosphorus modified H-ZSM-5, Microporous and Mesoporous Materials, 142, 1, 2011, 178-183.

[20] C.A. Fyfe, J.L. Bretherton, L.Y. Lam, Solid-state NMR detection, characterization, and quantification of the multiple aluminum environments in US-Y catalysts by ${ }^{27} \mathrm{Al}$ MAS and MQMAS experiments at very high field, Journal of the American Chemical Society, 123, 22, 2001, 5285-5291.

[21] G. Woolery, G. Kuehl, H. Timken, A. Chester, J. Vartuli, On the nature of framework Brønsted and Lewis acid sites in ZSM-5, Zeolites, 19, 4, 1997, 288-296.

[22] J.A. van Bokhoven, D. Koningsberger, P. Kunkeler, H. Van Bekkum, A. Kentgens, Stepwise dealumination of zeolite Beta at specific T-sites observed with ${ }^{27} \mathrm{Al}$ MAS and ${ }^{27} \mathrm{Al}$ MQ MAS NMR, Journal of the American Chemical Society, 122, 51, 2000, 12842-12847.

[23] Z. Yan, D. Ma, J. Zhuang, X. Liu, X. Liu, X. Han, X. Bao, F. Chang, L. Xu, Z. Liu, On the acid-dealumination of USY zeolite: a solid state NMR investigation, Journal of Molecular Catalysis A: Chemical, 194, 1-2, 2003, 153-167.

[24] C.A. Fyfe, J. Bretherton, L. Lam, Detection of the 'invisible aluminium'and characterisation of the multiple aluminium environments in zeolite USY by high-field solidstate NMR, Chemical Communications, 17, 2000, 1575-1576.

[25] W. Farneth, R. Gorte, Methods for characterizing zeolite acidity, Chemical Reviews, 95, $3, \mathbf{1 9 9 5}, 615-635$.

[26] A. Jentys, G. Rumplmayr, J.A. Lercher, Hydroxyl groups in phosphorus-modified HZSM-5, Applied Catalysis, 53, 2-3, 1989, 299-312.

[27] B. Rebenstorf, T. Lindblad, S.L.T. Andersson, Amorphous $\mathrm{AIPO}_{4}$ as catalyst support 2. Characterization of amorphous aluminum phosphates, Journal of Catalysis, 128, 2, 1991, 293-302. 
[28] G. Zhao, J. Teng, Z. Xie, W. Jin, W. Yang, Q. Chen, Y. Tang, Effect of phosphorus on HZSM-5 catalyst for $\mathrm{C}_{4}$-olefin cracking reactions to produce propylene, Journal of Catalysis, 248, 1, 2007, 29-37.

[29] C. Emeis, Determination of integrated molar extinction coefficients for infrared absorption bands of pyridine adsorbed on solid acid catalysts, Journal of Catalysis, 141, 2, 1993, 347-354.

[30] L. Damjanović, A. Auroux, Determination of acid/base properties by temperature programmed desorption (TPD) and adsorption calorimetry, in: Zeolite Characterization and Catalysis, Springer, 2009, 107-167.

[31] M. Niwa, N. Katada, K. Okumura, IRMS-TPD Measurements of Acid Sites, in: Characterization and Design of Zeolite Catalysts, Springer, 2010, 29-59.

[32] A. Clarke, C. Eberhardt, C.N. Eberhardt, Microscopy techniques for materials science, Woodhead Publishing, 2002.

[33] S. Amelinckx, D. Van Dyck, J. van Landuyt, G. Van Tendeloo, Handbook of Microscopy: Applications in Materials Science, Solid-State Physics, and Chemistry, Methods II, John Wiley \& Sons, 2008.

[34] T. Willhammar, Y. Yun, X. Zou, Structural determination of ordered porous solids by electron crystallography, Advanced Functional Materials, 24, 2, 2014, 182-199.

[35] E. Mugnaioli, U. Kolb, Structure characterization of nanocrystalline porous materials by tomographic electron diffraction, Zeitschrift für Kristallographie-Crystalline Materials, 230, 4, 2015, 271-288.

[36] P.A. Midgley, A.S. Eggeman, Precession electron diffraction-a topical review, IUCrJ, 2, 1, 2015, 126-136.

[37] M. Gemmi, M.G.I. La Placa, A.S. Galanis, E.F. Rauch, S. Nicolopoulos, Fast electron diffraction tomography, Journal of Applied Crystallography, 48, 3, 2015, 718-727.

[38] J. Simancas, R. Simancas, P.J. Bereciartua, J.L. Jorda, F. Rey, A. Corma, S. Nicolopoulos, P. Pratim Das, M. Gemmi, E. Mugnaioli, Ultrafast Electron Diffraction Tomography for Structure Determination of the New Zeolite ITQ-58, Journal of the American Chemical Society, 138, 32, 2016, 10116-10119.

[39] J.-L.M. Abboud, R. Notario, J. Bertran, M. Sola, One century of physical organic chemistry: the Menshutkin reaction, Progress in Physical Organic Chemistry, 19, 183, 1990, 7.

[40] L.L. Hench, J.K. West, The sol-gel process, Chemical Reviews, 90, 1, 1990, 33-72.

[41] G. Kühl, Chapter 1 - Source materials for zeolite synthesis, in: Verified Syntheses of Zeolitic Materials, Elsevier Science, 2001, 19-20. 
Synthesis and characterization of zeolitic materials using P-OSDA

[42] R. Simancas, Síntesis de Nuevos Materiales Zeolíticos empleando Agente Directores de Estructura Fosforados, Universitat Politècnica de València, 2015. 


\section{Chapter 4}

\section{Study on Stability \\ of OSDA's}

\subsection{Introduction}

The hydrothermal conditions used during the synthesis of zeolites are usually quite harsh for organic compounds, and therefore, OSDA's could be decomposed through different degradation pathways. The most typical decomposition mechanism is the $\beta$-Hofmann elimination because of the alkaline media usually employed, but thermal decomposition or carbon-chain rearrangement reactions are also possible, as schematized in Figure 4.1 for typical alkylammonium OSDA's. ${ }^{[1]}$ 


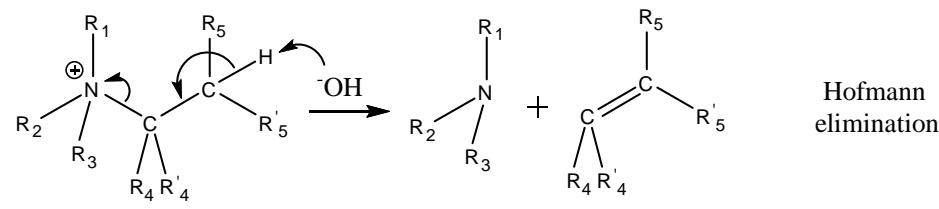

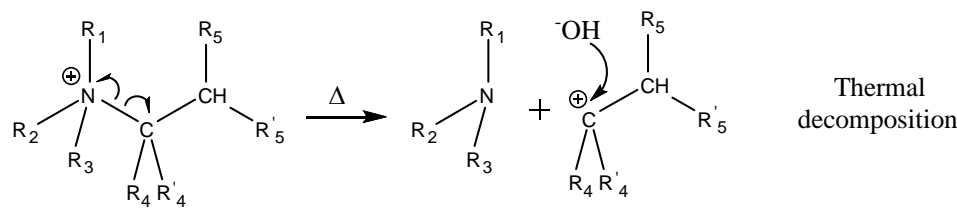

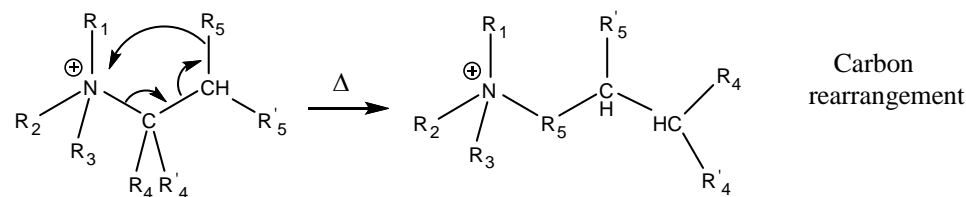

Figure 4.1. Main degradation pathways of ammonium cations under hydrothermal treatment.

Also, the Hofmann decomposition decreases the $\mathrm{OH}^{-}$concentration, affecting the equilibria between the different silica species present in the synthesis gel. This parameter is out of full control in the typical synthesis of zeolites, but heavily influences the phase selectivity of the crystallization process.

The stability of OSDA's of different chemical nature was tested under different experimental conditions. In all cases, the syntheses were carried out for a similar range of time, between 1 and 20 days. Two different experiments were designed:

- In experiment 1 , two simple commercially available OSDA's, the tetraethylammonium cation (OSDA-1), named here as TEA cation, and the tetraethylphosphonium cation (OSDA-2), named here as TEP cation, were studied. Three different temperatures, $135^{\circ} \mathrm{C}, 150^{\circ} \mathrm{C}$ and $175^{\circ} \mathrm{C}$, were used to study the thermal stability of the OSDA's. Also, the influence of the media was studied by comparing hydroxide and fluoride media syntheses. Finally, blank experiments, where silica precursors were excluded from the synthesis gel, were also carried out to study the influence of the presence of silica species on the stability of the OSDA's (Figure 4.2. Upper left).

- In experiment 2, the stabilities of some more complex yet well-known OSDA's were studied. The selected OSDA's were the methyl-tris-(dimethylamino)-phospho- 
nium cation (OSDA-3), named here as MNP cation; the methyl-tri-isopropylphosphonium cation (OSDA-4), named here as MIP cation; the di-isopropyl-diethylammonium cation (OSDA-5), named here as IEN cation; and the commercial phosphazene base P1-t-Bu (OSDA-6), named here as PB1, in its cationic phosphazenium form. In this case blank experiments were omitted, and instead, borosilicate synthesis gels were prepared. Under these synthesis conditions, crystalline materials were obtained using these synthesis gels. Also, only one temperature was used, $150^{\circ} \mathrm{C}$ (Figure 4.2. Upper right).
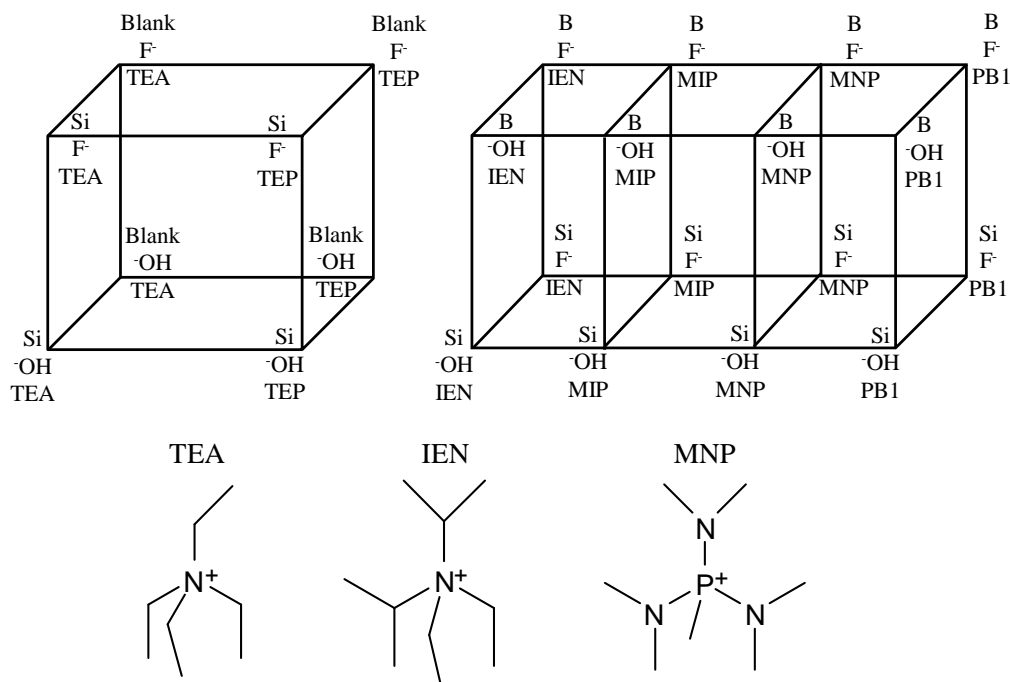<smiles>CC[N+](CC)(C(C)C)C(C)[NH3+]</smiles><smiles>CN(C)[P+](C)(N(C)C)N(C)C</smiles>

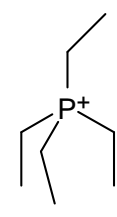

TEP<smiles>CC(C)[P+](C)(C(C)C)C(C)C</smiles>

MIP<smiles>CN(C)[P+](NC(C)(C)C)(N(C)C)N(C)C</smiles>

PB1

Figure 4.2. Upper left: experiment 1 design of synthesis conditions. For each experimental condition, syntheses were also carried out at three different temperatures: $135^{\circ} \mathrm{C}, 150^{\circ} \mathrm{C}$ and $175^{\circ} \mathrm{C}$. Upper right: experiment 2 design of synthesis conditions. Below: employed cations in each experiment, tetraethylammonium cation (TEA) and tetraethylphosphonium cation (TEP) in experiment 1, and di-isopropyl-diethylammonium cation (IEN), methyl-tris-(dimethylamino)phosphonium cation (MNP), methyl-tri-isopropylphosphonium cation (MIP) and phosphazene base P1-t-Bu (PB1) in experiment 2. 
Syntheses gels were prepared with the following compositions:

$$
0.4 \text { OSDA }: x \mathrm{SiO}_{2}: y \mathrm{~B}_{2} \mathrm{O}_{3}: 10 \mathrm{H}_{2} \mathrm{O}: z \mathrm{HF}
$$

where $x$ takes values of 0 (blank), 1 (all-silica, $\mathrm{Si}$ ) or 0.9 (borosilicate, $\mathrm{B}$ ); $y$ takes values of 0 (blank or all-silica, $\mathrm{Si}$ ) or 0.1 (borosilicate, B); and $z$ takes values of 0 (hydroxide media, $\mathrm{OH}$ ) or 0.4 (fluoride media, F). After synthesis, the products were filtered, keeping the weighted mother liquors for analysis by NMR and ICP spectroscopies, as detailed in section 3.2.2.

\subsection{Experiment 1: effect of the hydrothermal param- eters on OSDA's in MFI synthesis}

Experiment 1 was first performed to quickly and easily check for differences in the stability of OSDA's of two isochemical molecules of different nature, an ammonium OSDA, the tetraethylammonium cation (TEA, OSDA-1), and a phosphonium OSDA, the tetraethylphosphonium cation (TEP, OSDA-2), schemed in Figure 4.3.

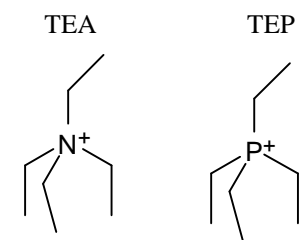

Figure 4.3. Tetraethylammonium cation (TEA) and tetraethylphosphonium cation (TEP) used as OSDA's in experiment 1.

The detailed characterization of the TEA (OSDA-1) and TEP (OSDA-2) are described in sections 3.2.1.1 and 3.2.1.2, respectively. Some examples of synthesis gels are described in section 3.2.2.1.

\subsubsection{Solid products}

In all cases, ZSM-5 zeolite (IZA structure code: MFI) was the final material when silicon precursors were present in the synthesis gel. It is important to note that the target of this study was put on the evolution of the OSDA's along the zeolite formation process, while the optimization of the crystallization kinetics plays a merely secondary role. Actually, the 
synthesis conditions were chosen to lengthen the synthesis time of the MFI zeolite by choosing a sub-optimal MFI OSDA, ${ }^{[2]}$ which should highlight the differences between the effect that the TEA and the TEP cations play on the zeolite formation.

\subsubsection{Crystallinity of solid products}

The crystallinity of the obtained solids after synthesis was assessed by powder X-Ray diffraction, whose patterns are shown in Figure 4.4.
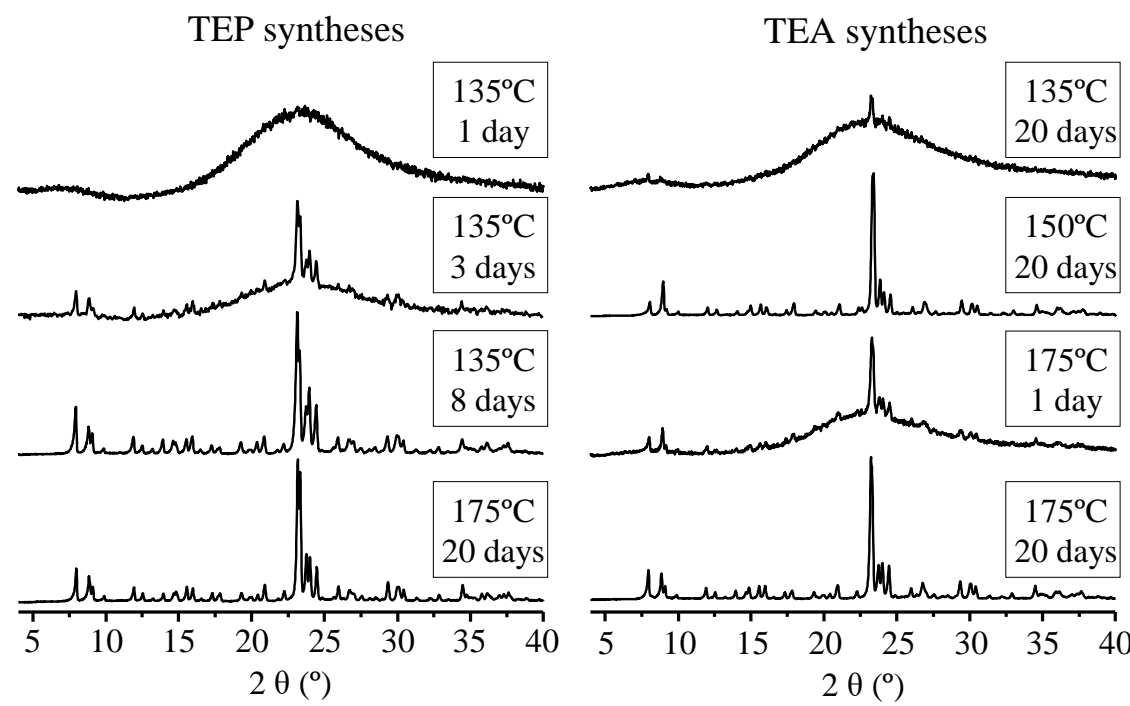

Figure 4.4. Powder X-Ray diffraction patterns of some of the materials obtained using TEP (left) and TEA (right) as OSDA's in fluoride media.

As expected, the temperature and the mineralizing agent used in the syntheses were critical factors regarding the crystallization rates. Actually, for lower temperatures, no crystalline products were collected when TEA was used as OSDA. Additional experiments for longer synthesis times (longer than 30 days at $135^{\circ} \mathrm{C}$ ) confirmed that MFI zeolite was obtained as the final product in fluoride media synthesis. However, TEA syntheses in hydroxide media yielded mostly amorphous phase, with tiny amounts of MFI zeolite at most, in the tested hydrothermal conditions tested during this study. This could be explained by the high concentration of hydroxide mobilizing agent in the hydroxide syntheses, which prevents the formation of stable zeolite nuclei. 
Similar synthesis gel compositions using TEA yields zeolite $\beta$ (BEA/BEB intergrowth), although with a higher OSDA to silicon and water to silicon ratios than those used here ${ }^{[3]}$ Thus, the $\mathrm{pH}$ of the synthesis gel is a critical factor, as side experiments yielded mixed MFI and BEA phases when the synthesis gel $\mathrm{pH}$ was slightly over 12 before pouring the synthesis gel inside the Teflon liner (hydroxide media syntheses) or before adding HF to the synthesis gel (fluoride media syntheses). This was the case when water to silicon ratio was lower than 7 while keeping the OSDA to silicon ratio of 0.4 , conditions which were preliminary tested. However, when the water to silica ratio was raised to 10 , the $\mathrm{pH}$ of the syntheses gel was lower than 12 and therefore the obtained product was only MFI zeolite without BEA zeolite impurities.

Conversely, syntheses using TEP only yielded the MFI zeolite regardless of the synthesis conditions and pH's. Actually, the use of TEP allowed obtaining MFI in hydroxide media in the crystallization time range of the study, although in low yields and with a considerable amount of amorphous phase, especially at lower temperatures and synthesis times. Side experiments increasing the synthesis time over 28 days allowed for the complete crystallization of MFI zeolite even at $135^{\circ} \mathrm{C}$. The zeolite $\beta$ was not obtained under any condition, even when lowering the water to silicon ratio to 5 , when the synthesis gel $\mathrm{pH}$ was higher than 12. Actually, the $\mathrm{pH}$ of the synthesis gel when using TEP was always slightly higher than using TEA under the same synthesis gel compositions.

In fluoride media syntheses, the fully crystallized MFI zeolite was obtained in the crystallization time range used in the experimental setup with both OSDA's. Crystallization rates of MFI zeolite in the obtained solids are shown in Figure 4.5. Sample crystallinity was calculated as a ratio between the intensity of the diffraction peaks of each sample and the most crystalline product for each synthesis media (OSDA and mineralizing agent). The diffraction peaks used in the calculus were the high intensity $2 \theta 23.2^{\circ}$ peak, also calculating the crystallinity with the diffraction peaks at $2 \theta 23.8^{\circ}, 24^{\circ}$ and $24.4^{\circ}$ as control test. 


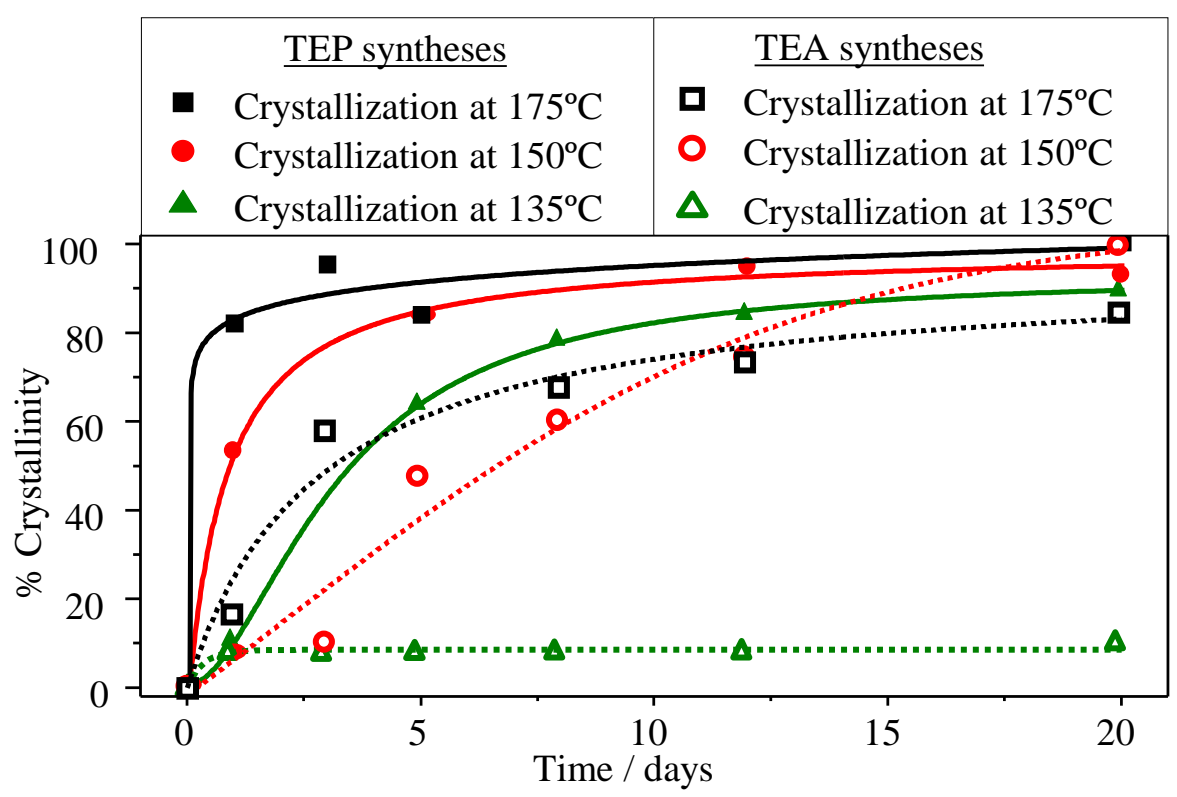

Figure 4.5. Crystallization kinetics of MFI obtained using TEP (solid dots and lines) and TEA (hollow dots and dotted lines) as OSDA's in fluoride media. Lines are just for guidance.

As Figure 4.5 shows, the crystallization rates strongly differ for each OSDA. Thus, MFI zeolite quickly crystallizes using TEP at almost any temperature, whereas when using TEA, crystallization time is considerably longer and more dependent on the synthesis temperature.

\subsubsection{Chemical analyses of solid products}

The collected materials were analysed in order to assess their OSDA content, regardless of the crystallinity of the zeolite or the presence of amorphous phase. The OSDA content and solid yield of the obtained are shown in Figure 4.6. 


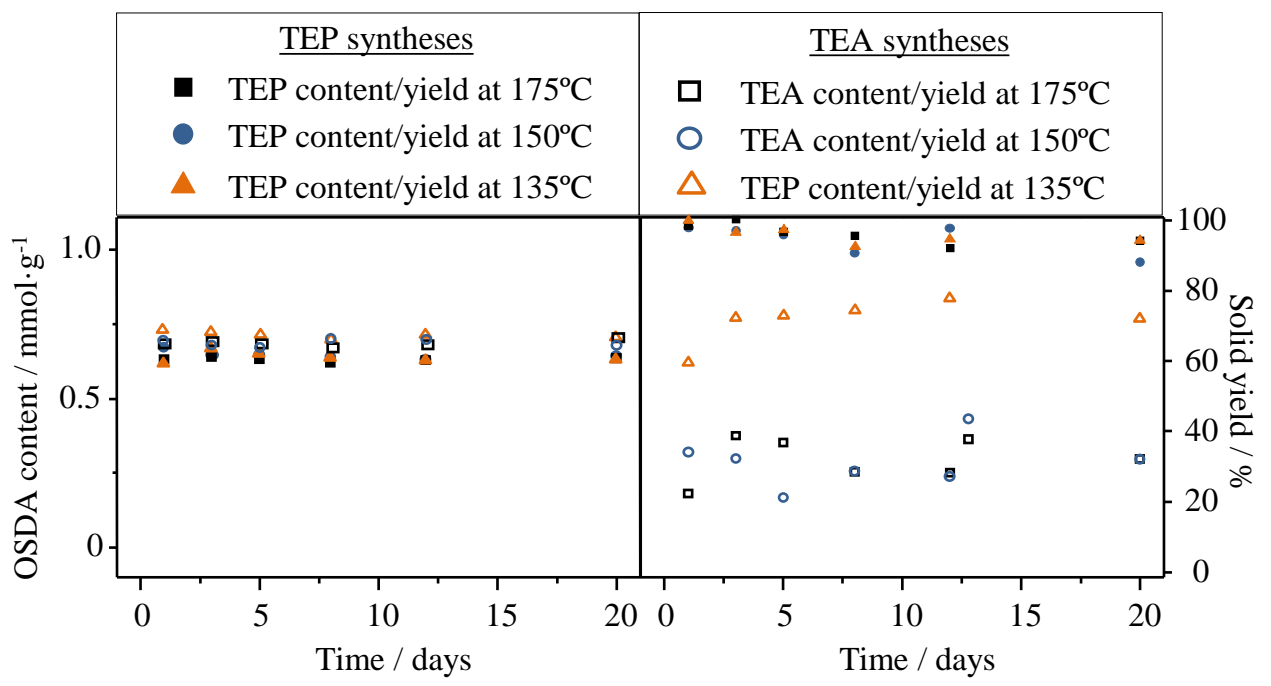

Figure 4.6. OSDA content (left) and yield (right) of solid products obtained after using TEP (solid dots) and TEA (hollow dots) as OSDA's in fluoride media.

As shown in Figure 4.6, all of the collected materials present a constant OSDA content around $0.6 \mathrm{mmol} \cdot \mathrm{g}^{-1}$, regardless of the used OSDA and crystallinity of the obtained materials. This content corresponds to a silicon to OSDA ratio of 24, which fits with 4 OSDA molecules per unit cell of MFI structure (96 T units per unit cell). The yield of the obtained solids was high when using the TEP as OSDA, while the yield decreases as temperature increases when TEA is used as OSDA. This could indicate that the strong interaction between the OSDA and the silica is taking place regardless of the long range order of the solid, and probably, the "amorphous" phase could consist in MFI zeolite building units interacting with the OSDA, but without having a full connectivity between them or in a very short spatial range. This short range interaction would yield nanocrystals too small to produce coherent X-Ray diffraction, and therefore, resulting in amorphous-like solids. ${ }^{[4,5]}$

The OSDA's incorporated in the solids are completely stable in all cases, as concluded from the chemical analyses and MAS-NMR spectroscopies, shown in Table 4.1 and Figure 4.7, respectively. 
Chapter 4: Study on Stability of OSDA's

Table 4.1. Typical chemical analyses of the obtained solids. Sample are named after the used OSDA, the synthesis media, the temperature $\left({ }^{\circ} \mathrm{C}\right)$ and synthesis time (days).

\begin{tabular}{ccccc}
\hline Sample & Phase & ${\text { OSDA } / \mathrm{mmol}^{-1}}^{-1}$ & $\mathrm{C} /(\mathrm{P}+\mathrm{N})_{\exp }$ & $\mathrm{C} /(\mathrm{P}+\mathrm{N})_{\mathrm{th}}$ \\
\hline TEP-HF-135-1 & Am. & 0.66 & 7.8 & \\
TEP-HF-135-20 & MFI & 0.62 & 8.0 & \\
TEP-HF-150-1 & MFI + Am. & 0.66 & 7.9 & \\
TEP-HF-150-12 & MFI & 0.63 & 8.2 & \\
TEP-HF-175-20 & MFI & 0.61 & 8.1 & 8 \\
TEA-HF-150-3 & Am. & 0.73 & 7.6 & \\
TEA-HF-150-12 & MFI & 0.71 & 7.7 & \\
\hline TEA-HF-175-3 & MFI + Am. & 0.75 & 7.5 & \\
TEA-HF-175-12 & MFI & 0.72 & 7.6 & \\
\hline
\end{tabular}
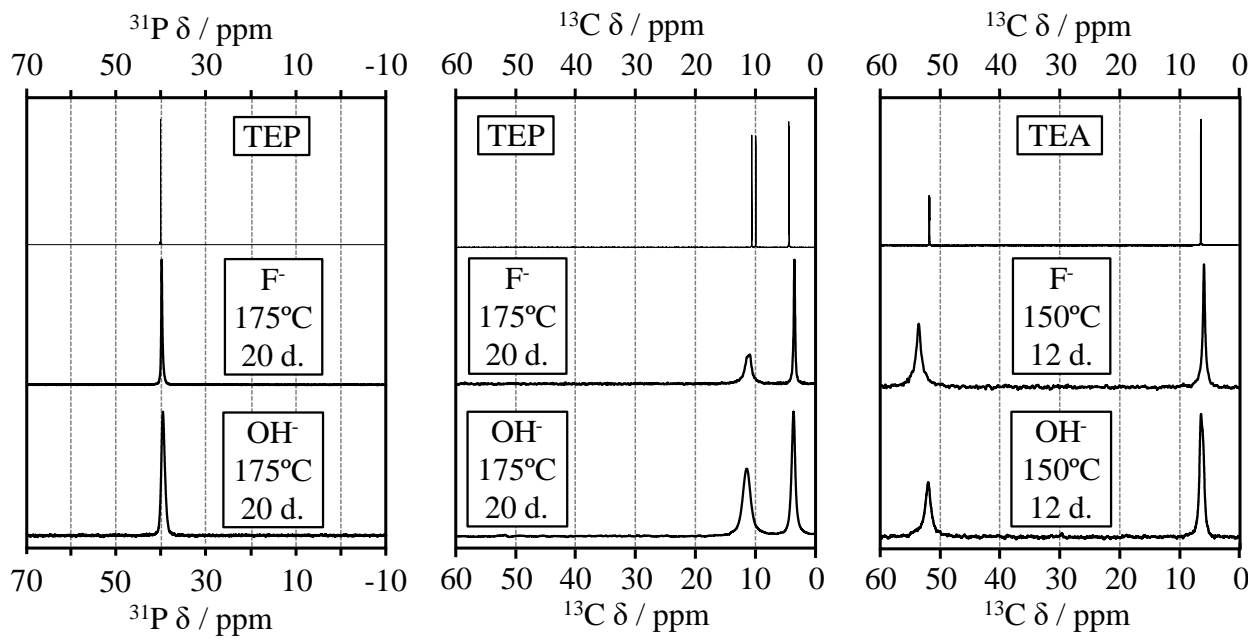

Figure 4.7. Typical ${ }^{31} \mathrm{P}-\mathrm{NMR}$ (left) and ${ }^{13} \mathrm{C}$-NMR (middle) spectra of the solids obtained using TEP as OSDA, and ${ }^{13} \mathrm{C}$-NMR spectra of solids obtained using TEA as OSDA (right). The upper liquid NMR spectra belong to the pure TEP and TEA OSDA's in deuterium oxide solution, and the middle and below spectra belong to MAS-NMR spectra of some the solid samples. 
Since the OSDA in the synthesis gel was used in a large excess, and most of the OSDA is not incorporated in the solid after the hydrothermal synthesis, the mother liquors were separated and recovered after synthesis for further studies.

\subsubsection{Mother liquor analyses}

The mother liquors were analysed to study the stability of the OSDA excess after undergoing the hydrothermal treatment. The mother liquor was analysed by liquid NMR spectroscopy, to check the stability of the OSDA in the hydrothermal media along the synthesis, and by ICP spectroscopy (in phosphorous containing solids), to check for possible losses of the OSDA during the crystallization, filtration and/or washing of the solid products.

\subsubsection{Quantification}

In the case of the phosphorous OSDA's, it is possible to easily quantify the amount of phosphorus in the solid and the solution by ICP spectroscopy, and therefore, a mass balance was calculated to check for any TEP loss. The mass balance results are shown in Figure 4.8.

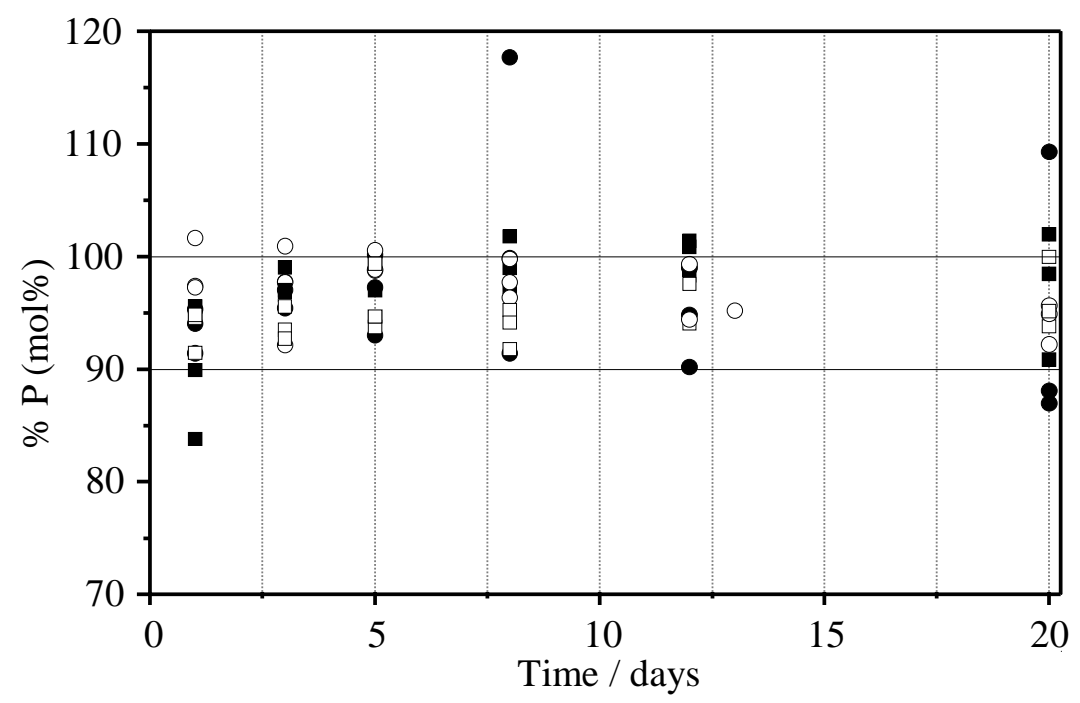

Figure 4.8. Mass balance of phosphorus in syntheses ( $\bullet$ : fluoride media; $\bullet$ : hydroxide media) and blank ( $\square$ : fluoride media; $\circ$ : hydroxide media) experiments carried out with TEP as OSDA. 
These data show that it is possible to track the evolution of the TEP cation during synthesis as most of the phosphorus, between $90 \%$ and $100 \%$, was quantified when taking in account the solids and the liquids collected for each synthesis. Despite this, some mass balance values present deviations, especially for values well over $100 \%$. This could be due to random errors in analyses, especially in the mother liquors, where a huge scaling factor because of the highly diluted media after the recovery of the mother liquor could lead to considerable quantification errors. However, it is clear that even a slight washing of the obtained solids results in an almost total recovery of the OSDA.

On the other hand, in the case of the TEA cation, it was not possible to quantify the amount of nitrogen in solution, and therefore, no mass balance was calculated. Because of that, the amount of stable TEA after syntheses reported here is actually the maximum stability of this compound, as it is possible that small quantities of some compounds may be lost, especially degradation compounds formed by the Hofmann decomposition, which could be evaporated from the solution.

\subsubsection{OSDA stability}

The stability of the OSDA's was tracked by analysis of liquid ${ }^{31} \mathrm{P}$ and ${ }^{13} \mathrm{C}-\mathrm{NMR}$ spectra. Due to the low concentration of species, the measure times were quite long to obtain resonances with enough signal to noise ratios for quantitative analyses. Some of the NMR spectra are shown in Figure 4.9, where the OSDA and the resonances of their decomposition products could be seen. 

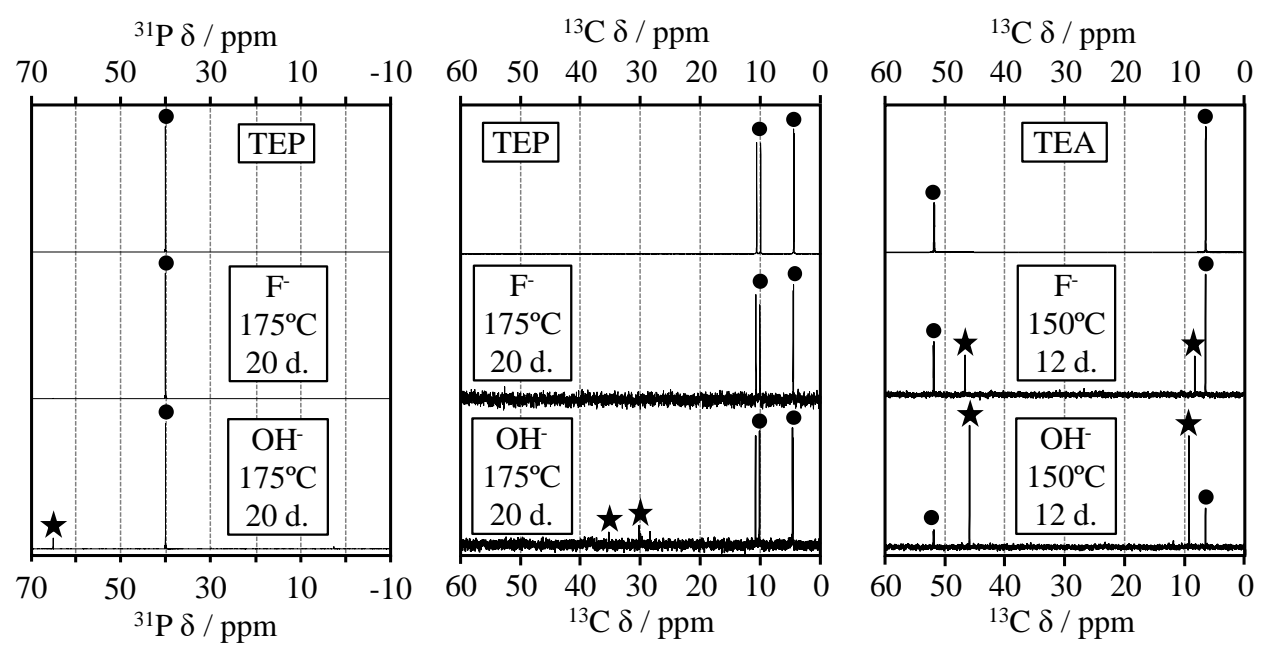

Figure 4.9. Liquid ${ }^{31} \mathrm{P}-\mathrm{NMR}$ (left) and ${ }^{13} \mathrm{C}$-NMR (middle) spectra of TEP mother liquors, and ${ }^{13} \mathrm{C}-\mathrm{NMR}$ spectra of TEA mother liquors (right). The upper spectra belong to the pure TEP and

TEA OSDA's. Signals marked with circles correspond to OSDA's and signals marked with asterisks are assigned to decomposition products. All samples were diluted in deuterium oxide solution.

For TEP OSDA, the ${ }^{31} \mathrm{P}-\mathrm{NMR}$ spectra were used to calculate the degradation of the OSDA taking in account the relative intensity of the different resonances. This could be done because the nuclear spin of ${ }^{31} \mathrm{P}$ is $1 / 2$, and thus, the area under each resonance is proportional to the concentration of each P-containing species. In this case, the TEP present a single resonance at $40 \mathrm{ppm}$, so any additional signal would correspond to a degradation product. The degradation of TEP was calculated by Equation 4.1.

$$
\text { Total \%TEP }=\frac{v_{\text {a.l. }} \cdot[P]_{\text {liq }} \cdot \frac{\text { TEP resonance area }}{\sum^{31} \text { P resonance area }}}{m_{\text {sol }} \cdot[P]_{\text {sol }}+v_{\text {m.l. }} \cdot[P]_{l i q}} \cdot 100
$$

\section{Equation 4.1.}

Where $[P]_{s o l}$ and $[P]_{l i q}$ are the concentrations of phosphorus obtained by ICP spectroscopy in the solids and in the mother liquors, respectively; $m_{s o l}$ is the amount of obtained solids; $v_{m . l}$ is the volume of mother liquor; $\frac{T E P \text { resonance area }}{\Sigma^{31} \text { Presonance area }}$ is the ratio between the area of the ${ }^{31} \mathrm{P}$ NMR TEP resonance and the sum of all the ${ }^{31} \mathrm{P}$ NMR resonances in the mother liquor. 
However, in the case of the TEA OSDA, a proper quantitative analysis is not possible because the absolute intensity of the different ${ }^{13} \mathrm{C}$ resonances in NMR spectra is not always proportional to the concentration of species. This is due to the use of cross polarization from ${ }^{1} \mathrm{H}$ to ${ }^{13} \mathrm{C}$ nuclei during measurements to improve the signal to noise ratio of the ${ }^{13} \mathrm{C}$ spectra. However, the relative resonance intensity between closely related carbon groups could be used as a semi-quantitative analysis. ${ }^{[6]}$ To minimize errors, the degradation was calculated by the arithmetic mean of different resonances, in this case, the $\mathrm{CH}_{3}$ and $\mathrm{CH}_{2}$ resonances of the OSDA and the degradation products, mainly triethylamine cation. Therefore, the minimum degradation of TEA OSDA was calculated by Equation 4.2.

$$
\text { Total \%TEA }=\frac{\left(\frac{\operatorname{Int}_{E t_{4} N\left(\mathrm{CH}_{3}\right)}}{\sum \text { Int } t_{\text {deg.prod. }}\left(\mathrm{CH}_{3}\right)}+\frac{\operatorname{Int}_{E t_{4} N\left(\mathrm{CH}_{2}\right)}}{\sum \operatorname{Int} t_{\text {deg.prod. }}\left(\mathrm{CH}_{2}\right)}\right)}{2} \cdot 100
$$

\section{Equation 4.2.}

Where $\frac{\operatorname{Int}_{\mathrm{Et}_{4} \mathrm{~N}\left(\mathrm{CH}_{3}\right)}}{\sum \operatorname{Int}{\text { deg.prod. }\left(\mathrm{CH}_{3}\right)}_{\text {in }}}$ is the ratio between the area of the ${ }^{13} \mathrm{C} \mathrm{NMR}$ of $\mathrm{CH}_{3}$ resonance in TEA and the sum of all the ${ }^{13} \mathrm{C}$ NMR of $\mathrm{CH}_{3}$ resonances in the mother liquor; $\frac{\operatorname{Int}_{E_{t} t_{4} N\left(\mathrm{CH}_{2}\right)}}{\sum \text { Int }{\text { deg.prod. }\left(\mathrm{CH}_{2}\right)}}$ is the ratio between the area of the ${ }^{13} \mathrm{C} \mathrm{NMR}$ of $\mathrm{CH}_{2}$ resonance in TEA and the sum of all the ${ }^{13} \mathrm{C}$ NMR of $\mathrm{CH}_{2}$ resonances in the mother liquor.

The stabilities of TEP and TEA cations in all syntheses were calculated with Equation 4.1 and Equation 4.2, respectively, and the calculated stability results of TEP and TEA cations are shown in Figure 4.10. 


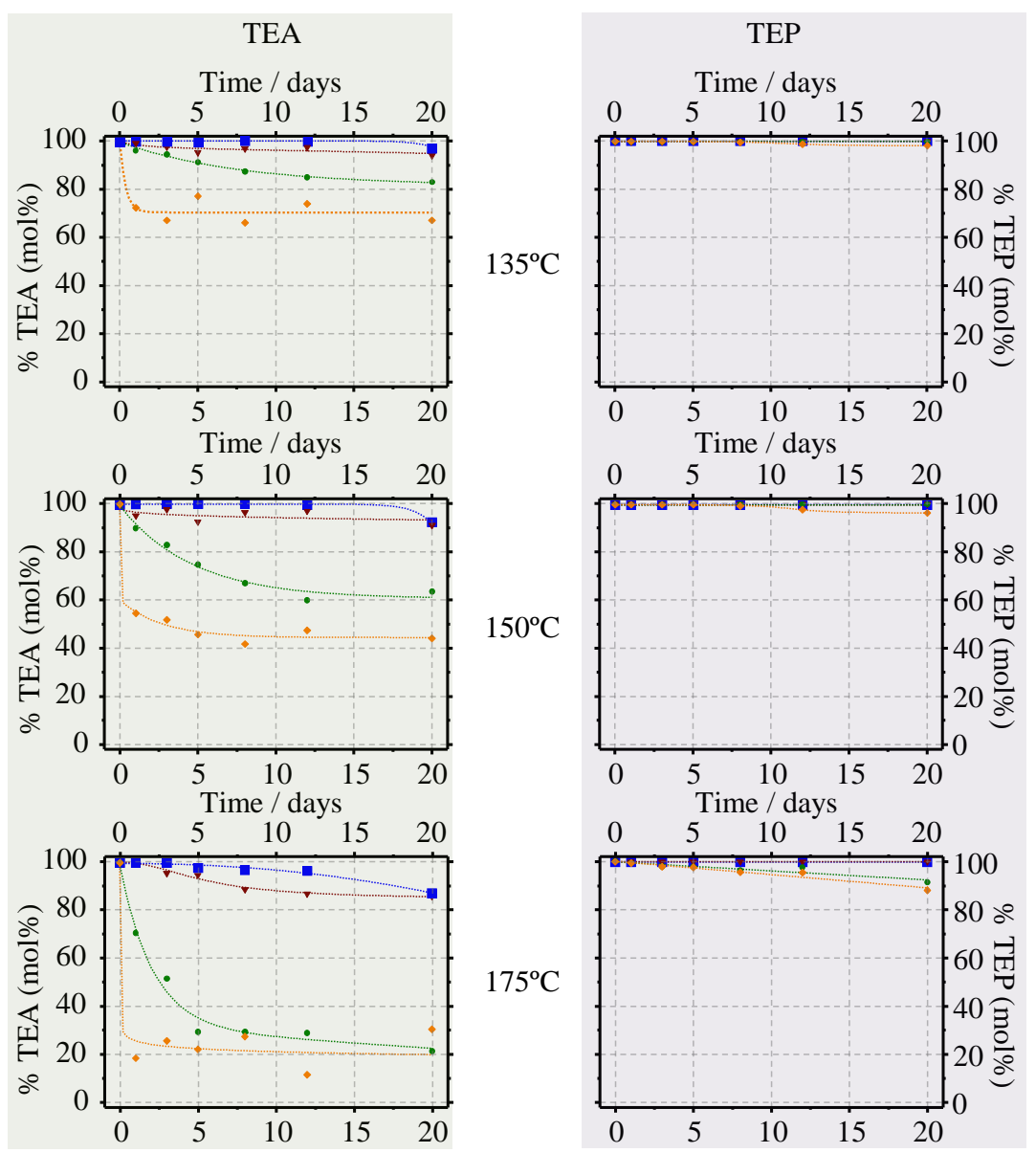

Figure 4.10. Stability curves of TEA (left, green background) and TEP (right, purple background) cations at different temperatures and synthesis conditions ( $\square$ : fluoride synthesis;

$\nabla$ : fluoride blank; $\bullet$ : hydroxide synthesis; $\diamond$ : hydroxide blank). Curves are just for guidance.

These results clearly show that the OSDA stability strongly depends on the $\mathrm{pH}$ of the synthesis media. Indeed, in fluoride media, the TEP cation shows no decomposition at all, while TEA cation begins to decompose after a long synthesis time. On the other hand, in hydroxide media, the TEA quickly decomposes until reaching a limit value defined by the synthesis temperature, while TEP only starts to slightly decompose at the longest synthesis times and temperatures. This means that the TEP cation is more stable than the TEA under any synthesis condition, especially in hydroxide media. 
These data are in agreement with a decomposition mainly guided by Hofmann degradation mechanism, where hydroxide anions are needed to decompose these cations. However, the TEP cation is less sensitive to this degradation mechanism, making it a more stable OSDA. Additionally, blank experiments show that the TEA and TEP cations are slightly less stable in hydroxide and fluoride media compared to experiments where silica is present in the media. This could be explained by a stabilizing effect of the different polymeric silica species in solution that should be interacting with the cations, even when no solids were collected.

Besides the compared stability results, two additional conclusions could be inferred: there is an inherent stability "limit" for each OSDA depending on the synthesis conditions, mainly the temperature, after which the OSDA does not decompose any further, with little influence of the synthesis time after reaching this value; and this stability "limit" could be quickly and easily established by blank synthesis experiment. These two conclusions would allow to easily identifying the feasibility for any given cation to properly work as OSDA instead of performing the typical screening at different synthesis conditions, as any cation that completely and quickly decompose would hardly yield any solid product because of lacking the cationic "active species". Therefore, the use of blank experiments would be useful to save resources and research time during screening under different synthesis conditions when testing cations as OSDA's, allowing a fast discard of cations that quickly decompose.

\subsection{Experiment 2: generalized study of the OSDA stability}

Experiment 2 was performed next to expand the results of experiment 1 with more complex OSDA's, which could yield different crystalline phases. In this case, two additional phosphorous OSDA's were studied, an aminophosphonium cation and a phosphazene base. Therefore, the used OSDA's were the methyl-tris-(dimethylamino)-phosphonium cation (MNP, OSDA-3); the methyl-tri-isopropylphosphonium cation (MIP, OSDA-4); the di-isopropyl-diethylammonium cation (IEN, OSDA-5); and the commercial phosphazene base P1-t-Bu (PB1, OSDA-6) in its cationic phosphazenium form, schemed in Figure 4.11. 


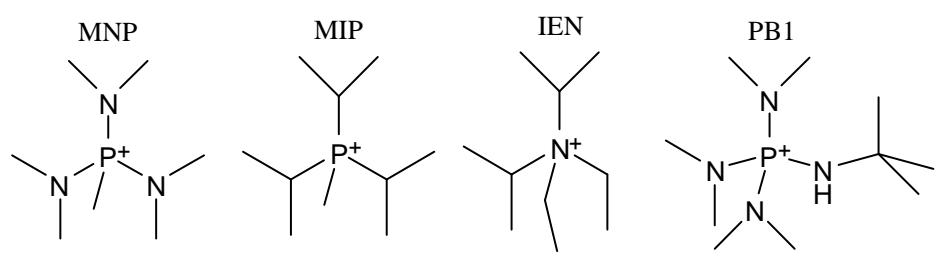

Figure 4.11. Methyl-tris-(dimethylamino)-phosphonium cation (MNP), methyl-tri-isopropylphosphonium cation (MIP), di-isopropyl-diethylammonium cation (IEN) and phosphazene base P1-t-Bu (PB1) used as OSDA's in experiment 2.

The detailed syntheses and analyses of the MNP (OSDA-3), MIP (OSDA-4), IEN (OSDA-5) and PB1 are described in sections 3.2.1.3, 3.2.1.4, 3.2.1.5 and 3.2.1.6, respectively. Some examples of synthesis gels are detailed in section 3.2.2.1.

\subsubsection{Solid products}

In this experiment, only one temperature, $150^{\circ} \mathrm{C}$, was studied to simplify the results of this experiment, as the previous experiment showed that, although the temperature is a critical parameter regarding stability, it could be however ruled out when comparing the relative stability of different OSDA's. Furthermore, a borosilicate composition was essayed instead of blank experiments to study the influence of the presence of heteroatoms for the stability of the OSDA's.

\subsubsection{Crystallinity of solid products}

In this experiment, different crystalline phases, which comprise STF, RTH, ITE and ITQ-45 zeolites, were obtained depending on the OSDA and the synthesis conditions as shown in Table 4.2 . 
Table 4.2. Tested synthesis conditions and phase selectivity obtained using the methyl-tris-(dimethylamino)-phosphonium cation (MNP), the methyl-tri-isopropylphosphonium cation (MIP), the di-isopropyl-diethylammonium cation (IEN), and the phosphazene base P1-t-Bu (PB1) as OSDA's.

\begin{tabular}{|c|c|c|c|c|c|}
\cline { 3 - 6 } \multicolumn{2}{c|}{} & \multicolumn{4}{c|}{ OSDA } \\
\hline \multicolumn{2}{c|}{ Composition } & IEN & MIP & MNP & PB1 \\
\hline Si & HF & & & & \\
\cline { 4 - 6 } & & & & \\
\hline B-Si & \multirow{2}{*}{$\mathrm{OH}$} & & & & \\
\hline B-Si & & & & \\
\hline
\end{tabular}

\section{\begin{tabular}{l|l|l|l|l|l} 
STF & RTH & ITE & ITQ-45 & MTN & Am.
\end{tabular}}

Further discussion on the phase selectivity and sample characterization of the materials obtained with these OSDA's could be found in previous works, ${ }^{[7,8]}$ while in this thesis, the discussion is focussed on the stability of the OSDA's. Because of that, little characterization of the solid materials is included in this chapter, besides identifying the phase crystallinity by powder X-Ray diffraction, whose patterns are shown in Figure 4.12. 


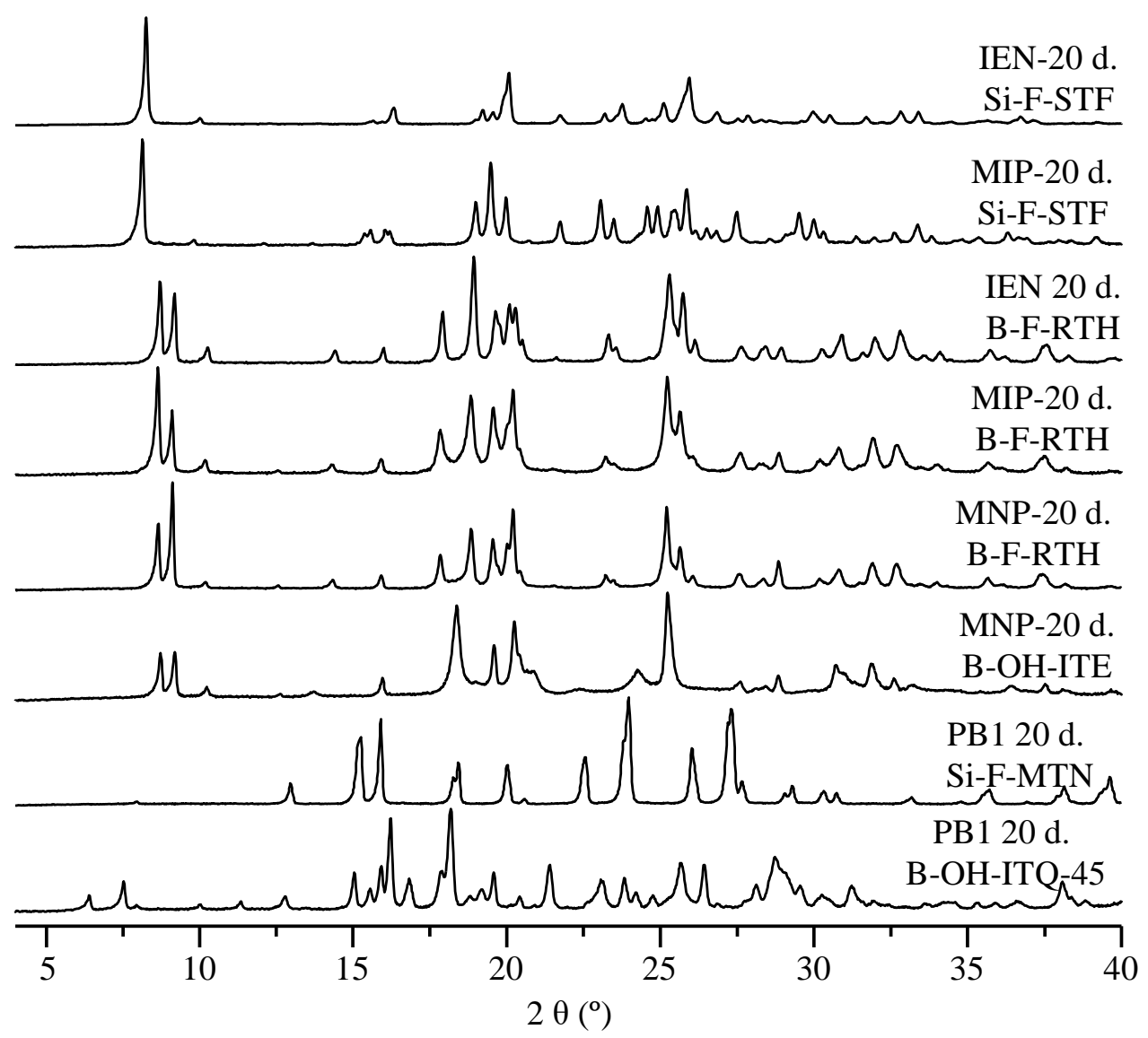

Figure 4.12. Powder X-Ray powder diffraction patterns of some of the obtained materials.

Samples are identified by used OSDA, synthesis time, composition and synthesis media.

As expected, the crystallinity of the different materials is linked with the synthesis times and thus, crystallization kinetics curves were calculated and shown in Figure 4.13. The crystallinity of the samples was calculated by the same methodology previously explained in section 4.2.1.1, but using the diffraction peaks between $2 \theta 18^{\circ}$ and $21^{\circ}$. However, only phases obtained with two or more OSDA's using the same synthesis gel compositions are compared. 


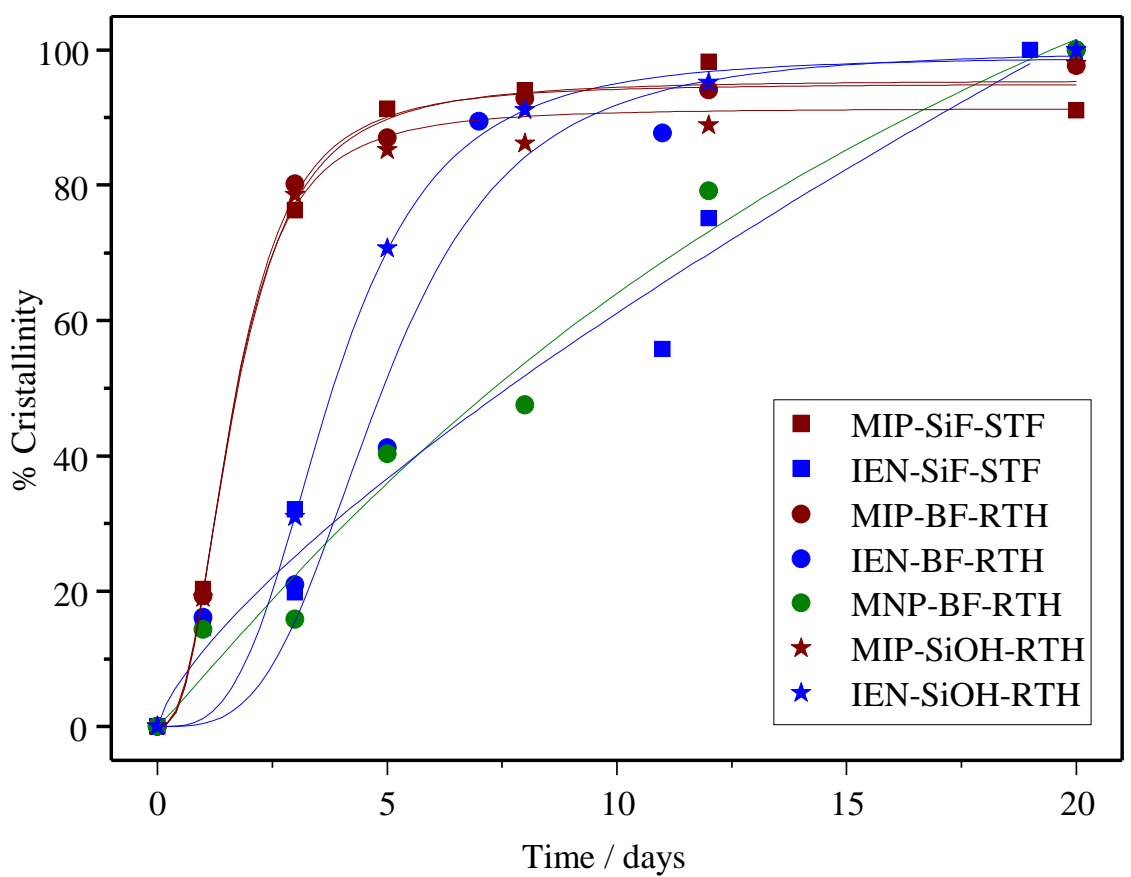

Figure 4.13. Crystallization kinetics of borosilicate RTH (circles), all-silica RTH (asterisks) and all-silica STF (squares) obtained with IEN (blue dots), MIP (red dots) and MNP (green dots) as OSDA's. Lines are just for guidance.

First, it could be seen that RTH and STF zeolites obtained using MIP as OSDA (red dots) crystallize very fast and can be obtained fully crystalline in less than 5 days. However, the corresponding materials obtained using IEN as OSDA (blue dots) present lower crystallization rates than the corresponding MIP materials, which is in good agreement with the results from experiment 1 in section 4.3.1.1.

On the other side, the crystallization rates between the RTH and STF zeolites obtained using IEN as OSDA strongly differ, as the crystallization rate of RTH zeolite (blue circles and asterisks) closely resembles to that obtained with MIP as OSDA (red circles and asterisks), although slightly slower. Conversely, the crystallization rate of STF zeolite obtained using IEN as OSDA (blue squares) is considerably lower than the corresponding material obtained using MIP as OSDA (red squares).

Finally, the crystallization rate of the RTH zeolite obtained using MNP as OSDA (green circles) is considerably lower than the corresponding RTH materials obtained using MIP (red circles) and IEN (blue circles) as OSDA's. 
From these data it could be hypothesized that the MIP cation fits well as OSDA for the synthesis of both RTH and STF zeolites, while the IEN cation fits better as OSDA for RTH zeolite than for STF zeolite.

About the other materials, the ITE zeolite fully crystallized after 3 days, while ITQ-45 started crystallizing between 8 and 12 days, being almost totally crystalline after 12 days, as reported in previous works. ${ }^{[7,8]}$ It is also noteworthy the crystallization of the dense phase dodecasil 3C (MTN).

\subsubsection{Chemical analyses of solid products}

The chemical composition of the most crystalline solid products are shown in Table 4.3 .

Table 4.3. Typical chemical compositions of some of the obtained materials. Ratios are given as molar ratios. Samples are named after the used OSDA and the obtained phase.

\begin{tabular}{cccccc}
\hline Phase & Si/B & Si/OSDA & $\begin{array}{c}\text { OSDA content } \\
/ \mathrm{mmol}^{-1} \mathrm{~g}^{-1}\end{array}$ & $\begin{array}{c}\mathrm{C} / \mathrm{P}_{\text {exp }} ; \\
\left(\mathrm{C} / \mathrm{N}_{\text {exp }}\right)\end{array}$ & $\begin{array}{c}\mathrm{C} / \mathrm{P}_{\text {th }} ; \\
\left(\mathrm{C} / \mathrm{N}_{\text {th }}\right)\end{array}$ \\
\hline IEN-STF & - & 15.4 & 0.88 & $(10.3)$ & $(10)$ \\
MIP-STF & - & 15.8 & 0.86 & 10.5 & 10 \\
IEN-RTH & 24.1 & 14.9 & 0.88 & $(10.0)$ & $(10)$ \\
MIP-RTH & 20.2 & 14.3 & 0.92 & 11.0 & 10 \\
MNP-RTH & 22.0 & 15.3 & 0.86 & $7.3(3.4)$ & $7(3.5)$ \\
MNP-ITE & - & 14.9 & 0.92 & $7.4(3.4)$ & $7(3.5)$ \\
PB1-MTN & - & - & - & $-(2.5)$ & $10(2.5)$ \\
\hline PB1-ITQ-45 & 24.6 & 22.8 & 0.58 & $10.4(2.7)$ & $10(2.5)$ \\
\hline
\end{tabular}

In this case, the OSDA content in the solid products differs for each phase, while the OSDA content for the same phase and different OSDA's remains constant, as previously seen in experiment 1 in section 4.2.1.2. It could be seen that in all borosilicate materials, the silicon to boron ratio is similar to the used in the synthesis gel, while the silicon to OSDA ratios are similar between the same phase regardless of the used OSDA. The kinetics of incorporation of the OSDA's were not calculated, as results from experiment 1 have shown that the OSDA content is constant from the beginning of the zeolite formation process. It is remarkable the analysis of the MTN phase, as no phosphorus was incorporated, suggesting that the PB1 OSDA is decomposed and their decomposition products leads to the MTN phase. 


\subsubsection{Mother liquor analyses}

Analogously to experiment 1 , the mother liquors were analysed to study the stability of the OSDA excess after undergoing the hydrothermal synthesis. The mother liquors were analysed by liquid NMR spectroscopy, but in this case, after taking in account the quantification results in experiment 1 , the quantification and mass balance were not calculated.

\subsubsection{OSDA stability}

Like in experiment 1 , the stability of the OSDA's was tracked by liquid ${ }^{31} \mathrm{P}$ and ${ }^{13} \mathrm{C}$ NMR spectroscopies. Some of the NMR spectra are shown in Figure 4.14, where the OSDA and decomposition resonances could be seen for all OSDA's.
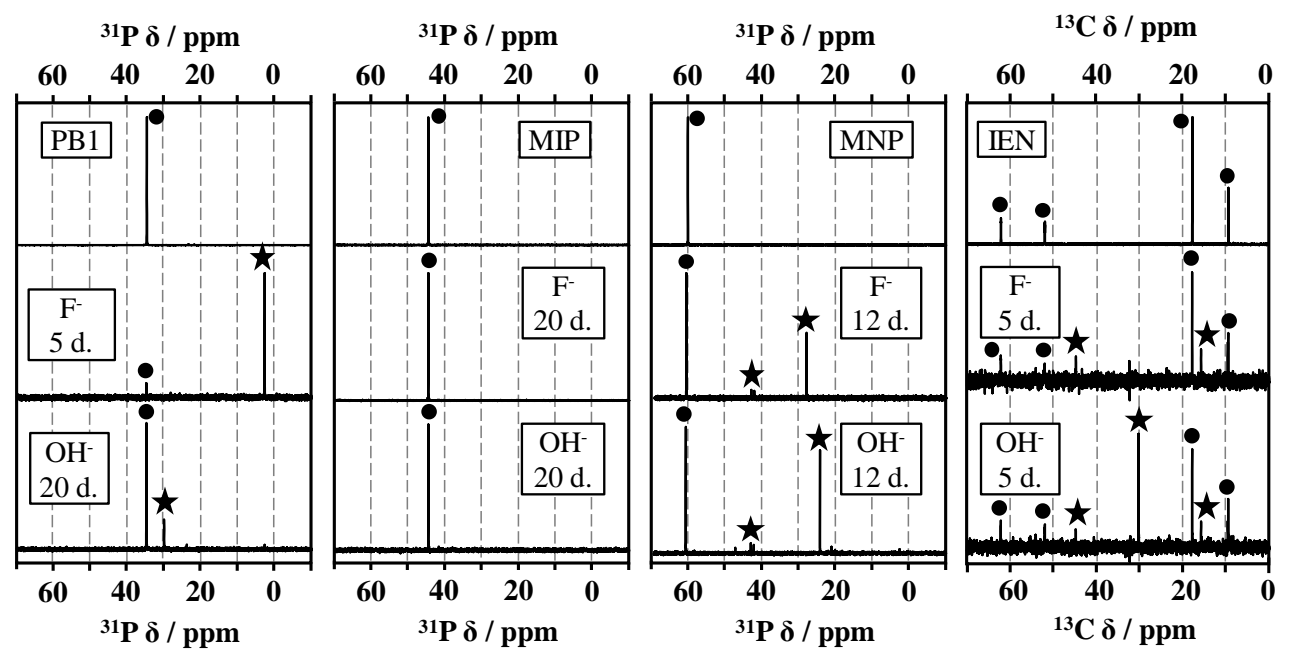

Figure 4.14. Liquid ${ }^{31}$ P-NMR spectra of PB1 cation (left), MIP cation (middle left), MNP cation (middle right) and ${ }^{13} \mathrm{C}$-NMR spectra (right) of IEN cation mother liquors. The upper spectra belong to the pure OSDA's. Resonances marked with asterisk are assigned to decomposition products. All samples were diluted in deuterium oxide solution.

The NMR spectra show resonances belonging to the intact OSDA's and several decomposition products, although in this case the higher complexity of the decomposition resonances makes it difficult to identify most of the decomposition compounds. 
In the case of the IEN OSDA, the methodology used in experiment 1 was adapted for this OSDA. In this case, there are more resonances in these spectra due to its more complex structure respect to TEA cation, and thus, decomposition products were not fully identified. Nevertheless, there is a clear correlation between closely related carbon resonances, which means that any decrease in the IEN cation carbon resonances belonging to the methyl or the methylene groups leads to an increase of a closely related carbon resonance.

$$
\text { Total \%IEN }=\frac{\left(\frac{\operatorname{Int}_{\text {IEN }}\left(\mathrm{CH}_{3}\right)}{\sum \text { Int } t_{\text {deg.prod. }}\left(\mathrm{CH}_{3}\right)}+\frac{\operatorname{Int} t_{\text {IEN }}\left(\mathrm{CH}_{2}\right)}{\sum \text { Int } t_{\text {deg.prod. }}\left(\mathrm{CH}_{2}\right)}\right)}{2} \cdot 100
$$

\section{Equation 4.3.}

Where $\frac{\operatorname{Int}_{I E N}\left(\mathrm{CH}_{3}\right)}{\sum I n t_{\text {deg.prod. }}\left(\mathrm{CH}_{3}\right)}$ is the ratio between the area of the ${ }^{13} \mathrm{C} \mathrm{NMR}$ spectra of $\mathrm{CH}_{3}$ resonance in IEN and the sum of all the ${ }^{13} \mathrm{C}$ NMR spectra of $\mathrm{CH}_{3}$ resonances in the mother liquor; $\frac{\text { Int } t_{I E N}\left(\mathrm{CH}_{2}\right)}{\sum I n t_{\text {deg.prod. }}\left(\mathrm{CH}_{2}\right)}$ is the ratio between the area of the ${ }^{13} \mathrm{C} \mathrm{NMR}$ spectra of $\mathrm{CH}_{2}$ resonance in IEN and the sum of all the ${ }^{13} \mathrm{C}$ NMR spectra of $\mathrm{CH}_{2}$ resonances in the mother liquor.

The degradation of the phosphorous OSDA's was studied only by liquid ${ }^{31} \mathrm{P}-\mathrm{NMR}$ spectroscopy, which simplifies the calculus and minimize any potential error introduced by additional analyses as ICP spectroscopy or sample weighting. Therefore, the degradation of phosphorous OSDA's was calculated by Equation 4.4.

$$
\text { Total } \% P_{O S D A}=\frac{P_{O S D A} \text { resonance area }}{\sum^{31} \text { P resonance area }} \cdot 100
$$

\section{Equation 4.4.}

Where $\frac{P_{\text {OSDA }} \text { resonance area }}{\sum^{31} \text { P resonance area }}$ is the ratio between the area of the ${ }^{31} \mathrm{P}$ NMR POSDA resonance and the sum of all the ${ }^{31} \mathrm{P}$ NMR resonances in the mother liquor.

Similarly to experiment 1 , the stabilities of IEN, MIP, MNP and PB1 cations in all syntheses were calculated by Equation 4.3 and Equation 4.4, respectively, and the corresponding stability results of IEN, MIP, MNP and PB1 cations are shown in Figure 4.15. 

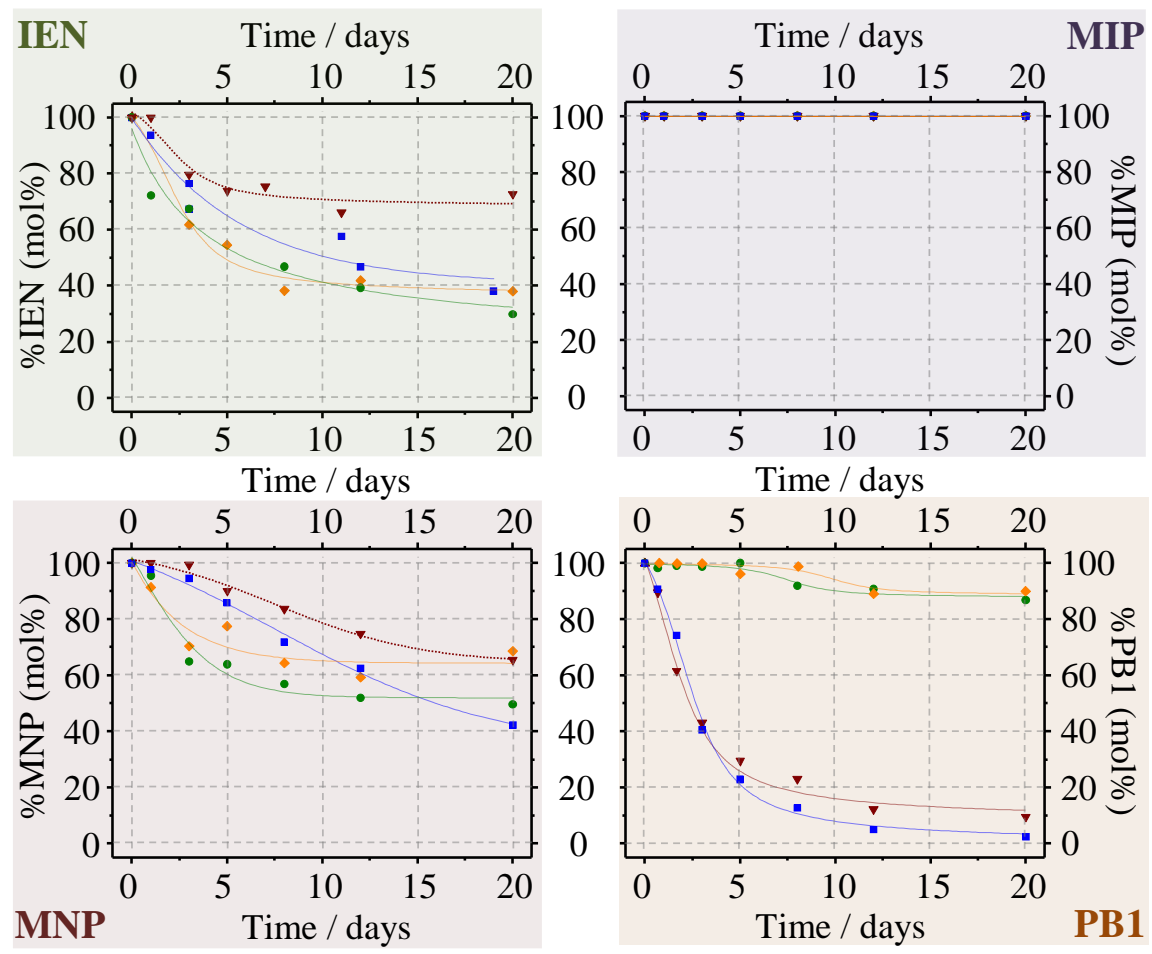

Figure 4.15. Stability curves of IEN (top left, green background), MIP (top right, purple background), MNP (bottom left, red background) and PB1 (bottom right, orange background) cations at different synthesis conditions ( $\square$ : all-silica fluoride synthesis; $\nabla$ : borosilicate fluoride synthesis; • : all-silica hydroxide synthesis; $\bullet$ : borosilicate hydroxide synthesis).

Curves are just for guidance.

The comparison between the IEN and MIP cations yields similar results to those obtained in experiment 1 , confirming that the phosphonium cations are more stable under hydrothermal conditions when compared with closely related ammonium cations. However, in this case the IEN cation is significantly less stable than the TEA cation at $150^{\circ} \mathrm{C}$, especially under fluoride media. This could be ascribed to the more complex carbon chain of the IEN cation compared with the TEA cation.

In the case of the MNP cation, a lower stability than its isostructural phosphonium counterpart, the MIP cation, was obtained. Actually, the stability exhibited by this cation closely resembles to the IEN cation. However, when comparing the MNP and IEN cations, it could be seen that the MNP cation is more stable under hydroxide media than the IEN 
cation, while under fluoride media, the MNP cation is less stable than the IEN cation, especially for longer synthesis times.

Finally, the PB1 cation present a completely different behaviour, as this cation is very stable under hydroxide media, but quickly decomposes under fluoride media. These stability results are in full agreement with the crystallization of the dense phase MTN, as this phase is known to be synthesized by small amines, obtained after the decomposition of the PB1 cation.

The PB1 cation is a special case because it is not closely related to the previously cations, as it presents a more complex molecular structure, but it was added in this study as the simplest model of the series of phosphazene bases.

The stability curves of the studied cations show that, generally, the cations are slightly more stable in borosilicate synthesis gels than in all-silica synthesis gels, following a similar trend than that observed in experiment 1, where all-silica and blank experiments were compared. This is assigned to the boron oxide species interacting, and eventually bonding, with the silicon oxide species, which generates an excess of negative charge in the borosilicate species. The interaction between the cationic OSDA's and these borosilicate species would lead to a higher stabilization of the OSDA cationic species than the interaction between the OSDA's and the silicate species.

\subsection{Conclusions}

The stability studies discussed in this chapter have proven that phosphorous cations generally present improved crystallization rates and stabilities respect to traditional alkylammonium cations when used as OSDA in the synthesis of zeolites.

- The use of phosphorous OSDA's increase the crystallization rate for a given phase compared with related ammonium OSDA's. This result suggests that there is a higher affinity between the phosphorous OSDA's and the zeolitic matrix than the corresponding ammonium OSDA's.

- The phosphorous OSDA stability is heavily influenced by the chemical nature of the phosphorous cations. Thus, phosphonium cations are more stable under any condition than closely related ammonium cations. Phosphazenium cations present a great stability in hydroxide media, but are highly unstable in fluoride media, while 
aminophosphonium cations present a middle stability under hydroxide and fluoride media.

- These results must be highlighted only while comparing closely related cations, as not every phosphorous OSDA is always more stable than any ammonium OSDA. However, these studies have led us to carry on more sensible screening syntheses for OSDA's in its more stable media depending on the chemical nature of the OSDA. For example, hydroxide media is prioritized over fluoride media when using phosphazene bases, while fluoride media is prioritized when using alkylphosphonium or alkylammonium cations as OSDA's in the synthesis of zeolites.

- The stability of OSDA's is influenced by the synthesis gel composition. Silicate species increase the stability of the cations, while the introduction of boron further increases the stability of the cation, even when no crystalline product is obtained. This leads to suggest the use of negatively charged additives which could enhance the stability of the cation in the synthesis media.

- The study of the stability of OSDA's is a useful complementary tool when testing cations as OSDA's. A quick decomposition could lead to the formation of species yielding different phase selectivity than the desired, while stable cations could be tested at higher temperatures and/or synthesis times. A stable OSDA could also be reused leading to an effective increase of the incorporation yield of the OSDA.

\subsection{References}

[1] L. Hey, C.K. Ingold, 136. Influence of poles and polar linkings on the course pursued by elimination reactions. Part XVII. Thermal decomposition of phosphonium ethoxides, Journal of the Chemical Society (Resumed), 0, 1933, 531-533.

[2] S. Kulkarni, V. Shiralkar, A. Kotasthanc, R. Borade, P. Ratnasamy, Studies in the synthesis of ZSM-5 zeolites, Zeolites, 2, 4, 1982, 313-318.

[3] M.A. Camblor, A. Corma, S. Valencia, Spontaneous nucleation and growth of pure silica zeolite-B free of connectivity defects, Chemical Communications, 20, 1996, 2365-2366.

[4] A. Corma, M.J. Díaz-Cabañas, Amorphous microporous molecular sieves with different pore dimensions and topologies: Synthesis, characterization and catalytic activity, Microporous and Mesoporous Materials, 89, 1, 2006, 39-46. 
[5] M.-A. Springuel-Huet, A.V. Moya, M. Diaz-Cabanas, A. Corma, A. Gedeon, Amorphous microporous molecular sieves studied by laser-polarized ${ }^{129} \mathrm{Xe}$ NMR spectroscopy, in: Studies in Surface Science and Catalysis, Elsevier, 170, 2007, 812-817.

[6] E.E. Ferg, A. Pizzi, D.C. Levendis, ${ }^{13} \mathrm{C}$ NMR analysis method for urea-formaldehyde resin strength and formaldehyde emission, Journal of Applied Polymer Science, 50, 5, 1993, 907-915.

[7] M. Hernández-Rodriguez, Empleo de Cationes Fosfonio como Agentes Directores de Estructura (ADEs) en la Síntesis de Zeolitas, Universitat Politècnica de València, 2014.

[8] R. Simancas, Síntesis de Nuevos Materiales Zeolíticos empleando Agente Directores de Estructura Fosforados, Universitat Politècnica de València, 2015. 


\section{Chapter 5}

\section{Phosphorus Modified}

\section{$\underline{\text { Zeolites }}$}

\subsection{Introduction}

The optimization of the catalytic performance is a critical issue in zeolitic materials. This could be done by post-synthesis treatments, as cation exchange,$^{[1,2]}$ desilication, ${ }^{[3,4]}$ dealumination ${ }^{[5,6]}$ or by the introduction of extra-framework phosphorous species, ${ }^{[7]}$ among others. ${ }^{[8,9]}$ The final properties of the catalyst will depend on the zeolite structure and pore topology, the textural and adsorption properties, the acid strength, concentration and type of acid sites (Brönsted and/or Lewis) of active sites, etc. These properties should be tuned in order to match with those required for the desired catalytic process.

The use of phosphorous OSDA's allows introducing phosphorous species by direct synthesis, and thus, after the thermal treatment of the material, extra-framework phosphorous species are formed avoiding further post-synthesis treatments. Because of that, zeolites synthesized using phosphorous OSDA's have the potential to selectively incorporate specific amounts of phosphorus as extra-framework phosphorous species. Moreover, this would 
allow for introducing phosphorus in small pore zeolites, where post-synthesis treatments are not available because of diffusion constraints. ${ }^{[7,10]}$

In this chapter, phosphorous-modified zeolites were synthesized using phosphorous OSDA's in order to get specific amounts of phosphorus into the final materials.

Two different materials were studied, the MFI and RTH zeolites. The MFI zeolite was selected for two main reasons: it is a well-known material with a large number of documented post-synthesis phosphorous treatments; ${ }^{[1-13]}$ and the phosphorous OSDA used for its synthesis, the TEP cation, is simple and commercially available, which allows to carry on a large number of experiments using different synthesis strategies until developing a successful methodology.

However, the synthesis of phosphorous-modified MFI zeolite is the starting point, because the final objective is the synthesis of phosphorous-modified small pore zeolites, where post-synthesis treatments with phosphoric acid are useless because of diffusion constraints. After developing the methodology to synthesize phosphorous-modified zeolites, this methodology was extended to the synthesis of RTH zeolite, as it is a small pore zeolite whose synthesis could be done with ammonium and phosphonium OSDA's. ${ }^{[14-18]}$

\subsection{MFI zeolite}

The ZSM-5 (IZA structure code: MFI) zeolite is a tri-directional medium pore channel system zeolite with $10 \mathrm{MR}$ pore openings. It presents two sets of perpendicular and intersecting channels, one straight and the other sinusoidal. This zeolite has achieved a large number of applications, especially in catalytic processes. ${ }^{[19-23]}$ Thus, the MFI zeolite has been deeply studied, and a broad range of several compositions ${ }^{[24-29]}$ and the use of several OSDA $^{\prime} \mathrm{s}^{[30-32]}$ have been reported for its synthesis.

The post-synthesis treatments in ZSM-5 zeolite play a key role in achieving the required properties for its industrial application. Among others, the post-synthesis treatment with phosphorus, especially with phosphoric acid, have been extensively applied and studied to increase the thermal stability under steam conditions of the aluminium-containing MFI zeolite. $^{[10,33-36]}$ The phosphorus-treated ZSM-5 zeolite has shown improved catalytic performance over untreated counterparts in cracking of vacuum gasoil, which is one of the major commercial applications of MFI zeolites. ${ }^{[21-23]}$ 
Chapter 5: Phosphorous-modified zeolites

\subsubsection{Dual template P-modified all-silica MFI zeolite}

In this section, the incorporation of phosphorus in the MFI zeolite was performed using a dual-template synthesis methodology. ${ }^{[37,38]}$ Two OSDA's, an ammonium OSDA, tetraethylammonium cation (TEA, OSDA-1), and a phosphonium OSDA, tetraethylphosphonium cation (TEP, OSDA-2), were jointly used in the same synthesis gel (Figure 5.1). The detailed characterization of the TEA and TEP cations are described in sections 3.2.1.1 and 3.2.1.2, respectively.

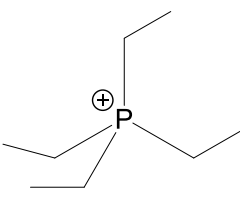

(a)

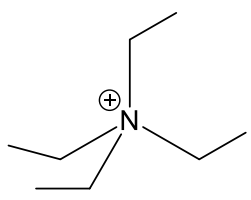

(b)

Figure 5.1. a) Tetraethylphosphonium cation (TEP) and b) tetraethylammonium cation (TEA).

Synthesis gels with the following molar composition were prepared:

$$
1.0 \mathrm{SiO}_{2}: 0.4 \mathrm{OSDA}_{\mathrm{P}+\mathrm{N}}: 10 \mathrm{H}_{2} \mathrm{O}: 0.4 \mathrm{HF}
$$

Where OSDA $_{P+N}$ is TEA, TEP or a mixture of both cations with TEP/(TEA+TEP) ratios ranging from 0 to 1 . Zeolites synthesized only with TEP or TEA are denoted as P-MFI or N-MFI, respectively, and those obtained with a mixture of OSDA's are named as $x \mathrm{P}-\mathrm{MFI}$ were $x$ refer to the TEP/(TEA+TEP), or $\mathrm{P} /(\mathrm{P}+\mathrm{N})$, molar ratio used in the synthesis gel or obtained in the solid, as specified. The details of the synthesis gel preparation are described in section 3.2.2.2. 
The obtained solids were identified by powder X-Ray diffraction, whose diffraction patterns are shown in Figure 5.2.

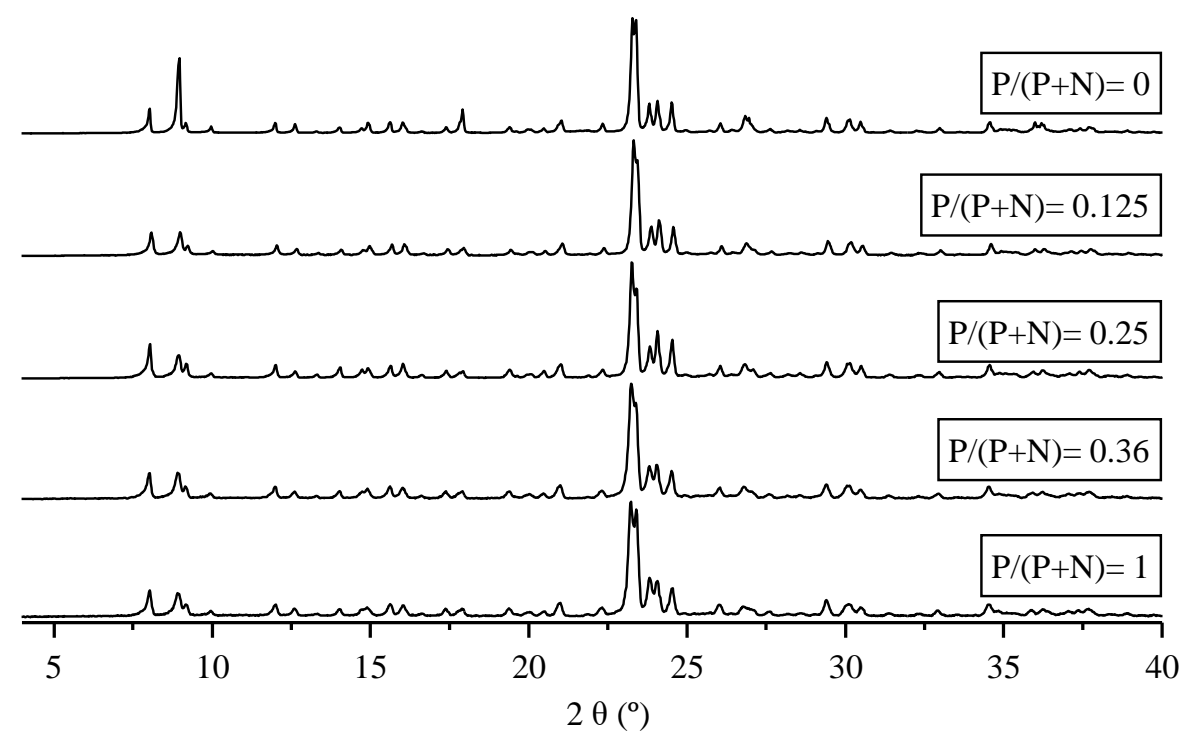

Figure 5.2. Powder X-Ray diffraction of some of the obtained materials. Diffractograms belong to the most crystalline material for each composition. Samples are identified by synthesis gel $\mathbf{P} /(\mathbf{P}+\mathbf{N})$ composition.

In all cases, highly crystalline MFI zeolite was the only product. The $\mathrm{pH}$ of the synthesis gels using a mix of TEA ad TEP as OSDA's was slightly higher than the synthesis gels using only TEA or TEP as OSDA. This fact drives these mixed OSDA synthesis gels towards the crystallization of zeolite $\beta$ when water to silica ratio is lower than 8 , leading to MFI samples with a little amount of zeolite $\beta$ impurities. However, when water to silica ratio is over 10 , no zeolite $\beta$ was obtained. 
The crystallization rates differ depending on the OSDA composition, as crystallization curves shown in Figure 5.3. Crystallinity was calculated as described in section 4.2.1.1.

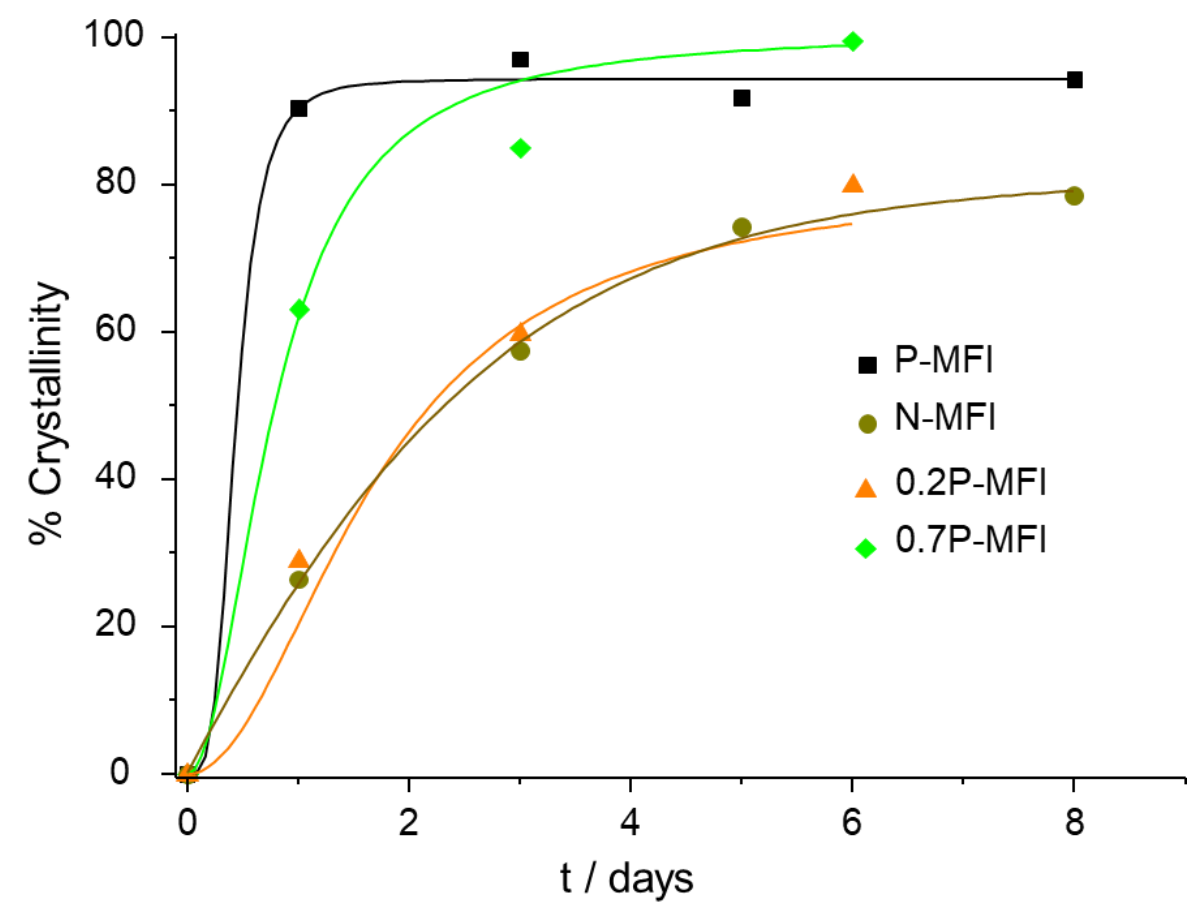

Figure 5.3. Crystallization kinetics of some of the obtained Si-MFI materials. Samples are identified by synthesis gel $\mathrm{P} /(\mathbf{P}+\mathrm{N})$ composition. Lines are just for guidance.

The crystallization rate using the P-OSDA is higher than the observed using the N-OSDA, although this increase in the crystallization rate does not proportionally increases as the P-OSDA content does. Actually, the crystallization rate of MFI with a majority of TEA or TEP closely resembles the crystallization rate when only using TEA or TEP as OSDA, respectively. These results are in agreement with previously observed from the stability study in section 4.2.2.2, which suggests that there is a higher affinity between the phosphonium OSDA's and the zeolitic matrix than the corresponding ammonium OSDA's. 


\subsubsection{Chemical analyses of as-made P-modified all-silica MFI zeolite}

The typical chemical compositions of the obtained all-silica MFI materials are shown in Table 5.1.

Table 5.1. Chemical compositions of some of the obtained Si-MFI materials. All ratios are given as molar ratios.

\begin{tabular}{cccccc}
\hline MFI Sample & {$[\mathrm{P} /(\mathrm{P}+\mathrm{N})]_{\text {gel }}$} & {$[\mathrm{P} /(\mathrm{P}+\mathrm{N})]_{\text {solid }}$} & wt.\%P & $(\mathrm{P}+\mathrm{N}) / \mathrm{mmol} \cdot \mathrm{g}^{-1}$ & $\mathrm{Si} / \mathrm{OSDA}$ \\
\hline N-MFI & 0 & 0.00 & 0.00 & 0.66 & 22.0 \\
\hline .1P-MFI & 0.0625 & 0.11 & 0.24 & 0.73 & 20.1 \\
\hline 0.2P-MFI & 0.12 & 0.26 & 0.54 & 0.67 & 22.8 \\
\hline 0.4P-MFI & 0.25 & 0.42 & 0.86 & 0.66 & 24.2 \\
\hline 0.5P-MFI & 0.36 & 0.53 & 1.07 & 0.65 & 23.3 \\
\hline $0.75 \mathrm{P}-\mathrm{MFI}$ & 0.5 & 0.75 & 1.52 & 0.66 & 24.6 \\
\hline 0.9P-MFI & 0.75 & 0.89 & 1.74 & 0.63 & 24.1 \\
\hline P-MFI & 1 & 1.00 & 1.99 & 0.64 & 23.5 \\
\hline
\end{tabular}

First, it could be observed that the amount of total OSDA, $(\mathrm{P}+\mathrm{N})$, and the silicon to OSDA ratios are similar in most of the materials regardless the synthesis gel composition, with a Si/OSDA ratio around 24, which fits with 4 OSDA molecules per unit cell of MFI structure (96 T units per unit cell). This result means that the incorporation of the OSDA is reliable and could be predicted beforehand.

Secondly, the ratio of P-OSDA respect to the amount of total OSDA, $\mathrm{P} /(\mathrm{P}+\mathrm{N})$, between the values added in the synthesis gel and the obtained in the synthesized material differ. The comparison between these values is plotted in Figure 5.4. 


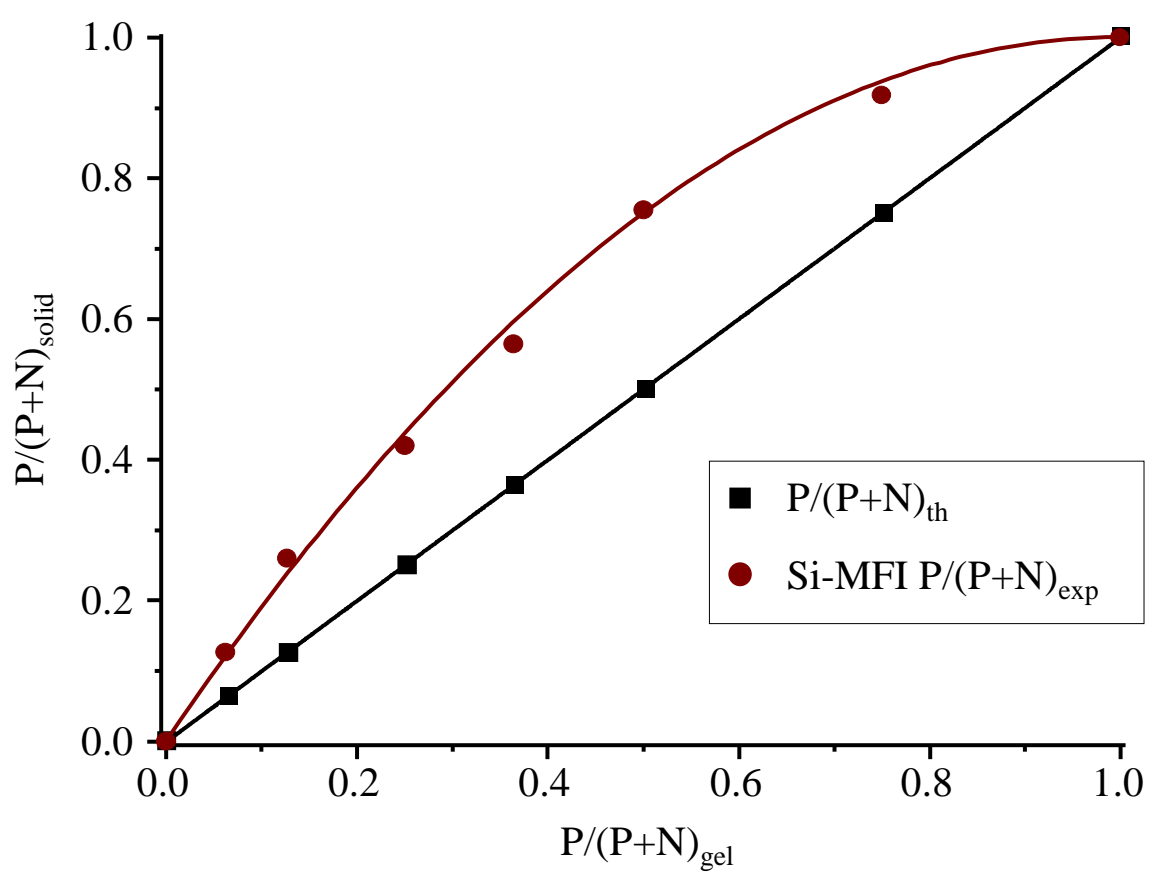

Figure 5.4. Comparison of $P /(P+N)$ compositions used in the synthesis gel, $P /(P+N)]_{\text {gel }}$, against the $\mathbf{P} /(\mathbf{P}+\mathrm{N})$ compositions obtained in Si-MFI zeolites, $[\mathrm{P} /(\mathbf{P}+\mathbf{N})]_{\text {solid. }} \mathrm{P} /(\mathbf{P}+\mathrm{N})_{\text {th }}$ refers to the theoretical compositions, while $\mathbf{P} /(\mathbf{P}+\mathrm{N})$ th refers to the experimental compositions.

The comparison of expected and experimental $\mathrm{P} /(\mathrm{P}+\mathrm{N})$ values reveals a clear preferential incorporation trend of the TEP cation over the TEA cation. This preferential incorporation could be indicative of a more powerful affinity and structure directing effect of the P-OSDA over the N-OSDA, which would agree with the increase of the crystallization rate previously described. This feature would help incorporating specific amounts of phosphorus in the final materials by direct synthesis. 


\subsubsection{Morphology of as-made P-modified all-silica MFI zeolite}

The crystallite shape and size of the as-made Si-MFI samples were assessed by FESEM microscopy analyses, depicted in Figure 5.5.
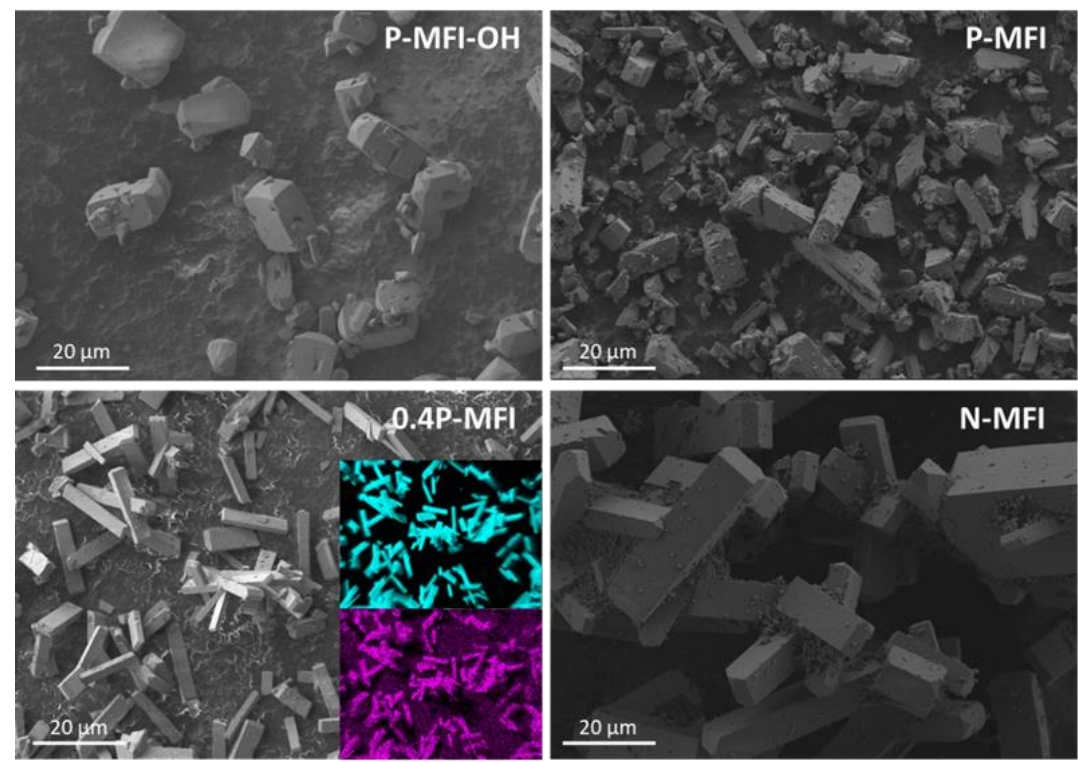

Figure 5.5. FESEM microimages of Si-MFI samples: P-MFI-OH, P-MFI, 0.4P-MFI (blue inset: Si mapping; purple inset: $P$ mapping) and N-MFI. Samples are identified by synthesized $\mathbf{P} /(\mathbf{P}+\mathbf{N})$ material composition. Hydroxide media P-MFI was included for comparison.

The crystallites of the obtained MFI zeolite exhibit a typical coffin shape. ${ }^{[39]}$ However, the crystal size and aspect ratio depends on the OSDA composition used during their syntheses. Thus, the N-MFI material present crystal sizes of about $60 \times 10 \mu \mathrm{m}$, decreasing to $20 \mathrm{x} 5 \mu \mathrm{m}$ for the 0.2P-MFI and the 0.4P-MFI materials, and even smaller in the P-MFI material. However, crystal size heterogeneity in this sample makes it difficult to give an average crystal size.

The phosphorus and silicon mapping EDX composition analyses of the materials (only 0.4P-MFI material shown in Figure 5.5 for simplicity), as well as dot EDX composition analyses (not shown here), reveal that the TEP OSDA is evenly distributed throughout the whole MFI crystals. Although the N-OSDA distribution could not be analysed by this technique, the evenly distribution of the P-OSDA leads to hypothesize that the N-OSDA is also evenly distributed, based on the nearly constant $\mathrm{P} /(\mathrm{P}+\mathrm{N})$ ratio obtained in each analysed 
Chapter 5: Phosphorous-modified zeolites

dot. Thus, it could be concluded that there is no inter- or intracrystalline gradients between the different OSDA's and the MFI zeolite matrix.

\subsubsection{Thermogravimetric analysis of as-made P-modified all-silica MFI zeolite}

The thermal stability and decomposition of the OSDA were studied by the thermogravimetry (TG) and differential thermogravimetry (DTG) analyses of the Si-MFI samples obtained with different OSDA compositions. Some thermogravimetric plots are shown in Figure 5.6.

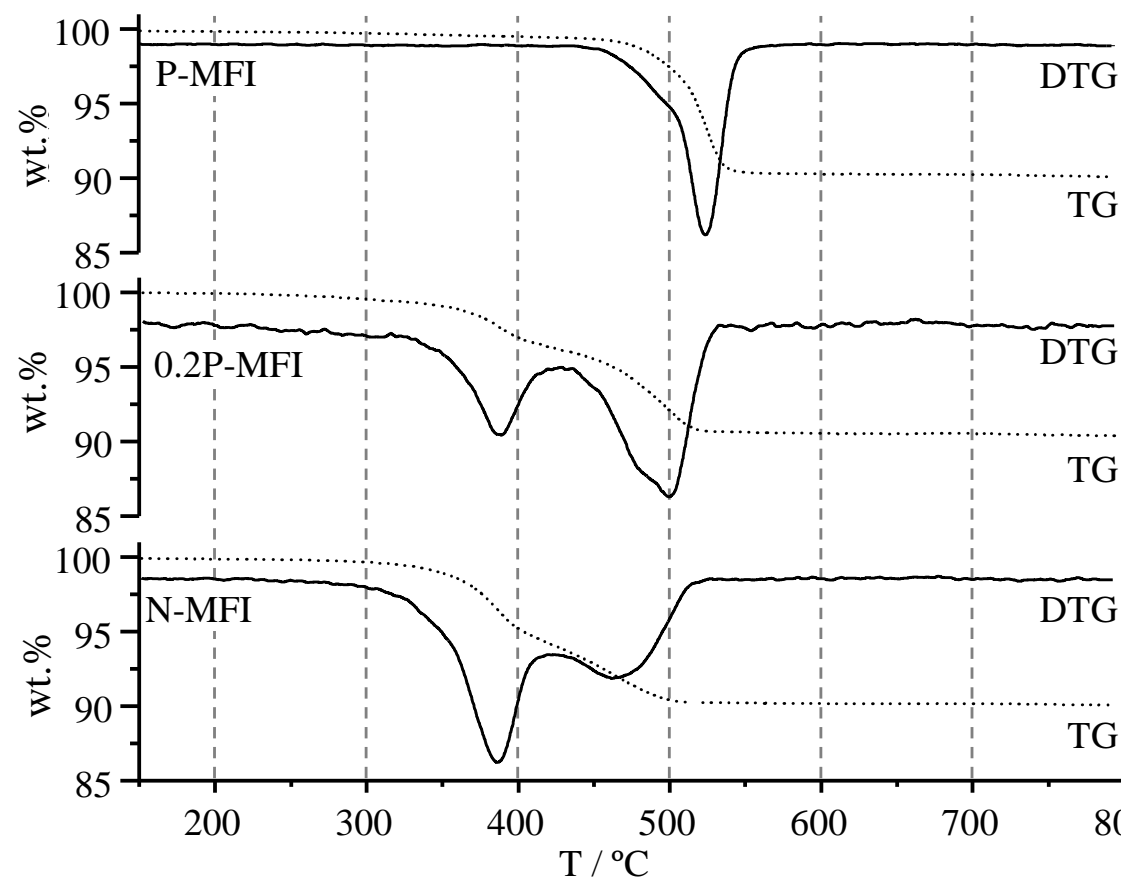

Figure 5.6. TG (dotted lines) and DTG (solid lines) analyses curves of the Si-MFI zeolites obtained with different $\mathrm{P} /(\mathrm{P}+\mathrm{N})$ ratios. Samples are identified by synthesized $\mathrm{P} /(\mathrm{P}+\mathrm{N})$ material composition. DTG curves are scaled up for a better view.

There is a clear difference between the thermal decomposition of the occluded TEP and TEA cations in MFI zeolite. The main weight losses occur at $\sim 380^{\circ} \mathrm{C}$ and at $\sim 520^{\circ} \mathrm{C}$ from the decomposition of TEA and TEP, respectively, indicating that the phosphonium cation is more thermally stable than the ammonium counterpart. As expected, the TG profile of the 
sample containing a mixture of OSDA's show two peaks due to the decompositions of TEA, slightly shifted towards higher temperature, and of TEP, shifted towards a lower temperature, at $\sim 500^{\circ} \mathrm{C}$.

The shift of the decomposition peaks towards a higher temperature for the TEA cation, and towards lower temperatures for the TEP cation, suggests that the two OSDA's are intimately mixed inside the MFI crystals and possibly interact between them.

The results obtained in this section constitute a benchmark for the synthesis of phosphorous-modified zeolites with a homogeneous distribution of the phosphorous species, so this methodology was applied for further studies on aluminosilicate materials, where the introduction of phosphorus becomes truly relevant. Further discussion and more detailed analyses, especially MAS-NMR spectra, of the samples obtained in this section are given in Martinez-Ortigosa et al. ${ }^{[40,41]}$

\subsubsection{Dual template P-modified aluminosilicate MFI zeolite}

After the results obtained in the previous section, the synthesis of MFI in its aluminosilicate form was performed. This was done preparing synthesis gels with the following molar composition:

$$
0.976 \mathrm{SiO}_{2}: 0.012 \mathrm{Al}_{2} \mathrm{O}_{3}: 0.4 \text { OSDA }_{\mathrm{P}+\mathrm{N}}: 15 \mathrm{H}_{2} \mathrm{O}: 0.4 \mathrm{HF}
$$

Where OSDA $_{\mathrm{P}+\mathrm{N}}$ is TEA, TEP or a mixture of both with TEP/(TEA+TEP) ratios ranging from 0 to 1 . Zeolites synthesized only with TEP or TEA are denoted as P-MFI or $\mathrm{N}-\mathrm{MFI}$, respectively, and those obtained with a mixture of OSDA's are named as $x \mathrm{P}-\mathrm{Al}(y)$-MFI were $x$ refer to the TEP/(TEA+TEP), or $\mathrm{P} /(\mathrm{P}+\mathrm{N})$ alternatively, molar ratio in the solid, and $y$ refers to the silicon to aluminium ratio, when used.

As previously, the obtained solids were identified by powder X-Ray diffraction, whose diffraction patterns are shown in Figure 5.7. 


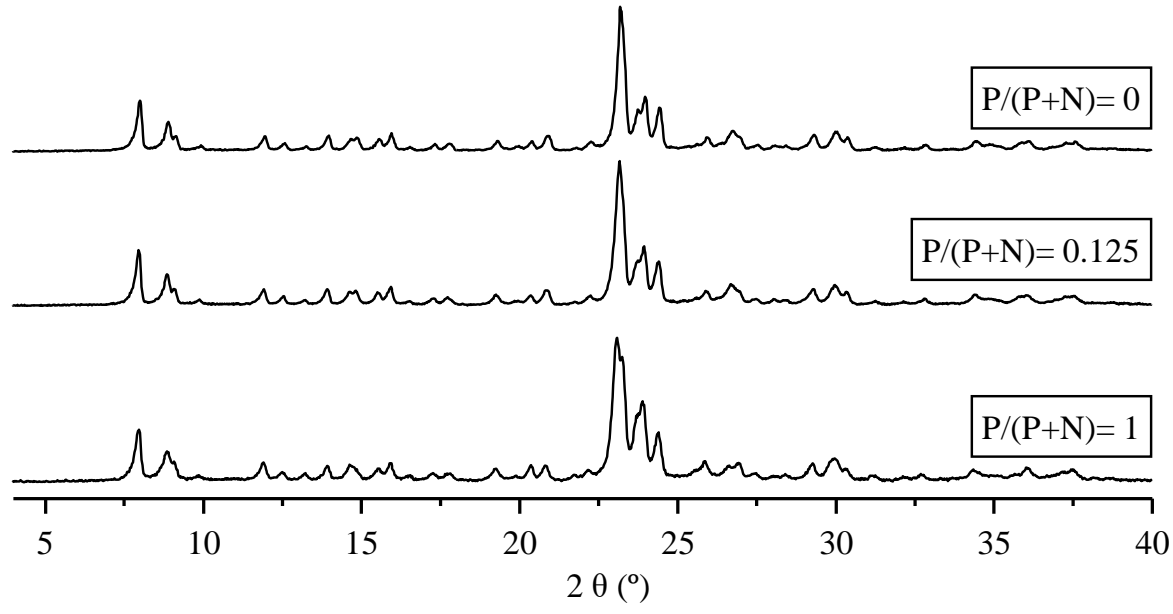

Figure 5.7. Powder X-Ray diffraction of some of the obtained materials. Diffractograms belong to the most crystalline material for each composition. Samples are identified by synthesis gel $\mathbf{P} /(\mathbf{P}+\mathbf{N})$ composition.

As previously observed, highly crystalline MFI zeolite was obtained in all cases. However, the water to silica ratio was increased to 15 in order to avoid zeolite $\beta$ impurities that were found at the first trials when using a water to silica ratio of 10 , as the $\mathrm{pH}$ in the synthesis gel further increases when aluminium hydroxide is added to the synthesis gel.

\subsubsection{Chemical analyses of as-made P-modified aluminosilicate MFI zeolite}

In this section only chemical analyses, thermogravimetry analyses and scanning electron microscopies of the obtained Al-MFI materials are compared, while MAS-NMR spectra is further discussed in sections 5.2.4.

The typical chemical compositions of the obtained Al-MFI materials are shown in Figure 5.2. 
Synthesis and characterization of zeolitic materials using P-OSDA

Table 5.2. Chemical compositions of some of the obtained Al-MFI materials. Ratios are given as molar ratios.

\begin{tabular}{cccccc}
\hline MFI Sample & {$[\mathrm{P} /(\mathrm{P}+\mathrm{N})]_{\text {gel }}[\mathrm{P} /(\mathrm{P}+\mathrm{N})]_{\text {sol }}$} & wt.\% $\mathrm{P}_{\text {sol }}$ & $(\mathrm{P}+\mathrm{N})(\mathrm{mmol} / \mathrm{g})$ & $(\mathrm{Si}+\mathrm{Al}) / \mathrm{OSDA}$ \\
\hline N-Al-MFI & 0 & 0 & 0 & 0.63 & 23.1 \\
\hline 0.1P-Al-MFI & 0.0625 & 0.12 & 0.23 & 0.60 & 24.4 \\
0.2P-Al-MFI & 0.125 & 0.23 & 0.45 & 0.64 & 22.8 \\
0.4P-Al-MFI & 0.25 & 0.40 & 0.78 & 0.62 & 22.2 \\
P-Al-MFI & 1 & 1 & 1.84 & 0.59 & 23.1 \\
\hline
\end{tabular}

As observed in the section 5.2.1, the amount of total OSDA, $(\mathrm{P}+\mathrm{N})$, and the silicon to OSDA ratio are similar in materials with different P-OSDA and N-OSDA ratios. The $\mathrm{Si} / \mathrm{OSDA}$ ratio present a value around 24 , which fits with 4 OSDA molecules per unit cell of MFI structure, as previously described in all-silica MFI materials. The ratio of phosphorous OSDA to the amount of total OSDA, $\mathrm{P} /(\mathrm{P}+\mathrm{N})$, between the values added in the synthesis gel and the obtained in the aluminosilicate materials are plotted Figure 5.8.

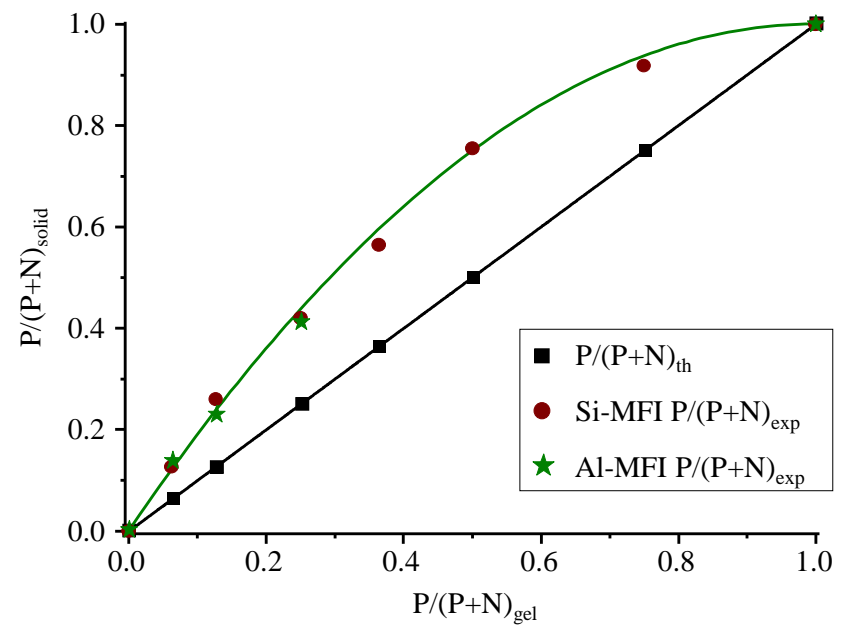

Figure 5.8. Comparison of $P /(P+N)$ values used in the synthesis gel, $P /(P+N)]_{\text {gel }}$, against the $\mathbf{P} /(\mathbf{P}+\mathbf{N})$ values obtained in Al-MFI materials, $[\mathrm{P} /(\mathbf{P}+\mathbf{N})]_{\text {solid. }} \mathbf{P} /(\mathbf{P}+\mathbf{N})$ th refers to the theoretical compositions, while $\mathrm{P} /(\mathrm{P}+\mathrm{N})_{\text {th }}$ refers to the experimental compositions. Values obtained for Si-MFI materials are also shown for comparison. 
Chapter 5: Phosphorous-modified zeolites

As previously seen in all-silica materials, there is a preferential incorporation of TEP over TEA that also follows the same trend as in all-silica MFI materials. This data confirms that this synthesis methodology is reliable to selectively incorporate specific amounts of phosphorus in the materials in the synthesis stage by tuning the P-OSDA and N-OSDA composition.

The aluminium and silicon incorporations to the materials are summarized in Table 5.3 .

Table 5.3. Heteroatom chemical compositions of some of the obtained Al-MFI materials. All ratios are given as molar ratios and $\mathrm{pH}_{\mathrm{gel}}$ was measured after adding $\mathrm{HF}$.

\begin{tabular}{cccccccc}
\hline MFI Sample & {$[\mathrm{Si} / \mathrm{Al}]_{\text {gel }}$} & $\mathrm{pH}_{\text {gel }}$ & $\eta_{\mathrm{Al}}(\%)$ & $\eta_{\mathrm{Si}}(\%)$ & {$[\mathrm{Si} / \mathrm{Al}]_{\mathrm{sol}}$} & $\mathrm{OSDA}_{\mathrm{P}+\mathrm{N}} / \mathrm{Al}$ & ${ }_{\mathrm{wt} .} \% \mathrm{P}_{\mathrm{sol}}$ \\
\hline N-Al-MFI & 40 & 8.2 & 100 & 85 & 35.9 & 1.5 & 0 \\
0.1P-Al-MFI & 40 & 8.4 & 100 & 84 & 33.5 & 1.4 & 0.23 \\
0.2P-Al-MFI & 40 & 8.4 & 100 & 86 & 36.4 & 1.6 & 0.45 \\
0.4P-Al-MFI & 40 & 8.5 & 100 & 82 & 31.2 & 1.4 & 0.78 \\
P-Al-MFI & 40 & 8.3 & 100 & 68 & 23.7 & 1.0 & 1.84 \\
\hline
\end{tabular}

The silicon to aluminium ratios of the materials decrease as the phosphorus content increases in the synthesis gel, giving rise to a high disparity between the silicon to aluminium ratios used in the synthesis gel and those obtained in the synthesized material in the all TEP material, P-Al-MFI. This could be explained by a stronger interaction between the phosphorous OSDA cation and the negatively charged tetrahedral aluminium centres over the corresponding ammonium OSDA cation interaction. Because of that, the aluminium to OSDA ratio falls from 1.5 in the N-Al-MFI to 1 in the P-Al-MFI, which would lead to a total compensation of charges. This stronger phosphorous OSDA-aluminium centres interaction would lead to a lower silica yield, as the aluminosilicate with a higher silicon to aluminium ratio would be less favoured during synthesis. 


\subsubsection{Morphology of P-modified aluminosilicate MFI zeolite}

The crystallite shape and size of the as-made Al-MFI samples were assessed by FESEM microscopy analyses, depicted in Figure 5.9.
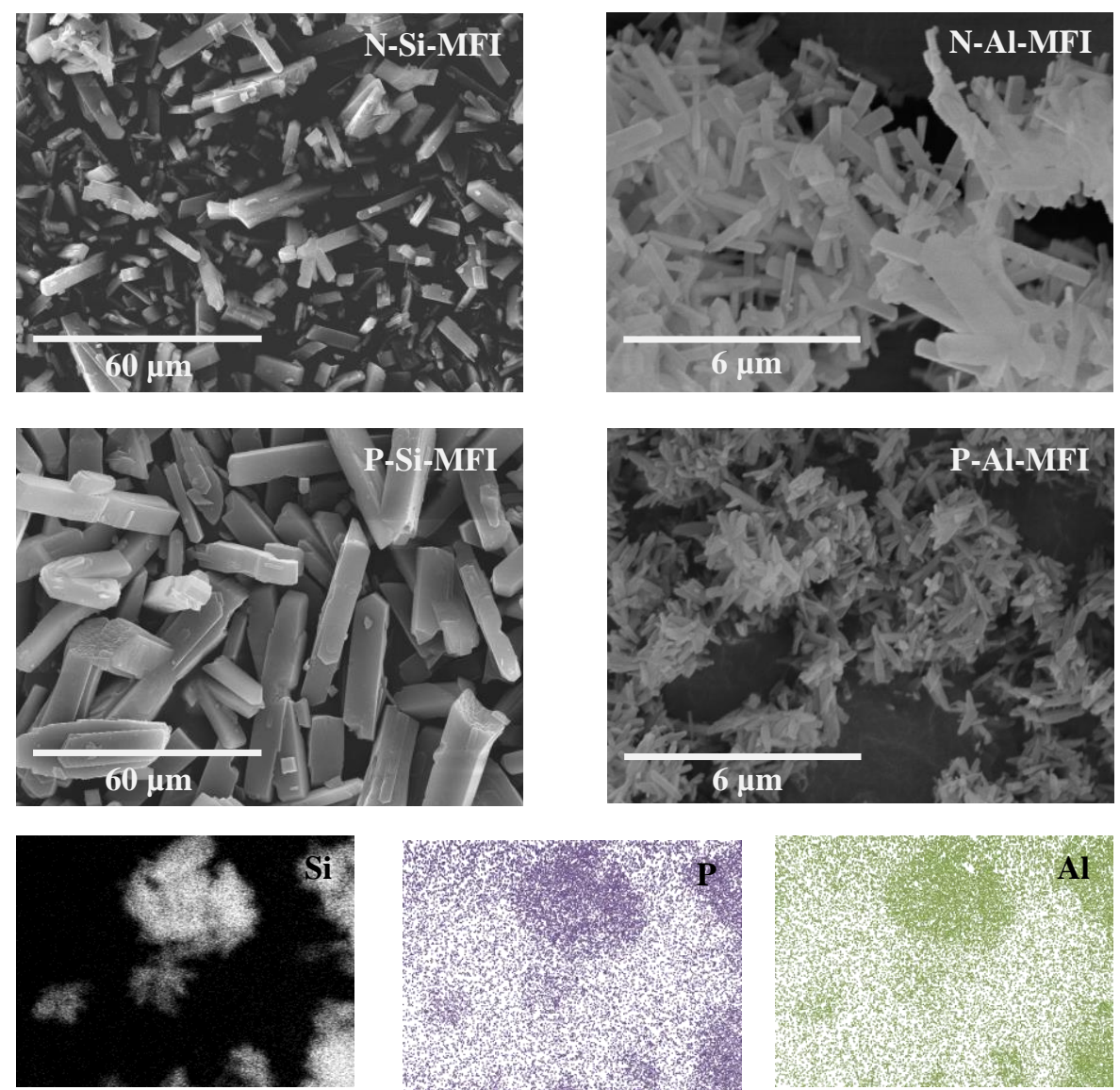

Figure 5.9. SEM microimages of N-OSDA (above) and P-OSDA (middle) comparing some Si-MFI (left) versus Al-MFI (right) samples. Below, Si (white), P (purple) and Al (green) compositional mapping of sample 0.4P-Al-MFI are shown. Samples are identified by synthesized $\mathbf{P} /(\mathbf{P}+\mathbf{N})$ material composition.

As previously observed in all-silica MFI samples, the crystallites of the obtained aluminosilicate MFI materials exhibit a typical coffin shape. However, the introduction of aluminium in the synthesis gels yields about ten-fold smaller MFI crystallites compared to the all silica MFI materials. Thus, N-Al-MFI presents crystal sizes of about $5 \times 0.5 \mu \mathrm{m}$, decreasing to $1 \mathrm{x} 0.2 \mu \mathrm{m}$ for P-Al-MFI, with mixed crystal sizes of intermediate samples 
ranging in-between (not shown here), although crystal size heterogeneity remains as high as in all-silica MFI samples.

Conversely to all-silica materials, P-Al-MFI crystallites are significantly smaller than N-Al-MFI crystallites, which could be derived from the lower silica incorporation in the P-Al-MFI due to the alumina source depletion. As previously, the chemical composition mapping of phosphorus, aluminium and silicon in the 0.4P-Al-MFI sample was assessed, revealing that the TEP OSDA is homogeneously distributed throughout the whole MFI crystals, which leads to hypothesize that the N-OSDA is also homogeneously distributed.

\subsubsection{Thermogravimetric analysis of as-made P-modified alumino- silicate MFI zeolite}

The thermal stability and decomposition of the OSDA were studied by the thermogravimetry (TG) and differential thermogravimetry analyses (DTG) of the Al-MFI samples obtained with different OSDA compositions. Some thermogravimetric plots are shown in Figure 5.10.

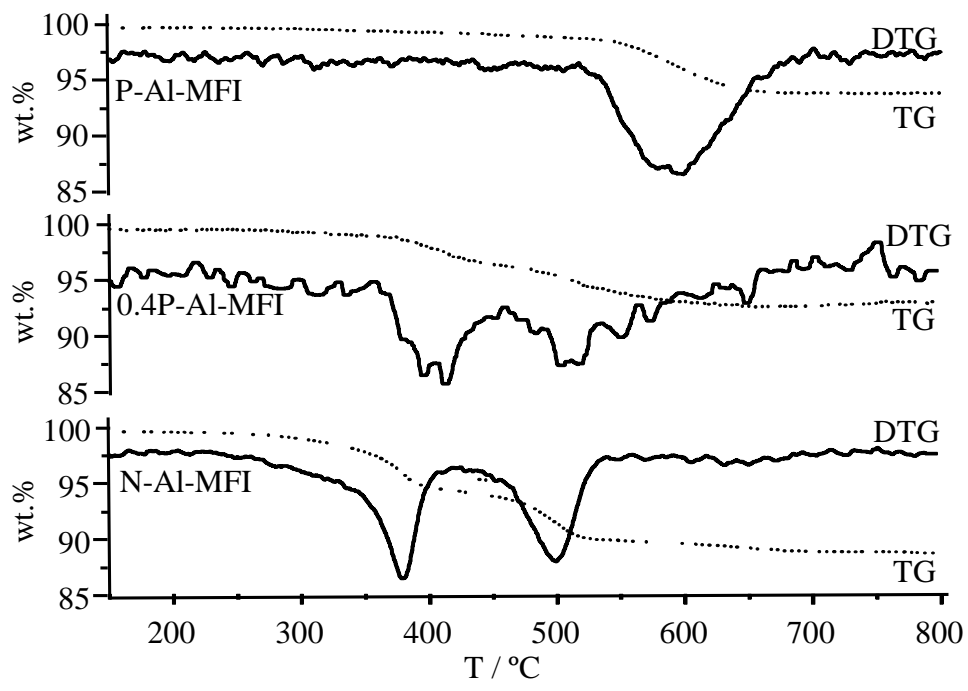

Figure 5.10. TG (dotted lines) and DTG (solid lines) analyses curves of the Al-MFI materials obtained with different $\mathrm{P} /(\mathrm{P}+\mathrm{N})$ ratios. Samples are identified by synthesized $\mathrm{P} /(\mathrm{P}+\mathrm{N})$ material composition. DTG curves are scaled up for a better view. 
As previously seen in 5.2.1.3 section, the decomposition of TEA still happens at $\sim 380^{\circ} \mathrm{C}$, but the main weight loss of the TEP shifts from $\sim 520^{\circ} \mathrm{C}$ to $\sim 600^{\circ} \mathrm{C}$, indicating that the TEP is further stabilized by the presence of aluminium, while the TEA cation decomposition temperature does not change due to the presence of aluminium. This is indicative of a stronger interaction between the P-OSDA and aluminium than between the $\mathrm{N}-\mathrm{OSDA}$ and aluminium.

Also, the TG patterns of samples containing a mixture of OSDA's show two peaks due to the decomposition of TEA, slightly shifted towards a higher temperature, and of TEP, that shifted towards a lower temperature, $\sim 550^{\circ} \mathrm{C}$. Like in all-silica materials, the shift of the OSDA decomposition temperatures suggests that the two OSDA's are intimately mixed inside the MFI crystals.

\subsubsection{Thermal treatments of P-modified aluminosilicate MFI zeolite}

The as-made aluminosilicate MFI materials were calcined under air and hydrogenated at high temperature following the general methodologies described in section 3.2.3, taking in account the presence of ammonium compounds in the as-made material. Powder X-Ray diffraction, chemical analyses, adsorption isotherms, and MAS-NMR spectroscopies were performed for the thermally treated Al-MFI materials. In this section only powder X-Ray diffraction, chemical analyses and adsorption isotherms are discussed, while MAS-NMR spectra are further discussed in section 5.2.4.

\subsubsection{Crystallinity of thermally treated P-modified aluminosilicate MFI zeolite}

The crystallinity of the aluminosilicate MFI samples after calcination was assessed by powder X-Ray diffraction, whose diffraction patterns are shown in Figure 5.11. 


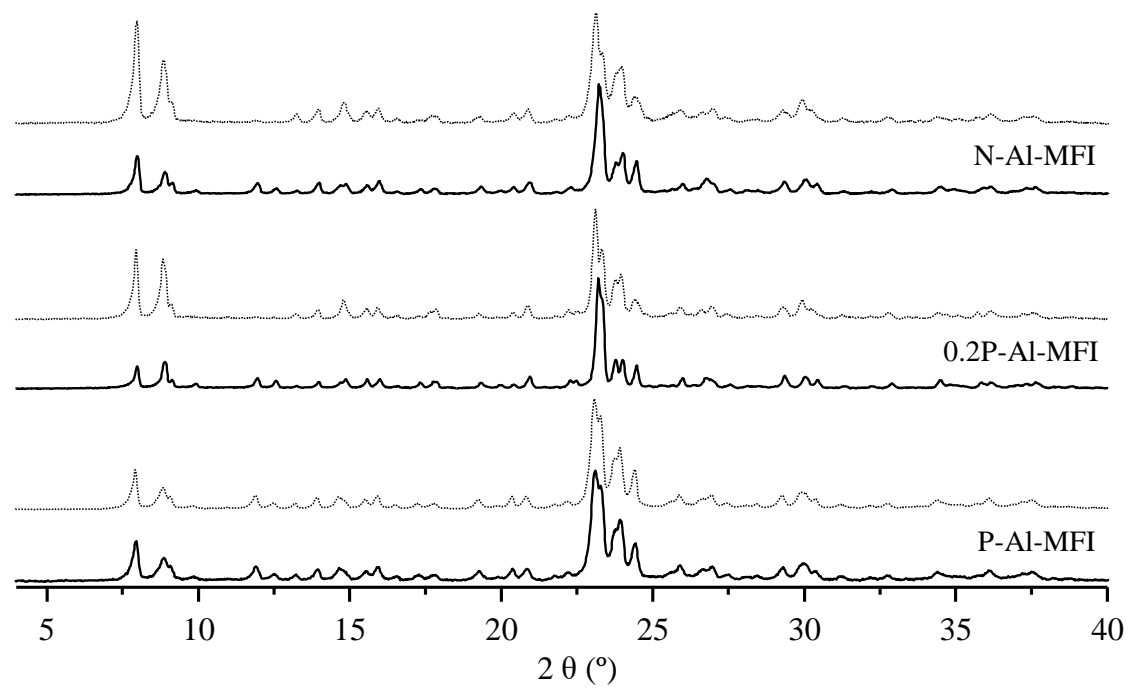

Figure 5.11. Powder X-Ray diffraction of some of the thermally treated Al-MFI materials. Solid lines correspond to as-made samples, while dotted lines correspond to calcined samples. Samples are identified by synthesized $\mathbf{P} /(\mathbf{P}+\mathbf{N})$ material composition.

The materials remain highly crystalline after the thermal treatments, and the X-Ray diffraction peaks are found at approximately the same $2 \theta$ degrees in all samples regardless of the thermal treatment. The main difference between the as-made and the thermally-treated samples is the intensity of the peaks at $2 \theta$ below $18^{\circ}$, as the intensity of these diffraction peaks are typically affected by the presence of the OSDA filling the pores of the zeolite.

\subsubsection{Chemical analyses of thermally treated P-modified alumino- silicate MFI zeolite}

The chemical compositions of the thermally treated aluminosilicate MFI materials are shown in Table 5.4. 
Synthesis and characterization of zeolitic materials using P-OSDA

Table 5.4. Chemical compositions of some of the thermally treated Al-MFI materials. Samples are identified by synthesized $\mathrm{P} /(\mathbf{P}+\mathrm{N})$ material composition. Ratios are given as molar ratios.

\begin{tabular}{ccccccc}
\hline Sample & Treatment & $\mathrm{Si}^{\prime} \mathrm{Al}_{\text {orig }}$ & $\mathrm{Si}^{\prime} \mathrm{Al}_{\text {treated }}$ & wt.\% $\mathrm{P}_{\text {orig }}$ & wt.\% $\mathrm{P}_{\text {treated }}$ & $\mathrm{P} / \mathrm{Al}$ \\
\hline N-Al-MFI & Calcination & 35.9 & 32.5 & 0 & 0 & 0 \\
\hline 0.1P-Al-MFI & Calcination & 33.5 & 31.0 & 0.23 & 0.26 & 0.2 \\
\hline 0.1P-Al-MFI & Hydrogenation & 33.5 & 32.0 & 0.23 & 0.09 & 0.1 \\
\hline 0.2P-Al-MFI & Calcination & 36.4 & 33.0 & 0.45 & 0.46 & 0.3 \\
\hline 0.2P-Al-MFI & Hydrogenation & 36.4 & 33.1 & 0.45 & 0.15 & 0.1 \\
\hline 0.4P-Al-MFI & Calcination & 31.2 & 29.8 & 0.78 & 0.84 & 0.5 \\
\hline 0.4P-Al-MFI & Hydrogenation & 31.2 & 29.9 & 0.78 & 0.12 & 0.1 \\
\hline P-Al-MFI & Calcination & 23.7 & 23.5 & 1.84 & 1.78 & 1.0 \\
\hline P-Al-MFI ${ }_{\text {was }}^{*}$ & Washing & 23.5 & 23.3 & 1.78 & 0.45 & 0.2 \\
\hline P-Al-MFI & Hydrogenation & 23.7 & 22.6 & 1.84 & 0.26 & 0.2 \\
\hline
\end{tabular}

*: parent sample correspond to calcined P-Al-MFI.

These data show that most of the phosphorus remains inside the solid after the calcination of the materials, while the hydrogenation at high temperature leads to the nearly total removal of the phosphorus from the material, up to $85 \mathrm{wt} . \%$.

The calcined P-MFI material was also washed with ammonium acetate $\left(\mathrm{NH}_{4} \mathrm{Ac}\right)$, resulting in a phosphorus removal of $75 \mathrm{wt} . \%$ respect to the parent material, yielding a final material with a slightly higher phosphorus content than the P-MFI material hydrogenated at high temperature. The details about the washing procedure with aqueous $\mathrm{NH}_{4} \mathrm{Ac}$ are given in section 3.2.3.3.

\subsubsection{Textural properties of P-modified aluminosilicate MFI zeolite}

The textural properties of the Al-MFI samples were calculated from the $\mathrm{N}_{2}$ adsorption isotherms at $77 \mathrm{~K}$ on the thermally treated samples, shown in Figure 5.12. 


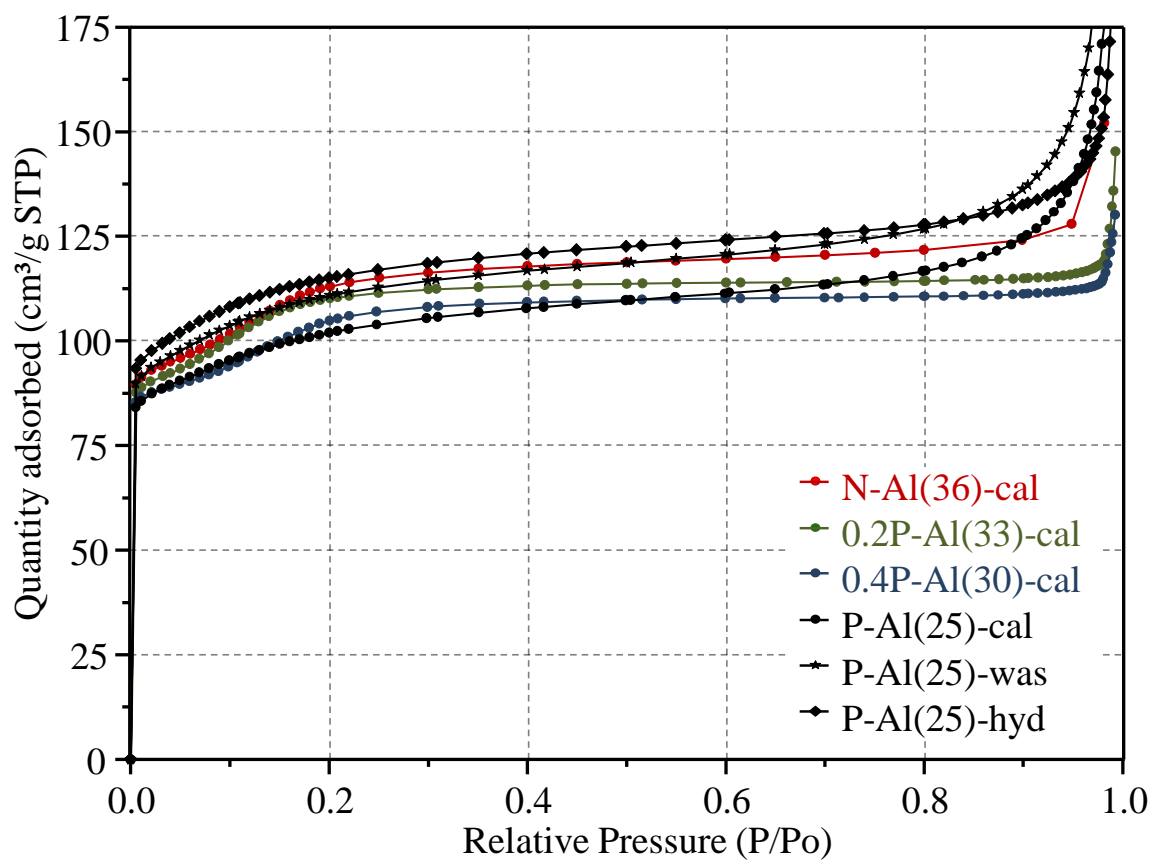

Figure 5.12. $\mathrm{N}_{2}$ adsorption isotherms of hydrogenated $\mathrm{P}$-AI(25)-MFI (red), calcined P-Al(25)MFI (green), calcined 0.2P-Al(32)-MFI (orange) and calcined N-AI(36)-MFI (blue).

The $\mathrm{N}_{2}$ adsorption isotherms of the thermally treated Al-MFI samples show the type Ia physisorption profile typical of microporous materials. ${ }^{[42]}$

The BET and micropore surface areas and the total micropore volume, calculated from the $\mathrm{N}_{2}$ adsorption isotherm at $77 \mathrm{~K}$ by applying the BET and t-plot method, are shown in Table 5.5. 
Table 5.5. Textural properties of some thermally treated Al-MFI samples. Samples are identified by synthesized $\mathrm{P} /(\mathbf{P}+\mathrm{N})$ material composition, with aluminium contents included in brackets. Ratios are given as molar ratios.

\begin{tabular}{cccccc}
\hline Sample & $\begin{array}{c}\text { BET } \\
\text { surface / } \\
\mathrm{m}^{2} \cdot \mathrm{g}^{-1}\end{array}$ & $\begin{array}{c}\text { Micropore } \\
\text { surface / } \\
\mathrm{m}^{2} \cdot \mathrm{g}^{-1}\end{array}$ & $\begin{array}{c}\text { Micropore } \\
\text { volume / } \\
\mathrm{cm}^{3} \cdot \mathrm{g}^{-1}\end{array}$ & P/Al & wt.\%P \\
\hline N-Al(36)-cal & 376.8 & 362.2 & 0.17 & 0 & 0 \\
\hline 0.1P-Al(32)-cal & 371.2 & 355.4 & 0.17 & 0.2 & 0.26 \\
\hline 0.2P-Al(33)-cal & 365.4 & 360.2 & 0.17 & 0.3 & 0.46 \\
\hline 0.4P-Al(30)-cal & 351.7 & 344.8 & 0.16 & 0.5 & 0.84 \\
\hline P-Al(25)-cal & 336.3 & 304.7 & 0.15 & 1.0 & 1.78 \\
\hline P-Al(25)-was & 364.7 & 330.9 & 0.16 & 0.2 & 0.45 \\
\hline P-Al(25)-hyd & 377.3 & 349.3 & 0.17 & 0.1 & 0.26 \\
\hline
\end{tabular}

The obtained BET surface area and micropore volume values show differences depending on the $\mathrm{P}$ content, both increasing as the phosphorus content decreases. These results are in agreement with the presence of extra-framework phosphorous species that hinder the diffusion throughout the pores of the zeolite.

\subsubsection{Acidic properties of thermally treated aluminosilicate MFI zeolite}

The acidic properties of the thermally treated aluminosilicate MFI samples were studied by ammonia thermoprogrammed desorption (TPD), obtaining the desorption mass spectrometry with $\mathrm{m} / \mathrm{e}=15$. The corresponding TPD curves are shown in Figure 5.13. 


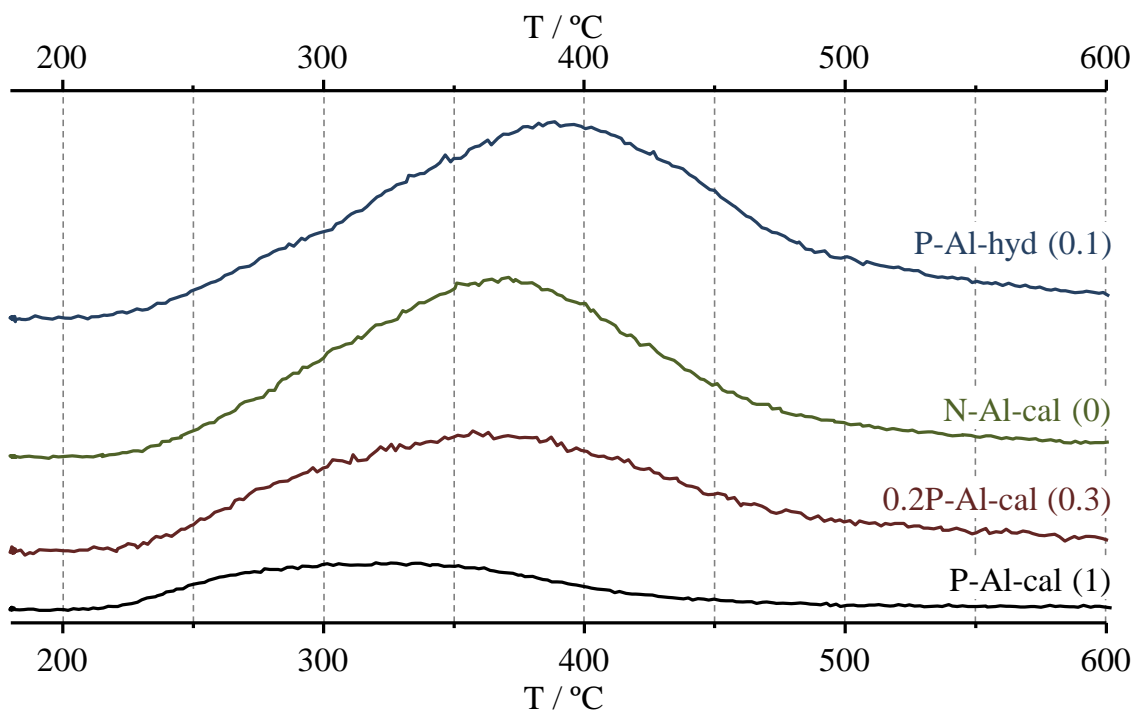

Figure 5.13. Ammonia TPD curves of some thermally treated Al-MFI samples. Samples are identified by synthesized $\mathrm{P} /(\mathrm{P}+\mathrm{N})$ material composition, with $\mathrm{P} / \mathrm{Al}$ ratio in brackets.

In all cases a single ammonia desorption peak was observed. This peak is due to ammonia strongly bounded to the material. ${ }^{[43,44]}$ The maximum temperature of ammonia desorption of the Al-MFI samples increases as the phosphorus content decreases, shifting from $325^{\circ} \mathrm{C}$ for P-Al-MFI sample, to $370^{\circ} \mathrm{C}$ for $\mathrm{N}$-Al-MFI sample. This temperature shift means a clear decrease of the acidity strength of the Al-MFI materials as phosphorus content increases, due to the interaction of the phosphorous species with the aluminium species. This interaction decreases the acid strength of these aluminium centres, and thus, the acidity of the final materials could be modulated by adjusting the $\mathrm{P} /(\mathrm{P}+\mathrm{N})$ ratio of the synthesized material, as was described in section 5.2.2.1.

The textural and acidic properties of the Al-MFI materials are summarized in Table 5.6. 
Table 5.6. Chemical analyses, textural properties and ammonia adsorption at $100^{\circ} \mathrm{C}$ of some thermally treated Al-MFI samples. Samples are identified by synthesized $\mathrm{P} /(\mathrm{P}+\mathrm{N})$ material composition. Ratios are given as molar ratios.

\begin{tabular}{ccccccc}
\hline Sample & Si/Al & P/Al & wt.\%P & $\begin{array}{c}\text { Micropore } \\
\text { volume } / \mathrm{cm}^{3} \cdot \mathrm{g}^{-1}\end{array}$ & $\begin{array}{c}\mathrm{V}_{\mathrm{NH} 3} / \\
\mathrm{cm}^{3} \cdot \mathrm{g}^{-1}\end{array}$ & $\mathrm{~T}_{\text {desorption }} /{ }^{\circ} \mathrm{C}$ \\
\hline N-Al-cal & 36 & 0 & 0 & 0.17 & 5.95 & 370 \\
\hline 0.1P-Al-cal & 32 & 0.2 & 0.26 & 0.17 & 4.20 & 365 \\
0.2P-Al-cal & 33 & 0.3 & 0.46 & 0.17 & 4.02 & 360 \\
P-Al-cal & 25 & 1.0 & 1.78 & 0.15 & 2.40 & 325 \\
P-Al-hyd & 25 & 0.1 & 0.26 & 0.17 & 6.23 & 390 \\
\hline
\end{tabular}

It should be noted that the sample hydrogenated at high temperature presents a higher maximum ammonia desorption, $390^{\circ} \mathrm{C}$, than the $\mathrm{N}$-Al-MFI sample, even though the hydrogenated sample keeps some phosphorous inside. This means that the hydrogenated $\mathrm{P}-\mathrm{Al}-\mathrm{MFI}$ sample presents a stronger acidity than the phosphorus-free Al-MFI, and thus, the acid strength of these materials is also affected by the OSDA used in the synthesis.

\subsubsection{NMR analyses of P-modified aluminosilicate MFI zeolite}

The incorporation of the phosphorous OSDA and aluminium, as well as the chemical species formed after thermal treatments were studied by MAS-NMR spectroscopy.

\subsubsection{OSDA incorporation and species}

The stability of the OSDA incorporated to the Al-MFI zeolite was studied by ${ }^{13} \mathrm{C}$ and ${ }^{31} \mathrm{P}$ MAS-NMR spectroscopies.

The ${ }^{13} \mathrm{C}$ MAS-NMR spectra of the as-made samples and the liquid ${ }^{13} \mathrm{C}$ NMR spectra of P-OSDA and N-OSDA of some of the Al-MFI materials are shown in Figure 5.14. 


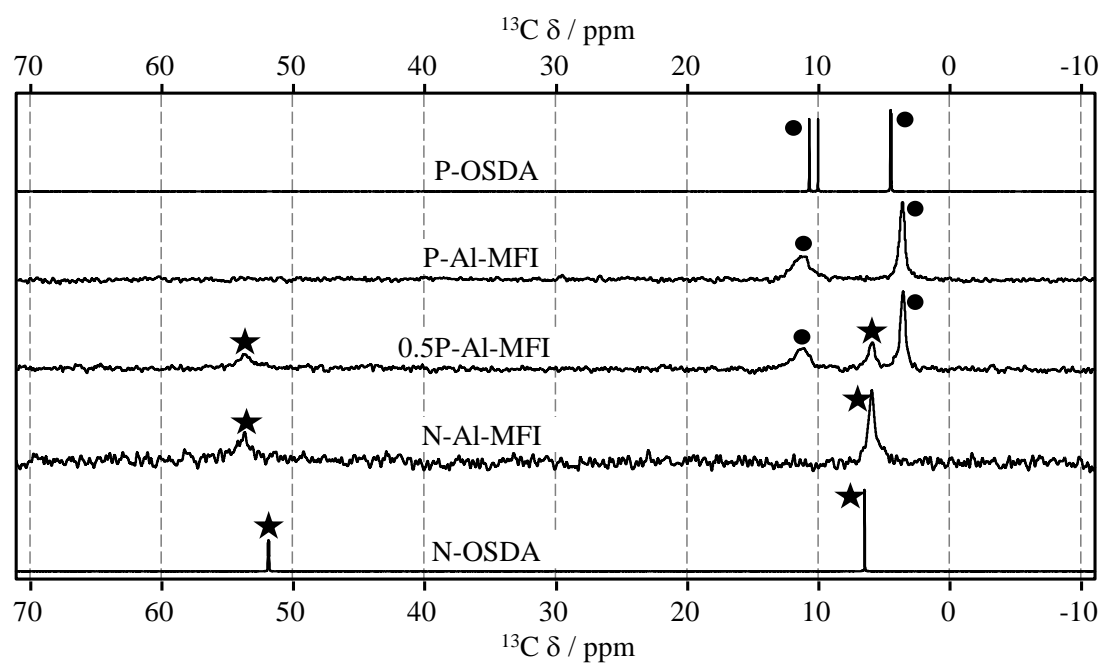

Figure 5.14. ${ }^{13} \mathrm{C}$ MAS-NMR spectra of Al-MFI materials. Samples are identified by synthesized $\mathbf{P} /(\mathbf{P}+\mathbf{N})$ material composition. Free OSDA liquid NMR spectra included for comparison.

The spectra of the as-made samples show resonances similar to the free P-OSDA and N-OSDA, which means that these OSDA's are incorporated to the material and are stable.

The ${ }^{31} \mathrm{P}$ MAS-NMR spectra of the as-made samples and the liquid ${ }^{31} \mathrm{P}$ NMR of P-OSDA spectrum are shown in Figure 5.15.

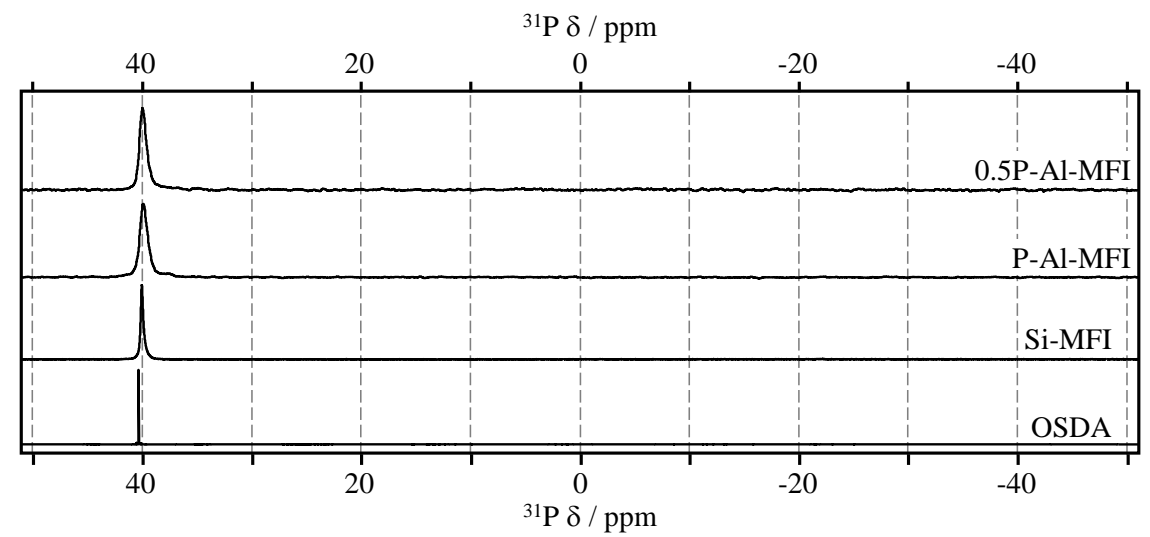

Figure 5.15. ${ }^{31} \mathrm{P}$ MAS-NMR spectra of Al-MFI materials. Samples are identified by synthesized $\mathbf{P} /(\mathbf{P}+\mathbf{N})$ material composition. All-silica sample MAS-NMR and free OSDA liquid NMR included for comparison. 
The spectra of the as-made samples show a single resonance at $40 \mathrm{ppm}$ which matches the chemical shift of the free OSDA. The resonances obtained in aluminosilicate samples are wider than the obtained in the all-silica spectrum, which could mean that the OSDA in as-made aluminosilicates could present different conformations.

After the thermal treatment of the materials, most of the phosphorus remains inside the material, giving the opportunity to study the chemical nature of the formed species by ${ }^{31}$ P MAS-NMR spectroscopy, whose spectra are shown in Figure 5.16.

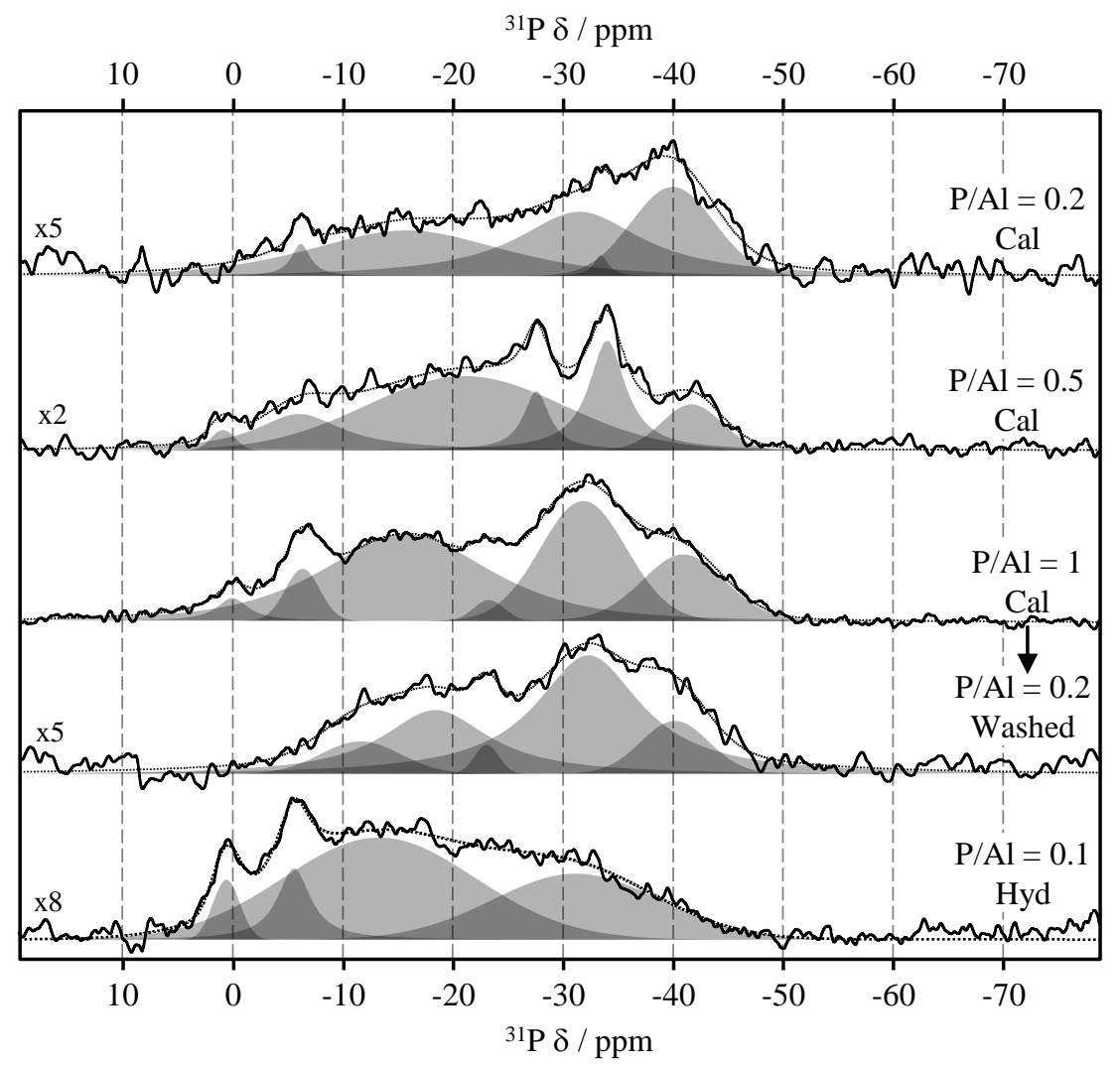

Figure 5.16. ${ }^{31} \mathrm{P}$ MAS-NMR spectra of calcined Al-MFI materials with different $\mathrm{P} / \mathrm{Al}$ ratios. Samples are identified by synthesized $\mathrm{P} /(\mathrm{P}+\mathrm{N})$ material composition, with thermal treatment below (cal: calcined; hyd: hydrogenated at high temperature). Solid lines correspond to experimental spectra; dotted lines correspond to the sum of deconvoluted signals. Spectra were deconvoluted as Gaussian/Lorentz curves. Washed sample with $\mathrm{P} / \mathrm{Al}=0.2$ was obtained after washing the $\mathrm{P} / \mathrm{Al}=1$ sample with $\mathrm{NH}_{4} \mathrm{Ac}$. 
It could be seen that after the thermal treatments, the organic compound is decomposed and the remaining phosphorous species display several resonances with chemical shifts ranging from $0 \mathrm{ppm}$ to $-45 \mathrm{ppm}$, characteristic of extra-framework $\mathrm{P}_{2} \mathrm{O}_{5}$-like species. The resulting spectra are quite complex, especially due to the low signal to noise ratio. The mathematical deconvolution of the spectra yields at least five main resonances, centred at $0,-28,-32$ and $-41 \mathrm{ppm}$, and a very broad resonance, centred at $-12 \mathrm{ppm}$. The intensities of these resonances vary depending on the $\mathrm{P} / \mathrm{Al}$ ratio, displacing the barycentre of the spectra towards lower chemical shifts as the $\mathrm{P} / \mathrm{Al}$ ratio decreases. The resonances between $-25 \mathrm{ppm}$ and $-45 \mathrm{ppm}$ are typically assigned to different (bi)phosphates interacting with to monodentate or bidentate aluminium in octahedral coordination, while the resonance at 0 ppm is usually assigned to phosphorus atoms in pyrophosphoric acid or to terminal $\left[\mathrm{P}_{4} \mathrm{O}_{3}\right]^{-}$ groups in polyphosphoric species. ${ }^{[45-48]}$

It is interesting to remark the differences between the two samples with P/Al ratio of 0.2 , the calcined material and the washed material. In the spectra of these materials, the resonances profiles are slightly different, which could be attributed to the removal of phosphorous species during the washing of the sample. These phosphorous species are probably weakly interacting, or not interacting at all, with the aluminium species, like the species related to the resonances over $-40 \mathrm{ppm}$, whose intensities decrease after the washing of the material. The intensity decrease in this resonance is accompanied with an intensity increase in the resonance at $-32 \mathrm{ppm}$, which indicates that after washing, the phosphorous species associated with the resonance at $-40 \mathrm{ppm}$ are turning into species associated with the $-32 \mathrm{ppm}$ resonance. This effect is more clearly visible when these spectra are compared with the spectra of the hydrogenated sample. In this case, the resonance at $-40 \mathrm{ppm}$ is very weak, while the intensities of the resonances at $0 \mathrm{ppm}$ and $-6 \mathrm{ppm}$ increase. The $0 \mathrm{ppm}$ resonance is associated with extra-framework $\mathrm{P}_{2} \mathrm{O}_{5}$ that is not interacting with the zeolitic matrix and is just filling the voids of the zeolite, while the $-6 \mathrm{ppm}$ resonance could be tentatively associated with similar species interacting with the silicon framework.

It should be noted the low intensity of the resonance at $0 \mathrm{ppm}$ in the calcined Al-MFI materials, corresponding to extra-framework $\mathrm{P}_{2} \mathrm{O}_{5}$ that are not interacting with the framework aluminium, compared with the phosphorous modified MFI samples obtained by postsynthesis treatments. ${ }^{[10,49]}$ This is mainly due to the amount of phosphorus incorporated in the zeolite by the post-synthesis treatment, as the treatment conditions should be tightly controlled to incorporate low amounts of phosphorous, being extremely difficult to incorporate phosphorus in $\mathrm{P} / \mathrm{Al}$ ratios below 0.5 . 


\subsubsection{Aluminium incorporation and species}

The aluminium incorporation was studied by ${ }^{27} \mathrm{Al}$ MAS-NMR spectroscopy of the as-made Al-MFI samples, whose spectra are shown in Figure 5.17.

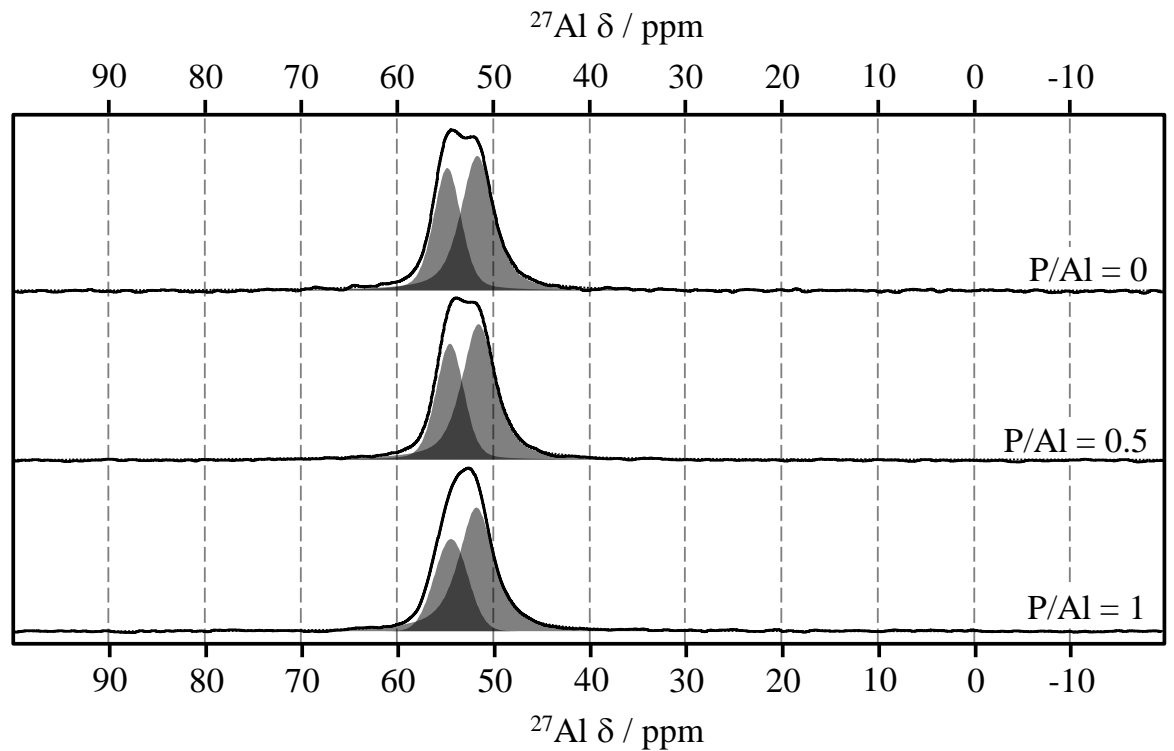

Figure 5.17. ${ }^{27} \mathrm{Al}$ MAS-NMR spectra of some samples of as-made Al-MFI with different P/Al ratios. Solid lines correspond to experimental spectra; dotted lines correspond to the sum of deconvoluted signals. Peaks were deconvoluted as Gaussian/Lorentz curves for an easier view.

All the as-made materials shows two ${ }^{27} \mathrm{Al}$ resonances centred at $54 \mathrm{ppm}$ and $51 \mathrm{ppm}$, regardless of the OSDA composition used in their syntheses. However, their intensities vary depending on the phosphorus content, increasing the contribution of the $51 \mathrm{ppm}$ resonance as the phosphorus content increases. These signals could be attributed to $\mathrm{Al}$ in tetrahedral coordination in two different crystallographic positions, as reported elsewhere. ${ }^{[50-55]}$

When materials are thermally treated, the aluminium atoms present up to three different chemical environments, depending on the samples, as shown in the ${ }^{27}$ Al MAS-NMR spectra depicted in Figure 5.18. 


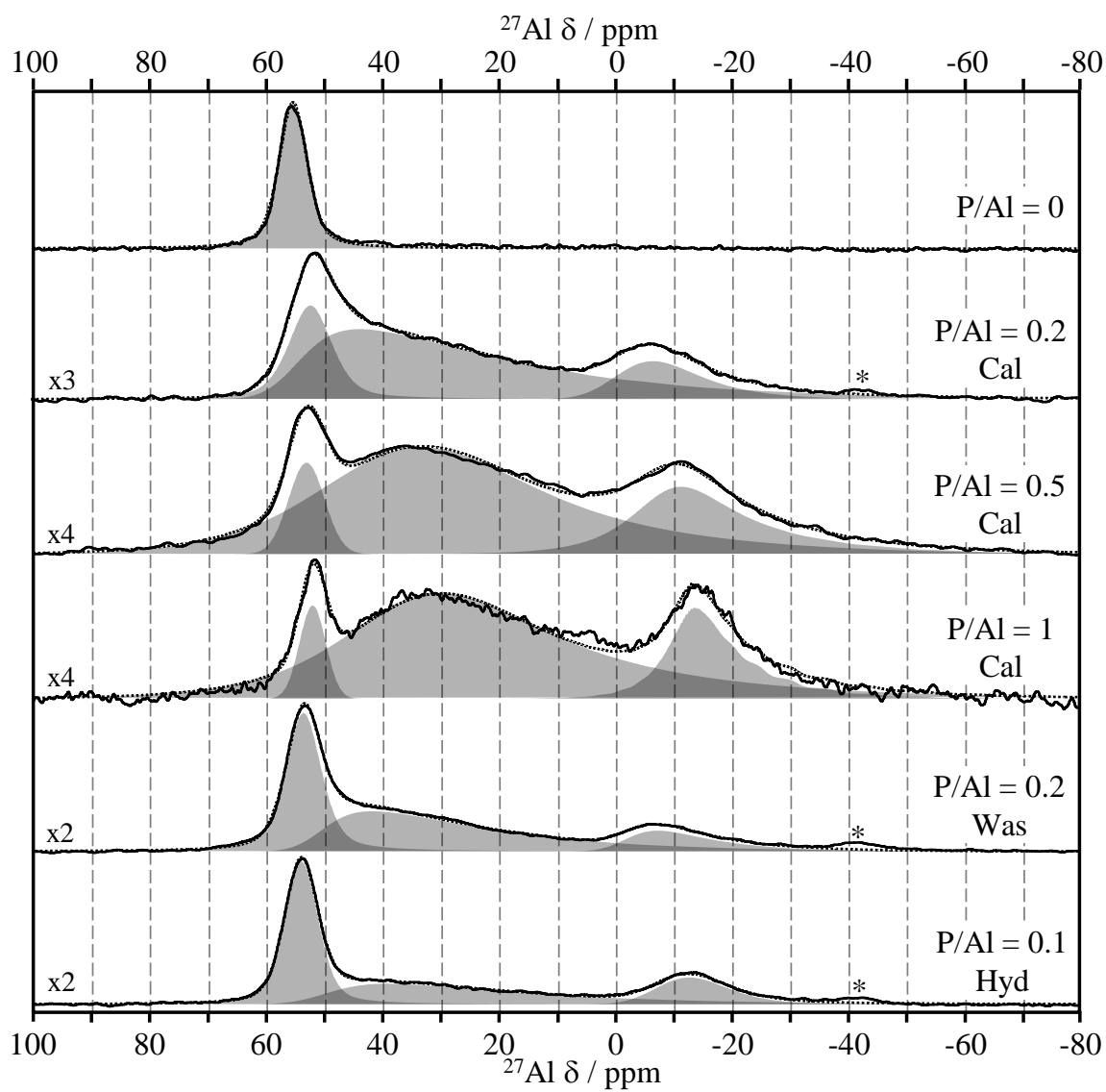

Figure 5.18. ${ }^{27} \mathrm{Al}$ MAS-NMR spectra of calcined Al-MFI materials with different $\mathrm{P} / \mathrm{Al}$ ratios.

Solid lines correspond to experimental spectra; dotted lines correspond to the sum of deconvoluted signals. The peak at $c a .55 \mathrm{ppm}$ was deconvoluted as a Gaussian/Lorentz curve (for an easier view), and the other peaks were deconvoluted using the CzSimple method. ${ }^{[56]}$

Asterisk marks NMR spinning bands.

There are three main resonances appearing at ca. $55 \mathrm{ppm}$ (narrow), at ca. $40 \mathrm{ppm}$ (very wide) and at $c a$. $-15 \mathrm{ppm}$ (wide). The intensity of these resonances vary depending on the $\mathrm{P} / \mathrm{Al}$ and $\mathrm{Si} / \mathrm{Al}$ ratios. Unlike as-made ${ }^{27} \mathrm{Al}$ MAS-NMR spectra, the resonance at $55 \mathrm{ppm}$ can be mathematically fitted as a single peak, although its width could be due to an unfolding into two close different resonances, corresponding to tetrahedral aluminium located in two different crystallographic position. The resonances at $40 \mathrm{ppm}$ and $-15 \mathrm{ppm}$ are typically attributed to pentacoordinated and octahedrally coordinated aluminium species. ${ }^{[57-59]}$ The resonance intensity at $55 \mathrm{ppm}$ decrease as the phosphorus content increases, contrary to the 
intensities of the $40 \mathrm{ppm}$ and $-15 \mathrm{ppm}$ resonances, which slowly decrease as phosphorus content decreases, even disappearing in the sample synthesized without P-OSDA. This is an evidence that these pentacoordinated and octahedral aluminium species are related to the presence of phosphorus inside the voids of the zeolite.

The washing of the calcined material with $\mathrm{NH}_{4} \mathrm{Ac}$ not only decrease the phosphorus content, but also has a great influence in the ${ }^{27} \mathrm{Al}$ MAS-NMR spectra decreasing, up to $35 \%$, the intensities of the ${ }^{27} \mathrm{Al}$ resonances at $40 \mathrm{ppm}$ and $-15 \mathrm{ppm}$, although the relative intensities between both signals is kept. This is in agreement with ${ }^{31} \mathrm{P}$ MAS-NMR results, as the washing of the calcined sample decreases the phosphorus content, but the ratio of the ${ }^{31} \mathrm{P}$ resonances at $-32 \mathrm{ppm}$ and $-40 \mathrm{ppm}$ is kept. Moreover, the ${ }^{27} \mathrm{Al}$ resonance at $-15 \mathrm{ppm}$ shift displaces downfield, to $-9 \mathrm{ppm}$. The resonances chemical shift fits with the calcined sample with a similar $\mathrm{P} / \mathrm{Al}$ ratio of 0.2 , although this latter sample is prepared using a dual template OSDA with a $\mathrm{P} /(\mathrm{P}+\mathrm{N})$ ratio of 0.0625 in the synthesis gel $(0.1 \mathrm{P}-\mathrm{Al}-\mathrm{MFI}$ sample). The main difference between the washed and the calcined sample with similar $\mathrm{P} / \mathrm{Al}$ ratio is the lower intensity of the ${ }^{27} \mathrm{Al} 40 \mathrm{ppm}$ resonance. This could be attributed to the different interaction between the phosphorous and aluminium species. As previously seen in the ${ }^{31} \mathrm{P}$ MAS-NMR, the spectra of the calcined sample present a higher intensity of the ${ }^{31} \mathrm{P}$ resonance at $-40 \mathrm{ppm}$, while the washed sample present a higher intensity of the ${ }^{31} \mathrm{P}$ resonance at $-32 \mathrm{ppm}$ (see Figure 5.19). This would mean that the phosphorous species corresponding to the ${ }^{31} \mathrm{P}$ resonance at $-40 \mathrm{ppm}$ would be interacting with pentacoordinated aluminium species.

The hydrogenation at high temperature of the sample with P/Al ratio of 1 also yields a sample with a low P/Al ratio, similar to the sample washed after calcination. The ${ }^{27} \mathrm{Al}$ MASNMR spectrum profile of the hydrogenated sample is similar to the washed sample with a similar P/Al ratio, but the ${ }^{27} \mathrm{Al}$ resonance at $40 \mathrm{ppm}$ presents a lower intensity, conversely to the ${ }^{27} \mathrm{Al}$ resonance at $-15 \mathrm{ppm}$. In this case, this latter resonance presents the same chemical shift than the observed in the spectra of the calcined sample, while in the washed sample this ${ }^{27} \mathrm{Al}$ resonance shifts to $-9 \mathrm{ppm}$. When comparing the ${ }^{31} \mathrm{P}$ MAS-NMR of these samples, it could be seen that the intensity of the ${ }^{31} \mathrm{P}$ resonance at $-40 \mathrm{ppm}$ is lower in the hydrogenated sample than in the calcined or the washed samples, which fits with the lowest intensity of the ${ }^{27} \mathrm{Al}$ resonance at $40 \mathrm{ppm}$ that the hydrogenated sample shows. 


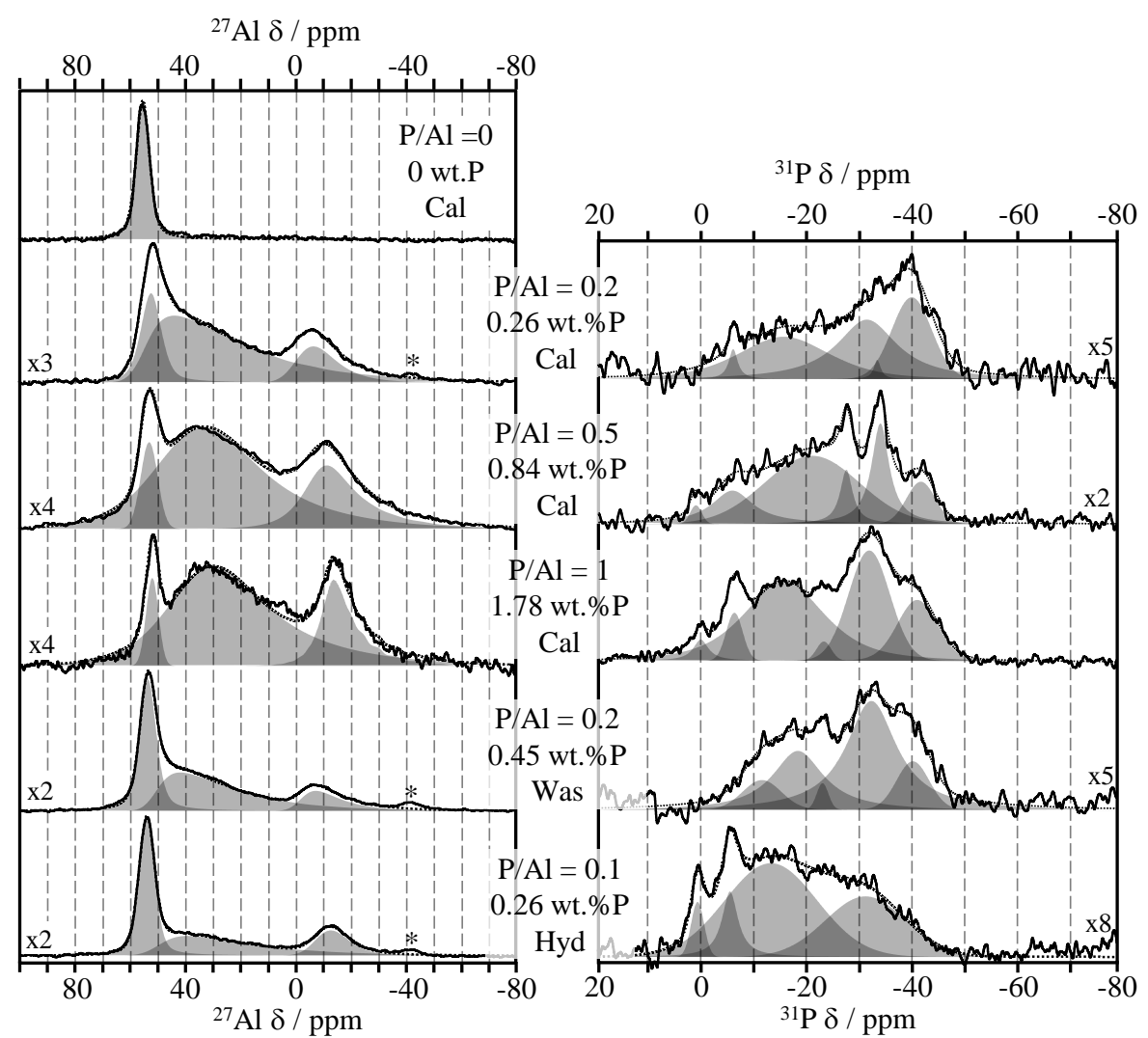

Figure 5.19. Comparison of ${ }^{27} \mathrm{Al}$ MAS-NMR spectra (left) and ${ }^{31} \mathrm{P}$ MAS-NMR spectra (right). Spectra shown here are the same than previously depicted, but aluminium spectra are linked with its corresponding phosphorus spectra for better comparison.

The comparison of the ${ }^{27} \mathrm{Al}$ and ${ }^{31} \mathrm{P}$ MAS-NMR spectra indicates that the phosphorous and aluminium species formed after post-synthesis treatments are not only dependent on the amount of phosphorus remaining in the material, but it is also dependent on the specific postsynthesis treatment. Thus, calcined, hydrogenated and washed samples exhibit different ${ }^{27} \mathrm{Al}$ and ${ }^{31} \mathrm{P}$ MAS-NMR spectra profiles despite having similar phosphorus contents and/or P/Al ratios, which correspond to different interactions between the phosphorous and the aluminium species. These different interactions translate into different textural and acidic properties between these materials, as previously discussed in sections 5.2.3.3 and 5.2.3.4, respectively. 
The results obtained in this section show that the incorporation of phosphorus during synthesis allows a close interaction between the extra-framework phosphorous species formed after thermal treatments and the aluminium species. Also, the introduction of phosphorus modifies the textural and adsorption properties. These two features were also found during the introduction of phosphorus by post-synthesis treatments, but the use of P-OSDA's allows to introduce these extra-framework phosphorous species during synthesis, which enables a more intimate interaction between the phosphorous and aluminium species. Thus, this methodology would be interesting to apply in the synthesis of small pore zeolite materials, where post-synthesis treatments to incorporate phosphorus cannot be applied.

\subsection{RTH zeolite}

The RUB-13 (IZA code: RTH) zeolite is a bi-directional small pore channel system zeolite with 8 MR pore openings, whose perpendicular channels create larges cages in their intersections. These properties make this material suitable for its application in catalysis like the MTO reaction. ${ }^{[60,61]}$

The RTH zeolite was first obtained as a borosilicate material employing a mix of amines (ethilendiamine and 1,2,2,6,6-pentamethylpiperidine) as OSDA. ${ }^{[62]}$ Later developments allowed it to be obtained in its aluminosilicate form, using a bicyclic ammonium as OSDA; ${ }^{[63]}$ as all-silica material in fluoride media; ${ }^{[64,65]}$ and as borosilicate material without using any OSDA. ${ }^{[60]}$

Although there have been tremendous advances, the zeolite RTH is still mostly synthesized using laborious-synthesis OSDA's and/or several post-treatments are required to get the catalytically active aluminosilicate composition. On the other hand, the aluminosilicate RTH just crystallizes in a narrow range of compositions, being only possible to obtain materials with silicon to aluminium ratios above 37 even with the use of seeds. ${ }^{[60]}$ This silicon to aluminium ratio means that few and strong acidic active sites are distributed along the zeolitic structure, which easily lead to the formation of coke and the poisoning of the material when applied in the MTO reaction.

Recently, the zeolite RTH has been obtained employing phosphorous OSDA's. ${ }^{[16-18]}$ There are two great advances in the employ of this kind of OSDA's. First, they allowed obtaining the RTH zeolite in a wider range of compositions, with silicon to aluminium ratios ranging from 14 to all-silica materials, and in both fluoride and hydroxide 
media. And secondly, they allow the one-step incorporation of phosphorus into the zeolite. This is an important feature because the incorporation of phosphorus as extra-framework phosphorous species in aluminosilicate zeolites allows modifying the acid strength, the textural properties, and the increase of the hydrothermal framework stability of the aluminium centres, as previously seen in MFI materials (see section 5.2.3). Typically, this is done via post-synthesis treatment with phosphoric acid, but this methodology is useless in small pore zeolites, like the RTH zeolite, because of diffusion restraints. ${ }^{[7,10]}$ After the results obtained in the dual-template synthesis of all-silica and aluminosilicate MFI, this methodology was used for the synthesis of aluminosilicate RTH materials.

\subsubsection{Dual template synthesis of RTH zeolite}

The synthesis of RTH zeolite was carried out employing two cations with different nature as OSDA's, a tetraalkylphosphonium cation, methyl-tri-isopropylphosphonium cation (MIP, OSDA-4), and a tetraalkylammonium cation, di-isopropyl-diethylammonium cation (IEN, OSDA-5). The detailed synthesis of the MIP (OSDA-4) and IEN (OSDA-5) are described in sections 3.2.1.4 and 3.2.1.5, respectively.

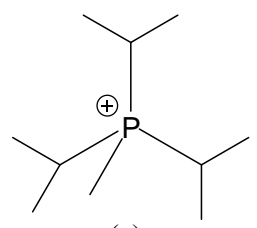

(a)

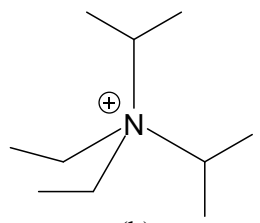

(b)

Figure 5.20. a) Methyl-tris-(dimethylamino)-phosphonium cation (OSDA-4) and b) di-isopropyl-diethylammonium cation (OSDA-5).

\subsubsection{Synthesis conditions}

Aluminosilicate RTH zeolites were synthesized using the dual template synthesis methodology. The OSDA solutions were mixed in different ratios and the silica and alumina sources were added after, obtaining synthesis gels with the following compositions:

$$
1.0 \mathrm{SiO}_{2}: 0.4 \mathrm{OSDA}_{\mathrm{P}+\mathrm{N}}(\mathrm{OH}): x \mathrm{Al}_{2} \mathrm{O}_{3}: 10 \mathrm{H}_{2} \mathrm{O}: 0.4 \mathrm{HF}
$$

Where $x$ varies from 0.012 to 0.016 as the phosphorus content decreases, to try to maintain the same or similar Si/Al ratio. The OSDA $\mathrm{P}+\mathrm{N}_{\text {is }}$ MIP, IEN or a mixture of both cations with MIP/(IEN+MIP) ratios ranging from 0 to 1 . RTH zeolites synthesized only with 
MIP or IEN are denoted as P-RTH or N-RTH, respectively, and those obtained with a mixture of OSDA's are named as $x \mathrm{P}-\mathrm{RTH}$ were $x$ refer to the MIP/(IEN+MIP), or P/(P+N), molar ratio used in the synthesis gel or obtained in the solid, as specified. The detailed synthesis of the Al-RTH material is described in section 3.2.2.3.

\subsubsection{Phase crystallinity}

The crystallinity of the samples after synthesis was studied by powder X-Ray diffraction, whose diffraction patterns are shown in Figure 5.21.

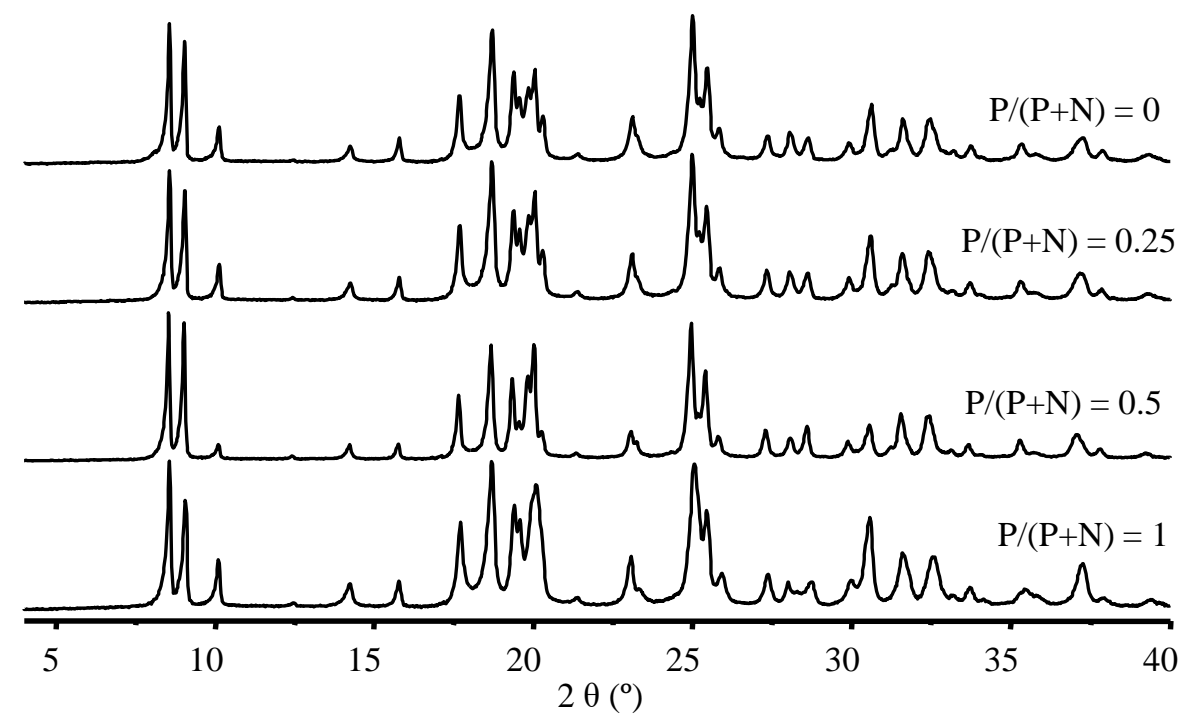

Figure 5.21. Powder X-Ray diffraction patterns of Al-RTH materials with different P-OSDA ratios. Samples are identified by synthesis gel OSDA composition.

All the Al-RTH materials show a high crystallinity regardless of the mix of OSDA's used. As noted in the previous sections, the lower the phosphorous OSDA amount, the longer the synthesis takes to completely crystallize. Actually, synthesis times nearly double from 6 days in all-phosphorous Al-RTH to 14 days in all-nitrogen Al-RTH. However, crystallization kinetics were not calculated due to the lack of samples with low or medium crystallinity. 


\subsubsection{Sample analyses of as-made P-modified RTH zeolite}

The obtained as-made Al-RTH materials were submitted to chemical analyses, thermogravimetry analyses, scanning electron microscopy and MAS-NMR spectroscopies. In this section only chemical analyses, thermogravimetry analyses and scanning electron microscopies of the as-made samples are compared, while MAS-NMR spectra are further discussed in section 5.2.4.

\subsubsection{Chemical analyses of as-made P-modified RTH zeolite}

The OSDA chemical composition of the as-made Al-RTH materials are shown in Table 5.7.

Table 5.7. OSDA chemical composition of as-made Al-RTH materials. All ratios are given as molar ratios. Samples are identified by OSDA ratio synthesis gel composition.

\begin{tabular}{cccccc}
\hline Sample & {$[\mathrm{P} /(\mathrm{P}+\mathrm{N})]_{\text {gel }}$} & {$[\mathrm{P} /(\mathrm{P}+\mathrm{N})]_{\text {sol }}$} & wt.\% $\mathrm{P}_{\text {sol }}$ & $(\mathrm{P}+\mathrm{N})(\mathrm{mmol} / \mathrm{g})$ & $\mathrm{Si} / \mathrm{OSDA}$ \\
\hline N-Al-RTH & 0 & 0 & 0 & 0.83 & 16.0 \\
$0.2 \mathrm{P}-\mathrm{Al}-\mathrm{RTH}$ & 0.125 & 0.2 & 0.6 & 0.90 & 15.5 \\
$0.3 \mathrm{P}-\mathrm{Al}-\mathrm{RTH}$ & 0.2 & 0.3 & 1.0 & 0.90 & 15.5 \\
0.5P-Al-RTH & 0.25 & 0.5 & 1.6 & 0.96 & 14.4 \\
$0.8 \mathrm{P}-\mathrm{Al}-\mathrm{RTH}$ & 0.5 & 0.8 & 2.3 & 0.92 & 14.4 \\
P-Al-RTH & 1 & 1 & 2.8 & 0.89 & 14.8 \\
\hline
\end{tabular}

The incorporation of the OSDA's in the Al-RTH materials synthesized in presence of different $\mathrm{P} /(\mathrm{P}+\mathrm{N})$ ratios was studied, being observed that the contents of the OSDA in all materials are very similar, around 16 , and close to 2 OSDA molecules per unit cell of RTH zeolite (32 $\mathrm{T}$ units per unit cell).

Also, as previously reported in Si-MFI and Al-MFI syntheses, there is a preferential incorporation of the P-OSDA over the N-OSDA in the Al-RTH material, which follows the same trend as in the MFI materials, as shown in Figure 5.22. 


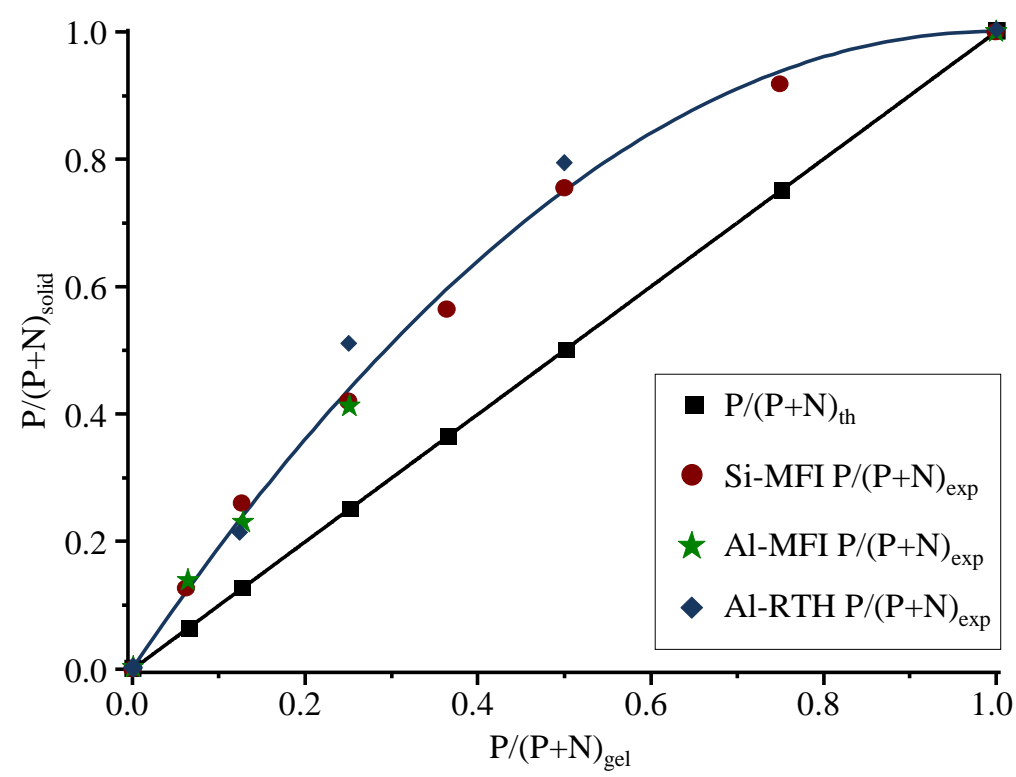

Figure 5.22. Comparison of $P /(P+N)$ values used in the synthesis gel, $P /(P+N)]_{\text {gel }}$, against the $\mathbf{P} /(\mathbf{P}+\mathbf{N})$ values obtained in Al-RTH zeolites, $[\mathbf{P} /(\mathbf{P}+\mathbf{N})]_{\text {solid. }} \mathbf{P} /(\mathbf{P}+\mathbf{N})$ th refers to the theoretical compositions, while $\mathrm{P} /(\mathrm{P}+\mathrm{N})_{\text {th }}$ refers to the experimental compositions. Values obtained for $\mathrm{Si}$ -

MFI and Al-MFI materials are also shown for comparison.

The preferential incorporation is indicative that the P-OSDA presents a stronger "templating" effect than the N-OSDA, as Al-RTH crystallization times decrease also indicates. However, as previously stated, crystallization curves were not calculated due to the lack of samples with low crystallinity.

These results contrast with previously reported results, where CHA zeolite was synthesized using a similar methodology, but using two OSDA's whose structure is significantly different. ${ }^{[66]}$ In that case, the N-OSDA displayed the preferential incorporation over the P-OSDA, and the latter was unable to "template" the CHA structure by itself, so the P-OSDA was just working as a pore filling agent, being required to use a large amount of the P-OSDA to incorporate significant amounts of phosphorus in the material. In this thesis, the RTH zeolite was synthesized using two similar OSDA's, being both able to synthesize the RTH structure by themselves, and with the main difference between them on the atom holding the charge. Because of these reasons, we could argue that the $\mathrm{P}$ atom possess a stronger "templating" effect. 
Chapter 5: Phosphorous-modified zeolites

The typical chemical compositions of the as-made Al-RTH materials are shown in Table 5.8.

Table 5.8. Heteroatom chemical composition of as-made Al-RTH materials. All ratios are given as molar ratios. Samples are identified by OSDA ratio synthesis gel composition and $\mathrm{pH}_{\mathrm{gel}}$ was measured after adding $\mathrm{HF}$.

\begin{tabular}{cccccccc}
\hline Sample & {$[\mathrm{Si} / \mathrm{Al}]_{\text {gel }}$} & $\mathrm{pH}_{\mathrm{gel}}$ & $\eta_{\mathrm{Al}}(\%)$ & $\eta_{\mathrm{Si}}(\%)$ & {$[\mathrm{Si} / \mathrm{Al}]_{\mathrm{sol}}$} & OSDA $_{\mathrm{P}+\mathrm{N}} / \mathrm{Al}$ & wt.\% $\mathrm{P}_{\text {sol }}$ \\
\hline N-Al-RTH & 30 & 7.79 & 100 & 45 & 14.9 & 0.9 & 0 \\
0.2P-Al-RTH & 30 & 8.12 & 100 & 90 & 23.4 & 1.5 & 0.6 \\
0.3P-Al-RTH & 30 & 8.02 & 100 & 88 & 22.8 & 1.5 & 1.0 \\
0.5P-Al-RTH & 35 & 7.84 & 100 & 46 & 13.7 & 0.9 & 1.6 \\
0.8P-Al-RTH & 35 & 7.94 & 100 & 38 & 13.4 & 0.9 & 2.3 \\
P-Al-RTH & 20 & 8.98 & 100 & 88 & 14.8 & 1.0 & 2.8 \\
\hline
\end{tabular}

It could be seen that the incorporation yields of silicon heavily relies on the $\mathrm{pH}$ media, and thus, on the different OSDA solutions employed, affecting to the final Si/Al ratio. This difference in the $\mathrm{pH}$ media could be mainly due to the synthesis gel ageing before the hydrothermal synthesis, although it has been difficult to completely control the $\mathrm{pH}$ without changing the ageing time and/or water to silica ratio in the synthesis gel.

\subsubsection{Morphology of as-made P-modified RTH zeolite}

The crystallite shape and size of the as-made Al-RTH samples were assessed by FESEM microscopy analyses, depicted in Figure 5.23.

The Al-RTH zeolite crystallized with a homogeneous crystal shape, while the crystallite size distribution seems to rely on the OSDA composition, as the crystallites are smaller as the phosphorus content increases. Indeed, rectangular prism crystals ranging from $4 \mathrm{x} 1 \mu \mathrm{m}$ (all P-OSDA) up to 10x3 $\mu \mathrm{m}$ (all N-OSDA) were obtained (Figure 5.23. Above). 


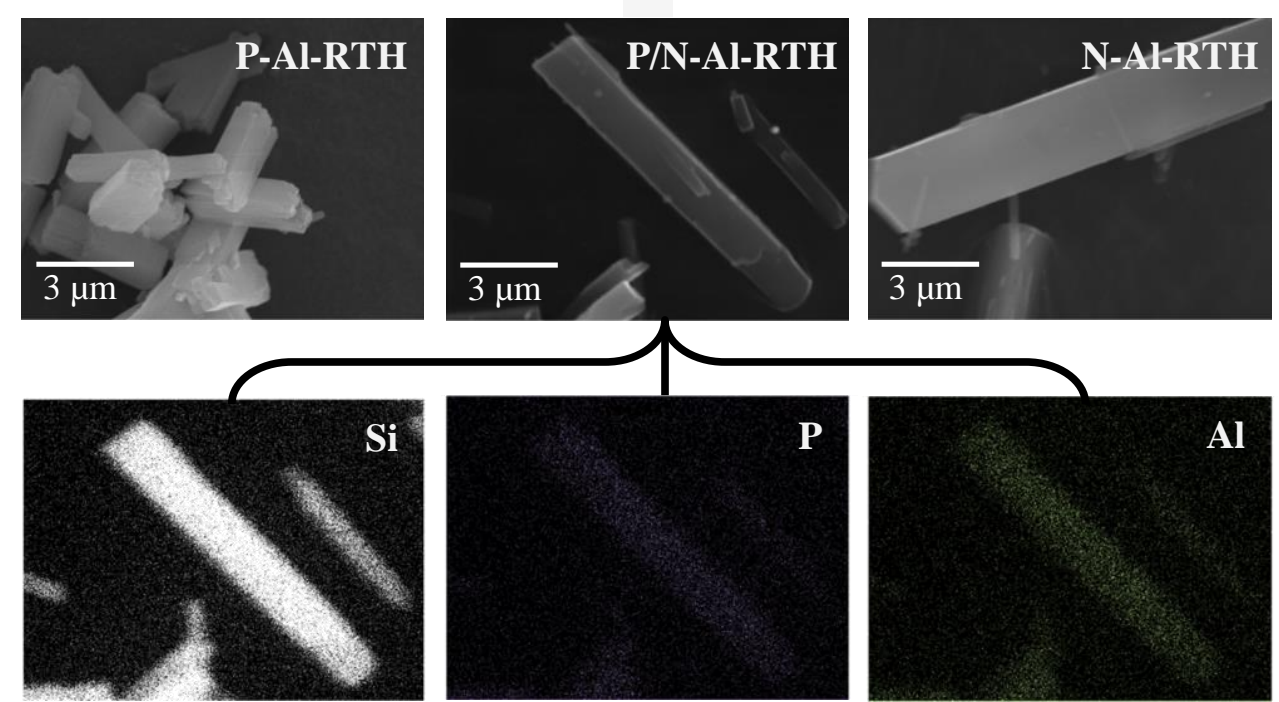

Figure 5.23. SEM microimages of RTH samples obtained with different OSDA compositions. All P RTH (P-Al-RTH, upper left), all N RTH (N-Al-RTH, upper right) and P/(P+N) = 0.5 RTH (P/N-Al-RTH, upper middle). Below, EDX mapping (white: Si; purple: P; green: Al) of the $\mathrm{P} /(\mathbf{P}+\mathrm{N})=0.8 \mathrm{RTH}$ sample is shown.

Because of the different incorporation yields of the two OSDA's, EDX mapping was measured to determine the existence of different compositional dominions made up from one OSDA or another, but no inter- or intra-crystalline chemical domains were found in any Al-RTH sample (Figure 5.23.Below, only $\mathrm{P} /(\mathrm{P}+\mathrm{N})=0.8 \mathrm{RTH}$ sample is shown for simplicity).

\subsubsection{Thermogravimetric analysis of as-made P-modified RTH zeolite}

The thermal stability and decomposition of the OSDA were studied by the thermogravimetry (TG) and differential thermogravimetry analyses (DTG) of the Al-RTH samples obtained with different OSDA compositions. Some thermogravimetric plots are shown in Figure 5.24. 


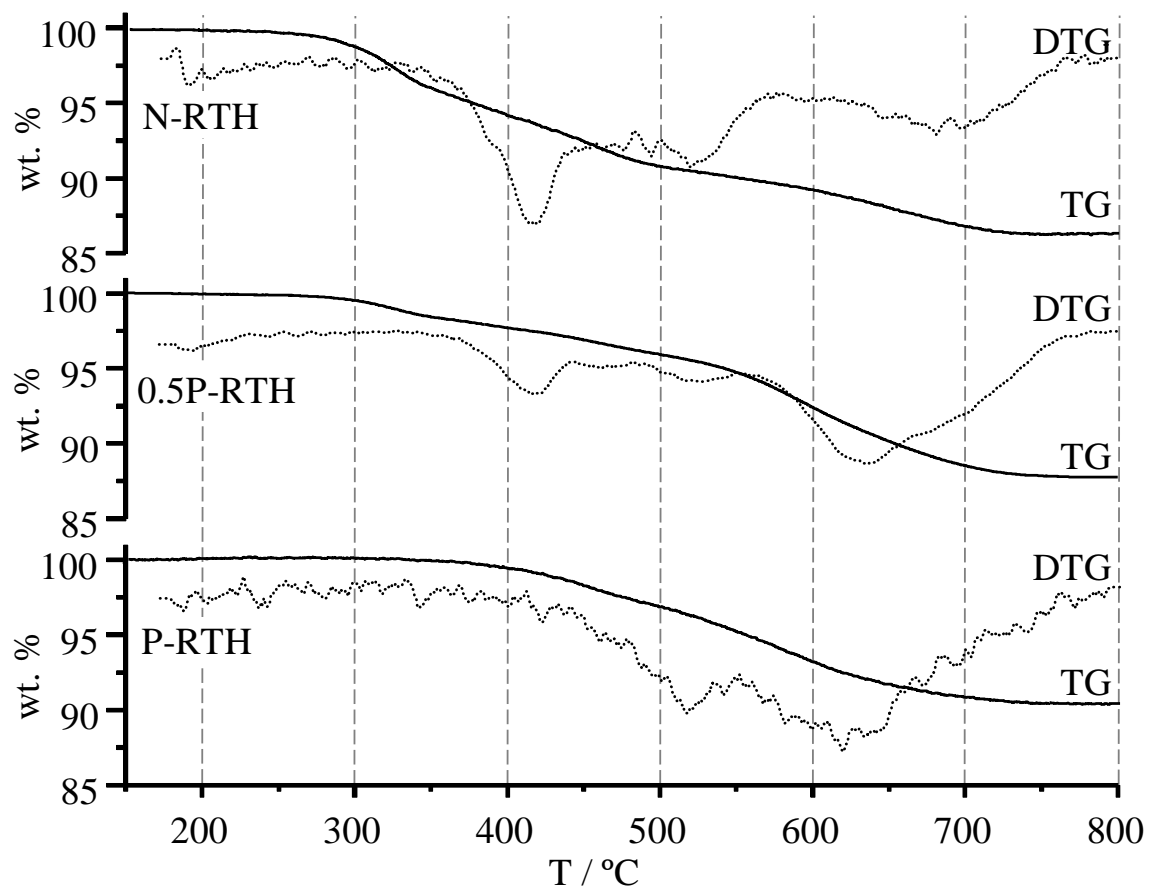

Figure 5.24. TG (dotted lines) and DTG (solid lines) analyses curves of the Al-RTH materials obtained with different $\mathrm{P} /(\mathrm{P}+\mathrm{N})$ ratios. Samples are identified by synthesized material composition. DTG curves are scaled up for a better view.

The figure shows two sets of weight loses, a low temperature profile corresponding to the N-OSDA that shows three main weight losses, a large one (ca. $8 \mathrm{wt} . \%$ ) centred at $\sim 420^{\circ} \mathrm{C}$, and two smaller ones centred at $\sim 510^{\circ} \mathrm{C}$ and $\sim 680^{\circ} \mathrm{C}$ ( $c a .2$ wt. $\%$ for each one), and a high temperature profile corresponding to the P-OSDA, with two main weight losses, one centred at $\sim 510^{\circ} \mathrm{C}$ (ca. 5 wt. $\%$ ), and another one centred at $\sim 610^{\circ} \mathrm{C}(\mathrm{ca} .5 \mathrm{wt} . \%)$.

The magnitude of the weight loss correlates with the amount of each OSDA in the as-made material, considering the weight of the $\mathrm{P}_{2} \mathrm{O}_{5}$ that remains inside the zeolite after the thermal treatment for each RTH material. 


\subsubsection{Thermal treatments of P-modified RTH zeolite}

The as-made Al-RTH materials were calcined under air as described in the section 3.2.3. Chemical analyses, scanning electron microscopy, adsorption isotherms, ammonia thermoprogrammed desorption and MAS-NMR spectroscopies were performed for the thermally treated Al-RTH materials. In this section only powder X-Ray diffraction, chemical analyses, adsorption isotherms and ammonia thermoprogrammed desorption analyses of the thermally treated samples are discussed, while MAS-NMR spectra are further discussed in section 5.3.4.

\subsubsection{Crystallinity of thermally treated P-modified RTH zeolite}

The stability and crystallinity of the Al-RTH samples after calcination was studied by powder X-Ray diffraction, whose diffraction patterns are shown in Figure 5.25.

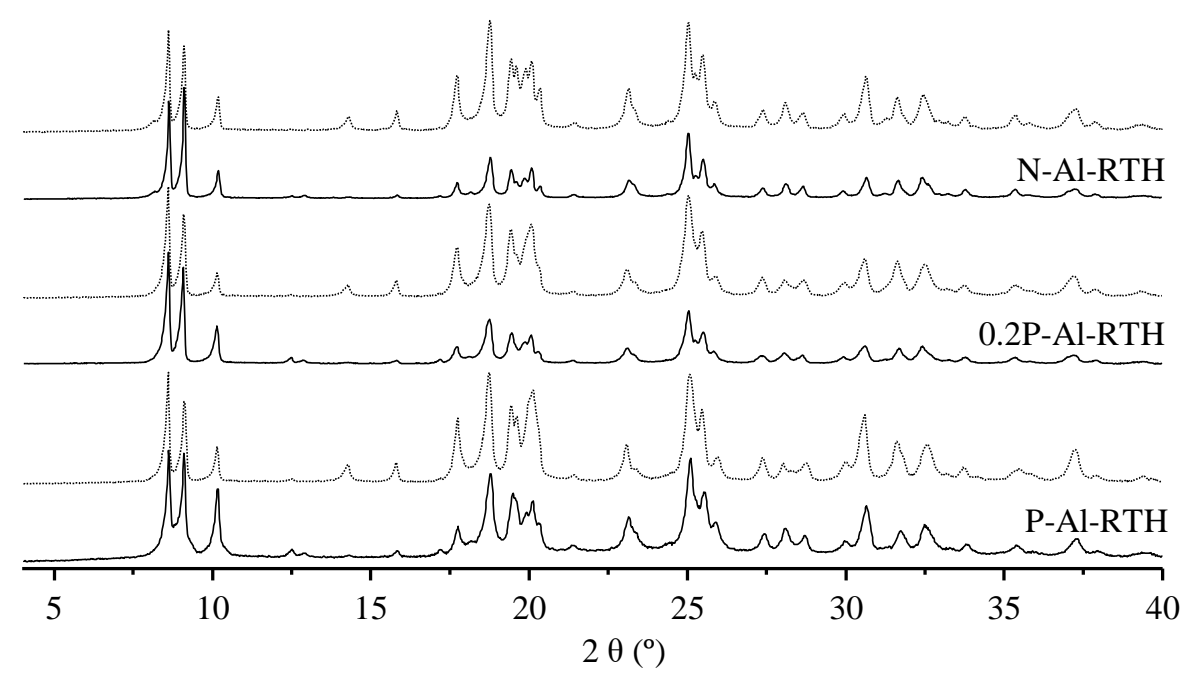

Figure 5.25. Powder X-Ray diffraction of some of the thermally treated Al-RTH materials. Solid lines correspond to as-made samples, while dotted lines correspond to calcined samples. Samples are identified by synthesized material composition.

The Al-RTH materials remained highly crystalline after the thermal treatments, with the X-Ray diffraction peaks being found at roughly the same $2 \theta$ degrees in all samples regardless of the thermal treatment. The main difference between the as-made and the thermally-treated samples was the intensity of the signals at $2 \theta$ below $18^{\circ}$, as the intensities of these peaks are typically affected by the presence of the OSDA filling the pores. 
Chapter 5: Phosphorous-modified zeolites

\subsubsection{Chemical analyses of thermally treated P-modified RTH zeolite}

The chemical compositions of the thermally treated Al-RTH materials are shown in Table 5.9.

Table 5.9. Chemical composition of some of the thermally treated Al-RTH materials. All ratios are given as molar ratios.

\begin{tabular}{|c|c|c|c|c|c|c|}
\hline Sample & Treatment & $\mathrm{Si} / \mathrm{Al}_{\text {as-made }}$ & $\mathrm{Si} / \mathrm{Al}_{\text {treated }}$ & wt. $\% \mathrm{P}_{\text {as-made }}$ & wt. $\% P_{\text {treated }}$ & $\mathrm{P} / \mathrm{Al}_{\text {treated }}$ \\
\hline N-Al-RTH & Calcination & 14.9 & 14.9 & 0 & 0 & 0 \\
\hline 0.2P-Al-RTH & Calcination & 23.4 & 23.1 & 0.6 & 0.7 & 0.3 \\
\hline 0.3P-Al-RTH & Calcination & 22.8 & 22.5 & 1.0 & 1.1 & 0.5 \\
\hline 0.5P-Al-RTH & Calcination & 13.7 & 13.7 & 1.6 & 1.6 & 0.5 \\
\hline 0.8P-Al-RTH & Calcination & 13.4 & 13.4 & 2.3 & 2.3 & 0.7 \\
\hline P-Al-RTH & Calcination & 14.8 & 14.5 & 2.8 & 2.7 & 1.0 \\
\hline P-Al-RTH & Hydrogenation & 14.8 & 13.8 & 2.8 & 0.7 & 0.2 \\
\hline
\end{tabular}

As expected, most of the phosphorus remains inside the Al-RTH zeolite after the calcination of the materials, while the hydrogenation at high temperature leads to the removal of most of the phosphorus from the material, up to $75 \mathrm{wt} . \%$. However, the observed content of phosphorus in Al-RTH zeolite is higher than the observed in the case of Al-MFI (85 wt.\% phosphorus removal). This could be either explained by the smaller pores of the RTH zeolite structure, hindering the diffusion of the phosphorous species generated during hydrogenation, or by a stronger interaction between the phosphorus and aluminium species formed upon calcination.

\subsubsection{Textural properties of thermally treated P-modified RTH zeolite}

The textural properties of the Al-RTH materials were calculated from the $\mathrm{N}_{2}$ adsorption isotherms on the thermally treated samples, shown in Figure 5.26. The $\mathrm{N}_{2}$ adsorption isotherms of the thermally treated Al-RTH samples show the type Ia physisorption profile typical of microporous materials. ${ }^{[42]}$ At first, the $\mathrm{N}_{2}$ adsorption isotherms were carried out at $77 \mathrm{~K}$ (Figure 5.26. Left), observing that only the samples with low phosphorus loadings were accessible to $\mathrm{N}_{2}$. Thus, the adsorption temperature was increased to $87 \mathrm{~K}$ (liquid $\mathrm{Ar}$ temperature), allowing the adsorption of $\mathrm{N}_{2}$ in all the Al-RTH materials (Figure 5.26. Right). 

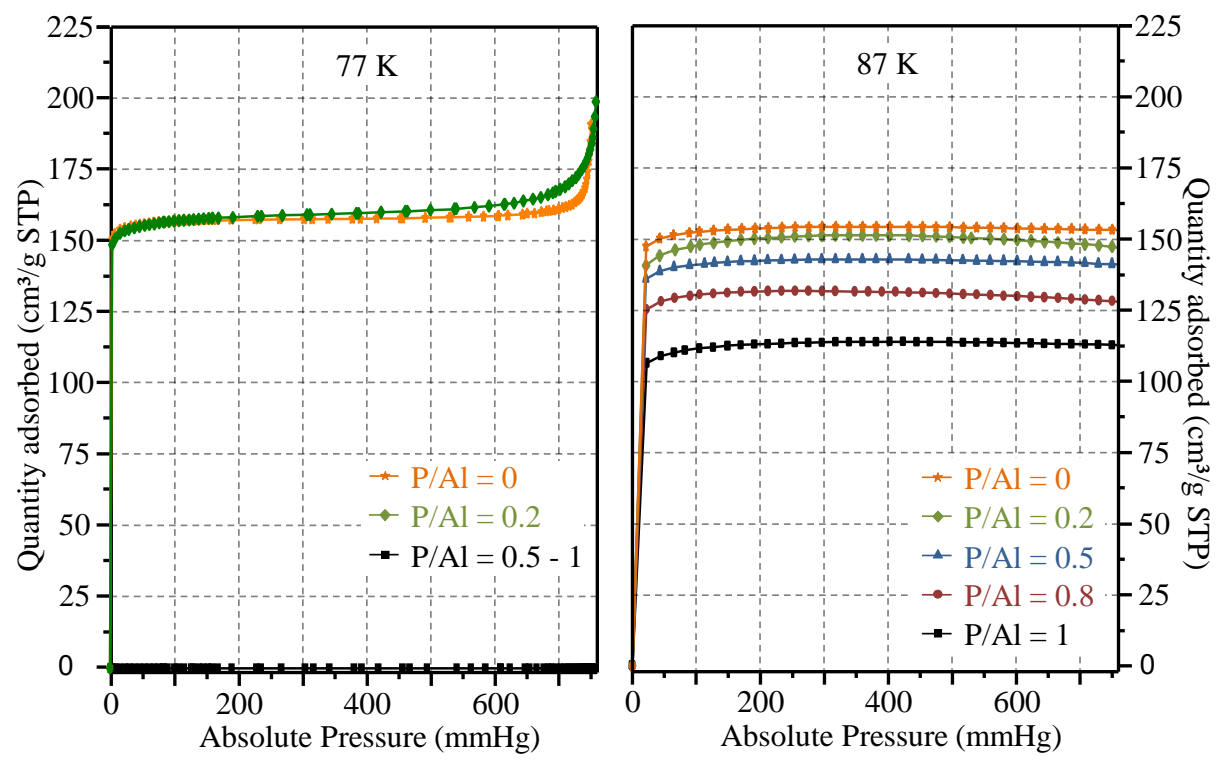

Figure 5.26. $\mathrm{N}_{2}$ adsorption isotherms of calcined Al-RTH materials with different P/Al ratios at $77 \mathrm{~K}$ (left) and $87 \mathrm{~K}$ (right).

Next, the adsorption capacity between the different materials was assessed by comparing the amount of adsorbed $\mathrm{N}_{2}$ for a given relative pressure $\left(\mathrm{P} / \mathrm{P}_{0}=0.15\right)$ at the $77 \mathrm{~K}$ and $87 \mathrm{~K}$, as shown in Figure 5.27.

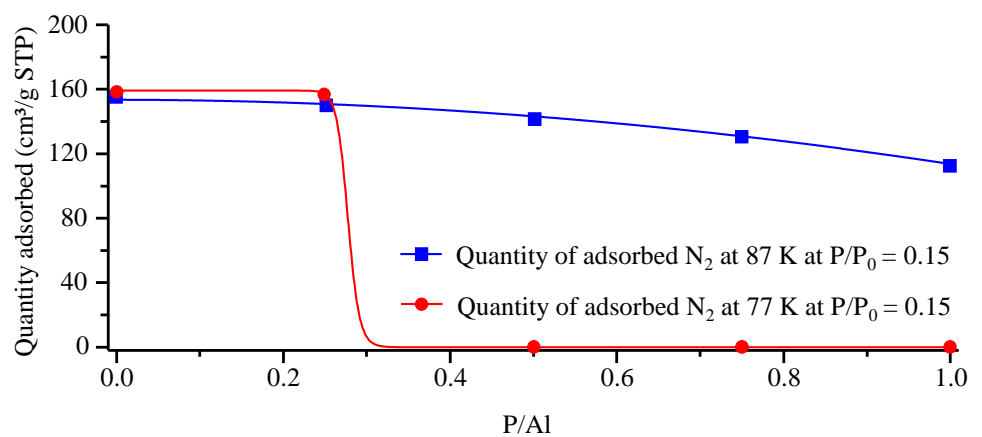

Figure 5.27. Quantity of adsorbed $N_{2}$ measured at $P / P_{0}=0.15$ of $N_{2}$ adsorption isotherms at liquid $\mathrm{N}_{2}$ temperature $(77 \mathrm{~K})$ and liquid Ar temperature $(87 \mathrm{~K})$ of Al-RTH materials with different $\mathrm{P} / \mathrm{Al}$ compositions. 
It could be seen that the amount of adsorbed $\mathrm{N}_{2}$ is very similar at $77 \mathrm{~K}$ and $87 \mathrm{~K}$ in the Al-RTH samples of lower P/Al ratios. This leads to suppose that these results could be extrapolated to the RTH samples with higher phosphorus contents.

Micropore volumes were only calculated from the isotherms measured at $77 \mathrm{~K}$, showing values close to $0.24 \mathrm{~cm}^{3} \cdot \mathrm{g}^{-1}$ in both materials, similar to the previously reported 0.25 $\mathrm{cm}^{3} \cdot \mathrm{g}^{-1} \cdot{ }^{[64]}$ As the amount of adsorbed $\mathrm{N}_{2}$ of the sample decreases as the phosphorus content increases, it could be supposed that the micropore volume will also decrease, and therefore, the adsorption capacity of the Al-RTH materials decreases as P/Al content increases, similarly to previously discussed results in MFI materials in section 5.2.3.3.

These results are in agreement with the presence of extra-framework phosphorous species that hinder the diffusion throughout the pores of the zeolite. Additionally, the presence of $\mathrm{P}_{2} \mathrm{O}_{5}$-like species formed along the calcination step leads to diffusional constraints of $\mathrm{N}_{2}$ at $77 \mathrm{~K}$ when the phosphorus content reaches a critical amount (between 0.6 and 1.2 wt.\%).

\subsubsection{Acidic properties of thermally treated RTH zeolite}

The acidic properties of the thermally treated Al-RTH samples were studied by ammonia thermoprogrammed desorption (TPD), tracking the desorption mass spectrometry with $\mathrm{m} / \mathrm{e}=15$. The corresponding desorption curves are shown in Figure 5.28.

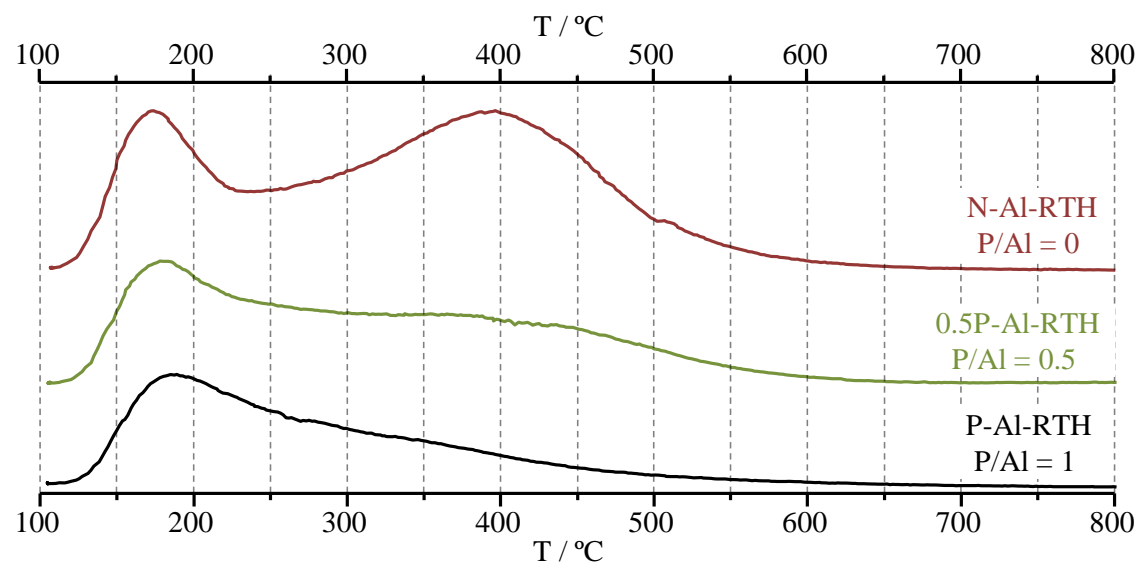

Figure 5.28. Ammonia TPD curves of calcined Al-RTH materials. Samples are identified by synthesized $\mathrm{P} /(\mathrm{P}+\mathrm{N})$ material composition, with $\mathrm{P} / \mathrm{Al}$ ratio below. 
The Al-RTH samples show two maximum ammonia desorption temperatures, the low temperature peak centred at $\sim 175^{\circ} \mathrm{C}$, and the high temperature peak centred at $\sim 400^{\circ} \mathrm{C}$. The low temperature peak is associated to weak acidic centres and physisorption, while the high temperature h-peak is associated to strong acidic centres. The h-peak decreases as the phosphorus content and the P/Al ratio increases, to the point of vanishing for the P-Al-RTH sample, which presents a $\mathrm{P} / \mathrm{Al}$ ratio of 1 . This indicates that the phosphorus is interacting with the strong acidic aluminium centres, but the amount of weak acidic centres remain roughly constant in all samples despite its phosphorus content, as summarized in Table 5.10.

Table 5.10. Summary of chemical analyses, textural properties and ammonia adsorption at $100^{\circ} \mathrm{C}$ of some thermally treated Al-RTH samples. Samples are identified by synthesized $\mathbf{P} /(\mathbf{P}+\mathbf{N})$ material composition. Ratios are given as molar ratios.

\begin{tabular}{ccccc}
\hline Sample & $\mathrm{Si} / \mathrm{Al}$ & $\mathrm{P} / \mathrm{Al}$ & wt.\%P & $\mathrm{V}_{\mathrm{NH} 3} / \mathrm{cm}^{3} \cdot \mathrm{g}^{-1}$ \\
\hline N-Al-RTH & 14.9 & 0 & 0 & 8.67 \\
$0.5 \mathrm{P}-\mathrm{Al}-\mathrm{RTH}$ & 13.7 & 0.5 & 1.6 & 5.27 \\
P-Al-RTH & 14.8 & 1 & 2.7 & 4.08 \\
\hline
\end{tabular}

These results show that the total amount of acid centres in the Al-RTH materials and their relative strength could be easily modulated by simply tuning the $\mathrm{P} /(\mathrm{P}+\mathrm{N})$ ratio used in the synthesis gel.

\subsubsection{NMR study of P-modified RTH zeolite}

The incorporation of the phosphorous OSDA and aluminium, as well as the chemical species formed after thermal treatments were studied by MAS-NMR spectroscopy.

\subsubsection{OSDA incorporation and species}

The stability of the OSDA incorporated in the Al-RTH zeolite was studied by ${ }^{13} \mathrm{C}$ and ${ }^{31} \mathrm{P}$ MAS-NMR spectroscopies.

The ${ }^{13} \mathrm{C}$ MAS-NMR spectra of the as-made samples compared with the liquid ${ }^{13} \mathrm{C}$ NMR spectrum of the free P-OSDA and N-OSDA are depicted in Figure 5.29. 


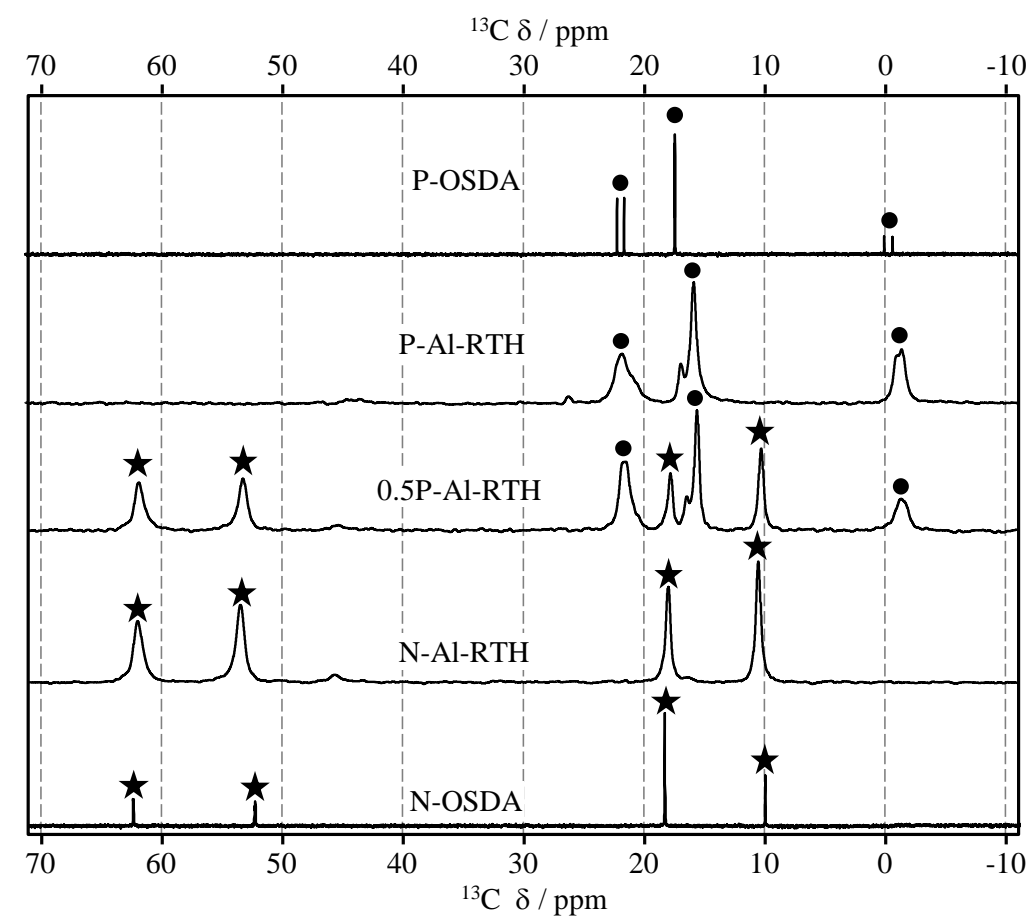

Figure 5.29. ${ }^{13} \mathrm{C}$ MAS-NMR spectra of some Al-RTH materials. Samples are named after their OSDA composition. Dots belong to $\mathrm{P}-\mathrm{OSDA}{ }^{13} \mathrm{C}$ resonances and asterisks belong to $\mathrm{N}-\mathrm{OSDA}$

${ }^{13} \mathrm{C}$ resonances. Free OSDA liquid NMR spectra are included for comparison.

The spectra of the as-made samples show the same resonance profile than the free P-OSDA and N-OSDA, which means that these OSDA's are incorporated into the material and are stable. However, the P-OSDA resonance at $18 \mathrm{ppm}$, which belong to the isopropyl carbon bonded to the phosphorus, is unfolded into two resonances, a minor one keeping the same chemical shift, and a major one which is shifted to $16 \mathrm{ppm}$. The unfolding of this resonance suggests that the P-OSDA presents two different chemical environments, probably due to the cation adopting two different positions and/or conformations inside the zeolite.

The ${ }^{31} \mathrm{P}$ MAS-NMR spectra of the as-made Al-RTH samples compared with the liquid ${ }^{31} \mathrm{P}$ NMR spectrum of the free P-OSDA are depicted in Figure 5.30. 


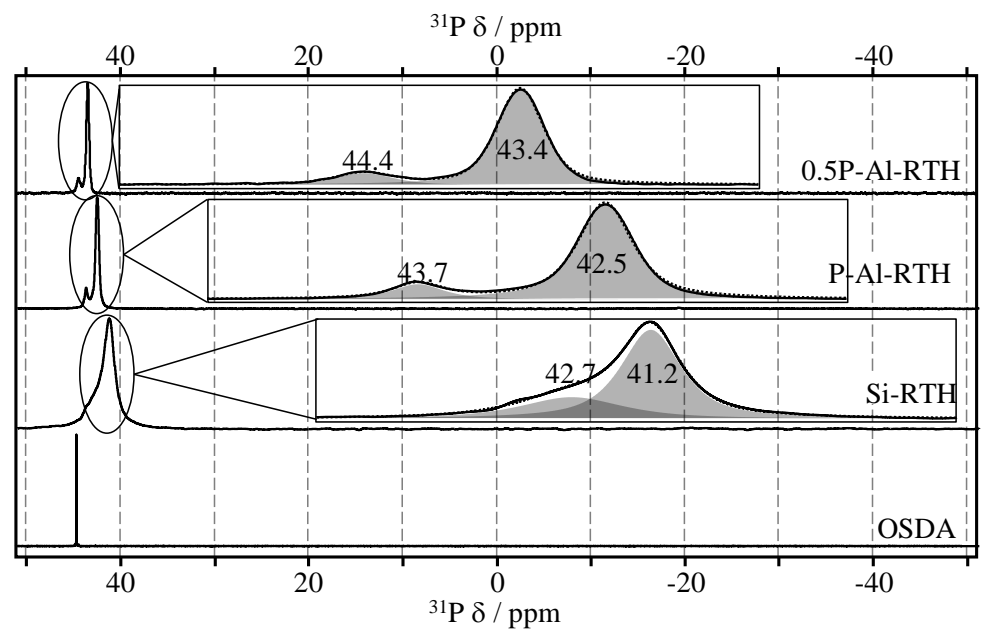

Figure 5.30. ${ }^{31} \mathrm{P}$ MAS-NMR spectra of some Al-RTH materials. Samples are named after their OSDA composition. All-silica sample and free OSDA liquid NMR spectra included for comparison. Solid lines correspond to experimental spectra; dotted lines correspond to the sum of deconvoluted signals. Spectra were deconvoluted as Gaussian/Lorentz curves. Spectra are not scaled up on phosphorus content. Inset figures include the chemical shift of the resonances.

The ${ }^{31} \mathrm{P}$ MAS-NMR spectra of the as-made samples show two resonances, a main resonance around 42.5-43 ppm and a smaller resonance around 43.5-44 ppm, depending on the sample. The mathematical integration of these resonances roughly yields a 1 to 8 ratio between the main and the secondary resonances in all samples, regardless of the P-OSDA content. These two resonances closely resemble to the liquid NMR of the P-OSDA in water solution (44.55 ppm), and thus, the two resonances could be attributed to two slightly different chemical environments of the intact OSDA. These two different environments must be due to two different positions and/or conformations that the P-OSDA would adopt inside the zeolite, as all-silica samples also exhibit a similar trend, although in this case only a shoulder signal could be observed due to the broadening of the resonances. ${ }^{[16]}$ This fact is in agreement with the previous results obtained from the ${ }^{13} \mathrm{C}$ NMR spectroscopy of these samples, as the ${ }^{13} \mathrm{C}$ resonance of the methylene group of the P-OSDA was unfolded in two resonances.

After the thermal treatment of the Al-RTH materials, most of the phosphorus remains inside the material, giving the opportunity to study the chemical nature of the generated species by ${ }^{31} \mathrm{P}$ MAS-NMR spectroscopy, whose spectra are shown in Figure 5.31. 


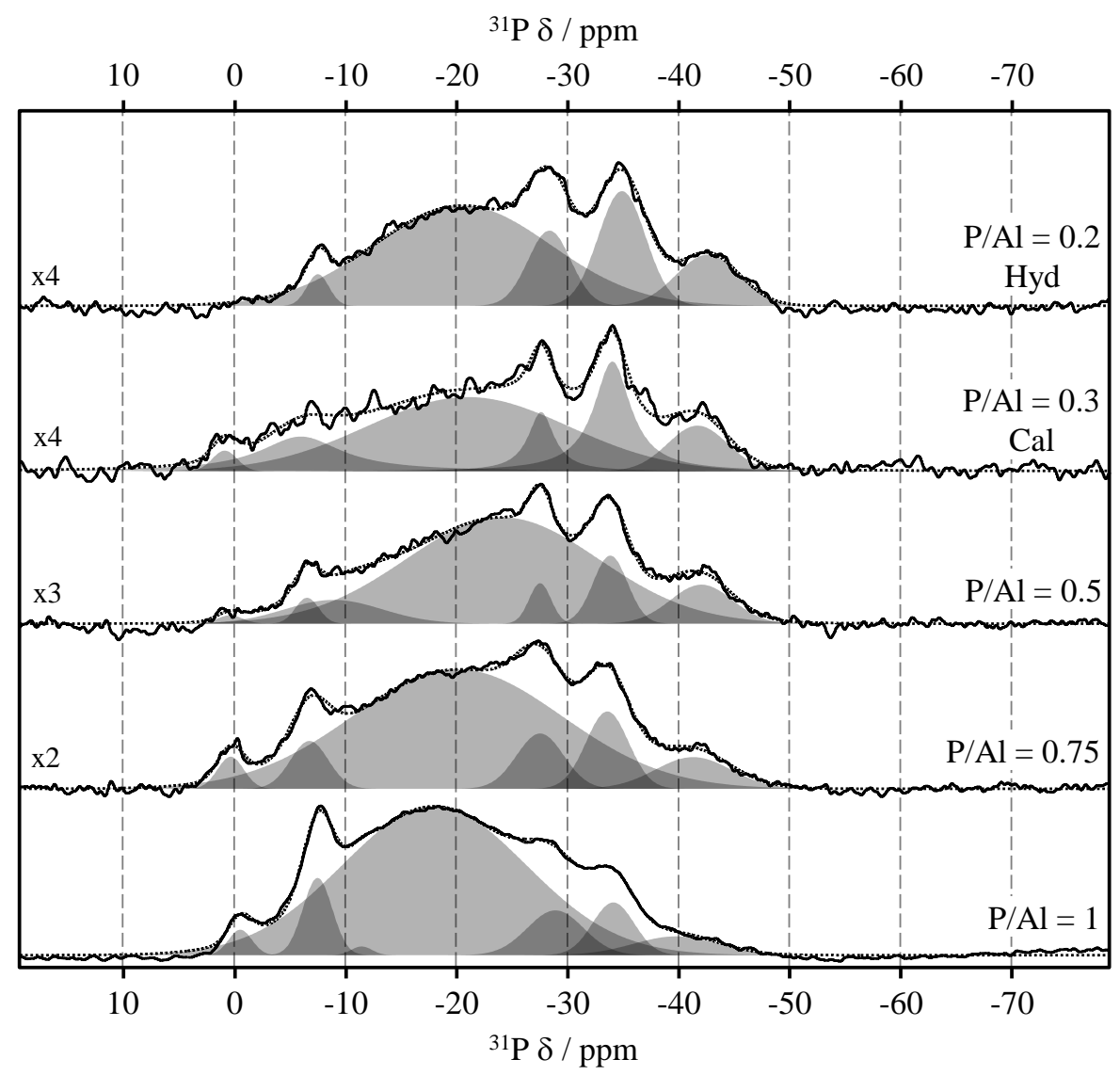

Figure 5.31. ${ }^{31} \mathrm{P}$ MAS-NMR spectra of some thermally treated (Cal: calcined;

Hyd: hydro-genated) Al-RTH materials with different P/Al ratios. Solid lines correspond to experimental spectra; dotted lines correspond to the sum of deconvoluted signals.

Peaks were deconvoluted as Gaussian/Lorentz curves.

It could be seen that upon thermal treatment, the organic compound is decomposed and the remaining phosphorous species gives rise to several resonances with chemical shifts ranging from $0 \mathrm{ppm}$ to $-45 \mathrm{ppm}$, which are characteristic of extra-framework $\mathrm{P}_{2} \mathrm{O}_{5}$-like species. The resulting spectra are complex, but the mathematical deconvolution of the spectra yields at least five thin resonances and a very broad resonance. Compared with the Al-MFI samples in section 5.2.4.1, it could be seen that Al-RTH spectra present a higher signal to noise ratio, which allows to identify more resonances which could be almost hidden due to the overlapping of these discrete resonances and the very broad resonance. 
The first sharp resonance at $0 \mathrm{ppm}$, corresponding to extra-framework $\mathrm{P}_{2} \mathrm{O}_{5}$ that is not interacting with the framework aluminium, increases its intensity as the phosphorus content increases. The same trend was observed for the resonance at $-8 \mathrm{ppm}$, that is usually assigned to phosphorus atoms in pyrophosphoric acid or to terminal $\left[\mathrm{P}_{4} \mathrm{O}_{3}\right]^{-}$groups of polyphosphoric species. ${ }^{[45-48]}$ The small resonance at $c a .-10 \mathrm{ppm}$ is assigned to the chemical shift usually obtained for middle groups in pyrophosphates or other short-chain polyphosphates. ${ }^{[47,48]}$ The broad resonance centred at $-18 \mathrm{ppm}$ normally contains signals of longer polymeric phosphate chains, as well as highly condensed polyphosphate species, and its intensity appears to be proportional with the phosphorus content. ${ }^{[67-69]}$ Finally, the last three resonances at $-28 \mathrm{ppm}$, $-35 \mathrm{ppm}$ and $-43 \mathrm{ppm}$, appear to keep their intensities, but are almost completely hidden under the broad resonance centred at $-18 \mathrm{ppm}$ at high P-loadings. These resonances have been usually assigned to different (bi)phosphates bounded to monodentate or bidentate aluminium octahedral atoms. ${ }^{[45-48]}$ This aluminium is expected to remain as framework aluminium, although the formation of some extra-framework aluminium could not be disclosed. ${ }^{[49]}$ This fact would be easily confirmed by washing the phosphorus-containing zeolite with ammonium acetate to remove the phosphorous residues. However, this methodology cannot be applied in small pore zeolites where $\mathrm{P}_{\mathrm{x}} \mathrm{O}_{\mathrm{y}}$ species are larger than the pore openings.

\subsubsection{Aluminium incorporation and species}

The aluminium incorporation was studied by ${ }^{27} \mathrm{Al}$ MAS-NMR spectroscopy on the as-made Al-RTH samples, whose spectra are shown in Figure 5.32. 


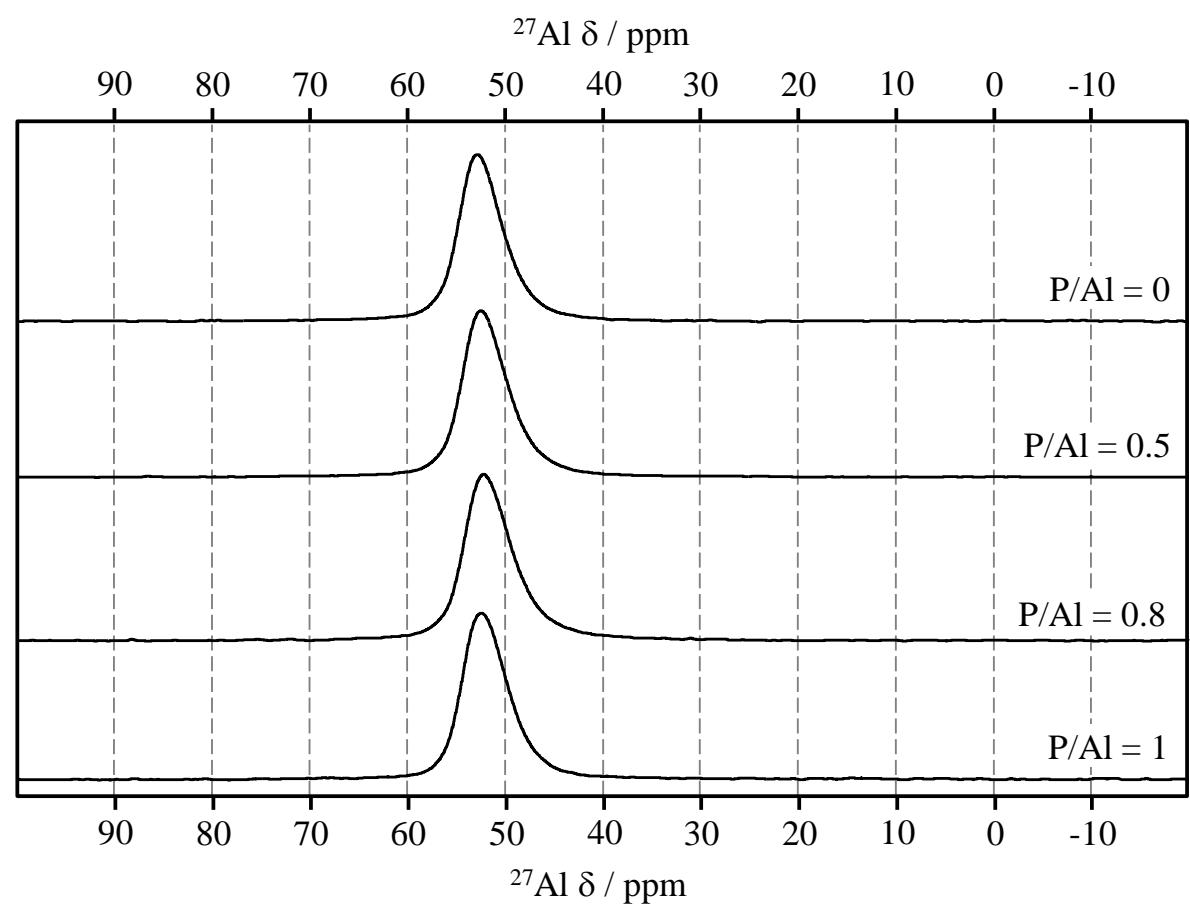

Figure 5.32. ${ }^{27} \mathrm{Al}$ MAS-NMR spectra of some as-made Al-RTH materials with different P/Al ratios.

All the as-made Al-RTH materials show a single resonance centred at $53 \mathrm{ppm}$, regardless of the OSDA composition used in their syntheses. This resonance is typically attributed to $\mathrm{Al}$ in tetrahedral coordination. ${ }^{[60]}$

When materials are thermally treated, the aluminium is distributed in three different chemical environments, as ${ }^{27} \mathrm{Al}$ MAS-NMR spectra show in Figure 5.33. 


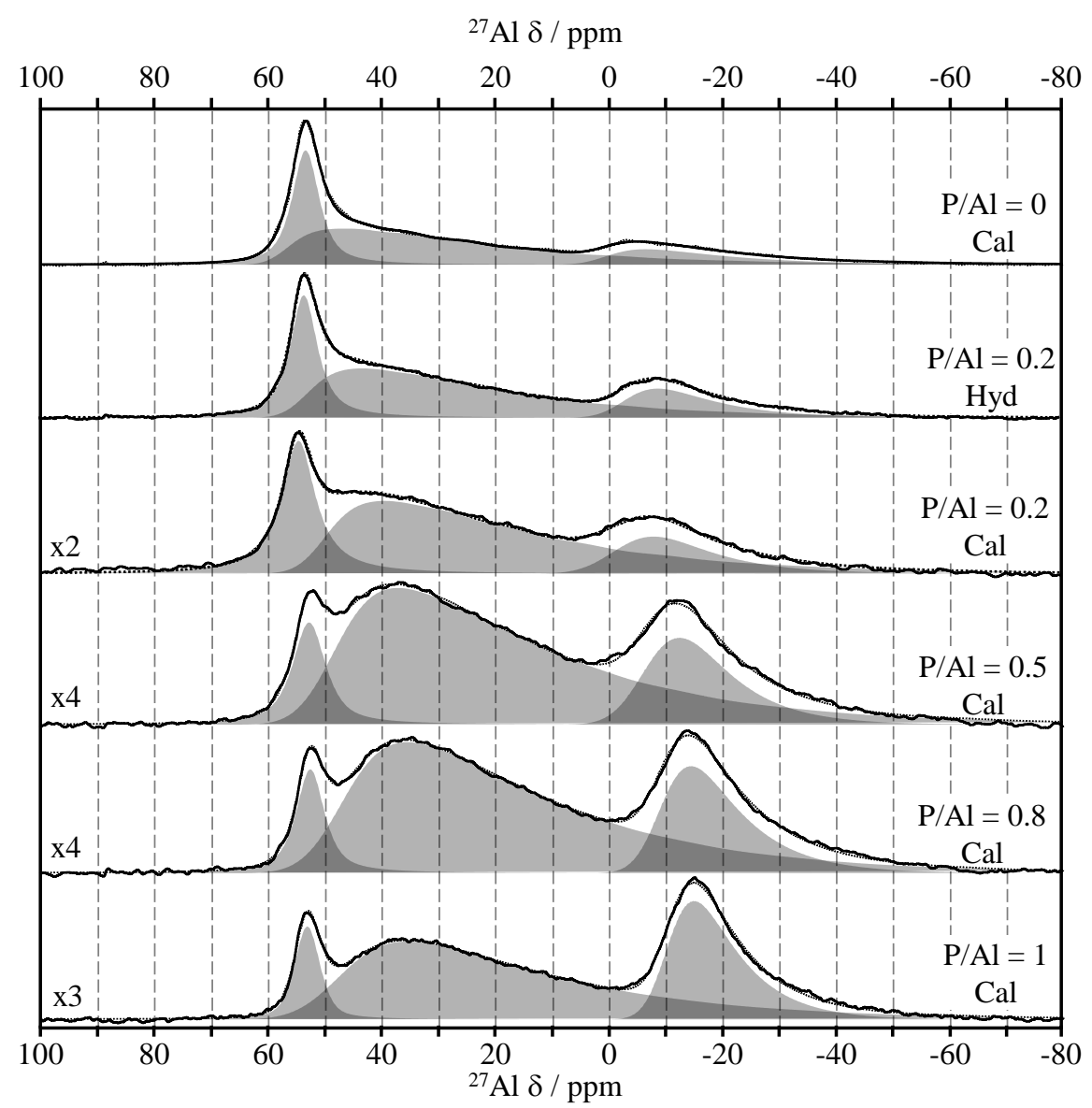

Figure 5.33. ${ }^{27} \mathrm{Al}$ MAS-NMR spectra of some thermally treated (Cal: calcined; Hyd: hydrogenated) Al-RTH materials with different $\mathrm{P} / \mathrm{Al}$ ratios. Solid lines correspond to experimental spectra; dotted lines correspond to the sum of deconvoluted signals. The resonance at $\mathrm{ca} .55$ ppm was deconvoluted as a Gaussian/Lorentz curve (for an easier view), and the other resonances were deconvoluted using the CzSimple method. ${ }^{[56]}$.

The main ${ }^{27} \mathrm{Al}$ resonances appear at $c a .55 \mathrm{ppm}$ (narrow), at $c a .38 \mathrm{ppm}$ (very wide) and at $c a .-15 \mathrm{ppm}$ (wide). These resonances greatly vary their intensities depending on the $\mathrm{P} / \mathrm{Al}$ and $\mathrm{Si} / \mathrm{Al}$ ratios. Indeed, the intensity of the resonance at $55 \mathrm{ppm}$, corresponding to tetrahedral $\mathrm{Al}$ atoms in framework positions decreases as the $\mathrm{P} / \mathrm{Al}$ ratio increases, while the resonances at $38 \mathrm{ppm}$ and -15 ppm increases. ${ }^{[57-59]}$ 
It should be noted that the chemical shift of the wide resonance at $38 \mathrm{ppm}$, and especially the resonance at $-15 \mathrm{ppm}$, are influenced by the phosphorus content in the Al-RTH material, shifting up-field as phosphorus content increases. The chemical shift displacement and the increase in the intensity of the resonances at $38 \mathrm{ppm}$ and $-15 \mathrm{ppm}$ evidence the interaction between phosphorous and aluminium species, as previously described. ${ }^{[49]}$

Finally, the hydrogenation treatment at high temperature yields an Al-RTH material with a higher proportion of tetrahedrally coordinated aluminium species compared with its $\mathrm{P} / \mathrm{Al}$ ratio equivalent calcined counterpart. As previously observed in Al-MFI in section 5.2.4.2, the increased intensity of ${ }^{27} \mathrm{Al}$ resonance at $55 \mathrm{ppm}$ is accompanied by a decreased intensity in the ${ }^{31} \mathrm{P}$ resonance at $-40 \mathrm{ppm}$, although the difference is less evident in the Al-RTH zeolite. Therefore, the nature of the phosphorous and aluminium species inside the zeolites also depends on the post-synthesis treatment. However, in this case the washing of the Al-RTH samples was not performed as phosphorus is barely removed from RTH zeolite because of its small pore opening. ${ }^{[16]}$

Comparing the Al-RTH spectra with the obtained for the Al-MFI synthesized by the same methodology, it could be seen that the amount of pentacoordinated and octahedrally coordinated aluminium species is considerably larger in the Al-RTH samples, where even the RTH synthesized only with the N-OSDA presents these two resonances, although in a smaller proportion than the phosphorus-containing samples. This indicates that the presence of these species is inherent to this zeolite, although magnified by the presence of phosphorus.

The ${ }^{27} \mathrm{Al} 38 \mathrm{ppm}$ resonance could correspond either to pentacoordinated $\mathrm{Al}$ atoms that are obtained as $\mathrm{Al}$ atoms in framework positions and coordinated to $\mathrm{H}_{2} \mathrm{O}$ molecules, or to highly distorted tetrahedral coordination aluminium. Indeed, the intensity and widening of this resonance heavily depends on the time exposed to air in a given sample, as dehydrated samples results in signals so wide that are almost invisible. ${ }^{[70,71]}$ The use of multiquantum ${ }^{27}$ Al-3Q-MAS experiments, whose bi-dimensional spectra are depicted in Figure 5.34, allows ensuring the chemical nature of the different $\mathrm{Al}$ resonances as this NMR technique allows lessening the large quadrupolar effects of the $\mathrm{Al}$ nuclei. ${ }^{[16,71,72]}$ 


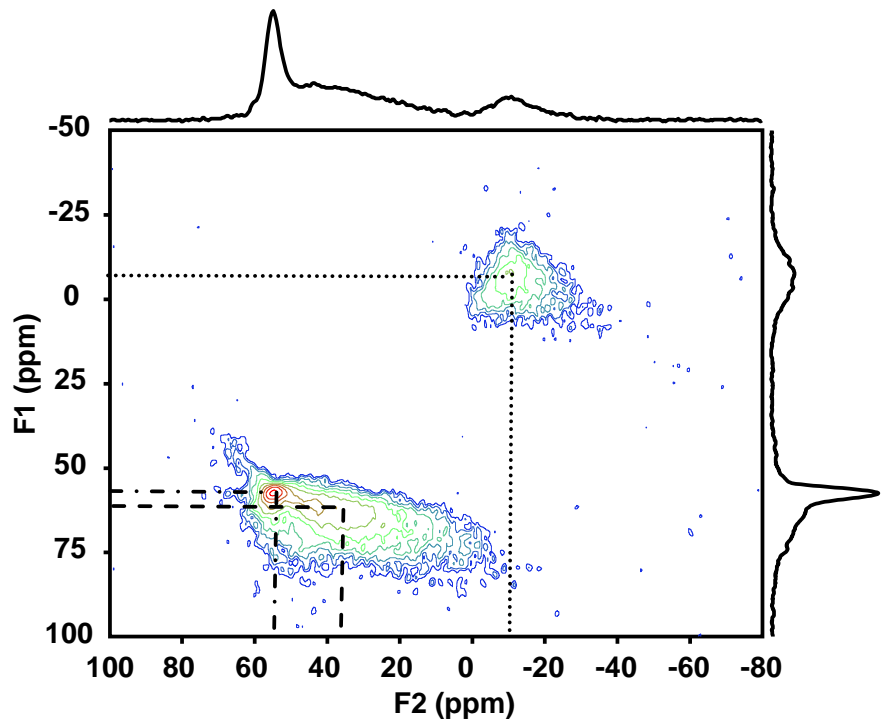

Figure 5.34. 3Q- ${ }^{27} \mathrm{Al}$ MAS-NMR spectrum of a $\mathrm{P} / \mathrm{Al}=\mathbf{0 . 5}$ RTH sample.

Using this technique, the chemical shift in the two dimensions of the spectra, $\delta_{\mathrm{F} 1}$ and $\delta_{\mathrm{F} 2}$, are obtained and then, the isotropic chemical shift $\left(\delta_{\text {iso }}\right)$ and the quadrupolar parameters $\left(\mathrm{P}_{\mathrm{Q}}\right)$ are calculated from the barycentre of the crossed signals. ${ }^{[59,73]}$ The observed $\delta_{\mathrm{F} 1}$ and $\delta_{\mathrm{F} 2}$ shifts and the calculated $\delta_{\text {iso }}$ shift and $\mathrm{P}_{\mathrm{Q}}$ parameter of the calcined 0.5P-Al-RTH sample are summarized in Table 5.11.

Table 5.11. Calculated values of the isotropic chemical shift $\left(\delta_{\text {iso }}\right)$ and the quadrupolar parameter (PQ) of the calcined $\mathrm{P} / \mathrm{Al}=0.5 \mathrm{RTH}$ sample.

\begin{tabular}{ccccc}
\hline Signal & $\delta_{\mathrm{F} 1} / \mathrm{ppm}$ & $\delta_{\mathrm{F} 2} / \mathrm{ppm}$ & $\delta_{\text {iso }} / \mathrm{ppm}$ & $\mathrm{P}_{\mathrm{Q}} / \mathrm{MHz}$ \\
\hline $\mathrm{Al}(\mathrm{IV})_{\mathrm{a}}$ & 56.6 & 54.9 & 56.0 & 1.41 \\
$\mathrm{Al}(\mathrm{IV})_{\mathrm{b}}$ & 62.6 & 38.8 & 53.8 & 5.19 \\
$\mathrm{Al}(\mathrm{VI})_{\mathrm{a}}$ & -7.2 & -11.2 & -8.7 & 2.14 \\
\hline
\end{tabular}

In this case, only three barycentres were identified, and the obtained $\delta_{\text {iso }}$ and $\mathrm{P}_{\mathrm{Q}}$ values clearly show that the resonance at $38 \mathrm{ppm}$ correspond to highly distorted tetrahedral $\mathrm{Al}$ species and not to pentacoordinated Al species. 


\subsection{NMR study of phosphorus species in P-modified MFI and RTH}

There have been many attempts at modelling and explaining the interaction between phosphorus and aluminium species. ${ }^{[10,49,74-78]}$ In this section, the interaction between phosphorus and aluminium has been studied by MAS-NMR following a similar approach to the previously reported by Pruski et al. ${ }^{[49,74]}$ Because of that, Al-MFI samples were compared with the results of this paper looking for the differences, if any, between the commonly used impregnation methodology and the dual template methodology described in this thesis. After that, Al-MFI results were compared with the Al-RTH results. A similar and complementary study of these materials has been recently published by Martínez-Ortigosa. ${ }^{[79]}$

It is important to note that, unlike samples prepared by post-synthesis methods, samples prepared by dual-template method present a lower phosphorus content, which lengthens the times required for the acquisition of the spectra, as well as limit their resolution due to a lower signal to noise ratio. Because of that, these experiment were performed during a short stay at the Institut Lavoisier de Versailles under the direction of Prof. C. Martineau, using a more powerful NMR spectrometer $(800 \mathrm{MHz})$ and taking advantage of the expertise of Prof. C. Martineau's group in the analysis of phosphorous and aluminium species interaction in aluminophosphate materials. ${ }^{[80-85]}$

\subsubsection{Proton-phosphorus interaction}

First of all, proton to phosphorus cross polarization experiments ( $\mathrm{H}>\mathrm{P} C \mathrm{CP}{ }^{31} \mathrm{P}$ MASNMR) were registered and compared against the Bloch decay experiments in Al-MFI and Al-RTH samples, shown in Figure 5.35. Cross polarization spectra excite one nuclei, proton in this case, to transfer the magnetization from this nuclei to another, phosphorus in this case. ${ }^{[86]}$ This transfer would only take place if there is any interaction between both nuclei, either by connectivity ( $J$ coupling) or by close proximity (dipolar coupling). 


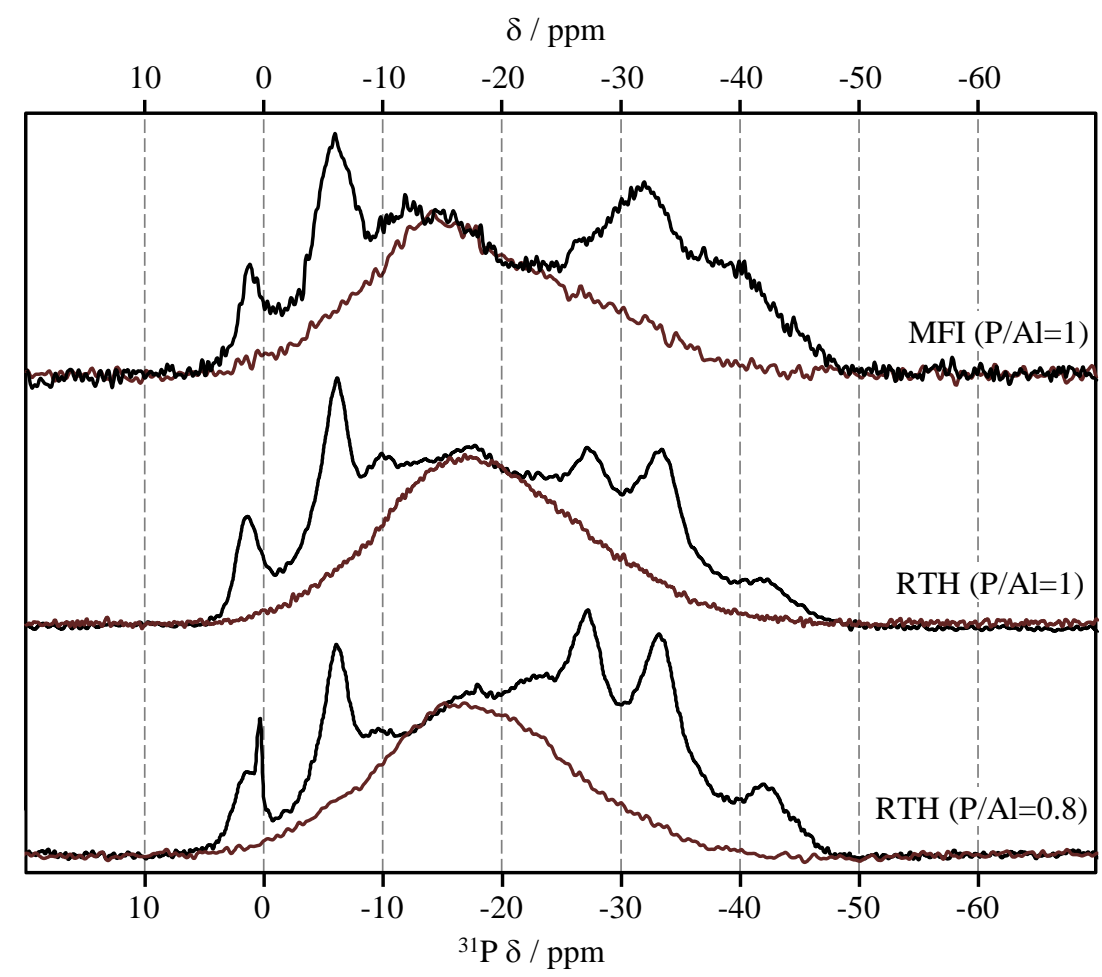

Figure 5.35. Bloch decay (black line) and H>P CP (red line) ${ }^{31} \mathrm{P}$ MAS-NMR spectra of some Al-MFI and Al-RTH materials.

In all cases, most of the phosphorus resonances disappear, which means that several phosphorous species do not interact with protons. However, a very broad resonance remains in all cases, whose mathematical integration yields about $50 \%$ in the Bloch decay experiments. This broad resonance is probably an envelopment signal formed by several discrete resonances belonging to discrete phosphorous species oriented towards multiple directions that, because of low $\mathrm{T}_{1}$ relaxation times, overlap between them. These phosphorous species would probably belong to $\mathrm{P}-\mathrm{OH}$ species formed after the calcination and the hydration of the materials. On the other side, the narrow resonances would belong to phosphorous species interacting with aluminium atoms, forming aluminophosphate species, or between themselves, forming pyrophosphates and polyphosphates.

Bi-dimensional heteronuclear correlation (HETCOR) experiments ${ }^{[87]}$ between proton and phosphorus nuclei were performed to check if any correlation between them could be stablished. The bi-dimensional spectra is shown in Figure 5.36. 


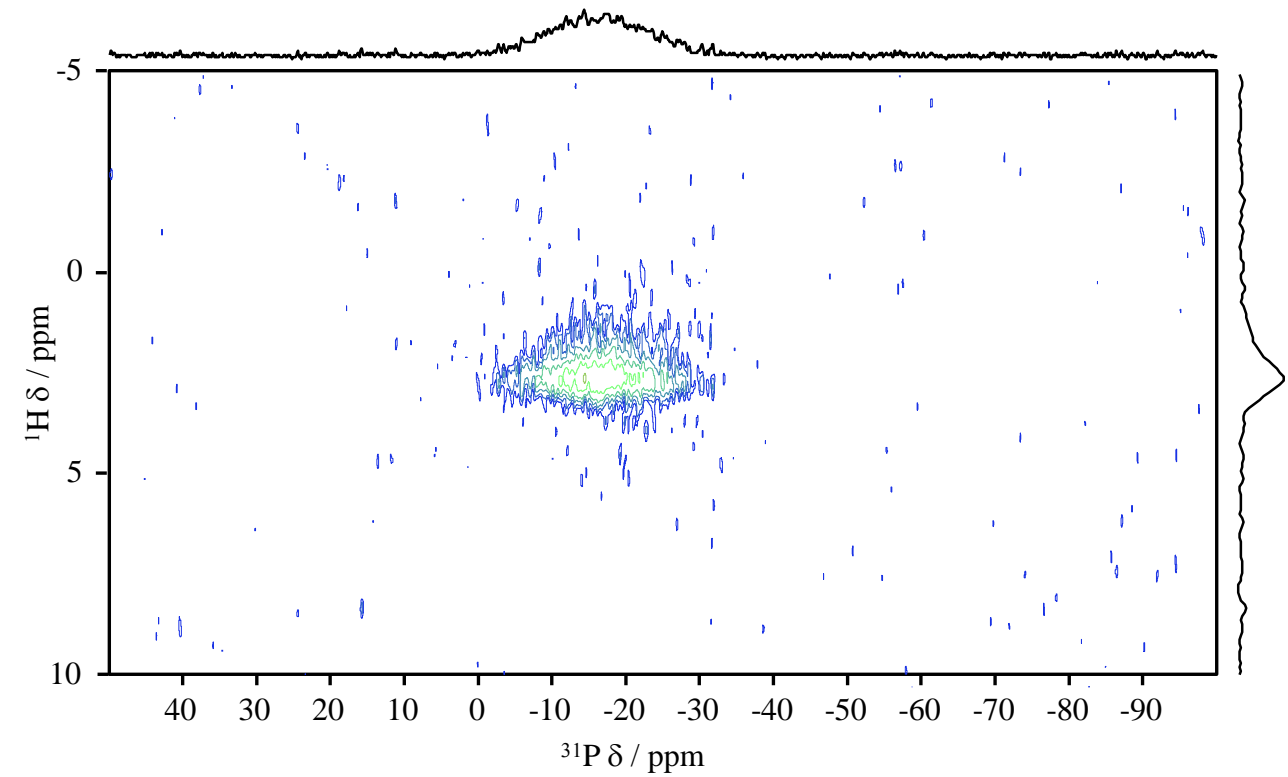

Figure 5.36. HETCOR H-P MAS-NMR experiment on the Al-RTH P/Al=1 sample.

The results were inconclusive in all cases, as a single broad resonance was found in both ${ }^{31} \mathrm{P}$ and ${ }^{1} \mathrm{H}$ spectra, and both resonances fully interact between them.

\subsubsection{Aluminium-phosphorus interaction}

The next step was to study the interaction between the phosphorous and the aluminium species. First, phosphorus to aluminium heteronuclear multiple-quantum coherence (HMQC) spectra $^{[82]}$ of Al-MFI and Al-RTH samples were measured. The corresponding bi-dimensional spectra are shown in Figure 5.37. 

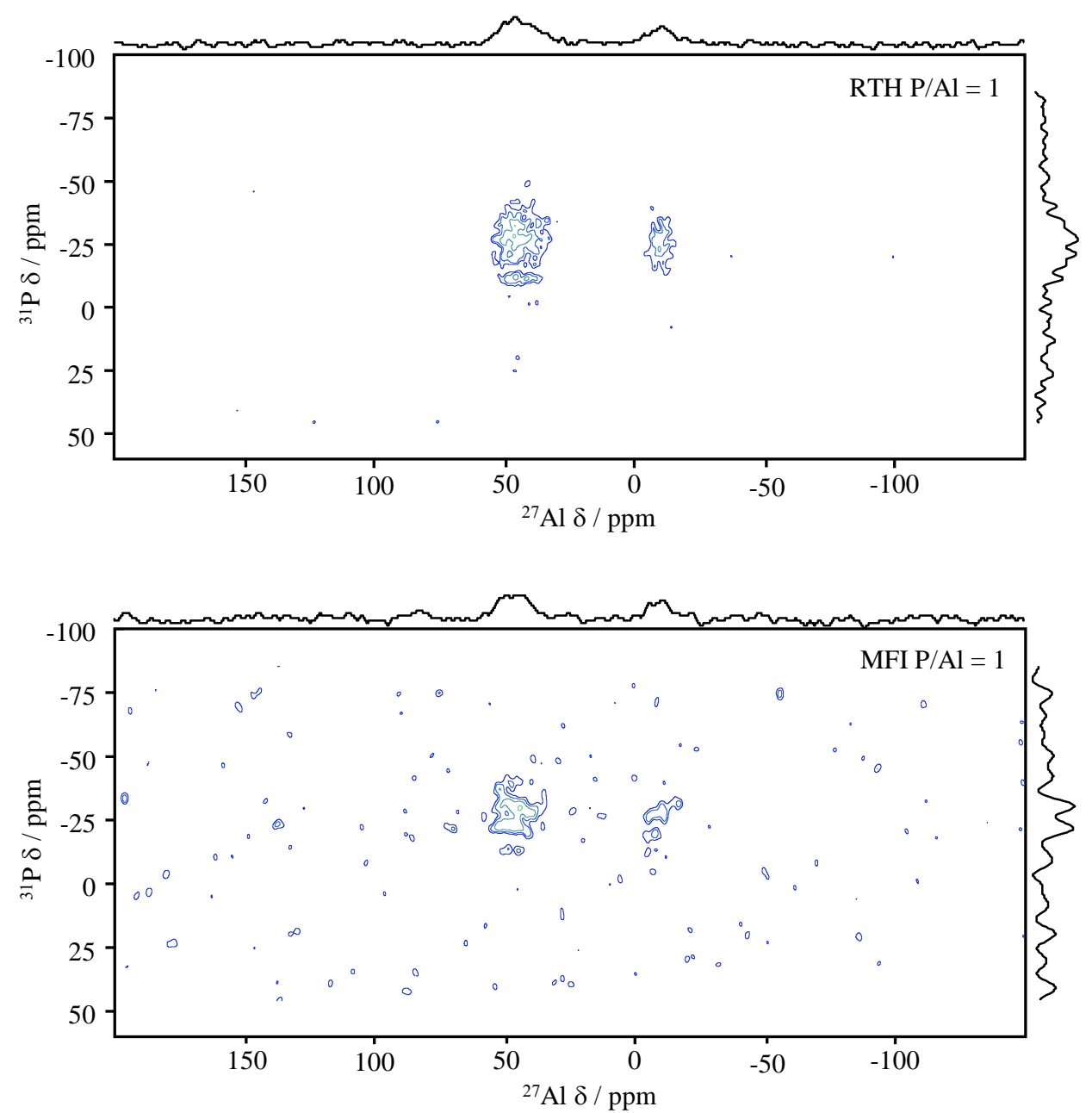

Figure 5.37. ${ }^{31} \mathrm{P}\left\{{ }^{27} \mathrm{Al}\right\}$ HMQC MAS-NMR experiments of Al-RTH (above) and Al-MFI (below) samples with $\mathbf{P} / \mathrm{Al}=1$.

In these spectra, it could be seen up to three different interactions signals. First of all, the ${ }^{27} \mathrm{Al}$ resonance at $c a .-10 \mathrm{ppm}$ only interacts with the ${ }^{31} \mathrm{P}$ resonances between -15 and -35 $\mathrm{ppm}$. These resonances also interact with the other ${ }^{27} \mathrm{Al}$ resonance at $c a .38 \mathrm{ppm}$, which also interacts with the ${ }^{31} \mathrm{P}$ resonance at $-8 \mathrm{ppm}$. This would mean that this latter resonance does not correspond to phosphorus atoms in pyrophosphoric acid or to terminal $\left[\mathrm{P}_{4} \mathrm{O}_{3}\right]^{-}$groups in polyphosphoric species as previously stated, and instead, these atoms should be linked to aluminium atoms via oxygen bonding. As expected, the ${ }^{27} \mathrm{Al}$ resonance at $55 \mathrm{ppm}$, assigned to tetrahedral aluminium species, does not interact with any phosphorus resonance. 
Finally, rotational-echo double-resonance (REDOR) experiments ${ }^{[88]}$ were performed on Al-MFI and Al-RTH samples. In these experiments, the phosphorus nuclei are excited and the magnetization is then transferred after a dephasing time to the aluminium nuclei, acquiring then the ${ }^{27} \mathrm{Al}$ NMR spectra. The transfer of the magnetization depends on the distance between the phosphorus and aluminium nuclei and the dephasing time to transfer this magnetization. The obtained aluminium spectra show scaled intensities in each resonance depending on the mean distance between the different aluminium species and the phosphorus nuclei. The scaling of the spectra between a reference spectra and the dephased spectra (signal saturation) was quantified and these values were plot against the dephasing time in Figure 5.38.

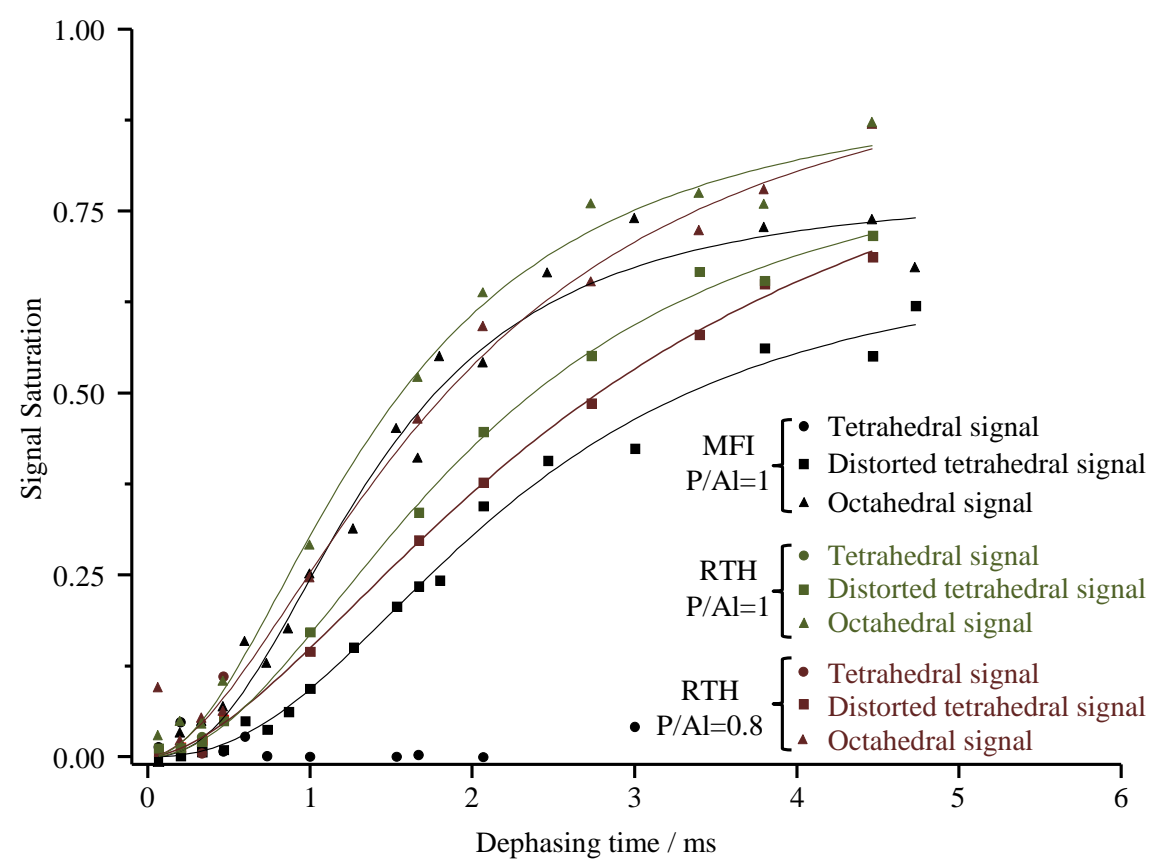

Figure 5.38. REDOR curves obtained from REDOR experiments of some Al-MFI and Al-RTH materials. In all samples spectra, three different resonances were identified: tetrahedral (circles), $c a .55 \mathrm{ppm}$; distorted tetrahedral (squares), $c a .35 \mathrm{ppm}$; and octahedral (triangles), $c a$. $-15 \mathrm{ppm}$. Curves are just for guidance.

As expected, the ${ }^{27} \mathrm{Al}$ resonance at $55 \mathrm{ppm}$ assigned as tetrahedral aluminium is not visible in the dephased spectra, so no interaction between this aluminium species and the phosphorous species occurs. On the other hand, the ${ }^{27} \mathrm{Al}$ resonances at $c a .38 \mathrm{ppm}$ (distorted tetrahedral) and $c a .-15 \mathrm{ppm}$ (octahedral) are affected by the magnetization transfer from the 
phosphorus nuclei. The slope of the REDOR curves is related to the mean distance between phosphorus and aluminium nuclei, being closer the distance as the slope increases. This indicates that the octahedral aluminium species are closer to the phosphorous species than the distorted tetrahedral aluminium species are. However, the REDOR curves of the octahedral species present minor differences between the Al-MFI and Al-RTH samples with different $\mathrm{P} / \mathrm{Al}$ ratios, while the distorted tetrahedral resonance is more affected by the phosphorus content and/or zeolite structure, as the Al-MFI and Al-RTH samples with higher phosphorus loadings present strongly differing REDOR curves, with a lower phosphorus content Al-RTH sample presenting middle ground values.

\subsection{Conclusions}

The use of phosphorous cations as OSDA's has allowed the synthesis of two phosphorous modified zeolites, the MFI and the RTH zeolites, using a dual template synthesis methodology jointly using closely related nitrogen and phosphorous OSDA's. This synthesis methodology provides the materials with the following features:

- The use of P-OSDA and N-OSDA yields zeolites with controlled phosphorus contents. The preferential incorporation of phosphorus allows to selectively and accurately incorporate the needed amount of phosphorus.

- The calcination of the aluminosilicate materials obtained by this methodology allows keeping most of the phosphorus incorporated, and thus, the P/Al ratio could be tuned just by using the required $\mathrm{P} /(\mathrm{P}+\mathrm{N})$ OSDA ratio in the synthesis gel.

- The introduction of phosphorus by this methodology allows modifying the textural and acidic properties of the final materials avoiding further post-synthesis treatments.

- The application of post-synthesis treatments, as calcination, hydrogenation at high temperature, or washing with $\mathrm{NH}_{4} \mathrm{Ac}$, allows the removal of different amounts of phosphorus. However, the use of the dual template synthesis methodology is more flexible than the hydrogenation at high temperature and the washing with $\mathrm{NH}_{4} \mathrm{Ac}$, since phosphorus removal by these latter methods is difficult to control.

- The use of the dual template methodology allows the incorporation of different amounts of phosphorus in a small pore zeolite, the RTH zeolite, that is impossible by post-synthesis treatments. 
- The introduction of phosphorus in the RTH small pore zeolite leads to diffusional constraints when the phosphorus content reaches a critical amount, between 0.6 and 1.2 wt.\%P, but pore blockage does not occur.

- The introduction of phosphorus in the synthesis stage avoids the formation of significant amounts of $\mathrm{P}_{2} \mathrm{O}_{5}$ phosphorous species that are not interacting with the aluminium species of the materials. These species negatively affect to the textural properties of the material without providing a positive effect due to its lack of interaction with framework aluminium species.

- The introduction of lower amounts of phosphorus by the dual template methodology than by post-synthesis treatment allows to identify discrete phosphorus resonances by ${ }^{31} \mathrm{P}$ MAS-NMR spectroscopy. These discrete resonances appear in aluminosilicate material's spectra of both MFI and RTH zeolites, but their intensities vary depending on the thermal treatment and the phosphorus content of each material.

- The intensity of some of the ${ }^{31} \mathrm{P}$ resonances could be linked with the relative intensity of the different ${ }^{27} \mathrm{Al}$ resonances. Likewise, these ${ }^{27} \mathrm{Al}$ resonances could be linked with the acidic properties of the materials. Although the specific phosphorous species have not yet been identified, additional NMR experiments could reveal more details about the chemical nature of these phosphorous species interacting with the framework aluminium species in zeolites.

\subsection{References}

[1] C. Chen, S. Zones, 11-P-16-From borosilicate to gallo-and aluminosilicate zeolites: new methods for lattice substitution via post-synthetic treatment, Studies in Surface Science and Catalysis, 135, 2001, 211.

[2] H. Koller, C.-Y. Chen, S.I. Zones, Selectivities in post-synthetic modification of borosilicate zeolites, Topics in Catalysis, 58, 7-9, 2015, 451-479.

[3] D. Verboekend, J. Pérez-Ramírez, Design of hierarchical zeolite catalysts by desilication, Catalysis Science \& Technology, 1, 6, 2011, 879-890.

[4] K.A. Tarach, J. Martinez-Triguero, F. Rey, K. Góra-Marek, Hydrothermal stability and catalytic performance of desilicated highly siliceous zeolites ZSM-5, Journal of Catalysis, 339, 2016, 256-269. 
[5] M.-C. Silaghi, C. Chizallet, J. Sauer, P. Raybaud, Dealumination mechanisms of zeolites and extra-framework aluminum confinement, Journal of Catalysis, 339, 2016, 242-255.

[6] M.-C. Silaghi, C. Chizallet, P. Raybaud, Challenges on molecular aspects of dealumination and desilication of zeolites, Microporous and Mesoporous Materials, 191, 2014, 82-96.

[7] H.E. van der Bij, B.M. Weckhuysen, Phosphorus promotion and poisoning in zeolitebased materials: synthesis, characterisation and catalysis, Chemical Society Reviews, 44, 20, 2015, 7406-7428.

[8] C. Martínez, A. Corma, Inorganic molecular sieves: Preparation, modification and industrial application in catalytic processes, Coordination Chemistry Reviews, 255, 13, 2011, 1558-1580.

[9] V. Valtchev, G. Majano, S. Mintova, J. Pérez-Ramírez, Tailored crystalline microporous materials by post-synthesis modification, Chemical Society Reviews, 42, 2013, 263-290.

[10] T. Blasco, A. Corma, J. Martínez-Triguero, Hydrothermal stabilization of ZSM-5 catalytic-cracking additives by phosphorus addition, Journal of Catalysis, 237, 2, 2006, 267 277.

[11] G. Caeiro, P. Magnoux, J. Lopes, F.R. Ribeiro, S. Menezes, A. Costa, H. Cerqueira, Stabilization effect of phosphorus on steamed H-MFI zeolites, Applied Catalysis A: General, 314, 2, 2006, 160-171.

[12] M. Derewinski, P. Sarv, X. Sun, S. Müller, A.C. van Veen, J.A. Lercher, Reversibility of the Modification of HZSM-5 with Phosphate Anions, The Journal of Physical Chemistry C, 118, 12, 2014, 6122-6131.

[13] N. Xue, R. Olindo, J.A. Lercher, Impact of forming and modification with phosphoric acid on the acid sites of HZSM-5, The Journal of Physical Chemistry C, 114, 37, 2010, 15763-15770.

[14] J.E. Schmidt, M.A. Deimund, M.E. Davis, Facile Preparation of Aluminosilicate RTH across a Wide Composition Range Using a New Organic Structure-Directing Agent, Chemistry of Materials, 26, 24, 2014, 7099-7105.

[15] J.E. Schmidt, M.A. Deimund, D. Xie, M.E. Davis, Synthesis of RTH-type zeolites using a diverse library of imidazolium cations, Chemistry of Materials, 27, 10, 2015, 3756-3762.

[16] M. Hernández-Rodriguez, Empleo de Cationes Fosfonio como Agentes Directores de Estructura (ADEs) en la Síntesis de Zeolitas, Universitat Politècnica de València, 2014.

[17] R. Simancas, Síntesis de Nuevos Materiales Zeolíticos empleando Agente Directores de Estructura Fosforados, Universitat Politècnica de València, 2015. 
Chapter 5: Phosphorous-modified zeolites

[18] T. Lemishko, J. Simancas, M. Hernández-Rodríguez, M. Jiménez-Ruiz, G. Sastre, F. Rey, An INS study of entrapped organic cations within the micropores of zeolite RTH, Physical Chemistry Chemical Physics, 18, 2016, 17244-17252.

[19] R.J. Quann, L.A. Green, S.A. Tabak, F.J. Krambeck, Chemistry of olefin oligomerization over ZSM-5 catalyst, Industrial \& Engineering Chemistry Research, 27, 4, 1988, 565-570.

[20] A. Walker, Mechanistic studies of the selective reduction of $\mathrm{NO}_{\mathrm{x}}$ over Cu/ZSM-5 and related systems, Catalysis Today, 26, 2, 1995, 107-128.

[21] N. Rahimi, R. Karimzadeh, Catalytic cracking of hydrocarbons over modified ZSM-5 zeolites to produce light olefins: A review, Applied Catalysis A: General, 398, 1, 2011, 1-17.

[22] Y. Ji, H. Yang, W. Yan, Strategies to enhance the catalytic performance of ZSM-5 zeolite in hydrocarbon cracking: A review, Catalysts, 7, 12, 2017, 367.

[23] M.F. Alotibi, B.A. Alshammari, M.H. Alotaibi, F.M. Alotaibi, S. Alshihri, R. Navarro, J. Fierro, ZSM-5 Zeolite Based Additive In Fcc Process: A review on modifications for improving propylene production, Catalysis Surveys from Asia, 24, 1, 2020, 1-10.

[24] M. Howden, Zeolite ZSM-5 containing boron instead of aluminium atoms in the framework, Zeolites, 5, 5, 1985, 334-338.

[25] T. Mole, J. Anderson, G. Creer, The reaction of propane over ZSM-5-H and ZSM-5-Zn zeolite catalysts, Applied Catalysis, 17, 1, 1985, 141-154.

[26] H. Kitagawa, Y. Sendoda, Y. Ono, Transformation of propane into aromatic hydrocarbons over ZSM-5 zeolites, Journal of Catalysis, 101, 1, 1986, 12-18.

[27] H. Kosslick, V. A. Tuan, R. Fricke', C. Peuker, W.P. Wissenschafler, W. Storek, Synthesis and Characterization of Ge-ZSM-5 Zeolites American Chemical Society, 97, 21, 1993, 5678-5684

[28] S.L. Burkett, M.E. Davis, Mechanisms of Structure Direction in the Synthesis of PureSilica Zeolites. 1. Synthesis of TPA/Si-ZSM-5, Chemistry of Materials, 7, 5, 1995, 920-928.

[29] S. Zhang, T. Kobayashi, Y. Nosaka, N. Fujii, Photocatalytic property of titanium silicate zeolite, Journal of Molecular Catalysis A: Chemical, 106, 1-2, 1996, 119-123.

[30] F. Van der Gaag, J. Jansen, H. Van Bekkum, Template variation in the synthesis of zeolite ZSM-5, Applied Catalysis, 17, 2, 1985, 261-271.

[31] V. Shen, A.T. Bell, Computer simulation of the interactions of tetraalkylammonium cations with ZSM-5 and ZSM-11, Microporous Materials, 7, 4, 1996, 187-199. 
[32] C. Falamaki, M. Edrissi, M. Sohrabi, Studies on the Crystallization Kinetics of Zeolite ZSM-5 With 1,6-Hexanediol as a Structure-Directing Agent, Zeolites, 19, 1, 1997, 2-5.

[33] J.C. Védrine, A. Auroux, P. Dejaifve, V. Ducarme, H. Hoser, S. Zhou, Catalytic and physical properties of phosphorus-modified ZSM-5 zeolite, Journal of Catalysis, 73, 1, 1982, 147-160.

[34] H. Vinek, G. Rumplmayr, J.A. Lercher, Catalytic properties of postsynthesis phosphorus-modified H-ZSM5 zeolites, Journal of Catalysis, 115, 2, 1989, 291-300.

[35] G. Zhao, J. Teng, Z. Xie, W. Jin, W. Yang, Q. Chen, Y. Tang, Effect of phosphorus on HZSM-5 catalyst for $\mathrm{C}_{4}$-olefin cracking reactions to produce propylene, Journal of Catalysis, 248, 1, 2007, 29-37.

[36] Z. Song, A. Takahashi, I. Nakamura, T. Fujitani, Phosphorus-modified ZSM-5 for conversion of ethanol to propylene, Applied Catalysis A: General, 384, 1-2, 2010, 201-205.

[37] B.T. Holland, L. Abrams, A. Stein, Dual templating of macroporous silicates with zeolitic microporous frameworks, Journal of the American Chemical Society, 121, 17, 1999, 4308-4309.

[38] Y. Kakiuchi, Y. Yamasaki, N. Tsunoji, Y. Takamitsu, M. Sadakane, T. Sano, One-pot Synthesis of Phosphorus-modified AEI Zeolites Derived by the Dual-template Method as a Durable Catalyst with Enhanced Thermal/Hydrothermal Stability for Selective Catalytic Reduction of $\mathrm{NO}_{\mathrm{x}}$ by $\mathrm{NH}_{3}$, Chemistry Letters, 45, 2, 2016, 122-124.

[39] M.B. Roeffaers, R. Ameloot, M. Baruah, H. Uji-i, M. Bulut, G. De Cremer, U. Müller, P.A. Jacobs, J. Hofkens, B.F. Sels, Morphology of large ZSM-5 crystals unraveled by fluorescence microscopy, Journal of the American Chemical Society, 130, 17, 2008, 57635772 .

[40] J. Martinez-Ortigosa, J. Simancas, J.A. Vidal-Moya, P. Gaveau, F. Rey, B. Alonso, T. Blasco, Host-Guest and Guest-Guest Interactions of P-and N-Containing Structure Directing Agents Entrapped inside MFI-Type Zeolite by Multinuclear NMR Spectroscopy, The Journal of Physical Chemistry C, 123, 36, 2019, 22324-22334.

[41] J. Martinez-Ortigosa, J. Simancas, J.A. Vidal-Moya, F. Rey, S. Valencia, T. Blasco, A Multi-Nuclear MAS-NMR Study on the Structural Properties of Silicalite-1 Zeolite Synthesized Using N- and P-Based Organic Structure Directing Agents, Applied Sciences, $11,15, \mathbf{2 0 2 1}, 6850$.

[42] M. Thommes, K. Kaneko, A.V. Neimark, J.P. Olivier, F. Rodriguez-Reinoso, J. Rouquerol, K.S. Sing, Physisorption of gases, with special reference to the evaluation of 
Chapter 5: Phosphorous-modified zeolites

surface area and pore size distribution (IUPAC Technical Report), Pure and Applied Chemistry, 87, 9-10, 2015, 1051-1069.

[43] L. Rodríguez-González, F. Hermes, M. Bertmer, E. Rodríguez-Castellón, A. JiménezLópez, U. Simon, The acid properties of H-ZSM-5 as studied by $\mathrm{NH}_{3}$-TPD and ${ }^{27} \mathrm{Al}-\mathrm{MAS}$ NMR spectroscopy, Applied Catalysis A: General, 328, 2, 2007, 174-182.

[44] F. Lónyi, J. Valyon, On the interpretation of the $\mathrm{NH}_{3}$-TPD patterns of H-ZSM-5 and Hmordenite, Microporous and Mesoporous Materials, 47, 2-3, 2001, 293-301.

[45] J. Caro, M. Bülow, M. Derewinski, J. Haber, M. Hunger, J. Kärger, H. Pfeifer, W. Storek, B. Zibrowius, NMR and IR studies of zeolite H-ZSM-5 modified with orthophosphoric acid, Journal of Catalysis, 124, 2, 1990, 367-375.

[46] G. Lischke, R. Eckelt, H.-G. Jerschkewitz, B. Parlitz, E. Schreier, W. Storek, B. Zibrowius, G. Öhlmann, Spectroscopic and physicochemical characterization of P-modified H-ZSM-5, Journal of Catalysis, 132, 1991, 229-243.

[47] A.-R. Grimmer, U. Haubenreisser, High-field static and MAS ${ }^{31}$ P NMR: chemical shift tensors of polycrystalline potassium phosphates $\mathrm{P}_{2} \mathrm{O}_{5} \cdot \mathrm{xK}_{2} \mathrm{O}(0 \leq \mathrm{x} \leq 3)$, Chemical Physics Letters, 99, 5, 1983, 487-490.

[48] T. Duncan, D. Douglas, On the 31P chemical shift anisotropy in condensed phosphates, Chemical Physics, 87, 3, 1984, 339-349.

[49] K. Damodaran, J.W. Wiench, S.M. Cabral de Menezes, Y.L. Lam, J. Trébosc, J.-P. Amoureux, M. Pruski, Modification of H-ZSM-5 zeolites with phosphorus. 2. Interaction between phosphorus and aluminum studied by solid-state NMR spectroscopy, Microporous and Mesoporous Materials, 95, 1-3, 2006, 296-305.

[50] N. Danilina, F. Krumeich, S.A. Castelanelli, J.A. van Bokhoven, Where are the active sites in zeolites? Origin of aluminum zoning in ZSM-5, The Journal of Physical Chemistry $C, 114,14,2010,6640-6645$.

[51] C.W. Kim, N.H. Heo, K. Seff, Framework Sites Preferred by Aluminum in Zeolite ZSM5. Structure of a Fully Dehydrated, Fully Cs ${ }^{+}$-Exchanged ZSM-5 Crystal (MFI, Si/Al= 24), The Journal of Physical Chemistry C, 115, 50, 2011, 24823-24838.

[52] J. Dědeček, Z. Sobalík, B. Wichterlová, Siting and distribution of framework aluminium atoms in silicon-rich zeolites and impact on catalysis, Catalysis Reviews, 54, 2, 2012, 135223.

[53] T. Yokoi, H. Mochizuki, S. Namba, J.N. Kondo, T. Tatsumi, Control of the Al distribution in the framework of ZSM-5 zeolite and its evaluation by solid-state NMR 
technique and catalytic properties, The Journal of Physical Chemistry C, 119, 27, 2015, 15303-15315.

[54] T. Biligetu, Y. Wang, T. Nishitoba, R. Otomo, S. Park, H. Mochizuki, J.N. Kondo, T. Tatsumi, T. Yokoi, Al distribution and catalytic performance of ZSM-5 zeolites synthesized with various alcohols, Journal of Catalysis, 353, 2017, 1-10.

[55] J. Holzinger, P. Beato, L.F. Lundegaard, J. Skibsted, Distribution of Aluminum over the Tetrahedral Sites in ZSM-5 Zeolites and Their Evolution after Steam Treatment, The Journal of Physical Chemistry C, 122, 27, 2018, 15595-15613.

[56] D.R. Neuville, L. Cormier, D. Massiot, Al environment in tectosilicate and peraluminous glasses: A ${ }^{27} \mathrm{Al}$ MQ-MAS NMR, Raman, and XANES investigation, Geochimica et Cosmochimica Acta, 68, 24, 2004, 5071-5079.

[57] M. Hunger, E. Brunner, NMR Spectroscopy, in: Characterization I: Molecular Sieves Science and Technology, Springer Berlin Heidelberg, 4, 2004, 201-293.

[58] M. Hunger, Solid-State NMR Spectroscopy, in: Zeolite Characterization and Catalysis: A Tutorial, Springer Netherlands, 2009, 65-105.

[59] C.A. Fyfe, J.L. Bretherton, L.Y. Lam, Solid-state NMR detection, characterization, and quantification of the multiple aluminum environments in US-Y catalysts by ${ }^{27} \mathrm{Al}$ MAS and MQMAS experiments at very high field, Journal of the American Chemical Society, 123, 22, 2001, 5285-5291.

[60] T. Yokoi, M. Yoshioka, H. Imai, T. Tatsumi, Diversification of RTH-Type Zeolite and Its Catalytic Application, Angewandte Chemie International Edition, 48, 52, 2009, 98849887.

[61] C. Li, C. Paris, J. Martínez-Triguero, M. Boronat, M. Moliner, A. Corma, Synthesis of reaction-adapted zeolites as methanol-to-olefins catalysts with mimics of reaction intermediates as organic structure-directing agents, Nature Catalysis, 1, 7, 2018, 547-554.

[62] S. Vortmann, B. Marler, H. Gies, P. Daniels, Synthesis and crystal structure of the new borosilicate zeolite RUB-13, Microporous Materials, 4, 2, 1995, 111-121.

[63] G.S. Lee, S.I. Zones, Polymethylated [4.1.1] octanes leading to zeolite SSZ-50, Journal of Solid State Chemistry, 167, 2, 2002, 289-298.

[64] D.S. Wragg, R. Morris, A.W. Burton, S.I. Zones, K. Ong, G. Lee, The synthesis and structure of SSZ-73: An all-silica zeolite with an unusual framework topology, Chemistry of Materials, 19, 16, 2007, 3924-3932.

[65] C. Kim, S.-J. Hwang, A.W. Burton, S.I. Zones, A case study of divergent structure directing effects of geometric isomers: The discovery of a new structure directing agent for 
Chapter 5: Phosphorous-modified zeolites

an all-silica RTH zeolite prepared in fluoride media, Microporous and Mesoporous Materials, 116, 1, 2008, 227-232.

[66] Y. Yamasaki, N. Tsunoji, Y. Takamitsu, M. Sadakane, T. Sano, Synthesis of phosphorus-modified small-pore zeolites utilizing tetraalkyl phosphonium cations as both structure-directing and phosphorous modification agents, Microporous and Mesoporous Materials, 223, 2016, 129-139.

[67] D. Müller, E. Jahn, G. Ladwig, U. Haubenreisser, High-resolution solid-state ${ }^{27} \mathrm{Al}$ and ${ }^{31} \mathrm{P}$ NMR: correlation between chemical shift and mean Al-O-P angle in $\mathrm{AlPO}_{4}$ polymorphs, Chemical Physics Letters, 109, 4, 1984, 332-336.

[68] C. Blackwell, R. Patton, Aluminum-27 and phosphorus-31 nuclear magnetic resonance studies of aluminophosphate molecular sieves, American Chemical Society, 88, 25, 1984, 6135-6139.

[69] E.C. Decanio, J.C. Edwards, T.R. Scalzo, D.A. Storm, J.W. Bruno, FT-IR and solidstate NMR investigation of phosphorus promoted hydrotreating catalyst precursors, Journal of Catalysis, 132, 2, 1991, 498-511.

[70] E. Bourgeat-Lami, P. Massiani, F. Di Renzo, P. Espiau, F. Fajula, T. Des Courières, Study of the state of aluminium in zeolite- $\beta$, Applied Catalysis, 72, 1, 1991, 139-152.

[71] K.U. Gore, A. Abraham, S.G. Hegde, R. Kumar, J.-P. Amoureux, S. Ganapathy, ${ }^{29} \mathrm{Si}$ and ${ }^{27} \mathrm{Al}$ MAS/3Q-MAS NMR studies of high silica USY zeolites, The Journal of Physical Chemistry B, 106, 23, 2002, 6115-6120.

[72] G. Engelhardt, D. Michel, High-Resolution Solid-State NMR of Silicates and Zeolites, John Wiley \& Sons Inc., 1987.

[73] S. Sklenak, J. Dědeček, C. Li, B. Wichterlova, V. Gabova, M. Sierka, J. Sauer, Aluminium siting in the ZSM-5 framework by combination of high resolution ${ }^{27} \mathrm{Al} \mathrm{NMR}$ and DFT/MM calculations, Physical Chemistry Chemical Physics, 11, 8, 2009, 1237-1247.

[74] S.M. Cabral de Menezes, Y.L. Lam, K. Damodaran, M. Pruski, Modification of H-ZSM5 zeolites with phosphorus. 1. Identification of aluminum species by ${ }^{27} \mathrm{Al}$ solid-state NMR and characterization of their catalytic properties, Microporous and Mesoporous Materials, 95, 1-3, 2006, 286-295.

[75] Y. Chu, X. Gao, X. Zhang, G. Xu, G. Li, A. Zheng, Identifying the effective phosphorous species over modified P-ZSM-5 zeolite: a theoretical study, Physical Chemistry Chemical Physics, 20, 17, 2018, 11702-11712.

[76] H. van der Bij, Phosphatation of Zeolites: A Combined Spectroscopy, Microscopy and Catalysis Study, Utrecht University, 2014. 
[77] N. Villamizar, M. Eugenia, Estudio del Efecto de la Modificacion con Fosforo sobre la Estructura de la Zeolita ZSM-5 mediante RMN de ${ }^{29} \mathrm{Si}^{27} \mathrm{Al} \mathrm{Y}^{31} \mathrm{P}$, Universidad Industrial de Santander, Escuela De Quimica, 2013.

[78] R. Simancas, A. Chokkalingam, S.P. Elangovan, Z. Liu, T. Sano, K. Iyoki, T. Wakihara, T. Okubo, Recent progress in the improvement of hydrothermal stability of zeolites, Chemical Science, 12, 2021, 7677-7695.

[79] J. Martínez-Ortigosa, Caracterización estructural de zeolitas por Resonancia Magnética Nuclear y su aplicación como catalizadores, Universitat Politècnica de València, 2021.

[80] C. Martineau, Caractérisation structurale de fluorures inorganiques par RMN du solide haute résolution multidimensionnelle et multi-noyaux, Université du Maine, 2008.

[81] C. Martineau, F. Taulelle, NMR crystallography, EPJ Web of Conferences, EDP Sciences, 30, 2012, 02003.

[82] B. Bouchevreau, C. Martineau, C. Mellot-Draznieks, A. Tuel, M.R. Suchomel, J. Trébosc, O. Lafon, J.P. Amoureux, F. Taulelle, An NMR-Driven Crystallography Strategy to Overcome the Computability Limit of Powder Structure Determination: A Layered Aluminophosphate Case, Chemistry-A European Journal, 19, 16, 2013, 5009-5013.

[83] C. Martineau, NMR crystallography: Applications to inorganic materials, Solid State Nuclear Magnetic Resonance, 63, 2014, 1-12.

[84] M. Haouas, F. Taulelle, C. Martineau, Recent advances in application of ${ }^{27} \mathrm{Al}$ NMR spectroscopy to materials science, Progress in Nuclear Magnetic Resonance Spectroscopy, 94, 2016, 11-36.

[85] H. Nagashima, C. Martineau-Corcos, G. Tricot, J. Trebosc, F. Pourpoint, J.-P. Amoureux, O. Lafon, Recent Developments in NMR Studies of Aluminophosphates, in: Annual Reports on NMR Spectroscopy, Elsevier, 94, 2018, 113-185.

[86] O.B. Peersen, X. Wu, I. Kustanovich, S.O. Smith, Variable-amplitude cross-polarization MAS NMR, Journal of Magnetic Resonance, 104, 1993, 334-339.

[87] A. Bielecki, D. Burum, D. Rice, F. Karasz, Solid-State Two-Dimensional ${ }^{13} \mathrm{C}-{ }^{1} \mathrm{H}$ Correlation (HETCOR) NMR Spectrum of Amorphous Poly (2, 6-dimethyl-p-phenylene oxide)(PPO), Macromolecules, 24, 17, 1991, 4820-4822.

[88] T. Gullion, Rotational-echo, double-resonance NMR, in: Modern Magnetic Resonance, Springer, 2008, 713-718. 


\section{Chapter 6}

\section{Synthesis of ITQ-27 (IWV) and UTD-1 (DON) Zeolites}

\subsection{Introduction}

The synthesis of zeolites using novel OSDA's most usually lead to the synthesis of known materials. Despite obtaining known materials, these syntheses are potentially interesting since they open up new synthesis pathways and allow materials with novel compositions and/or properties to be obtained.

This chapter is a continuation of previous works which have given rise to several new zeolites using novel phosphorus containing OSDA's, like ITQ-26, ${ }^{[1]}$ ITQ-27, ${ }^{[2]}$ ITQ-34, ${ }^{[3]}$ ITQ-40, ${ }^{[4]}$ ITQ-45, ${ }^{[5]}$ ITQ-49, ${ }^{[6]}$ ITQ-52 ${ }^{[7]}$ and ITQ-53 ${ }^{[8]}$ zeolites. Also, several known zeolites had been obtained with new chemical compositions, like ITQ-47 ${ }^{[9]}$ or RTH zeolites. ${ }^{[10]}$ The success of these OSDA's could be attributed to the still not well understood beneficial effect of the presence of phosphorus in the OSDA during the crystallization stage.

Special interest leans towards obtaining large and extra-large pore zeolites because of its potential applications. ${ }^{[1-14]}$ Also, the introduction of phosphorus in the synthesis stage 
allows for its use as probe atom for an in-depth characterization of the OSDA guest-host zeolite interaction. ${ }^{[10,15]}$

In this chapter, the syntheses of ITQ-27 (IZA code: IWV) and UTD-1 (IZA code: DON) zeolites are described using a phosphorous OSDA.

\subsection{Synthesis}

The tris(diethylamino)(methyl)phosphonium cation, or OSDA-7 (Figure 6.1), was tested as OSDA in a wide range of synthesis conditions. The detailed synthesis of the OSDA-7 is described in section 3.2.1.7.

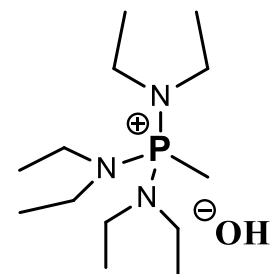

Figure 6.1. Tris(diethylamino)(methyl)phosphonium cation or OSDA-7.

\subsubsection{Synthesis conditions}

Synthesis gels with the following molar composition were prepared:

$$
0.3 \operatorname{OSDA}(\mathrm{OH}):(1-x) \mathrm{SiO}_{2}: x \mathrm{~A}_{\mathrm{m}} \mathrm{O}_{\mathrm{n}}: w \mathrm{H}_{2} \mathrm{O}: 0.3 \mathrm{HF}
$$

with $x$ ranging from 0.025 to $0, w$ ranging from 3.5 to 15 , A being $\mathrm{Al}, \mathrm{B}$ or $\mathrm{Ge}$, and HF being added when needed. Tested conditions are summarized in Table 6.1. 
Table 6.1. Tested synthesis conditions and phase selectivity obtained using tris(diethylamino)(methyl)phosphonium hydroxide as OSDA.

\begin{tabular}{|c|c|c|c|c|c|}
\hline & & \multicolumn{2}{|c|}{$\mathrm{H}_{2} \mathrm{O} / \mathrm{Si}\left({ }^{-} \mathrm{OH}\right)$} & \multicolumn{2}{|c|}{$\mathrm{H}_{2} \mathrm{O} / \mathrm{Si}\left(\mathrm{F}^{-}\right)$} \\
\hline $\mathrm{x}$ & $\mathrm{x} / \mathrm{Si}$ & $<7$ & $>7$ & $<7$ & $>7$ \\
\hline \multicolumn{2}{|c|}{ All Si } & & & $*$ & \\
\hline B & $20-30$ & & & & \\
\hline $\mathrm{Al}$ & $20-50$ & & & & \\
\hline $\mathrm{Ge}$ & $5-50$ & & & & \\
\hline \multicolumn{2}{|c|}{ ITQ-27 (IWV) } & \multicolumn{2}{|c|}{ UTD-1 (DON) } & \multicolumn{2}{|c|}{ No data } \\
\hline
\end{tabular}

*: Only obtained with seeds.

The synthesis gels yielded the zeolite ITQ-27 (IWV) and the zeolite UTD-1 (DON) upon zeolite crystallization depending on the synthesis conditions. The main factor affecting phase selectivity is the synthesis gel concentration. Thus, highly concentrated synthesis gels with water to silica ratios below 7, preferably below 5, favour the IWV phase, while more diluted synthesis media favour the DON phase, preferably with water to silica ratios over 12 . The mineralizing agent is also an important parameter towards phase selectivity. Thus, syntheses in hydroxide media favour the DON phase, while syntheses in fluoride media favour the IWV phase.

The IWV zeolite crystallizes in a wide range of compositions as aluminosilicate, borosilicate, germanosilicate, and even as all-silica material when IWV seeds are used. This is the first time that all-silica IWV zeolite has been obtained. These IWV compositions were obtained both in fluoride and hydroxide media, except the all-silica material which was only obtained in fluoride media.

On the other hand, the DON zeolite was obtained as aluminosilicate, borosilicate and all-silica material. However, the DON zeolite only crystallizes when the content of boron or aluminium is moderately low ( $\mathrm{Si} / \mathrm{B}$ or $\mathrm{Si} / \mathrm{Al}$ ratios higher than 30 ), and hardly crystallized in fluoride media.

The detailed syntheses conditions of IWV and DON zeolites with the OSDA-7 are described in sections 3.2.2.4 and 3.2.2.5, respectively. 


\subsubsection{Phase crystallinity}

The crystallinity of the as-made materials was assessed by powder X-Ray diffraction, whose patterns are shown in Figure 6.2 and Figure 6.3 for IWV and DON materials, respectively.

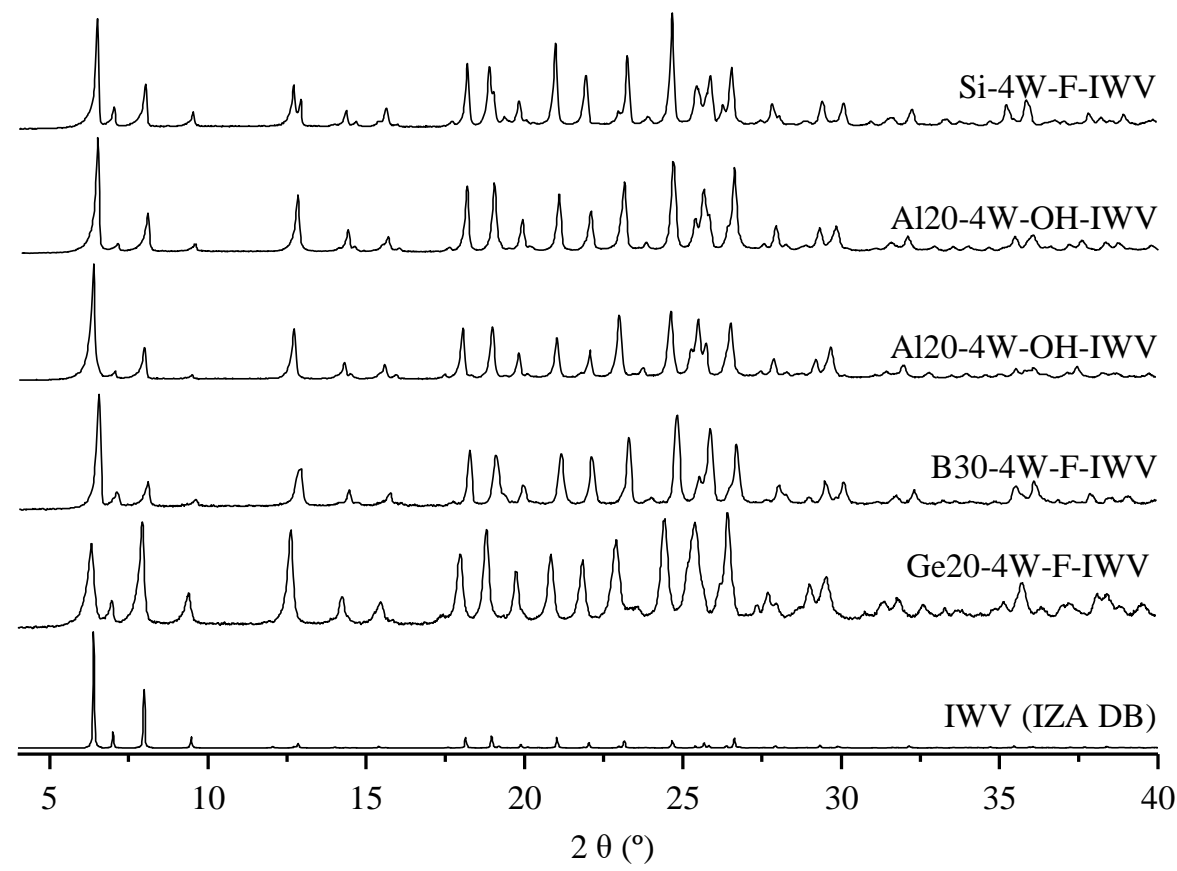

Figure 6.2. Powder X-Ray diffraction patterns of some obtained IWV materials compared with theoretical diffraction pattern (IZA DB). ${ }^{[16]}$ Samples are identified by the synthesis gel composition: heteroatom type and silica to heteroatom ratio; water to silica ratio $(\mathrm{W})$; and synthesis media (OH or F).

All IWV materials were highly crystalline regardless of the synthesis media or heteroatom composition. As expected, small shifts in the $2 \theta$ degrees were found depending on the heteroatom concentration in the synthesis gel, which is indicative of its incorporation in the framework. Additionally, the relative intensities of the diffraction peaks vary, especially at $2 \theta$ below $12^{\circ}$, which could be due to the presence of the OSDA and/or preferred orientation of the crystallites. Also, it should be noted that the germanosilicate sample presents wider diffraction peaks compared to other samples, which could be explained by considerably smaller crystallites. Finally, the all-silica sample present the sharpest diffraction peaks, allowing to identify previously overlapped diffraction peaks. 


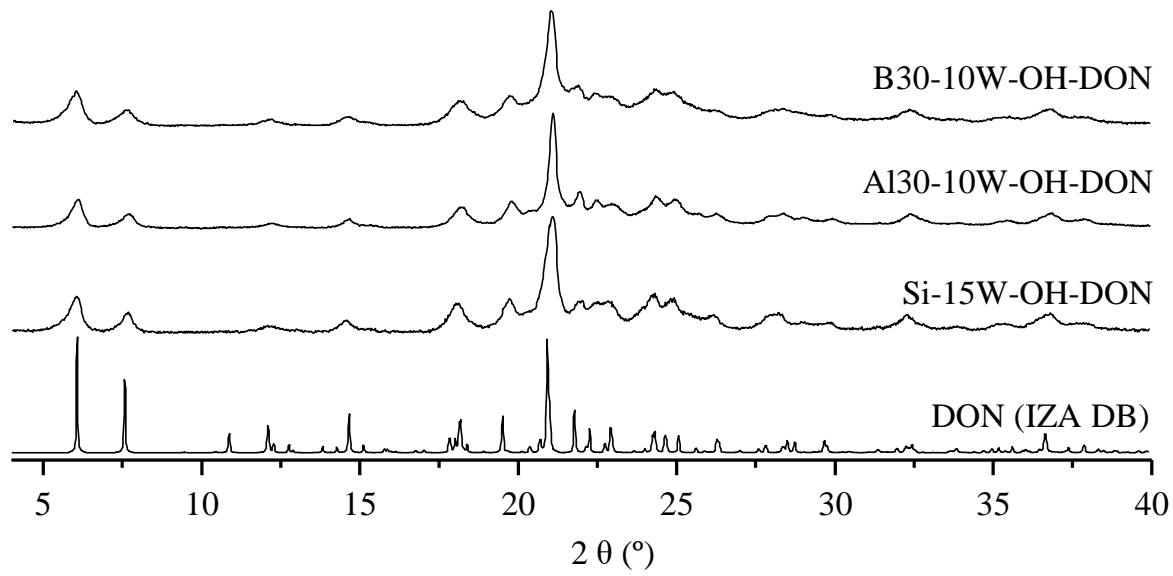

Figure 6.3. Powder X-Ray diffraction patterns of some DON materials compared with theoretical diffraction pattern (IZA DB). ${ }^{[16]}$ Samples are identified by the synthesis gel composition: heteroatom type and silica to heteroatom ratio; water to silica ratio $(\mathrm{W})$; and synthesis media (OH or $\mathrm{F})$.

On the other hand, DON materials present wide diffraction peaks, yet no amorphous phase was detected, as there was no background centred at $22^{\circ}$ typical of amorphous materials. Most of the diffraction peaks of DON samples are then overshadowed by the wide peaks, but the most representative peaks at $6^{\circ}, 7.6^{\circ}, 18^{\circ}$ and $21^{\circ} 2 \theta$ degrees match with the previously reported. ${ }^{[17,18]}$

Most of the syntheses carried out yielded pure IWV or DON phases, but they are competing phases during zeolite crystallization under specific synthesis conditions, for example, in a borosilicate synthesis gel composition with a water to silica ratio of 7 in hydroxide media. The powder X-Ray diffraction patterns of the obtained materials over time from that synthesis conditions are shown in Figure 6.4. 


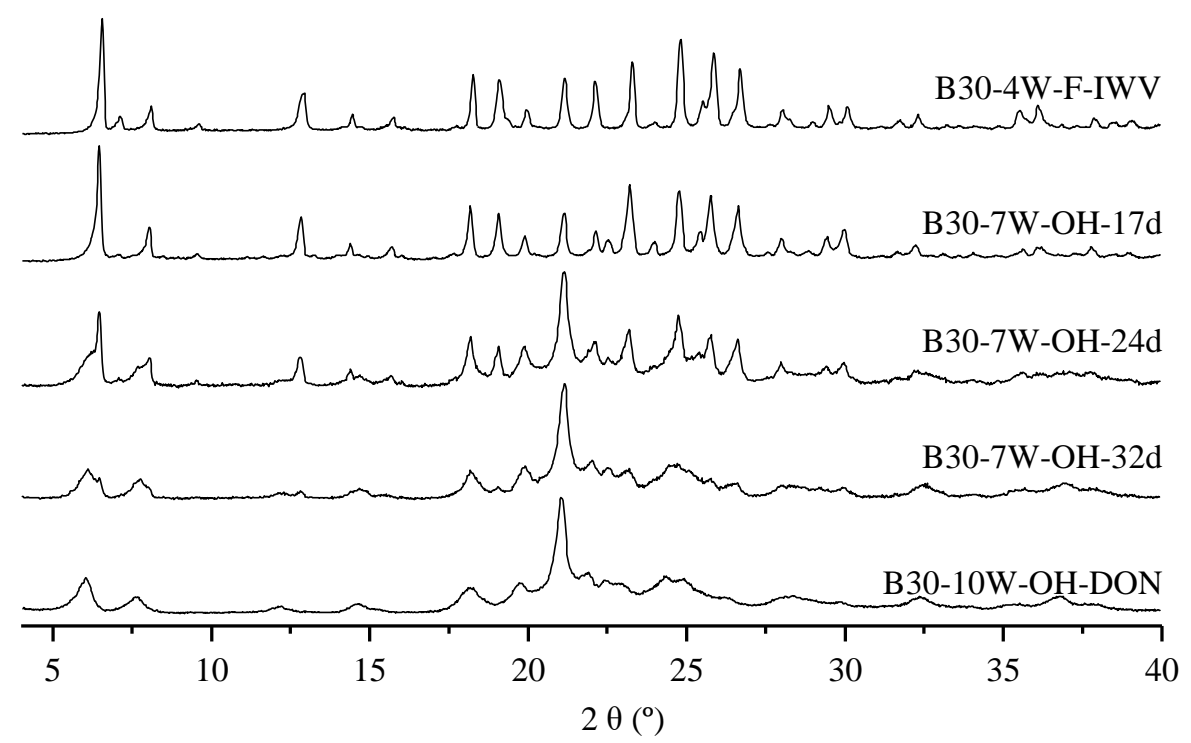

Figure 6.4. Powder X-Ray diffraction patterns of borosilicate IWV and DON materials, and the synthesis with a mix of both phases. Samples are identified by the synthesis gel composition: heteroatom type and silica to heteroatom ratio; water to silica ratio $(\mathrm{W})$; synthesis media (OH or F); and crystalline phase or synthesis time when not a single phase is present.

In this synthesis, the IWV phase was first obtained almost pure below 17 days. Increasing the synthesis time yielded an increasing DON phase, which finally becomes the main phase. Thus, the IWV phase is the kinetic product and the DON phase is the thermodynamic product for the OSDA-7.

\subsection{ITQ-27 (IWV) zeolite}

The ITQ-27 (IZA code: IWV) zeolite was first described by Dorset et al. in 2006 as an aluminosilicate material employing a tetraalkylphosphonium cation as OSDA. ${ }^{[2]}$ It was one of the first zeolites synthesized with a phosphorous OSDA, besides ITQ-26 (IZA code: IWS $)^{[1]}$ and ITQ-34 (IZA code: ITR). ${ }^{[3]}$

The IWV zeolite is a bi-directional large pore zeolite, with a straight $12 \mathrm{MR}$ channel crossed by a tortuous $14 \mathrm{MR}$ channel. The $14 \mathrm{MR}$ channel is arranged such that a molecule must transverse one-half of a unit cell along the $12 \mathrm{MR}$ channel to arrive at the next 14-MR 
opening, and therefore, this zeolite is best described as a bi-directional $12 \mathrm{MR}$ zeolite. The continuous 12 MR channel presents an elliptical shape with a diameter of the $6.9 \AA-6.2 \AA$. This value is similar to the channel diameter in the 12 MR ISV zeolite, ${ }^{[19]}$ which also present an elliptical channel, but is smaller compared to circular 12 MR channel present in LTL and FAU zeolites. ${ }^{[20,21]}$ The diameter of the tortuous 14 MR channel opening measures 8.5 - 7.2 $\AA$, similar to the $8.7-7.9 \AA$ found for the 14 MR pore opening of AET zeotype. ${ }^{[22]}$

The zeolite IWV presents an orthorhombic symmetry and belongs to the Fmmm $\left(n^{\circ} 69\right)$ spatial group, with the following framework parameters for the idealized all silica material: ${ }^{[16]}$

$$
a=27.8621 \AA \quad b=26.0805 \AA \quad c=13.9443 \AA \quad \text { Volume }=10119.64 \AA^{3}
$$

Previously reported synthesis times of IWV zeolite were extremely long (>60 days) even when seeds were used, and a narrow compositional range. ${ }^{[2]}$ Recently, it has been reported the synthesis of IWV in its aluminosilicate and titanogermanosilicate forms, in both hydroxide and fluoride media, in a shortened synthesis time, and with a non-phosphorous containing OSDA. ${ }^{[23]}$ In this thesis, the synthesis time to yield well-crystallized IWV zeolite has been reduced to less than 12 days in most cases.

In this chapter, the synthesis and characterization of the zeolite IWV using the tris(diethylamino)(methyl)phosphonium cation, or OSDA-7, is described.

\subsubsection{Sample analyses of as-made IWV zeolite}

The obtained as-made IWV materials were submitted to chemical analyses, thermogravimetry analyses, scanning electron microscopies and MAS-NMR spectroscopies. In this section only chemical analyses, thermogravimetry analyses and scanning electronic microscopies are compared, while MAS-NMR spectra are further discussed in section 6.3.3.

\subsubsection{Chemical analyses of as-made IWV zeolite}

The typical chemical compositions of the obtained as-made IWV materials are shown in Table 6.2. 
Table 6.2. Chemical composition of some of the obtained IWV materials. All ratios are given as molar ratios. Samples are identified by heteroatom $(\mathrm{X})$ synthesis gel composition and pHgel was measured after adding HF (when needed).

\begin{tabular}{ccccccccc}
\hline Sample & {$[\mathrm{Si} / \mathrm{X}]_{\text {gel }}$} & $\mathrm{pH}_{\text {gel }}$ & $\eta_{\mathrm{X}}(\%)$ & $\eta_{\mathrm{Si}}(\%)$ & {$[\mathrm{Si} / \mathrm{X}]_{\text {sol }}$} & wt.\% $\mathrm{P}_{\text {sol }}$ & \multicolumn{2}{c}{$\mathrm{Si} /$ OSDA OSDA/X } \\
\hline Si-IWV & - & 10.4 & - & 70 & - & 2.0 & 18.8 & - \\
Si-IWV & - & 8.5 & - & 94 & - & 2.1 & 20.5 & - \\
Al30-IWV & 30 & 8.4 & 85 & 100 & 19.5 & 1.9 & 22.5 & 0.9 \\
Al35-IWV & 35 & 14.0 & 100 & 79 & $42.7(2)$ & 2.2 & 17.7 & 2.4 \\
B30-IWV & 30 & 11.1 & 51 & 61 & 37.1 & 2.3 & 17.6 & 2.1 \\
Ge5-IWV & 5 & 8.8 & 68 & 71 & 5.3 & 2.1 & $18.5^{*}$ & 0.3 \\
Ge20-IWV & 30 & 8.2 & 94 & 76 & 32.8 & 2.0 & $18.6^{*}$ & 1.8 \\
\hline
\end{tabular}

*: value corresponds to $(\mathrm{Si}+\mathrm{Ge}) / \mathrm{OSDA}$ ratio.

First, it could be seen that the silicon to OSDA ratio fluctuate around 19, which yields 8 OSDA molecules per unit cell (152 T positions per unit cell). The incorporation yields of aluminium are different depending on the synthesis media, with fluoride media samples giving roughly the same $\mathrm{Si} / \mathrm{Al}$ ratios than the added in the syntheses gels, while the incorporation yields in hydroxide media syntheses are lower, leading to materials with higher $\mathrm{Si} / \mathrm{Al}$ ratios than the added in the syntheses gels. Borosilicate and germanosilicates materials present more consistent yields, leading to materials with similar silicon to boron or germanium ratios than the added in syntheses gels. Overall, the incorporation yield increases as $\mathrm{pH}$ of the synthesis gel decreases.

\subsubsection{Morphology of as-made IWV zeolite}

The crystallite shape and size of the as-made IWV samples were assessed by FESEM microscopy analyses, depicted in Figure 6.5. 

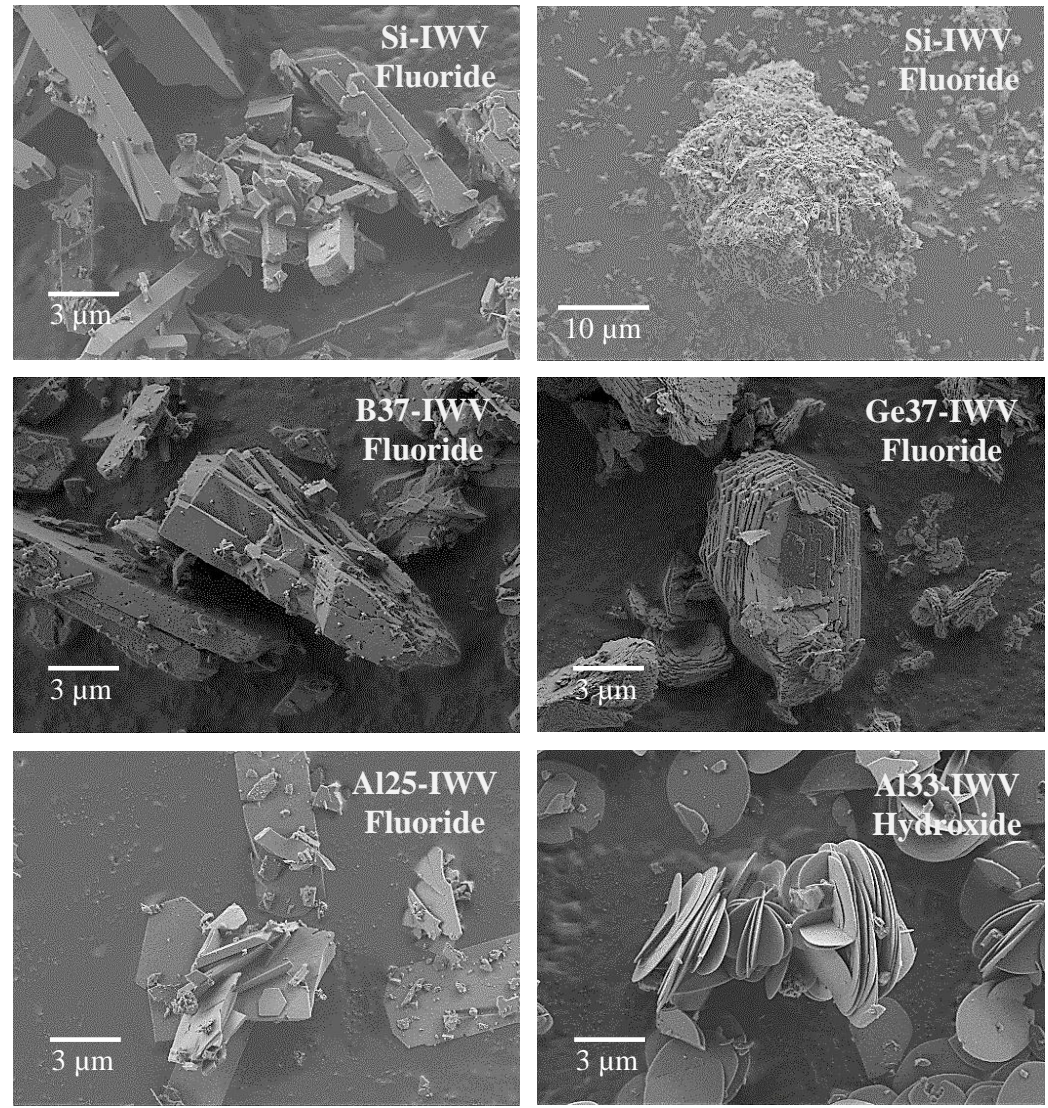

Figure 6.5. FESEM microimages of some as-made IWV materials. Samples are named after the containing heteroatom followed by the as-made heteroatom to silica ratio content, with the synthesis media below when needed.

The IWV zeolite crystallized with a non-homogeneous shape crystallite distribution strongly depending on the solid composition and synthesis media. Indeed, it is possible to find plate-like, stick-like, rectangular and oval prism crystals, with crystallite sizes ranging from $0.2 \times 0.2 \mu \mathrm{m}$ to $3 \times 8 \mu \mathrm{m}$.

The all-silica and germanosilicate materials favour the formation of large aggregates, while in borosilicate and aluminosilicate materials, mostly discrete crystals were observed. As previously guessed from the widening of X-Ray peaks in section 6.2.1.2, the germanosilicate sample presents smaller crystallites compared to other IWV materials.

The crystallization media strongly affects the crystal shape in aluminosilicate materials, but crystal size remains roughly the same. Thus, fluoride media syntheses show 
plate-like crystals, while hydroxide media synthesis shows oval crystals, with a crystal thickness between 50 and $100 \mathrm{~nm}$ in both cases.

\subsubsection{Thermogravimetric analysis of the as-made IWV zeolite}

The thermal stability and decomposition of the OSDA were studied by the thermogravimetry (TG) and differential thermogravimetry (DTG) analyses of some of the obtained IWV samples. Some thermogravimetric plots are shown in Figure 6.6.

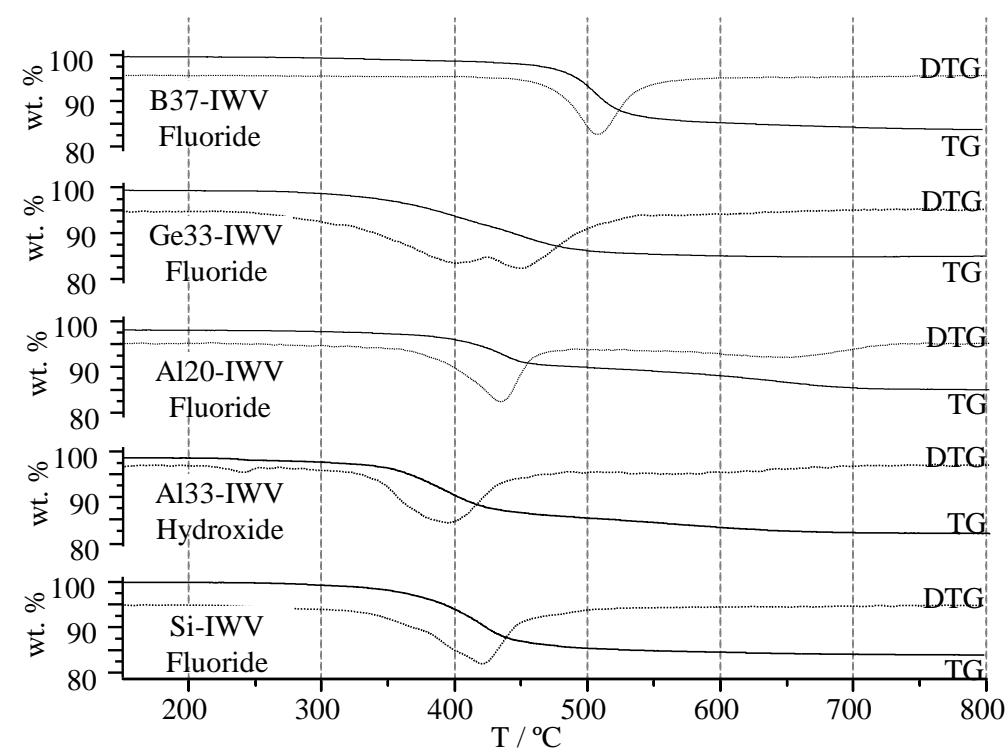

Figure 6.6. TG (solid lines) and DTG (dotted lines) analyses curves of some IWV samples.

Samples are named after the containing heteroatom followed by the as-made heteroatom to silica ratio content, with the synthesis media below. DTG curves are scaled up for a better view.

The thermogravimetric analyses of the IWV samples show a main weight loss of ca. $16 \mathrm{wt} . \%$ in all cases. The temperature and its range for the decomposition of the OSDA is highly dependent on the heteroatom content and type. For example, in the all-silica material, the weight loss happens between $350^{\circ} \mathrm{C}$ and $500^{\circ} \mathrm{C}$, similar to the germanosilicates material. On the other hand, the weight loss in the borosilicate material occurs at higher temperatures, in a temperature range between $475^{\circ} \mathrm{C}$ and $600^{\circ} \mathrm{C}$.

On the other side, the aluminosilicate materials, both the sample synthesized in fluoride media and in hydroxide media, present their weight losses in a wide temperature 
range, from $350^{\circ} \mathrm{C}$ up to $700^{\circ} \mathrm{C}$. However, the main weight loss of both samples takes place at temperatures similar (fluoride synthesis), or even lower (hydroxide synthesis), than the observed in the all-silica material. This fact suggests that most of the OSDA is weakly interacting with the aluminium atoms, or even that aluminium is not being fully incorporated to the zeolite framework, especially in the case of the aluminosilicate synthesized in hydroxide media.

The relatively low temperature required for the decomposition of the OSDA is in good agreement with a large pore zeolite. However, the high temperature required for the removal of the organic species formed during OSDA decomposition in borosilicate material indicates a stabilizing effect on the OSDA when interacting with the boron species inside the material. However, this stabilizing effect is not so relevant in other IWV zeolite compositions.

\subsubsection{Thermal treatments of IWV zeolite}

The as-made IWV materials were thermally treated by the general methodologies described in the section 3.2.3. Additionally, some materials were further treated to completely remove the remaining phosphorous species washing them with ethanol after thermal treatments, as described in section 3.2.3.3. For the treated IWV materials, powder X-Ray diffraction, chemical analyses, scanning electron microscopy, adsorption isotherms, FTIR using pyridine as probe molecule and MAS-NMR spectroscopies were performed. In this section only powder X-Ray diffraction, chemical analyses, adsorption isotherms and FTIR using pyridine as probe molecule analyses of the thermally treated samples are compared, while MAS-NMR spectra are further discussed in section 6.3.3.

\subsubsection{Crystallinity of thermally treated IWV zeolite}

The stability and crystallinity of the IWV samples after the different thermal and washing treatments were assessed by powder X-Ray diffraction, whose patterns are shown in Figure 6.7. 


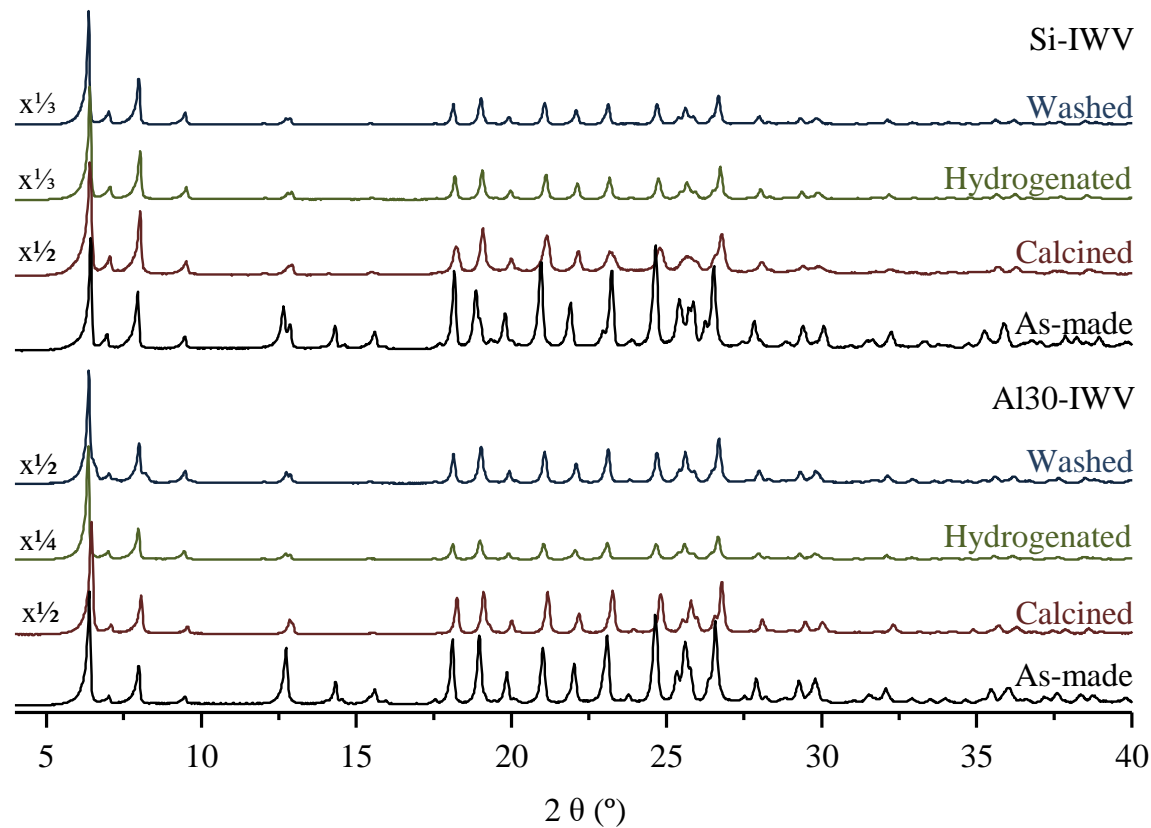

Figure 6.7. Powder X-Ray diffraction of some of the thermally treated IWV materials. Black lines correspond to as-made samples; red lines to calcined samples; green lines to samples hydrogenated at high temperature; blue lines to samples hydrogenated at high temperature and washed with ethanol. Samples are identified by synthesized material composition.

The materials remained highly crystalline after the thermal and washing treatments, with the X-Ray diffraction peaks being found at roughly the same $2 \theta$ degrees in all samples regardless of the post-synthesis treatment. The main difference between the as-made and the thermally-treated samples was the higher intensity of the diffraction peaks at $2 \theta$ below $10^{\circ}$, as the intensity of these signals is typically affected by the presence of the OSDA filling the voids of the zeolite.

\subsubsection{Chemical analyses of thermally treated IWV zeolite}

The typical chemical compositions of the thermally treated IWV materials, as well as the samples washed with ethanol, are shown in Table 6.3. 
Chapter 6: Synthesis of ITQ-27 (IWV) and UTD-1 (DON)

Table 6.3. Chemical composition of some of the thermally treated IWV materials. All ratios are given as molar ratios. Samples are identified by heteroatom $(X)$ synthesis gel composition.

\begin{tabular}{|c|c|c|c|c|c|c|}
\hline Sample & Treatment & $\mathrm{Si} / \mathrm{X}_{\text {as-made }}$ & $\mathrm{Si} / \mathrm{X}_{\text {treated }}$ & wt. $\% \mathrm{P}_{\text {as-made }}$ & wt. $\% \mathrm{P}_{\text {treated }}$ & $\mathrm{P} / \mathrm{X}_{\text {treated }}$ \\
\hline Si-IWV & Calcination & - & - & 2.4 & 1.6 & - \\
\hline Si-IWV & Hydrogenation & - & - & 2.4 & 0.8 & - \\
\hline Si-IWV was $^{*}$ & Washed & - & - & $0.8^{4}$ & $<0.1$ & - \\
\hline Al25-IWV & Calcination & 25.5 & 23.3 & 2.1 & 2.1 & 1.0 \\
\hline Al25-IWV & Hydrogenation & 25.5 & 25.3 & 2.1 & 1.6 & 0.8 \\
\hline $\mathrm{Al} 25-\mathrm{IWV}_{\mathrm{was}} *$ & Washed & $25.3^{\wedge}$ & 27.9 & 1.6 & 0.3 & 0.2 \\
\hline B30-IWV & Calcination & 37.1 & 53.4 & 2.3 & 1.0 & 1.2 \\
\hline Ge5-IWV & Calcination & 5.3 & 4.9 & 2.1 & 1.0 & 0.2 \\
\hline
\end{tabular}

*: parent sample correspond to hydrogenated IWV samples.

After calcination, most of the phosphorus remains inside the materials. In the case of all-silica materials, up to $35 \mathrm{wt} \%$ was removed by calcination, while in borosilicate and germanosilicates materials up to $50 \mathrm{wt} \%$ was removed. On the other hand, aluminosilicate samples keep almost all the phosphorus incorporated by the OSDA. This is indicating a stronger interaction of the phosphorous oxide-like species with the aluminium species than with the boron sites inside the IWV materials.

The treatment with hydrogen at high temperature allows for the removal of ca. $65 \mathrm{wt} . \%$ of the phosphorus in all-silica IWV, while aluminosilicate samples keep ca. 75 wt.\% of the phosphorus. This indicates that the phosphorous species, formed during this thermal treatment, are strongly interacting with aluminium and thus, are better retained than in all-silica IWV.

Finally, a further phosphorus removal treatment was performed by washing the hydrogenated samples with ethanol. In this case, phosphorus is fully removed from all-silica IWV, while aluminosilicate materials still keep some phosphorous, up to $15 \mathrm{wt}$.\% respect to the phosphorus incorporated in the as-made material. The same results (not shown here) were obtained when an ammonium acetate aqueous solution was used, so ethanol was kept for 
removing phosphorous species on the thermally treated samples because of its softer effect over the material.

\subsubsection{Morphology of thermally treated IWV zeolite}

As previously, the morphology of the thermally treated IWV zeolite was studied by FESEM, and their comparison with as-made materials is depicted in Figure 6.8.
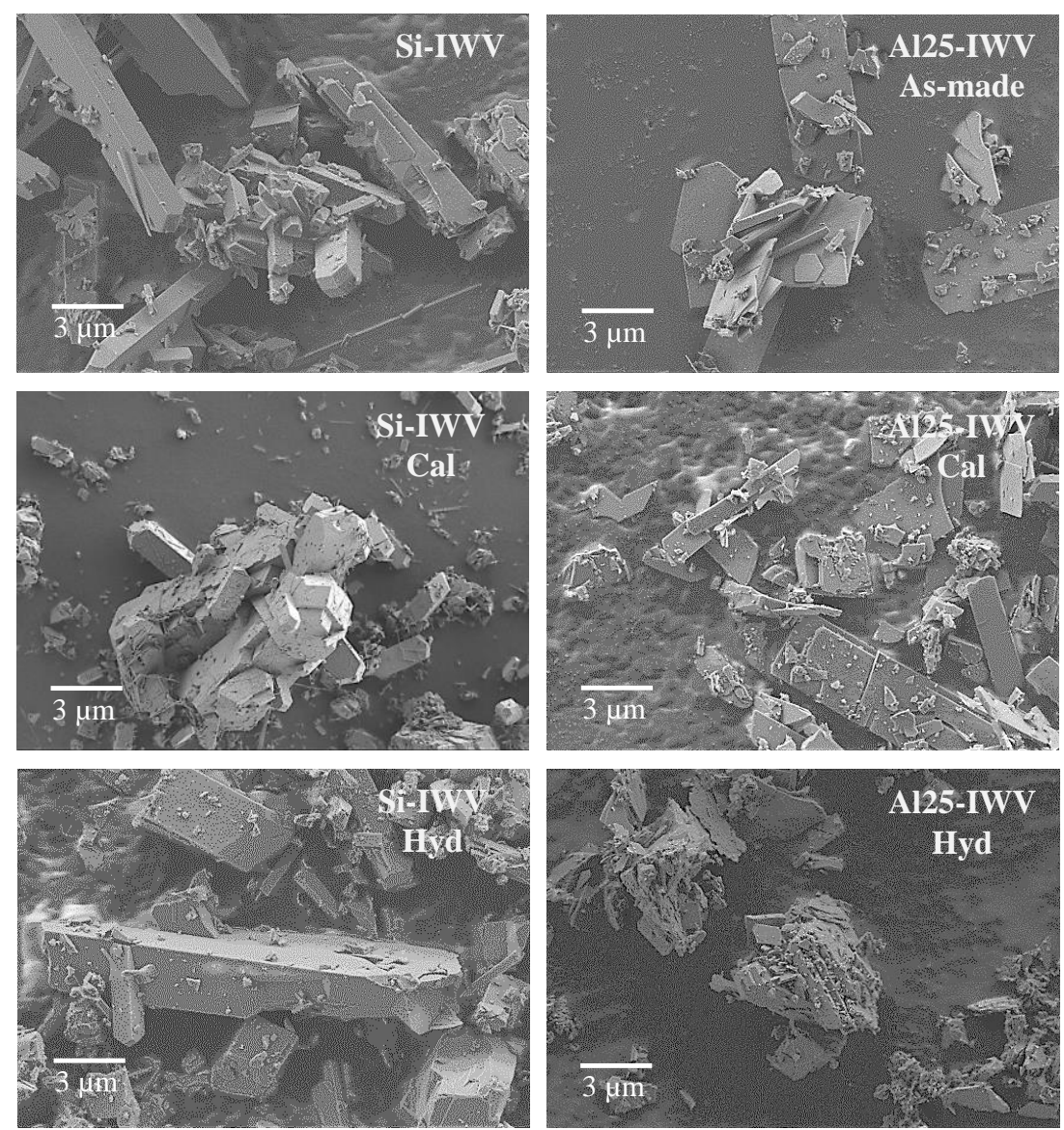

Figure 6.8. FESEM microimages of some thermally treated IWV materials. Samples are named after the containing heteroatom followed by the as-made heteroatom to silica ratio content, with the thermal treatment below (Cal: calcined; Hyd: hydrogenated at high temperature).

After the harsh thermal treatments, some crystallites break, especially in the samples hydrogenated at high temperature. Also, the decrease of the phosphorus content in 
hydrogenated samples leads to more hydrophobic samples, favouring the formation of larger aggregates. These effects are more clearly seen in the aluminosilicate material, probably due to the smaller size of its crystallites.

\subsubsection{Textural properties of thermally treated IWV zeolite}

The textural properties of the IWV samples were calculated from the $\mathrm{N}_{2}$ adsorption isotherms at $77 \mathrm{~K}$ on the thermally treated samples, shown in Figure 6.9.
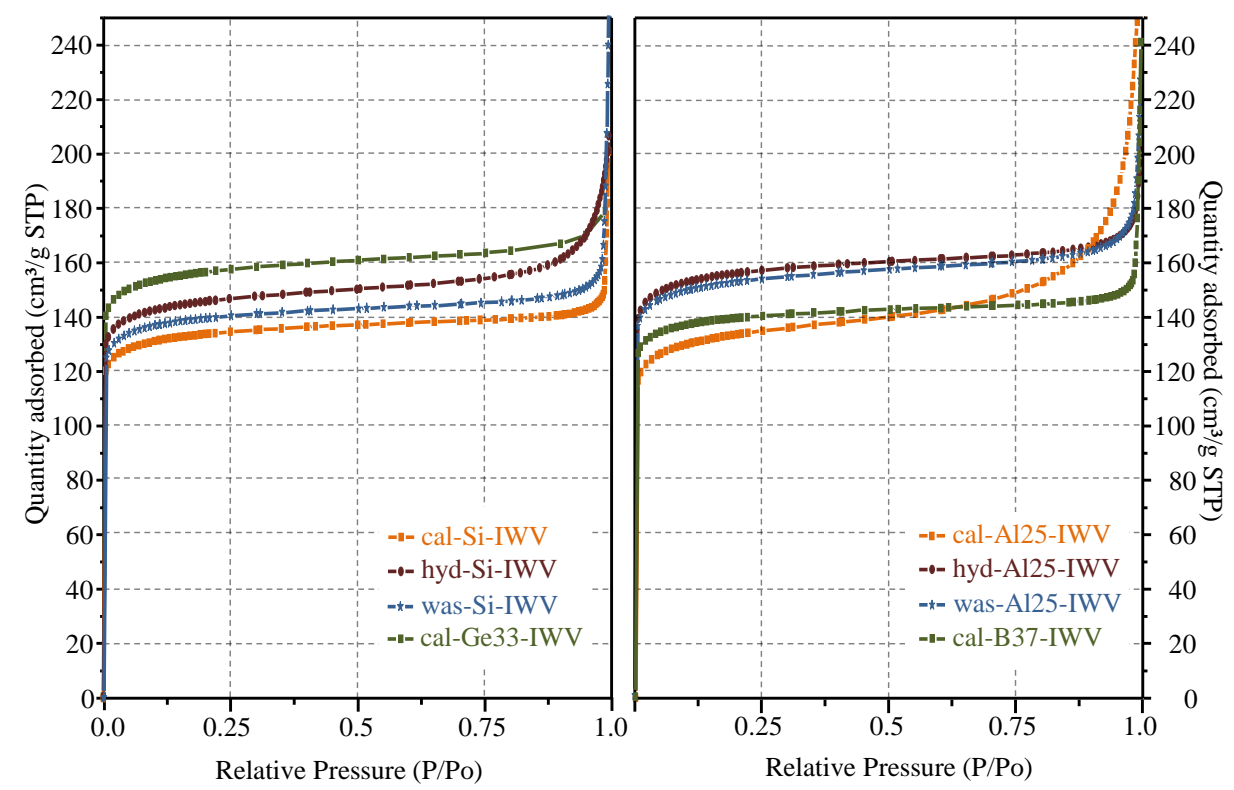

Figure 6.9. $\mathrm{N}_{2}$ adsorption isotherms of some of the thermally treated IWV samples (left: allsilica and germanosilicate; right: aluminosilicate and borosilicate). Samples are named after the thermal treatment (cal: calcined under air; hyd: hydrogenated at high temperature; was: hydrogenated at high temperature and washed with ethanol), followed by the containing heteroatom and by the as-made heteroatom to silica ratio content.

The $\mathrm{N}_{2}$ adsorption isotherms of IWV zeolite show the type Ia physisorption profile typical of microporous materials. ${ }^{[24]}$

The BET and micropore surface areas and the total micropore volume of the IWV zeolite, calculated from the $\mathrm{N}_{2}$ adsorption isotherm at $77 \mathrm{~K}$ by applying the BET and t-plot method, are shown in Table 6.4. 
Table 6.4. Textural properties of thermally treated IWV samples. Samples are identified after its heteroatom content and post-synthesis treatments (cal: calcined; hyd: hydrogenated at high temperature; was: washed with ethanol after hydrogenation at high temperature).

\begin{tabular}{cccccc}
\hline Sample & $\begin{array}{c}\text { BET } \\
\text { surface / } \\
\mathrm{m}^{2} \cdot \mathrm{g}^{-1}\end{array}$ & $\begin{array}{c}\text { Micropore } \\
\text { surface / } \\
\mathrm{m}^{2} \cdot \mathrm{g}^{-1}\end{array}$ & $\begin{array}{c}\text { Micropore } \\
\text { volume / } \\
\mathrm{cm}^{3} \cdot \mathrm{g}^{-1}\end{array}$ & P/Al & wt.\%P \\
\hline Si-IWV-cal & 425.5 & 412.4 & 0.20 & - & 1.6 \\
\hline Si-IWV-hyd & 463.7 & 441.2 & 0.22 & - & 0.8 \\
\hline Si-IWV-was & 443.4 & 429.1 & 0.21 & - & $<0.1$ \\
\hline Al25-IWV-cal & 386.4 & 377.0 & 0.19 & 1.0 & 2.1 \\
\hline Al25-IWV-hyd & 496.8 & 480.0 & 0.23 & 0.9 & 1.6 \\
\hline Al25-IWV-was & 484.0 & 445.7 & 0.23 & 0.2 & 0.3 \\
\hline B37-IWV-cal & 442.0 & 430.5 & 0.21 & 1.2 & 1.0 \\
\hline Ge33-IWV-cal & 494.5 & 476.6 & 0.23 & 1.0 & 0.2 \\
\hline
\end{tabular}

The obtained BET surface area and micropore volume values show differences depending on the phosphorus and heteroatom content. Calcined samples, due to their higher phosphorus content, always yield lower BET surface and micropore volumes than hydrogenated samples. These results indicate that there is a hindrance of the channels by the phosphorous species. However, washed materials, despite presenting lower phosphorus loadings, present slightly lower BET surface and micropore volumes than hydrogenated materials, but higher than calcined materials.

When aluminosilicates of similar compositions are compared, the BET surface value of $386 \mathrm{~m}^{2} \cdot \mathrm{g}^{-1}$ obtained in this thesis is lower than the equivalent material $450 \mathrm{~m}^{2} \cdot \mathrm{g}^{-1}$ reported in the literature, ${ }^{[2]}$ as well as the $0.18 \mathrm{~cm}^{3} \cdot \mathrm{g}^{-1}$ micropore volume against $0.21 \mathrm{~cm}^{3} \cdot \mathrm{g}^{-1[2]}$ and $0.193 \mathrm{~cm}^{3} \cdot \mathrm{g}^{-1} \cdot{ }^{[23]}$ However, the partial removal of phosphorus by hydrogenation at high temperature increases these values to $496 \mathrm{~m}^{2} \cdot \mathrm{g}^{-1}$ and $0.23 \mathrm{~cm}^{3} \cdot \mathrm{g}^{-1}$ BET surface and micropore volume, respectively, slightly higher than previously reported values. This fact evidences that, despite the large pore openings of the IWV zeolite, the phosphorous species formed after thermal treatment significantly decrease the adsorption capacity and accessibility of the materials. 
The micropore distribution was calculated by applying the Horvath-Kawazoe formalism ${ }^{[25]}$ to the Ar adsorption isotherm at $87 \mathrm{~K}$ of the calcined and hydrogenated at high temperature Si-IWV samples. The corresponding calculated pore size distribution is shown in Figure 6.10.

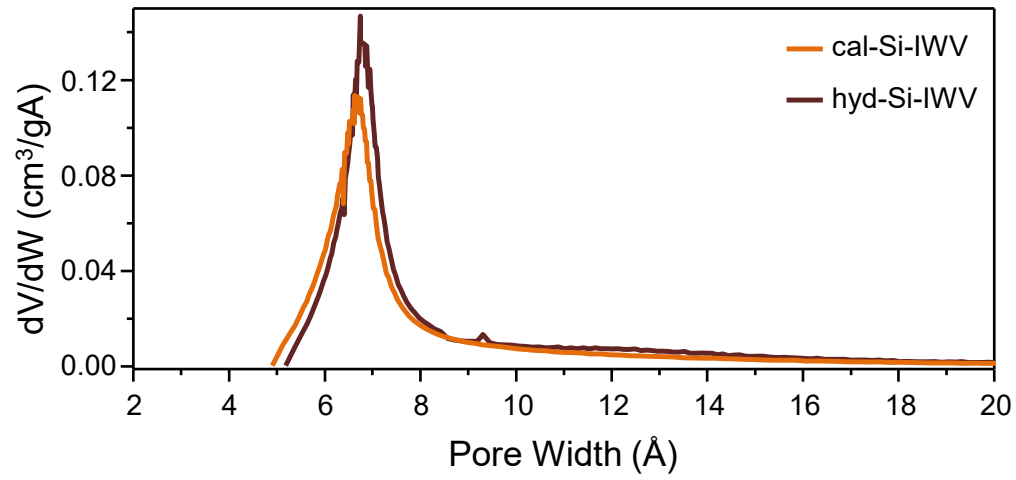

Figure 6.10. Pore size distribution of calcined all-silica (green) and hydrogenated (red) IWV materials.

The micropore distribution shows a single maximum at $6.6 \AA$ for the calcined sample and $6.7 \AA$ for the hydrogenated at high temperature sample. These results are in good agreement with the $6.7 \AA$ for the aluminosilicate material reported in the original work. ${ }^{[2]}$

\subsubsection{Acidic properties of thermally treated IWV zeolite}

The acidic properties of the thermally treated aluminosilicate IWV samples were studied by FTIR spectroscopy using the adsorption and step-wise thermal desorption of pyridine as probe molecule, whose spectra are shown in Figure 6.11. 


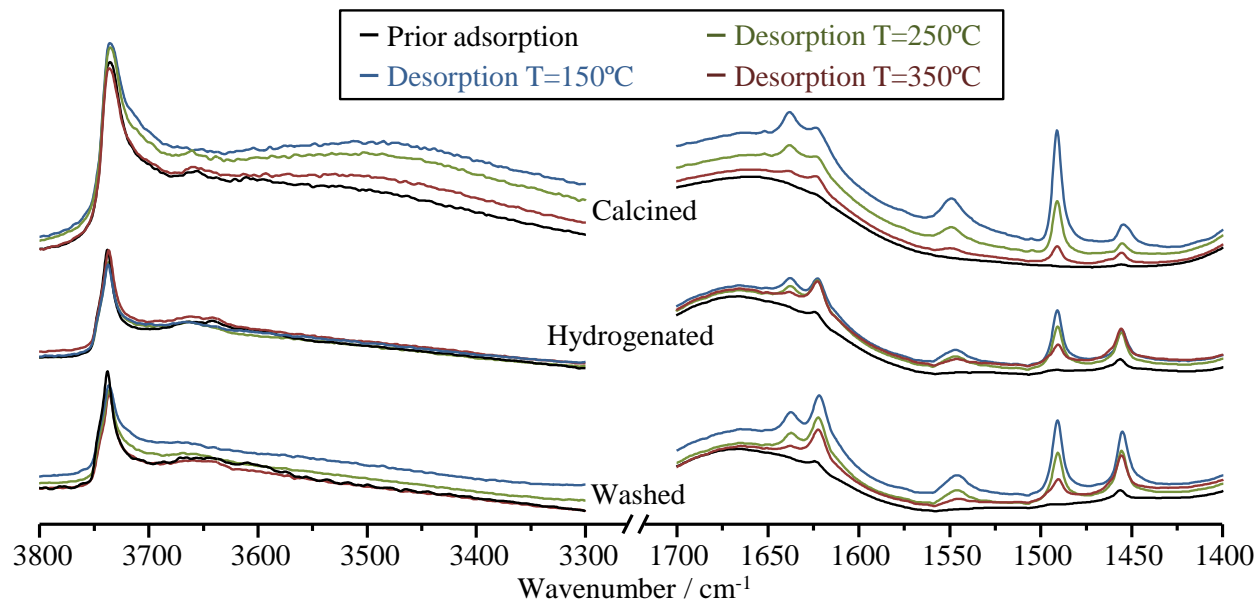

Figure 6.11. FTIR spectra (solid black line: prior pyridine adsorption; coloured lines: after pyridine adsorption and desorption at different temperatures) of the Al-IWV materials with $\mathrm{Si} / \mathrm{Al}$ ratio of 25 after different post-synthesis treatments.

The type and strength of the acidic centres were calculated from the FTIR spectra obtained after the desorption of the pyridine molecule at $150^{\circ} \mathrm{C}$ and $350^{\circ} \mathrm{C}$, as detailed in Table 6.5.

Table 6.5. Acidic properties of some Al-IWV samples after different post-synthesis treatments. Washed refers to the sample washed after hydrogenation at high temperature. Acidic centres correspond to the sum of Brönsted and Lewis acid centres at $150^{\circ} \mathrm{C} ; \mathrm{B}_{350} / \mathrm{B}_{150}$ corresponds to the ratio between Brönsted acid centres at $350^{\circ} \mathrm{C}$ and $150^{\circ} \mathrm{C}$.

\begin{tabular}{|c|c|c|c|c|c|c|c|c|}
\hline \multirow[b]{2}{*}{ Sample } & \multirow[b]{2}{*}{$\mathrm{Si} / \mathrm{Al}$} & \multirow[b]{2}{*}{$\mathrm{P} / \mathrm{Al}$} & \multicolumn{5}{|c|}{ Acidity ( $\mu \mathrm{mol} \mathrm{py} \cdot \mathrm{g}^{-1}$ zeolite $)$} & \multirow[b]{2}{*}{$\begin{array}{l}\mathrm{B}_{350} \\
\mathrm{~B}_{150}\end{array}$} \\
\hline & & & $\mathrm{B}_{150}$ & $\mathrm{~B}_{350}$ & $\mathrm{~L}_{150}$ & $\mathrm{~L}_{350}$ & $\begin{array}{l}\text { Acidic } \\
\text { centres }\end{array}$ & \\
\hline Al-IWV & 25.5 & 1.1 & - & - & - & - & - & - \\
\hline Calcined & 23.3 & 1.0 & 52.3 & 8.4 & 35.3 & 10.4 & 87.5 & 0.16 \\
\hline Hydrogenated & 28.7 & 0.8 & 19.7 & 11.5 & 26.5 & 27.2 & 46.2 & 0.59 \\
\hline Washed & 27.9 & 0.2 & 29.7 & 9.0 & 52.4 & 31.1 & 82.2 & 0.30 \\
\hline
\end{tabular}

From these data, the total number of acidic centres and the concentration of Brönsted acid centres decrease as the phosphorus content increases, especially after the hydrogenation treatment at high temperature. However, the relative strength $\left(\mathrm{B}_{350} / \mathrm{B}_{150}\right)$ of the Brönsted acid sites increase as the phosphorus content decreases. These facts would mean that the 
phosphorous species interact with the aluminium species lowering their acidity, instead of just blocking their accessibility.

It should be noted that the calcined sample presents a larger concentration of Brönsted acid centres than the hydrogenated and washed samples, while in the latter samples the concentration of Lewis acid centres increases compared to calcined sample. This could be indicative of a partial dealumination of the material after the hydrogenation treatment of the IWV zeolite. This dealumination could be explained by the extraction of aluminium from the zeolite framework and the subsequent precipitation of aluminium oxide, which present Lewis acidic properties.

\subsubsection{NMR study of the IWV zeolite}

The incorporation of the phosphorous OSDA and the aluminium and boron heteroatoms, as well as the lattice framework were studied by MAS-NMR spectroscopy on the as-made and the thermally treated IWV materials.

\subsubsection{Incorporation and stability of the OSDA into the IWV zeolite}

The stability of the OSDA incorporated to the IWV materials was studied by ${ }^{13} \mathrm{C}$ and ${ }^{31} \mathrm{P}$ MAS-NMR spectroscopies.

The ${ }^{13} \mathrm{C}$ MAS-NMR spectra of the as-made samples compared with the liquid ${ }^{13} \mathrm{C}$ NMR spectrum of the free P-OSDA are shown in Figure 6.12.

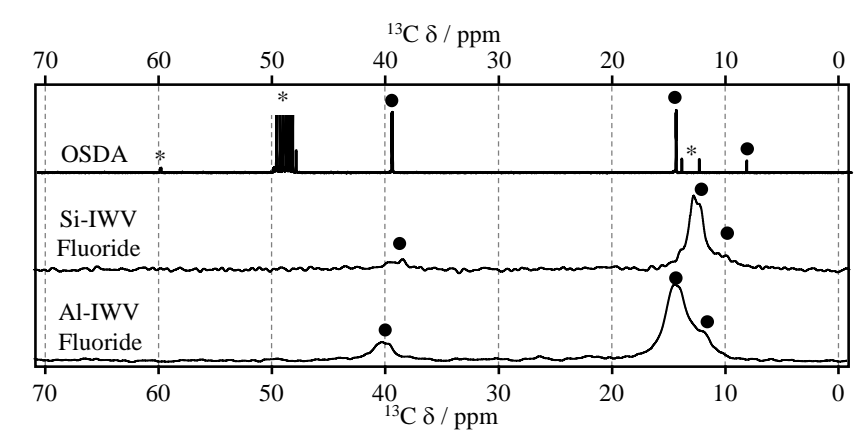

Figure 6.12. ${ }^{13} \mathrm{C}$ MAS-NMR spectra of some samples of IWV. Free OSDA liquid NMR spectrum included for comparison (•). Asterisks in OSDA NMR marks solvent resonances. 
The ${ }^{13} \mathrm{C}$ spectra of the as-made samples show similar resonance profiles than the free OSDA, with small displacement in the chemical shift of the resonances at $c a .39 \mathrm{ppm}$ and 14 ppm. A larger displacement was observed for the resonance at $8 \mathrm{ppm}$ in the free OSDA that corresponds to the methyl group directly bonded to the phosphorus atom. This resonance shifts downfield to $10 \mathrm{ppm}$ in the all-silica sample, and up to $12 \mathrm{ppm}$ in the aluminosilicate, which could be indicative of a different interaction between the OSDA and the zeolitic matrix depending on the material composition. However, the non-existence of additional resonances means that the OSDA is incorporated to the material and is stable.

The ${ }^{31} \mathrm{P}$ MAS-NMR spectra of the as-made samples compared with the liquid ${ }^{31} \mathrm{P}$ NMR spectrum of the free P-OSDA are shown in Figure 6.13.

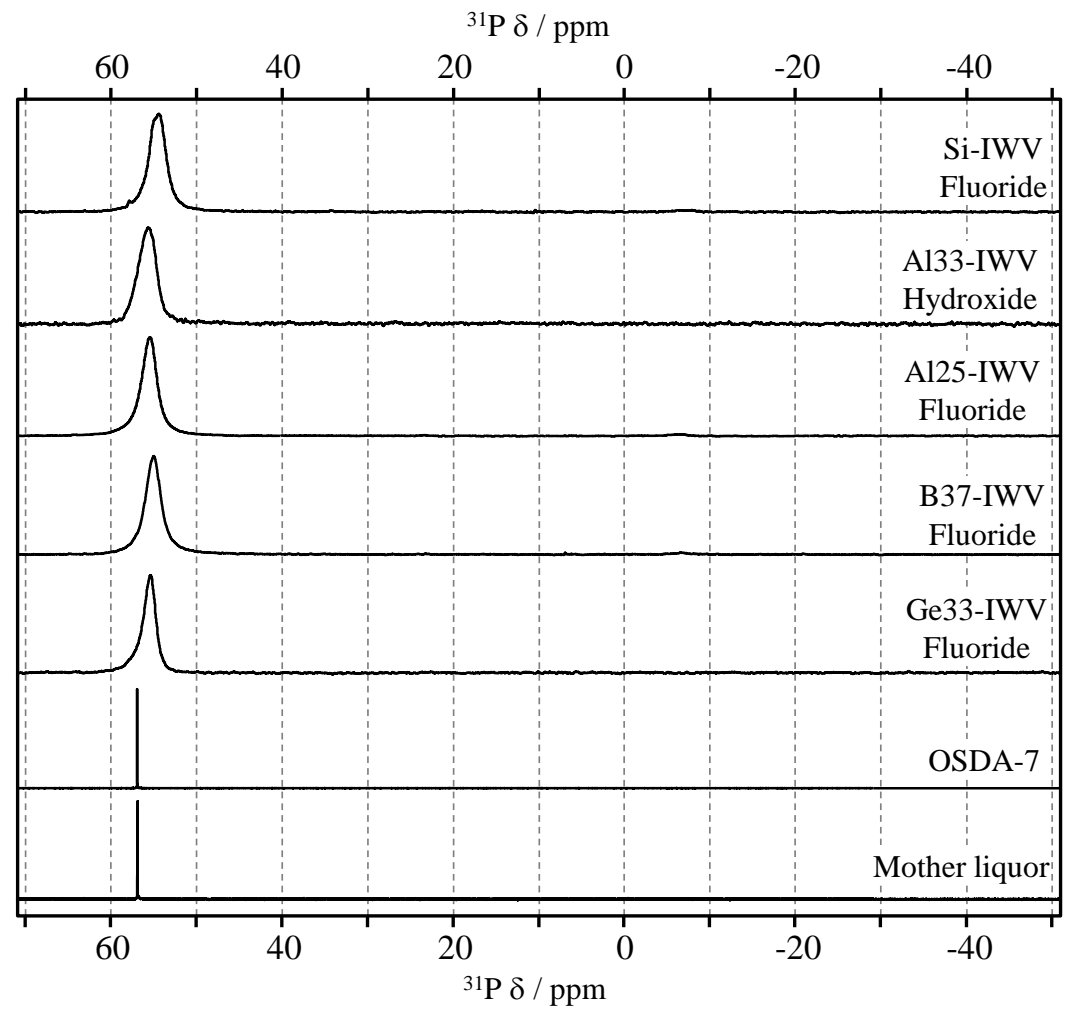

Figure 6.13. ${ }^{31} \mathrm{P}$ MAS-NMR spectra of some of the obtained IWV samples. Samples are named after the containing heteroatom followed by the as-made heteroatom to silica ratio content, with the synthesis media below. Free OSDA and mother liquor (obtained from Al25-IWV-Fluoride synthesis) liquid NMR spectra are included for comparison. 
The ${ }^{31} \mathrm{P}$ MAS-NMR spectra of the as-made samples show a single resonance at 55 ppm in all cases, which closely resembles to the liquid NMR of the OSDA in water solution (56.9 $\mathrm{ppm})$, concluding that the OSDA remains intact inside of the pores of the zeolite.

Additionally, the ${ }^{31} \mathrm{P}$ NMR of the mother liquor evidences that the OSDA remains completely stable after the hydrothermal treatment. Actually, this OSDA show no degradation at all under the tested hydrothermal synthesis conditions. This result allows the reuse of the excess of OSDA used in synthesis gels, and actually, this was successfully tested once to synthesize an aluminosilicate material in hydroxide media.

After the thermal treatment of the materials, some of the phosphorus remains inside the material, giving the opportunity to study the chemical nature of the generated species by ${ }^{31} \mathrm{P}$ MAS-NMR spectroscopy, whose spectra are shown in Figure 6.14.

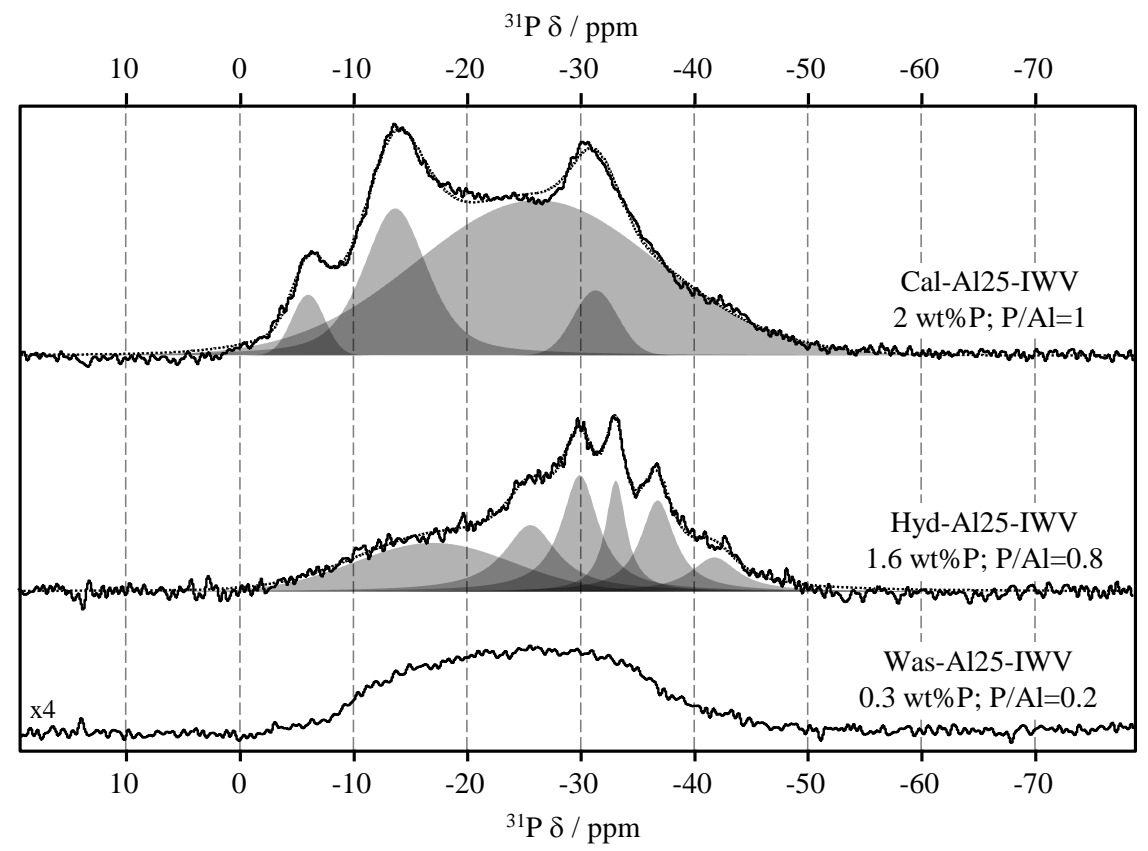

Figure 6.14. ${ }^{31} \mathrm{P}$ MAS-NMR spectra of thermally treated Al-IWV. Samples are named after the thermal treatment (cal: calcined under air; hyd: hydrogenated at high temperature; was: hydrogenated at high temperature and washed with ethanol), followed by the containing heteroatom and by the as-made heteroatom to silica ratio content. Solid lines correspond to experimental spectra; dotted lines correspond to the sum of deconvoluted signals. Spectra were deconvoluted as Gaussian/Lorentz curves. 
After the thermal treatments, the organic compound is decomposed and the remaining phosphorous species gives rise to several ${ }^{31} \mathrm{P}$ resonances with chemical shifts ranging between -5 ppm and $-42 \mathrm{ppm}$, which are characteristic of extra-framework $\mathrm{P}_{2} \mathrm{O}_{5}$-like species.

The calcined sample gives three discrete resonances: i) at $-7 \mathrm{ppm}$, assigned to phosphorus atoms in pyrophosphoric acid or to terminal $\left[\mathrm{P}_{4} \mathrm{O}_{3}\right]^{-}$groups in polyphosphoric species; ${ }^{[26-29]}$ ii) at -13 ppm, assigned to middle groups in pyrophosphates or other short-chain polyphosphates; ${ }^{[28,29]} \mathrm{iii}$ ) and at $-31 \mathrm{ppm}$, assigned to different (bi)phosphates bounded to monodentate or bidentate aluminium octahedral atoms. However, the most prominent resonance is a very broad resonance centred at $-25 \mathrm{ppm}$. This resonance is difficult to assign, but it is probably overshadowing many overlapped resonances, which could correspond either to polymeric phosphate chains and highly condensed polyphosphate species, ${ }^{[30-32]}$ or to a large number of phosphorous species, probably different (bi)phosphates bounded to monodentate or bidentate aluminium octahedral atoms, ${ }^{[26-29,33]}$ or both given the asymmetry and wide chemical shift span of this wide resonance.

The hydrogenation at high temperature decreases the P/Al ratio below 1, which translates into a large decrease of the $-26 \mathrm{ppm}$ broad resonance. This decrease allows to identify that the resonance at $-31 \mathrm{ppm}$ is actually an overlapping of two narrower resonances at $-30 \mathrm{ppm}$ and $-33 \mathrm{ppm}$. Also, two additional resonances at $-37 \mathrm{ppm}$ and $-42 \mathrm{ppm}$ are now visible, which are assigned to different (bi)phosphates bounded to monodentate or bidentate aluminium octahedral atoms. On the other hand, the resonance at $-7 \mathrm{ppm}$ vanishes, while the resonance at $-13 \mathrm{ppm}$ turns into a weak intensity very broad resonance, probably built by smaller overlapping resonances. Finally, the washed sample shows no discrete resonances at all, presenting a single very broad resonance centred at $-25 \mathrm{ppm}$ and built by many overlapped resonances belonging to $\mathrm{P}_{2} \mathrm{O}_{5}$-like species in multiple conformations and/or orientations.

The disappearance of the resonances below $-15 \mathrm{ppm}$ and the increase of the resonances at $c a .-30 \mathrm{ppm}$ in the hydrogenated sample could suggest the formation of discrete $\mathrm{AlPO}_{4}$ species inside the zeolite. 


\subsubsection{Aluminium incorporation in the IWV zeolite}

The aluminium incorporation in the IWV materials was studied by ${ }^{27} \mathrm{Al}$ MAS-NMR spectroscopy on the as-made aluminosilicate samples, whose spectra are shown in Figure 6.15.

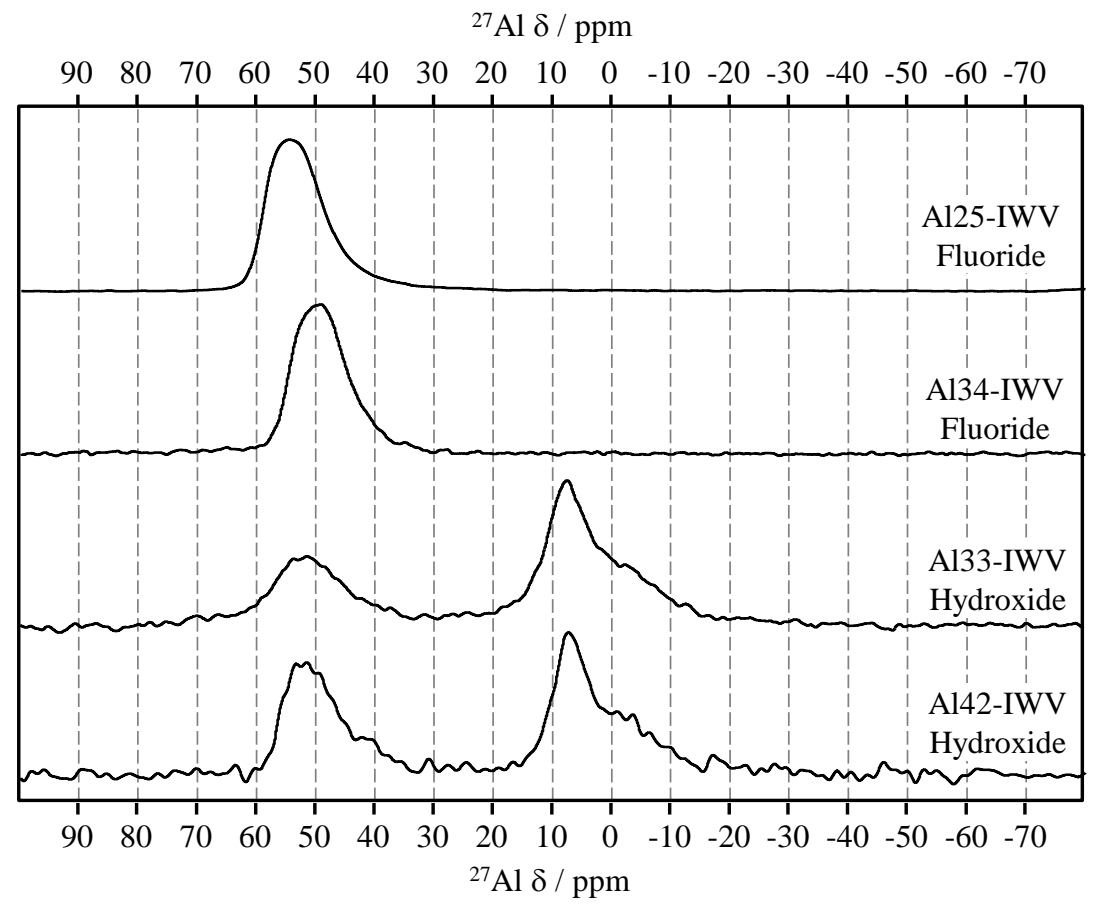

Figure 6.15. ${ }^{27} \mathrm{Al}$ MAS-NMR spectra of some samples of as-made IWV materials with different $\mathrm{Si} / \mathrm{Al}$ ratios. Samples are named as the containing heteroatom followed by the as-made heteroatom to silica ratio content and synthesis media below.

The as-made materials synthesized in fluoride media show a single wide resonance centred at $56 \mathrm{ppm}$, regardless of the aluminium content. This resonance is typically attributed to $\mathrm{Al}$ in tetrahedral coordination and occupying framework positions. ${ }^{[34-38]}$ On the other hand, the materials synthesized in hydroxide media show two resonances, one at $56 \mathrm{ppm}$ like those synthesized in fluoride media, an another wider signal centred around $8 \mathrm{ppm}$. This latter resonance is typically attributed to aluminium species in octahedral coordination, in this case, to extra-framework gibbsite aluminium hydroxide, ${ }^{[39]}$ probably due to unreacted alumina source. These results are in agreement with the results of the TG analyses of these samples in section 6.3.1.3, which suggested that not all aluminium was incorporated in the framework. 
Unfortunately, experiments with different alumina sources were not performed. Because of that, minor characterization was performed on aluminosilicate materials synthesized in hydroxide media.

The ${ }^{27}$ Al MAS-NMR spectra of the thermally treated materials synthesized in fluoride are shown in Figure 6.16.

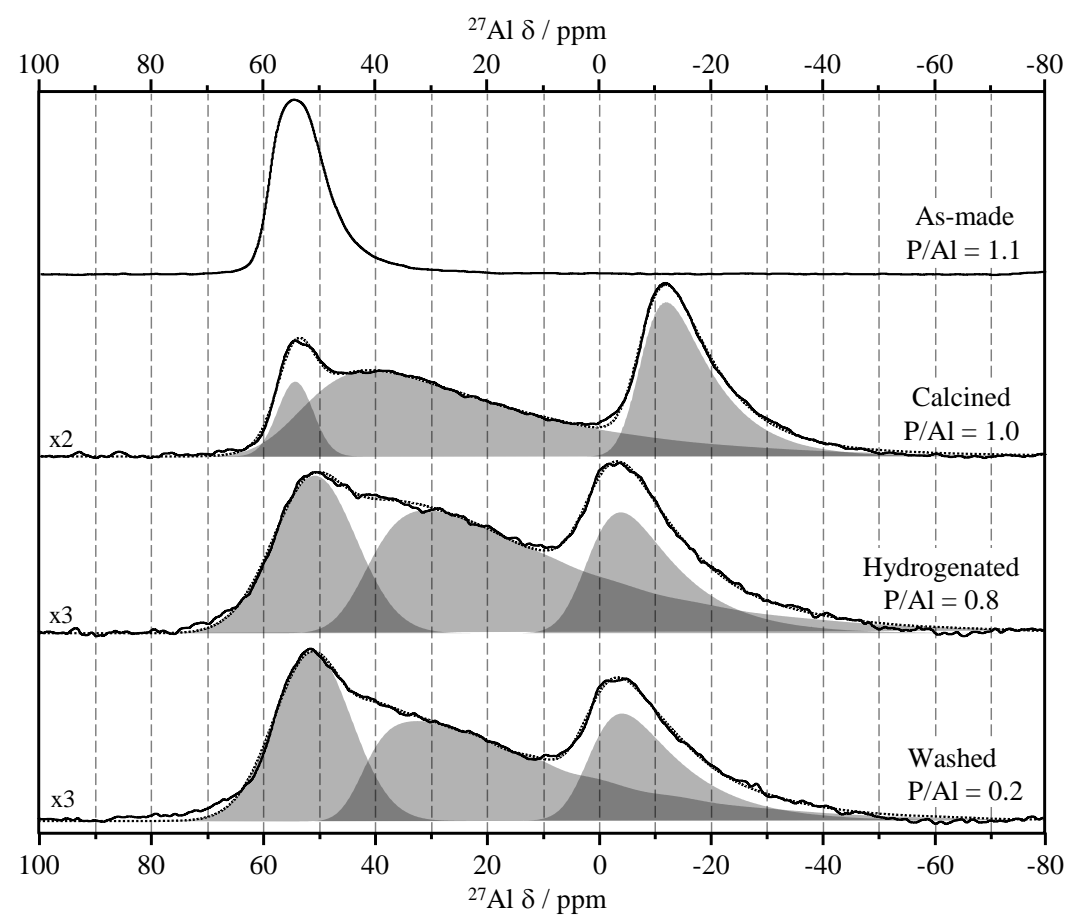

Figure 6.16. ${ }^{27} \mathrm{Al}$ MAS-NMR spectra of some samples of the thermally treated IWV sample with $\mathrm{Si} / \mathrm{Al}=25$. Solid lines correspond to experimental spectra; dotted lines correspond to the sum of deconvoluted signals. The peak at ca. $56 \mathrm{ppm}$ was deconvoluted as a Gaussian/Lorentz curve (for an easier view), and the other peaks were deconvoluted using the CzSimple method. ${ }^{[40]}$

The ${ }^{27} \mathrm{Al}$ MAS-NMR spectra shows up to three different resonances, indicating that aluminium atoms are located in three different chemical environments. The main resonances appear at $c a .56 \mathrm{ppm}$ (narrow), at $c a .40 \mathrm{ppm}$ (very wide) and at $c a .-12 \mathrm{ppm}$ (wide). These resonances greatly vary their intensities depending on the $\mathrm{P} / \mathrm{Al}$ and $\mathrm{Si} / \mathrm{Al}$ ratios, and, in the case of the $40 \mathrm{ppm}$ and the $-12 \mathrm{ppm}$ resonances, their chemical shift also vary.

The relative intensity of the resonance at $55 \mathrm{ppm}$, corresponding to tetrahedral $\mathrm{Al}$ in framework positions, increases as the P/Al ratio decreases, following a similar trend to the 
described in the MFI and RTH materials in sections 5.2.4 and 5.3.4, respectively. On the other hand, the relative intensities of the resonances at $40 \mathrm{ppm}$, assigned to pentacoordinated aluminium species, and $-12 \mathrm{ppm}$, assigned to octahedral aluminium species, decrease after the hydrogenation of the IWV zeolite. ${ }^{[36-38]}$ Also, the chemical shift of these resonances displace up-field, to $30 \mathrm{ppm}$ and $-5 \mathrm{ppm}$, respectively. The chemical shifts and relative intensities of these resonances are approximately the same after washing, despite the decrease in the phosphorus content of the washed material.

The relative increase of the tetrahedral aluminium species agrees with the acidic properties, as the removal of phosphorus increases the concentration of strong acid centres, similar to RTH results in section 5.3.3.4. However, in the case of IWV zeolite, the resonances at $30 \mathrm{ppm}$ and $-5 \mathrm{ppm}$ of the hydrogenated material are greatly affected after the hydrogenation treatment despite presenting a high $\mathrm{P} / \mathrm{Al}$ ratio, and after this treatment, these resonances are not affected at all. These results are indicating that the aluminium is being extracted from the framework, which fit with the decrease of Brönsted acid sites and the increase of Lewis acid sites observed in section 6.3.2.5.

The results obtained from ${ }^{27} \mathrm{Al}$ MAS-NMR and ${ }^{31} \mathrm{P}$ MAS-NMR spectra suggests that the aluminium tetrahedrally coordinated in the as-made IWV material is being extracted from the IWV framework after the hydrogenation of the material. These aluminium species, both pentacoordinated and octahedral, would interact with some of the remaining phosphorus in the material, giving rise to discrete $\mathrm{AlPO}_{4}$ species inside the voids of the zeolite. The formation of these $\mathrm{AlPO}_{4}$ species decreases the number of Brönsted acid sites while maintaining the number of Lewis sites, although the additional removal of phosphorus by washing with ethanol would lead to the formation of aluminium hydroxide species which increase the number of Lewis acid sites of the washed IWV material. 


\subsubsection{Boron incorporation in the IWV zeolite}

The boron incorporation was studied by ${ }^{11} \mathrm{~B}$ MAS-NMR spectroscopy on the as-made borosilicate samples, whose spectrum is shown in Figure 6.17.

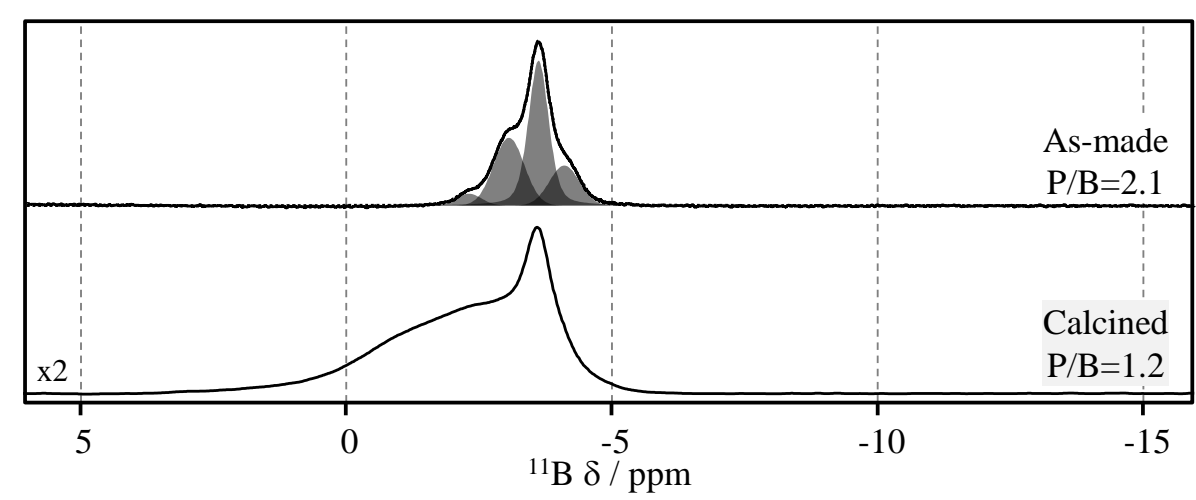

Figure 6.17. ${ }^{11} \mathrm{~B}$ MAS-NMR spectra of the as-made and calcined borosilicate sample with $\mathrm{Si} / \mathrm{B}=37$.

The as-made 37B-IWV spectrum shows a ${ }^{11} \mathrm{~B}$ resonance centred at $-3.65 \mathrm{ppm}$ with shoulder resonances up- and downfield spanning between $-2 \mathrm{ppm}$ and $-4.5 \mathrm{ppm}$. The chemical shifts of these signals fit with boron in tetrahedral coordination, ${ }^{[41-43]}$ but the shoulder evidence the existence of different environment, probably due to boron atoms located in different framework positions. Therefore, it is concluded the boron is getting incorporated in IWV zeolite during synthesis in different environments.

After calcination, a single resonance at $-3.6 \mathrm{ppm}$ is observed, which confirms that boron remains in tetrahedral positions. However, a wide resonance appears down-field, spanning from $1 \mathrm{ppm}$ to $-4 \mathrm{ppm}$, which is usually attributed to boron species in trigonal coordination and are typical of dehydrated borosilicate zeolites. ${ }^{[43]}$ 


\subsubsection{Fluorine incorporation in the IWV zeolite framework}

The incorporation of fluorine to the IWV materials and its interaction with the siliceous framework was studied by ${ }^{19} \mathrm{~F}$ MAS-NMR spectroscopy, whose spectra are shown in Figure 6.18.

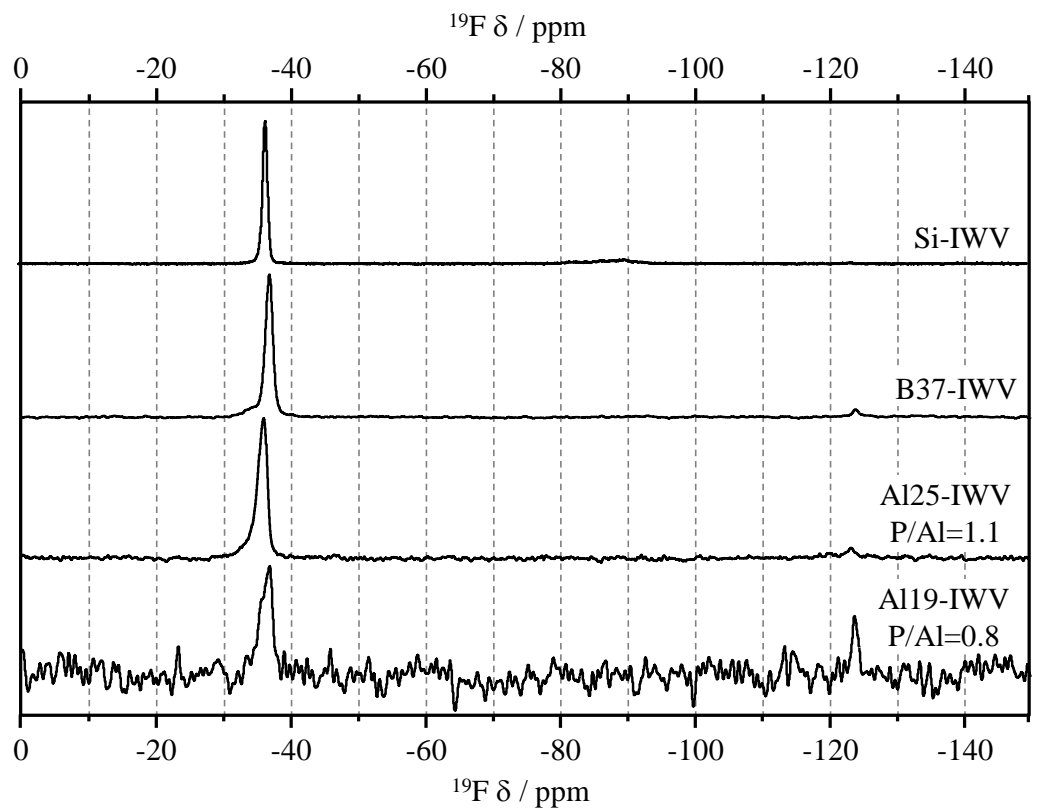

Figure 6.18. ${ }^{19}$ F MAS-NMR spectra of some as-made IWV materials. Samples are named after the containing heteroatom followed by the as-made heteroatom to silica ratio content. Spectra are not scaled up on fluorine content.

In all cases two resonances were observed, a main resonance at ca. $-37 \mathrm{ppm}$, and a minor signal at $-122 \mathrm{ppm}$. The peak at $-37 \mathrm{ppm}$ is typically assigned to fluorine located in silica rich D4R cages, ${ }^{[4,}{ }^{45]}$ although chemical shift differs from the $-31.6 \mathrm{ppm}$ originally reported for this zeolite. ${ }^{[2]}$ This difference could be attributed to a lower long range dipolar interaction of the OSDA with the fluorine anions, as aminophosphonium cations are more nucleophilic than the original phosphonium cation. On the other hand, the resonance at $-122 \mathrm{ppm}$ is attributed to mobile fluoride ions in the channels, which act as chargebalancing for the OSDA cations. ${ }^{[46]}$ The intensity of the resonance at $-122 \mathrm{ppm}$ is independent of the content of trivalent atoms (boron or aluminium), as clearly seen in the samples with phosphorus to aluminium ratio below 1 . Anyway, most of fluoride anions charge-balance the OSDA cations locating in the D4R cages. 


\subsubsection{Silicon framework of the IWV zeolite}

The zeolite framework was studied by analysing the silicon species of the as-made and the thermally treated IWV samples in all-silica and aluminosilicate materials.

\section{- All-silica materials}

The ${ }^{29} \mathrm{Si}$ MAS-NMR spectra of the as-made and thermally treated all-silica IWV materials are shown in Figure 6.19.

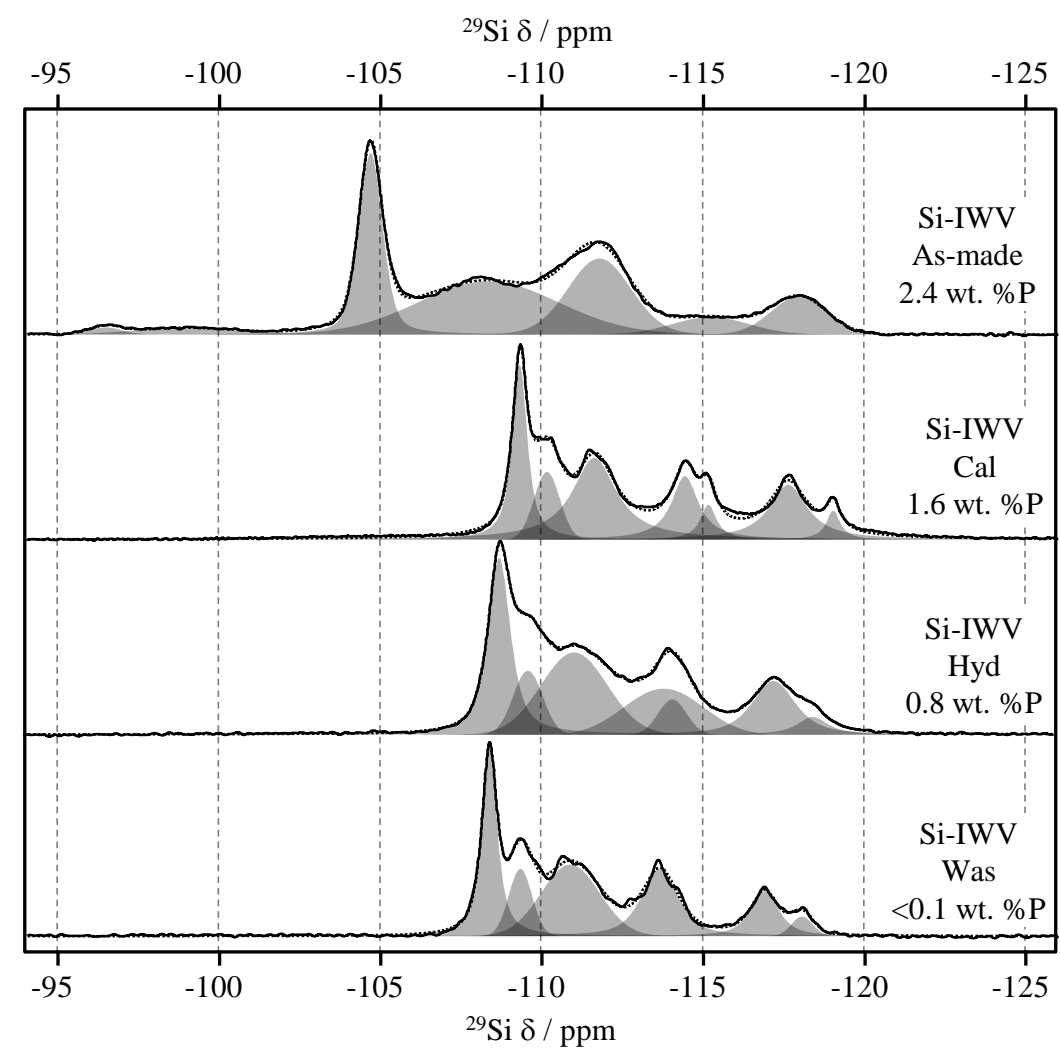

Figure 6.19. ${ }^{29} \mathrm{Si}$ MAS-NMR spectra of some as-made and thermally treated all-silica IWV samples (cal: calcined under air; hyd: hydrogenated at high temperature; was: hydrogenated at high temperature and washed with ethanol). Solid lines correspond to experimental spectra; dotted lines correspond to the sum of deconvoluted signals.

The as-made all-silica IWV ${ }^{29} \mathrm{Si}$ MAS-NMR spectra present four main resonances centred at -105 ppm, -108 ppm, -112 pm and -118 ppm, which correspond to $\mathrm{Q}^{4}$ silicon atoms. 
Also, two wide resonances centred at $-96 \mathrm{ppm}$ and $-99 \mathrm{ppm}$ could be observed, corresponding to $\mathrm{Q}^{3}$ silicon atoms. These latter resonances could be explained by silanol framework defects formed during synthesis, which suggests that fluoride anions are not completely charge balancing the OSDA cation. However, fluoride was not quantified to probe that hypothesis.

The thermal treatment of the samples yields a drastic change in the resonance signal pattern. Firstly, in all cases the resonances belonging to silanol defects completely disappear, due to the condensation of silanol groups during thermal treatments. Also, the spectra barycentres shifts up-field, disappearing the resonance at $-105 \mathrm{ppm}$, assigned to silicon atoms in D4R cages interacting with fluoride anions trapped inside. Upon thermal treatment, fluoride anions are removed provoking the shift of the ${ }^{29} \mathrm{Si}-105 \mathrm{ppm}$ resonance up-field. The calcined sample and the sample washed with ethanol after hydrogenation yield well resolved spectra, being the washed spectra slightly better resolved.

The mathematical deconvolution of the spectra of the sample washed with ethanol after hydrogenation at high temperature presents at least six different resonances at $-108 \mathrm{ppm}$, $-109 \mathrm{ppm},-111 \mathrm{ppm},-114 \mathrm{ppm},-117 \mathrm{ppm}$ and $-118 \mathrm{ppm}$, with roughly relative intensities 4:2:4:3:2:1, which sums a total of 16 different $T$ atoms in six different silicon environments. The peak at $-111 \mathrm{ppm}$ is wide enough to be considered as two roughly symmetrical overlapping resonances, which would yield seven different environments with relative intensities $4: 2: 2: 2: 2: 2: 1$. However, this result disagrees with the idealized cell data already elucidated, which should yield a spectrum of seven different silicon environments with 3:3:3:2:2:2:1 relative intensities.

The previous deconvolutions were made using boundary conditions to match the number of $\mathrm{T}$ atoms and the number environments from experimental spectra with the crystallographic data. However, if these conditions are removed, a better fitting spectra with relative intensities 6:2:7:5:3:1 could be inferred, which sums 24 different $T$ atoms, in at least six different silicon environments, probably eight different $\mathrm{T}$ atoms due to the wide resonances at $-111 \mathrm{ppm}$ and $-114 \mathrm{ppm}$, which could be unfolded into more overlapped resonances. The mismatch between the experimental spectra and the theoretical spectra suggests that the IWV zeolite presents the same $\mathrm{T}$ sites connectivity but a lower symmetry than previously described. The spatial group elucidated from an aluminosilicate material was the Fmmm ( ${ }^{\circ}$ 69) group, while the crystallographic data obtained from the all-silica IWV here described leans towards the $F 222\left(\mathrm{n}^{\circ} 22\right)$ or $F m m 2\left(\mathrm{n}^{\circ} 42\right)$ spatial groups. These groups present one less symmetry plane in the different axes $(F m m 2, F m 2 m, F 2 m m)$ or in the three axes (F222) However, it has been impossible to fully determine the spatial group up to now. 


\section{- Aluminosilicate materials}

The ${ }^{29} \mathrm{Si}$ MAS-NMR spectra of the as-made and thermally treated aluminosilicate IWV materials are shown in Figure 6.20.

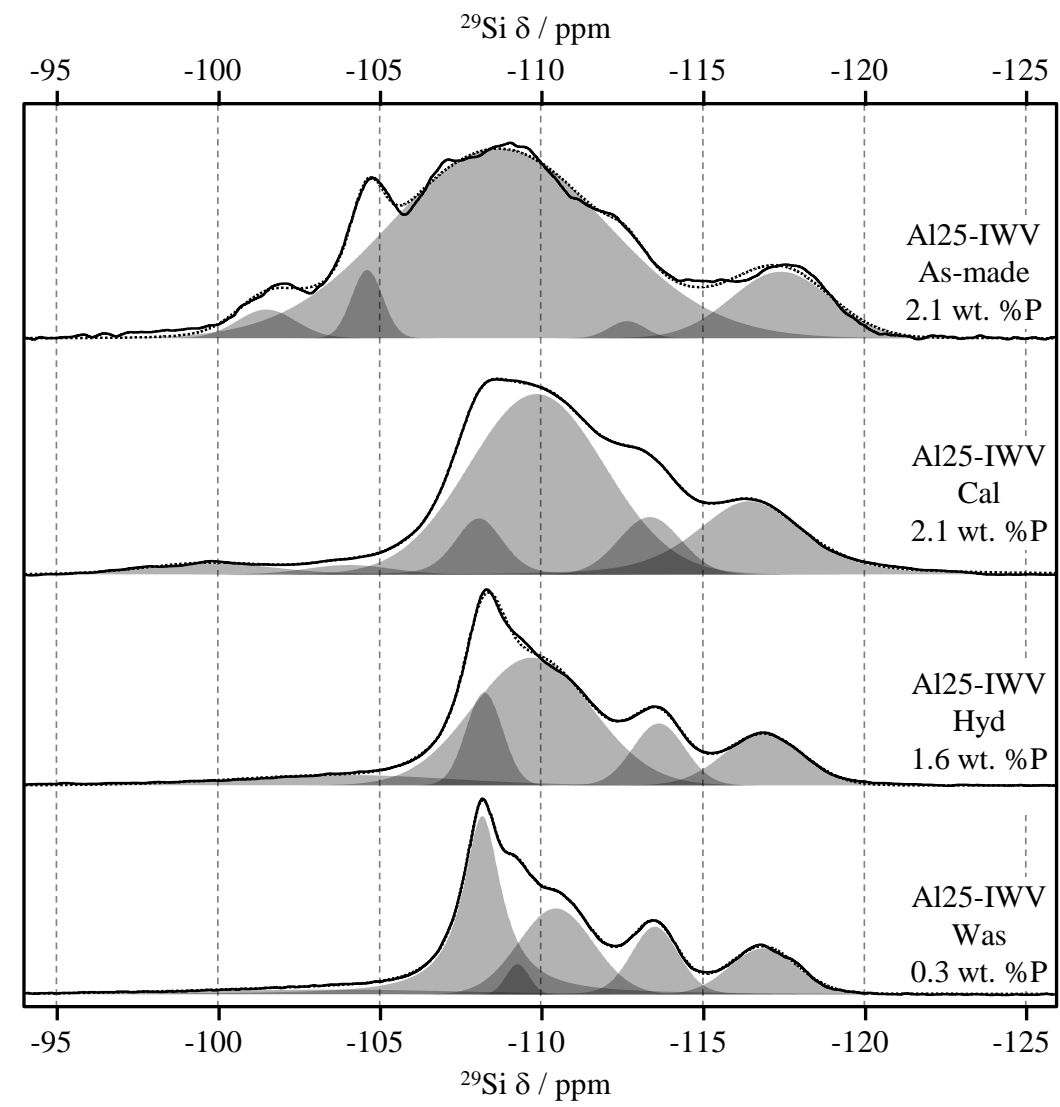

Figure 6.20. ${ }^{29} \mathrm{Si}$ MAS-NMR spectra of some as-made and thermally treated aluminosilicate IWV samples (cal: calcined under air; hyd: hydrogenated at high temperature; was: hydrogenated at high temperature and washed with ethanol). Solid lines correspond to experimental spectra; dotted lines correspond to the sum of deconvoluted signals.

The ${ }^{29} \mathrm{Si}$ MAS-NMR spectra of the as-made Al25-IWV shows several wide resonances, similar to previously reported. ${ }^{[2]}$ Four main resonances could be identified centred at $-101 \mathrm{ppm},-105 \mathrm{ppm},-109 \mathrm{ppm}$ and $-117 \mathrm{ppm}$. The two latter resonances are ascribed to $\mathrm{Q}^{4}$ silicon atoms in the zeolite, tetrahedrally coordinated silicon atoms having silicon atoms in the second neighbourhood. On the other hand, the resonance centred 
at $-101 \mathrm{ppm}$ is assigned to $\mathrm{Q}^{3}$ silicon atoms due to $\mathrm{Si}(\mathrm{OAl})(\mathrm{OSi})_{3}$ environments. Finally, the resonance centred at $-105 \mathrm{ppm}$ could either be assigned to $\mathrm{Q}^{3}, \mathrm{Q}^{4}$, or an overlap of resonances due to $\mathrm{Q}^{3}$ and $\mathrm{Q}^{4}$ silicon atoms.

The thermal treatment of the Al-IWV materials yields a drastic change in the resonance pattern, yielding to a ${ }^{29} \mathrm{Si}$ MAS-NMR spectra of the calcined sample similar to previously reported. ${ }^{[23]}$ The hydrogenation treatment at high temperature yields a slightly clearer spectra than the obtained after calcination. In all cases, the spectra barycentres shift up-field, almost disappearing the resonances at $-101 \mathrm{ppm}$ and $-105 \mathrm{ppm}$, which turn into very wide low intensity resonances. As previously stated in the all-silica ${ }^{29} \mathrm{Si} \mathrm{NMR}$, the $-105 \mathrm{ppm}$ could be assigned to silicon atoms in D4R cages interacting with fluoride anions, which are removed after thermal treatment, provoking the disappearance of the $-105 \mathrm{ppm}$ resonance. The spectrum of the calcined sample presents four main overlapping resonances centred at $-108 \mathrm{ppm},-110 \mathrm{ppm},-113 \mathrm{ppm}$ and $-116 \mathrm{ppm}$, assigned as $\mathrm{Q}^{4}$ silicon atoms. Also, two low intensity resonances at -100 and $-104 \mathrm{ppm}$ could be observed, which are assigned as $\mathrm{Si}(\mathrm{OAl})(\mathrm{OSi})_{3} \mathrm{Q}^{3}$ silicon atoms.

When the material is hydrogenated at high temperature and the phosphorus content decreases, the resonances width decrease, yielding spectra with better resolved signals, although keeping the same profile and chemical shifts as the calcined spectrum. Thus, in the sample washed with ethanol after hydrogenation, a new resonance centred at $-109 \mathrm{ppm}$, previously overshadowed by the resonances centred at $-108 \mathrm{ppm}$ and $-110 \mathrm{ppm}$, could be identified. Also, the wide resonances at $-100 \mathrm{ppm}$ and $-104 \mathrm{ppm}$, corresponding to $\mathrm{Q}^{3}$ silicon atoms, almost disappear, which is indicative of the dealumination of the material. This result is in good agreement with the acidic properties of these materials discussed in section 6.3.2.5, and the results from ${ }^{31} \mathrm{P}$ NMR in section 6.3.3.1 and ${ }^{27} \mathrm{Al}$ NMR in section 6.3.3.2. 


\subsection{UTD-1 (DON) zeolite}

The UTD-1 zeolite was first obtained by Balkus et al. in 1995. ${ }^{[47]}$ The UTD-1 zeolite was the first extra-large pore zeolite, with $14 \mathrm{MR}$ pore openings of $1.0 \mathrm{~nm}$ diameter. It is a mono-directional pore system zeolite with a straight channel running along the $c$ axis.

The UTD-1 zeolite consists in a family of intergrowth polymorphs. The disorder arises from the connection between layers, as silicon tetrahedra could be located in two different orientations, resulting in four different polymorphs. Polymorphs A and B have not been experimentally obtained yet, while polymorphs $\mathrm{C}$ and $\mathrm{D}$ are usually obtained as a mix enriched in polymorph C. ${ }^{[17,47]}$ Only polymorph $\mathrm{C}$ has been obtained as pure phase using fluoride as mineralizing agent. ${ }^{[18]}$

The UTD-1F or polymorph C (IZA code: DON) shows an orthorhombic symmetry, belonging to the $\mathrm{Cmcm}\left(\mathrm{n}^{\circ}\right.$ 63) spatial group, with the following framework parameters for the idealized all silica material: ${ }^{[16]}$

$$
a=18.8900 \AA \quad b=23.3650 \AA \quad c=8.4690 \AA \text { Volume }=3737.9 \AA^{3}
$$

This material has been obtained as all-silica and borosilicate, ${ }^{[47]}$ titanosilicate $^{[48]}$ and as aluminosilicate by introducing aluminium by post-synthesis treatments. ${ }^{[17]}$ The materials were obtained using a cobalt organometallic compound as OSDA, the cation bis(pentamethylcyclopentadienyl)cobalt (III) cation, or $\left[\mathrm{Me}_{5} \mathrm{Cp}_{2} \mathrm{Co}^{+}\right.$(Figure 6.21.a). The use of $\left[\mathrm{Me}_{5} \mathrm{Cp}_{2} \mathrm{Co}^{+}\right.$as OSDA requires several intermediate steps starting from the commercial $\left[\mathrm{Me}_{5} \mathrm{Cp}\right]_{2} \mathrm{CoPF}_{6}$ salt. This salt should be cation exchanged to the chloride form and extracted with chloroform before being able to exchange it to the hydroxide form. All these steps require an intensive use of solvent and the working up is very laborious from the point of view of its practical application.

Recently, two novel synthesis routes have been developed: by using a phosphazene base as OSDA, the phosphazene base 1,1,1,3,3,3-Hexakis[tris(dimethylamino)]diphosphazenium, or phosphazene base P2 (Figure 6.21.b); ${ }^{[49]}$ and by supramolecular assembly templating approach, using N,N-dimethyl-(2-methyl)benzimidazolium (DMBI) hydroxide as OSDA (Figure 6.21.c). ${ }^{[50]}$ Both methodologies have allowed obtaining the aluminosilicate material from direct synthesis. The use of the phosphazene base P2 get rid of most intermediate steps needed when using the $\left[\mathrm{Me}_{5} \mathrm{Cp}_{2} \mathrm{Co}^{+}\right.$or the DMBI hydroxide as OSDA's, as only an anionic exchange is needed to get the phosphazenium cation from the commercial 
phosphazenium $\mathrm{BF}_{4}^{-}$salt. However, this reagent, although being commercial, is expensive and its supply is often discontinued.

The UTD-1 zeolite material is interesting because of its potential catalytic applications involving the use of bulky molecules. ${ }^{[48,51]}$

In the following section, the synthesis and characterization of the zeolite DON employing the tris(diethylamino)(methyl)phosphonium cation, or OSDA-7 (Figure 6.21.d), is described.

a)

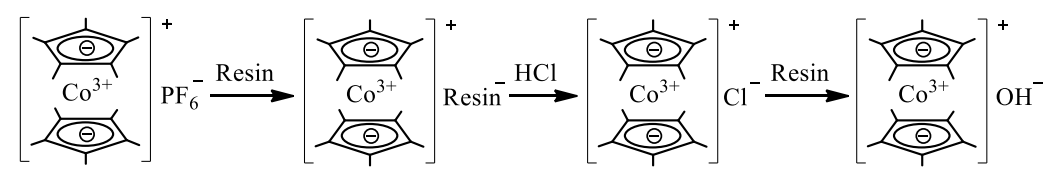

b)

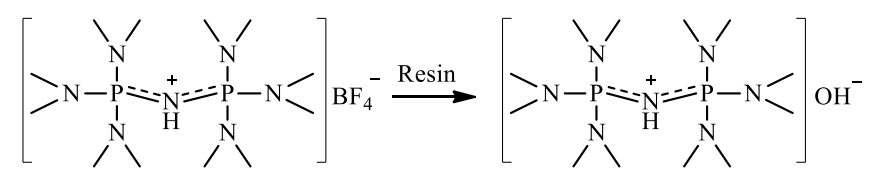

c)

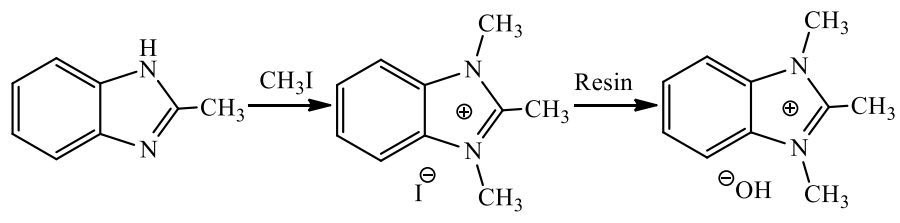

d)

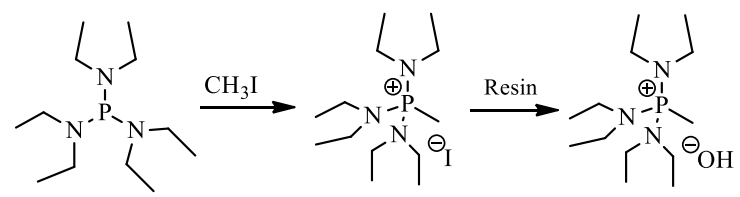

Figure 6.21. Synthesis scheme of OSDA's used in the synthesis of DON zeolite: a) $\left[\mathrm{Me}_{5} \mathrm{Cp}_{2} \mathrm{Co}^{+}\right.$ cation; b) phosphazene base P2; c) DMBI hydroxide; d) OSDA-7.

\subsubsection{Sample analyses of as-made DON zeolite}

The obtained as-made DON materials were submitted to chemical analyses, thermogravimetry, scanning electron microscopy and MAS-NMR spectroscopy. In this section only chemical analyses, thermogravimetry and scanning electronic microscopy analyses are compared, while MAS-NMR spectra are further discussed in section 6.4.3. 


\subsubsection{Chemical analyses of as-made DON zeolite}

The typical chemical compositions of the obtained as-made DON materials are shown in Table 6.6.

Table 6.6. Chemical composition of some of the obtained DON materials. All ratios are given as molar ratios. Samples are identified by heteroatom $(X)$ synthesis gel composition.

\begin{tabular}{ccccccccc}
\hline Sample & {$[\mathrm{Si} / \mathrm{X}]_{\text {gel }}$} & $\mathrm{pH}_{\text {gel }}$ & $\eta_{\mathrm{X}}(\%)$ & $\eta_{\mathrm{Si}}(\%)$ & {$[\mathrm{Si} / \mathrm{X}]_{\text {sol }}$} & wt.\% $\mathrm{P}_{\text {sol }}$ & \multicolumn{2}{c}{$\mathrm{Si} /$ OSDA OSDA/X } \\
\hline Si-DON & - & 11.47 & - & 61 & - & 1.6 & 27.4 & - \\
$\mathrm{Al30-DON}$ & 30 & 11.82 & 89 & 65 & 21.8 & 2.1 & 21.5 & 1.0 \\
$\mathrm{~B} 30-\mathrm{DON}$ & 30 & 11.65 & 60 & 68 & 34.4 & 1.6 & 23.3 & 1.5 \\
\hline
\end{tabular}

First, it could be seen that the silicon to OSDA ratio fluctuate between 21 and 27, which would yield between 2.4 and 3 OSDA molecules per unit cell (64 T positions per unit cell). This value differs from previous values of Si/OSDA ratios around 16 , corresponding to 2 OSDA molecules per unit cell, ${ }^{[49]}$ or 1 OSDA molecule per unit cell. ${ }^{[50]}$ The discrepancies between the different reported Si/OSDA ratios in different work could be ascribed to the large presence of structural ${ }^{-} \mathrm{OH}$ defects because of the disordered nature of DON zeolite.

On the other hand, the incorporation of aluminium and boron was considerably higher than previously reported, even reaching a OSDA/X ratio of 1 , while in previous works this ratio barely reached 2.5 . This has allowed to incorporate more heteroatom species than previously reported, achieving $\mathrm{Si} / \mathrm{Al}$ ratios of 22 against higher values as 35 (by postsynthesis treatment ${ }^{[17]}$ or 38 (by direct synthesis). ${ }^{[49]}$ 


\subsubsection{Morphology of as-made DON zeolite}

The crystallite shape and size of the as-made DON samples was assessed by FESEM microscopy analyses, depicted in Figure 6.22.
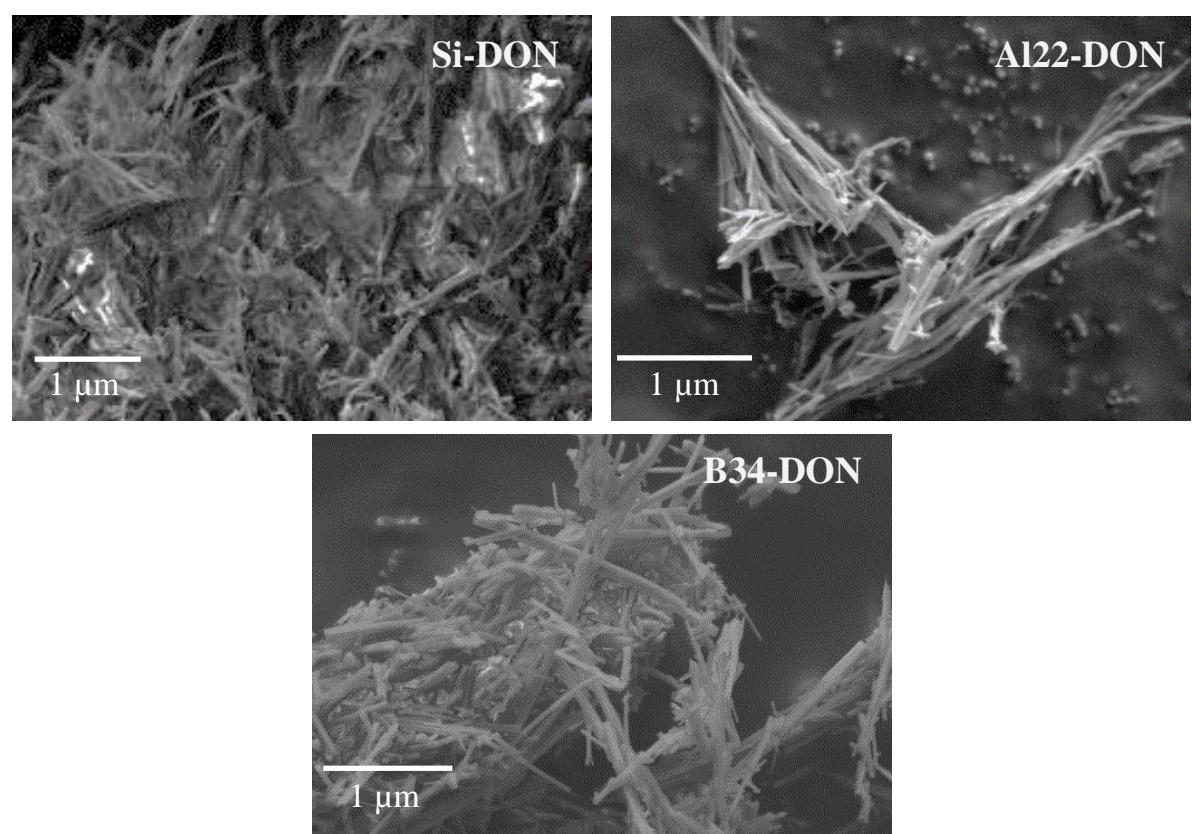

Figure 6.22. FESEM microimages of some as-made DON materials. Samples are named after the containing heteroatom followed by the as-made heteroatom to silica ratio content.

The obtained DON materials show a homogeneous crystallization as needle-like crystallite with sizes around $0.1 \times 5 \mu \mathrm{m}$, similarly to previously reported. ${ }^{[17,49]}$ In all cases the crystallites form aggregates, being these aggregates bigger the lower the heteroatom content, up to the point where all-silica material only form large aggregates. 


\subsubsection{Thermogravimetric analysis of the as-made DON zeolite}

The thermal stability and decomposition of the OSDA were studied by the thermogravimetry (TG) and differential thermogravimetry (DTG) analyses of some DON samples. Some thermogravimetric plots are shown in Figure 6.23.

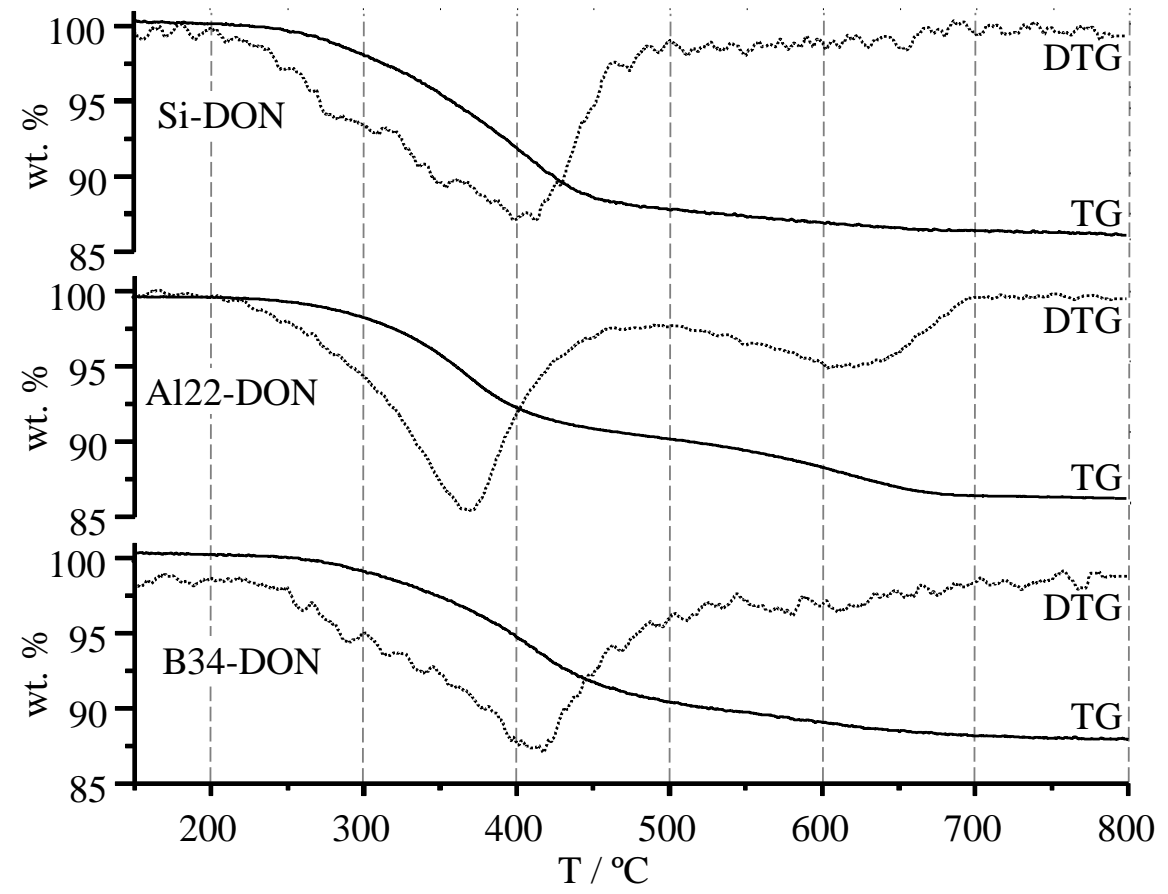

Figure 6.23. TG (solid lines) and DTG (dotted lines) analyses curves of some DON samples.

Samples are named as the containing heteroatom followed by the as-made heteroatom to silica ratio content. DTG curves are scaled up for a better view.

The thermogravimetric analysis of the DON samples shows a weight loss of $c a .15$ wt. \% in all cases. The temperature and its range for the decomposition of the OSDA is dependent on the heteroatom content and type. In all cases the weight loss occurs between $275^{\circ} \mathrm{C}$ and $650^{\circ} \mathrm{C}$, but the weight loss could be split in two stages, a low temperature weight loss between $275^{\circ} \mathrm{C}$ and $425^{\circ} \mathrm{C}$, and a high temperature weight loss between $425^{\circ} \mathrm{C}$ and $650^{\circ} \mathrm{C}$. The relative extent of the weight loss in each stage is clearly differentiated by sample composition.

The all-silica material presents most of the weight loss, up to $12 \mathrm{wt} \%$, below $450^{\circ} \mathrm{C}$, while the remaining $2 \mathrm{wt} . \%$ is lost at higher temperatures (14 wt.\% final weight loss). On the 
other hand, aluminosilicate sample presents 8 wt.\% weight loss below $425^{\circ} \mathrm{C}$, and an additional $7 \mathrm{wt} . \%$ weight loss at higher temperatures ( $15 \mathrm{wt} . \%$ final weight loss). The large weight loss at low temperature, similar to all-silica material, suggests that the OSDA is weakly interacting with the aluminium atoms, like previously observed in the IWV zeolite in section 6.3.1.3. However, the minor weight loss at higher temperature, could suggest that at least some of the OSDA is strongly interacting with the aluminium atoms.

The borosilicate material presents a similar TG behaviour than the aluminosilicate sample, but the weight loss at lower temperature shifts towards a higher temperature, while the high temperature weight loss slightly shifts towards a lower temperature. Thus, 9 wt.\% weight loss takes place at $\sim 450^{\circ} \mathrm{C}$, and $6 \mathrm{wt} . \%$ weight loss at higher temperatures $(15 \mathrm{wt} . \%$ final weight loss). This result could suggest that the OSDA-boron interaction is stronger than the OSDA-aluminium interaction.

The relatively low temperature required for the decomposition of the OSDA is in good agreement with an extra-large pore zeolite. However, the high temperature required for the full removal of the organic species formed during OSDA decomposition in the case of borosilicate and aluminosilicate indicate a stabilizing effect of part of the OSDA when interacting with the aluminium and the boron species inside the material.

\subsubsection{Thermal treatments on the DON zeolite}

The as-made DON materials were thermally treated by the general methodologies described in the section 3.2.3. For the thermally treated materials, powder X-Ray diffraction, chemical analyses, scanning electron microscopy, adsorption isotherms and MAS-NMR spectroscopies were performed. In this section only powder X-Ray diffraction, chemical analyses, scanning electron microscopy and adsorption isotherms analyses of the thermally treated samples are compared, while MAS-NMR spectra are further discussed in section 6.4.3. 


\subsubsection{Crystallinity of thermally treated DON zeolite}

The stability and crystallinity of the DON samples after calcination were assessed by powder X-Ray diffraction, whose patterns are shown in Figure 6.24.

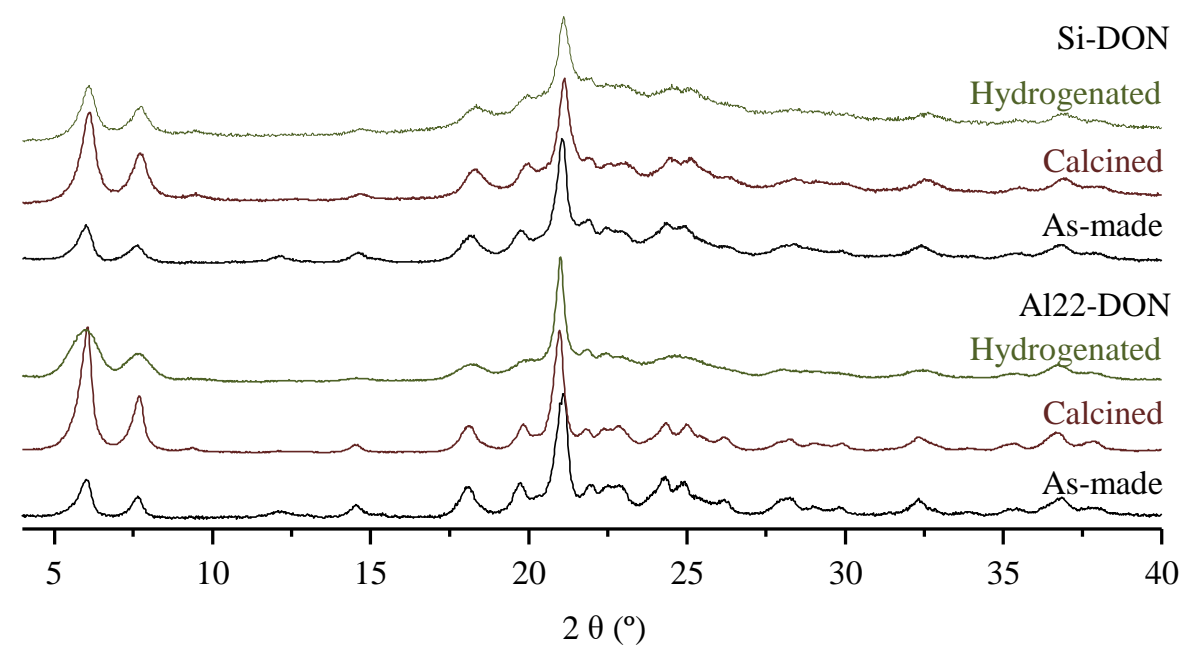

Figure 6.24. Powder X-Ray diffraction of some of the thermally treated DON materials. Black lines correspond to as-made samples; red lines to calcined samples; green lines to samples hydrogenated at high temperature. Samples are identified by synthesized material composition.

The materials remained crystalline after calcination, with the X-Ray diffraction peaks being found at roughly the same $2 \theta$ degrees in all samples regardless of the thermal treatment. However, when materials are treated with hydrogen at high temperature, the diffraction peaks considerably widen and a very broad diffraction peak at $22^{\circ}$ could be discerned. This broad peak corresponds to amorphous silica, which could be attributed to a partial amorphization of the hydrogenated materials. This amorphization would also explain the widening of the diffraction peaks due to a loss of long range order in the crystalline structure.

These results could be explained by the thermal stability of the DON material, as higher temperatures are applied in the hydrogenation treatment, higher than $700^{\circ} \mathrm{C}$, than in the calcination treatments, below $700^{\circ} \mathrm{C}$.

\subsubsection{Chemical analyses of thermally treated DON zeolite}

The typical chemical compositions of the thermally treated DON materials are shown in Table 6.7. 
Chapter 6: Synthesis of ITQ-27 (IWV) and UTD-1 (DON)

Table 6.7. Chemical composition of some of the thermally treated DON materials. All ratios are given as molar ratios. Samples are identified by heteroatom $(\mathrm{X})$ synthesis gel composition.

\begin{tabular}{rcccccc}
\hline Sample & Treatment & $\mathrm{Si} / \mathrm{X}_{\text {as-made }}$ & $\mathrm{Si} / \mathrm{X}_{\text {treated }}$ & wt.\% $\mathrm{P}_{\text {as-made }}$ & wt.\% & $\mathrm{P}_{\text {treated }} \mathrm{P} / \mathrm{X}_{\text {treated }}$ \\
\hline Si-DON & Calcination & - & - & 1.6 & 1.2 & - \\
Si-DON & Hydrogenation & - & - & 1.6 & 0.4 & - \\
Al22-DON & Calcination & 22.4 & 21.9 & 1.7 & 1.5 & 0.8 \\
A122-DON & Hydrogenation & 22.4 & 22.3 & 1.7 & 0.8 & 0.4 \\
\hline
\end{tabular}

After calcination, most of the phosphorus remains inside the material, keeping at least $80 \mathrm{wt} . \%$ of the phosphorus introduced by the incorporation of the OSDA. The hydrogenation at high temperature allows for a higher phosphorus removal, up to $70 \mathrm{wt} . \%$ for the all-silica material and up to $50 \mathrm{wt} . \%$ for the aluminosilicate material. As observed in the IWV zeolite, this indicates that some of the phosphorous species which are formed during the hydrogenation treatment are interacting with the aluminium species and are thus better retained than in all-silica material. However, this interaction is lower in the case of the DON zeolite as evidenced by the higher phosphorus removal respect to the IWV zeolite as shown in Table 6.3. 


\subsubsection{Morphology of thermally treated DON zeolite}

As previously, the morphology of the thermally treated DON zeolite was studied by FESEM, and their comparison with as-made materials is depicted in Figure 6.25.
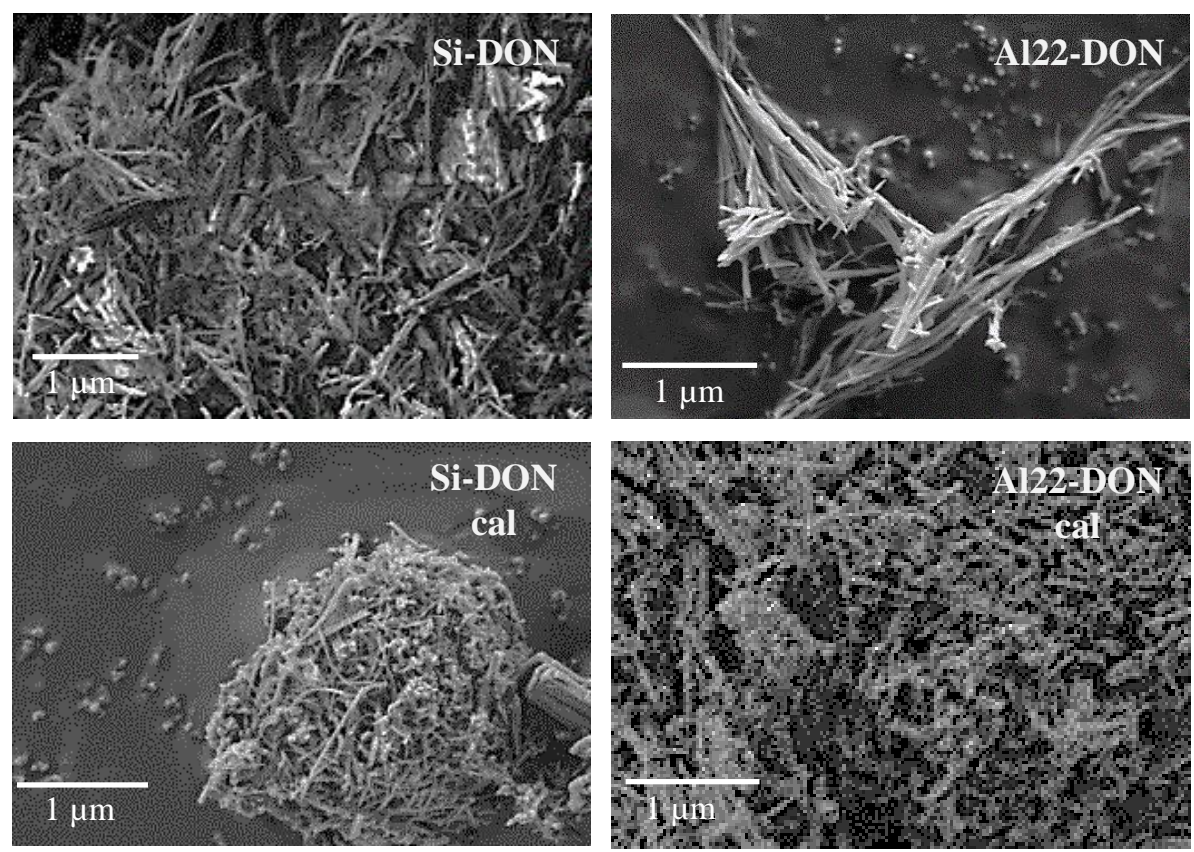

Figure 6.25. FESEM microimages of some thermally treated DON materials. Samples are named after the containing heteroatom followed by the as-made heteroatom to silica ratio content, with the thermal treatment below (Cal: calcined).

After the thermal treatments, the DON crystallites keep their size and shape. However, the decrease of the phosphorus content in the materials favour the formation of larger aggregates. 


\subsubsection{Textural properties of thermally treated DON zeolite}

The textural properties of the DON samples were calculated from the $\mathrm{N}_{2}$ adsorption isotherms at $77 \mathrm{~K}$ on the thermally treated samples, shown in Figure 6.26.
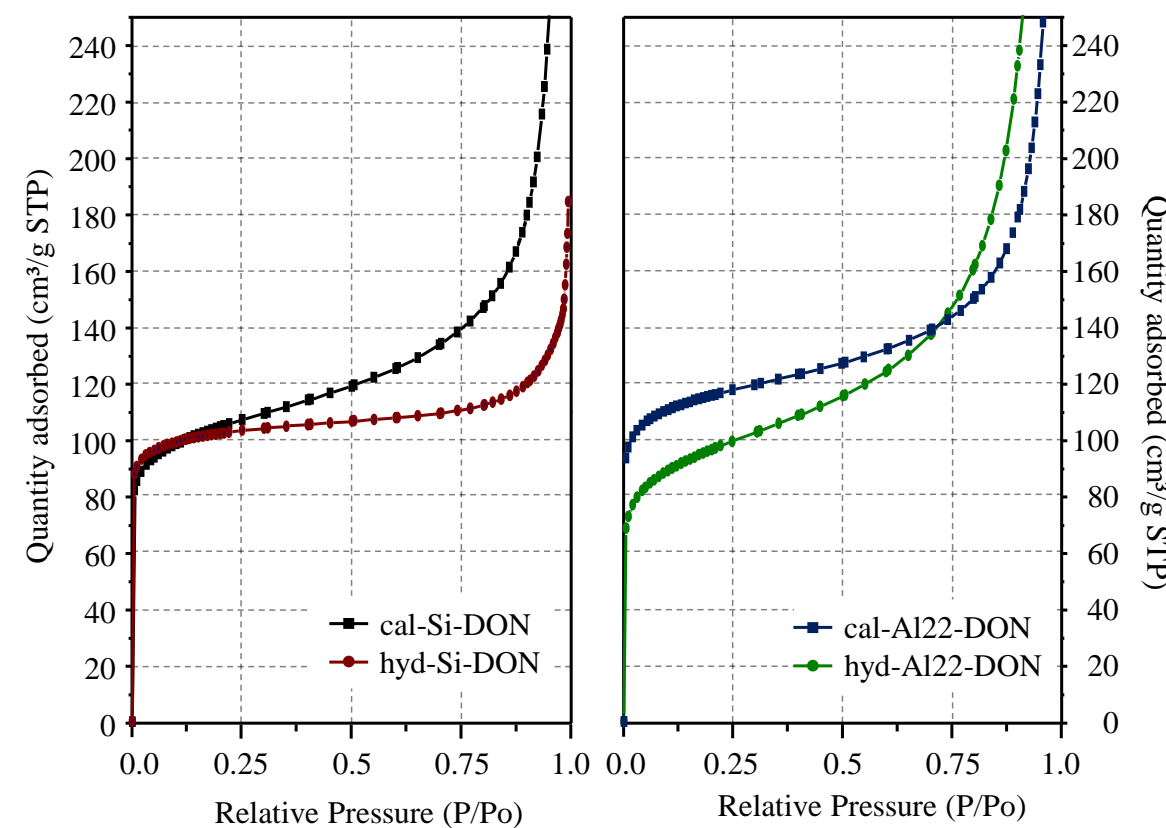

Figure 6.26. $\mathrm{N}_{2}$ adsorption isotherm of some of the thermally treated DON samples (black: calcined all-silica; red: hydrogenated at high temperature all-silica; blue: calcined aluminosilicate; green: hydrogenated at high temperature aluminosilicate).

The $\mathrm{N}_{2}$ adsorption isotherms show the type Ia physisorption profile typical of microporous materials, but with a considerable multilayer adsorption due to a considerable mesoporosity in the DON materials synthesized in this work. ${ }^{[24]}$

The BET and micropore surface areas and the total micropore volume (calculated from the $\mathrm{N}_{2}$ adsorption isotherm at $77 \mathrm{~K}$ by applying the t-plot method) were calculated for the DON materials synthesized in this work, as shown in Table 6.8. 
Table 6.8. Textural properties of thermally treated DON samples. Samples are named after the heteroatom content and thermal treatments (cal: calcined; hyd: hydrogenated at high temperature).

\begin{tabular}{cccccc}
\hline Sample & $\begin{array}{c}\text { BET } \\
\text { surface / } \\
\mathrm{m}^{2} \cdot \mathrm{g}^{-1}\end{array}$ & $\begin{array}{c}\text { Micropore } \\
\text { surface / } \\
\mathrm{m}^{2} \cdot \mathrm{g}^{-1}\end{array}$ & $\begin{array}{c}\text { Micropore } \\
\text { volume / } \\
\mathrm{cm}^{3} \cdot \mathrm{g}^{-1}\end{array}$ & P/Al & wt.\%P \\
\hline Si-DON-cal & 343.3 & 240.7 & 0.12 & - & 1.2 \\
\hline Si-DON-hyd & 327.8 & 306.5 & 0.15 & - & 0.4 \\
Al22-DON-cal & 376.1 & 294.7 & 0.14 & 0.8 & 1.5 \\
A122-DON-hyd & 322.5 & 177.7 & 0.08 & 0.4 & 0.8 \\
\hline
\end{tabular}

The obtained BET surface area and micropore volume values show differences depending on the phosphorus and heteroatom content. Thus, in all-silica materials it could be seen that the removal of most of the phosphorous by the hydrogen treatment at high temperature results in an increase of the micropore volume to $0.15 \mathrm{~cm}^{3} \cdot \mathrm{g}^{-1}$, which is lower than previously reported $0.17 \mathrm{~cm}^{3} \cdot \mathrm{g}^{-1[49]}$ and $0.18 \mathrm{~cm}^{3} \cdot \mathrm{g}^{-1[50]}$ micropore volumes.

In the case of the aluminosilicate, the decrease of the micropore volume when phosphorus is removed could be attributed to the partial collapse of the crystalline framework, which is in accordance with the presence of a very broad diffraction peak at $2 \theta$ $22^{\circ}$ in the X-Ray diffraction pattern as seen in section 6.4.2.1.

\subsubsection{NMR study of the DON zeolite}

The incorporation of the phosphorous OSDA and the aluminium and boron heteroatoms were studied by MAS-NMR on the as-made and thermally treated DON materials. 
Chapter 6: Synthesis of ITQ-27 (IWV) and UTD-1 (DON)

\subsubsection{Incorporation and stability of the OSDA to the DON zeolite}

The stability of the OSDA incorporated in the DON zeolite was studied by ${ }^{31} \mathrm{P}$ MASNMR spectroscopy.

The ${ }^{31} \mathrm{P}$ MAS-NMR spectra of the as-made samples compared with the liquid ${ }^{31} \mathrm{P}$ NMR spectrum of the free P-OSDA are shown in Figure 6.27.

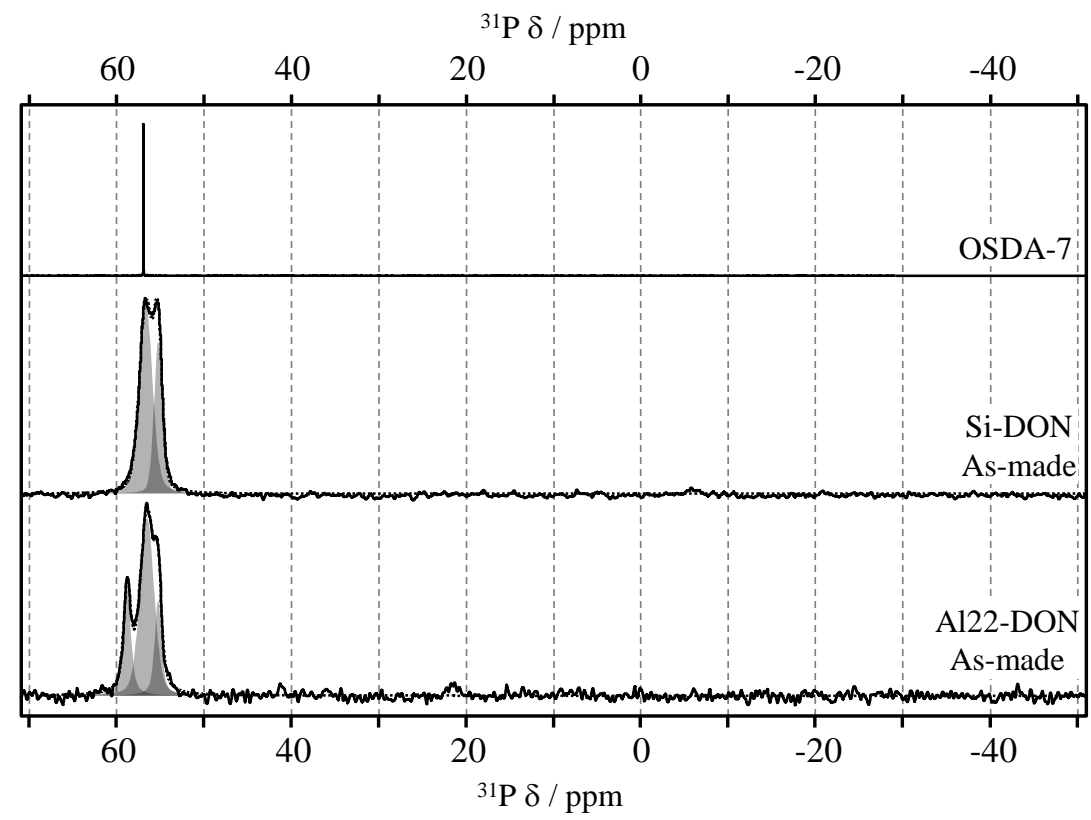

Figure 6.27. ${ }^{31} \mathrm{P}$ MAS-NMR spectra of some as-made DON samples. Samples are named after the containing heteroatom followed by the as-made heteroatom to silica ratio content. Free OSDA NMR spectrum is included for comparison.

The ${ }^{31} \mathrm{P}$ MAS-NMR spectra of the as-made samples show several resonances around $57 \mathrm{ppm}$, two in the all-silica sample and three in the aluminosilicate samples. These resonances appear in the same region than in the liquid NMR spectrum of the OSDA in water solution (56.92 ppm, see section 3.2.1.7), suggesting that the OSDA remains intact inside of the pores of the zeolite but in different conformations or chemical environments.

After the thermal treatment of the materials, most of the phosphorus remains inside the material, giving the opportunity to study the chemical nature of the generated species by ${ }^{31} \mathrm{P}$ MAS-NMR spectroscopy, whose spectra are shown in Figure 6.28. 


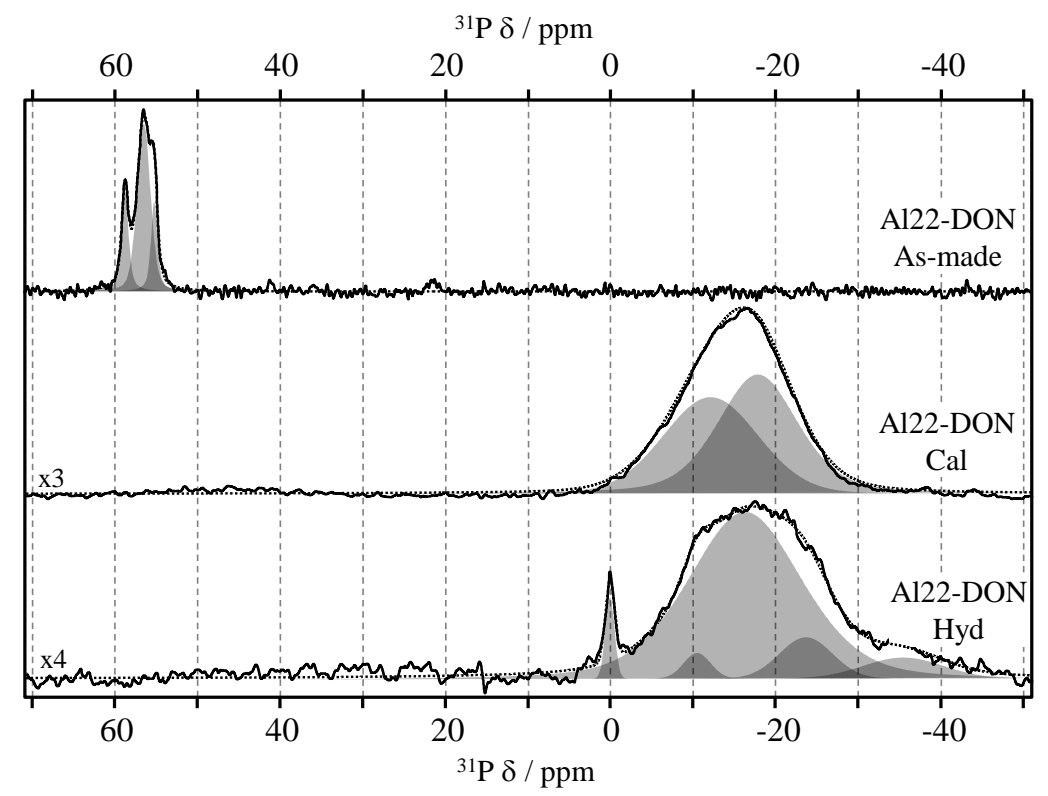

Figure 6.28. ${ }^{31} \mathrm{P}$ MAS-NMR spectra of thermally treated AI-DON materials. Samples are named after the thermal treatment (cal: calcined under air; hyd: hydrogenated at high temperature), followed by the containing heteroatom and by the as-made heteroatom to silica ratio content.

Solid lines correspond to experimental spectra; dotted lines correspond to the sum of deconvoluted signals. Spectra were deconvoluted as Gaussian/Lorentz curves.

After the thermal treatments it could be observed that the signal at $57 \mathrm{ppm}$ disappears, and thus, the OSDA is completely decomposed.

In the case of the calcined sample, a single wide resonance centred at ca. $-16 \mathrm{ppm}$ appears. This asymmetric resonance is probably composed by at least two signals, but no discrete resonances up-field or down-field could be identified like in previously discussed MFI, RTH or IWV zeolites. These wide resonances are assigned to multiple overlapped resonances, which would correspond to polymeric phosphate chains, as well as highly condensed polyphosphate species. ${ }^{[30-32]}$

Similarly, the sample hydrogenated at high temperature also exhibits a similar wide signal centred at $-16 \mathrm{ppm}$ and a narrow resonance at $0 \mathrm{ppm}$. This latter resonance is assigned to extra-framework $\mathrm{P}_{2} \mathrm{O}_{5}$ species. On the other hand, the mathematical deconvolution of the $-16 \mathrm{ppm}$ resonance leads to smaller and wide signals at $-10 \mathrm{ppm},-24 \mathrm{ppm}$ and $-37 \mathrm{ppm}$, although it is impossible to notice discrete signals. As previously, the wide resonance at -16 ppm is assigned to polymeric phosphate chains and highly condensed polyphosphate 
species, ${ }^{[30-32]}$ while the resonances at $-24 \mathrm{ppm}$ and $-37 \mathrm{ppm}$ are assigned to different (bi)phosphates bounded to monodentate or bidentate aluminium octahedral atoms. ${ }^{[26-29]}$ The lack of discrete phosphorus species could be indicative of a weaker interaction of the phosphorous species with the DON zeolite framework and aluminium centres than the previously observed in the cases of IWV, RTH or MFI zeolites.

\subsubsection{Aluminium incorporation in the DON zeolite}

The aluminium incorporation was studied by ${ }^{27} \mathrm{Al}$ MAS-NMR spectroscopy on the as-made aluminosilicate samples, as well as on the different aluminium species formed after thermal treatments, whose spectra are shown in Figure 6.29.

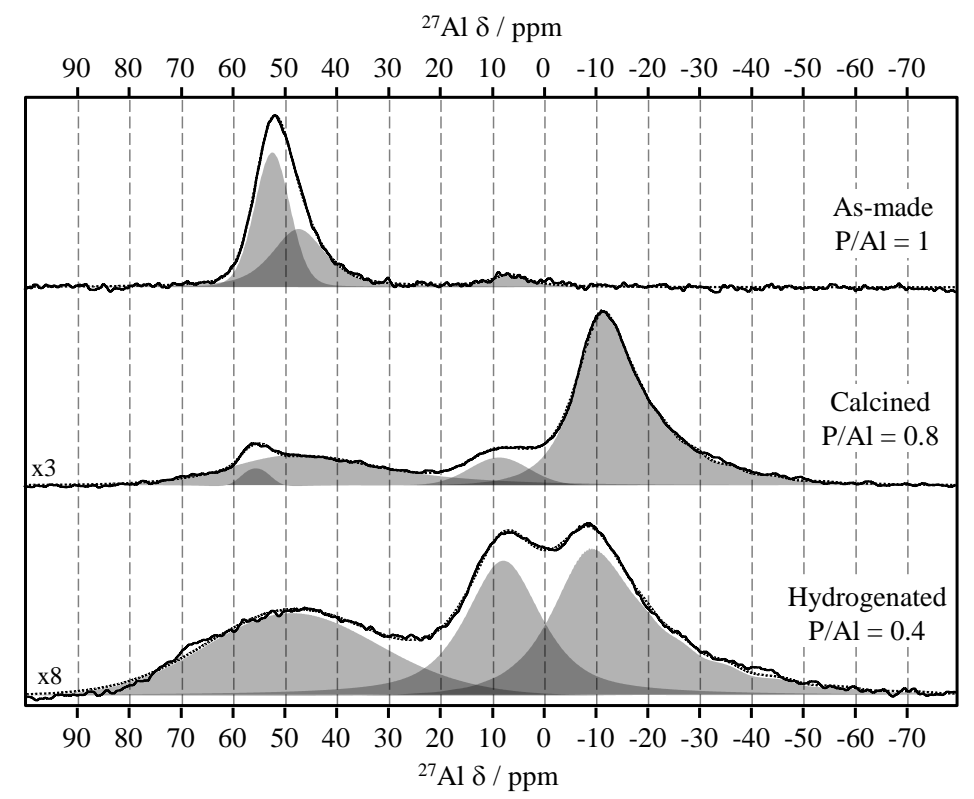

Figure 6.29. ${ }^{27} \mathrm{Al}$ MAS-NMR of samples of the as-made and the thermally treated DON sample with $\mathrm{Si} / \mathrm{Al}=22$. Solid lines correspond to experimental spectra; dotted lines correspond to the

sum of deconvoluted signals. The resonances in as-made sample were deconvoluted as a

Gaussian/Lorentz curve (for an easier view); the resonances of thermally treated were deconvoluted as a Gaussian/Lorentz curve (peaks at $56 \mathrm{ppm}$ and $9 \mathrm{ppm}$, for an easier view) or using the CzSimple method (peaks at 45-50 ppm and -10 ppm. ${ }^{[40]}$ 
The as-made sample presents three resonances, two overlapping resonances centred at $52 \mathrm{ppm}$ and $48 \mathrm{ppm}$, and a minor resonance centred at $9 \mathrm{ppm}$. The resonances centred at $52 \mathrm{ppm}$ and $48 \mathrm{ppm}$ could be attributed to $\mathrm{Al}$ in tetrahedral coordination, ${ }^{[34,35]}$ probably in two different lattice position inside the zeolite framework. Similarly to the Al-IWV zeolite, the resonance centred at $9 \mathrm{ppm}$ is typically attributed to aluminium species in octahedral coordination, in this case, to gibbsite aluminium hydroxide, ${ }^{[39]}$ probably due to unreacted alumina source.

When materials are thermally treated, the aluminium atoms present up to four different chemical environments. Thus, calcined sample presents a minor resonance centred at $56 \mathrm{ppm}$, attributed to tetrahedral aluminium species; a broad resonance at $c a .40 \mathrm{ppm}$ attributed to distorted tetrahedral aluminium species; an increase in the resonance at $9 \mathrm{ppm}$ attributed to gibbsite aluminium hydroxide; and a major broad resonance $-12 \mathrm{ppm}$ attributed to octahedral aluminium species interacting with phosphorous species, similar to the results reported for Al-RTH zeolite in section 5.3.4.2.

The treatment under hydrogen at high temperature leads to a huge increase in the resonance at $9 \mathrm{ppm}$, which could be attributed to aluminium species formed after the partial framework collapse as previously observed by X-Ray diffraction and confirmed by the lowering of the micropore volume obtained from the $\mathrm{N}_{2}$ adsorption isotherm. It is also interesting the wide resonance at $50 \mathrm{ppm}$, which is probably made up of two signal belonging to undistorted and distorted tetrahedral aluminium species. The widening of this signal could be attributed to the partial amorphization of the sample after the hydrogenation thermal treatment. Finally, the hydrogenated sample also shows the resonance attributed to octahedral aluminium species interacting with phosphorous species, although this resonance is shifted downfield, from $-12 \mathrm{ppm}$ in the calcined sample to $-9 \mathrm{ppm}$ in the hydrogenated sample. 


\subsection{Conclusions}

The use of a novel aminophosphonium cation as OSDA, the tris(diethylamino) (methyl)phosphonium cation, has allowed the synthesis of two known materials, the ITQ-27 (IWV) and the UTD-1 (DON). Thus, the use of this OSDA constitute an alternative synthesis pathway, presenting the following features:

- The aminophosphonium OSDA allowed obtaining the IWV zeolite as aluminosilicate, borosilicate, germanosilicate and all-silica materials, both in fluoride and hydroxide media, and in highly concentrated synthesis gels. However, aluminium was not fully incorporated to the zeolite framework in hydroxide media syntheses. A deeper study of the synthesis conditions could fix this result.

- The all-silica IWV zeolite has been synthesized for the first time, which allowed a deeper study of the IWV structure by MAS-NMR, suggesting a lower symmetry. However, the final spatial group has not been determined yet.

- The use of a phosphorous OSDA allows the introduction of phosphorus in the IWV zeolite during the synthesis stage. The different post-synthesis treatment allows modifying the phosphorus content, which translate in a modification and modulation of the textural and acidic properties of the final material.

- The hydrogenation at high temperature of the IWV materials has allowed obtaining materials with the highest BET surface and micropore volumes ever reported in IWV zeolite.

- The aminophosphonium OSDA allowed obtaining the DON zeolite as aluminosilicate, borosilicate and all-silica materials in hydroxide media. However, aluminium was not fully incorporated to the zeolite framework. A deeper study of the synthesis conditions could improve this result.

- The DON materials obtained present similar properties to previously reported, but the aminophosphonium OSDA is easier and/or cheaper to synthesize than previous described OSDA's.

- The aminophosphonium OSDA is easily recoverable after zeolite synthesis and remains stable after hydrothermal treatment, which allows its reuse. 


\subsection{References}

[1] D.L. Dorset, K.G. Strohmaier, C.E. Kliewer, A. Corma, M.J. Díaz-Cabañas, F. Rey, C.J. Gilmore, Crystal structure of ITQ-26, a 3D framework with extra-large pores, Chemistry of Materials, 20, 16, 2008, 5325-5331.

[2] D.L. Dorset, G.J. Kennedy, K.G. Strohmaier, M.J. Diaz-Cabañas, F. Rey, A. Corma, PDerived Organic Cations as Structure-Directing Agents: Synthesis of a High-Silica Zeolite (ITQ-27) with a Two-Dimensional 12-Ring Channel System, Journal of the American Chemical Society, 128, 27, 2006, 8862-8867.

[3] A. Corma, M.J. Diaz-Cabanas, J.L. Jorda, F. Rey, G. Sastre, K.G. Strohmaier, A Zeolitic Structure (ITQ-34) with Connected 9- and 10-Ring Channels Obtained with Phosphonium Cations as Structure Directing Agents, Journal of the American Chemical Society, 130, 49, 2008, 16482-16483.

[4] A. Corma, M. Díaz-Cabañas, J. Jiang, M. Afeworki, D. Dorset, S. Soled, K. Strohmaier, Extra-large pore zeolite (ITQ-40) with the lowest framework density containing double fourand double three-rings, Proceedings of the National Academy of Sciences, 107, 32, 2010, 13997-14002.

[5] A. Corma, F. Rey, M.T. Navarro, R. Simancas, N. Velamazan, Á. Cantín, J.L. Jordá, ITQ 45 material, method for obtaining same and use thereof, Consejo Superior de Investigaciones Científicas, WO2012049344, 2012.

[6] F. Rey, M. Hernández-Rodríguez, J.L. Jordá, ITQ-49 material, method for the production thereof and use of same, Consejo Superior de Investigaciones Científicas, CA2870579, 2014.

[7] R. Simancas, J.L. Jordá, F. Rey, A. Corma, A. Cantín, I. Peral, C. Popescu, A New Microporous Zeolitic Silicoborate (ITQ-52) with Interconnected Small and Medium Pores, Journal of the American Chemical Society, 136, 9, 2014, 3342-3345.

[8] Y. Yun, M. Hernandez, W. Wan, X. Zou, J.L. Jorda, A. Cantin, F. Rey, A. Corma, The first zeolite with a tri-directional extra-large 14-ring pore system derived using a phosphonium-based organic molecule, Chemical Communications, 51, 36, 2015, 7602-7605.

[9] R. Simancas, D. Dari, N. Velamazán, M.T. Navarro, A. Cantín, J.L. Jordá, G. Sastre, A. Corma, F. Rey, Modular organic structure-directing agents for the synthesis of zeolites, Science, 330, 6008, 2010, 1219-1222.

[10] T. Lemishko, J. Simancas, M. Hernández-Rodríguez, M. Jiménez-Ruiz, G. Sastre, F. Rey, An INS study of entrapped organic cations within the micropores of zeolite RTH, Physical Chemistry Chemical Physics, 18, 2016, 17244-17252. 
Chapter 6: Synthesis of ITQ-27 (IWV) and UTD-1 (DON)

[11] R. Jäger, A.M. Schneider, P. Behrens, B. Henkelmann, K.W. Schramm, D. Lenoir, Selective Adsorption of Polychlorinated Dibenzo-p-dioxins and Dibenzofurans by the Zeosils UTD-1, SSZ-24, and ITQ-4, Chemistry-A European Journal, 10, 1, 2004, 247-256.

[12] K. Balkus Jr, A. Khanmamedova, A. Gabrielov, S. Zones, Molecular sieve Ti-UTD-1: a novel oxidation catalyst, in: Studies in Surface Science and Catalysis, Elsevier, 101, 1996, 1341-1348.

[13] J.A. Martens, M. Tielen, P.A. Jacobs, Attempts to rationalize the distribution of hydrocracked products. III. Mechanistic aspects of isomerization and hydrocracking of branched alkanes on ideal bifunctional large-pore zeolite catalysts, Catalysis Today, 1, 4, 1987, 435-453.

[14] J. Jiang, J. Yu, A. Corma, Extra-Large-Pore Zeolites: Bridging the Gap between Micro and Mesoporous Structures, Angewandte Chemie International Edition, 49, 18, 2010, 31203145 .

[15] J. Martinez-Ortigosa, J. Simancas, J.A. Vidal-Moya, P. Gaveau, F. Rey, B. Alonso, T. Blasco, Host-Guest and Guest-Guest Interactions of P-and N-Containing Structure Directing Agents Entrapped inside MFI-Type Zeolite by Multinuclear NMR Spectroscopy, The Journal of Physical Chemistry C, 123, 36, 2019, 22324-22334.

[16] C. Baerlocher, M. L., Database of Zeolite Structures: http://www.izastructure.org/databases/.

[17] R.F. Lobo, M. Tsapatsis, C.C. Freyhardt, S. Khodabandeh, P. Wagner, C.-Y. Chen, K.J. Balkus, S.I. Zones, M.E. Davis, Characterization of the Extra-Large-Pore Zeolite UTD-1, Journal of the American Chemical Society, 119, 36, 1997, 8474-8484.

[18] T. Wessels, C. Baerlocher, L.B. McCusker, E.J. Creyghton, An Ordered Form of the Extra-Large-Pore Zeolite UTD-1: Synthesis and Structure Analysis from Powder Diffraction Data, Journal of the American Chemical Society, 121, 26, 1999, 6242-6247.

[19] L.A. Villaescusa, P.A. Barrett, M.A. Camblor, ITQ-7: A New Pure Silica Polymorph with a Three-Dimensional System of Large Pore Channels, Angewandte Chemie International Edition, 38, 13-14, 1999, 1997-2000.

[20] R. Barrer, H. Villiger, The crystal structure of the synthetic zeolite L, Zeitschrift für Kristallographie-Crystalline Materials, 128, 3-6, 1969, 352-370.

[21] G. Bergerhoff, W. Baur, W. Nowacki, Über die kristallstrukturen des faujasits, $N$. $J b$. Miner. Mh., 198, 1958, 193-200.

[22] R.M. Dessau, J.L. Schlenker, J.B. Higgins, Framework topology of $\mathrm{AIPO}_{4}-8$ : The first 14-ring molecular sieve, Zeolites, 10, 6, 1990, 522-524. 
[23] J.E. Schmidt, C.-Y. Chen, S.K. Brand, S.I. Zones, M.E. Davis, Facile Synthesis, Characterization, and Catalytic Behavior of a Large-Pore Zeolite with the IWV Framework, Chemistry - A European Journal, 22, 2016, 4022-4029.

[24] M. Thommes, K. Kaneko, A.V. Neimark, J.P. Olivier, F. Rodriguez-Reinoso, J. Rouquerol, K.S. Sing, Physisorption of gases, with special reference to the evaluation of surface area and pore size distribution (IUPAC Technical Report), Pure and Applied Chemistry, 87, 9-10, 2015, 1051-1069.

[25] G. Horváth, K. Kawazoe, Method for the calculation of effective pore size distribution in molecular sieve carbon, Journal of Chemical Engineering of Japan, 16, 6, 1983, 470-475.

[26] J. Caro, M. Bülow, M. Derewinski, J. Haber, M. Hunger, J. Kärger, H. Pfeifer, W. Storek, B. Zibrowius, NMR and IR studies of zeolite H-ZSM-5 modified with orthophosphoric acid, Journal of Catalysis, 124, 2, 1990, 367-375.

[27] G. Lischke, R. Eckelt, H.-G. Jerschkewitz, B. Parlitz, E. Schreier, W. Storek, B. Zibrowius, G. Öhlmann, Spectroscopic and physicochemical characterization of P-modified H-ZSM-5, Journal of Catalysis, 132, 1991, 229-243.

[28] A.-R. Grimmer, U. Haubenreisser, High-field static and MAS ${ }^{31} \mathrm{P}$ NMR: chemical shift tensors of polycrystalline potassium phosphates $\mathrm{P}_{2} \mathrm{O}_{5} \cdot \mathrm{xK}_{2} \mathrm{O}(0 \leq \mathrm{x} \leq 3)$, Chemical Physics Letters, 99, 5, 1983, 487-490.

[29] T. Duncan, D. Douglas, On the 31P chemical shift anisotropy in condensed phosphates, Chemical Physics, 87, 3, 1984, 339-349.

[30] D. Müller, E. Jahn, G. Ladwig, U. Haubenreisser, High-resolution solid-state ${ }^{27} \mathrm{Al}$ and ${ }^{31} \mathrm{P}$ NMR: correlation between chemical shift and mean Al-O-P angle in $\mathrm{AlPO}_{4}$ polymorphs, Chemical Physics Letters, 109, 4, 1984, 332-336.

[31] C. Blackwell, R. Patton, Aluminum-27 and phosphorus-31 nuclear magnetic resonance studies of aluminophosphate molecular sieves, American Chemical Society, 88, 25, 1984, 6135-6139.

[32] E.C. Decanio, J.C. Edwards, T.R. Scalzo, D.A. Storm, J.W. Bruno, FT-IR and solidstate NMR investigation of phosphorus promoted hydrotreating catalyst precursors, Journal of Catalysis, 132, 2, 1991, 498-511.

[33] K. Damodaran, J.W. Wiench, S.M. Cabral de Menezes, Y.L. Lam, J. Trébosc, J.-P. Amoureux, M. Pruski, Modification of H-ZSM-5 zeolites with phosphorus. 2. Interaction between phosphorus and aluminum studied by solid-state NMR spectroscopy, Microporous and Mesoporous Materials, 95, 1-3, 2006, 296-305. 
Chapter 6: Synthesis of ITQ-27 (IWV) and UTD-1 (DON)

[34] G. Engelhardt, D. Michel, High-Resolution Solid-State NMR of Silicates and Zeolites, John Wiley \& Sons Inc., 1987.

[35] J. Klinowski, Solid-state NMR studies of molecular sieve catalysts, Chemical Reviews, 91, 7, 1991, 1459-1479.

[36] M. Hunger, E. Brunner, NMR Spectroscopy, in: Characterization I: Molecular Sieves Science and Technology, Springer Berlin Heidelberg, 4, 2004, 201-293.

[37] M. Hunger, Solid-State NMR Spectroscopy, in: Zeolite Characterization and Catalysis: A Tutorial, Springer Netherlands, 2009, 65-105.

[38] C.A. Fyfe, J.L. Bretherton, L.Y. Lam, Solid-state NMR detection, characterization, and quantification of the multiple aluminum environments in US-Y catalysts by ${ }^{27} \mathrm{Al}$ MAS and MQMAS experiments at very high field, Journal of the American Chemical Society, 123, 22, 2001, 5285-5291.

[39] J.Z. Hu, X. Zhang, N.R. Jaegers, C. Wan, T.R. Graham, M. Hu, C.I. Pearce, A.R. Felmy, S.B. Clark, K.M. Rosso, Transitions in Al coordination during gibbsite crystallization using high-field ${ }^{27} \mathrm{Al}$ and ${ }^{23} \mathrm{Na}$ MAS NMR spectroscopy, The Journal of Physical Chemistry C, 121, 49, 2017, 27555-27562.

[40] D.R. Neuville, L. Cormier, D. Massiot, Al environment in tectosilicate and peraluminous glasses: A ${ }^{27} \mathrm{Al}$ MQ-MAS NMR, Raman, and XANES investigation, Geochimica et Cosmochimica Acta, 68, 24, 2004, 5071-5079.

[41] R. Millini, G. Perego, G. Bellussi, Synthesis and characterization of boron-containing molecular sieves, Topics in Catalysis, 9, 1-2, 1999, 13-34.

[42] S.-J. Hwang, C.-Y. Chen, S.I. Zones, Boron sites in borosilicate zeolites at various stages of hydration studied by solid state NMR spectroscopy, The Journal of Physical Chemistry B, 108, 48, 2004, 18535-18546.

[43] C. Fild, D.F. Shantz, R.F. Lobo, H. Koller, Cation-induced transformation of boroncoordination in zeolites, Physical Chemistry Chemical Physics, 2, 13, 2000, 3091-3098.

[44] A. Pulido, G. Sastre, A. Corma, Computational Study of ${ }^{19}$ F NMR Spectra of Double Four Ring-Containing Si/Ge-Zeolites, ChemPhysChem, 7, 5, 2006, 1092-1099.

[45] J.A. Vidal-Moya, T. Blasco, F. Rey, A. Corma, M. Puche, Distribution of Fluorine and Germanium in a New Zeolite Structure ITQ-13 Studied by ${ }^{19} \mathrm{~F}$ Nuclear Magnetic Resonance, Chemistry of Materials, 15, 21, 2003, 3961-3963.

[46] Z.H. Gao, F.J. Chen, L. Xu, L. Sun, Y. Xu, H.B. Du, A Stable Extra-Large-Pore Zeolite with Intersecting 14-and 10-Membered-Ring Channels, Chemistry-A European Journal, 22, 40, 2016, 14367-14372. 
[47] K. Balkus, A. Gabrielov, S. Zones, The synthesis of UTD-1, Ti-UTD-1 and Ti-UTD-8 using $\mathrm{CP}_{2} \mathrm{CoOH}$ as a structure directing agent, Studies in Surface Science and Catalysis, 97, 1995, 519-525.

[48] K.J. Balkus Jr, A.K. Khanmamedova, Oxidations catalyzed by zeolite Ti-UTD-1, in: Studies in Surface Science and Catalysis, Elsevier, 110, 1997, 1007-1014.

[49] R. Simancas, Síntesis de Nuevos Materiales Zeolíticos empleando Agente Directores de Estructura Fosforados, Universitat Politècnica de València, 2015.

[50] W.-W. Zi, Z. Gao, J. Zhang, J.-H. Lv, B.-X. Zhao, Y.-F. Jiang, H.-B. Du, F.-J. Chen, Designed synthesis of an extra-large pore zeolite with a 14-membered ring channel via supramolecular assembly templating approach, Microporous and Mesoporous Materials, 290, 2019, 109654.

[51] J. Martinez-Triguero, M. Diaz-Cabanas, M. Camblor, V. Fornes, T.L. Maesen, A. Corma, The catalytic performance of 14-membered ring zeolites, Journal of Catalysis, 182, 2, 1999, 463-469. 


\section{Chapter 7}

\section{Synthesis of New Zeolite}

\section{Materials}

\subsection{Introduction}

The synthesis of new zeolites is usually linked with the use of new organic structure directing agents (OSDA's). The chemical nature of these OSDA's is varied, being the ammonium cations the most widely used for this purpose. However, in last years, several OSDA's with different chemical natures have been introduced, like phosphonium or sulfonium cations, ionic liquids, metallic complexes, etc. ${ }^{[1-4]}$

In recent years, several zeolites had been successfully synthesized using phosphorus containing OSDA's. ${ }^{[5]}$ This approach has been very successful, allowing to obtaining a number of new zeolite structures, like ITQ-26, ${ }^{[6]}$ ITQ-27, ${ }^{[7]}$ ITQ-34, ${ }^{[8]}$ ITQ-40, ${ }^{[9]}$ ITQ-45, ${ }^{[10]}$ ITQ-49, ${ }^{[11]}$ ITQ-52, ${ }^{[12]}$ ITQ-53 ${ }^{[13]}$ and ITQ-58 ${ }^{[14]}$ zeolite up to date. Also, several known zeolites have been obtained with broader chemical compositions, like UTD-1 ${ }^{[15]}$, ITQ- $47^{[16]}$ or RTH. ${ }^{[17]}$

Also, the employ of P-containing OSDA's has been found as a suitable technique for incorporating extra-framework phosphorous species in small pore zeolites and thus 
modifying the textural and acid properties of the resulting material, as discussed in section 5.2.3. ${ }^{[18-20]}$ Furthermore, the incorporation of phosphorous OSDA's allows to track the phosphorus nuclei by MAS-NMR techniques, which makes phosphorus an extremely useful probe atom for the characterization of entrapped OSDA's inside of zeolites, together with other characterization techniques. ${ }^{[17]}$ The latter feature is especially interesting as it allows to study the host-guest interaction between the OSDA and the zeolite framework. ${ }^{[1-24]}$

In this chapter, the synthesis and the structure of two new zeolite structures are described. The first zeolite was named ITQ-58, and was obtained using three different novel phosphorous OSDA's. The second zeolite was named ITQ-66, and was obtained using a phosphonium-OSDA.

\subsection{ITQ-58 zeolite}

The ITQ-58 zeolite was firstly detected as an impurity during the synthesis of the zeolite ITQ-52 (IFW). ${ }^{[12]}$

\subsubsection{Previous work: aminophosphonium OSDA}

The ITQ-58 zeolite was first obtained using the butane-1,4-diylbis[tris (dimethylamino)phosphonium] cation (PN-PN) as OSDA, shown in Figure 7.1.

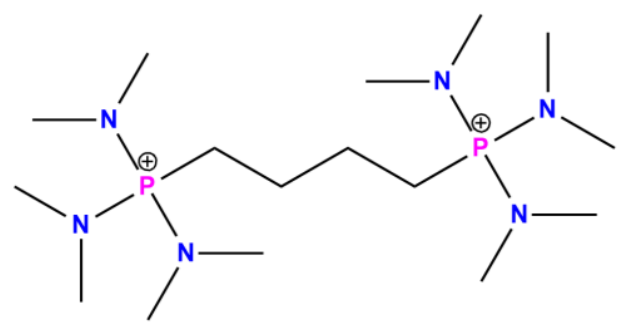

Figure 7.1. Butane-1,4-diylbis[tris(dimethylamino)phosphonium] cation (PN-PN). 
After the detection of the ITQ-58 zeolite, the synthesis conditions were refined to obtain the pure ITQ-58. The synthesis gels conditions leading to the ITQ-58 were deeply discussed in Simancas, $R$., 2015, ${ }^{[15]}$ while in this thesis only the samples and conditions leading to the elucidation of the ITQ-58 structure are included.

\subsubsection{Synthesis conditions}

The butane-1,4-diylbis[tris(dimethylamino)phosphonium] hydroxide (PN-PN), or OSDA-8, was tested as OSDA in a wide range of synthesis conditions, summarized in Table 7.1. The detailed synthesis of the OSDA-8 is described in section 3.2.1.8.

Table 7.1. Tested synthesis conditions and phase selectivity obtained using butane - 1,4diylbis[tris(dimethylamino)phosphonium] (PN-PN) hydroxide as OSDA.

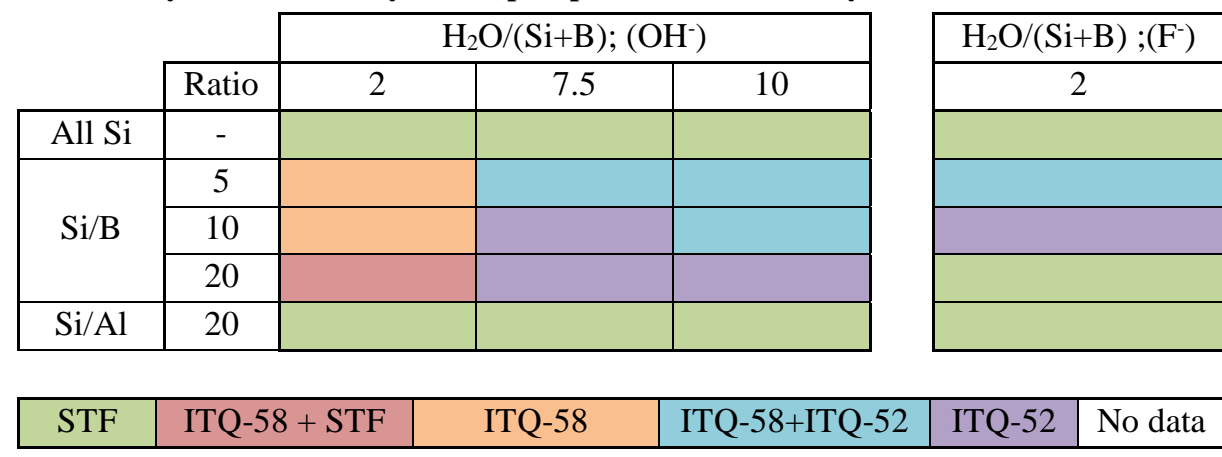

The zeolite ITQ-58 crystallizes in a narrow range of compositions and it competes with impurities of ITQ-52 and STF zeolites. The ITQ-58 was only obtained with high boron contents $(\mathrm{Si} / \mathrm{B}<12)$ and in highly concentrated syntheses gels $\left(\mathrm{H}_{2} \mathrm{O} / \mathrm{Si}<5\right)$. The detailed synthesis of the PN-PN ITQ-58 is described in section 3.2.2.6.

The purity of the as-made samples was studied by powder X-Ray diffraction, whose patterns are shown in Figure 7.2. 


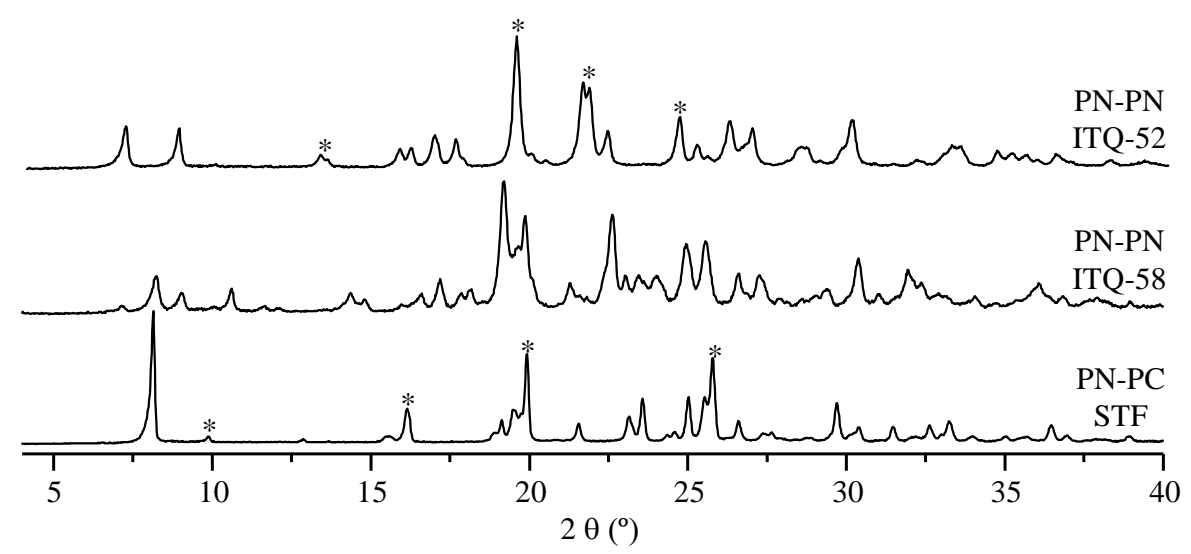

Figure 7.2. Powder X-Ray diffraction patterns of the ITQ-58 zeolite obtained with the PN-PN OSDA (middle), compared with the powder X-Ray diffraction patterns of zeolite

ITQ-52 (above) and zeolite STF (below). Asterisk marks the characteristic peaks of the STF and ITQ-52 zeolites.

At first sight, when comparing the powder X-Ray diffraction pattern of the ITQ-58 zeolite with other zeolites obtained with the same OSDA, like the ITQ-52 and STF zeolites, it could be seen that there are several overlapped diffraction peaks. However, taking a closer look to some regions in the diffraction pattern, some differences arise, as there are some diffraction peaks, as well as the absence of others, that confirms the presence of impurities. First, diffraction peaks appear in regions where no ITQ-52 or STF diffraction peaks appear, being the most easily identifiable peaks at $10.6^{\circ}, 18.2^{\circ}$ and $20.1^{\circ} 2 \theta$ degrees. The presence of these peaks was the first hint about the presence of a new crystalline phase. Also, there are some $2 \theta$ values at which we should expect peaks if there were impurities of ITQ-52 or STF zeolites. The absence of diffraction peaks at $16.1^{\circ}$ and $25.8^{\circ} 2 \theta$ suggest that there are no STF impurities. In the same line, the absence of the peak at $24.6^{\circ}$ and the double peaks at $13.3^{\circ}-13.5^{\circ}$ and $21.6^{\circ}-21.7^{\circ} 2 \theta$ values, indicates that there are no ITQ-52 impurities.

\subsubsection{PN-PN ITQ-58 chemical analyses}

The typical chemical composition of the as-made ITQ-58 obtained using the PN-PN OSDA, as well as the chemical compositions of the thermally treated under air and under hydrogen at high temperature ITQ-58 samples, are shown in Table 7.2. 
Chapter 7: Synthesis of New Zeolite Materials

Table 7.2. Chemical analyses of the as-made, calcined and hydrogenated at high temperature PN-PN ITQ-58 zeolite. All ratios are given as molar ratios.

\begin{tabular}{cccccc}
\hline Sample & Treatment & $\mathrm{Si} / \mathrm{B}$ & wt \%P & $(\mathrm{Si}+\mathrm{B}) / \mathrm{P}$ & $\mathrm{P} / \mathrm{B}$ \\
\hline ITQ-58 & As-made & 11.8 & 2.8 & 14.3 & 0.8 \\
ITQ-58-cal & Calcination & 11.6 & 2.8 & 14.3 & 0.8 \\
ITQ-58-hyd & Hydrogenation & 11.1 & 1.7 & 25.0 & 0.4 \\
\hline
\end{tabular}

Chemical analysis of the as-made ITQ-58 sample gave a $\mathrm{Si} / \mathrm{B}$ ratio of 11.8 , much higher than the synthesis gel composition $(\mathrm{Si} / \mathrm{B}=5)$, and a $(\mathrm{Si}+\mathrm{B}) / \mathrm{P}$ ratio of 14.3 . The elemental analyses show a N/P ratio of 3.2 and a $\mathrm{C} / \mathrm{P}$ ratio of 9.1 , which are close to that of the pure OSDA ( 3 and 8 , respectively). This indicates that the OSDA incorporated in the solid remains intact inside the channels filling the pores. The $\mathrm{P} / \mathrm{B}$ ratio of the as-made ITQ-58 is 0.8 , indicating that most of the OSDA is compensating the negatively charged borosilicate framework.

Chemical analyses of the zeolite thermally treated under air and under $\mathrm{H}_{2} / \mathrm{N}_{2}$ show a $\mathrm{Si} / \mathrm{B}$ ratio around 11 , very close to that obtained in the as-made ITQ-58. On the other hand, ITQ-58 treated under air and under $\mathrm{H}_{2} / \mathrm{N}_{2}$ gives a $(\mathrm{Si}+\mathrm{B}) / \mathrm{P}$ ratio of 14.3 and 25 , respectively, and thus, two ITQ-58 samples with different phosphorus content were obtained.

\subsubsection{Morphology of PN-PN ITQ-58 zeolite}

The crystallite shape and size of the PN-PN ITQ-58 samples were studied by SEM microscopy, depicted in Figure 7.3.

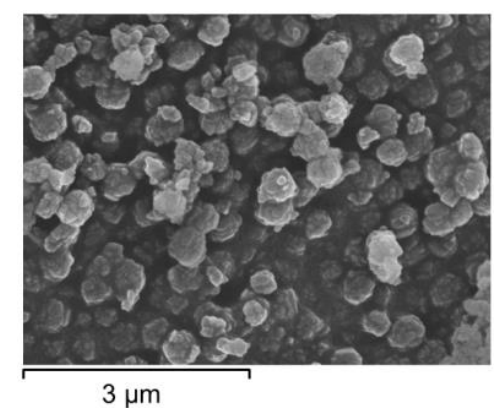

Figure 7.3. SEM microimage of the as-made PN-PN ITQ-58 zeolite. 
The PN-PN ITQ-58 zeolite was obtained as plate-like crystallites with a nonhomogeneous crystal size distribution. Average crystal size ranges from $0.1 \times 0.2 \mu \mathrm{m}$ to 0.3 $\mathrm{x} 0.5 \mu \mathrm{m}$. Crystals show a minor tendency to aggregation, forming aggregates by stacking of crystals sharing the planar face, and building aggregates of roughly spherical shape.

\subsubsection{Thermogravimetric analysis of the PN-PN ITQ-58 zeolite}

Thermogravimetric analyses revealed a weight loss of $11.1 \mathrm{wt} . \%$ centred at $\sim 600^{\circ} \mathrm{C}$, and the sample continues losing weight until $750^{\circ} \mathrm{C}$. The high temperature required for the total OSDA decomposition is similar to the P-OSDA RTH zeolite as seen in section 5.2.2.3, which initially suggested that this zeolite had a small-pore structure.

The as-made ITQ-58 was thermally treated by the general methodologies described in the section 3.2 .5 .3 , but the temperature of the thermal treatments was lowered to $600^{\circ} \mathrm{C}$, to avoid the melting and/or amorphization of the material because of the high concentration of boron in its composition.

\subsubsection{Structural resolution attempts}

The elucidation of the PN-PN ITQ-58 structure was tried using two different methodologies. First, the structure solution was attempted using direct methods as implemented in the program Sir2014, without success. ${ }^{[25]}$ At that point, the structure of the zeolite ITQ-58 was studied through EDT (see section 3.1.7.4). However, the sample was still very sensitive to radiation damage and suffered a severe amorphization after less than five minutes under the electron beam. Also, because of the rotation of the sample, it was difficult at first to keep the electron beam over the sample because of the small size of the PN-PN ITQ-58 crystallites.

Two ways of action were proposed in order to elucidate the structure of the ITQ-58: decreasing the time for the data collection to minimize the amorphization of the samples; and synthesize ITQ-58 samples of larger crystallite size to increase the stability of the sample under the electron beam and facilitate the measure of the sample under continuous tilting. The first step was to increase the stability of the samples to facilitate the data collection of the EDT technique. One of the typical ways to get crystallites of large sizes is the use of fluoride synthesis gels. Although ITQ-58 was successfully obtained with the PN-PN OSDA in fluoride media, the crystallite sizes of these samples were still too small for EDT. ${ }^{[15]}$ 


\subsubsection{Phosphonium cation OSDA}

Due to the difficulties that arose trying to elucidate the ITQ-58 structure, another phosphorous OSDA was proposed. This new OSDA was selected as the phosphonium analogue of the used in the previous section, the butane-1,4-diylbis(triisopropylphosphonium) cation (PC-PC), shown in Figure 7.4.

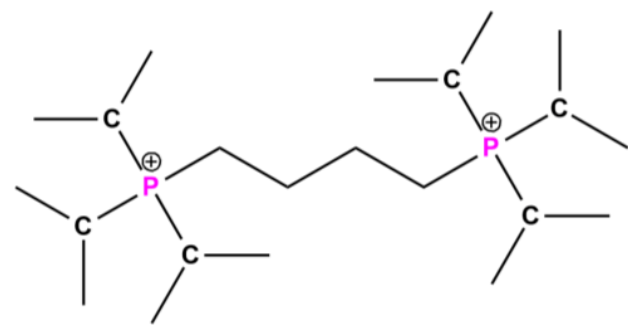

Figure 7.4. Butane-1,4-diylbis(triisopropylphosphonium) cation (PC-PC).

The election of this OSDA was made taking in account the results obtained in section 4.3, as for isochemical structural OSDA's, the phosphonium cations tend to be more stable and selective for zeolite crystallization under fluoride media. The synthesis of this OSDA and some materials obtained using it were described in a previous thesis, although the full study of synthesis conditions for obtaining the pure ITQ-58 zeolite were not attempted before. ${ }^{[26]}$

\subsubsection{Synthesis}

The butane-1,4-diylbis(triisopropylphosphonium) hydroxide (PC-PC), or OSDA-9, was tested as OSDA in a wide range of synthesis conditions, summarized in Table 7.3. The detailed synthesis of the OSDA-9 is described in section 3.2.1.9. 
Table 7.3. Tested synthesis conditions and phase selectivity obtained using butane-1,4diylbis(triisopropylphosphonium) (PC-PC) hydroxide as OSDA.

\begin{tabular}{|c|c|c|c|c|}
\hline & & \multicolumn{3}{|c|}{$\mathrm{H}_{2} \mathrm{O} /(\mathrm{Si}+\mathrm{B}+\mathrm{Al}+\mathrm{Ge}) ;\left(\mathrm{F}^{-}\right)$} \\
\hline & Ratio & 5 & 7.5 & 10 \\
\hline \multicolumn{5}{|l|}{ All Si } \\
\hline \multirow{3}{*}{$\mathrm{Si} / \mathrm{B}$} & 5 & & & \\
\hline & 10 & & & \\
\hline & 20 & & & \\
\hline $\mathrm{Si} / \mathrm{Al}$ & All & & & \\
\hline $\mathrm{Si} / \mathrm{Ge}$ & All & & & \\
\hline
\end{tabular}

\begin{tabular}{|c|c|c|c|c|c|}
\hline STF & ITQ-58 + STF & ITQ-58* & ITQ-58 + ITQ-52 & ITQ-52 & No data \\
\hline
\end{tabular}

*: Almost pure ITQ-58

The zeolite ITQ-58 was only obtained with minor ITQ-52 and STF impurities in a narrow range of compositions. All syntheses were carried out in fluoride media, as it usually helps to get large crystals with low defects, especially when employing phosphonium cations. Interestingly, ITQ-58 was only obtained in the presence of lower boron contents and more diluted syntheses gels than those used by applying the PN-PN OSDA as discussed in section 7.2.1.1.

The purity of the as-made samples was studied by powder X-Ray diffraction, whose patterns are shown in Figure 7.5. 


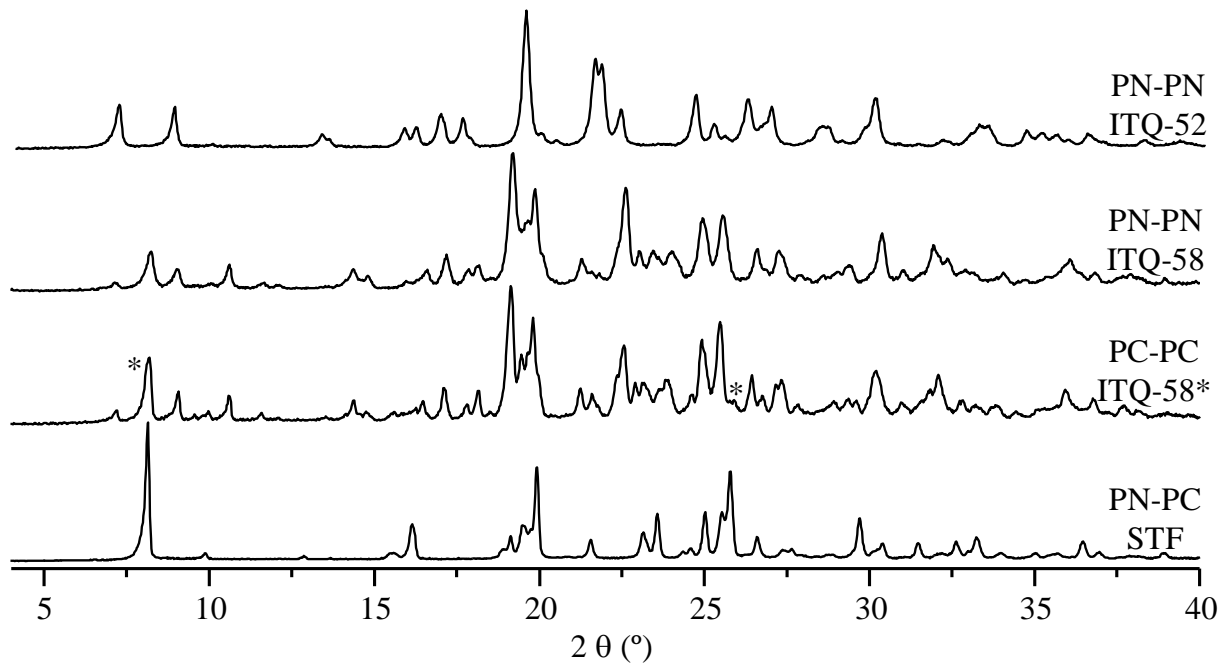

Figure 7.5. Powder X-Ray diffraction pattern of the ITQ-58* zeolite obtained with the PC-PC OSDA (low middle), compared with the powder X-Ray diffraction patterns of PN-PN ITQ-58

zeolite (up middle), ITQ-52 zeolite (above) and STF zeolite (below). Asterisks mark the characteristic peaks belonging to STF zeolite in the PC-PC ITQ-58 sample.

It could be seen that the PC-PC ITQ-58* presents the same X-Ray diffraction profile than the PN-PN ITQ-58, but additional peaks were found at $8.1^{\circ}$ (as a shoulder peak of $8.2^{\circ}$ ) and at $25.8^{\circ}$, which indicates that the sample presents impurities of STF zeolite.

\subsubsection{PC-PC ITQ-58 chemical analyses}

The chemical composition of the as-made ITQ-58 with small impurities of STF zeolite obtained with the PC-PC OSDA (ITQ-58*) is shown in Table 7.4.

Table 7.4. Chemical analysis of the as-made PC-PC ITQ-58* zeolite. All ratios are given as molar ratios.

\begin{tabular}{cccccc}
\hline Sample & Treatment & $\mathrm{Si} / \mathrm{B}$ & wt.\%P & $(\mathrm{Si}+\mathrm{B}) / \mathrm{P}$ & $\mathrm{P} / \mathrm{B}$ \\
\hline ITQ-58* & As-made & 18.3 & 2.8 & 15.0 & 1.3 \\
\hline
\end{tabular}

Chemical analyses of the ITQ-58* sample gave a Si/B ratio of 18.3 , similar to the synthesis gel composition $(\mathrm{Si} / \mathrm{B}=20)$, and a $(\mathrm{Si}+\mathrm{B}) / \mathrm{P}$ ratio of 15.0 . Elemental analyses show a $\mathrm{C} / \mathrm{P}$ ratio of 11.3 , which is very close to that of the pure OSDA (11.0). This suggests that the OSDA does not decompose during zeolite crystallization and remains inside the channels filling the pores. The P/B ratio of the as-made ITQ-58* is 1.3 , indicating that the OSDA is 
over-compensating the negatively charged borosilicate framework. This could be explained by the incorporation of fluoride anions into the framework of the zeolite, which would also compensate for the positively charged OSDA cation. Further analyses of samples calcined and treated under hydrogen at high temperature were not performed because of the small impurity detected by XRD.

The crystallite shape and size of the PN-PN and PC-PC ITQ-58 samples were studied by FESEM microscopy analyses, depicted in Figure 7.6.

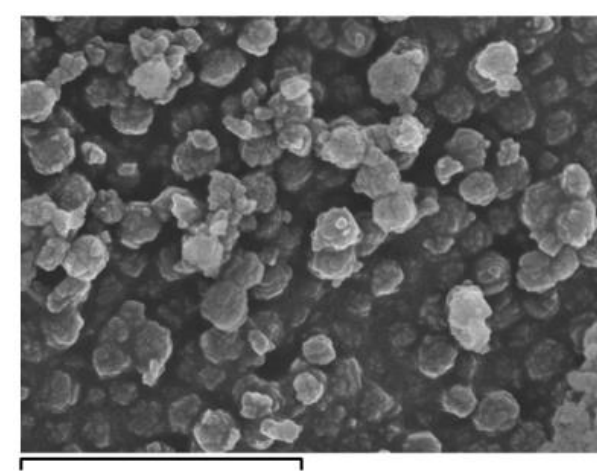

$3 \mu \mathrm{m}$

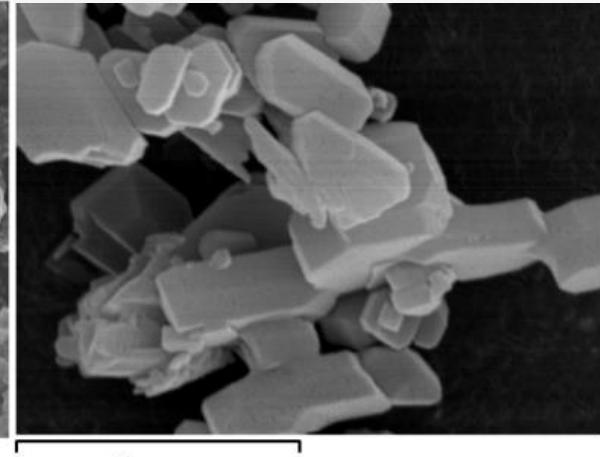

$3 \mu \mathrm{m}$

Figure 7.6. Scanning electron microscopy (SEM) microimages of as-made PN-PN ITQ-58 zeolite (left) and as-made PC-PC ITQ-58* zeolite with slight STF impurities (right).

The PC-PC ITQ-58* zeolite was obtained with a non-homogeneous crystal size distribution. The PC-PC ITQ-58* crystals were significantly larger than the ones found in PN-PN ITQ-58, and the shape is more elongated. Indeed, average crystal size ranges from $0.5 \times 1 \mu \mathrm{m}$ to $1 \times 2 \mu \mathrm{m}$. STF zeolite impurities were impossible to identify in this sample, either due to the low number of STF crystallites in the sample, or due to the STF zeolite presenting a similar morphology than the ITQ-58 zeolite.

Because of the presence of impurities in the PC-PC ITQ-58* samples, no further analyses on this samples were performed at first, and therefore, no thermal treatments, textural properties nor MAS-NMR measures were measured. 


\subsubsection{Phosphonium-aminophosphonium OSDA}

After the results obtained with the phosphonium cation, a final conclusion was established: it was possible to obtaining the ITQ-58 zeolite in fluoride media with larger crystallites sizes, but the phase selectivity affinity was higher for the aminophosphonium cation than the phosphonium cation. As OSDA's leading to ITQ-58 zeolite are diquaternary, a mixed phosphonium and aminophosphonium cation was proposed, trying to combine the advantages of both OSDA's. After a first unsuccessfully trial with the isochemical structures of the PN-PN and PC-PC cations to obtain the ITQ-58 zeolite (in all cases under any synthesis condition the STF zeolite was the only product), a change of the phosphonium "head" was tested. Thus, the synthesis of ITQ-58 zeolite using the tris(dimethylamino) [4-(tri-tertbutylphosphonio) butyl] phosphonium cation (PN-PC) as OSDA, shown in Figure 7.7, will be next described.

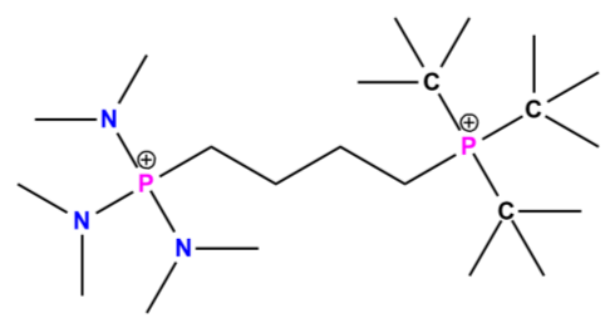

Figure 7.7. Tris(dimethylamino) [4-(tri-tert-butylphosphonio) butyl] phosphonium cation (PN-PC).

\subsubsection{Synthesis}

The tris(dimethylamino)[4-(tri-tert-butylphosphonio)butyl]phosphonium hydroxide (PN-PC), or OSDA-10, was tested as OSDA in a sharp range of synthesis conditions, summarized in Table 7.5, based on the results shown in sections 7.2.1 and 7.2.2. The detailed synthesis of the OSDA-10 is described in section 3.2.2.6. In the synthesis conditions used here, the zeolite ITQ-58 strongly competes with the ITQ-52 zeolite, which is often obtained as impurity, especially in syntheses gels of the highest boron content $(\mathrm{Si} / \mathrm{B}=20)$. 
Table 7.5. Tested synthesis conditions and phase selectivity obtained using tri-tert-butyl (4- (tris (dimethylamino) phosphonio) butyl) phosphonium (PN-PC) hydroxide as OSDA.

\begin{tabular}{|c|c|c|c|c|}
\cline { 3 - 5 } \multicolumn{1}{c|}{} & \multicolumn{3}{c|}{$\mathrm{H}_{2} \mathrm{O} /(\mathrm{Si}+\mathrm{B}) ;\left(\mathrm{OH}^{-}\right)$} \\
\cline { 2 - 5 } \multicolumn{1}{c|}{} & Ratio & 2 & 7.5 & 10 \\
\hline \multirow{3}{*}{$\mathrm{Si} / \mathrm{B}$} & 5 & & & \\
& 10 & & & \\
& 20 & & & \\
\cline { 2 - 5 } & 20 & & & \\
\hline
\end{tabular}

\begin{tabular}{|c|c|c|}
\hline \multicolumn{3}{|c|}{$\mathrm{H}_{2} \mathrm{O} /(\mathrm{Si}+\mathrm{B}) ;\left(\mathrm{F}^{-}\right)$} \\
\hline 2 & 7.5 & 10 \\
\hline & & \\
\hline & \multicolumn{2}{|l|}{} \\
\hline & & \\
\hline
\end{tabular}

\begin{tabular}{|l|l|l|l|}
\hline ITQ-58 & ITQ-58+ ITQ-52 & Amorphous & No data \\
\hline
\end{tabular}

The purity of the as-made samples was studied by powder X-Ray diffraction, whose patterns are shown in Figure 7.8.

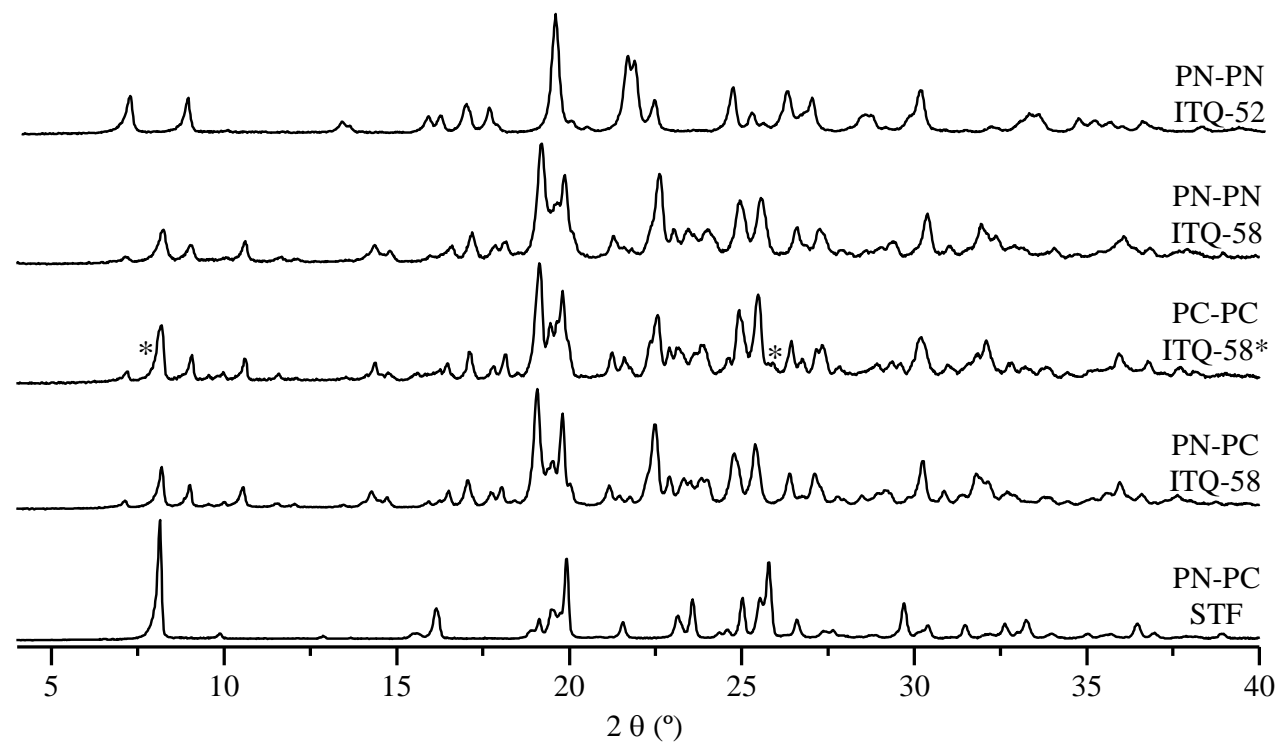

Figure 7.8. Powder X-Ray diffraction pattern of the ITQ-58 zeolite obtained with the PN-PC OSDA (middle), compared with the powder X-Ray diffraction patterns of zeolite PN-PN ITQ-58 zeolite (up middle), PC-PC ITQ-58* zeolite (low middle), ITQ-52 zeolite (above) and STF zeolite (below). Asterisks mark the characteristic peaks belonging to STF zeolite in the PC-PC ITQ-58 sample.

As previously, the diffraction pattern of the as-made PN-PC ITQ-58 is compared with its typical impurities, ITQ-52 and STF zeolites, and the as-made PN-PN and PC-PC ITQ-58 zeolites. Firstly, it could be seen that no STF impurities were found as the lack of the 
Chapter 7: Synthesis of New Zeolite Materials

diffraction peak at $16.1^{\circ}$ and the shoulder at $8.2^{\circ}$ indicates, both of them easily identifiable in the PC-PC ITQ-58. Also, ITQ-52 zeolite was also disregarded as impurity due to the lack of the diffraction peak at $24.6^{\circ}$ and the twin peaks at $13.3^{\circ}-13.5^{\circ}$ and $21.6^{\circ}-21.7^{\circ}$.

The diffraction pattern of the PN-PC ITQ-58 is better resolved than the previously obtained PN-PN ITQ-58, as several overlapped peaks are now resolved into discrete diffraction peaks. Because of that, the elucidation of the crystalline structure was expected to be achievable using this new ITQ-58 sample.

\subsubsection{PN-PC ITQ-58 chemical analyses}

The typical chemical composition of the as-made ITQ-58 obtained using the PN-PC OSDA, as well as the chemical compositions of the calcined and hydrogenated at high temperature ITQ-58 samples, are shown in Table 7.6.

Table 7.6. Chemical analyses of the as-made, calcined and hydrogenated at high temperature PN-PC ITQ-58 zeolite. All ratios are given as molar ratios.

\begin{tabular}{cccccc}
\hline Sample & Treatment & $\mathrm{Si} / \mathrm{B}$ & wt.\%P & $(\mathrm{Si}+\mathrm{B}) / \mathrm{P}$ & $\mathrm{P} / \mathrm{B}$ \\
\hline ITQ-58 & As-made & 16.4 & 2.58 & 15.8 & 1.1 \\
ITQ-58-cal & Calcination & 17.4 & 2.53 & 17.1 & 1.1 \\
ITQ-58-hyd & Hydrogenation & 16.2 & 1.21 & 37.3 & 0.5 \\
\hline
\end{tabular}

Chemical analyses of the ITQ-58 sample gave a $\mathrm{Si} / \mathrm{B}$ ratio of 16.4 , higher than the synthesis gel composition $(\mathrm{Si} / \mathrm{B}=10)$, and $\mathrm{a}(\mathrm{Si}+\mathrm{B}) / \mathrm{P}$ ratio of 15.8 , following the same trend of heteroatom incorporation than that observed for the PN-PN ITQ-58, but with boron contents values in between those found for PN-PN ITQ-58 and PC-PC ITQ-58 samples.

Elemental analyses show a N/P ratio of 1.9 and a C/P ratio of 11.4 , which are close to that of the pure OSDA (1.5 and 11, respectively). This suggests that most of the OSDA remains intact during zeolite crystallization and remains inside the channels filling the pores. As in previous samples, the $\mathrm{P} / \mathrm{B}$ ratio of the as-made ITQ-58 is 1.1 indicating that the OSDA is compensating the negatively charged borosilicate framework.

The chemical analyses of the calcined and hydrogenated at high temperature ITQ-58 samples show a $\mathrm{Si} / \mathrm{B}$ ratio of 17.4 and 16.1 , respectively, which are very close to the parent as-made ITQ-58 material, which confirms that boron remains in the solid during the thermal treatment. On the other hand, the calcined and hydrogenated at high temperature ITQ-58 
materials give a $(\mathrm{Si}+\mathrm{B}) / \mathrm{P}$ ratio of 17.1 and 36.3 , respectively, and thus, two ITQ-58 samples with different phosphorus contents were obtained, with $\mathrm{P} / \mathrm{B}$ ratios of 1.1 and 0.5 , respectively.

\subsubsection{Morphology of PN-PC ITQ-58 zeolite}

The crystallite shape and size of the PN-PC ITQ-58 samples were studied by SEM microscopy analysis, depicted in Figure 7.9.

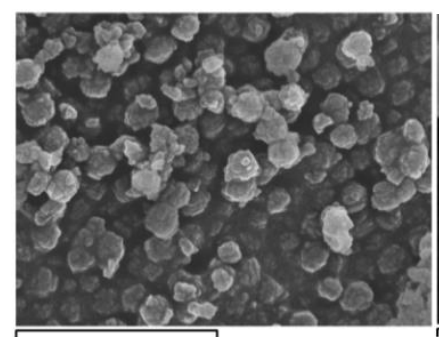

$3 \mu \mathrm{m}$

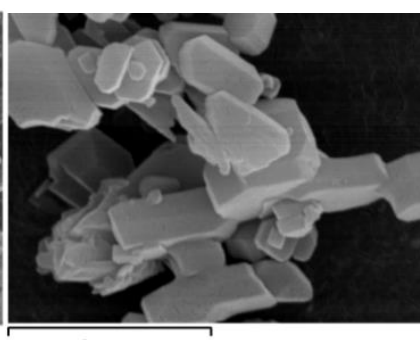

$3 \mu \mathrm{m}$

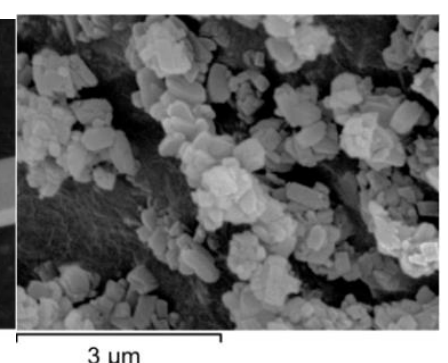

$3 \mu \mathrm{m}$

Figure 7.9. SEM microimages of as-made PN-PN ITQ-58 zeolite (left), as-made PC-PC ITQ-58* zeolite with slight STF impurities (middle), and as-made PN-PC ITQ-58 zeolite (right).

The zeolite PN-PC ITQ-58 was obtained as plate-like crystallites with an almost homogeneous crystal size distribution, with an average crystal size ranging from $0.5 \times 0.5 \mu \mathrm{m}$ to $1 \mathrm{x} 2 \mu \mathrm{m}$. The PN-PC ITQ-58 crystals shape was more alike to the found in PN-PN ITQ-58 and, although not so large than the obtained for PC-PC ITQ-58, they are significantly larger than the obtained in the PN-PN ITQ-58 material.

\subsubsection{Thermogravimetric analysis of the PN-PC ITQ-58 zeolite}

The thermal stability and decomposition of the OSDA were studied by thermogravimetry (TG) and differential thermogravimetry (DTG) analyses of the ITQ-58 samples. Some thermogravimetric plots are shown in Figure 7.10. 


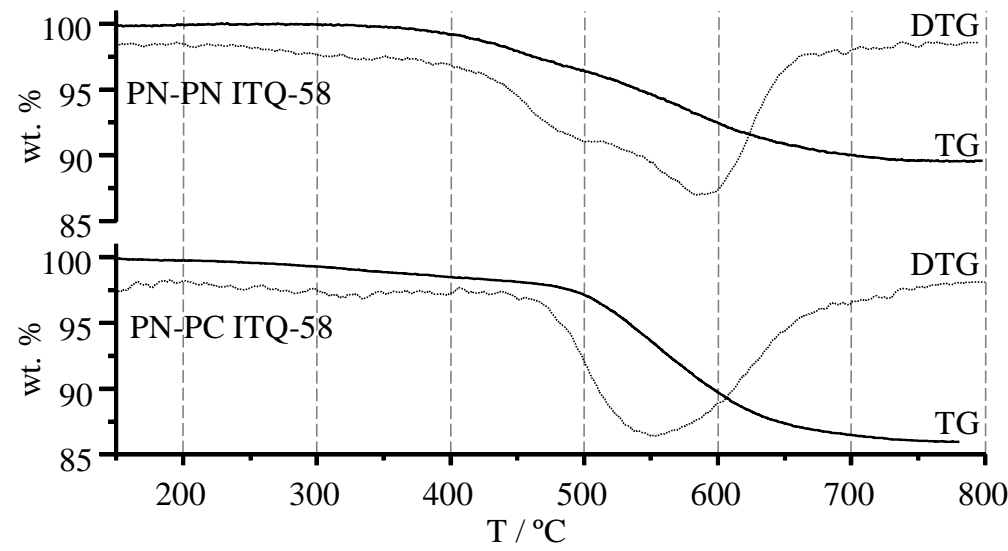

Figure 7.10. TG (solid lines) and DTG (dotted lines) analyses curves of PN-PN and PN-PC ITQ-58 zeolite samples. DTG curves are scaled up for a better view.

The thermogravimetric analyses reveal a variable weight loss centred at $\sim 550^{\circ} \mathrm{C}$ and the sample continues losing weight until $750^{\circ} \mathrm{C}$. The PN-PC ITQ-58 present a higher weight loss of 14.3 wt.\% compared with the 11.1 wt.\% weight loss from the PN-PN ITQ-58. This difference is explained by the higher molecular weight of the PN-PC OSDA compared with the PN-PN OSDA.

The required temperature for the starting decomposition of the PN-PC OSDA was slightly higher, $475^{\circ} \mathrm{C}$, than the found for the PN-PN OSDA, $400^{\circ} \mathrm{C}$. This results could indicate that the OSDA guest-host zeolite interaction could be higher for this PN-PC OSDA than for the PN-PN OSDA.

The stability and crystallinity of the PN-PN ITQ-58 sample after thermal treatments were assessed by powder X-Ray diffraction, whose patterns are shown in Figure 7.11. 


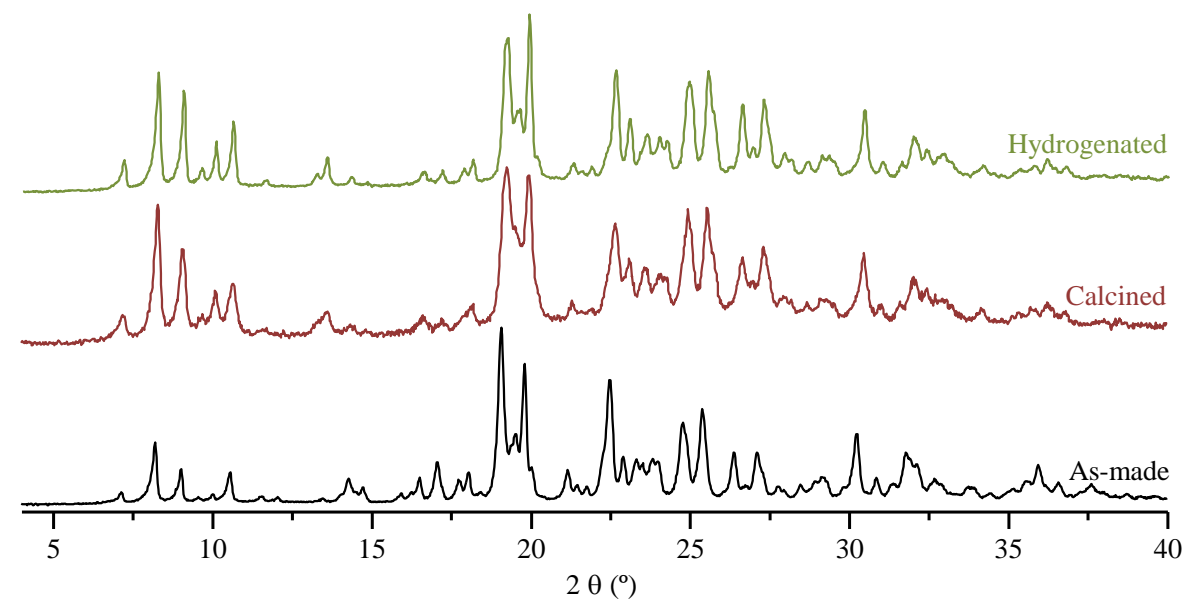

Figure 7.11. Powder X-Ray diffraction patterns of the as-made and the thermally treated PN-PC ITQ-58 materials. Black lines correspond to as-made samples; red lines to calcined samples; green lines to samples hydrogenated at high temperature.

The temperature of the thermal treatments was lowered down to $650^{\circ} \mathrm{C}$ respect to the typical temperatures specified in section 3.2.3. This was done to avoid the melting and/or amorphization of the material because of its high boron content, remaining the materials completely stable after the different thermal treatments.

\subsubsection{NMR analyses of the ITQ-58 zeolite}

The incorporation of the phosphorous OSDA and boron heteroatoms, and the lattice framework were studied by MAS-NMR spectroscopy.

\section{- Incorporation and stability of the OSDA into the ITQ-58}

The stability of the OSDA incorporated to the ITQ-58 zeolite was studied by ${ }^{13} \mathrm{C}$ MAS-NMR and ${ }^{31} \mathrm{P}$ MAS-NMR spectroscopies, comparing these spectra with the liquid ${ }^{13} \mathrm{C}$ NMR and ${ }^{31} \mathrm{P}$ NMR of the free P-OSDA, whose spectra are shown in Figure 7.12. 


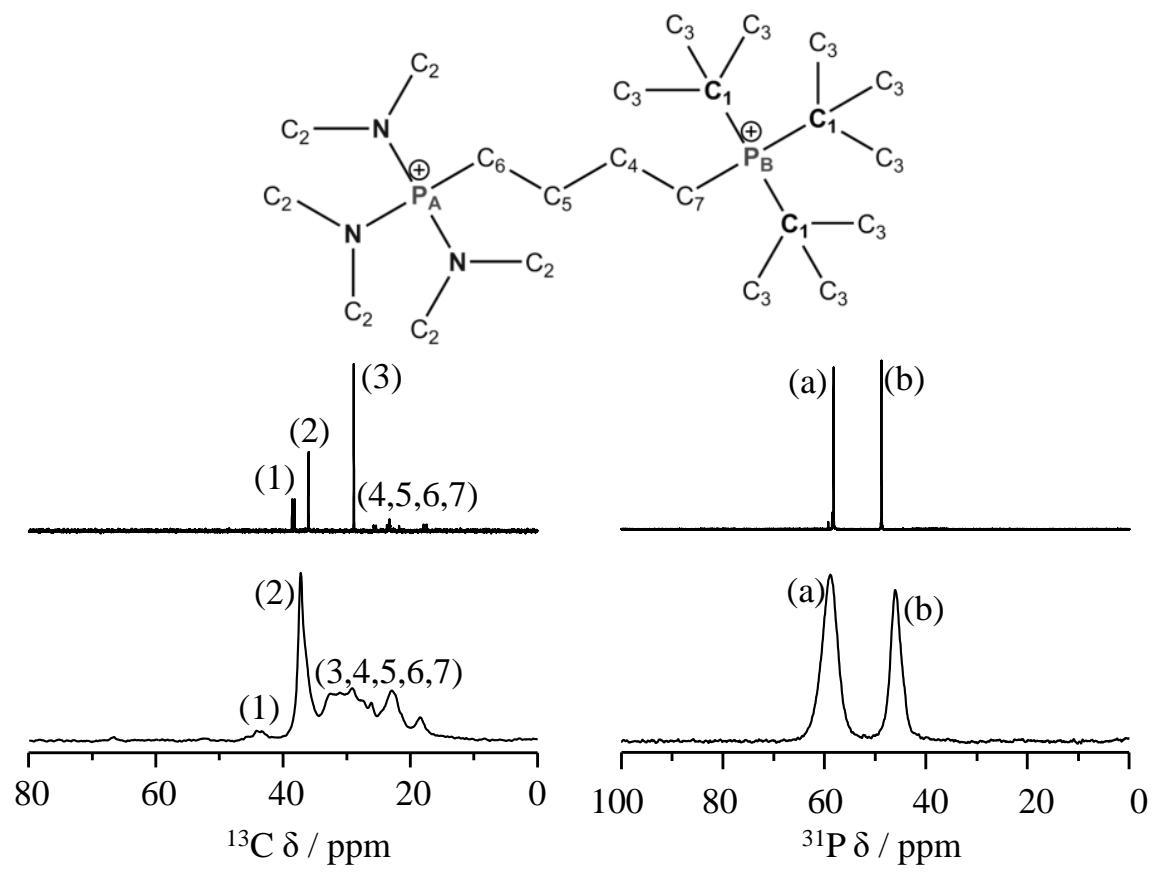

Figure 7.12. Top: schematic view of PN-PC cation. Left: liquid ${ }^{13} \mathrm{C}$ NMR spectrum of the OSDA in deuterated water (top) and solid ${ }^{13} \mathrm{C}$ MAS-NMR spectrum of the as-made ITQ-58 (bottom).

Right: liquid ${ }^{31} \mathrm{P}$ NMR spectrum of the pure OSDA in deuterated water (top) and solid ${ }^{31} \mathrm{P}$ MAS-NMR spectrum of the as-made ITQ-58 (bottom).

The ${ }^{13} \mathrm{C}$ MAS-NMR spectrum of the as-made ITQ-58 zeolite present several overlapped resonances that difficult their assignation. In general, the as-made ITQ-58 present a ${ }^{13} \mathrm{C}$ resonance profile similar to the PN-PC OSDA in solution, although slightly shifted down-field.

The ${ }^{31} \mathrm{P}$ MAS-NMR spectrum of the as-made ITQ-58 zeolite shows two resonances at $58.9 \mathrm{ppm}$ and at $46.1 \mathrm{ppm}$ corresponding to the aminophosphonium and phosphonium groups, respectively, and analogues to the resonances of the free OSDA.

The ${ }^{13} \mathrm{C}$ MAS-NMR and ${ }^{31} \mathrm{P}$ MAS-NMR spectra of the as-made ITQ-58 PN-PC, together with the chemical analyses results (see section 7.2.3.2), confirm that the OSDA remains intact during zeolite formation, occupying the voids of the ITQ-58 zeolite. 
- Boron incorporation into the ITQ-58 zeolite

The incorporation of boron in the as-made ITQ-58 and the boron species formed during calcination were studied by ${ }^{11} \mathrm{~B}$ MAS-NMR spectroscopy, whose spectra are shown in Figure 7.13.

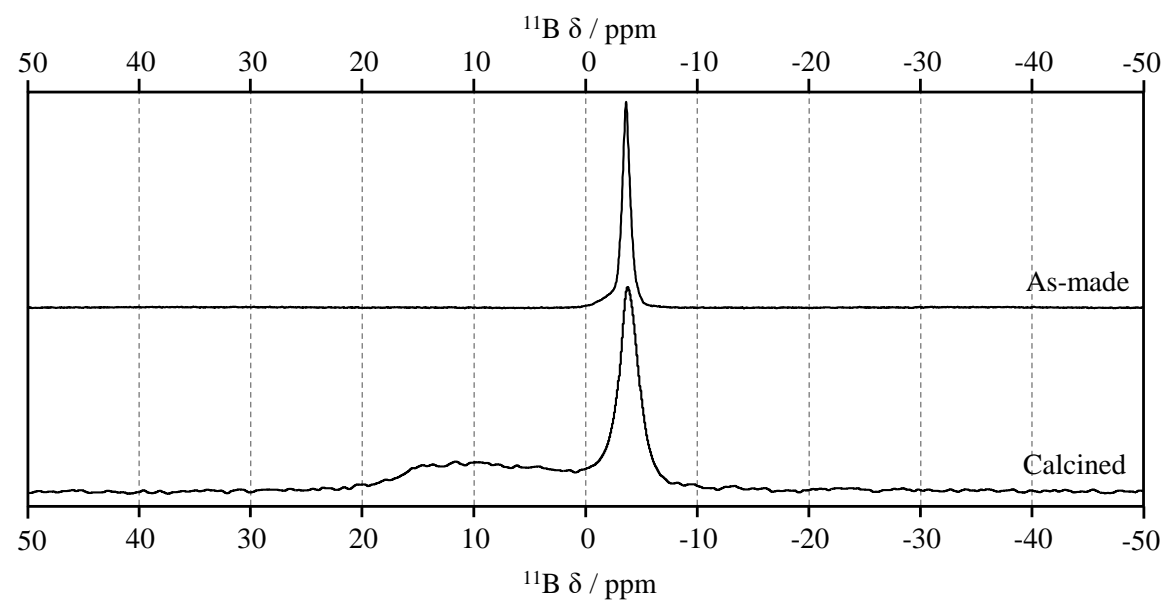

Figure 7.13. ${ }^{11} \mathrm{~B}$ MAS-NMR spectra of as-made and calcined PN-PN ITQ-58 materials.

The as-made ${ }^{11} \mathrm{~B}$ spectrum of the ITQ-58 zeolite shows a single resonance at $-3.6 \mathrm{ppm}$, which is typical of boron in tetrahedral coordination, ${ }^{[27-29]}$ and therefore, it can be concluded that boron is incorporated to the framework lattice in the as-made ITQ-58 zeolite.

After calcination, the resonance at $-3.6 \mathrm{ppm}$ remains, but an additional wide resonance centred at $11 \mathrm{ppm}$ appears, which is typically assigned to boron species in trigonal coordination, typical of dehydrated borosilicate zeolites. ${ }^{[28,30]}$ These trigonal boron species are generally considered as boron in framework positions, but the presence of some impurities cannot be completely ruled out. 


\section{- Silicon framework of the ITQ-58 zeolite}

The different chemical environments of the silicon species in the as-made and calcined ITQ-58 samples were studied by ${ }^{29} \mathrm{Si}$ MAS-NMR spectroscopy, whose spectra are shown in Figure 7.14.

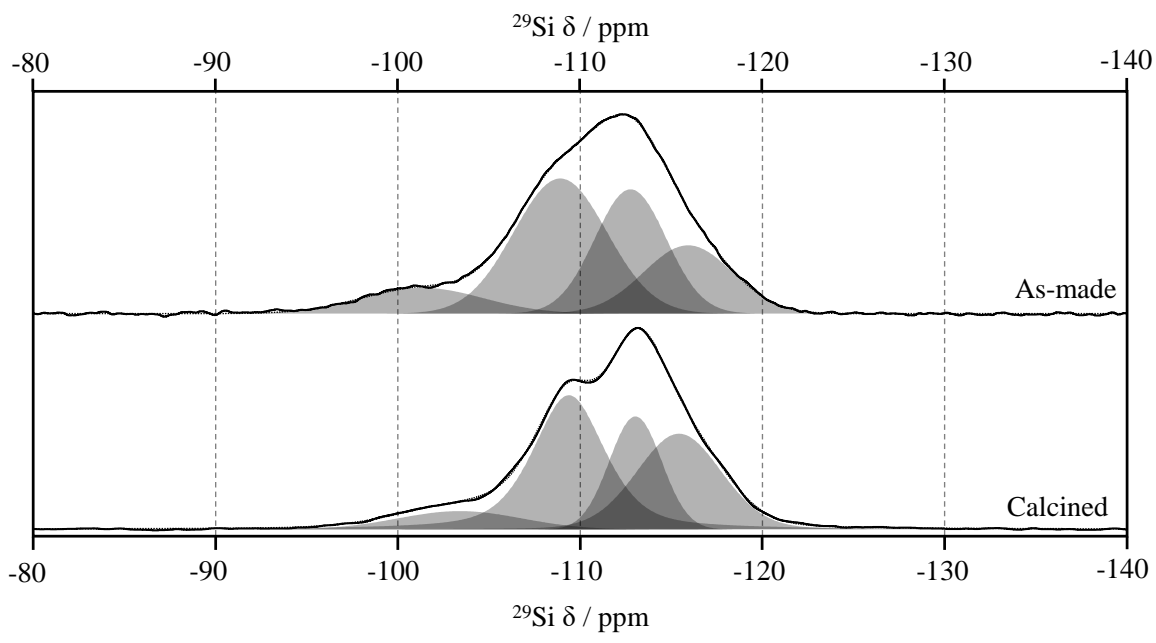

Figure 7.14. ${ }^{29}$ Si MAS-NMR spectra of as-made and calcined PN-PC ITQ-58 materials. Solid line corresponds to experimental spectra; dotted line corresponds to the sum of deconvoluted signals.

The ${ }^{29}$ Si MAS-NMR spectrum of the as-made PN-PC ITQ-58 presents a broad and asymmetrical overlapped spectrum, which can be deconvoluted into at least four sets of resonances. At lower fields, there are three main resonances centred at $-109 \mathrm{ppm},-113 \mathrm{ppm}$ and -116 ppm, with relative intensities 4:3:2 approximatively. These resonances correspond to $\mathrm{Q}^{4} \mathrm{Si}$ atoms, tetrahedrally coordinated silicon atoms having four silicon atoms in the second neighbourhood. At higher fields, a broader and smaller resonance centred on -101 ppm is observed, which is assigned to $\mathrm{Q}^{3} \mathrm{Si}$ atoms, tetrahedrally coordinated silicon atoms having three silicon atoms and a fourth heteroatom, Si-O-B and/or Si-OH groups, in the second neighbourhood.

The ${ }^{29} \mathrm{Si}$ MAS-NMR spectrum of the calcined PN-PC ITQ-58 present the $\mathrm{Q}^{3}$ resonance slightly shifted down-field, from -101 ppm in the as-made sample to $-103 \mathrm{ppm}$ in the calcined sample, but the calcined sample present a similar profile of $\mathrm{Q}^{4}$ resonances than the as-made sample nevertheless. 


\subsubsection{Textural properties of the ITQ-58 zeolite}

The textural properties of the PN-PC ITQ-58 samples were calculated from the $\mathrm{N}_{2}$ adsorption isotherms at $77 \mathrm{~K}$ on the thermally treated samples, shown in Figure 7.15.

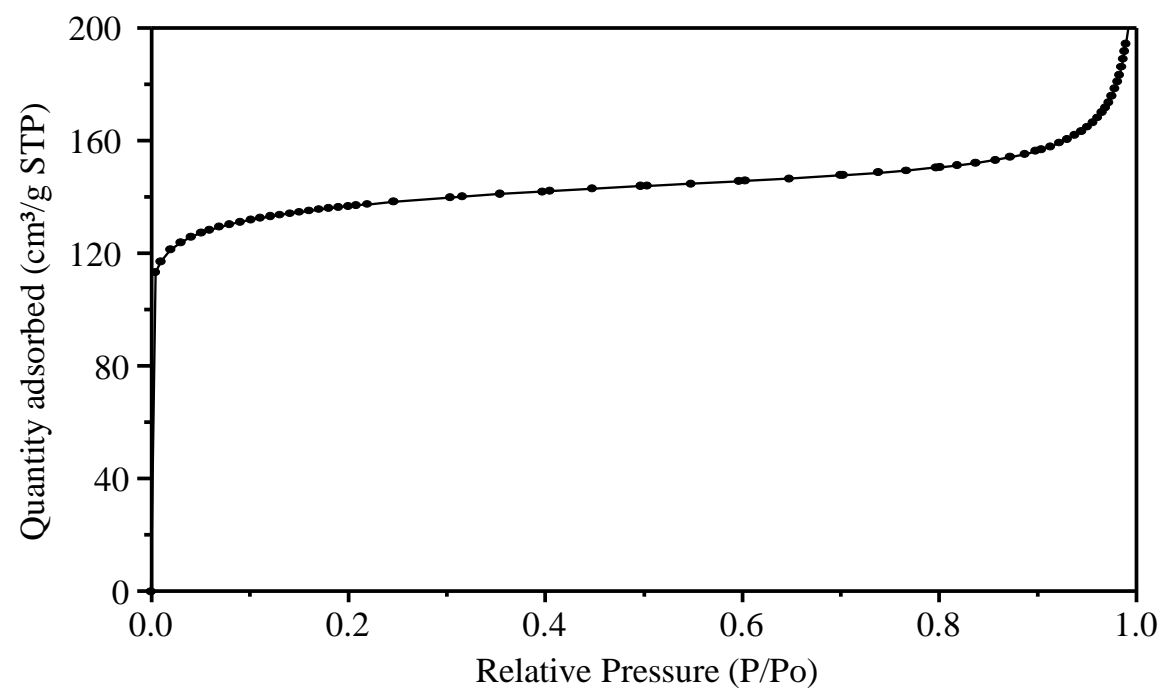

Figure 7.15. $\mathrm{N}_{2}$ adsorption isotherm of the PN-PC ITQ-58 sample hydrogenated at high temperature.

The $\mathrm{N}_{2}$ adsorption isotherms of the thermally treated ITQ-58 samples show the type Ia physisorption profile typical of microporous materials. ${ }^{[31]}$

In the case of the samples calcined under air, $\mathrm{N}_{2}$ was not adsorbed on the PN-PN nor the PN-PC ITQ-58 samples at $77 \mathrm{~K}$. In both materials, most of the phosphorus remains inside the materials after calcination, 2.8 wt.\%P (100\% remaining) in the PN-PN ITQ-58, and 2.5 wt.\%P (98\% remaining) in the PN-PC ITQ-58. This phosphorus remains inside the zeolite as extra-framework phosphorous oxide-like species, which are hindering the $\mathrm{N}_{2}$ uptake in the pore openings of the materials. These results strongly suggest that the ITQ-58 zeolite is a small pore or a monodirectional medium pore zeolite.

On the other hand, the hydrogenated materials presented a lower phosphorus content, 1.7 wt.\%P (61\% remaining) in the PN-PN ITQ-58, and $1.21 \mathrm{wt} \% \mathrm{P}$ (47\% remaining) in the PN-PC ITQ-58, and then, $\mathrm{N}_{2}$ was successfully adsorbed. The $\mathrm{N}_{2}$ adsorption isotherm shows the type Ia physisorption profile, typical of microporous materials. ${ }^{[31]}$ The BET surface area, the micropore surface and the total micropore volume, calculated from the $\mathrm{N}_{2}$ adsorption 
isotherm by applying the t-plot method were $443 \mathrm{~m}^{2} / \mathrm{g}, 411 \mathrm{~m}^{2} / \mathrm{g}$ and $0.202 \mathrm{~cm}^{3} / \mathrm{g}$, respectively.

The micropore distribution was calculated by applying the Horvath-Kawazoe formalism to the Ar adsorption isotherm at $87 \mathrm{~K}$ of the PN-PC ITQ-58 hydrogenated at high temperature, as shown in Figure 7.16.

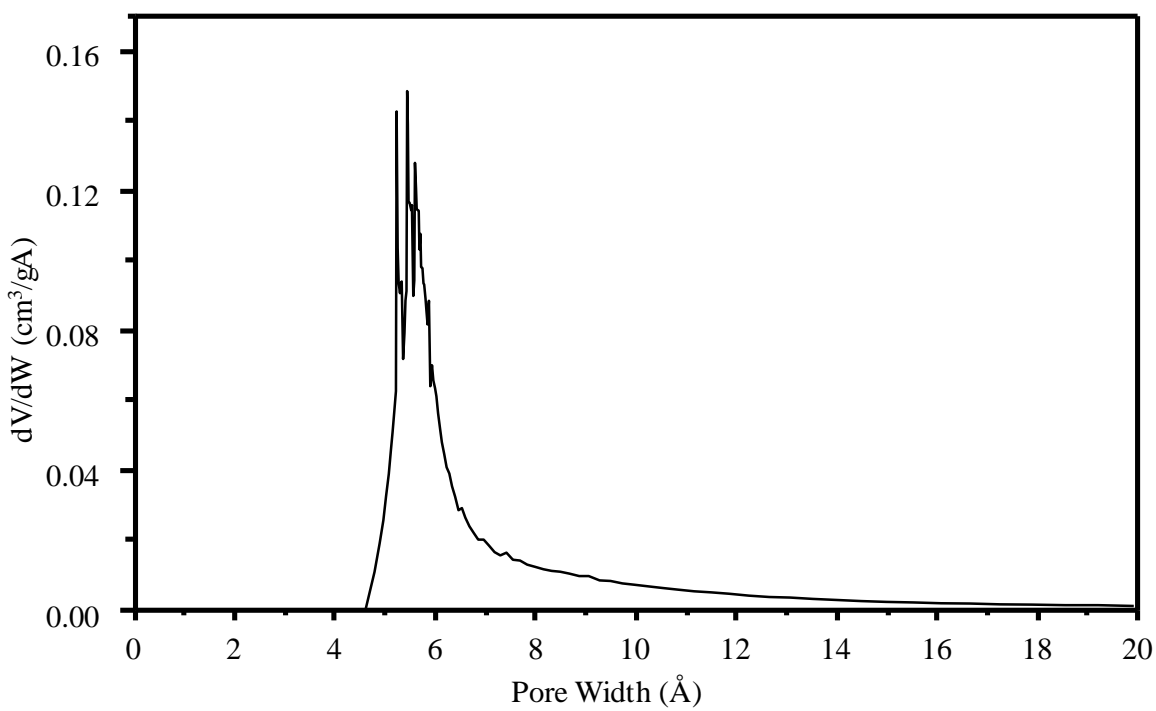

Figure 7.16. Pore size distribution of the PN-PC ITQ-58 sample hydrogenated at high temperature.

The micropore distribution shows a maximum at $5.4 \AA$, matching the previously obtained for the PN-PC ITQ-58. ${ }^{[15]}$ This value fits with a small or medium pore opening zeolite as previously hypothesized from TG results in section 7.2.3.4.

\subsubsection{Structural resolution of the ITQ-58 zeolite}

The methodology previously described in section 7.2.1.5 was applied to the PN-PC ITQ-58 sample. However, this was unsuccessful at first, due to the still small crystallite size. To overcome this problem, the PC-PC ITQ-58* was measured because of its large crystallite size. This sample was used for attempting different modifications on the EDT methodology. The use of this sample allowed an optimization of the crystal positioning, ensuring that it remained inside the diffracting area along the whole rotation of the sample. Other parameters were also optimized, like the goniometer angular speed and the CCD configuration, allowing 
to finally collecting diffraction datasets covering an angular range of $50^{\circ}$ in only 30 seconds, much faster than previously reported, minimizing the degradation of the sample specimen under the electron beam. ${ }^{[32,33]}$

\subsubsection{Unit cell parameters}

Five different datasets were collected for five different crystals The collected data were processed and the unit cell corresponding to each crystal was obtained using the program ADT3D. ${ }^{[34]}$

One of the crystals corresponded to an impurity, the zeolite STF, already detected by powder X-Ray diffraction as described in section 7.2.2. The four remaining datasets were indexed with the same triclinic unit cell, the ITQ-58 zeolite, with the following unit cell parameters:

$$
\begin{gathered}
a=11.2 \AA \quad b=12.9 \AA \quad c=13.7 \AA \\
\alpha=77.0^{\circ} \quad \beta=76.0^{\circ} \quad \gamma=74.4^{\circ}
\end{gathered}
$$

Volume: $1620.5 \AA^{3}$

Structure solution was performed using direct methods as implemented in the program Sir2014. The unit cell projections along the $a, b$ and $c$ axes are shown in Figure 7.17.
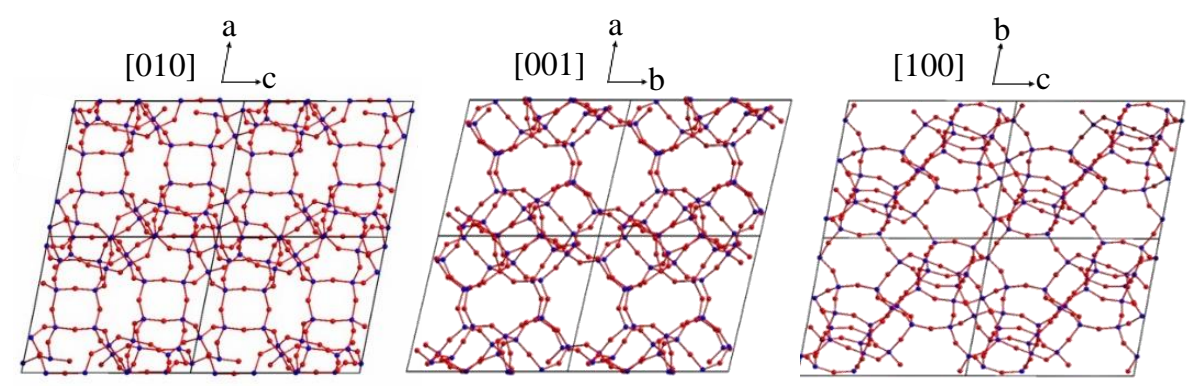

Figure 7.17. Projections of the structure of the ITQ-58 zeolite along the main crystallographic axes (blue: Si; red: 0 ).

The validation of the obtained model by EDT analysis was done by applying the Rietveld method using the program FullProf on the calcined PN-PC ITQ-58 sample, due to 
the better X-Ray pattern resolution achieved in this sample compared to other ITQ-58 samples. The PN-PC ITQ-58 sample Rietveld refinement is shown in Figure 7.18. ${ }^{[35]}$

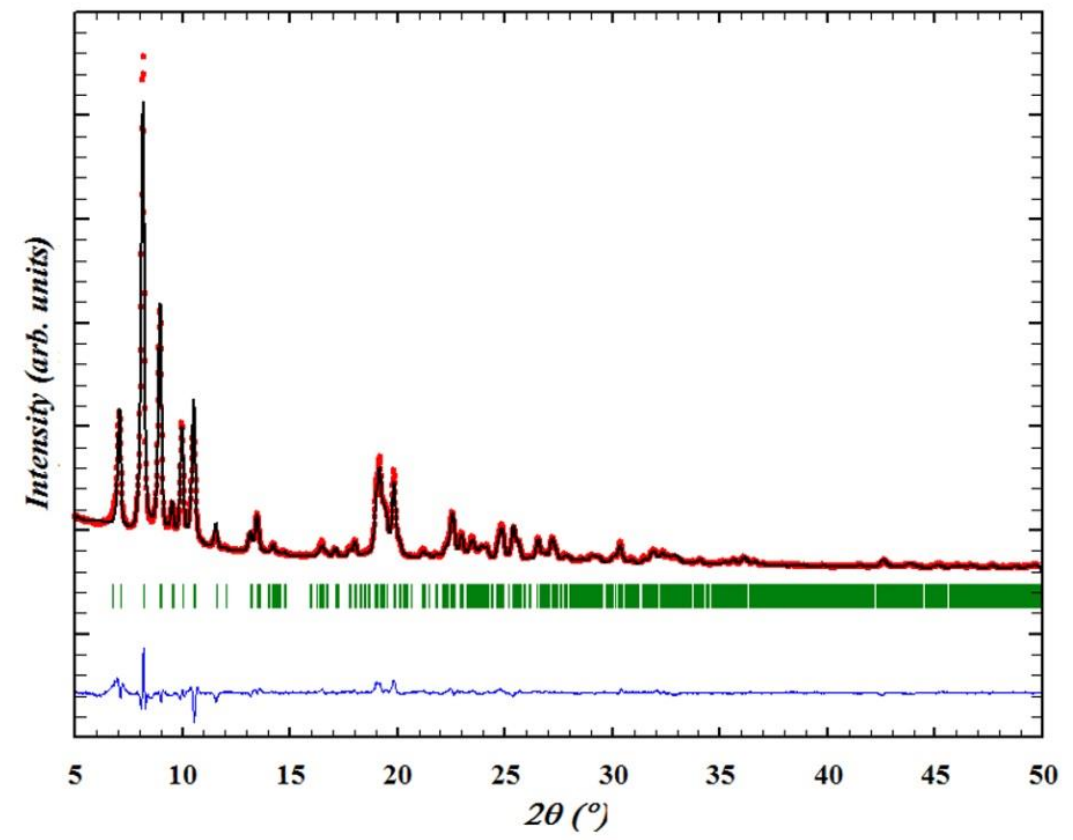

Figure 7.18. Rietveld refinement of the X-Ray diffraction pattern of PN-PC ITQ-58 hydrogenated at high temperature. Red data points show the observed XRPD pattern; the black line along these points is the calculated XRPD pattern, with the difference profile at the bottom in blue. The green vertical tick marks below the pattern give the positions of the Bragg reflections.

The ITQ-58 zeolite was indexed as a triclinic $P-1\left(\mathrm{n}^{\circ} 2\right)$ unit cell with the following parameters:

$$
\begin{gathered}
a=11.385 \AA b=13.040 \AA c=13.660 \AA \\
\alpha=77.78^{\circ} \quad \beta=76.21^{\circ} \quad \gamma=74.55^{\circ}
\end{gathered}
$$

Volume: $1874.6 \AA^{3}$

More information about the application and methodology of the ultra-fast electron diffraction tomography technique discussed here could be found in Simancas, 2016. ${ }^{[14]}$ 


\subsubsection{ITQ-58 zeolite building}

The structure of the ITQ-58 zeolite can be described using four basic cages: [ $\left.4^{3} 5^{4}\right]$, $\left[4^{3} 5^{4} 6^{1}\right],\left[5^{4} 6^{2}\right]$ and the large $\left[4^{12} 5^{12} 6^{12} 8^{4}\right]$ cavity, formed by two twinned $\left[4^{6} 5^{6} 6^{6} 8^{2} 10^{1}\right]$ cages sharing a common $10 \mathrm{MR}$ opening (Figure 7.19).
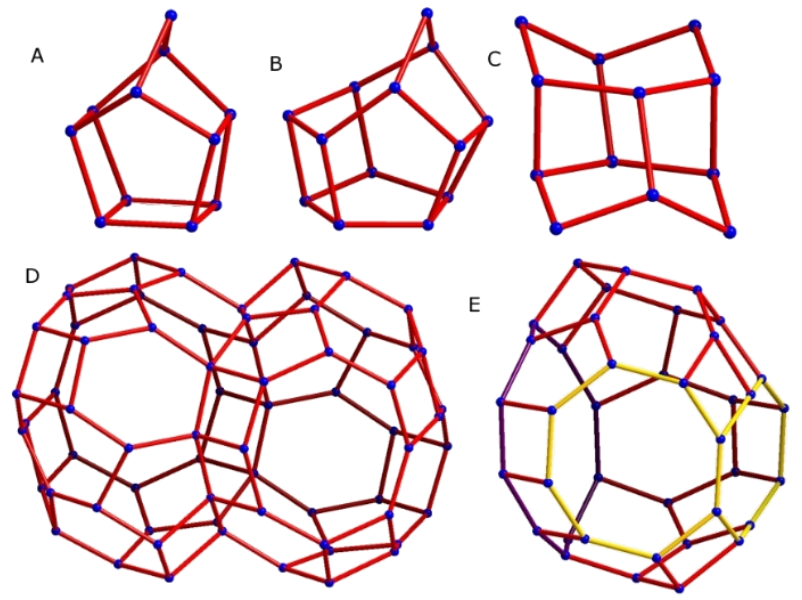

Figure 7.19. Basic cages of ITQ-58 zeolite. (A) $\left[4^{3} 5^{4}\right]$, (B) $\left[4^{3} 5^{4} 6^{1}\right]$, (C) $\left[5^{4} 6^{2}\right]$ and (D) $\left[4^{12} 5^{12} 6^{12} 8^{4}\right]$. The openings of the half cavity $\left[4^{6} 5^{6} 6^{6} 8^{2} 10^{1}\right]$ are highlighted in (E) (large inner $10 \mathrm{MR}$ in purple and the two 8 MR opening windows in yellow). Oxygen atoms have been removed for clarity.

The secondary units are connected giving rise to a more complex building block formed by a central $\left[5^{4} 6^{2}\right]$ cage (yellow) connected to two $\left[4^{3} 5^{4}\right]$ cages (blue) and another two $\left[4^{3} 5^{4} 6^{1}\right]$ cages (green) by sharing five rings, as shown in Figure 7.20.A.

A

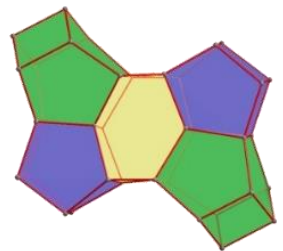

B
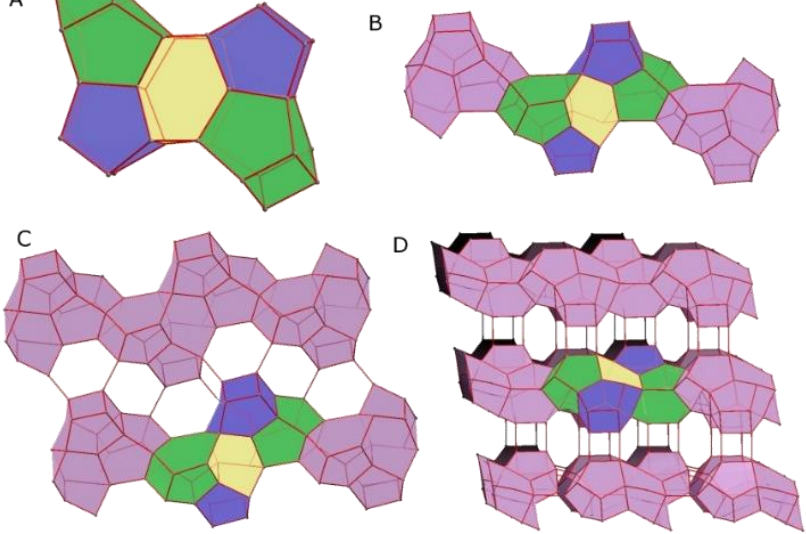
Chapter 7: Synthesis of New Zeolite Materials

Figure 7.20. Construction of the structure of the ITQ-58 zeolite. (A) Two [4 $\left.4^{3} 5^{4}\right]$ (blue), two $\left[4^{3} 5^{4} 6^{1}\right]$ (green) and one $\left[5^{4} 6^{2}\right]$ (yellow) cages connect forming a basic block. (B) The previous blocks connect to each other sharing a 4 MR forming chains along $c$. (C) Each chain connects to the adjacent ones in the $b c$ plane forming layers. $4 \mathrm{MR}$ and $6 \mathrm{MR}$ are formed in the process. (D) Layers stack along the $a$ direction forming the complete 3D structure.

These building blocks are connected to their neighbours by sharing 4 MR rings faces forming chains along the $c$ direction (Figure 7.20.B). Then, the different chains are connected to their neighbours forming layers in the $b c$ plane, with formation of series of three $6 \mathrm{MR}$ and one 4 MR (Figure 7.20.C). Finally, the layers are interconnected forming 4 MR, giving raise to the formation of the tridimensional structure with large cavities (Figure 7.20.D).

The access to the large cavities is through 8 MR openings. Each cavity is accessible through two $8 \mathrm{MR}$ with a pore aperture of 4.0x3.3 $\AA$ and two distorted $8 \mathrm{MR}$ with a pore aperture of $5.9 \times 2.5 \AA$. The large twin cavities are isolated from each other, and thus, the ITQ-58 zeolite could be described as a bi-directional small pore zeolite.

The crystallographic pore apertures and cavity volume are in good agreement with those estimated from the $\mathrm{Ar}$ and $\mathrm{N}_{2}$ adsorption isotherms in section 7.2.4, as the distorted pores are inaccessible for $\mathrm{Ar}$ or $\mathrm{N}_{2}$.

\subsection{ITQ-66 zeolite}

The synthesis of the ITQ-66 was achieved after realizing that a relatively simple phosphorous cation as the butane-1,4-diylbis(triethylphosphonium) cation was not tested before as OSDA for the synthesis of zeolites. Its ammonium counterpart has been previously reported yielding zeolite $\beta$ intergrowth. ${ }^{[36]}$ Actually, the main objectives to study the butane-1,4-diylbis(triethylphosphonium) cation were to either obtain zeolite $\beta$ intergrowth with a phosphorous OSDA, or gallosilicate MFI zeolite to compare the corresponding gallosilicate MFI obtained with the analogous arsonium OSDA. ${ }^{[37]}$ Instead, a novel zeolite structure was obtained. 


\subsubsection{Synthesis}

The ITQ-66 zeolite is a new zeolite material which was obtained using the butane-1,4-diylbis(triethylphosphonium) hydroxide cation, or OSDA-11, as OSDA, shown in Figure 7.21. The detailed synthesis of the OSDA-11 is described in section 3.2.1.11.

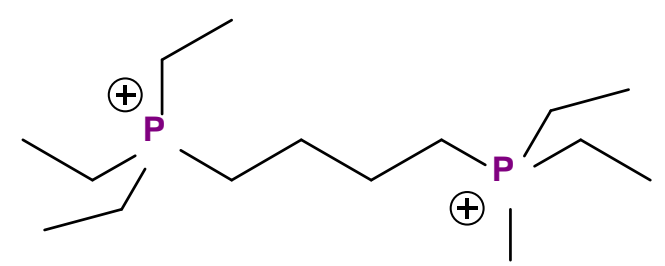

Figure 7.21. Butane-1,4-diylbis(triethylphosphonium) cation.

\subsubsection{Synthesis conditions}

This incorporation of the butane-1,4-diylbis(triethylphosphonium) cation to the synthesis gels was studied in a wide range of synthesis conditions, detailed in Table 7.7, with synthesis gels of the following molar composition:

$$
0.2 \text { OSDA : (1-x) } \mathrm{SiO}_{2}: x \mathrm{~A}_{\mathrm{m}} \mathrm{O}_{\mathrm{n}}: y \mathrm{H}_{2} \mathrm{O}: 0.4 \mathrm{HF}
$$

with $x$ ranging from 0 to $0.025, y$ being 5 or 10 , and $\mathrm{A}_{\mathrm{m}} \mathrm{O}_{\mathrm{n}}$ being $\mathrm{B}_{2} \mathrm{O}_{3}, \mathrm{Al}_{2} \mathrm{O}_{3}, \mathrm{Ga}_{2} \mathrm{O}_{3}$ or $\mathrm{GeO}_{2}$.

Table 7.7. Tested synthesis conditions and phase selectivity obtained using butane-1,4diylbis(triethylphosphonium) hydroxide as OSDA.

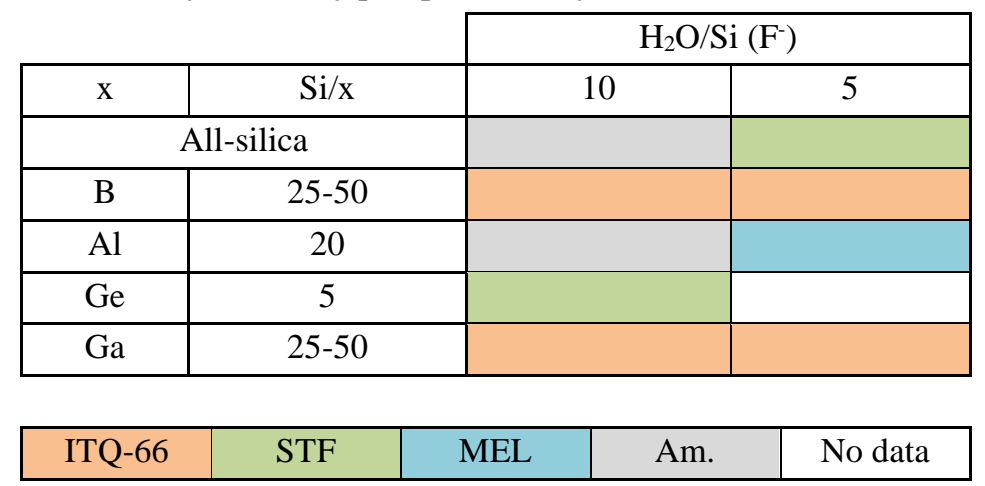

The crystallization yielded the pure zeolite ITQ-66 only in gallium and boroncontaining syntheses gels, while all-silica and germanium-containing synthesis gels yielded 
pure STF zeolite. On the other hand, aluminium-containing synthesis gels yielded pure ZSM-11 (MEL) zeolite. It was not possible obtaining ITQ-66 when aluminium was introduced in the synthesis gel composition, even using ITQ-66 seeds or mixed boronaluminium synthesis gel compositions. The detailed synthesis of the ITQ-66 zeolite is described in section 3.2.2.7.

\subsubsection{Phase crystallinity}

The crystallinity of the as-made materials was assessed by powder X-Ray diffraction, whose patterns are shown in Figure 7.22.

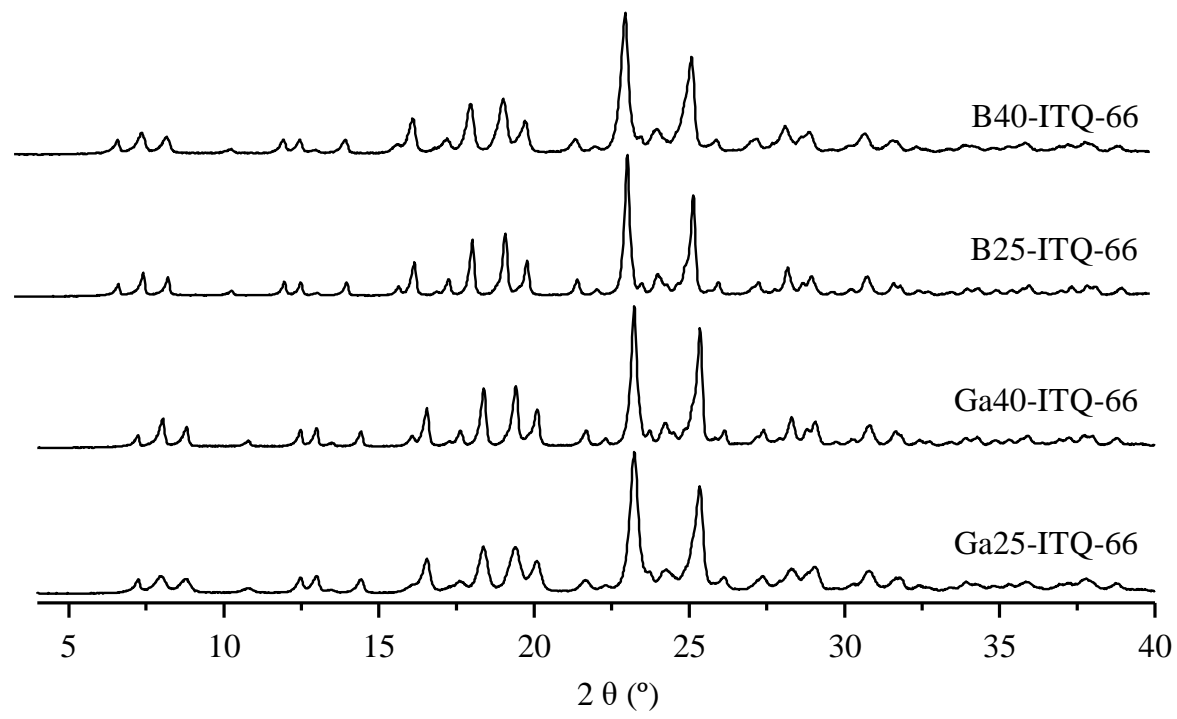

Figure 7.22. Powder X-Ray diffraction patterns of some ITQ-66 materials. Samples are identified by the heteroatom type and the silica to heteroatom ratio in synthesis gel composition.

The powder X-Ray diffraction patterns show that there is no amorphous material in any syntheses. Also, there are almost no differences between the X-Ray patterns of the samples containing the different gallium or boron heteroatoms, except the Ga25-ITQ-66 sample, that presents wider diffraction peaks than the other samples, probably due to a small crystal size in this sample. Samples are named after the heteroatom used in the synthesis gel followed by the $\mathrm{Si}$ to heteroatom ratio. 


\subsubsection{Sample analyses of the ITQ-66 zeolite}

The obtained as-made ITQ-66 zeolites were submitted to chemical analyses, thermogravimetry, electron scanning microscopy and MAS-NMR spectroscopies. In this section only chemical analyses and electron scanning microscopy analyses are compared, while MAS-NMR spectra are further discussed in section 7.3.5.

\subsubsection{Chemical analyses of the ITQ-66 zeolite}

The typical chemical compositions of the as-made ITQ-66 materials are shown in Table 7.8.

Table 7.8. Chemical composition of some of the as-made ITQ-66 materials. All ratios are given as molar ratios. Samples are identified by heteroatom (X: B or Ga) synthesis gel composition and $\mathrm{pH}_{\mathrm{gel}}$ was measured after adding $\mathrm{HF}$.

\begin{tabular}{ccccccccc}
\hline Sample & {$[\mathrm{Si} / \mathrm{X}]_{\text {gel }}$} & $\mathrm{pH}_{\text {gel }}$ & $\eta_{\mathrm{X}}(\%)$ & $\eta_{\mathrm{Si}}(\%)$ & {$[\mathrm{Si} / \mathrm{X}]_{\mathrm{sol}}$} & wt.\% $\mathrm{P}_{\text {sol }}$ & $\mathrm{Si} / \mathrm{P}$ & $\mathrm{P} / \mathrm{X}$ \\
\hline B25-ITQ-66 & 25 & 10.79 & 97 & 98 & 25.3 & 2.4 & 18.5 & 1.4 \\
B40-ITQ-66 & 40 & 10.16 & 100 & 84 & 35.8 & 2.4 & 18.4 & 1.9 \\
Ga25-ITQ-66 & 25 & 10.55 & 93 & 96 & 27.5 & 2.3 & 18.5 & 1.5 \\
Ga40-ITQ-66 & 40 & 9.94 & 68 & 81 & 46.4 & 2.4 & 17.5 & 2.6 \\
\hline
\end{tabular}

First, it could be seen that the silicon to phosphorus ratio is close to $18(\mathrm{Si} / \mathrm{OSDA}=36)$, which hints that the number of $\mathrm{T}$ atoms in the structure should probably be a multiple of 36 . The incorporation yields of boron, gallium and silicon are high and thus, the silicon to heteroatom ratios obtained in the materials almost match the added in the synthesis gels. In all cases, the $\mathrm{P}$ to heteroatom ratio is well over 1 , which could be indicative of the presence of silanol defects, or a significant fluoride incorporation to compensate the positively incorporated cation.

\subsubsection{Morphology of the ITQ-66 zeolite}

The crystallite shape and size of the as-made ITQ-66 samples were assessed by FESEM microscopy analyses, depicted in Figure 7.23. 

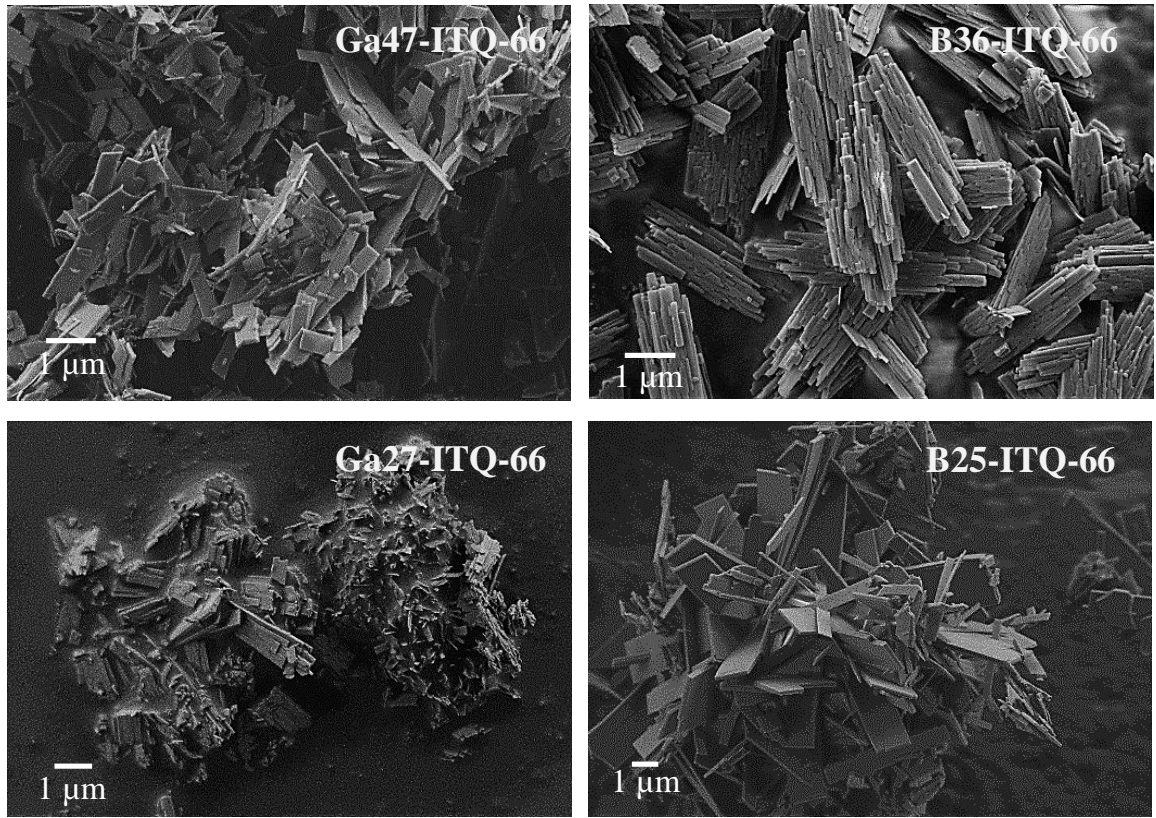

Figure 7.23. FESEM microimages of as-made ITQ-66 materials. Samples are named after the containing heteroatom followed by the as-made heteroatom to silica ratio content.

The ITQ-66 crystallized with a homogeneous shape and a heterogeneous size distribution. The materials present a plate-like shape, almost lamellar-like, with typical sizes ranging from $0.2 \times 0.5 \mu \mathrm{m}$ up to $0.5 \times 3 \mu \mathrm{m}$, and with a thickness around $50 \mathrm{~nm}$ in all cases. The platelets show a tendency to form large spherical aggregates, larger as the content of the heteroatom lowers.

\subsubsection{Thermogravimetric analysis of the as-made ITQ-66 zeolite}

The thermal stability and decomposition of the OSDA were studied by thermogravimetry (TG) and differential thermogravimetry (DTG) analyses of the ITQ-66 samples. Some thermogravimetric plots are shown in Figure 7.24. 


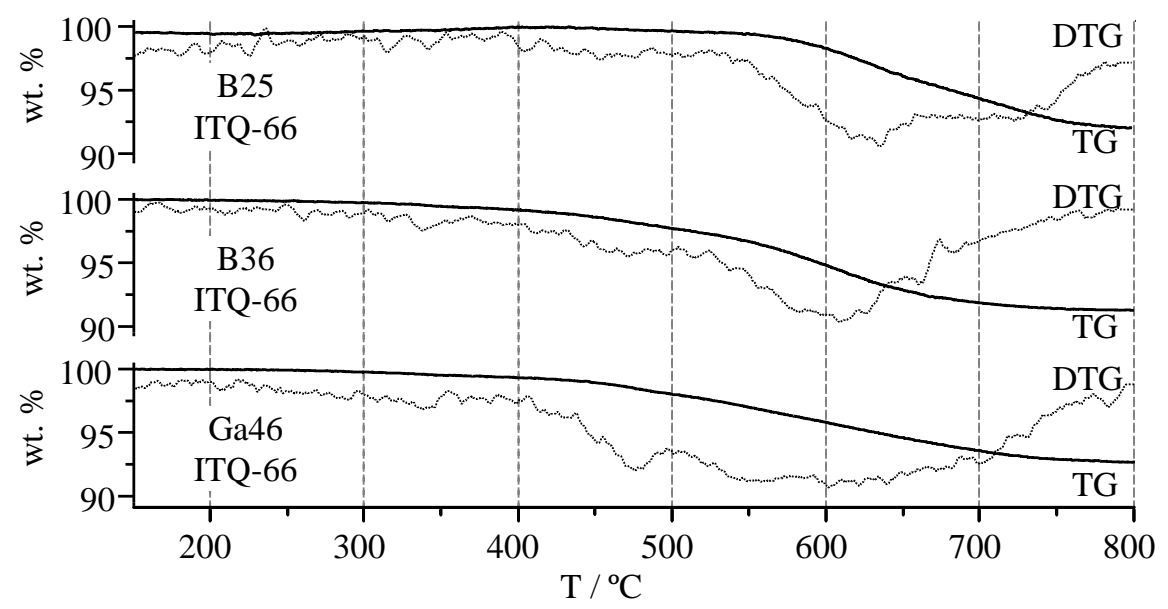

Figure 7.24. TG (solid lines) and DTG (dotted lines) analyses curves of some ITQ-66 samples.

Samples are named as the containing heteroatom followed by the as-made heteroatom to silica ratio content. DTG curves are scaled up for a better view.

The thermogravimetry shows a single weight loss of $c a .8 \mathrm{wt} . \%$ between $400^{\circ} \mathrm{C}$ and $750^{\circ} \mathrm{C}$. The starting temperature of the weight loss depends on the heteroatom content, increasing as the boron or gallium content increases, but no difference was found when the chemical nature of the trivalent atom changed from boron to gallium. From our experience, the thermogravimetric profile is usually heavily linked with the pore size and channel connectivity, especially when using phosphorous OSDA's. Thus, because of the high temperature required, it is hypothesized that the ITQ-66 could be a bi-directional small pore or a mono-directional medium pore zeolite.

\subsubsection{Thermal treatments of the ITQ-66 zeolite}

The as-made ITQ-66 materials were thermally treated following the general methodologies described in the section 3.2.3. For the thermally treated materials, powder $\mathrm{X}$-Ray diffraction, chemical analyses, scanning electron microscopy, adsorption isotherms and MAS-NMR spectroscopy were performed. In this section only powder X-Ray diffraction, chemical analyses, scanning electron microscopy and adsorption isotherms are discussed, while MAS-NMR spectra are further discussed in section 7.3.5. 


\subsubsection{Crystallinity of thermally treated ITQ-66 zeolite}

The stability and crystallinity of the ITQ-66 samples after thermal treatments were studied by powder X-Ray diffraction, whose patterns are shown in Figure 7.25.

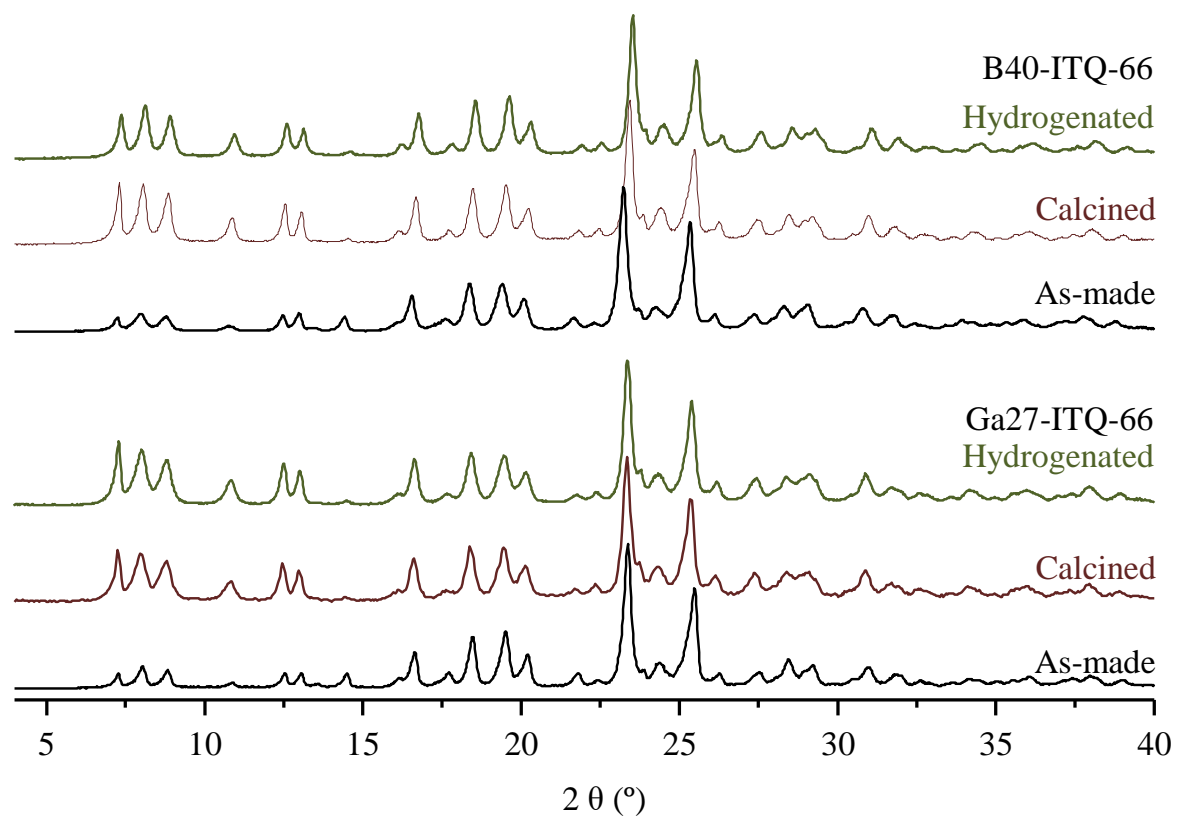

Figure 7.25. Powder X-Ray diffraction patterns of some of the thermally treated ITQ-66 materials. Black lines correspond to as-made samples; red lines to calcined samples; green lines to samples hydrogenated at high temperature. Samples are identified by synthesized material composition.

The materials remained highly crystalline after the thermal treatments. The X-Ray diffraction peaks were found at roughly the same $2 \theta^{\circ}$ values in all samples regardless of the thermal treatment and chemical composition of the final material. The main difference between the as-made and the thermally-treated samples was the intensity of the signals at $2 \theta^{\circ}$ below $17^{\circ}$, as the intensity of these signals is typically affected by the presence of the OSDA occluded within the pores of the material. 


\subsubsection{Chemical analyses of thermally treated ITQ-66 zeolite}

The chemical compositions of the thermally treated ITQ-66 materials are shown in Table 7.9.

Table 7.9. Chemical composition of some of the thermally treated ITQ-66 materials. All ratios are given as molar ratios. Samples are identified by heteroatom (X: B or Ga) synthesis gel composition.

\begin{tabular}{ccccccc}
\hline Sample & Treatment & $\mathrm{Si} / \mathrm{X}_{\text {as-made }} \mathrm{Si} / \mathrm{X}_{\text {treated }}$ wt.\% & Pas-made & wt.\% & treated & P/X \\
\hline B25-ITQ-66 & Calcination & 25.3 & 28.9 & 2.4 & 2.2 & 1.4 \\
\hline B25-ITQ-66 & Hydrogenation & 25.3 & 27.5 & 2.4 & 0.2 & 0.1 \\
\hline B36-ITQ-66 & Calcination & 35.8 & 35.9 & 2.4 & 2.2 & 1.7 \\
\hline B36-ITQ-66 & Hydrogenation & 35.8 & 35.9 & 2.4 & 0.3 & 0.2 \\
\hline Ga27-ITQ-66 & Calcination & 27.5 & 27.7 & 2.3 & 2.1 & 1.2 \\
\hline Ga27-ITQ-66 & Hydrogenation & 27.5 & 33.2 & 2.3 & 0.5 & 0.3 \\
\hline Ga46-ITQ-66 & Calcination & 46.4 & 43.9 & 2.4 & 2.3 & 2.1 \\
\hline Ga46-ITQ-66 & Hydrogenation & 46.4 & 45.6 & 2.4 & 0.3 & 0.3 \\
\hline
\end{tabular}

After calcination, most of the phosphorus remains inside the material, which could indicate a strong interaction of the phosphorous species with the boron and gallium species inside the materials. On the other hand, the hydrogenation treatment at high temperature allows for the removal of roughly $85 \mathrm{wt} . \%$ of the phosphorus. Thus, the use of different thermal treatments allows obtaining materials with different phosphorus contents and phosphorus to heteroatom ratios. 


\subsubsection{Morphology of thermally treated ITQ-66 zeolite}

As previously, the morphology of the thermally treated ITQ-66 zeolites were studied by FESEM, and their comparison with as-made materials is depicted in Figure 7.26.
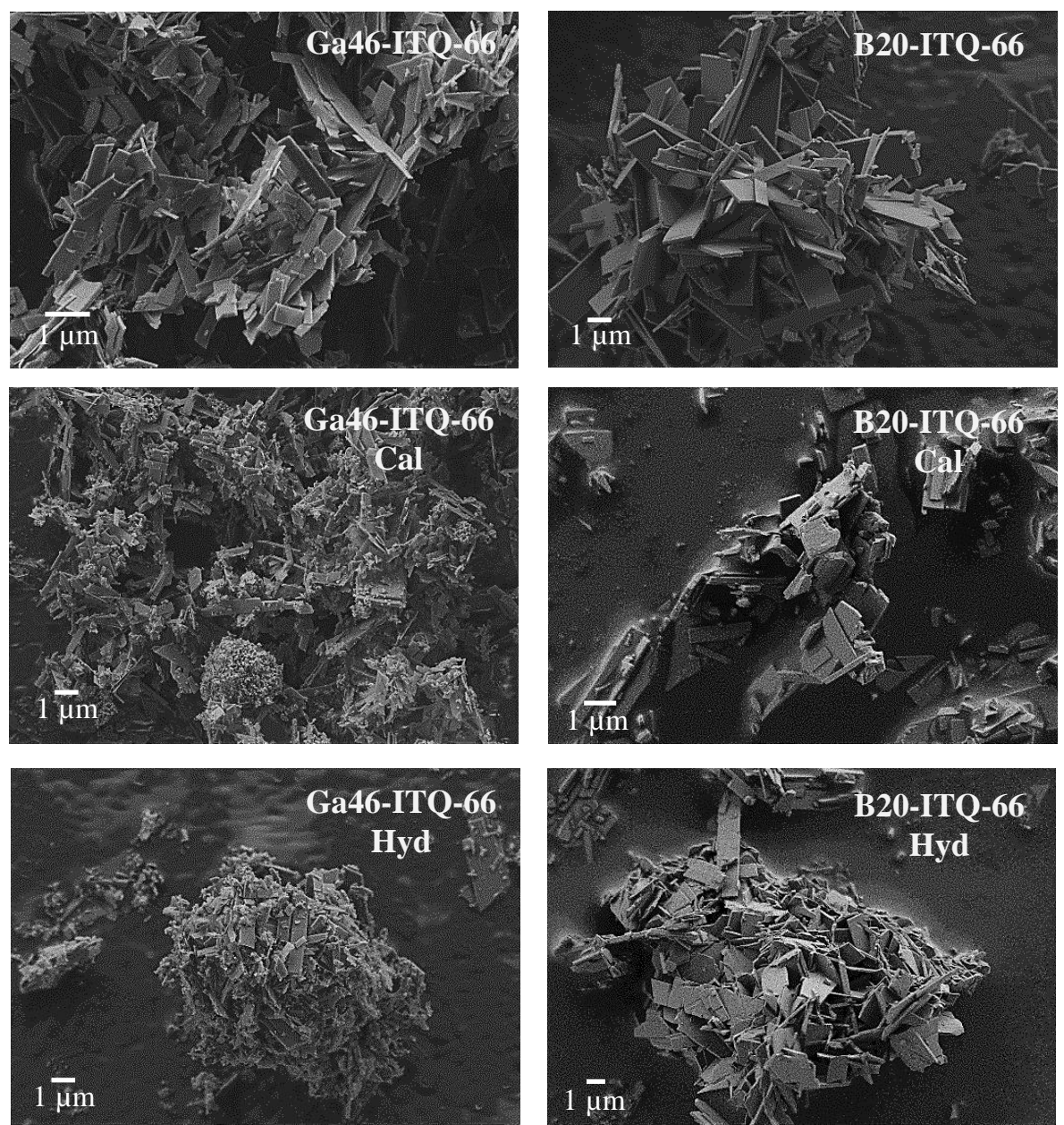

Figure 7.26. FESEM microimages of some thermally treated ITQ-66 materials. Samples are named as the containing heteroatom followed by the as-made heteroatom to silica ratio content, with the thermal treatment below (Cal: calcined; Hyd: hydrogenated at high temperature).

After the thermal treatments, the borosilicate material crystallites keep their size, but gallosilicate material crystallites break into smaller crystals, especially after the hydrogenation at high temperature. 


\subsubsection{Textural properties of the ITQ-66 zeolite}

The textural properties of the ITQ-66 samples were calculated from the $\mathrm{N}_{2}$ adsorption isotherms at $77 \mathrm{~K}$ on the thermally treated samples, shown in Figure 7.27.
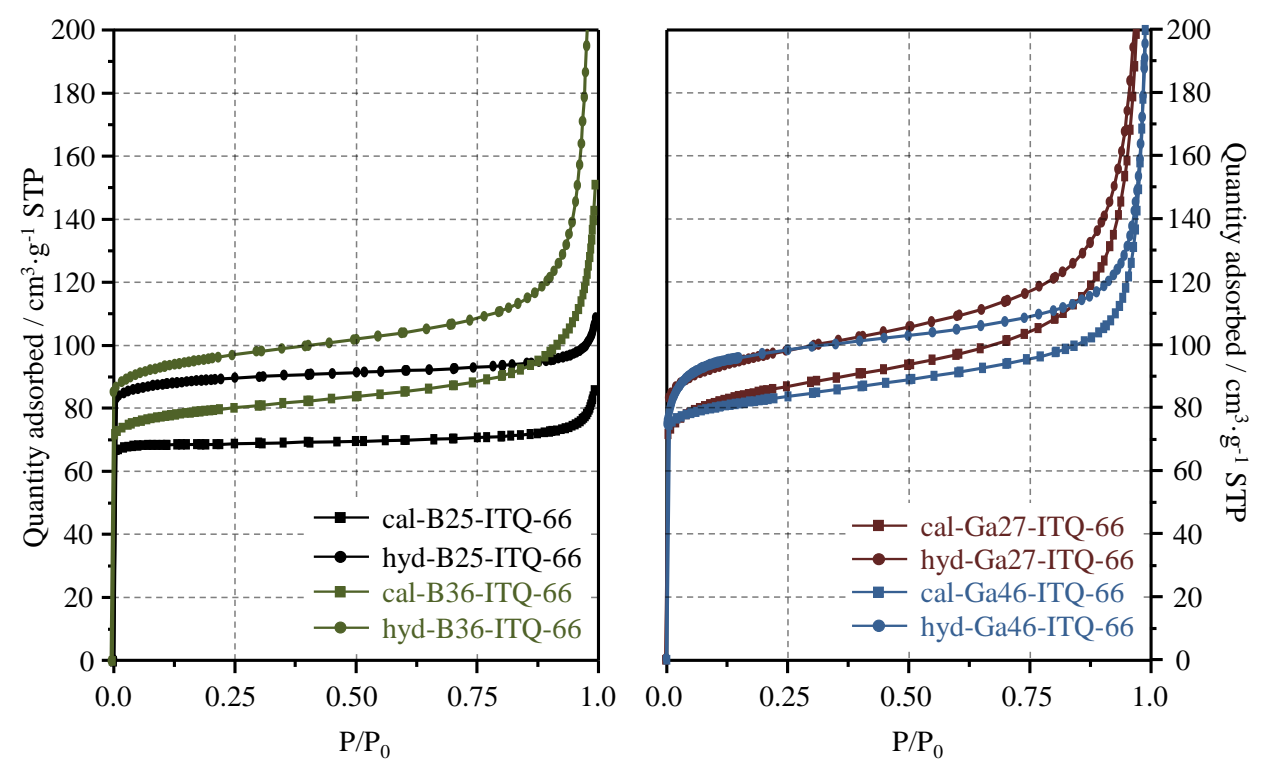

Figure 7.27. $\mathrm{N}_{2}$ adsorption isotherms of some of the thermally treated ITQ-66 samples (black and green: borosilicate materials; red and blue: gallosilicate materials). Samples are named after the thermal treatment (cal: calcined under air; hyd: hydrogenated at high temperature), followed by the containing heteroatom and by the as-made heteroatom to silica ratio content.

The $\mathrm{N}_{2}$ adsorption isotherms show the type Ia physisorption profile, typical of microporous materials. ${ }^{[31]}$

The BET and micropore surface areas and the total micropore volume, calculated from the $\mathrm{N}_{2}$ adsorption isotherm at $77 \mathrm{~K}$ by applying the t-plot method, are summarized in Table 7.10 . 
Chapter 7: Synthesis of New Zeolite Materials

Table 7.10. Textural properties of thermally treated ITQ-66 materials. Samples are identified by its heteroatom (X: B or Ga) content and post-synthesis treatments (cal: calcined; hyd: hydrogenated at high temperature).

\begin{tabular}{cccccc}
\hline Sample & $\begin{array}{c}\text { BET } \\
\text { surface / } \\
\mathrm{m}^{2} \cdot \mathrm{g}^{-1}\end{array}$ & $\begin{array}{c}\text { Micropore } \\
\text { surface / } \\
\mathrm{m}^{2} \cdot \mathrm{g}^{-1}\end{array}$ & $\begin{array}{c}\text { Micropore } \\
\text { volume / } \\
\mathrm{cm}^{3} \cdot \mathrm{g}^{-1}\end{array}$ & $\mathrm{P} / \mathrm{X}$ & wt.\%P \\
\hline Ga27-cal & 278.2 & 223.2 & 0.11 & 1.2 & 2.1 \\
\hline Ga27-hyd & 314.6 & 255.0 & 0.12 & 0.3 & 0.5 \\
Ga46-cal & 247.7 & 188.1 & 0.10 & 2.1 & 2.1 \\
Ga46-hyd & 265.7 & 226.2 & 0.11 & 0.3 & 0.3 \\
B25-cal & 216.8 & 210.8 & 0.10 & 1.4 & 2.5 \\
\hline B25-hyd & 283.7 & 273.2 & 0.13 & 0.1 & 0.20 \\
\hline B36-cal & 255.8 & 228.6 & 0.11 & 1.7 & 2.2 \\
\hline B36-hyd & 308.5 & 271.8 & 0.13 & 0.2 & 0.3 \\
\hline
\end{tabular}

The obtained BET surface area and micropore volume values show differences depending on the phosphorus and heteroatom content, increasing the adsorption capacity as phosphorus content decreases. The relatively low adsorption capacity of the ITQ-66 suggests that the zeolitic structure does not present cavities. Calcined samples, due to their higher phosphorus content, always yield lower BET surface and micropore volumes than hydrogenated samples due to channel hindrance by the phosphorous species.

The micropore distribution was calculated by applying the Horvath-Kawazoe formalism $^{[38]}$ to the Ar adsorption isotherm at $87 \mathrm{~K}$ of the B20-ITQ-66 and Ga46-ITQ-66 samples hydrogenated at high temperature, as shown in Figure 7.28. 


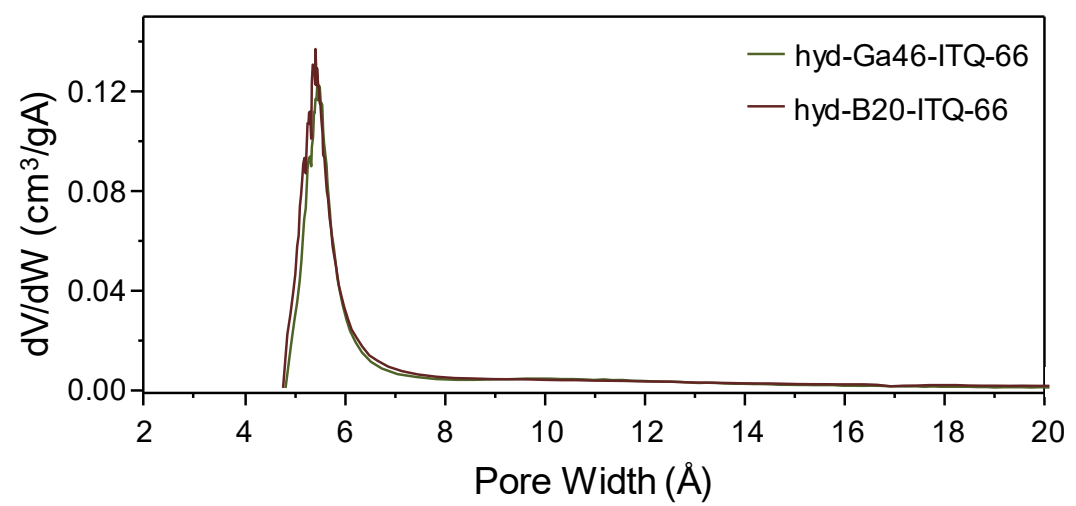

Figure 7.28. Pore size distribution of some ITQ-66 samples hydrogenated at high temperature.

The micropore distribution shows a single maximum at $5.45 \AA$ for both borosilicate and gallosilicate materials hydrogenated at high temperature, which suggests that the ITQ-66 is a medium pore size channel zeolite. ${ }^{[7]}$

The micropore volume and the pore diameter distribution results fit well with a bi-directional medium-pore zeolite without cavities, as previously suggested from the TG analyses in section 7.3.2.3.

\subsubsection{Structural resolution of the ITQ-66 zeolite}

The ITQ-66 zeolite crystalline structure was resolved using the Ultrafast Electron Diffraction Tomography technique, and the structure solution was performed using direct methods as implemented in the program Sir2014, as previously described in section 7.2.1.5. ${ }^{[14]}$ The validation of the obtained model by EDT analysis was carried out using the Rietveld method using the program FullProf. ${ }^{[35]}$

\subsubsection{Description of the unit cell of the ITQ-66}

The zeolite ITQ-66 presents an orthorhombic symmetry, belonging to the $\mathrm{Cmcm}$ $\left(n^{\circ} 63\right)$ spatial group. The unit cell parameters assuming an all-silica framework composition are given below:

$$
a=7.519 \AA \quad b=21.7164 \AA \quad c=24.2826 \AA \quad \text { Volume: } 3965.00 \AA^{3}
$$


Chapter 7: Synthesis of New Zeolite Materials

The crystallographic number of independent silicon atoms ( $\mathrm{T}$ positions) and their multiplicity are shown in Table 7.11.

Table 7.11. Multiplicity and atomic coordinates of the Si atoms in the ITQ-66 structure.

\begin{tabular}{ccccc}
\hline Atom & $x$ & $y$ & $z$ & Multiplicity \\
\hline Si1 & 0.00 & $0.2205(8)$ & $0.3137(3)$ & 8 \\
Si2 & $0.2038(10)$ & $0.4028(6)$ & $0.4070(4)$ & 16 \\
Si3 & $0.2977(10)$ & $0.3158(7)$ & $0.3129(3)$ & 16 \\
Si4 & 0.50 & $0.3668(8)$ & $0.5885(5)$ & 8 \\
Si5 & 0.50 & $0.5052(8)$ & $0.5643(3)$ & 8 \\
Si6 & $0.2043(10)$ & $0.3194(4)$ & $0.5109(4)$ & 16 \\
\hline
\end{tabular}

The total number of crystallographic positions in the unit cell is 72 , which gives two OSDA molecules per unit cell (i.e. 4 phosphorus atoms per unit cell) in the as-made materials, as previously guessed by elemental analyses. The unit cell projections are shown in Figure 7.29.

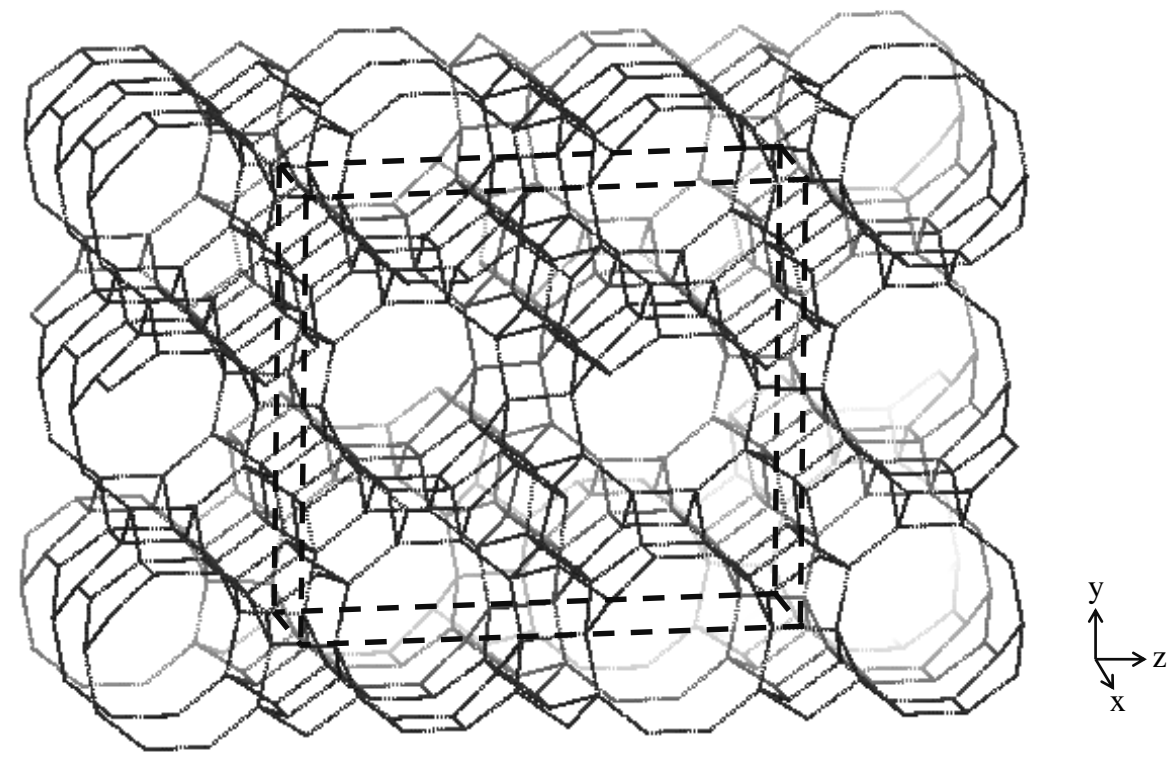



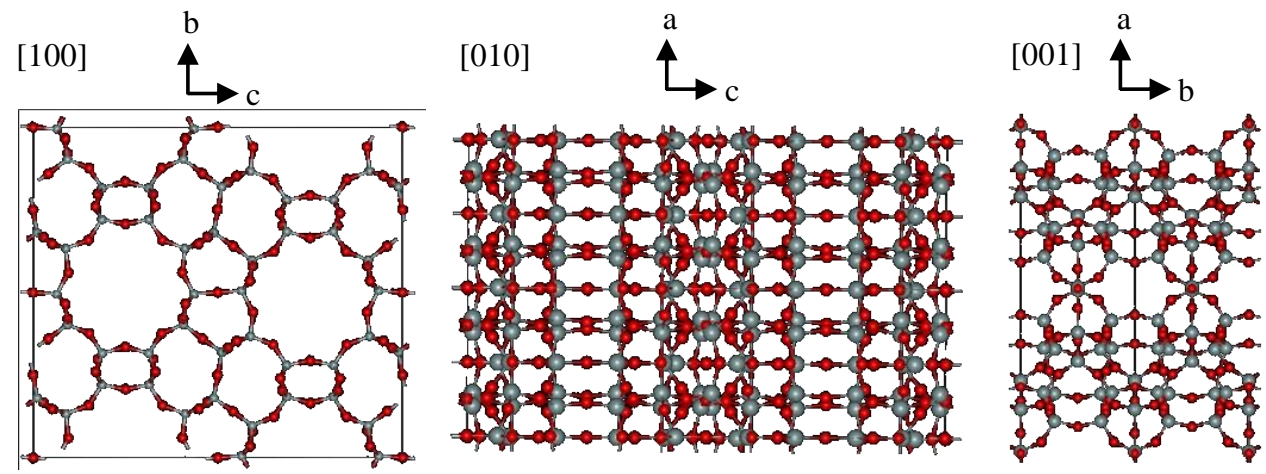

Figure 7.29. Above: Unit cell projection of the zeolite ITQ-66, with the unit cell marked by dashed lines. Below: projections along the main crystallographic axes (grey: $\mathrm{Si}$; red: $\mathrm{O}$ ).

\subsubsection{Channel system description of the ITQ-66}

The channel structure of the zeolite ITQ-66 could be described as a $10 \mathrm{MR}$ and an 8 MR bi-directional pore system zeolite, as depicted in Figure 7.30.

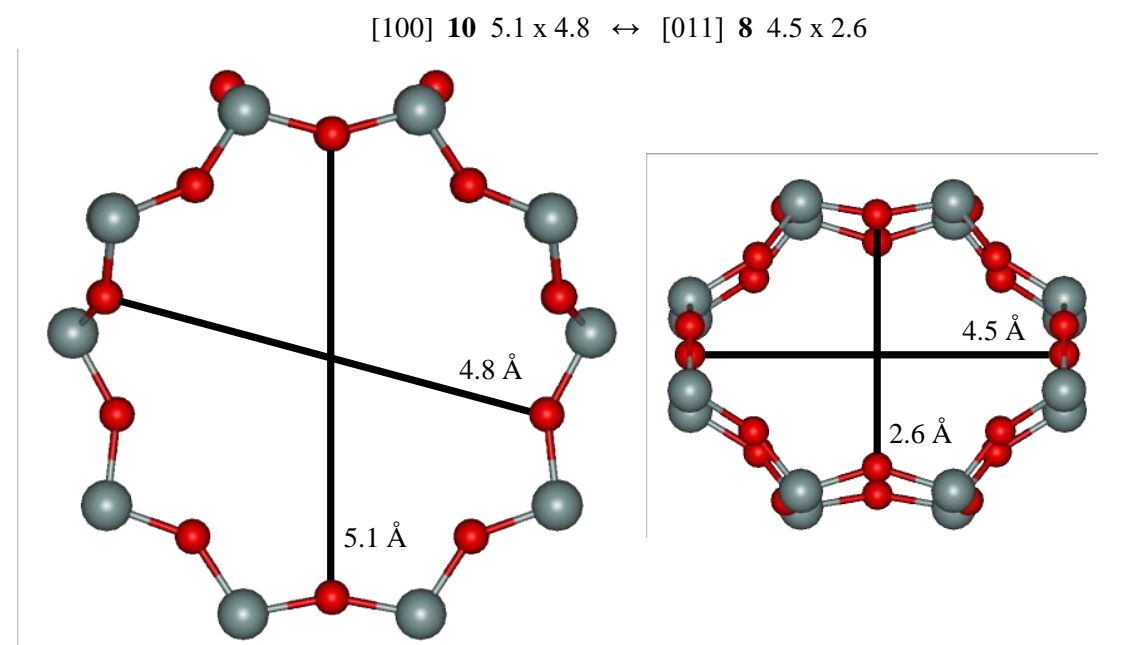

Figure 7.30. Pore channel topologies in zeolite ITQ-66 (grey: Si; red: O). Left: 10 MR channel viewed along [100]. Right: 8 MR channel viewed along [011].

The 10 MR channel runs straight along the $c$ direction ([001] direction) and it is intersected by the $8 \mathrm{MR}$ channel, connecting two $10 \mathrm{MR}$ channels by a tortuous zig-zag channel along the $b$ direction ([110] and [1-10] directions). The pore topology of the $10 \mathrm{MR}$ 
is nearly circular, while the $8 \mathrm{MR}$ present a highly distorted shape. This distortion of the pore opening explains why only the $10 \mathrm{MR}$ channel was observed in the Ar adsorption isotherm at $87 \mathrm{~K}$ in section 7.3.3.4, as the $8 \mathrm{MR}$ channel would not be accessible for most except the smaller molecules, like $\mathrm{H}_{2}$ or water.

\subsubsection{Location of heteroatoms in ITQ-66}

After the validation of the model obtained from Ultrafast Electron Diffraction Tomography, the Rietveld refinements of the borosilicate and gallosilicate samples showed slight differences between them. These differences arose from different values in the tetrahedral (TOT) angles between the two materials attached to specific $\mathrm{T}$ sites. The isomorphical substitution of Si atoms by atoms with different ionic radii leads to a slight modification of the TOT angles. ${ }^{[39,40]}$ Therefore, the different TOT angles in some T sites suggest that the B and the Ga atoms are being preferentially located in specific $\mathrm{T}$ atoms in the ITQ-66 framework. The framework positions were located by using the charge flipping method.$^{[41-44]}$ Using this method, the X-Ray diffraction data gives the electronic density of each framework position. The presence of positions with a defect or an excess of electronic density respect to the silicon atoms means that this positions are partially occupied by boron (electronic density defect) or gallium (electronic density excess) atoms. The results were again validated using the Rietveld method, showing a better fitting between the experimental X-Ray pattern and the proposed borosilicate and gallosilicate models, as shown in Figure 7.31.
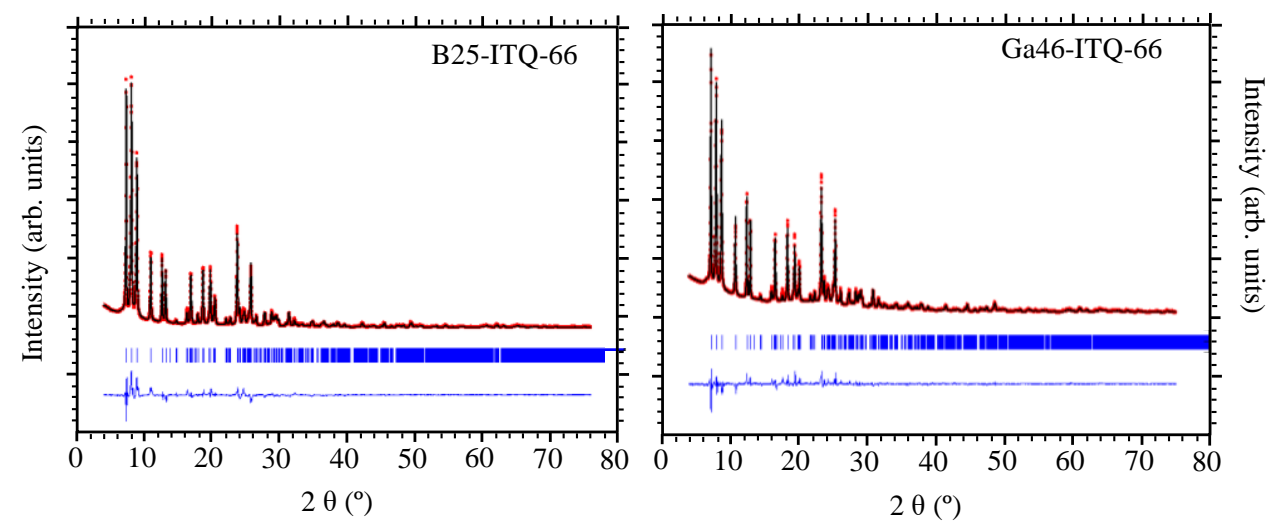

Figure 7.31. Rietveld refinement of the X-Ray diffraction pattern of B25 (left) and Ga46 (right) ITQ-66 materials hydrogenated at high temperature. Red data points show the observed XRPD pattern; the black line along these points is the calculated XRPD pattern, with the difference 
profile at the bottom in blue. The blue vertical tick marks below the pattern give the positions of the Bragg reflections.

The results show that boron atoms are preferentially located in T1, T4 and T6 sites, while gallium atoms are preferentially located in T3 and T5 sites, which are shown in the unit cell in Figure 7.32.

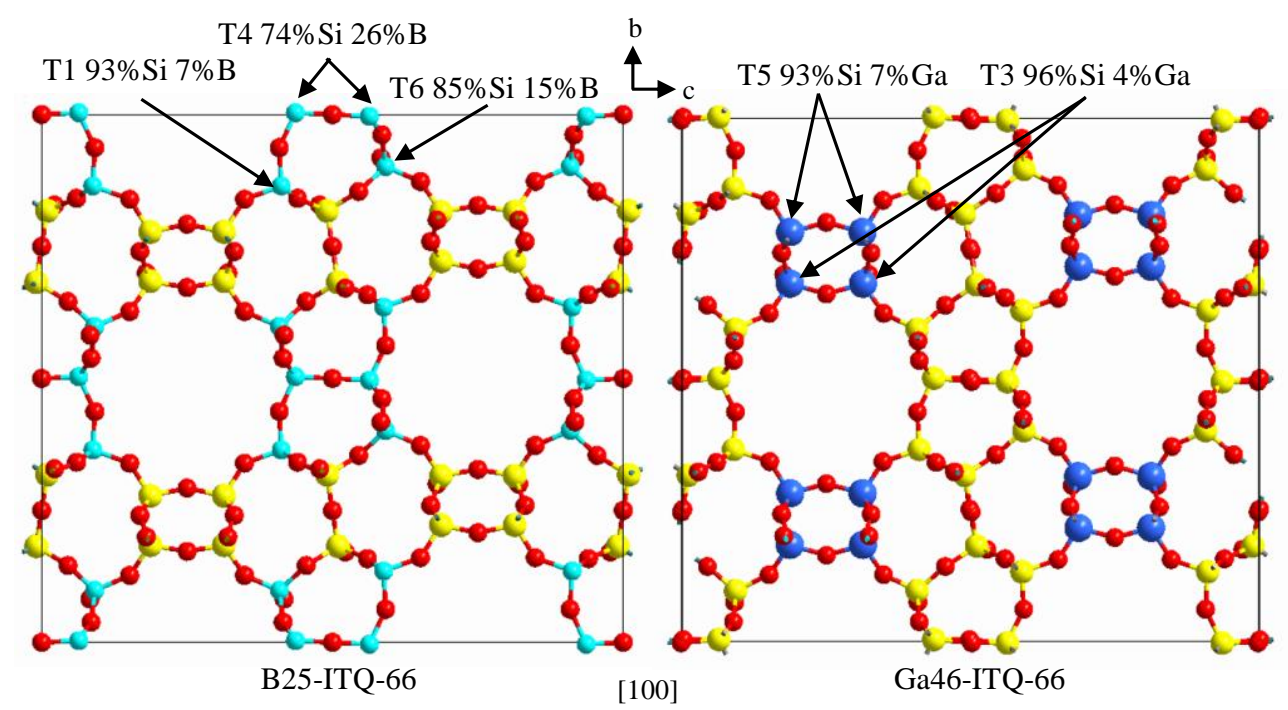

Figure 7.32. Unit cell [100] projection (yellow: silicon atoms; red: oxygen atoms) of borosilicate (left) and gallosilicate (right) ITQ-66 with $\mathrm{T}$ sites preferentially occupied by boron atoms (light blue) and gallium atoms (dark blue).

Interestingly, the $\mathrm{T}$ positions preferentially occupied by the boron and gallium atoms are different for each heteroatom. This suggest that probably aluminium is not preferentially located nor stabilised in any framework position, which would justify the impossibility to synthesize the ITQ-66 as aluminosilicate material. The post-synthesis treatment incorporation of aluminium in this zeolite could potentially allow incorporating $\mathrm{Al}$ in different framework positions depending on the parent material. However, post-synthesis treatments to incorporate aluminium were not performed yet. 


\subsubsection{NMR analyses of the ITQ-66 zeolite}

The incorporation of the phosphorous OSDA and the gallium and boron heteroatoms, as well as the lattice framework were studied by MAS-NMR spectroscopies on the as-made and thermally treated ITQ-66 materials.

\subsubsection{Incorporation and stability of the OSDA into the ITQ-66 zeolite}

The stability of the OSDA incorporated to the ITQ-66 zeolite was studied by ${ }^{31} \mathrm{P}$ MAS-NMR spectroscopy. The ${ }^{31} \mathrm{P}$ MAS-NMR spectra of the as-made samples and the liquid ${ }^{31} \mathrm{P}$ NMR spectrum of the free P-OSDA are shown in Figure 7.33.

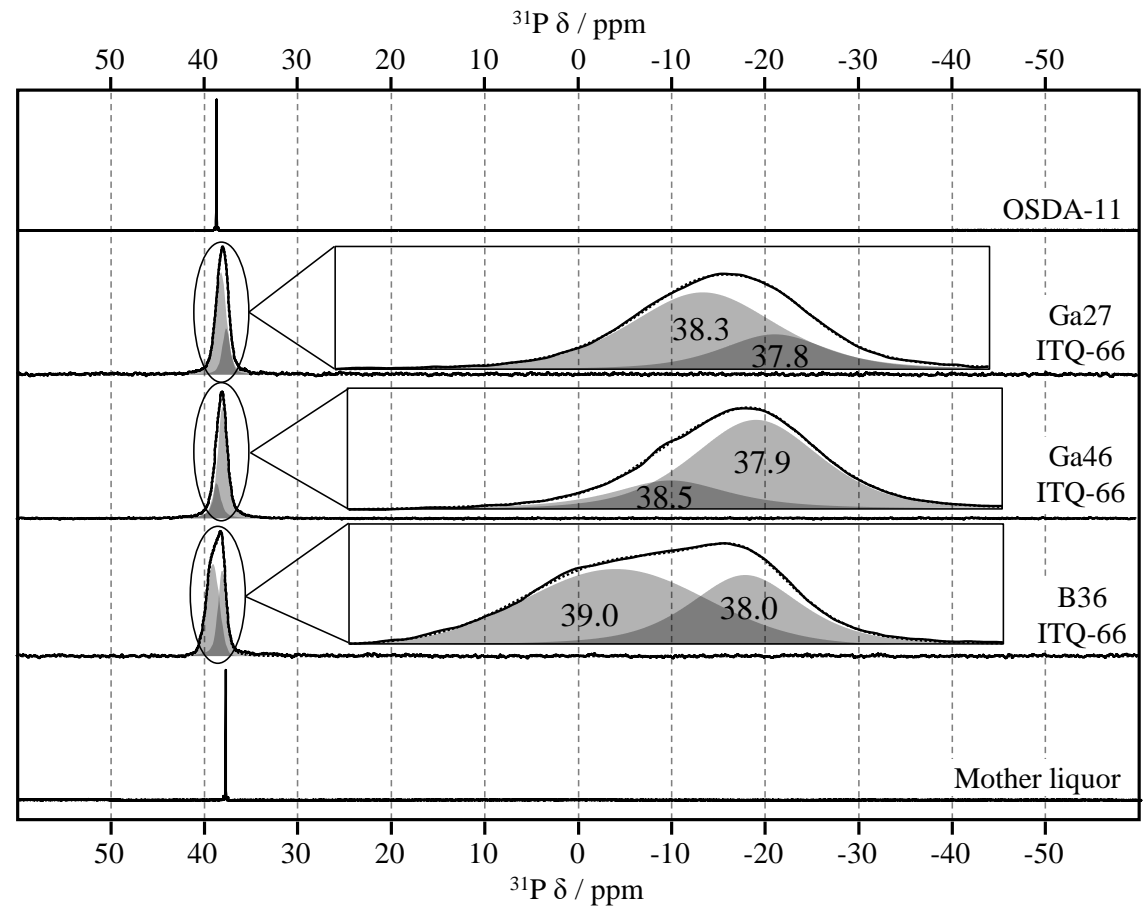

Figure 7.33. ${ }^{31} \mathrm{P}$ MAS-NMR spectra of some as-made ITQ-66 samples. Samples are named after the heteroatom and the as-made heteroatom to silica ratio content. Free OSDA and mother

liquor (obtained from B36 synthesis) liquid NMR spectra included for comparison.

The ${ }^{31} \mathrm{P}$ MAS-NMR spectra of the as-made samples show two close resonances, a main resonance around $38.0 \mathrm{ppm}$ and a smaller one around 39.0-38.5 ppm, depending on the sample. The relative intensity of these resonances depend on the sample composition, 
although no trend could be firmly stablished. These two resonances closely resemble to the liquid NMR of the P-OSDA in water solution (38.74 ppm), and thus, the two resonances must be due to two different chemical environments. These environments could be due to two different positions that the OSDA would adopt inside the channel of the zeolite.

After the thermal treatment of the materials, some of the phosphorus remains inside the material, giving the opportunity to study the chemical nature of the generated species by ${ }^{31} \mathrm{P}$ MAS-NMR spectroscopy, whose spectra are shown in Figure 7.34.

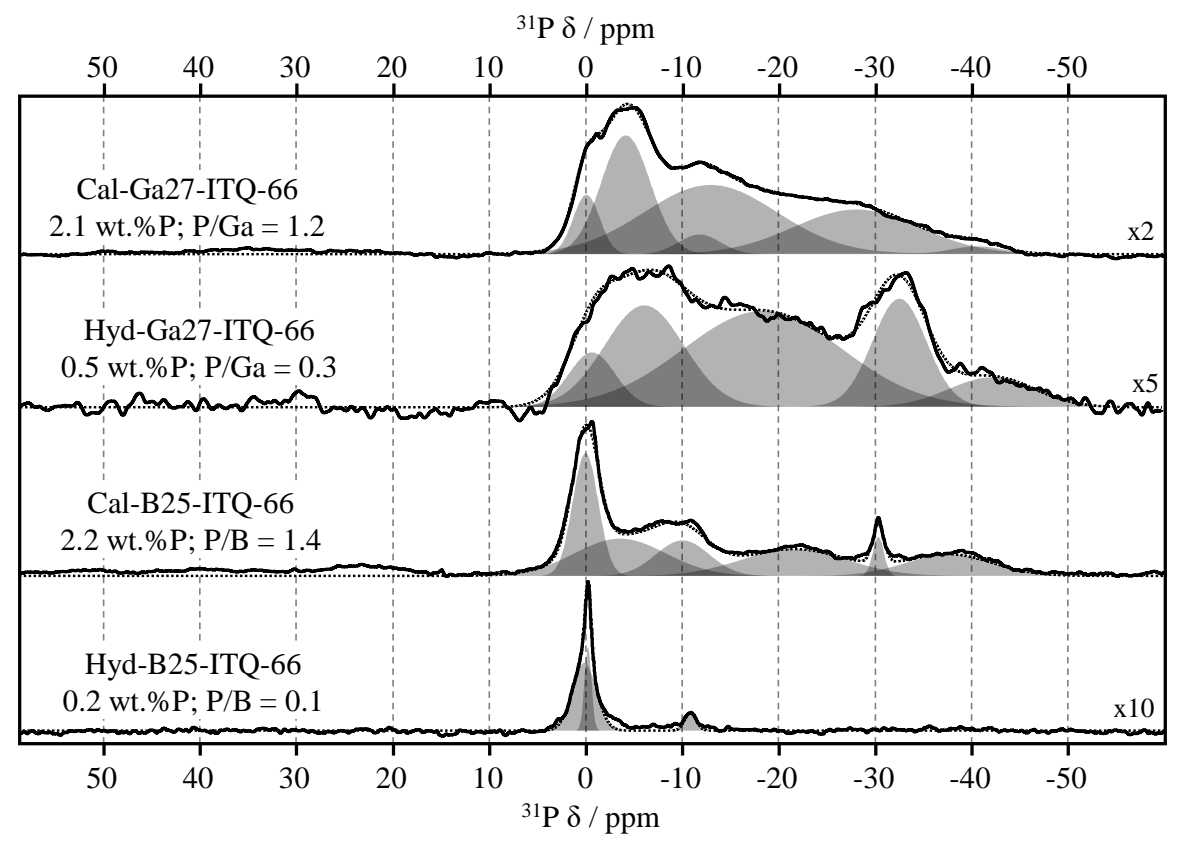

Figure 7.34. ${ }^{31} \mathrm{P}$ MAS-NMR spectra of thermally treated ITQ-66 materials. Samples are named after the thermal treatment (cal: calcined; hyd: hydrogenated at high temperature), followed by the heteroatom and as-made heteroatom to silica ratio content. Solid lines correspond to experimental spectra; dotted lines correspond to the sum of deconvoluted signals. Spectra were deconvoluted as Gaussian/Lorentz curves. Spectra not scaled on phosphorus content.

After the thermal treatments of the ITQ-66 materials, the organic compound is decomposed and the remaining phosphorous species gives rise to several ${ }^{31} \mathrm{P}$ resonances with chemical shifts ranging between $0 \mathrm{ppm}$ and $-42 \mathrm{ppm}$, which are characteristic of extraframework $\mathrm{P}_{2} \mathrm{O}_{5}$-like species. 
The calcined ITQ-66 samples give several wide ${ }^{31} \mathrm{P}$ resonances, with a different resonance profile depending on the composition. The mathematical deconvolution of the calcined ITQ-66 gallosilicate spectrum yields five different resonances: i) 0 ppm, assigned to assigned to extra-framework $\mathrm{P}_{2} \mathrm{O}_{5}$; ii) $-5 \mathrm{ppm}$, assigned to phosphorus atoms in pyrophosphoric acid or to terminal $\left[\mathrm{P}_{4} \mathrm{O}_{3}\right]^{-}$groups short in polyphosphoric species; ${ }^{[45-48]}$ iii) $-12 \mathrm{ppm}$, assigned to middle groups in pyrophosphates or other short-chain polyphosphates; ${ }^{[47,48]}$ and iv) $-28 \mathrm{ppm}$ and v) $-40 \mathrm{ppm}$, typically assigned to different (bi)phosphates bounded to monodentate or bidentate aluminium octahedral atoms, although in this case these signals should be attributed to phosphorous species interacting with gallium or boron. ${ }^{[45-48]}$

The calcined borosilicate ITQ-66 material also presents several resonances, with a particularly high intensity $0 \mathrm{ppm}$ resonance. In this sample, the $-5 \mathrm{ppm}$ resonance keeps the same chemical shift than the gallosilicate sample, while other resonances are shifted. Thus, the $-12 \mathrm{ppm}$ resonance in the gallosilicate sample is shifted to $-10 \mathrm{ppm}$ in the borosilicate sample; the $-28 \mathrm{ppm}$ resonance in the gallosilicate sample is shifted to $-30 \mathrm{ppm}$ in the borosilicate sample; and the $-40 \mathrm{ppm}$ resonance in the gallosilicate sample is shifted to $-38 \mathrm{ppm}$ in the borosilicate sample. Also, a resonance at $-22 \mathrm{ppm}$, typically assigned to longer polymeric phosphate chains, as well as highly condensed polyphosphate species ${ }^{[49-51]}$, is clearly visible in the borosilicate sample, while in the gallosilicate sample this resonance could be present but overshadowed by the wide -12 and -28 ppm resonances.

The hydrogenation at high temperature of the ITQ-66 materials decreases the phosphorus content of the gallosilicate sample, while in the borosilicate sample almost all phosphorus is removed. In the borosilicate sample, only three discrete resonances could be found: at $2 \mathrm{ppm}$ and $0 \mathrm{ppm}$, assigned to extra-framework $\mathrm{P}_{2} \mathrm{O}_{5}$ species; and at $-11 \mathrm{ppm}$, typically assigned to middle groups in pyrophosphates or other short-chain polyphosphates. ${ }^{[47,48]}$ This means that after the hydrogenation of the borosilicate ITQ-66 materials there is little interaction between the remaining phosphorous and boron species.

On the other hand, in the gallosilicate sample there is a significant amount of phosphorus remaining in the sample after the hydrogenation treatment. In this case, the mathematical deconvolution yields five wide resonances: i) $0 \mathrm{ppm}$, assigned to extra-framework $\mathrm{P}_{2} \mathrm{O}_{5}$; ii) $-6 \mathrm{ppm}$, assigned to middle groups in pyrophosphates or other short-chain polyphosphates; ${ }^{[47,48]}$ iii) $-18 \mathrm{ppm}$, typically assigned to longer polymeric phosphate chains, as well as highly condensed polyphosphate species $^{[49-51]}$; iv) -32 ppm and v) $-42 \mathrm{ppm}$, assigned to different (bi)phosphates bounded to monodentate or bidentate 
gallium octahedral atoms. ${ }^{[45-48]}$ Conversely with the borosilicate ITQ-66 sample, in the gallosilicate ITQ-66 sample most of the remaining phosphorus present chemical shifts typical of extra-framework $\mathrm{P}_{2} \mathrm{O}_{5}$-like species, suggesting a stronger interaction between the phosphorous species and the gallium than with the boron.

The chemical shifts of the resonances are close to the obtained for the RTH and IWV samples in sections 5.3.4 and 6.3.3.1, respectively, although in the case of ITQ-66 samples, the barycentres of the spectra are shifted down-field, towards resonances typically attributed to low condensed phosphorous species. This could be attributed to a lower interaction between the phosphorous species and the gallium or boron species than the interaction between the phosphorous and aluminium species from the RTH and IWV materials.

\subsubsection{Gallium incorporation into the ITQ-66 zeolite}

The gallium incorporation was studied by ${ }^{71} \mathrm{Ga}$ MAS-NMR spectroscopy on the as-made ITQ-66 gallosilicate samples, as well as on the different gallium species formed after thermal treatments, whose spectra are shown in Figure 7.35.

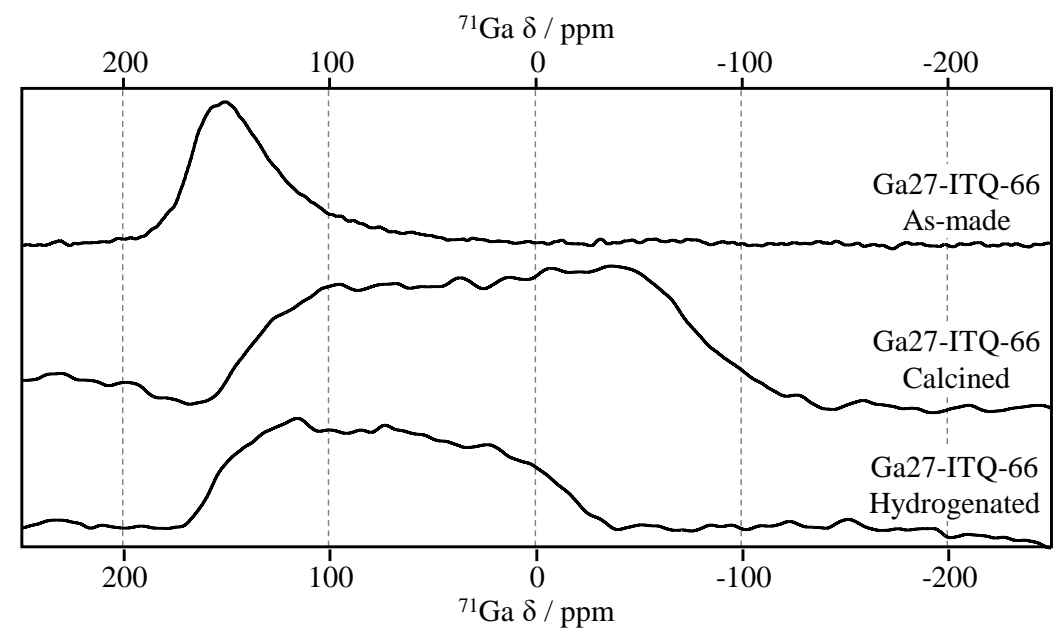

Figure 7.35. ${ }^{71}$ Ga MAS-NMR spectra of the as-made and the thermally treated gallosilicate ITQ-66 sample with $\mathrm{Si} / \mathrm{Ga}=27$.

The as-made Ga-ITQ-66 spectrum shows a wide single ${ }^{71} \mathrm{Ga}$ resonance at $151 \mathrm{ppm}$, which is typical of gallium atoms in tetrahedral coordination, and therefore, it can be concluded that the gallium is incorporated to the framework during synthesis. ${ }^{[52]}$ However, the ${ }^{71} \mathrm{Ga}$ MAS-NMR of the thermally treated samples shows the presence of up-field 
resonances, especially in the calcined sample, which closely resembles to previously reported gallium phosphate NMR spectra. ${ }^{[53]}$ The chemical shifts of these resonances, between 100

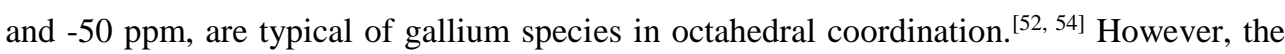
great width and asymmetry of the resonances in all spectra, especially in the calcined sample, make it difficult to guess the number and nature of the different gallium species in the thermally treated ITQ-66 samples.

\subsubsection{Boron incorporation into the ITQ-66 zeolite}

The boron incorporation was studied by ${ }^{11} \mathrm{~B}$ MAS-NMR spectroscopy in the as-made ITQ-66 borosilicate samples, as well as on the different boron species formed after thermal treatments, whose spectra are shown in Figure 7.36.

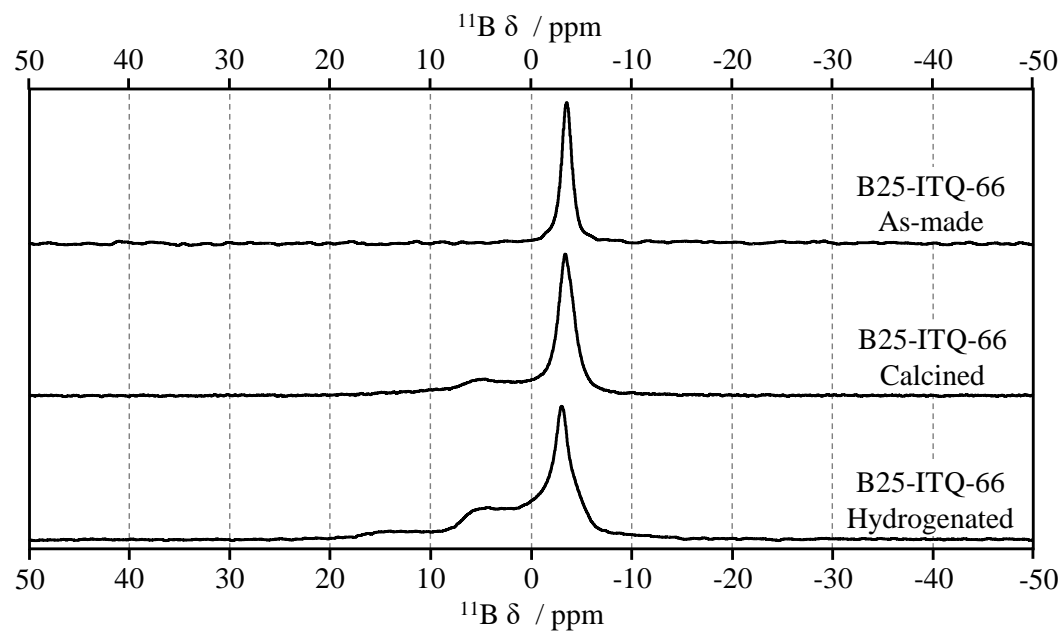

Figure 7.36. ${ }^{11} \mathrm{~B}$ MAS-NMR spectra of the as-made and thermally treated borosilicate ITQ-66 sample with $\mathrm{Si} / \mathrm{B}=25$.

The as-made spectrum shows a single ${ }^{11} \mathrm{~B}$ resonance at $-3.5 \mathrm{ppm}$, typical of boron in tetrahedral coordination, ${ }^{[27-29]}$ and therefore, the boron is getting incorporated to the framework during synthesis. After calcination, a new small and broad resonance appears around $5 \mathrm{ppm}$. This signal also appears in the hydrogenated sample, together with another resonance centred around $12 \mathrm{ppm}$. These two resonances are assigned to boron species in trigonal coordination and are typical of dehydrated borosilicate zeolites. ${ }^{[28,30]}$ 


\subsubsection{Fluorine incorporation into the ITQ-66 zeolite framework}

The incorporation of fluorine to the ITQ-66 zeolite and its interaction with the siliceous framework was studied by ${ }^{19} \mathrm{~F}$ MAS-NMR spectroscopy, whose spectra are shown in Figure 7.37.

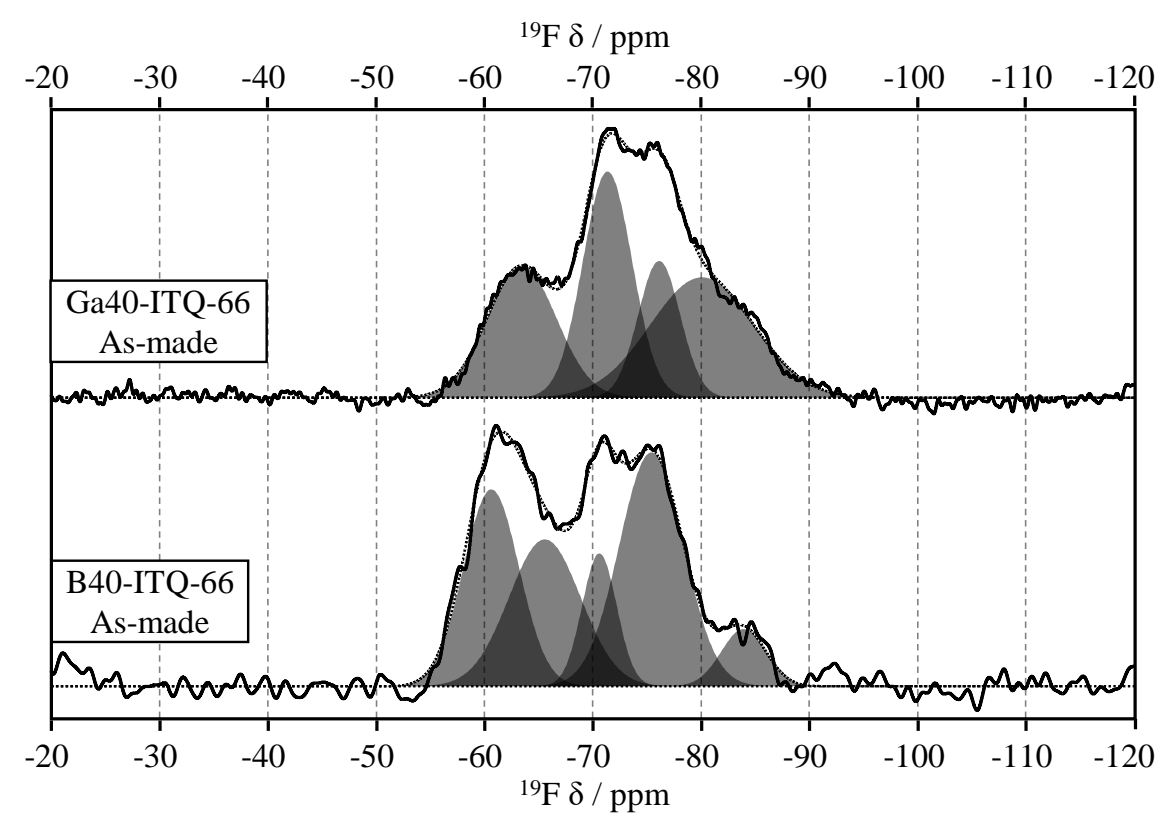

Figure 7.37. ${ }^{19}$ F MAS-NMR spectra of as-made ITQ-66 samples. Solid lines correspond to experimental spectra; dotted lines correspond to the sum of deconvoluted signals.

Several ${ }^{19} \mathrm{~F}$ resonances were observed in the range between $-60 \mathrm{ppm}$ and $-90 \mathrm{ppm}$, corresponding to fluorine atoms located inside different silica cages. ${ }^{[55-57]}$ It is noticeable that changing the heteroatom from $\mathrm{Ga}$ to $\mathrm{B}$ drastically modifies the relative fluorine occupation of the cages. This could be indicative of the different location of $\mathrm{B}$ and $\mathrm{Ga}$ atoms in the ITQ-66 zeolite framework, as previously detailed in section 7.3.4.3. 


\subsubsection{Silicon framework of the ITQ-66 zeolite}

The different chemical environments of the silicon species in the as-made and thermally treated gallosilicate ITQ-66 samples were studied by ${ }^{29} \mathrm{Si}$ MAS-NMR spectroscopy, whose spectra are shown in Figure 7.38.

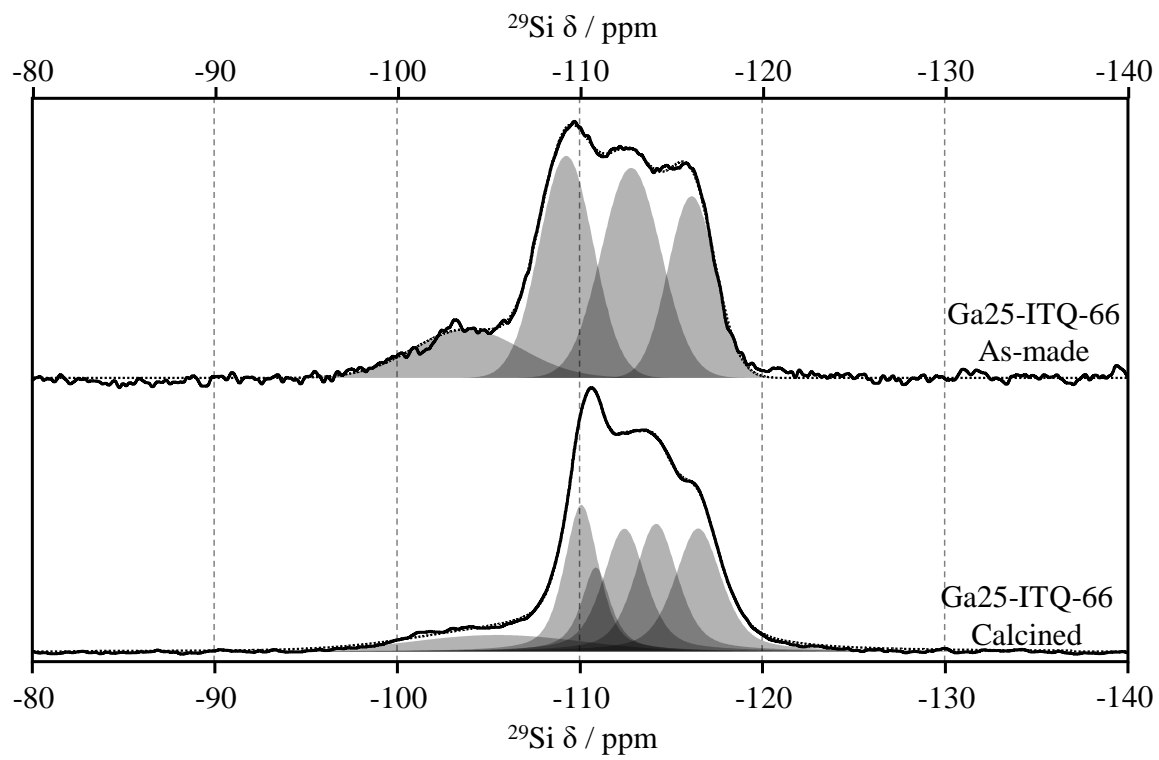

Figure 7.38. ${ }^{29} \mathrm{Si}$ MAS-NMR spectra of as-made and calcined gallosilicate ITQ-66 samples. Solid lines correspond to experimental spectra; dotted lines correspond to the sum of deconvoluted signals.

The mathematical deconvolution of ${ }^{29} \mathrm{Si}$ MAS-NMR spectrum of the as-made 25Ga-ITQ-66 yields at least four sets of ${ }^{29} \mathrm{Si}$ resonances. At higher field, there are three ${ }^{29} \mathrm{Si}$ resonances centred at $-110 \mathrm{ppm},-112 \mathrm{ppm}$ and $-115 \mathrm{ppm}$ and relative intensities 1:1:1 approximatively, although they are probably composed of multiple narrower signals. These resonances correspond to $\mathrm{Q}^{4} \mathrm{Si}$ atoms, tetrahedrally coordinated silicon atoms having silicon atoms in their second neighbourhood. At lower-field, a broad and smaller resonance is observed, centred on -104 ppm, which is assigned to $\mathrm{Q}^{3} \mathrm{Si}$ atoms in the zeolite (Si-O-Ga and $\mathrm{Si}-\mathrm{OH}$ groups). The area of this signal corresponds to $13.5 \%$, while the amount due to $\mathrm{Si}-\mathrm{O}-\mathrm{Ga}$ groups should correspond to $8.6 \%$ by chemical analyses (calculated by Equation $7.1)^{[58]}$, and therefore, the as-made material presents approximately $6 \%$ of Si-OH defects. 


$$
n_{S i} n_{G a}=\sum_{n=0}^{4} I_{S i(n G a)} / \sum_{n=0}^{4} 0.25 \cdot n \cdot I_{S i(n G a)}
$$

\section{Equation 7.1}

After calcination, the ${ }^{29} \mathrm{Si}$ NMR profile changes, increasing the intensities of the $\mathrm{Q}^{4}$ signals, and decrease the intensity of the $\mathrm{Q}^{3}$ signal. The area of the $\mathrm{Q}^{3}$ signal, 8.6\%, now perfectly matches with the amount of $\mathrm{Si}-\mathrm{Ga}$ groups obtained by chemical analysis (calculated by Equation 7.1), and therefore, no silanol groups remain after thermal treatment.

The mathematical deconvolution of the overlapped $\mathrm{Q}^{4}$ signal yielded at least five different resonances centred at -110 ppm, -111 ppm, -112 ppm, -114 ppm and -117 ppm, with relative intensities $2: 1: 2: 2: 2$. These relative intensities sums a total of 9 different $\mathrm{T}$ atoms, which results in a divisor of the 72 crystallographic positions found after structural resolution. The elucidation of the crystalline structure of the ITQ-66 yielded six crystallographic independent silicon positions, while the deconvolution of the ${ }^{29} \mathrm{Si}$ MAS-NMR spectra gave only five different silicon environments This could be explained as one of the deconvoluted signals is actually composed of two overlapping silicon environments, probably the wider resonance, centred at $-117 \mathrm{ppm}$.

\subsection{Conclusions}

The use of two novel phosphonium cations as OSDA's, the tris(dimethylamino) [4-(tri-tert-butylphosphonio)butyl]phosphonium (PN-PC) and the butane-1,4-diylbis (triethylphosphonium) cations, has allowed the synthesis of two new materials, the ITQ-58 and the ITQ-66 zeolites. The use of these OSDA's present the following features:

- The use of different phosphorous cations as OSDA's has allowed the synthesis and the structural resolution of the ITQ-58 zeolite, taking advantage of the different features that each kind of phosphorous OSDA present. Thus, the problems due to the smaller crystallite size of aminophosphonium cations was overcome using a dual "head" phosphonium and aminophosphonium OSDA, favouring the crystallization of larger crystallites. 
- A novel fast data collection methodology, the Ultrafast Electron Diffraction Tomography technique, has been developed for easily collect diffraction data from crystalline samples before the degradation of the sample under the highly energetic electron beam. The use of this technique is especially useful in the structural resolution of materials where the application of direct methods is difficult due to their complex structure.

- The butane-1,4-diylbis(triethylphosphonium) cation as OSDA has allowed the synthesis of the new ITQ-66 zeolite. The use of this relatively simple OSDA presents a clearly different structure directing role than its ammonium counterpart, which strengthen the fact that phosphorous OSDA's could present a different structure directing agent than ammonium OSDA's.

- The ITQ-66 zeolite present a bi-directional pore system, with medium (10 MR) and small ( $8 \mathrm{MR})$ pores. The presence of pores of different size could be useful in applications which require the diffusion of molecules of different size, although in this case, only the smallest molecules (like $\mathrm{H}_{2}$ ) could diffuse through the small pore channel of the ITQ-66 zeolite.

- The ITQ-66 zeolite presents a preferential incorporation of boron and gallium in specific lattice positions. However, aluminium was not successfully incorporated in the material, limiting the potential applications of this zeolite to weak acid catalyst or separation/adsorption for the time being.

\subsection{References}

[1] M.E. Davis, R.F. Lobo, Zeolite and molecular sieve synthesis, Chemistry of Materials, 4, 4, 1992, 756-768.

[2] M.E. Davis, Zeolites from a materials chemistry perspective, Chemistry of Materials, 26, 1, 2013, 239-245.

[3] C.S. Cundy, P.A. Cox, The hydrothermal synthesis of zeolites: history and development from the earliest days to the present time, Chemical Reviews, 103, 3, 2003, 663-702.

[4] J. Li, A. Corma, J. Yu, Synthesis of new zeolite structures, Chemical Society Reviews, 44, 20, 2015, 7112-7127. 
[5] F. Rey, J. Simancas, Beyond Nitrogen OSDAs, in: Insights into the Chemistry of Organic Structure-Directing Agents in the Synthesis of Zeolitic Materials, Springer International Publishing, 2018, 103-138.

[6] D.L. Dorset, K.G. Strohmaier, C.E. Kliewer, A. Corma, M.J. Díaz-Cabañas, F. Rey, C.J. Gilmore, Crystal structure of ITQ-26, a 3D framework with extra-large pores, Chemistry of Materials, 20, 16, 2008, 5325-5331.

[7] D.L. Dorset, G.J. Kennedy, K.G. Strohmaier, M.J. Diaz-Cabañas, F. Rey, A. Corma, PDerived Organic Cations as Structure-Directing Agents: Synthesis of a High-Silica Zeolite (ITQ-27) with a Two-Dimensional 12-Ring Channel System, Journal of the American Chemical Society, 128, 27, 2006, 8862-8867.

[8] A. Corma, M.J. Diaz-Cabanas, J.L. Jorda, F. Rey, G. Sastre, K.G. Strohmaier, A Zeolitic Structure (ITQ-34) with Connected 9- and 10-Ring Channels Obtained with Phosphonium Cations as Structure Directing Agents, Journal of the American Chemical Society, 130, 49, 2008, 16482-16483.

[9] A. Corma, M. Díaz-Cabañas, J. Jiang, M. Afeworki, D. Dorset, S. Soled, K. Strohmaier, Extra-large pore zeolite (ITQ-40) with the lowest framework density containing double fourand double three-rings, Proceedings of the National Academy of Sciences, 107, 32, 2010, 13997-14002.

[10] A. Corma, F. Rey, M.T. Navarro, R. Simancas, N. Velamazan, Á. Cantín, J.L. Jordá, ITQ-45 material, method for obtaining same and use thereof, Consejo Superior de Investigaciones Científicas, WO2012049344, 2012.

[11] F. Rey, M. Hernández-Rodríguez, J.L. Jordá, ITQ-49 material, method for the production thereof and use of same, Consejo Superior de Investigaciones Científicas, CA2870579, 2014.

[12] R. Simancas, J.L. Jordá, F. Rey, A. Corma, A. Cantín, I. Peral, C. Popescu, A New Microporous Zeolitic Silicoborate (ITQ-52) with Interconnected Small and Medium Pores, Journal of the American Chemical Society, 136, 9, 2014, 3342-3345.

[13] Y. Yun, M. Hernandez, W. Wan, X. Zou, J.L. Jorda, A. Cantin, F. Rey, A. Corma, The first zeolite with a tri-directional extra-large 14-ring pore system derived using a phosphonium-based organic molecule, Chemical Communications, 51, 36, 2015, 7602-7605.

[14] J. Simancas, R. Simancas, P.J. Bereciartua, J.L. Jorda, F. Rey, A. Corma, S. Nicolopoulos, P. Pratim Das, M. Gemmi, E. Mugnaioli, Ultrafast Electron Diffraction Tomography for Structure Determination of the New Zeolite ITQ-58, Journal of the American Chemical Society, 138, 32, 2016, 10116-10119. 
[15] R. Simancas, Síntesis de Nuevos Materiales Zeolíticos empleando Agente Directores de Estructura Fosforados, Universitat Politècnica de València, 2015.

[16] R. Simancas, D. Dari, N. Velamazán, M.T. Navarro, A. Cantín, J.L. Jordá, G. Sastre, A. Corma, F. Rey, Modular organic structure-directing agents for the synthesis of zeolites, Science, 330, 6008, 2010, 1219-1222.

[17] T. Lemishko, J. Simancas, M. Hernández-Rodríguez, M. Jiménez-Ruiz, G. Sastre, F. Rey, An INS study of entrapped organic cations within the micropores of zeolite RTH, Physical Chemistry Chemical Physics, 18, 2016, 17244-17252.

[18] T. Maruo, N. Yamanaka, N. Tsunoji, M. Sadakane, T. Sano, Facile Synthesis of AEI Zeolites by Hydrothermal Conversion of FAU Zeolites in the Presence of Tetraethylphosphonium Cations, Chemistry Letters, 43, 3, 2014, 302-304.

[19] Y. Kakiuchi, Y. Yamasaki, N. Tsunoji, Y. Takamitsu, M. Sadakane, T. Sano, One-pot synthesis of phosphorus-modified AEI zeolites derived from the dual-template method as a durable catalyst with enhanced thermal/hydrothermal stability for selective catalytic reduction of $\mathrm{NO}_{\mathrm{x}}$ by $\mathrm{NH}_{3}$, Chemistry Letters, 45, 2, 2016, 122-124.

[20] Y. Yamasaki, N. Tsunoji, Y. Takamitsu, M. Sadakane, T. Sano, Synthesis of phosphorus-modified small-pore zeolites utilizing tetraalkyl phosphonium cations as both structure-directing and phosphorous modification agents, Microporous and Mesoporous Materials, 223, 2016, 129-139.

[21] T. Blasco, A. Corma, J. Martínez-Triguero, Hydrothermal stabilization of ZSM-5 catalytic-cracking additives by phosphorus addition, Journal of Catalysis, 237, 2, 2006, 267277.

[22] K. Damodaran, J.W. Wiench, S.M. Cabral de Menezes, Y.L. Lam, J. Trébosc, J.-P. Amoureux, M. Pruski, Modification of H-ZSM-5 zeolites with phosphorus. 2. Interaction between phosphorus and aluminum studied by solid-state NMR spectroscopy, Microporous and Mesoporous Materials, 95, 1-3, 2006, 296-305.

[23] N. Xue, R. Olindo, J.A. Lercher, Impact of forming and modification with phosphoric acid on the acid sites of HZSM-5, The Journal of Physical Chemistry C, 114, 37, 2010, 15763-15770.

[24] J.C. Védrine, A. Auroux, P. Dejaifve, V. Ducarme, H. Hoser, S. Zhou, Catalytic and physical properties of phosphorus-modified ZSM-5 zeolite, Journal of Catalysis, 73, 1, 1982, 147-160. 
[25] M.C. Burla, R. Caliandro, B. Carrozzini, G.L. Cascarano, C. Cuocci, C. Giacovazzo, M. Mallamo, A. Mazzone, G. Polidori, Crystal structure determination and refinement viaSIR2014, Journal of Applied Crystallography, 48, 1, 2015, 306-309.

[26] M. Hernández-Rodriguez, Empleo de Cationes Fosfonio como Agentes Directores de Estructura (ADEs) en la Síntesis de Zeolitas, Universitat Politècnica de València, 2014.

[27] R. Millini, G. Perego, G. Bellussi, Synthesis and characterization of boron-containing molecular sieves, Topics in Catalysis, 9, 1-2, 1999, 13-34.

[28] S.-J. Hwang, C.-Y. Chen, S.I. Zones, Boron sites in borosilicate zeolites at various stages of hydration studied by solid state NMR spectroscopy, The Journal of Physical Chemistry B, $108,48,2004,18535-18546$.

[29] C. Fild, D.F. Shantz, R.F. Lobo, H. Koller, Cation-induced transformation of boroncoordination in zeolites, Physical Chemistry Chemical Physics, 2, 13, 2000, 3091-3098.

[30] H.T.T. Tong, H. Koller, Control of Al for B framework substitution in zeolite Beta by counterions, Microporous and Mesoporous Materials, 148, 1, 2012, 80-87.

[31] M. Thommes, K. Kaneko, A.V. Neimark, J.P. Olivier, F. Rodriguez-Reinoso, J. Rouquerol, K.S. Sing, Physisorption of gases, with special reference to the evaluation of surface area and pore size distribution (IUPAC Technical Report), Pure and Applied Chemistry, 87, 9-10, 2015, 1051-1069.

[32] E. van Genderen, M.T.B. Clabbers, P.P. Das, A. Stewart, I. Nederlof, K.C. Barentsen, Q. Portillo, N.S. Pannu, S. Nicolopoulos, T. Gruene, J.P. Abrahams, Ab initio structure determination of nanocrystals of organic pharmaceutical compounds by electron diffraction at room temperature using a Timepix quantum area direct electron detector, Acta Crystallographica Section A, 72, 2, 2016.

[33] M. Gemmi, M.G.I. La Placa, A.S. Galanis, E.F. Rauch, S. Nicolopoulos, Fast electron diffraction tomography, Journal of Applied Crystallography, 48, 3, 2015, 718-727.

[34] U. Kolb, E. Mugnaioli, T. Gorelik, Automated electron diffraction tomography-a new tool for nano crystal structure analysis, Crystal Research and Technology, 46, 6, 2011, 542554.

[35] J. Rodriguez-Carvajal, Commission on powder diffraction (IUCr), Newsletter, 26, 2001, 12.

[36] M. Sasidharan, A. Bhaumik, Designing the synthesis of catalytically active Ti- $\beta$ by using various new templates in the presence of fluoride anion, Physical Chemistry Chemical Physics, 13, 36, 2011, 16282-16294. 
Chapter 7: Synthesis of New Zeolite Materials

[37] S. Saez Ferre, Nuevas rutas de síntesis de materiales porosos y su aplicación en procesos de separación, Universitat Politècnica de València, 2019.

[38] G. Horváth, K. Kawazoe, Method for the calculation of effective pore size distribution in molecular sieve carbon, Journal of Chemical Engineering of Japan, 16, 6, 1983, 470-475.

[39] G. Sastre, J.A. Vidal-Moya, T. Blasco, J. Rius, J.L. Jordá, M.T. Navarro, F. Rey, A. Corma, Preferential Location of Ge Atoms in Polymorph C of Beta Zeolite (ITQ-17) and Their Structure-Directing Effect: A Computational, XRD, and NMR Spectroscopic Study, Angewandte Chemie International Edition, 41, 24, 2002, 4722-4726.

[40] T. Blasco, A. Corma, M.J. Díaz-Cabañas, F. Rey, J.A. Vidal-Moya, C.M. ZicovichWilson, Preferential location of Ge in the double four-membered ring units of ITQ-7 zeolite, The Journal of Physical Chemistry B, 106, 10, 2002, 2634-2642.

[41] G. Oszlányi, A. Sütő, Ab initio structure solution by charge flipping, Acta Crystallographica Section A: Foundations of Crystallography, 60, 2, 2004, 134-141.

[42] G. Oszlányi, A. Sütő, The charge flipping algorithm, Acta Crystallographica Section A: Foundations of Crystallography, 64, 1, 2008, 123-134.

[43] A.B. Pinar, L.B. McCusker, C. Baerlocher, J. Schmidt, S.J. Hwang, M.E. Davis, S.I. Zones, Location of $\mathrm{Ge}$ and extra-framework species in the zeolite ITQ-24, Dalton Transactions, 44, 13, 2015, 6288-6295.

[44] A. Altomare, C. Cuocci, A. Moliterni, R. Rizzi, Charge flipping, 2019.

[45] J. Caro, M. Bülow, M. Derewinski, J. Haber, M. Hunger, J. Kärger, H. Pfeifer, W. Storek, B. Zibrowius, NMR and IR studies of zeolite H-ZSM-5 modified with orthophosphoric acid, Journal of Catalysis, 124, 2, 1990, 367-375.

[46] G. Lischke, R. Eckelt, H.-G. Jerschkewitz, B. Parlitz, E. Schreier, W. Storek, B. Zibrowius, G. Öhlmann, Spectroscopic and physicochemical characterization of P-modified H-ZSM-5, Journal of Catalysis, 132, 1991, 229-243.

[47] A.-R. Grimmer, U. Haubenreisser, High-field static and MAS ${ }^{31}$ P NMR: chemical shift tensors of polycrystalline potassium phosphates $\mathrm{P}_{2} \mathrm{O}_{5} \cdot \mathrm{xK}_{2} \mathrm{O}(0 \leq \mathrm{x} \leq 3)$, Chemical Physics Letters, 99, 5, 1983, 487-490.

[48] T. Duncan, D. Douglas, On the 31P chemical shift anisotropy in condensed phosphates, Chemical Physics, 87, 3, 1984, 339-349.

[49] D. Müller, E. Jahn, G. Ladwig, U. Haubenreisser, High-resolution solid-state ${ }^{27} \mathrm{Al}$ and ${ }^{31} \mathrm{P}$ NMR: correlation between chemical shift and mean Al-O-P angle in $\mathrm{AlPO}_{4}$ polymorphs, Chemical Physics Letters, 109, 4, 1984, 332-336. 
[50] C. Blackwell, R. Patton, Aluminum-27 and phosphorus-31 nuclear magnetic resonance studies of aluminophosphate molecular sieves, American Chemical Society, 88, 25, 1984, 6135-6139.

[51] E.C. Decanio, J.C. Edwards, T.R. Scalzo, D.A. Storm, J.W. Bruno, FT-IR and solidstate NMR investigation of phosphorus promoted hydrotreating catalyst precursors, Journal of Catalysis, 132, 2, 1991, 498-511.

[52] R. Fricke, H. Kosslick, G. Lischke, M. Richter, Incorporation of gallium into zeolites: Syntheses, properties and catalytic application, Chemical Reviews, 100, 6, 2000, 2303-2406.

[53] L.K. Broom, G.J. Clarkson, N. Guillou, J.E. Hooper, D.M. Dawson, C.C. Tang, S.E. Ashbrook, R.I. Walton, A gel aging effect in the synthesis of open-framework gallium phosphates: structure solution and solid-state NMR of a large-pore, open-framework material, Dalton Transactions, 46, 48, 2017, 16895-16904.

[54] A. Arnold, S. Steuernagel, M. Hunger, J. Weitkamp, Insight into the dry-gel synthesis of gallium-rich zeolite [Ga] Beta, Microporous and Mesoporous Materials, 62, 1-2, 2003, 97-106.

[55] J.A. Vidal-Moya, T. Blasco, F. Rey, A. Corma, M. Puche, Distribution of Fluorine and Germanium in a New Zeolite Structure ITQ-13 Studied by ${ }^{19} \mathrm{~F}$ Nuclear Magnetic Resonance, Chemistry of Materials, 15, 21, 2003, 3961-3963.

[56] H. Koller, M. Weiß, Solid state NMR of porous materials, in: Solid state NMR, Springer, 2011, 189-227.

[57] A. Pulido, G. Sastre, A. Corma, Computational Study of ${ }^{19}$ F NMR Spectra of Double Four Ring-Containing Si/Ge-Zeolites, ChemPhysChem, 7, 5, 2006, 1092-1099.

[58] J. Thomas, C. Fyfe, S. Ramdas, J. Klinowski, G. Gobbi, High-resolution silicon-29 nuclear magnetic resonance spectrum of zeolite ZK-4: its significance in assessing magic angle spinning nuclear magnetic resonance as a structural tool for aluminosilicates, American Chemical Society, 86, 16, 1982, 3061-3064. 


\section{Chapter 8}

\section{$\underline{\text { Conclusions }}$}

\subsection{General conclusions}

As a general conclusion of this thesis, several zeolite structures have been obtained by using phosphorous cations as OSDA's. The main general conclusions are:

- It has been proved that phosphorous OSDA's present a higher stability than ammonium OSDA's depending on the synthesis media and conditions.

- Also, the joint use of phosphorous and ammonium OSDA's has allowed the selective incorporation of phosphorus to the target material.

- Two new zeolite structures, the ITQ-58 and the ITQ-66 zeolites, have been obtained.

- Several known zeolites have been obtained with alternative synthesis pathways, like the ITQ-27 (IWV) and UTD-1 (DON) zeolites, and the less studied STF, ITE and MEL zeolites.

As previously detailed in section 1.3, at least 18 zeolitic structures had been successfully synthesized by using phosphorous OSDA's. After this thesis, the number of zeolite structures obtained with phosphorous OSDA's have been increased to 22 . 
The detailed conclusions for each chapter are summarized below:

\subsection{OSDA stability}

The stability studies discussed in this chapter have proven that phosphorous cations generally present improved crystallization rates and stabilities respect to traditional alkylammonium cations when used as OSDA in the synthesis of zeolites.

- The use of phosphorous OSDA's increase the crystallization rate for a given phase compared with related ammonium OSDA's. This result suggests that there is a higher affinity between the phosphorous OSDA's and the zeolitic matrix than the corresponding ammonium OSDA's.

- The phosphorous OSDA stability is heavily influenced by the chemical nature of the phosphorous cations. Thus, phosphonium cations are more stable under any condition than closely related ammonium cations. Phosphazenium cations present a great stability in hydroxide media, but are highly unstable in fluoride media, while aminophosphonium cations present a middle stability under hydroxide and fluoride media.

- These results must be highlighted only while comparing closely related cations, as not every phosphorous OSDA is always more stable than any ammonium OSDA. However, these studies have led us to carry on more sensible screening syntheses for OSDA's in its more stable media depending on the chemical nature of the OSDA. For example, hydroxide media is prioritized over fluoride media when using phosphazene bases, while fluoride media is prioritized when using alkylphosphonium or alkylammonium cations as OSDA's in the synthesis of zeolites.

- The stability of OSDA's is influenced by the synthesis gel composition. Silicate species increase the stability of the cations, while the introduction of boron further increases the stability of the cation, even when no crystalline product is obtained. This leads to suggest the use of negatively charged additives which could enhance the stability of the cation in the synthesis media.

The study of the stability of OSDA's is a useful complementary tool when testing cations as OSDA's. A quick decomposition could lead to the formation of species yielding different phase selectivity than the desired, while stable cations could be tested at higher 
temperatures and/or synthesis times. A stable OSDA could also be reused leading to an effective increase of the incorporation yield of the OSDA.

\subsection{Phosphorous-modified zeolite}

The use of phosphorous cations as OSDA's has allowed the synthesis of two phosphorous modified zeolites, the MFI and the RTH zeolites, using a dual template synthesis methodology jointly using closely related nitrogen and phosphorous OSDA's. This synthesis methodology provides the materials with the following features:

- The use of P-OSDA and N-OSDA yields zeolites with controlled phosphorus contents. The preferential incorporation of phosphorus allows to selectively and accurately incorporate the needed amount of phosphorus.

- The calcination of the aluminosilicate materials obtained by this methodology allows keeping most of the phosphorus incorporated, and thus, the $\mathrm{P} / \mathrm{Al}$ ratio could be tuned just by using the required $\mathrm{P} /(\mathrm{P}+\mathrm{N})$ OSDA ratio in the synthesis gel.

- The introduction of phosphorus by this methodology allows modifying the textural and acidic properties of the final materials avoiding further post-synthesis treatments.

- The application of post-synthesis treatments, as calcination, hydrogenation at high temperature, or washing with $\mathrm{NH}_{4} \mathrm{Ac}$, allows the removal of different amounts of phosphorus. However, the use of the dual template synthesis methodology is more flexible than the hydrogenation at high temperature and the washing with $\mathrm{NH}_{4} \mathrm{Ac}$, since phosphorus removal by these latter methods is difficult to control.

- The use of the dual template methodology allows the incorporation of different amounts of phosphorus in a small pore zeolite, the RTH zeolite, that is impossible by post-synthesis treatments.

- The introduction of phosphorus in the RTH small pore zeolite leads to diffusional constraints when the phosphorus content reaches a critical amount, between 0.6 and $1.2 \mathrm{wt} . \% \mathrm{P}$, but pore blockage does not occur.

- The introduction of phosphorus in the synthesis stage avoids the formation of significant amounts of $\mathrm{P}_{2} \mathrm{O}_{5}$ phosphorous species that are not interacting with the aluminium species of the materials. These species negatively affect to the textural 
properties of the material without providing a positive effect due to its lack of interaction with framework aluminium species.

- The introduction of lower amounts of phosphorus by the dual template methodology than by post-synthesis treatment allows to identify discrete phosphorus resonances by ${ }^{31} \mathrm{P}$ MAS-NMR spectroscopy. These discrete resonances appear in aluminosilicate material's spectra of both MFI and RTH zeolites, but their intensities vary depending on the thermal treatment and the phosphorus content of each material.

- The intensity of some of the ${ }^{31} \mathrm{P}$ resonances could be linked with the relative intensity of the different ${ }^{27} \mathrm{Al}$ resonances. Likewise, these ${ }^{27} \mathrm{Al}$ resonances could be linked with the acidic properties of the materials. Although the specific phosphorous species have not yet been identified, additional NMR experiments could reveal more details about the chemical nature of these phosphorous species interacting with the framework aluminium species in zeolites.

\subsection{Synthesis of IWV and DON zeolites}

The use of a novel aminophosphonium cation as OSDA, the tris(diethylamino)(methyl)phosphonium cation, has allowed the synthesis of two known materials, the ITQ-27 (IWV) and the UTD-1 (DON). Thus, the use of this OSDA constitute an alternative synthesis pathway, presenting the following features:

- The aminophosphonium OSDA allowed obtaining the IWV zeolite as aluminosilicate, borosilicate, germanosilicate and all-silica materials, both in fluoride and hydroxide media, and in highly concentrated synthesis gels. However, aluminium was not fully incorporated to the zeolite framework in hydroxide media syntheses. A deeper study of the synthesis conditions could fix this result.

- The all-silica IWV zeolite has been synthesized for the first time, which allowed a deeper study of the IWV structure by MAS-NMR, suggesting a lower symmetry. However, the final spatial group has not been determined yet.

- The use of a phosphorous OSDA allows the introduction of phosphorus in the IWV zeolite during the synthesis stage. The different post-synthesis treatment allows modifying the phosphorus content, which translate in a modification and modulation of the textural and acidic properties of the final material. 
- The hydrogenation at high temperature of the IWV materials has allowed obtaining materials with the highest BET surface and micropore volumes ever reported in IWV zeolite.

- The aminophosphonium OSDA allowed obtaining the DON zeolite as aluminosilicate, borosilicate and all-silica materials in hydroxide media. However, aluminium was not fully incorporated to the zeolite framework. A deeper study of the synthesis conditions could fix this result.

- The DON materials obtained present similar properties to previously reported, but the aminophosphonium OSDA is easier and/or cheaper to synthesize than previous described OSDA's.

- The aminophosphonium OSDA is easily recoverable after zeolite synthesis and remains stable after hydrothermal treatment, which allows its reuse.

\subsection{Synthesis of new zeolite materials}

The use of two novel phosphonium cations as OSDA's, the tris(dimethylamino)[4(tri-tert-butylphosphonio)butyl]phosphonium (PN-PC) and the butane-1,4-diylbis(triethylphosphonium) cations, has allowed the synthesis of two new materials, the ITQ-58 and the ITQ-66 zeolites. The use of these OSDA's present the following features:

- The use of different phosphorous cations as OSDA's has allowed the synthesis and the structural resolution of the ITQ-58 zeolite, taking advantage of the different features that each kind of phosphorous OSDA present. Thus, the problems due to the smaller crystallite size of aminophosphonium cations was overcome by using a dual "head" phosphonium and aminophosphonium OSDA, favouring the crystallization of larger crystallites.

- A novel fast data collection methodology, the Ultrafast Electron Diffraction Tomography technique, has been developed for easily collect diffraction data from crystalline samples before the degradation of the sample under the highly energetic electron beam. The use of this technique is especially useful in the structural resolution of materials where the application of direct methods is difficult due to their complex structure. 
- The butane-1,4-diylbis(triethylphosphonium) cation as OSDA has allowed the synthesis of the new ITQ-66 zeolite. The use of this relatively simple OSDA present a clearly different structure directing agent than its ammonium counterpart, which strengthen the fact that phosphorous OSDA's could present a different structure directing agent than ammonium OSDA's.

- The ITQ-66 zeolite present a bi-directional pore system, with medium (10 MR) and small ( $8 \mathrm{MR})$ pores. The presence of pores of different size could be useful in applications which require the diffusion of molecules of different size, although in this case, only the smallest molecules (like $\mathrm{H}_{2}$ ) could diffuse through the small pore channel of the ITQ-66 zeolite.

- The ITQ-66 zeolite presents a preferential incorporation of boron and gallium in specific lattice positions. However, aluminium was not successfully incorporated in the material, limiting the potential applications of this zeolite to weak acid catalyst or separation/adsorption for the time being. 



\section{Figure index}

Figure 1.1. Zeolitic Secondary Building Units (SBU’s). Frequency of occurrence is given in

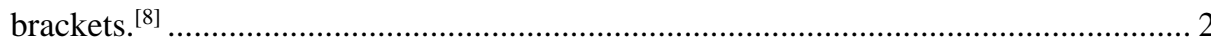

Figure 1.2. Zeolitic Composite Building Units (CBU's). ${ }^{[8]}$.............................................. 3

Figure 1.3. Number of material science (red), zeolite materials (green) and zeolite synthesis (blue) publications per year (left), number of publications per year in logarithmic scale (middle) and share of publications for each field (right). Font: Web of Science. ....... 10

Figure 1.4. Synthesis mechanism scheme of zeolites from zeolite precursors into crystalline zeolite during the synthesis of zeolites

Figure 1.5. Schematic representation of the nucleation rate (blue) and crystal growth rate (red) of zeolites along synthesis time. 12

Figure 1.6. Hydrothermal synthesis scheme of a zeolite 15

Figure 1.7. Number of zeolite structures synthesized and share of each type of SDA described for the synthesis of zeolitic structures per year. 19

Figure 1.8. Main degradation pathways of ammonium cations under hydrothermal treatment. 22

Figure 1.9. General schematic pathway for the synthesis of tetraalkylphosphonium cations. 23

Figure 1.10. Main degradation pathways of tetraalkylphosphonium cations under

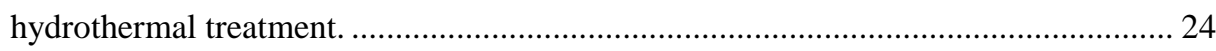

Figure 1.11. Types of phosphorous cations used as OSDA's.......................................... 24

Figure 1.12. Proposed models for phosphorus-zeolite interaction. (a) Vedrine et al., ${ }^{[158]}$ (b) Lercher et al., ${ }^{[144]}$ (c) and (d) Corma et al., ${ }^{[138]}$ (e) Xue et al. ${ }^{[159]}$............................... 30

Figure 1.13. Schematic view of the calcination process of N-OSDA and P-OSDA inside a zeolite structure. 31

Figure 3.1. Schematic view of the interaction between X-Rays and a crystalline material, following the Bragg's law. 70

Figure 3.2. Classification of adsorption-desorption isotherms. ...................................... 72

Figure 3.3. Energy levels of a $1 / 2$ spin nuclei exposed to a magnetic field......................... 76

Figure 3.4. ${ }^{29} \mathrm{Si}$ MAS-NMR chemical shifts of $\mathrm{Si}(n \mathrm{Al})$ units in zeolite frameworks. The dotted lines for $\mathrm{Si}(4 \mathrm{Al})$ designate the chemical shift range observed for $1: 1$ aluminosilicate sodalites with different cage fillings. .78 
Figure 3.5. ${ }^{1} \mathrm{H}-\mathrm{NMR}$ (above) and ${ }^{13} \mathrm{C}-\mathrm{NMR}$ (below) spectra of tetraethylammonium hydroxide in deuterated water solution $\left(\mathrm{D}_{2} \mathrm{O}\right)$. Asterisk in ${ }^{1} \mathrm{H}-\mathrm{NMR}$ spectrum marks proton resonance of water.

Figure 3.6. ${ }^{1} \mathrm{H}-\mathrm{NMR}$ (above), ${ }^{13} \mathrm{C}-\mathrm{NMR}$ (middle) and ${ }^{31} \mathrm{P}-\mathrm{NMR}$ (below) spectra of tetraethylphosphonium bromide in deuterated water solution $\left(\mathrm{D}_{2} \mathrm{O}\right)$. Asterisk in ${ }^{1} \mathrm{H}-$ NMR spectrum marks proton resonance of water.

Figure 3.7. Synthesis scheme of the methyl-tris-(dimethylamino)-phosphonium cation (MNP).

Figure 3.8. ${ }^{1} \mathrm{H}-\mathrm{NMR}$ (above) ${ }^{13} \mathrm{C}-\mathrm{NMR}$ (middle) and ${ }^{31} \mathrm{P}-\mathrm{NMR}$ (below) spectra of methyltris-(dimethylamino)-phosphonium iodide in deuterated water solution $\left(\mathrm{D}_{2} \mathrm{O}\right)$. Asterisk in ${ }^{1} \mathrm{H}$-NMR spectrum marks proton resonance of water.

Figure 3.9. Synthesis scheme of the methyl-tri-isopropylphosphonium cation (MIP).........91

Figure 3.10. ${ }^{1} \mathrm{H}-\mathrm{NMR}$ (above), ${ }^{13} \mathrm{C}-\mathrm{NMR}$ (middle) and ${ }^{31} \mathrm{P}-\mathrm{NMR}$ (below) spectra of methyltri-isopropylphosphonium iodide in deuterated water solution $\left(\mathrm{D}_{2} \mathrm{O}\right)$. Asterisk in ${ }^{1} \mathrm{H}$ NMR spectrum marks proton resonance of water. .92

Figure 3.11. Synthesis scheme of the di-isopropyl-diethylammonium cation (IEN) ...........93

Figure 3.12. ${ }^{1} \mathrm{H}-\mathrm{NMR}$ (above) and ${ }^{13} \mathrm{C}-\mathrm{NMR}$ (below) spectra of di-isopropyldiethylammonium iodide in deuterated water solution $\left(\mathrm{D}_{2} \mathrm{O}\right)$. Asterisk in ${ }^{1} \mathrm{H}-\mathrm{NMR}$ spectrum marks proton resonance of water.

Figure 3.13. ${ }^{1} \mathrm{H}-\mathrm{NMR}$ (above), ${ }^{13} \mathrm{C}-\mathrm{NMR}$ (middle) and ${ }^{31} \mathrm{P}-\mathrm{NMR}$ (below) spectra of phosphazene base P1-t-Bu in deuterated methanol solution (MeOD). Asterisk in ${ }^{1} \mathrm{H}-$ NMR and ${ }^{13} \mathrm{C}-\mathrm{NMR}$ spectra marks proton and carbon resonances of MeOD.

Figure 3.14. Synthesis scheme of the tris(diethylamino)(methyl)phosphonium cation (PN$\mathrm{PN})$ .95

Figure 3.15. ${ }^{1} \mathrm{H}-\mathrm{NMR}$ (above), ${ }^{13} \mathrm{C}-\mathrm{NMR}$ (middle) and ${ }^{31} \mathrm{P}-\mathrm{NMR}$ (below) spectra of tris(diethylamino)(methyl)phosphonium iodide in deuterated methanol (MeOD). Asterisk in ${ }^{1} \mathrm{H}-\mathrm{NMR}$ and ${ }^{13} \mathrm{C}$-NMR marks proton and carbon resonances of MeOD, $\dagger$ in ${ }^{13} \mathrm{C}$-NMR marks residual ethyl acetate resonances.

Figure 3.16. Synthesis scheme of the butane-1,4-diylbis[tris(dimethylamino)phosphonium] cation (PN-PN). . .97

Figure 3.17. ${ }^{1} \mathrm{H}-\mathrm{NMR}$ (above), ${ }^{13} \mathrm{C}-\mathrm{NMR}$ (middle) and ${ }^{31} \mathrm{P}-\mathrm{NMR}$ (below) spectra of butane 1,4-diylbis[tris(dimethylamino)phosphonium] iodide in deuterated water solution $\left(\mathrm{D}_{2} \mathrm{O}\right)$. Asterisk in ${ }^{1} \mathrm{H}-\mathrm{NMR}$ marks proton resonance of water. . .98

Figure 3.18. Synthesis scheme of the butane-1,4-diylbis(triisopropylphosphonium) cation (PC-PC). 
Figure 3.19. ${ }^{1} \mathrm{H}-\mathrm{NMR}$ (above), ${ }^{13} \mathrm{C}-\mathrm{NMR}$ (middle) and ${ }^{31} \mathrm{P}-\mathrm{NMR}$ (below) spectra of butane1,4-diylbis(triisopropylphosphonium) iodide in deuterated water solution $\left(\mathrm{D}_{2} \mathrm{O}\right)$. Asterisk in ${ }^{1} \mathrm{H}-\mathrm{NMR}$ marks proton resonance of water. 100

Figure 3.20. Synthesis scheme of the tris(dimethylamino)[4-(tri-tert-butylphosphonio) butyl]phosphonium cation (PN-PC) 101

Figure 3.21. ${ }^{1} \mathrm{H}-\mathrm{NMR}$ (above), ${ }^{13} \mathrm{C}-\mathrm{NMR}$ (middle) and ${ }^{31} \mathrm{P}-\mathrm{NMR}$ (below) spectra of tris(dimethylamino)[4-(tri-tert-butylphosphonio)butyl]phosphonium iodide in deuterated methanol solution (MeOD). Asterisk in ${ }^{1} \mathrm{H}-\mathrm{NMR}$ spectrum marks proton resonance of water, $\uparrow$ in ${ }^{1} \mathrm{H}$-NMR spectrum marks proton resonance of $\mathrm{MeOH}, \sharp$ in ${ }^{1} \mathrm{H}$ NMR spectrum marks small impurities in the product; Asterisk in ${ }^{13} \mathrm{C}-\mathrm{NMR}$ marks carbon resonance of $\mathrm{MeOH}$. 103

Figure 3.22. Synthesis scheme of the butane-1,4-diylbis(triethylphosphonium) cation. ... 104 Figure 3.23. ${ }^{1} \mathrm{H}-\mathrm{NMR}$ (above), ${ }^{13} \mathrm{C}-\mathrm{NMR}$ (middle) and ${ }^{31} \mathrm{P}-\mathrm{NMR}$ (below) spectra of butane-

1,4-diylbis(triethylphosphonium) iodide in deuterated water solution $\left(\mathrm{D}_{2} \mathrm{O}\right)$. Asterisk in ${ }^{1} \mathrm{H}-\mathrm{NMR}$ marks proton resonance of water. 105

Figure 3.24. Schematic view of the synthesis of zeolite materials. .................................. 106

Figure 3.25. Schematic view of the calcination of as-made zeolites synthesized using alkylammonium cations as OSDA's (tetraethylammonium cation shown here)....... 119

Figure 3.26. Schematic view of the calcination of as-made zeolites synthesized using phosphorous cations as OSDA's (methyl-tri-isopropyl-phosphonium cation shown here). 119

Figure 3.27. Heating ramp used for the calcination of zeolites in air. ............................ 120

Figure 3.28. Heating ramp used for the thermal treatment of zeolites under $\mathrm{H}_{2}$ stream.... 121

Figure 4.1. Main degradation pathways of ammonium cations under hydrothermal treatment.

128

Figure 4.2. Upper left: experiment 1 design of synthesis conditions. For each experimental condition, syntheses were also carried out at three different temperatures: $135^{\circ} \mathrm{C}, 150^{\circ} \mathrm{C}$ and $175^{\circ} \mathrm{C}$. Upper right: experiment 2 design of synthesis conditions. Below: employed cations in each experiment, tetraethylammonium cation (TEA) and tetraethylphosphonium cation (TEP) in experiment 1, and di-isopropyldiethylammonium cation (IEN), methyl-tris-(dimethylamino)-phosphonium cation (MNP), methyl-tri-isopropylphosphonium cation (MIP) and phosphazene base P1-t-Bu (PB1) in experiment 2 .

Figure 4.3. Tetraethylammonium cation (TEA) and tetraethylphosphonium cation (TEP) used as OSDA's in experiment 1. 130 
Figure 4.4. Powder X-Ray diffraction patterns of some of the materials obtained using TEP (left) and TEA (right) as OSDA's in fluoride media.

Figure 4.5. Crystallization kinetics of MFI obtained using TEP (solid dots and lines) and TEA (hollow dots and dotted lines) as OSDA's in fluoride media. Lines are just for guidance. .133

Figure 4.6. OSDA content (left) and yield (right) of solid products obtained after using TEP (solid dots) and TEA (hollow dots) as OSDA's in fluoride media.

Figure 4.7. Typical ${ }^{31} \mathrm{P}-\mathrm{NMR}$ (left) and ${ }^{13} \mathrm{C}-\mathrm{NMR}$ (middle) spectra of the solids obtained using TEP as OSDA, and ${ }^{13} \mathrm{C}-\mathrm{NMR}$ spectra of solids obtained using TEA as OSDA (right). The upper liquid NMR spectra belong to the pure TEP and TEA OSDA's in deuterium oxide solution, and the middle and below spectra belong to MAS-NMR spectra of some the solid samples.

Figure 4.8. Mass balance of phosphorus in syntheses ( $\bullet$ : fluoride media; $\bullet$ : hydroxide media) and blank ( $\square$ : fluoride media; $\bigcirc$ : hydroxide media) experiments carried out with TEP as OSDA

Figure 4.9. Liquid ${ }^{31} \mathrm{P}-\mathrm{NMR}$ (left) and ${ }^{13} \mathrm{C}-\mathrm{NMR}$ (middle) spectra of TEP mother liquors, and ${ }^{13} \mathrm{C}-\mathrm{NMR}$ spectra of TEA mother liquors (right). The upper spectra belong to the pure TEP and TEA OSDA's. Signals marked with circles correspond to OSDA's and signals marked with asterisks are assigned to decomposition products. All samples were diluted in deuterium oxide solution. .138

Figure 4.10. Stability curves of TEA (left, green background) and TEP (right, purple background) cations at different temperatures and synthesis conditions ( $\bullet$ : fluoride synthesis; $\boldsymbol{\nabla}$ : fluoride blank; $\bullet$ : hydroxide synthesis; $\bullet$ : hydroxide blank). Curves are just for guidance.

Figure 4.11. Methyl-tris-(dimethylamino)-phosphonium cation (MNP), methyl-triisopropylphosphonium cation (MIP), di-isopropyl-diethylammonium cation (IEN) and phosphazene base P1-t-Bu (PB1) used as OSDA's in experiment 2.

Figure 4.12. Powder X-Ray powder diffraction patterns of some of the obtained materials. Samples are identified by used OSDA, synthesis time, composition and synthesis media.

Figure 4.13. Crystallization kinetics of borosilicate RTH (circles), all-silica RTH (asterisks) and all-silica STF (squares) obtained with IEN (blue dots), MIP (red dots) and MNP (green dots) as OSDA's. Lines are just for guidance.

Figure 4.14. Liquid ${ }^{31} \mathrm{P}-\mathrm{NMR}$ spectra of PB1 cation (left), MIP cation (middle left), MNP cation (middle right) and ${ }^{13} \mathrm{C}-\mathrm{NMR}$ spectra (right) of IEN cation mother liquors. The 
upper spectra belong to the pure OSDA's. Resonances marked with asterisk are assigned to decomposition products. All samples were diluted in deuterium oxide solution.

Figure 4.15. Stability curves of IEN (top left, green background), MIP (top right, purple background), MNP (bottom left, red background) and PB1 (bottom right, orange background) cations at different synthesis conditions ( $\mathbf{a}$ : all-silica fluoride synthesis; $\boldsymbol{\nabla}$ : borosilicate fluoride synthesis; $\bullet$ : all-silica hydroxide synthesis; $\bullet$ borosilicate hydroxide synthesis). Curves are just for guidance. 149

Figure 5.1. a) Tetraethylphosphonium cation (TEP) and b) tetraethylammonium cation (TEA). 155

Figure 5.2. Powder X-Ray diffraction of some of the obtained materials. Diffractograms belong to the most crystalline material for each composition. Samples are identified by synthesis gel $\mathrm{P} /(\mathrm{P}+\mathrm{N})$ composition. 156

Figure 5.3. Crystallization kinetics of some of the obtained Si-MFI materials. Samples are identified by synthesis gel $\mathrm{P} /(\mathrm{P}+\mathrm{N})$ composition. Lines are just for guidance. 157

Figure 5.4. Comparison of $\mathrm{P} /(\mathrm{P}+\mathrm{N})$ compositions used in the synthesis gel, $\mathrm{P} /(\mathrm{P}+\mathrm{N})]_{\text {gel }}$, against the $\mathrm{P} /(\mathrm{P}+\mathrm{N})$ compositions obtained in Si-MFI zeolites, $[\mathrm{P} /(\mathrm{P}+\mathrm{N})]_{\text {solid. }} \mathrm{P} /(\mathrm{P}+\mathrm{N})_{\text {th }}$ refers to the theoretical compositions, while $\mathrm{P} /(\mathrm{P}+\mathrm{N})_{\text {th }}$ refers to the experimental compositions. 159

Figure 5.5. FESEM microimages of Si-MFI samples: P-MFI-OH, P-MFI, 0.4P-MFI (blue inset: Si mapping; purple inset: P mapping) and N-MFI. Samples are identified by synthesized $\mathrm{P} /(\mathrm{P}+\mathrm{N})$ material composition. Hydroxide media $\mathrm{P}-\mathrm{MFI}$ was included for comparison. 160

Figure 5.6. TG (dotted lines) and DTG (solid lines) analyses curves of the Si-MFI zeolites obtained with different $\mathrm{P} /(\mathrm{P}+\mathrm{N})$ ratios. Samples are identified by synthesized $\mathrm{P} /(\mathrm{P}+\mathrm{N})$ material composition. DTG curves are scaled up for a better view 161

Figure 5.7. Powder X-Ray diffraction of some of the obtained materials. Diffractograms belong to the most crystalline material for each composition. Samples are identified by synthesis gel $\mathrm{P} /(\mathrm{P}+\mathrm{N})$ composition. 163

Figure 5.8. Comparison of $\mathrm{P} /(\mathrm{P}+\mathrm{N})$ values used in the synthesis gel, $\mathrm{P} /(\mathrm{P}+\mathrm{N})]_{\text {gel }}$, against the $\mathrm{P} /(\mathrm{P}+\mathrm{N})$ values obtained in Al-MFI materials, $[\mathrm{P} /(\mathrm{P}+\mathrm{N})]_{\text {solid. }} \mathrm{P} /(\mathrm{P}+\mathrm{N})_{\text {th }}$ refers to the theoretical compositions, while $\mathrm{P} /(\mathrm{P}+\mathrm{N})_{\text {th }}$ refers to the experimental compositions. Values obtained for Si-MFI materials are also shown for comparison. 164

Figure 5.9. SEM microimages of N-OSDA (above) and P-OSDA (middle) comparing some Si-MFI (left) versus Al-MFI (right) samples. Below, Si (white), P (purple) and Al 
(green) compositional mapping of sample 0.4P-Al-MFI are shown. Samples are identified by synthesized $\mathrm{P} /(\mathrm{P}+\mathrm{N})$ material composition. 166

Figure 5.10. TG (dotted lines) and DTG (solid lines) analyses curves of the Al-MFI materials obtained with different $\mathrm{P} /(\mathrm{P}+\mathrm{N})$ ratios. Samples are identified by synthesized $\mathrm{P} /(\mathrm{P}+\mathrm{N})$ material composition. DTG curves are scaled up for a better view.

Figure 5.11. Powder X-Ray diffraction of some of the thermally treated Al-MFI materials. Solid lines correspond to as-made samples, while dotted lines correspond to calcined samples. Samples are identified by synthesized $\mathrm{P} /(\mathrm{P}+\mathrm{N})$ material composition. ......169

Figure 5.12. $\mathrm{N}_{2}$ adsorption isotherms of hydrogenated P-Al(25)-MFI (red), calcined P$\mathrm{Al}(25)-\mathrm{MFI}$ (green), calcined 0.2P-Al(32)-MFI (orange) and calcined N-Al(36)-MFI (blue).

Figure 5.13. Ammonia TPD curves of some thermally treated Al-MFI samples. Samples are identified by synthesized $\mathrm{P} /(\mathrm{P}+\mathrm{N})$ material composition, with $\mathrm{P} / \mathrm{Al}$ ratio in brackets.

Figure 5.14. ${ }^{13} \mathrm{C}$ MAS-NMR spectra of Al-MFI materials. Samples are identified by synthesized $\mathrm{P} /(\mathrm{P}+\mathrm{N})$ material composition. Free OSDA liquid NMR spectra included for comparison. . .175

Figure 5.15. ${ }^{31} \mathrm{P}$ MAS-NMR spectra of Al-MFI materials. Samples are identified by synthesized $\mathrm{P} /(\mathrm{P}+\mathrm{N})$ material composition. All-silica sample MAS-NMR and free OSDA liquid NMR included for comparison. 175

Figure 5.16. ${ }^{31} \mathrm{P}$ MAS-NMR spectra of calcined Al-MFI materials with different $\mathrm{P} / \mathrm{Al}$ ratios. Samples are identified by synthesized $\mathrm{P} /(\mathrm{P}+\mathrm{N})$ material composition, with thermal treatment below (cal: calcined; hyd: hydrogenated at high temperature). Solid lines correspond to experimental spectra; dotted lines correspond to the sum of deconvoluted signals. Spectra were deconvoluted as Gaussian/Lorentz curves. Washed sample with $\mathrm{P} / \mathrm{Al}=0.2$ was obtained after washing the $\mathrm{P} / \mathrm{Al}=1$ sample with $\mathrm{NH}_{4} \mathrm{Ac}$. 176

Figure 5.17. ${ }^{27} \mathrm{Al}$ MAS-NMR spectra of some samples of as-made Al-MFI with different P/Al ratios. Solid lines correspond to experimental spectra; dotted lines correspond to the sum of deconvoluted signals. Peaks were deconvoluted as Gaussian/Lorentz curves for an easier view. 178

Figure 5.18. ${ }^{27} \mathrm{Al}$ MAS-NMR spectra of calcined Al-MFI materials with different $\mathrm{P} / \mathrm{Al}$ ratios. Solid lines correspond to experimental spectra; dotted lines correspond to the sum of deconvoluted signals. The peak at $c a .55 \mathrm{ppm}$ was deconvoluted as a Gaussian/Lorentz curve (for an easier view), and the other peaks were deconvoluted using the CzSimple method. ${ }^{[56]}$ Asterisk marks NMR spinning bands. . .179 
Figure 5.19. Comparison of ${ }^{27} \mathrm{Al}$ MAS-NMR spectra (left) and ${ }^{31} \mathrm{P}$ MAS-NMR spectra (right). Spectra shown here are the same than previously depicted, but aluminium spectra are linked with its corresponding phosphorus spectra for better comparison.

181

Figure 5.20. a) Methyl-tris-(dimethylamino)-phosphonium cation (OSDA-4) and b) diisopropyl-diethylammonium cation (OSDA-5) 183

Figure 5.21. Powder X-Ray diffraction patterns of Al-RTH materials with different P-OSDA ratios. Samples are identified by synthesis gel OSDA composition. 184

Figure 5.22. Comparison of $\mathrm{P} /(\mathrm{P}+\mathrm{N})$ values used in the synthesis gel, $\mathrm{P} /(\mathrm{P}+\mathrm{N})]_{\mathrm{gel}}$, against the $\mathrm{P} /(\mathrm{P}+\mathrm{N})$ values obtained in Al-RTH zeolites, $[\mathrm{P} /(\mathrm{P}+\mathrm{N})]_{\text {solid. }} \mathrm{P} /(\mathrm{P}+\mathrm{N})_{\text {th }}$ refers to the theoretical compositions, while $\mathrm{P} /(\mathrm{P}+\mathrm{N})_{\text {th }}$ refers to the experimental compositions. Values obtained for Si-MFI and Al-MFI materials are also shown for comparison. 186

Figure 5.23. SEM microimages of RTH samples obtained with different OSDA compositions. All P RTH (P-Al-RTH, upper left), all N RTH (N-Al-RTH, upper right) and $\mathrm{P} /(\mathrm{P}+\mathrm{N})=0.5 \mathrm{RTH}(\mathrm{P} / \mathrm{N}-\mathrm{Al}-\mathrm{RTH}$, upper middle). Below, EDX mapping (white: Si; purple: $\mathrm{P}$; green: $\mathrm{Al})$ of the $\mathrm{P} /(\mathrm{P}+\mathrm{N})=0.8 \mathrm{RTH}$ sample is shown. 188

Figure 5.24. TG (dotted lines) and DTG (solid lines) analyses curves of the Al-RTH materials obtained with different $\mathrm{P} /(\mathrm{P}+\mathrm{N})$ ratios. Samples are identified by synthesized material composition. DTG curves are scaled up for a better view...... 189

Figure 5.25. Powder X-Ray diffraction of some of the thermally treated Al-RTH materials. Solid lines correspond to as-made samples, while dotted lines correspond to calcined samples. Samples are identified by synthesized material composition. 190

Figure 5.26. $\mathrm{N}_{2}$ adsorption isotherms of calcined Al-RTH materials with different $\mathrm{P} / \mathrm{Al}$ ratios at $77 \mathrm{~K}$ (left) and $87 \mathrm{~K}$ (right). 192

Figure 5.27. Quantity of adsorbed $\mathrm{N}_{2}$ measured at $\mathrm{P} / \mathrm{P}_{0}=0.15$ of $\mathrm{N}_{2}$ adsorption isotherms at liquid $\mathrm{N}_{2}$ temperature $(77 \mathrm{~K})$ and liquid Ar temperature $(87 \mathrm{~K})$ of Al-RTH materials with different $\mathrm{P} / \mathrm{Al}$ compositions. 192

Figure 5.28. Ammonia TPD curves of calcined Al-RTH materials. Samples are identified by synthesized $\mathrm{P} /(\mathrm{P}+\mathrm{N})$ material composition, with $\mathrm{P} / \mathrm{Al}$ ratio below 193

Figure 5.29. ${ }^{13} \mathrm{C}$ MAS-NMR spectra of some Al-RTH materials. Samples are named after their OSDA composition. Dots belong to P-OSDA ${ }^{13} \mathrm{C}$ resonances and asterisks belong to N-OSDA ${ }^{13} \mathrm{C}$ resonances. Free OSDA liquid NMR spectra are included for comparison 195

Figure 5.30. ${ }^{31} \mathrm{P}$ MAS-NMR spectra of some Al-RTH materials. Samples are named after their OSDA composition. All-silica sample and free OSDA liquid NMR spectra 
included for compa- rison. Solid lines correspond to experimental spectra; dotted lines correspond to the sum of deconvoluted signals. Spectra were deconvoluted as Gaussian/Lorentz curves. Spectra are not scaled up on phosphorus content. Inset figures include the chemical shift of the resonances. . .196

Figure 5.31. ${ }^{31} \mathrm{P}$ MAS-NMR spectra of some thermally treated (Cal: calcined; Hyd: hydrogenated) Al-RTH materials with different P/Al ratios. Solid lines correspond to experimental spectra; dotted lines correspond to the sum of deconvoluted signals. Peaks were deconvoluted as Gaussian/Lorentz curves.

Figure 5.32. ${ }^{27} \mathrm{Al}$ MAS-NMR spectra of some as-made Al-RTH materials with different P/Al ratios. 199

Figure 5.33. ${ }^{27} \mathrm{Al}$ MAS-NMR spectra of some thermally treated (Cal: calcined; Hyd: hydrogenated) Al-RTH materials with different P/Al ratios. Solid lines correspond to experimental spectra; dotted lines correspond to the sum of deconvoluted signals. The resonance at $c a .55 \mathrm{ppm}$ was deconvoluted as a Gaussian/Lorentz curve (for an easier view), and the other resonances were deconvoluted using the CzSimple method. ${ }^{[56]}$.

200

Figure 5.34. 3Q ${ }^{27} \mathrm{Al}$ MAS-NMR spectrum of a $\mathrm{P} / \mathrm{Al}=0.5 \mathrm{RTH}$ sample. ...................... 202

Figure 5.35. Bloch decay (black line) and $\mathrm{H}>\mathrm{P} \mathrm{CP}$ (red line) ${ }^{31} \mathrm{P}$ MAS-NMR spectra of some

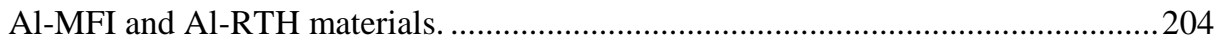

Figure 5.36. HETCOR H-P MAS-NMR experiment on the Al-RTH P/Al=1 sample. ......205

Figure 5.37. ${ }^{31} \mathrm{P}\left\{{ }^{27} \mathrm{Al}\right\}$ HMQC MAS-NMR experiments of Al-RTH (above) and Al-MFI (below) samples with $\mathrm{P} / \mathrm{Al}=1$. 206

Figure 5.38. REDOR curves obtained from REDOR experiments of some Al-MFI and Al-

RTH materials. In all samples spectra, three different resonances were identified: tetrahedral (circles), ca. $55 \mathrm{ppm}$; distorted tetrahedral (squares), ca. $35 \mathrm{ppm}$; and octahedral (triangles), $c a .-15 \mathrm{ppm}$. Curves are just for guidance.

Figure 6.1. Tris(diethylamino)(methyl)phosphonium cation or OSDA-7 ..........................218

Figure 6.2. Powder X-Ray diffraction patterns of some obtained IWV materials compared with theoretical diffraction pattern (IZA DB). ${ }^{[16]}$ Samples are identified by the synthesis gel composition: heteroatom type and silica to heteroatom ratio; water to silica ratio $(\mathrm{W})$; and synthesis media ( $\mathrm{OH}$ or $\mathrm{F})$. .220

Figure 6.3. Powder X-Ray diffraction patterns of some DON materials compared with theoretical diffraction pattern (IZA DB) ${ }^{[16]}$ Samples are identified by the synthesis gel composition: heteroatom type and silica to heteroatom ratio; water to silica ratio (W); and synthesis media $(\mathrm{OH}$ or $\mathrm{F})$ .221 
Figure 6.4. Powder X-Ray diffraction patterns of borosilicate IWV and DON materials, and the synthesis with a mix of both phases. Samples are identified by the synthesis gel composition: heteroatom type and silica to heteroatom ratio; water to silica ratio (W); synthesis media ( $\mathrm{OH}$ or $\mathrm{F}$ ); and crystalline phase or synthesis time when not a single phase is present.

222

Figure 6.5. FESEM microimages of some as-made IWV materials. Samples are named after the containing heteroatom followed by the as-made heteroatom to silica ratio content, with the synthesis media below when needed.

Figure 6.6. TG (solid lines) and DTG (dotted lines) analyses curves of some IWV samples. Samples are named after the containing heteroatom followed by the as-made heteroatom to silica ratio content, with the synthesis media below. DTG curves are scaled up for a better view. 226

Figure 6.7. Powder X-Ray diffraction of some of the thermally treated IWV materials. Black lines correspond to as-made samples; red lines to calcined samples; green lines to samples hydrogenated at high temperature; blue lines to samples hydrogenated at high temperature and washed with ethanol. Samples are identified by synthesized material composition. 228

Figure 6.8. FESEM microimages of some thermally treated IWV materials. Samples are named after the containing heteroatom followed by the as-made heteroatom to silica ratio content, with the thermal treatment below (Cal: calcined; Hyd: hydrogenated at high temperature). 230

Figure 6.9. $\mathrm{N}_{2}$ adsorption isotherms of some of the thermally treated IWV samples (left: allsilica and germanosilicate; right: aluminosilicate and borosilicate). Samples are named after the thermal treatment (cal: calcined under air; hyd: hydrogenated at high temperature; was: hydrogenated at high temperature and washed with ethanol), followed by the containing heteroatom and by the as-made heteroatom to silica ratio content

Figure 6.10. Pore size distribution of calcined all-silica (green) and hydrogenated (red) IWV materials

Figure 6.11. FTIR spectra (solid black line: prior pyridine adsorption; coloured lines: after pyridine adsorption and desorption at different temperatures) of the Al-IWV materials with $\mathrm{Si} / \mathrm{Al}$ ratio of 25 after different post-synthesis treatments. 234

Figure 6.12. ${ }^{13} \mathrm{C}$ MAS-NMR spectra of some samples of IWV. Free OSDA liquid NMR spectrum included for comparison $(\bullet)$. Asterisks in OSDA NMR marks solvent resonances. 
Figure 6.13. ${ }^{31} \mathrm{P}$ MAS-NMR spectra of some of the obtained IWV samples. Samples are named after the containing heteroatom followed by the as-made heteroatom to silica ratio content, with the synthesis media below. Free OSDA and mother liquor (obtained from Al25-IWV-Fluoride synthesis) liquid NMR spectra are included for comparison.

.236

Figure 6.14. ${ }^{31} \mathrm{P}$ MAS-NMR spectra of thermally treated Al-IWV. Samples are named after the thermal treatment (cal: calcined under air; hyd: hydrogenated at high temperature; was: hydrogenated at high temperature and washed with ethanol), followed by the containing heteroatom and by the as-made heteroatom to silica ratio content. Solid lines correspond to experimental spectra; dotted lines correspond to the sum of deconvoluted signals. Spectra were deconvoluted as Gaussian/Lorentz curves.

Figure 6.15. ${ }^{27} \mathrm{Al}$ MAS-NMR spectra of some samples of as-made IWV materials with different $\mathrm{Si} / \mathrm{Al}$ ratios. Samples are named as the containing heteroatom followed by the as-made heteroatom to silica ratio content and synthesis media below.

Figure 6.16. ${ }^{27} \mathrm{Al}$ MAS-NMR spectra of some samples of the thermally treated IWV sample with $\mathrm{Si} / \mathrm{Al}=25$. Solid lines correspond to experimental spectra; dotted lines correspond to the sum of deconvoluted signals. The peak at $c a .56 \mathrm{ppm}$ was deconvoluted as a Gaussian/Lorentz curve (for an easier view), and the other peaks were deconvoluted using the CzSimple method. ${ }^{[40]}$

Figure 6.17. ${ }^{11} \mathrm{~B}$ MAS-NMR spectra of the as-made and calcined borosilicate sample with $\mathrm{Si} / \mathrm{B}=37$.

Figure 6.18. ${ }^{19}$ F MAS-NMR spectra of some as-made IWV materials. Samples are named after the containing heteroatom followed by the as-made heteroatom to silica ratio content. Spectra are not scaled up on fluorine content.

Figure 6.19. ${ }^{29} \mathrm{Si}$ MAS-NMR spectra of some as-made and thermally treated all-silica IWV samples (cal: calcined under air; hyd: hydrogenated at high temperature; was: hydrogenated at high temperature and washed with ethanol). Solid lines correspond to experimental spectra; dotted lines correspond to the sum of deconvoluted signals...244

Figure $6.20 .{ }^{29} \mathrm{Si}$ MAS-NMR spectra of some as-made and thermally treated aluminosilicate IWV samples (cal: calcined under air; hyd: hydrogenated at high temperature; was: hydro-genated at high temperature and washed with ethanol). Solid lines correspond to experimental spectra; dotted lines correspond to the sum of deconvoluted signals...246

Figure 6.21. Synthesis scheme of OSDA's used in the synthesis of DON zeolite: a) $\left[\mathrm{Me}_{5} \mathrm{Cp}\right]_{2} \mathrm{Co}^{+}$cation; b) phosphazene base P2; c) DMBI hydroxide; d) OSDA-7.....249 
Figure 6.22. FESEM microimages of some as-made DON materials. Samples are named after the containing heteroatom followed by the as-made heteroatom to silica ratio content.

Figure 6.23. TG (solid lines) and DTG (dotted lines) analyses curves of some DON samples. Samples are named as the containing heteroatom followed by the as-made heteroatom to silica ratio content. DTG curves are scaled up for a better view. 252

Figure 6.24. Powder X-Ray diffraction of some of the thermally treated DON materials. Black lines correspond to as-made samples; red lines to calcined samples; green lines to samples hydrogenated at high temperature. Samples are identified by synthesized material composition. 254

Figure 6.25. FESEM microimages of some thermally treated DON materials. Samples are named after the containing heteroatom followed by the as-made heteroatom to silica ratio content, with the thermal treatment below (Cal: calcined). 256

Figure 6.26. $\mathrm{N}_{2}$ adsorption isotherm of some of the thermally treated DON samples (black: calcined all-silica; red: hydrogenated at high temperature all-silica; blue: calcined aluminosilicate; green: hydrogenated at high temperature aluminosilicate). 257

Figure 6.27. ${ }^{31} \mathrm{P}$ MAS-NMR spectra of some as-made DON samples. Samples are named after the containing heteroatom followed by the as-made heteroatom to silica ratio content. Free OSDA NMR spectrum is included for comparison. 259

Figure 6.28. ${ }^{31} \mathrm{P}$ MAS-NMR spectra of thermally treated Al-DON materials. Samples are named after the thermal treatment (cal: calcined under air; hyd: hydrogenated at high temperature), followed by the containing heteroatom and by the as-made heteroatom to silica ratio content. Solid lines correspond to experimental spectra; dotted lines correspond to the sum of deconvoluted signals. Spectra were deconvoluted as Gaussian/Lorentz curves.

Figure 6.29. ${ }^{27} \mathrm{Al}$ MAS-NMR of samples of the as-made and the thermally treated DON sample with $\mathrm{Si} / \mathrm{Al}=22$. Solid lines correspond to experimental spectra; dotted lines correspond to the sum of deconvoluted signals. The resonances in as-made sample were deconvoluted as a Gaussian/Lorentz curve (for an easier view); the resonances of thermally treated were deconvoluted as a Gaussian/Lorentz curve (peaks at $56 \mathrm{ppm}$ and 9 ppm, for an easier view) or using the CzSimple method (peaks at 45-50 ppm and -10 ppm. ${ }^{[40]}$ 261

Figure 7.1. Butane-1,4-diylbis[tris(dimethylamino)phosphonium] cation (PN-PN)........ 270

Figure 7.2. Powder X-Ray diffraction patterns of the ITQ-58 zeolite obtained with the PNPN OSDA (middle), compared with the powder X-Ray diffraction patterns of zeolite 
ITQ-52 (above) and zeolite STF (below). Asterisk marks the characteristic peaks of the STF and ITQ-52 zeolites.

Figure 7.3. SEM microimage of the as-made PN-PN ITQ-58 zeolite................................2273

Figure 7.4. Butane-1,4-diylbis(triisopropylphosphonium) cation (PC-PC). .......................275

Figure 7.5. Powder X-Ray diffraction pattern of the ITQ- $58^{*}$ zeolite obtained with the PC-

PC OSDA (low middle), compared with the powder X-Ray diffraction patterns of PN-

PN ITQ-58 zeolite (up middle), ITQ-52 zeolite (above) and STF zeolite (below).

Asterisks mark the characteristic peaks belonging to STF zeolite in the PC-PC ITQ-58

sample.

.277

Figure 7.6. Scanning electron microscopy (SEM) microimages of as-made PN-PN ITQ-58 zeolite (left) and as-made PC-PC ITQ-58* zeolite with slight STF impurities (right).

..278

Figure 7.7. Tris(dimethylamino) [4-(tri-tert-butylphosphonio) butyl] phosphonium cation (PN-PC).

Figure 7.8. Powder X-Ray diffraction pattern of the ITQ-58 zeolite obtained with the PN-PC OSDA (middle), compared with the powder X-Ray diffraction patterns of zeolite PNPN ITQ-58 zeolite (up middle), PC-PC ITQ-58* zeolite (low middle), ITQ-52 zeolite (above) and STF zeolite (below). Asterisks mark the characteristic peaks belonging to STF zeolite in the PC-PC ITQ-58 sample. 280

Figure 7.9. SEM microimages of as-made PN-PN ITQ-58 zeolite (left), as-made PC-PC ITQ$58 *$ zeolite with slight STF impurities (middle), and as-made PN-PC ITQ-58 zeolite (right)

Figure 7.10. TG (solid lines) and DTG (dotted lines) analyses curves of PN-PN and PN-PC ITQ-58 zeolite samples. DTG curves are scaled up for a better view. .283

Figure 7.11. Powder X-Ray diffraction patterns of the as-made and the thermally treated PNPC ITQ-58 materials. Black lines correspond to as-made samples; red lines to calcined samples; green lines to samples hydrogenated at high temperature. .284

Figure 7.12. Top: schematic view of PN-PC cation. Left: liquid ${ }^{13} \mathrm{C}$ NMR spectrum of the OSDA in deuterated water (top) and solid ${ }^{13} \mathrm{C}$ MAS-NMR spectrum of the as-made ITQ-58 (bottom). Right: liquid ${ }^{31} \mathrm{P}$ NMR spectrum of the pure OSDA in deuterated water (top) and solid ${ }^{31} \mathrm{P}$ MAS-NMR spectrum of the as-made ITQ-58 (bottom)....285

Figure 7.13. ${ }^{11} \mathrm{~B}$ MAS-NMR spectra of as-made and calcined PN-PN ITQ-58 materials. 286 Figure 7.14. ${ }^{29} \mathrm{Si}$ MAS-NMR spectra of as-made and calcined PN-PC ITQ-58 materials. Solid line corresponds to experimental spectra; dotted line corresponds to the sum of deconvoluted signals .. 287 
Figure 7.15. $\mathrm{N}_{2}$ adsorption isotherm of the PN-PC ITQ-58 sample hydrogenated at high temperature. 288

Figure 7.16. Pore size distribution of the PN-PC ITQ-58 sample hydrogenated at high temperature. 289

Figure 7.17. Projections of the structure of the ITQ-58 zeolite along the main crystallographic axes (blue: $\mathrm{Si}$; red: $\mathrm{O}$ ). 290

Figure 7.18. Rietveld refinement of the X-Ray diffraction pattern of PN-PC ITQ-58 hydrogenated at high temperature. Red data points show the observed XRPD pattern; the black line along these points is the calculated XRPD pattern, with the difference profile at the bottom in blue. The green vertical tick marks below the pattern give the positions of the Bragg reflections.

Figure 7.19. Basic cages of ITQ-58 zeolite. (A) $\left[4^{3} 5^{4}\right]$, (B) $\left[4^{3} 5^{4} 6^{1}\right]$, (C) $\left[5^{4} 6^{2}\right]$ and (D) $\left[4^{12} 5^{12} 6^{12} 8^{4}\right]$. The openings of the half cavity $\left[4^{6} 5^{6} 6^{6} 8^{2} 10^{1}\right]$ are highlighted in (E) (large inner $10 \mathrm{MR}$ in purple and the two $8 \mathrm{MR}$ opening windows in yellow). Oxygen atoms have been removed for clarity. 292

Figure 7.20. Construction of the structure of the ITQ-58 zeolite. (A) Two $\left[4^{3} 5^{4}\right]$ (blue), two $\left[4^{3} 5^{4} 6^{1}\right]$ (green) and one $\left[5^{4} 6^{2}\right]$ (yellow) cages connect forming a basic block. (B) The previous blocks connect to each other sharing a 4 MR forming chains along $c$. (C) Each chain connects to the adjacent ones in the $b c$ plane forming layers. $4 \mathrm{MR}$ and $6 \mathrm{MR}$ are formed in the process. (D) Layers stack along the $a$ direction forming the complete 3D structure 293

Figure 7.21. Butane-1,4-diylbis(triethylphosphonium) cation. 294

Figure 7.22. Powder X-Ray diffraction patterns of some ITQ-66 materials. Samples are identified by the heteroatom type and the silica to heteroatom ratio in synthesis gel composition.

Figure 7.23. FESEM microimages of as-made ITQ-66 materials. Samples are named after the containing heteroatom followed by the as-made heteroatom to silica ratio content.

297

Figure 7.24. TG (solid lines) and DTG (dotted lines) analyses curves of some ITQ-66 samples. Samples are named as the containing heteroatom followed by the as-made heteroatom to silica ratio content. DTG curves are scaled up for a better view. 298

Figure 7.25. Powder X-Ray diffraction patterns of some of the thermally treated ITQ-66 materials. Black lines correspond to as-made samples; red lines to calcined samples; green lines to samples hydrogenated at high temperature. Samples are identified by synthesized material composition. 299 
Figure 7.26. FESEM microimages of some thermally treated ITQ-66 materials. Samples are named as the containing heteroatom followed by the as-made heteroatom to silica ratio content, with the thermal treatment below (Cal: calcined; Hyd: hydrogenated at high temperature).

Figure 7.27. $\mathrm{N}_{2}$ adsorption isotherms of some of the thermally treated ITQ-66 samples (black and green: borosilicate materials; red and blue: gallosilicate materials). Samples are named after the thermal treatment (cal: calcined under air; hyd: hydrogenated at high temperature), followed by the containing heteroatom and by the as-made heteroatom to silica ratio content. 302

Figure 7.28. Pore size distribution of some ITQ-66 samples hydrogenated at high temperature.

Figure 7.29. Above: Unit cell projection of the zeolite ITQ-66, with the unit cell marked by dashed lines. Below: projections along the main crystallographic axes (grey: $\mathrm{Si}$; red: O).

Figure 7.30. Pore channel topologies in zeolite ITQ-66 (grey: Si; red: O). Left: $10 \mathrm{MR}$ channel viewed along [100]. Right: 8 MR channel viewed along [011] 306

Figure 7.31. Rietveld refinement of the X-Ray diffraction pattern of B25 (left) and Ga46 (right) ITQ-66 materials hydrogenated at high temperature. Red data points show the observed XRPD pattern; the black line along these points is the calculated XRPD pattern, with the difference profile at the bottom in blue. The blue vertical tick marks below the pattern give the positions of the Bragg reflections.

Figure 7.32. Unit cell [100] projection (yellow: silicon atoms; red: oxygen atoms) of borosilicate (left) and gallosilicate (right) ITQ-66 with T sites preferentially occupied by boron atoms (light blue) and gallium atoms (dark blue). . .308

Figure 7.33. ${ }^{31} \mathrm{P}$ MAS-NMR spectra of some as-made ITQ-66 samples. Samples are named after the heteroatom and the as-made heteroatom to silica ratio content. Free OSDA and mother liquor (obtained from B36 synthesis) liquid NMR spectra included for comparison. 309

Figure 7.34. ${ }^{31} \mathrm{P}$ MAS-NMR spectra of thermally treated ITQ-66 materials. Samples are named after the thermal treatment (cal: calcined; hyd: hydrogenated at high temperature), followed by the heteroatom and as-made heteroatom to silica ratio content. Solid lines correspond to experimental spectra; dotted lines correspond to the sum of deconvoluted signals. Spectra were deconvoluted as Gaussian/Lorentz curves. Spectra not scaled on phosphorus content. 
Figure $7.35 .{ }^{71} \mathrm{Ga}$ MAS-NMR spectra of the as-made and the thermally treated gallosilicate

ITQ-66 sample with $\mathrm{Si} / \mathrm{Ga}=27$. 312

Figure 7.36. ${ }^{11} \mathrm{~B}$ MAS-NMR spectra of the as-made and thermally treated borosilicate ITQ66 sample with $\mathrm{Si} / \mathrm{B}=25$. 313

Figure 7.37. ${ }^{19}$ F MAS-NMR spectra of as-made ITQ-66 samples. Solid lines correspond to experimental spectra; dotted lines correspond to the sum of deconvoluted signals. Spectra are not scaled up on fluorine content 314

Figure 7.38. ${ }^{29} \mathrm{Si}$ MAS-NMR spectra of as-made and calcined gallosilicate ITQ-66 samples. Solid lines correspond to experimental spectra; dotted lines correspond to the sum of deconvoluted signals. 315

\section{Table index}

Table 1.1. Classification of zeolites attending their pore size.

4

Table 1.2. New zeolites obtained using P-OSDA. The middle column corresponds to the POSDA used to obtain the zeolite structures in column $\mathrm{Zeo}_{\text {str. }}$ Further to the left, it is listed the N-OSDA also used to obtain these zeolite structures. The analogous N-OSDA column corresponds to the chemically equivalent of the listed P-OSDAs column (if any), and the analogous zeolites corresponds to the zeolite structures obtained with those analogous N-OSDA's. 26

Table 1.3. Known zeolites obtained using P-OSDA. The middle column corresponds to the

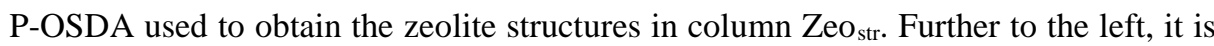
listed the N-OSDA also used to obtain these zeolite structures. The analogous N-OSDA column corresponds to the chemically equivalent of the listed P-OSDAs column (if any), and the analogous zeolites corresponds to the zeolite structures obtained with those analogous N-OSDA's. 28

Table 3.1. Single pulse MAS-NMR acquisition parameters for each nucleus..................... 80

Table 3.2. Theoretical and experimental chemical composition of methyl-tris(dimethylamino)-phosphonium iodide. Ratios are given as molar ratios.

Table 3.3. Theoretical and experimental chemical composition of methyl-triisopropylphosphonium iodide. Ratios are given as molar ratios.

Table 3.4. Theoretical and experimental chemical composition of di-isopropyldiethylammonium cation iodide. Ratios are given as molar ratios.

Table 3.5. Theoretical and experimental chemical composition of butane - 1,4-diylbis [tris(dimethylamino) phosphonium] iodide. Ratios are given as molar ratios. 97 
Table 3.6. Theoretical and experimental chemical composition of butane-1,4diylbis(triisopropylphosphonium) iodide. Ratios are given as molar ratios.

Table 3.7. Theoretical and experimental chemical composition of tris(dimethylamino)[4-(tritert-butylphosphonio)butyl]phosphonium iodide. Ratios are given as molar ratios. . 102

Table 3.8. Theoretical and experimental chemical composition of butane-1,4diylbis(triethylphosphonium) iodide. Ratios are given as molar ratios. 104

Table 3.9. Summary of the amounts of OSDA hydroxide solutions used in blank experiments. 108

Table 3.10. Summary of the amounts of OSDA hydroxide solutions used in all-silica syntheses

Table 3.11. Summary of the amounts of OSDA hydroxide solutions used in borosilicate syntheses. 109

Table 3.12. Summary of the amounts of P-OSDA and N-OSDA hydroxide solutions used in the dual template syntheses of all-silica MFI materials

Table 3.13. Summary of the amounts of P-OSDA and N-OSDA hydroxide solutions used in the dual template syntheses of aluminosilicate MFI materials.

Table 3.14. Summary of the amount of TEOS, $\mathrm{Al}(\mathrm{OH})_{3}$, P-OSDA and N-OSDA hydroxide solutions used in the dual template syntheses of aluminosilicate RTH materials

Table 4.1. Typical chemical analyses of the obtained solids. Sample are named after the used OSDA, the synthesis media, the temperature $\left({ }^{\circ} \mathrm{C}\right)$ and synthesis time (days)

Table 4.2. Tested synthesis conditions and phase selectivity obtained using the methyl-tris(dimethylamino)-phosphonium cation (MNP), the methyl-tri-isopropylphosphonium cation (MIP), the di-isopropyl-diethylammonium cation (IEN), and the phosphazene base P1-t-Bu (PB1) as OSDA's.

Table 4.3. Typical chemical compositions of some of the obtained materials. Ratios are given as molar ratios. Samples are named after the used OSDA and the obtained phase. .. 146

Table 5.1. Chemical compositions of some of the obtained Si-MFI materials. All ratios are given as molar ratios

Table 5.2. Chemical compositions of some of the obtained Al-MFI materials. Ratios are given as molar ratios . .164

Table 5.3. Heteroatom chemical compositions of some of the obtained Al-MFI materials. All ratios are given as molar ratios and $\mathrm{pH}_{\text {gel }}$ was measured after adding $\mathrm{HF}$. .165

Table 5.4. Chemical compositions of some of the thermally treated Al-MFI materials. Samples are identified by synthesized $\mathrm{P} /(\mathrm{P}+\mathrm{N})$ material composition. Ratios are given as molar ratios 
Table 5.5. Textural properties of some thermally treated Al-MFI samples. Samples are identified by synthesized $\mathrm{P} /(\mathrm{P}+\mathrm{N})$ material composition, with aluminium contents included in brackets. Ratios are given as molar ratios.

Table 5.6. Chemical analyses, textural properties and ammonia adsorption at $100^{\circ} \mathrm{C}$ of some thermally treated Al-MFI samples. Samples are identified by synthesized $\mathrm{P} /(\mathrm{P}+\mathrm{N})$ material composition. Ratios are given as molar ratios.

Table 5.7. OSDA chemical composition of as-made Al-RTH materials. All ratios are given as molar ratios. Samples are identified by OSDA ratio synthesis gel composition... 185

Table 5.8. Heteroatom chemical composition of as-made Al-RTH materials. All ratios are given as molar ratios. Samples are identified by OSDA ratio synthesis gel composition and $\mathrm{pH}_{\text {gel }}$ was measured after adding $\mathrm{HF}$

Table 5.9. Chemical composition of some of the thermally treated Al-RTH materials. All ratios are given as molar ratios 191

Table 5.10. Summary of chemical analyses, textural properties and ammonia adsorption at $100^{\circ} \mathrm{C}$ of some thermally treated Al-RTH samples. Samples are identified by synthesized $\mathrm{P} /(\mathrm{P}+\mathrm{N})$ material composition. Ratios are given as molar ratios. 194

Table 5.11. Calculated values of the isotropic chemical shift $\left(\delta_{\text {iso }}\right)$ and the quadrupolar parameter $(\mathrm{PQ})$ of the calcined $\mathrm{P} / \mathrm{Al}=0.5 \mathrm{RTH}$ sample 202

Table 6.1. Tested synthesis conditions and phase selectivity obtained using tris(diethylamino)(methyl)phosphonium hydroxide as OSDA.

219

Table 6.2. Chemical composition of some of the obtained IWV materials. All ratios are given as molar ratios. Samples are identified by heteroatom $(\mathrm{X})$ synthesis gel composition and $\mathrm{pH}_{\text {gel }}$ was measured after adding $\mathrm{HF}$ (when needed) 224

Table 6.3. Chemical composition of some of the thermally treated IWV materials. All ratios are given as molar ratios. Samples are identified by heteroatom (X) synthesis gel composition

Table 6.4. Textural properties of thermally treated IWV samples. Samples are identified after its heteroatom content and post-synthesis treatments (cal: calcined; hyd: hydrogenated at high temperature; was: washed with ethanol after hydrogenation at high temperature).

Table 6.5. Acidic properties of some Al-IWV samples after different post-synthesis treatments. Washed refers to the sample washed after hydrogenation at high temperature. Acidic centres correspond to the sum of Brönsted and Lewis acid centres at $150^{\circ} \mathrm{C} ; \mathrm{B}_{350} / \mathrm{B}_{150}$ corresponds to the ratio between Brönsted acid centres at $350^{\circ} \mathrm{C}$ and $150^{\circ} \mathrm{C}$ 
Table 6.6. Chemical composition of some of the obtained DON materials. All ratios are given as molar ratios. Samples are identified by heteroatom (X) synthesis gel composition.

Table 6.7. Chemical composition of some of the thermally treated DON materials. All ratios are given as molar ratios. Samples are identified by heteroatom $(\mathrm{X})$ synthesis gel composition.

Table 6.8. Textural properties of thermally treated DON samples. Samples are named after the heteroatom content and thermal treatments (cal: calcined; hyd: hydrogenated at high temperature) .258

Table 7.1. Tested synthesis conditions and phase selectivity obtained using butane - 1,4diylbis[tris(dimethylamino)phosphonium] (PN-PN) hydroxide as OSDA.

Table 7.2. Chemical analyses of the as-made, calcined and hydrogenated at high temperature PN-PN ITQ-58 zeolite. All ratios are given as molar ratios.

Table 7.3. Tested synthesis conditions and phase selectivity obtained using butane-1,4diylbis(triisopropylphosphonium) (PC-PC) hydroxide as OSDA .276

Table 7.4. Chemical analysis of the as-made PC-PC ITQ-58* zeolite. All ratios are given as molar ratios.

Table 7.5. Tested synthesis conditions and phase selectivity obtained using tri-tert-butyl (4(tris (dimethylamino) phosphonio) butyl) phosphonium (PN-PC) hydroxide as OSDA.

Table 7.6. Chemical analyses of the as-made, calcined and hydrogenated at high temperature PN-PC ITQ-58 zeolite. All ratios are given as molar ratios.

Table 7.7. Tested synthesis conditions and phase selectivity obtained using butane-1,4diylbis(triethylphosphonium) hydroxide as OSDA. .294

Table 7.8. Chemical composition of some of the as-made ITQ-66 materials. All ratios are given as molar ratios. Samples are identified by heteroatom (X: B or Ga) synthesis gel composition and $\mathrm{pH}_{\text {gel }}$ was measured after adding $\mathrm{HF}$. .296

Table 7.9. Chemical composition of some of the thermally treated ITQ-66 materials. All ratios are given as molar ratios. Samples are identified by heteroatom (X: B or $\mathrm{Ga}$ ) synthesis gel composition. .300

Table 7.10. Textural properties of thermally treated ITQ-66 materials. Samples are identified by its heteroatom (X: B or Ga) content and post-synthesis treatments (cal: calcined; hyd: hydrogenated at high temperature).

Table 7.11. Multiplicity and atomic coordinates of the Si atoms in the ITQ-66 structure. 305 